\title{
MSTER
}

\section{SNAP-23A PROGRAM}

\section{THERMOELECTRIC CONVERTER \\ DEVELOPMENT PROGRAM}

\section{FINAL REPORT}

THIS DOCUMENT CONFIRMED AS

UNCLASSIFIED

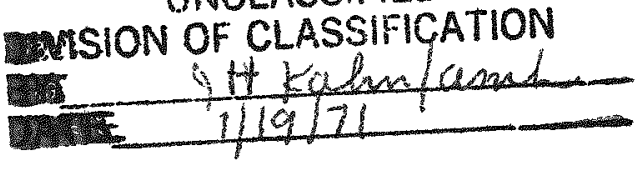




\section{DISCLAIMER}

This report was prepared as an account of work sponsored by an agency of the United States Government. Neither the United States Government nor any agency Thereof, nor any of their employees, makes any warranty, express or implied, or assumes any legal liability or responsibility for the accuracy, completeness, or usefulness of any information, apparatus, product, or process disclosed, or represents that its use would not infringe privately owned rights. Reference herein to any specific commercial product, process, or service by trade name, trademark, manufacturer, or otherwise does not necessarily constitute or imply its endorsement, recommendation, or favoring by the United States Government or any agency thereof. The views and opinions of authors expressed herein do not necessarily state or reflect those of the United States Government or any agency thereof. 


\section{DISCLAIMER}

Portions of this document may be illegible in electronic image products. Images are produced from the best available original document. 


\section{NOTICE}

This report was prepared as an account of work sponsored by the United States Government. Neither the United States nor the United States Atomic Energy Commission nor any of their employees, nor any of their contractors, subcontractors or their employees, makes any warranty, express or implied, or assumes any legal liability or responsibility for the accuracy, completeness, or usefulness of any information, apparatus, product or process disclosed, or represents that its use would not infringe privately owned rights.

Printed in the United States of America

Available from

National Technical Information Services Springfield, Virginia 22151

Price: Printed Copy $\$ 3.00$; Microfiche $\$ 0.65$ 
Issue Date: December 30, 1970

\section{AEC RESEARCH AND DEVELOPIMENT REPORT}

This report has been prepared under Contract AT(30-1)-4187

with the U. S. Atomic Energy Commission

\section{SNAP-23A PROGRAM}

\section{THERMOELECTRIC CONVERTER}

\section{DEVELOPMENT PROGRAM}

\section{FINAL REPORT}

Prepared by:

SNAP-23A

Technical Staff

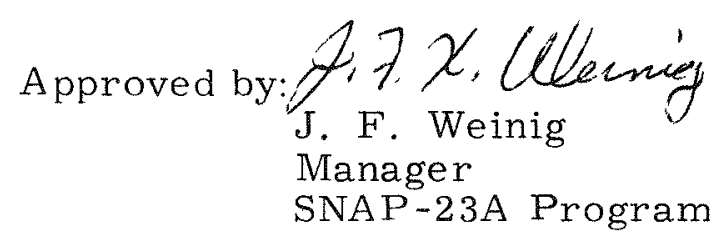

LEGAL NOTICE

This report was prepared as an account of work This report was prepared as ans by the United States Government. Neither
sponsored by United States nor the United States Atomic Energy Commission, nor any of their employees, nor any of their contractors, subcontractors, or their employees, makes any warranty, express or implied, or assumes any makes any warranty, express or implied, or assumes any pleteness or usefulness of any information, apparatus, product or process disclosed, or represents that its use would not infringe privately owned rights.

Issued by

Space and Defense Products

St. Paul, Minnesota 55101 
BLANK 
Addressee

U. S. Atomic Energy Commission

Division of Reactor Development and Technology

Washington, D. C. 20545

Attn: S. J. Seiken

U. S. Atomic Energy Commission

New York Operations Office

376 Hudson Street

New York, New York 10014

Attn. L. Wasser

U. S. Atomic Energy Commission

NY Patents Group

Upton, New York 11973

Westinghouse Electric Corporation

Astronuclear Laboratory

Post Office Box 10864

Pittsburgh, Pennsylvania 15236

Attn: Mr. J. W. Sadler

Director, Nuclear Engineering Division

Naval Facilities Engineering Command

Washington, D. C.

U. S. Atomic Energy Commission

RDT Site Office, 3M Company

P. O. Box 154

Madison, Pennsylvania 15663

Attn: T. J. Iltis

Isotopes Development Center ORNL

Post Office Box X

Oak Ridge, Tennessee 37830

Attn: R. A. Robinson

Hittman Associates, Inc.

Technical Information Department

9190 Red Branch Road

Columbia Maryland 21043

Attn: J. Leiken

U. S. Atomic Energy Commission

Division of Reactor Development and Technology

Washington, D. C. 20545

Attn: Mr. J. M. Simmons

TID -4500

Category UC -33
No. of Copies 


\section{BLANK}


TABLE OF CONTENTS

Section

Page

1.0

INTRODUCTION AND SUMMARY

$1-1$

1.1 INTRODUCTION

$1-1$

1.2

SUMMARY

1-2

1. 2.1

Converter Summary Design Description

$1-4$

1.2 .1 .1

Converter Function and Description

$1-4$

1.2.1.2 Technical Descriptive Data

1-5

2.0

DEVICE DESIGN AND DEVELOPMENT

$2-1$

2.1

TECHNOLOGY BASE LINE

$2-1$

2.2

TECHNOLOGY IMPROVEMENT

$2-2$

2.2.1 Purpose and Relationship with Balance of the Program

$2-2$

$2,2.2$

Initial Bell Jar Tests

$2-3$

2.2 .3

Ten-Couple Modules

$2-18$

2. 2.3 .1

Ten-Couple Module Design

$2-18$

2.2 .3 .2

Test Variables

$2-22$

2.2 .4

Post-Test Analysis of SNAP -23 Devices

$2-29$

2.2 .5

Cold End Temperature Drop Tests

$2-31$

2. 3

CONVERTER DEVELOPMENT

$2-37$

2. 3.1 Basic Configuration and Description

$2-37$

2.3 .2

EMC (Engineering Mockup Converter) Series

$2-40$

2. 3.2.1

Introduction

$2-40$

2.3 .2 .2

EMC-1

2- 41

2.3 .2 .3

EMC-2

2-93 
TABLE OF CONTENTS (Continued)

Section

Page

2. 3.2.4 EMC-3

$2-104$

2.3 .3

PIMC Series Converters

$2-113$

2.3 .3 .1

Introduction

$2-113$

2.3.3.2 PMC-1A and $1 \mathrm{~B}$ Converter

$2-113$

2.3 .3 .3

PMC-2 Converter

$2-163$

2.3 .3 .4

PMC-3 Converter

$2-221$

3.0

PHASE II, ADVANCED PROTOTYPE CONVERTERS (APC)

$3-1$

3.1

INTR ODUCTION

$3-1$

3.2

CONVERTER DEVELOPMENT

$3-2$

3.2 .1

Design Changes

$3-2$

3.2 .2

Development of Thermoelectric Leg and Couple Acceptance Test Methods

$3-2$

3.2.2.1 Introduction

$3-2$

3.2 .2 .2

Qualification of TEMP for Acceptance Testing

$3-3$

3.2 .3 Procurement and Fabrication

$3-8$

4.0 WANL-3M INTERFACE ACTIVITIES

4-1

4. 1

INTERFACE DOCUMENTS

4-1

4. 2

INTERFACE DRAWINGS

$4-2$

4. 3

INTERFACE MEETINGS

$4-3$

5. 0

THERMOELECTRIC COUPLE DEVELOPMENT

$5-1$

5. 1

INTRODUCTION

$5-1$

5.2

BELL JAR TESTS

$5-2$ 
TABLE OF CONTENTS (Continued)

Section

5.2.1 PMC -2 Couples: Test 20

Page

5.2 .2

PMC-3 Couples: Tests 21 and 22

$5-2$

5.2 .3

APC Couples: Tests 23 and 24

$5-2$

5.3

TEN COUPLE MODULES

$5-4$

5.3 .1

History

$5-9$

5.3 .2

Modules No. 2 and 4

$5-9$

5.3 .3

Modules No. 1 and No. 3

$5-9$

5.3 .4

Modules 5 through 12 (Factorial Test Modules)

$5-11$

5.4

SNAP-23A CONVERTER PERFORMANCE SUMMARY

$5-19$

5.4 .1

EMC-1

$5-39$

5.4 .1 .1

$\mathrm{EMC}-1$

$5-39$

5.4 .1 .2

EMC-1 History

$5-39$

5.4 .1 .3

EMC-1 Performance Predictions

$5-41$

5.4 .1 .4

EMC-1 Performance Data

$5-41$

5.4 .2

EMC-2

$5-45$

5.4 .2 .1

EMC - 2

$5-47$

5.4 .2 .2

$\mathrm{EMC}-2$ History

$5-47$

5.4 .2 .3

EMC-2 Performance Predictions

$5-47$

5.4 .2 .4

EMC-2 Performance Data

$5-47$

5.4 .3

EMC - 3

$5-47$

5.4 .3 .1

$\mathrm{EMC}-3$

$5-52$

5.4 .3 .2

EMC-3 History

$5-52$

5.4 .3 .3

EMC-3 Performance Predictions

$5-52$

$5-52$ 


\section{TABLE OF CONTENTS (Continued)}

Section

5.4.3.4 EMC-3 Performance Data 5-53

5.4.4 PMC-1A 5-57

5.4.4.1 PMC-1A Thermal and Thermoelectric Description Summary 5-57

5.4.4.2 PMC-1A History $\quad 5-57$

5.4.4.3 PMC-1A Performance Predictions 5-57

5.4.4.4 PMC-1A Performance Data 5-60

5.4.5 PMC-1B 5-60

5.4.5.1 PMC-1B Thermal and Thermoelectric Description Summary 5-60

5.4.5.2 PMC-1B History 5-63

5.4.5.3 PMC-1B Performance Predictions 5-63

5.4.5.4 PMC-1B Performance Data 5-63

5.4.6 PMC-2 5-67

5.4.6.1 PMC-2 Description 5-67

5.4.6.2 PMC -2 History 5-67

5.4.6.3 PMC-2 Performance Predictions 5-68

5.4.6.4 PMC-2 Performance Data 5-71

5.4.7 PMC-3 5-71

5.4.7.1 Description 5-71

5.4.7.2 PMC-3 History 5-74

5.4.7.3 PMC-3 Performance Predictions 5-74

5.4.7.4 PMC-3 Performance Data 5-76

5.5 TELPS MATERIAL CHARACTERIZATION $5-80$

5.5.1 General Description of TELPS Apparatus and Procedures 5-80

5.5.2 Thermoelectric Material Characteristics 5-81 
TABLE OF CONTENTS (Continued)

Section

Page

5. 6 CONTINUATION TESTING OF SNAP-23 CONVERTER

$5-91$ P2 AND MODULES A3

5.7

MODULE 23A3

$5-92$

5.8

CONVERTER 23-P2

$5-95$

6.0

FIRE TEST MODULE

$6-1$

6.1

INTRODUCTION

$6-1$

6.2

TEST DESCRIPTION

$6-2$

6.3

MODULE DESIGNS

$6-3$

6.4

FIXTURE DESIGN

$6-4$

6.5

TEST RESULTS

$6-10$

6.5 .1

Dummy Module Test

6-10

6.5 .2

Instrumented Couple Module Tests

$6-10$

6.5 .3

Fixture Calibration Tests

$6-10$

6.5 .4

$1475^{\circ} \mathrm{F}$ and $1850^{\circ} \mathrm{F}$ Fire Module Test Results

$6-11$

6.5 .5

Post-Test Fire Module Disassembly

$6-12$ 
BLANK

1 


\section{LIST OF FIGURES}

Figure

Page

$2-1$

Bell Jar Test Station

$2-5$

$2-2$

Typical Brazed Wire to Cold Cap Assembly

$2-6$

$2-3$

Instrumented Cold Caps Brazed

$2-6$

$2-4$

SNAP-23A Bell Jar Test Station

$2-8$

$2-5$

Couple Misalignment Exaggerated for Clarity

$2-12$

$2-6$

Design Configuration of the Ten-Couple Module

$2-19$

$2-7$

Instrumentation Array, SNAP-23A Ten-Couple Module

$2-20$

$2-8$

Ten-Couple Module Test Cabinet (With Module Installed)

$2-21$

$2-9$

10-Couple Modules 1 through 4 on Long-Term Test

$2-27$

$2-10$

Detail - Thermoelectric Couple

$2-32$

$2-11$

Follower/Cold Cap Contact Configurations

$2-34$

$2-12$

Cold End Temperature Drop versus Radial Mismatch

$2-35$

$2-13$

Cold End Temperature Drop versus Follower-to-Hole

$2-36$

$2-14$ Clearance

$2-38$

$2-15$

SNAP-23 Experimental Mockup Converter (Cross Section)

$2-42$

$2-16$

Thermal Interface Boundary Definition

$2-48$ for EOL Conditions

2-17 Total Head Input Rate versus Cold Junction Temperature

2-18 Number of Couples versus Cold Junction Temperature

$2-19$ for EOL Conditions

$2-20$

Converter-Fins-System Stud Assembly

$2-56$

Cold Frame Force-Loading

$2-60$

$2-21$

Converter Hot Frame - System Stud Interface

$2-62$

$2-22$

System Stud Force Diagrams

$2-62$ 


\section{LIST OF FIGURES (Continued)}

Figure

$2-23$

$2-24$

$2-25$

$2-26$

$2-27$

$2-28$

$2-29$

$2-30$

2- 31

$2-32$

$2-33$

$2-34$

$2-35$

$2-36$

$2-37$

$2-38$

$2-39$

$2-40$

$2-41$

$2-42$

Jacking Base Loading Diagram

Page

$2-63$

Experimental Mockup Converter Anticipated Surface

$2-65$

Temperatures

Sketch Showing Thermoelectric Couple Alignment Parameters

2-67

SNAP-23A Experimental Mockup Converter Electrical

$2-69$

Insulation (Boron Nitride Strip) Anchoring Method

Nitride on IN1 02

Process Test Station for SNAP-23A

$2-79$

Converter with Simulator and Jacket Assembly Mlounted in Test Fixture

Converter Mounted in Shock and Vibration Fixture

Thermoelectric Couples in Associated Hardware

$2-83$

Placement of Hot Junction Electrodes into Insulating Strip

$2-83$

Placement of Thermoelectric Couples into Assembly

Fixture

Thermoelectric Couple Assembly Fixture

Locking Couples into Generator

SNAP-23A 60-Watt Thermoelectric Converter

$2-85$

EMC Series Converter - Test Configuration

$2-86$

Conductivity versus Temperature for Powdered

$2-94$

Min-K 1301, at 12.5 $1 \mathrm{bs} / \mathrm{cu}$. ft. density

Dynamic Testing of SNAP-23A Converter EMC-2 Thermoelectric Couple Cold Caps 
LIST OF FIGURES (Continued)

Figure

2-43

2- 44

2-45

$2-46$

$2-47$

$2-48$

2-49

$2-50$

$2-51$

2-52

2-53

2-54

2-55

2-56

$2-57$

2-58

2-59

2-60
Couple Cold Junction Temperature versus Hot Junction Temperature at EOL

SNAP-23A PMC Theoretical Mapping $\mathrm{T}_{\mathrm{c}}=177^{\circ} \mathrm{F}, \mathrm{T}_{\mathrm{h}}=920^{\circ} \mathrm{F}$

Top View of Assembled SNAP-23A Converter PMC-1A

Showing Support Cone Weld

Assembled SNAP-23A PMC-1A Converter on Leak Detector Station

SNAP-23A Converter PMC-1B Thermoelectric Legs from

Row 16 (Legs A8 through A10 from right to left)

SNAP-23A Convert PMC-1B Thermoelectric Legs from Row 16

SNAP-23A Converter/System Electrical Interface Concept

SNAP-23A Converter Long-Term Performance vs Hot Junction Temperature

SNAP-23A Converter PMC-2 Configuration - Upper Area

SNAP-23A Converter PMC-2 Power Header Concept

Cut-Away View of Power Output Termination for

SNAP-23A Converter PMC-2

PMC-2 Cold Frame Interface

PMC-2 Cold Frame Force Loading

SNAP-23A Converter PMC-2 Support Cone Stress

Definition

Sketch Showing Thermoelectric Couple Alignment

Parameters

Converter Power Output Leads

Top View of Cold Frame T/E Couples and Hot Frame

Assy for SNAP-23A Converter PMC-2

Bottom View of Cold Frame, T/E Couples and Hot Frame Assy for SNAP-23A Converter PMC-2
Page

$2-119$

$2-134$

$2-148$

$2-149$

$2-160$

$2-161$

$2-164$

$2-174$

$2-181$

$2-182$

2-183

2-184

2-184

2-185

$2-188$

2-195

2-198

2-198 


\section{LIST OF FIGURES (Continued)}

Figure

$2-61$

$2-62$

$2-63$

$2-64$

$2-65$

$2-66$

$2-67$

2-68

$2-69$

$2-70$

$5-1$

$5-2$

$5-3$

$5-4$

$5-5$

$5-6$

$5-7$

$5-8$

$5-9$
Assembled Row of T/E Couples

Visual Inspect on the The rmopile

Modified Boron Nitride Insulation Strip for SNAP-23A Converter PMC-2 Rebuild

Comparison of P-Legs Removed From PMC-2

Erosion of Hot Junction Electrode Removed From PMC-2

SNAP-23A Converter PMC-2 Thermal Performance

Temperature Rise of Spud and Hot Frame versus Position of Converter and Time

Hot Junction Electrode Comparison Couples in Bell Jar Test No. 2

Temperature Rise of Spud and Hot Frame versus Position of Converter and Time

APC Couple B. J. Tests N-Leg Performance

APC Couple B.J. Tests P-Leg Performance

SNAP-23A Ten Couple Module No. 1 - Seebeck Ratio vs Time

SNAP-23A Ten Couple Module No. 1 - Resistance Ratio vs Time

SNAP-23A Ten Couple Module No. 1 - Power Ratio vs Time

SNAP-23A Ten Couple Module No. 3 - Seebeck Ratio vs Time

SNAP-23A Ten Couple Module No. 4 - Resistance vs Time

SNAP-23A Ten Couple Module No. 3 - Power Ratio vs Time

N-Leg Statistical Analysis (Microquartz Modules)

Average and Main Effects for Seebeck Ratio
$2-223$

$2-229$

$2-234$

$5-6$

5-7

5-13

Page

2-198

2-200

2-207

2-209

2-110

2-115

2-117

5-14

5-15

5-16

5-17

5-18

5-25 


\section{LIST OF FIGURES (Continued)}

Figure

Page

5-10 N-Leg Statistical Analysis (Microquartz Modules) Average and Main Effects for Resistance Ratio

Average and Main Effects for Power Ratio

5-13 N-Leg Statistical Analysis (Min-K 1301 Modules) Average and Main Effects for Resistance Ratio

5-14 N-Leg Statistical Analysis (Min-K 1301 Modules) Average and Main Effects for Power Ratio Average and Main Effects for Seebeck Ratio

5-16 P-Leg Statistical Analysis (Microquartz Modules) Average and Main Effects for Resistance Ratio

5-17 P-Leg Statistical Analysis (Microquartz Modules) Average and Main Effects for Power Ratio Average and Main Effects for Resistance Ratio

5-20 P-Leg Statistical Analysis (Min-K 1301 Modules) Average and Main Effects for Power Ratio

Combinations of P-Legs and Hot Junction Temperatures (Min-K 1301 Modules)

5-22 Comparison of Average Power Ratio for Various

Combinations of $\mathrm{P}$-Legs and Thermal Insulations 


\section{LIST OF FIGURES (Continued)}

Figure

Page

$5-26$

Individual TELPS Fixture With Isothermal Furnace

$5-82$ Used for Thermocouple Calibration

$5-27$

TELPS Laboratory

$5-83$

$5-28$

Seebeck Coefficient(S) (N-Leg, Hot Segment LTN-120,

$5-85$ $\mathrm{PbTe}$ ES 1103-3N)

5-29 Resistivity (o) (N-Leg, Hot Segment LTN-120,

$5-85$ $\mathrm{PbTe}$ ES 1103-3N)

$5-30$

Thermal Conductivity (K) (N-Leg, Hot Segment LTN-120, $\mathrm{PbTe}$ ES 1103-3N)

5-31 Dimensionless Figure of Merit (ZT) (N-Leg, Hot Segment LTN-120, PbTe ES 1103-3N)

5-32 Seebeck Coefficient (S) (N-Leg, Cold Segment LTN-400, 5-86 $\mathrm{PbTe}$ ES 1104, ES 1104-4N)

5-33 Resistivity (o) (N-Leg, Cold Segment LTN-400, 5-86 $\mathrm{PbTe}$ ES 1104-4N)

5-34 Thermal Conductivity (K) (N-Leg, Cold Segment LTN-400, PbTe ES $1104-4 N$ )

Dimensionless Figure of Merit (ZT) (N-Leg, Cold Segment LTN-400, PbTe ES 1104-4N)

$5-86$

Seebeck Coefficient (S) (P-Leg, Hot Segment TPM-76, $\mathrm{PbSnTe}$ ES 1113-7P)

5-37 Resistivity (O) (P-Leg, Hot Segment TPM-76, PbSnTe ES 1113-7P)

5-38 Thermal Conductivity (K) (P-Leg, Hot Segment TPM-76, $\mathrm{PbSnTe}$ ES 1113-7P)

Dimensionless Figure of Merit (ZT) (P-Leg, Hot Segment TPM-76, PbSnTe ES 1113-7P)

Seebeck Coefficient (S) (P-Leg, Cold Segment TPM-29, 


\section{LIST OF FIGURES (Continued)}

\begin{tabular}{|c|c|c|}
\hline Figure & & Page \\
\hline $5-42$ & $\begin{array}{l}\text { Thermal Conductivity (K) (P-Leg, Cold Segment } \\
\text { TPM-29, BiSbTe ES } 1116-10 \mathrm{P})\end{array}$ & $5-88$ \\
\hline $5-43$ & $\begin{array}{l}\text { Dimensionless Figure of Merit }(Z T) \text { (P-Leg, Cold Segment } \\
\text { TPM-29, BiSbTe ES 1116-10P) }\end{array}$ & $5-88$ \\
\hline $5-44$ & $\begin{array}{l}\text { Seebeck Coefficient (S) (P-Leg Hot Segment For } \\
\text { Separately Pressed and Bonded PbSnTe ES 1110-3P) }\end{array}$ & $5-89$ \\
\hline $5-45$ & $\begin{array}{l}\text { Resistivity }(\rho)(P-L e g, \text { Hot Segment For Separately } \\
\text { Pressed and Bonded PbSnTe ES 1110-3P) }\end{array}$ & $5-89$ \\
\hline $5-46$ & $\begin{array}{l}\text { Thermal Conductivity (K) (P-Leg, Hot Segment for } \\
\text { Separately Pressed and Bonded PbSnTe ES 1110-3P) }\end{array}$ & $5-89$ \\
\hline $5-47$ & $\begin{array}{l}\text { Dimensionless Figure of Merit }(Z T)(P-L e g, \text { Hot Segment } \\
\text { Pressed and Bonded PbSnTe ES } 1110-3 P)\end{array}$ & $5-89$ \\
\hline $5-48$ & $\begin{array}{l}\text { SNAP- } 23 \text { Six-Couple Module } 23-\mathrm{A} 3, \mathrm{~N} \text {-Leg Performance } \\
\text { History }\left(\mathrm{T}_{\mathrm{H}}=11^{\circ} \mathrm{F}, \mathrm{T}_{\mathrm{C}}=200^{\circ} \mathrm{F}\right)\end{array}$ & $5-93$ \\
\hline $5-49$ & $\begin{array}{l}\text { SNAP-23 Prototype Converter } 23-\mathrm{P} 2 \mathrm{BOL} \text { History } \\
\left.\text { (Normalized Data } \mathrm{T}_{\mathrm{H}}=1070^{\circ} \mathrm{F}, \mathrm{T}_{\mathrm{C}}=200^{\circ} \mathrm{F}\right)\end{array}$ & $5-96$ \\
\hline $6-1$ & $\begin{array}{l}\text { Calculated Response of SNAP-23A Generator Components } \\
\text { During } 1475^{\circ} \mathrm{F} \text { Half Hour Fire }\end{array}$ & $6-5$ \\
\hline $6-2$ & $\begin{array}{l}\text { Calculated Response of SNAP-23A Generator Components } \\
\text { During } 1850^{\circ} \mathrm{F} \text { Half Hour Fire }\end{array}$ & $6-6$ \\
\hline $6-3$ & Six-Couple Fire Module & $6-7$ \\
\hline $6-4$ & Fire Module Test Stand & $6-9$ \\
\hline $6-5$ & Cut-Away View of Fire Module After $1475^{\circ} \mathrm{F}$ Test & $6-16$ \\
\hline $6-6$ & Cut-Away View of Fire Module After $1850^{\circ} \mathrm{F}$ Test & $6-16$ \\
\hline
\end{tabular}


d

BLANK 


\section{LIST OF TABLES}

Table

Page

2-1 Technology Improvement Program 2-3

2-2 10-Couple Modules Test Variable Matrix 2-23

2-3 SNAP-23A Experimental Mockup Converter Parts 2-39

2-4 Initial Converter Couple Geometry 2-44

2-5 Component Geometries for Various EOL Cold Junction 2-46

2-6 SNAP-23A Experimental Mockup Converter Performance . 2-46 Characteristics at $\mathrm{BOL}$

2-7 SNAP-23A Experimental Mockup Converter 2-47

2-8 SNAP-23A Experimental Mockup Converter EOL 2-52 Operating Parameters

2-9 SNAP-23A. Experimental Mockup Converter BOL 2-53 Operating Parameters

2-10 SNAP-23A Experimental Mockup Converter Thermoelectric 2-55 Couple Parameters

2-11 Spring Rate Analysis Results 2-57

2-12 Converter Weldment Stresses $2-59$

2-13 Assembly/Disassembly Forces For Two Taper Conditions 2-61

2-14 Couple Alignment Hot and Cold Condition Dimensions 2-66

2-15 Tensile Strength for Boron Nitride at Various Temperatures $2-68$

2-16 SNAP-23A Converter EMC-1 Initial Performance 2-89

2-17 SNAP-23A Converter EMC-1 Initial Performance Ratios 2-89

2-18 SNAP-23A Converter EMC-1 Test Data for EOL Off-Design 2-91

Cold Junction Temperatures (Nominal EOL $\mathrm{T}_{c}=174^{\circ} \mathrm{F}$ )

2-19 SNAP-23A Converter EMC-1 Test Data for BOL Off-Design 2-92 Cold Junction Temperatures (Nominal BOL $\mathrm{T}_{\mathrm{c}}=191^{\circ} \mathrm{F}$ )

2-20 Converter Shunt Heat Loss, EOL 
LIST OF TABLES (Continued)

Table

Page

$2-21$

SNAP-23A Converter EMC-2 Initial Performance

$2-97$

$2-22$

$2-23$

SNAP-23A Converter EMC-2 Initial Performance

$2-99$

SNAP-23A Converter EMC-2 Test Data for EOL Off-Design Cold Junction Temperatures

$2-101$

$2-24$

SNAP-23A Converter EMC-2 Test Data for BOL Off-Design

$2-101$ Cold Junction Temperatures

Performance Data for SNAP-23A Converter EMC-2

$2-103$ Dynamic Test

$2-26$

Thermoelectric Generator Performance Comparison

$2-106$

$2-27$

SNAP-23A Converter EMC-3 Initial Performance

$2-109$

$2-28$

SNAP-23A Converter EMC-3 Initial Performance Ratios

$2-111$

$2-29$

SNAP-23A Converter EMC-3 Test Data for EOL Off-Design Cold Junction Temperatures

2-30 SNAP-23A Converter EMC-3 Test Data for BOL Off-Design Cold Junction Temperatures

$2-31$

$2-32$

Shunt Heat Loss - Cold Frame Size Comparison at EOL

$2-112$

$2-33$

Heat Balance Tabulation

$2-112$

$2-116$

$2-120$

Abbreviated Heat Balance Tabulation for EOL Conditions

$2-121$

Temperature Drop From Leg Cold Junction to Outer Case

$2-123$

$2-34$

$2-35$

Seebeck Voltage and Resistance Ratios

$2-130$

Dimensional and Material Leg Characteristics for

$2-131$ 252-Couple PMC Converter

2-37 Performance Characteristics for 252-Couple PMC

$2-132$

Converter with Nominal Adjustment Factors

2-38 Performance Characteristics for 252-Couple PMC

$2-133$

Converter With Design Case Adjustment Factors

$2-133$

$2-39$

Total Converter Heat Input Comparison at EOL

$2-136$ 


\section{LIST OF TABLES (Continued)}

Table

Page

2-41 PMC Sensitivity to Resistance Ratio

$2-136$

$2-42$

Shunt Heat Losses for EMC and PMC Converters

$2-137$

$2-43$

SNAP-23A PMC Parametric Design Data Summary

$2-138$

$2-44$

SNAP-23A Converter PMC Theoretical Design for EOL

$2-140$ Conditions of $\mathrm{T}_{\mathrm{c}}=177^{\circ} \mathrm{F}$ and $\mathrm{T}_{\mathrm{h}}=920^{\circ} \mathrm{F}$ (Worst Case)

2-45 SNAP-23A Converter Theoretical Performance for EOL Conditions of $T_{C}=177^{\circ} \mathrm{F}$ and $T_{h}=900^{\circ} \mathrm{F}$ (Worst Case)

$2-141$

2-46 SNAP-23A Converter PMC Theoretical Performance for
EOL Conditions of $\mathrm{T}_{\mathrm{C}}=178^{\circ} \mathrm{F}$ and $\mathrm{T}_{\mathrm{h}}=880^{\circ} \mathrm{F}$ (Worst Case)

$2-142$

$2-47$

Effect of Conditions on EOL Performance $\left(\mathrm{T}_{\mathrm{c}}=177^{\circ} \mathrm{F}\right.$ and $\left.\mathrm{T}_{\mathrm{h}}=920^{\circ} \mathrm{F}\right)$

2-48 Influence of Cold End $\Delta \mathrm{T}$ Between Cold Junction and Fin Base (Fixed Design at Worst Case)

SNAP-23A Converter PMC-1A Initial Performance

$2-143$

$2-144$

$2-150$

$2-50$

SNAP-23A Converter PMC-1A Performance Data (Ratio of Experimental-to-Theoretical Values)

$2-152$

SNAP-23A Converter PMC-1B Initial Performance Data

$2-155$ (Ratio of Experimental-to-Theoretical Values)

2-53 SNAP-23A Converter Cold End Heat Transfer Data

$2-157$

$2-54$

SNAP-23A Converter PMC-1B Performance Data for

$2-158$ Off-Design Temperatures (EOL Conditions)

2-55 SNAP-23A Converter PMC-2 Thermopile Design 2-166 Adjustment Ratios

2-56 SNAP-23A Converter PMC-2 Thermopile Design 2-168 Characteristics

2-57 SNAP-23A Converter PMC-2 Thermopile Design Supplemental Data

2-58 Modified SNAP-23A Converter PMC-2 Thermopile Design

$2-169$ 


\section{LIST OF TABLES (Continued)}

Table

2-59 SNAP-23A Converter PMC-2 Increased Ambient Temperature Data

2-60 Thermoelectric Characteristics

$2-61$

$2-62$

2-63

$2-64$

$2-65$

$2-66$

$2-67$

$2-68$

$2-69$

$2-70$

$2-71$

$2-72$

$2-73$

$2-74$

$2-75$

$2-76$

$2-77$

SNAP-23A Converter PMC-2 Parameter Study

SNAP-23A Converter PMC-2 Parameter Study Reference Heat Input Case

SNAP-23A Converter Support Cone Stresses (Preliminary)

$$
\text { SNAP-23A Converter PMC-2 Instrumentation }
$$
Design Criteria

SNAP-23A Converter Q. C. Data Summary in $\mathrm{PMC}-2$ (Ratio of Experimental-to-Theoretical Values)

Nominal SNAP-23A Converter PIC-2 $3 \mathrm{MI}$ and Westinghouse Minimum Heat Input Case

SNAP-23A Converter PMC-2 Parameter Study Maximum
Heat Input Case

Change in SNAP-23A Converter PMC-2 Shunt Heat Losses

Revised SNAP-23A Converter PMC-2 Heat Requirements

SNAP-23A Converter PMC-2 Top Cover Heat Losses

SNAP-23A Converter PMC-2 Performance versus

Emission Spectrographic Analysis of Foreign Material

Microprobe Analysis of Foreign Material in PMC-2

SNAP-23A Converter PMC-2 Initial Performance

SNAP-23A Converter PMC-2 Initial Performance Data

SNAP-23A Converter PMC-2 Electrical Performance at

SNAP-23A Converter PMC-2 Removal From FPMS
$2-213$

Page

$2-172$

$2-175$

$2-176$

$2-177$

2-178

2-186

2-189

2-190

2-192

$2-193$

2-203

2-204

2-205

2-205

2-211

2-212

2-218

$2-220$ 


\section{LIST OF TABLES (Continued)}

Table

Page

2-78 Selection of SNAP-23A Converter PMC-3 P-Leg 2-224 Hot Segment Material

Mating Schedule of SNAP-23A Converter PMC-3 to

$2-232$ (BOL Conditions) (EOL Conditions) 


\section{LIST OF TABLES (Continued)}

Table

Page

5-11 SNAP-23A Converter EMC-2 Performance Data -

BOL Conditions (Ratio of Experimental-to-Theoretical Values) (BOL Conditions)

SNAP-23A Converter PMC-2 Performance Predictions Nominal Fuel Loading Conditions

5-24 SNAP-23A Converter PMC-2 Thermopile Design 5-70 Adjustment Ratios Conditions (Ratio of Experimental-to-Theoretical Values) 
LIST OF TABLES (Continued)

Table

Page

$5-28$

SNAP-23A Converter PIM- 3 Performance Data

$5-76$

(Ratio of Experimental-to-Theoretical Values)

$5-77$

$5-29$

SNAP-23A Converter PIC-3 Performance Data

$5-90$

$5-30$

$\mathrm{P}$ - and N-Leg Bell Jar Performance Test Data

$(5-90$

$\left(\mathrm{T}_{\mathrm{h}}=1100^{\circ} \mathrm{F}, \mathrm{T}_{\mathrm{c}}=190^{\circ} \mathrm{F}, 250\right.$ psi Contact Pressure, 50-100 Hour Data

$5-31$

Thermoelectric Element Data Converter 23-P2 and

$5-91$ Module 23-A3

5-32 SNAP-23 Six-Couple Module 23-A3 N-Leg Performance

$5-94$ Data

$5-33$

SNAP-23 Converter 23-P2 Performance Data

$5-97$

$5-34$

SNAP-23 Converter 23-P2 BOL, Performance Data

$5-98$

$6-1$

Fire Module Design Summary

$6-8$

$6-2$

Couple Instrumented Fire Test Module Comparison with

$6-13$ PMC-2 Converter

$6-3$

Fire Calibration Module Test Results

$6-13$

$6-4$

Fire Test Reduced Data Test Module Conductance and

$6-14$

$6-5$ Predicted Converter Total Conductance

$6-15$

Fire Test Reduced Data Test Module Conductance and Predicted Converter Total Conductance 


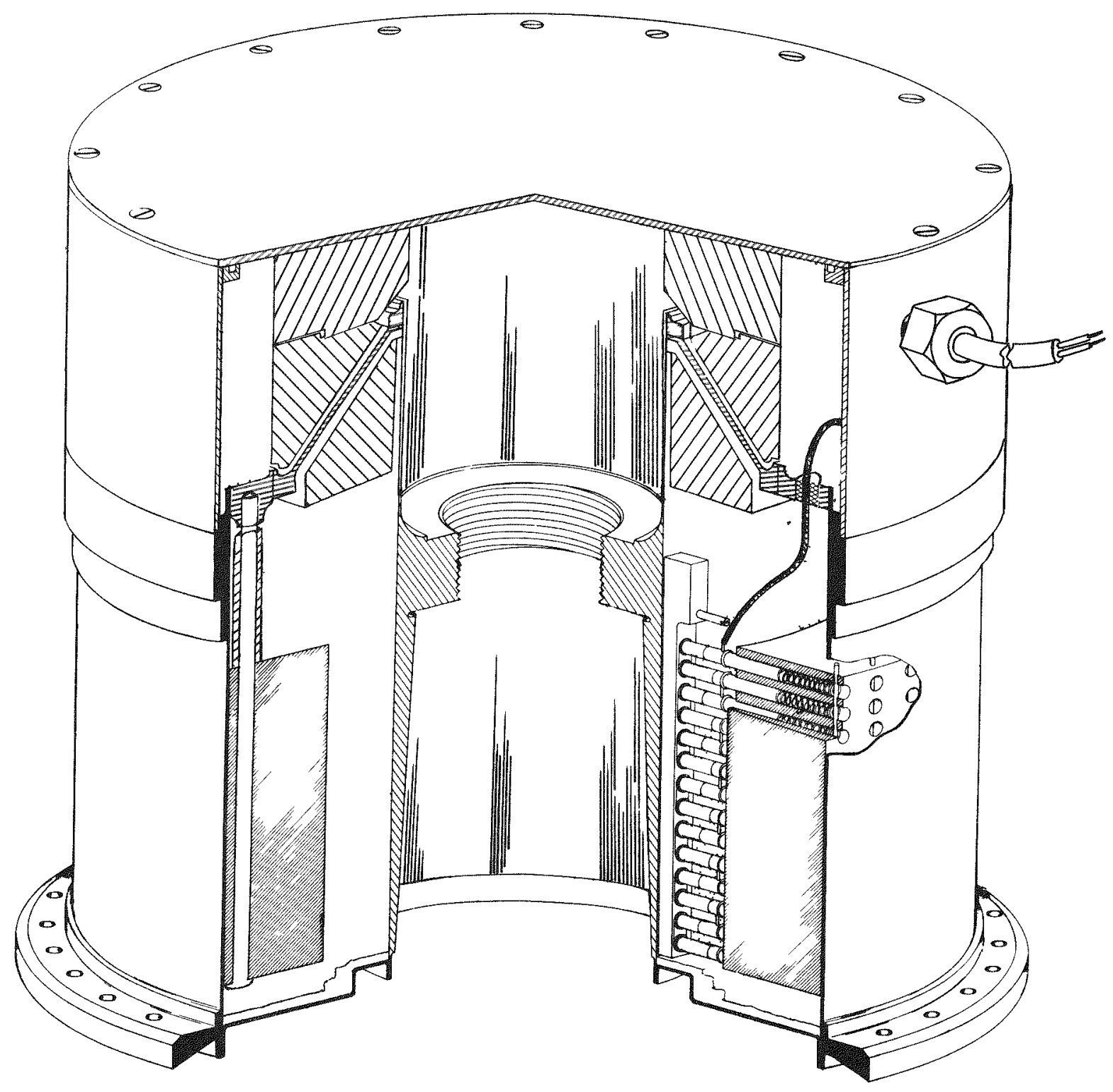

Figure 1-1

SNAP-23A 60-Watt Thermoelectric Converter (PMC-3 Configuration) 


\subsection{INTRODUCTION AND SUMMARY}

\section{1 INTRODUCTION}

The 3M Company under contract to the Atomic Energy Commission, designed, developed, fabricated, and demonstrated the SNAP-23 60-watt mockup radioisotope power system. This initial work was performed under Contract AT(30-1)-3418, during the period June 1964 through June 1967, and culminated in the fabrication and demonstration of two 60 -watt thermoelectric converters and several test modules using segmented thermoelectric legs and couples. This initial program, designated SNAP-23, was directed toward the development of high performance, reliable thermoelectric converter modules, using segmented thermoelectric legs, and having an objective five-year design life.

As a result of the significant early achievements in the application of segmented thermoelectric technology demonstrated with these laboratory devices, and on the basis of other demonstrated technological development and operating experience obtained with radioisotope systems, the AEC initiated a follow-on program to develop a series of advanced terrestrial radioisotope power systems in the 25 to 100 watt (e) power range.

The overall objectives of this program, designated SNAP-23A, were to design, develop, and demonstrate operation of a series of advanced radioisotope power systems for terrestrial application which are capable of achieving operating lifetimes of ten years; which have inherent high reliability, and which are significantly superior to available systems in terms of size, weight, and unit power cost. 
The 3MI Company (3M) was selected to contimue development of the improved SNAP-23A thermoelectric converters. Westinghouse Astronuclear Laboratory (WANL) was selected to design the SNAP-23A Advanced Power System. 3M and WANL interfaced to integrate the thermoelectric converters into this system.

The SNAP-23A program was conducted in two phases. Phase I, AEC Contract $\mathrm{AT}(30-1)-3824$, which was initiated in February 1967 and extended to February 1970, included improving the technological base by providing the engineering design, materials, and component development effort which culminated in fabrication, testing, and successful integration of 60-watt (e) prototype converters with the SNAP-23A system.

Phase II, AEC Contract AT(30-1)-4187, which was initiated in February 1970, involved completion of the final converter design and fabrication of 60-watt (e) converters intended for field service application as part of the SNAP-23A Advanced Prototype Systems. Phase II work was terminated on June 30, 1970.

The initial program objectives called for preparation of converter designs for application to systems of $25-, 60-$, and 100-watt (e) power output with emphasis on "commonality" of technology. A specific converter design was prepared only for the 60-watt system. However, the technology and specific design details incorporated into the 60-watt converter configuration were developed for potential applicability to the entire range of system sizes.

\subsection{SUMMARY}

This report summarizes the SNAP-23A Converter Development Program conducted in Phases I and II.

The 60-watt converter development effort was initiated with the Experimental Mockup Converter (EMC) Series which were designed to incorporate the "technology baseline" successfully demonstrated in the prior SNAP-23 program, but adapted in configuration to integrate with the SNAP-23A system under development by WANL. Three units were built and operated: EMC-1, EMC-2, and EMC-3. These converters made the following contributions toward meeting program objectives: 
- Verification of the "technology baseline" in the SNAP-23A hardware configuration.

- Establishment of critical thermal, electrical, and mechanical interfaces between the converter and system.

- Demonstration of capability of the converter design to meet MII-STD-810A shock and vibration requirements.

- Incorporation of improved technology from the SNAP-23A supporting development task and from other programs.

- Generation of experimental data which was used to improve subsequent converter design.

The EMC converters were followed by the Prototype Mockup Converter (PMC) series which were design-oriented toward field service capability. Each succeeding converter design incorporated changes or improvements based on previous converter experience and supporting development task data. Four units were built and operated: $\mathrm{PMC}-1 \mathrm{~A}, \mathrm{PMC}-1 \mathrm{~B}, \mathrm{PMC}-2$, and $\mathrm{PMC}-3$. These four converters demonstrated the achievement of the following program objectives:

- Converter energy conversion efficiency at end-of-life (EOL) in excess of 7.7 percent.

- Mating of converters to both electrically heated and nuclear fueled systems.

- Successful thermal and thermoelectric operation of three of the converters when integrated with the system.

- Converter configuration and materials of construction suitable for system field service operation.

In addition to the programatic accomplishments several outstanding technical achievements were attained during the program. These achievements were of significance to the SNAP-23A Program and are considered potentially applicable to other thermoelectric programs: 
- Thermopile design and operating temperatures were established on the basis of thermoelectric degradation as a function of operating time and temperature.

- Increased converter efficiency was obtained at end-of-life conditions by using the Peltier cooling effect at beginning-oflife to reduce hot junction temperature.

- Measured converter efficiency of 8.1 percent at end-of-life conditions.

- Reliability demonstrated by a total of 7.5 converter-years of operation and a total of 1962 couple-years of operation in a converter. The EMC-3 converter operated 20,266 hours continuously.

- Use of ingradient thermoelectric performance data to verify the acceptability of production batches of legs for use in a converter.

- A total of 17,108 hours of converter operating hours accumulated while mated to the system, without measureable degradation.

\subsubsection{Converter Summary Design Description}

\subsubsection{Converter Function and Description}

The function of the thermoelectric converter is to convert heat directly into electricity with maximum efficiency and reliability for a ten-year operating period. The SNAP-23A thermoelectric converter must satisfy the following functional requirements:

- Be mechanically, physically, electrically, thermally, and dynamically compatible with the 60-watt system objectives.

- Interface with the 60-watt system in a manner which will permit repair, removal, or replacement of the converter in the field without the use of hot cell facilities.

- Produce a minimum power output of 60-watts (e) at 24 volts over the operating lifetime of ten years. 
The converter assembly, as illustrated in Figure 1-1, is a hermetically sealed unit configured as a right cylinder which contains the thermoelectric couples, thermal insulation, electrical insulation, instrumentation, and electrical connections. The hot frame provides an interface for attachment to the heat source assembly (stud). The outer case is an integral part of the converter assembly and provides the interface for attachment of the system heat rejection assembly (radiator).

Electrical connection of the convertex to the system power conditioner utilizes hermetic feedthroughs and a watertight cable through the upper converter enclosure.

\subsubsection{Technical Descriptive Data}

Converter Designation: SNAP-23A Prototype Mockup Converter Number Three (PMC-3) as illustrated by Figure $1-1$.

Status: Prototype design complete for field service on Nuclear Fueled System.

Date: June 30,1970

\subsection{System Interfacing}

Thermoelectric converter mates with system in three areas; system stud, fin array radiator, and electric power conditioner.

Interface with System Stud:

Interface Pressure - 500 psi

Interface Dimensions - Taper surface, 3.29 diameter which increases in diameter 1.25 inch per foot for a length of 3.75 inches.

\begin{tabular}{|c|c|c|}
\hline & $\mathrm{BOL}$ & EOI \\
\hline Average Hot Frame Temperature ${ }^{\circ} \mathrm{F}$ & 1054 & 897 \\
\hline Temperature at Hot Frame Top ${ }^{\circ} \mathrm{F}$ & 1069 & 912 \\
\hline Temperature at Hot Frame Bottom ${ }^{\circ} \mathrm{F}$ & 1039 & 882 \\
\hline Heat Input to Converter Watts & 1048 & 818 \\
\hline
\end{tabular}


Interface with System Radiator:

Interface Pressure - 150 psi Average

Interface Dimension - Cylindrical surface, 9.34 diameter, 3.74 length.

Ambient Temperature ${ }^{\circ} \mathrm{F}$

BOL EOL

Average Cold Frame Temperature ${ }^{\circ} F$

$70 \quad 70$

Heat Rejected to Radiator Watts

$152 \quad 139$

$965 \quad 755$

Electrical Interface:

Physical Connection - Blocked construction cable manufactured to meet specification MIL-C-915/8A Type DSS-2.

Load Voltage

BOL EOL

Nominal Load Current

$24 \quad 24$

Nominal Power, Watts

$3.45 \quad 2.61$

$82.7 \quad 62.7$

1.2.1.2.2 General Converter Characteristics:

Operating Life

Storage Life

Overall Size;

Length

Diameter

Thermopile Active Length

Weight
10 years

1 year

9.52 inches

10.625 inches

3.740 inches

$42 \mathrm{lbs}$

1.2.1.2.3 Externally Applied Mechanical Loads:

Vibration - Double the amplitude below $50 \mathrm{cps}$ frequency of Figure 514-6

(10G Max) of MIL-STD-810A applied to converter hot frame

Shock - 10G maximum shock pulse per procedure I, III, and VI Method

516.1 of MIL-STD-810A applied to converter hot frame.

Weight Supported by Converter Outercase -77 pounds 
1.2.1.2.4 Thermopile Characteristics:

Physical:

Couples

Type of Circuit

Leg Arrangement

Number of Rows

Couples per Row

Couple Description:

Leg Construction

Hot Segment Material

Cold Segment Material

Hot Contact Material

Leg Diagmeter

Leg Length

Cold Segment Length

Length/Area Ratio
280

Series

Radial around hot frame

40

7

\begin{tabular}{|c|c|}
\hline N-Leg & P-Leg \\
\hline Segmented & Segmente \\
\hline $\mathrm{PbTe}$ & $(\mathrm{PbSn}) \mathrm{Te}$ \\
\hline $\mathrm{PbTe}$ & $(\mathrm{BiSb})_{2} \mathrm{~T}$ \\
\hline Normal & Soft Nose \\
\hline $.187 \mathrm{in}$ & $.187 \mathrm{in}$. \\
\hline .466 in. & .355 in. \\
\hline $.163 \mathrm{in}$ & .138 in. \\
\hline 17 & 12.9 \\
\hline
\end{tabular}

1.2.1.2.5 Nominal Operating Characteristics:

Thermoelectric:

Open Circuit Voltage

Load Voltage

Current

Power Output, Watts

Efficiency

Thermal:

Max. Hot Junction Temperature ${ }^{\circ} \mathrm{F}$

Average Hot Junction Temperature ${ }^{\circ} \mathrm{F}$

Average Cold Junction Temperature ${ }^{\circ} \mathrm{F}$

Converter Heat Input, Watts

Converter Heat Rejected, Watts

$\Delta^{t^{O}} \mathrm{~F}$. Hot Frame to Hot Junction

$\Delta^{t} F$, Cold Junction to Outer Case
BOL EOL

$53.0 \quad 41.4$

$24.0 \quad 24.0$

$3.45 \quad 2.61$

$82.7 \quad 62.7$

$7.92 \quad 7.70$

BOL EOL

1022867

$1004 \quad 852$

$187 \quad 169$

$1048 \quad 818$

$965 \quad 755$

$50 \quad 45$

$35 \quad 30$ 


\subsection{DEVICE DESIGN AND DEVELOPMENT}

\subsection{TECHNOLOGY BASE LINE}

The technology base line for the SNAP-23A thermoelectric converters was established under the SNAP-23 program which was conducted during the period June 15, 1964 to September 30, 1966. In this program two six-couple test modules, two full-sized converters and one electrically heated mockup system were built and tested. The two six-couple modules were operated 14,910 hours and 14,840 hours; the two converters were operated 6749 hours and 9183 hours. The performance of these four devices established the feasibility of the thermoelectric technology. The performance of the two full-sized converters established the feasibility of the overall configuration and specific arrangement of components.

The design of the first converters of the Experimental Mockup Converters (EMC) series was based on the SNAP-23 technology. Initial EM $\overline{M C}$ devices did incorporate certain improvements to the base line technology, such as improved methods and controls for producing thermoelectric legs, which had been made since SNAP-23 was completed and SNAP-23A started. 


\subsection{TECHNOLOGY IMPROVEMENT}

2.2.1 Purpose and Relationship with Balance of the Program

As the objectives of this program were to improve on the SNAP -23 technology to achieve longer life, greater reliability, and reduced cost, a technology improvement task was conducted. A portion of this effort was devoted specifically to thermoelectric technology. This included the following items:

- Thermoelectric materials selection

- Thermoelectric material properties characterization

- Method of leg fabrication

- Leg contacting materials

- Leg alignment.

In addition to the thermoelectric leg variables, an evaluation of the following items was conducted:

- Thermal insulation

- Leg contact pressure

- Hot junction operating temperatures

- Thermoelectric couple related hardware

- Cold end heat transfer system.

To evaluate the different variables, several types of tests were conducted, some of which required long-term operation before the effect could be determined. For this reason, the technology developed during this improvement program was not prescheduled to be incorporated into any specific converter. Instead, the new or revised technology would be incorporated into the converter design when the technology was developed to the extent that its effect could be reliably predicted. In this way, the development of the converters as related to structure and enclosure design, fabrication techniques, assembly methods, and quality control procedures could proceed without being delayed for inputs from thermoelectric development. 
The technology improvement was carefully planned to make use of previously developed knowledge and techniques; each test had a specific purpose to develop data in areas where unknowns existed. Table 2-1 is a summary of the tests conducted.

Table 2-1

Technology Improvement Program

\begin{tabular}{|c|c|c|}
\hline Device & $\begin{array}{c}\text { Number of } \\
\text { Devices or Tests }\end{array}$ & $\begin{array}{l}\text { Objective of } \\
\text { the Operation }\end{array}$ \\
\hline Bell Jar & 18 & $\begin{array}{l}\text { Conduct short-term } \\
\text { performance tests with } \\
\text { thermoelectric couples. }\end{array}$ \\
\hline 10-Couple Modules & 12 & $\begin{array}{l}\text { Conduct long-term } \\
\text { performance tests with } \\
\text { thermoelectric couples. }\end{array}$ \\
\hline SNAP-23 PI & 1 & $\begin{array}{l}\text { Conduct post-test analysis } \\
\text { of generator which had been } \\
\text { on long-term operation. }\end{array}$ \\
\hline TELPS Fixture & 4 & $\begin{array}{l}\text { Perform thermoelectric } \\
\text { material characterization. }\end{array}$ \\
\hline $\begin{array}{l}\text { SNAP-23 6-Couple } \\
\text { Module A } 2\end{array}$ & 1 & $\begin{array}{l}\text { Conduct post-test analysis } \\
\text { of module which had been } \\
\text { on long-term operation. }\end{array}$ \\
\hline $\begin{array}{l}\text { Cold End Heat } \\
\text { Transfer Bell Jar }\end{array}$ & 1 & $\begin{array}{l}\text { Conduct tests to determine } \\
\text { effect of part fit on cold } \\
\text { end temperature drop. }\end{array}$ \\
\hline
\end{tabular}

\subsubsection{Initial Bell Jar Tests}

Bell jar tests were conducted as a part of the termoelectric technology improvement program. The bell jar fixture was a convenient laboratory tool to evaluate performance of legs at converter operating temperature conditions; the fixtures were used as short-term devices with an arbitrary limitation of about 1000 hours maximum operating time for each test set up. The bell jar was used to evaluate variations from the base line technology which were directly related to thermoelectric performance. Variables were either the thermoelectric legs, hot and cold contact materials, leg positioning, processing schedule or operating temperature. In some cases the conclusions from the bell jar tests were applied directly to converter design changes. Because it was only a short-term, two-couple fixture, the results were generally used in conjunction with other data to make 
design decisions. In some cases the resultant data established the basis for longterm tests in the ten-couple modules. Those areas of design which bell jar data contributed to, either directly or with other data, are included in the following list.

- To select method of leg fabrication.

- To determine if iron or molybdenum should be used as leg hot end contacting material.

- To determine if "soft-nose" contacting material should be used on hot end of P-leg.

- To determine effect of leg tilt or misalignment on hot contact electrical resistance.

- To compare thermoelectric performance of different batches of couples or similar couples in different devices.

- To determine effect of elapsed time and environment during assembly and processing on thermoelectric performance.

- To determine effect of the 100-hour elevated temperature excursion.

During the program these determinations were made when the necessary data became available and were incorporated in the next converter that was being designed or built.

The bell jar fixture is shown schematically by Figure $2-1$. This figure shows the bell jar enclosure and location of the test samples. The bell jar cover fits onto a base plate which forms the sealed enclosure. Two thermoelectric couples, each consisting of one N-type and one P-type leg, are tested in the fixture. Figure 2-2 shows a typical couple assembly. Figure $2-3$ shows the cold cap assembly instrumented for measurement of cold junction temperature.

These couples are mounted in the bell jar in the same manner and with the same related couple hardware as in a full size converter. The thermoelectric legs are subjected to the same temperatures at the hot and cold end, similar temperature gradients along the leg length and the same spring loading system, hot and cold end contacts, and current flow. The legs are not subjected to physical movement from thermal expansion in the same manner as legs in the full sized converter. 


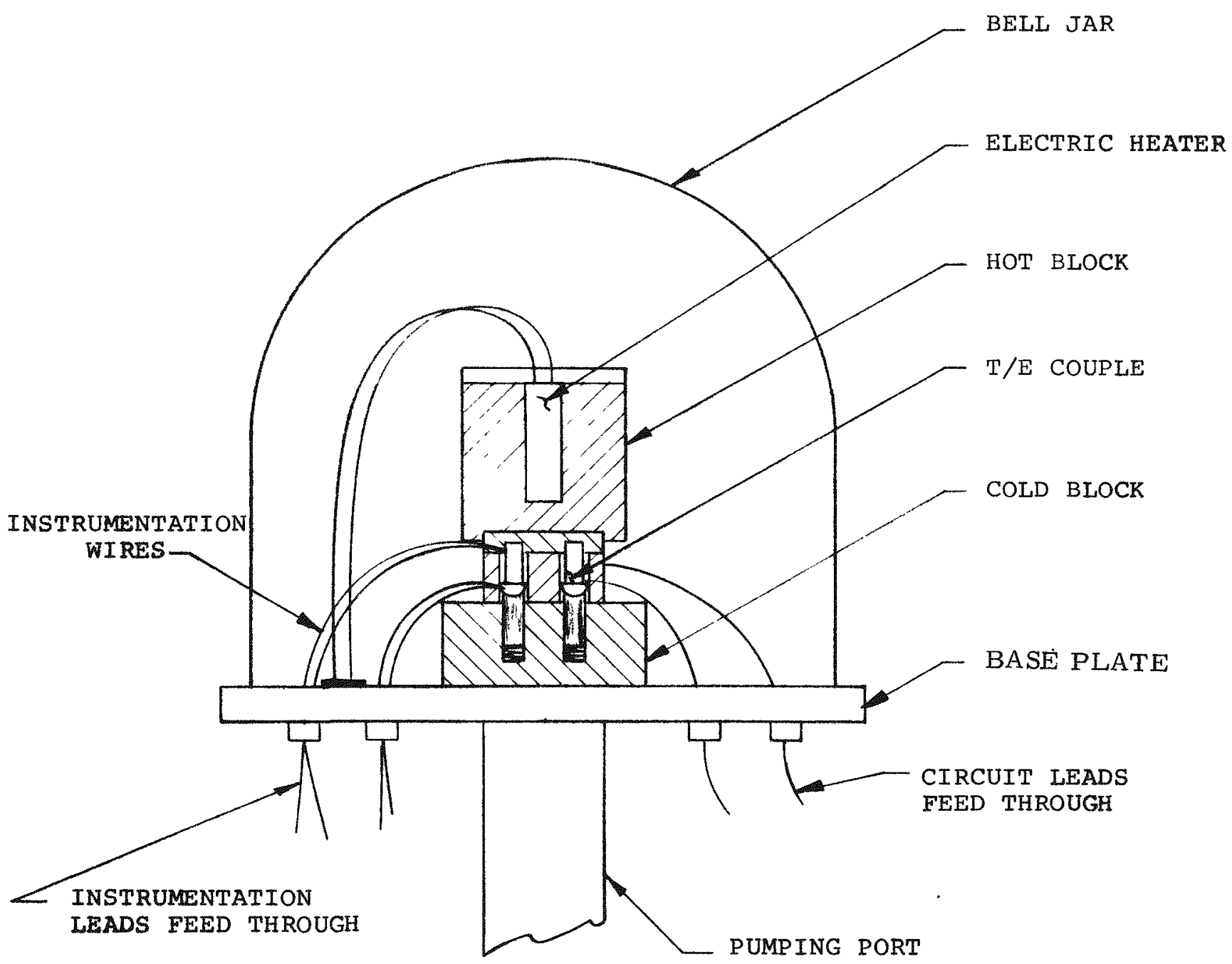

Figure 2-1

Bell Jar Test Station 


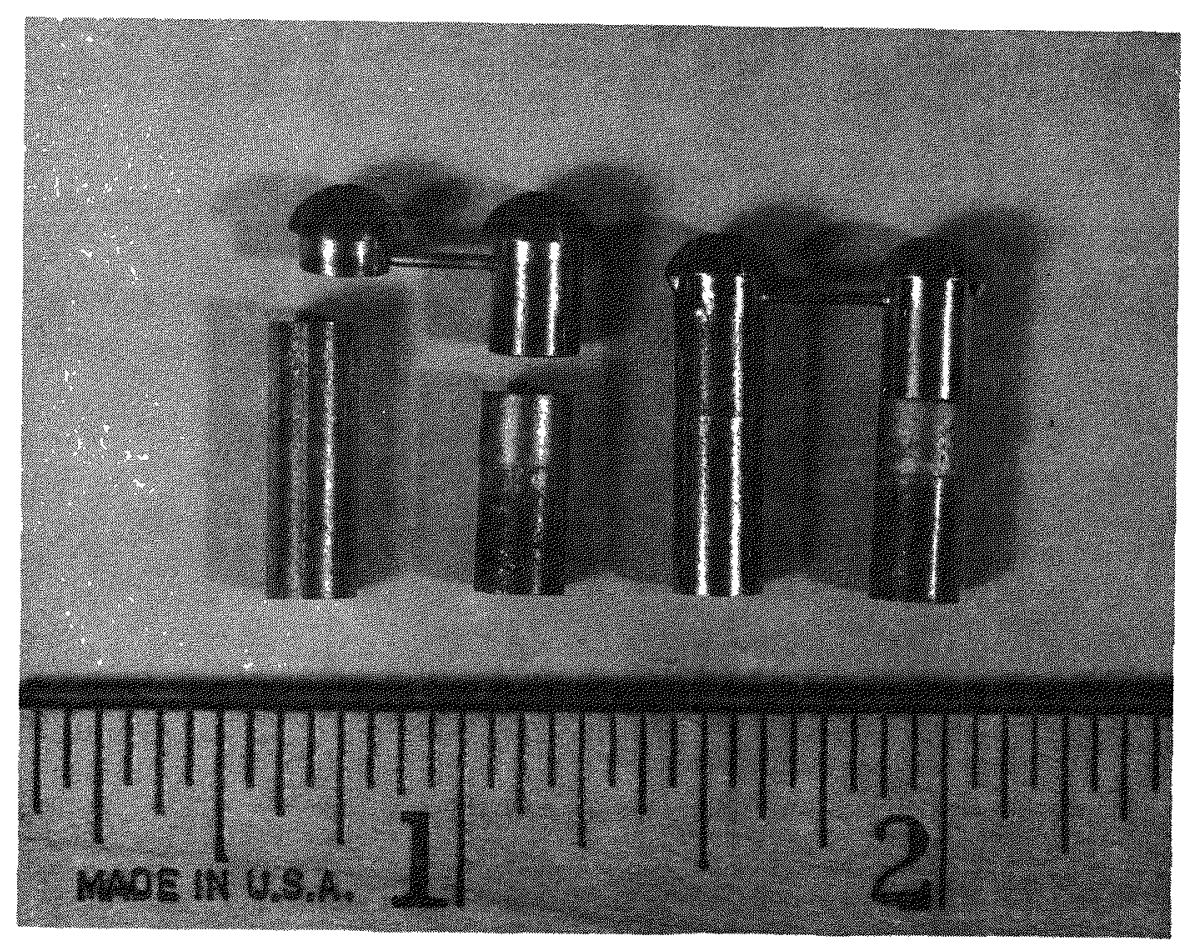

Figure 2-2

Typical Brazed Wire to Cold Cap Assembly

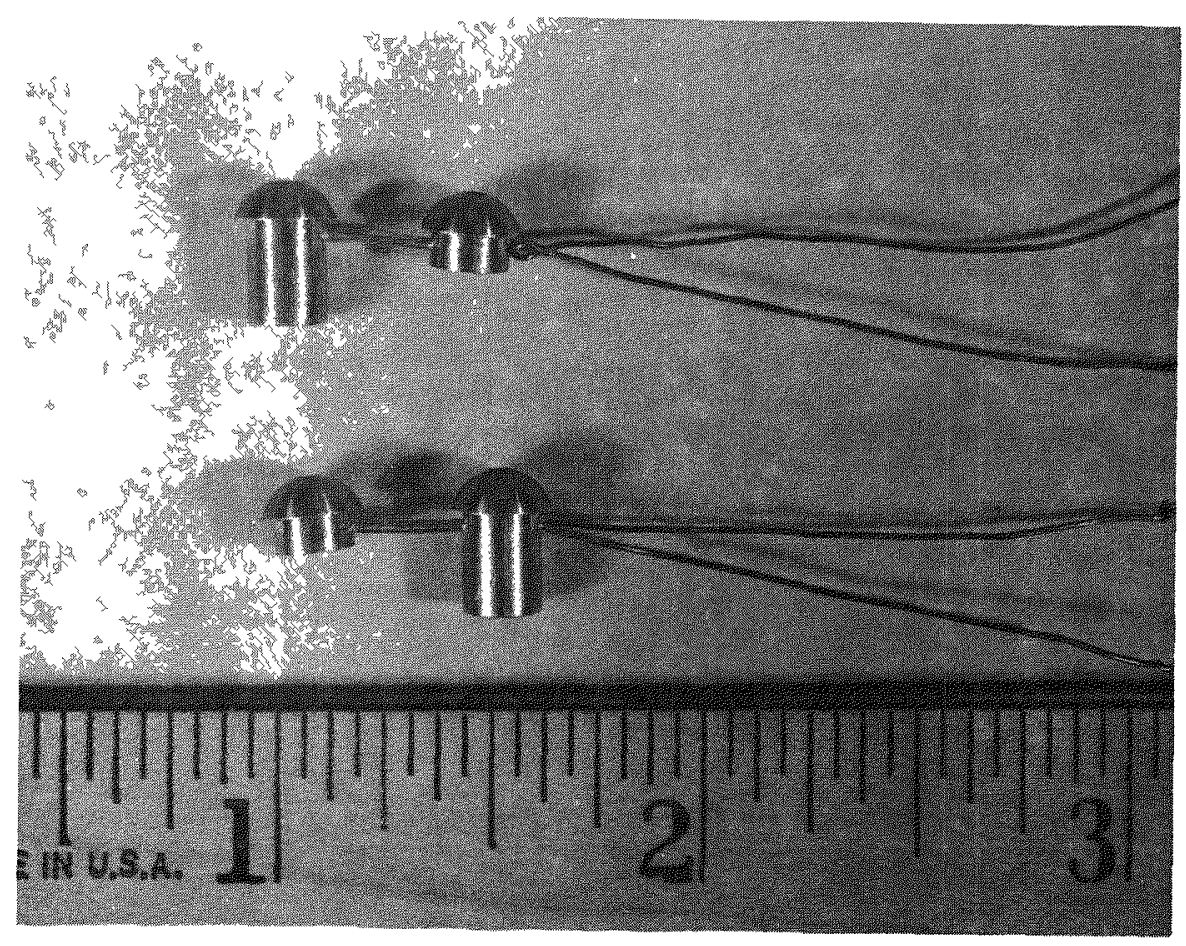

Figure 2-3

Instrumented Cold Caps, Brazed 
With this fixture a test can be set up and prepared for operation in a relatively short time. All components of the fixture itself are reuseable from test to test. Only the test specimens must be replaced.

After the bell jar, with the test samples, is assembled the enclosure is processed. This process is a series of pumping and gas backfilling operations at various temperatures similar to actual converter processing.

The bell jar fixture is mounted to a test console as shown by Figure 2-4. This figure shows two bell jar fixtures mounted on the same station. This station contains piping and valves for processing, controls for maintaining proper temperature, and terminals to attach meters for data readout.

During testing in the bell jar the following data is recorded.

- Leg hot and cold junction temperatures

- Current flow in thermoelectric circuit

- Voltage in each leg.

This recorded data was reduced to terms which were used to evaluate and compare the performance of the legs. These terms were:

$\begin{array}{ll}\text { Seebeck Ratio } & =\frac{\text { Measured Seebeck Voltage }}{\text { Theoretical Seebeck Voltage }} \\ \text { Resistance Ratio } & = \\ \text { Power Ratio } & =\frac{\text { Measured Leg Resistance }}{\text { Theoretical Leg Resistance }} \\ & \frac{\text { Measured Power Output }}{\text { Theoretical Power Output }}\end{array}$

These terms are very versatile for evaluating and comparing performance because the effects of leg dimension and slight differences in temperature between individual bell jar tests are normalized in these nondimensional terms.

Each bell jar test will be described and discussed. The results and conclusions from the first 18 bell jars are summarized together to show the inter-relationship of the individual tests. The detailed data from all the bell jar tests is listed in SNAP-23A Quarterly Report, Numbers 3 through 6. 


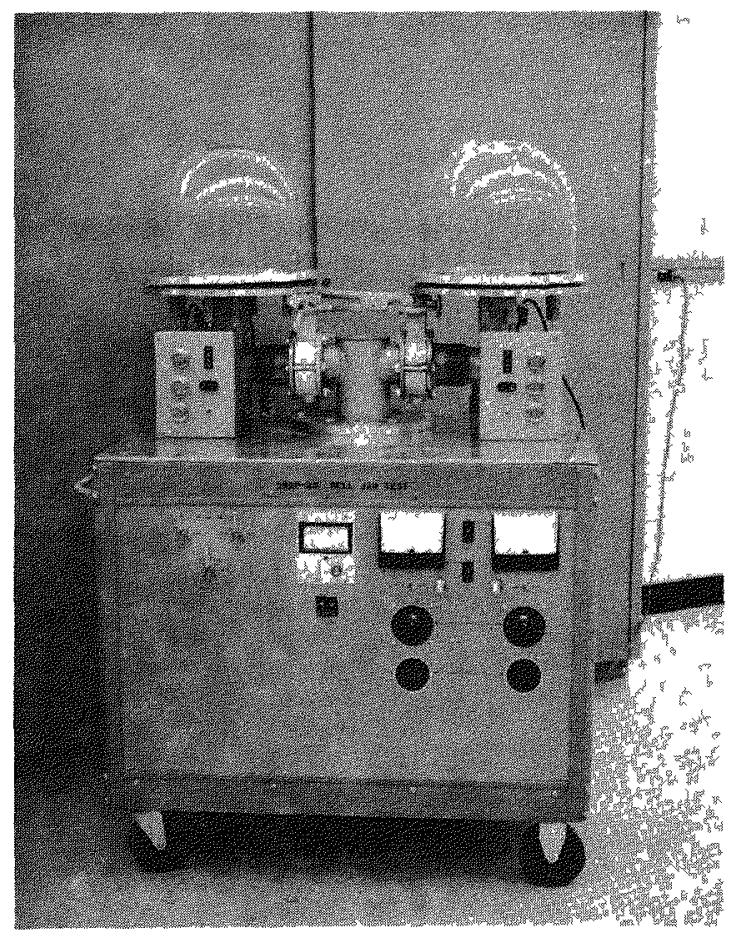

Figure 2-4

SNAP-23A Bell Jar Test Station 
The following nominal conditions were established for the bell jar tests; any deviation from nominal conditions is specifically noted in the description of the test conditions:

1. Leg alignment was within $1 / 2$ degree。

2. The leg hot end was contacted to an iron hot junction button (HJB).

3. The cold end cap was nickel plated copper.

4. Leg contact pressure was 250 psi.

5. Two couples, consisting of two $\mathrm{N}$ - and two P-legs, were included in each bell jar test.

6. The material at the hot end of the leg which contacts the hot junction button was the hot segment material. These legs are identified as being "conventional".

The following preplanned tests were conducted in the bell jar fixture.

Identification: $1-2$ and $1-3$

Test Specimen: Simultaneously pressed N- and P-legs, unplated copper cold caps, first legs fabricated from new thermoelectric materials formulated for SNAP-23A.

Test Purpose: To record performance data of legs fabricated of SNAP-23A material for comparison with SNAP-23 leg performance and leg performance with other variations in technology tested in other bell jars. This data would establish the performance of the base line thermoelectric technology with SNAP-23A materials.

Identification: $1-4$

Test Specimen: Simultaneously pressed N- and P-legs, nickel-plated copper cold caps, sample couples from the lot made for ten-couple modules using thermoelectric material formulated for SNAP-23A. 
Test Purpose: To record performance data of legs fabricated for ten-couple modules. Compare performance of these legs with SNAP-23 leg performance and leg performance with other variations in technology which were tested in other bell jars. This data was also used to establish the correlation between leg performance from the same lot and batch in the bell jar with the ten-couple module.

Identification: $7 / 18-5$

Test Specimen: Ten-couple module fabricated legs, both $\mathrm{N}$ - and P-legs segments separately pressed and then bonded, one couple with molybdenum hot junction buttons and one couple with iron hot junction buttons.

Test Purpose: To record performance data of legs. Performance of legs fabricated by separately pressing segments and then bonding to be compared with performance of legs fabricated by simultaneously pressing. Also to compare performance of legs contacted to iron and molybdenum at the hot end.

\section{Identification: $16-6$}

Test Specimen: Legs fabricated for ten-couple module use, one each $\mathrm{N}$ - and $\mathrm{P}$ leg separately pressed and bonded segments and the others simultaneously pressed. Both P-legs had a short segment of soft material at the hot end (soft nose).

Test Purpose: To record performance data of the legs. Performance of the legs fabricated by the two different techniques to be compared along with data taken during other bell jar tests. Performance data for the soft nose P-legs was compared with P-leg without special segment at hot end (conventional).

Identification: $18-7$

Test Specimen: Ten-couple module fabricated legs. All legs, $P$ and $N$, fabricated of separately pressed and bonded segments. The two P-legs had the "soft nose" feature at the hot end. Both P-legs and one N-leg were contacted to molybdenum hot junction buttons. 
Test Purpose: To record performance data of legs. The performance of the $\mathrm{N}$-legs contacted to iron and molybdenum was compared as well as the performance of $\mathrm{N}$-legs in other bell jar tests. The P-leg performance was compared to the performance of other $\mathrm{P}$-legs in different bell jars.

Identification: $16-8$

Test Specimen: Both the $\mathrm{N}$ - and P-legs for the ten-couple modules were fabricated by simultaneously pressing. The P-legs also had the "soft nose" feature at the hot end.

Test Purpose: To record performance data of legs. Primary purpose was to compare the performance of the P-legs with those tested in bell jar test 16-6 (simultaneously pressed).

Identification: $17-/ 18-9$

Test Specimen: These are legs fabricated for use in ten-couple modules. One P-leg was fabricated of separately pressed and bonded segments. The other P-leg was simultaneously pressed with the "soft nose" feature at the hot end and was contacted to a molybdenum hot junction button. Both the N-legs were simultaneously pressed.

Test Purpose: To record performance data for these legs. The performance of the two types of P-legs with different hot end contacting material was compared directly. That P-leg performance data as well as the N-leg was compared with legs in other bell jar tests.

Identification: $8 / 18-10$

Test Specimen: These legs were from those fabricated for use in the ten-couple modules. Both $\mathrm{N}$ - and P-legs were simultaneously pressed. One P-leg was contacted to a molybdenum hot junction button. All legs were mounted in the fixture with 5 degrees misalignment or tilt. Figure 2-5 shows this misalignment. 


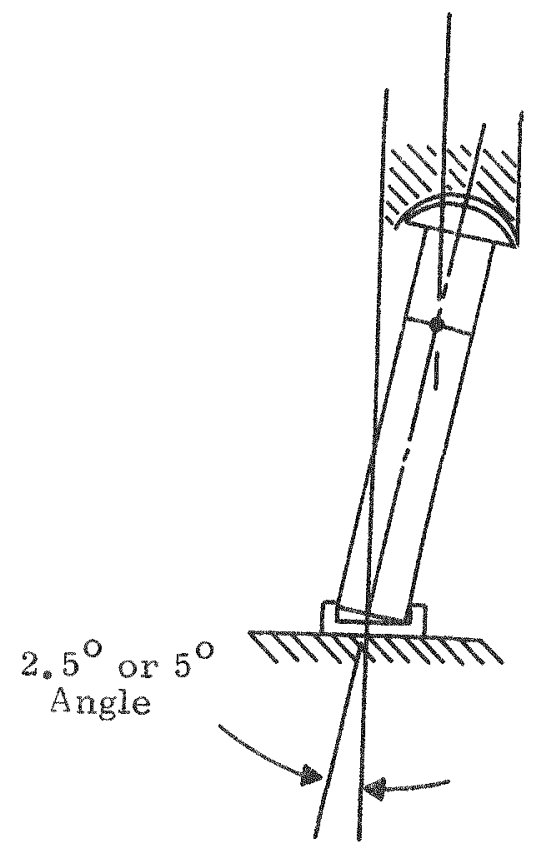

Figure 2-5

Couple Misalignment Exaggerated for Clarity 
Test Purpose: To record performance data from these legs mounted with a 5 degree tilt to compare with performance of legs from other bell jar tests which had less than $1 / 2$ degree leg tilt.

Identification: $5-11$

Test Specimen: These legs are from those fabricated for the EMC series converters. Both $\mathrm{N}$ - and P-legs were simultaneously pressed.

Test Purpose: To record performance data of the legs. The performance of these legs from the batch made for EMC was compared directly with those made for ten-couple modules. Performance data was also used for comparisons with various other technologies being evaluated in the bell jars.

Identification: $9 / 18-12$

Test Specimen: These legs were from those fabricated for use in the ten-couple module. The P-leg was from separately pressed and bonded segments. One P-leg had the "soft nose" feature at the hot end and the other was conventional. The P-leg with conventional hot end was mated with a molybdenum hot junction button. The $\mathrm{N}-\mathrm{leg}$ was from separately pressed and bonded segments. All legs were assembled with a 2.5 degree misalignment.

Test Purpose: To record performance data with legs under the given conditions. The performance of the two P-legs was mutually compared and the performance of all the legs was compared to legs without tilt as tested in other bell jars.

Identification: $8 / 18-13$

Test Specimen: These legs were from those fabricated for use in the ten-couple modules. All N- and P-legs were simultaneously pressed. One N- and one Pleg was contacted to a molybdenum hot junction button.

Test Purpose: To record performance data of the legs. The performance of the legs contacted at the hot end to molybdenum was compared directly with the legs in the same bell jar contacted to iron. The performance of all legs in this bell jar was also compared to the performance of legs in the other bell jars. 
Identification: 11-14

Test Specimen: These legs were from those fabricated for use in ten-couple modules. Both the $\mathrm{N}-$ and $\mathrm{P}$-legs were fabricated by separately pressed and bonded segments. Each leg was assembled in the bell jar with a 2.5 degree misalignment.

Test Purpose: To record performance data with these legs under the given test conditions. Performance data was compared with performance of other legs in other bell jars.

Identification: $5-15$

Test Specimen: These legs were samples from those used to assemble EMC-1. Both the N- and P-legs were simultaneously pressed.

Test Purpose: The legs were subjected to a relatively long and complex test cycle which would duplicate the conditions EMC-1 experienced during its early life; this was done to determine the effect of the processing time and environment cycle on couple performance in the bell jar. If the couples in the bell jar performed similar to those in EMC-1 the cause of EMC 1 poor performance could be associated with these processing and operating conditions.

Identification: 16

Test Specimen: These were leg samples selected from the lot fabricated for SNAP-21 generators. Both the $N$ - and $P$-legs were fabricated by separately pressed and bonded segments. The P-leg also had the "soft nose" feature at the hot end.

Test Purpose: The test was conducted to record data on the performance of legs fabricated for SNAP-21 generators and to compare their performance in the bell jar with legs fabricated for ten couple modules and EMC units. 
Identification: $5-17$

Test Specimen: The legs were samples from those made for EMC-3。 The N-leg was simultaneously pressed. The P-leg was separately pressed and bonded segments with the soft nose feature at the hot end.

Test Purpose: To record performance data of the legs fabricated for EMC-3 for comparison with other bell jar test data and performance of these legs in EMC-3。

Identification: $9-18$

Test Specimen: These legs were samples from those fabricated for ten-couple modules. The N-legs were simultaneously pressed and the P-legs were separately pressed and bonded segments with the soft nose feature at the hot end.

Test Purpose: Legs were assembled in the bell jar with a 5 degree misalignment. Leg performance data was recorded for comparison with other bell jar test data. Of particular interest was the performance of the P-legs with soft nose at the hot end when assembled with the 5 degree tilt or misalignment.

Identification: $5-19$

Test Specimen: These legs were samples from those fabricated for PMC-1. The $\mathrm{N}$-legs were simultaneously pressed and the $\mathrm{P}$-leg was separately pressed and bonded segments with the soft nose feature at the hot end.

Test Purpose: To record performance data with these legs for comparison with other bell jar performance data and for comparison with EMC-3 converter performance.

The test data from these first 18 bell jars was recorded, normalized and tabulated in terms of Seebeck ratio, resistance ratio and power ratio. This tabulated data is listed in SNAP-23A Quarterly Report, Numbers 3 through 6. The data was evaluated and the following conclusions were reached. 
A. The legs fabricated for SNAP-23A did vary from those of converter P-1 of SNAP-23. The Seebeck ratio of the SNAP-23A legs was lower but the resistance ratio of the SNAP-23A legs was also lower. The net result was that the power ratio for the SNAP-23A legs was higher than that for the SNAP-23 legs in converter P-1.

B. The legs which were fabricated for the ten-couple modules and tested in both the bell jar and ten-couple module performed similarly.

C. The difference between the performance of the $\mathrm{N}$-legs fabricated by simultaneously pressing and of separately pressed and bonded segments was slight. The separately pressed and bonded legs did exhibit slightly better power ratio but without measurement of heat flow through the legs a comparison of relative efficiency could not be made. Due to the reduced number of fabrication operations and long-term operating history, the simultaneous method of $\mathrm{N}-\mathrm{leg}$ fabrication was selected for SNAP-23A converters.

D. The P-leg which was fabricated of separately pressed and bonded segments performed significantly better than those which were simultaneously pressed. The separately pressed and bonded P-legs were incorporated into the converters as a design improvement.

E. The operating time was so short in the bell jar that a conclusion could not be made as to the effect of an unplated copper cold cap on leg performance.

F. The legs contacted to the iron hot junction buttons consistently performed better than those contacted to the molybdenum hot junction electrodes.

G. The P-legs with the soft nose feature at the hot end performed markedly better than the conventional P-legs when the legs were misaligned. The soft nose P-leg was incorporated into the converter design because in practice perfect alignment cannot be achieved in the assembly of a full scale converter.

$\mathrm{H}$. In every case, misalignment of both $\mathrm{N}$ - and $\mathrm{P}$-legs decreased the power ratio. This was the case for both the 2.5 degree and 5 degree tilt. The performance of the $\mathrm{P}$-legs with conventional hot end material was most adversely effected by the tilt; however, this effect was evaluated only on a short-term basis and long-term operation would be expected to diminish this effect. 
I. The performance of legs fabricated for the ten-couple module and for the EMC units was similar in the bell jar, which verified that the batch-tobatch variations were being controlled to result in only small variations in couple performance.

J. The legs from EMC-1, which were subjected in the bell jar to EMC-1 assembly time-cycle and environment conditions did not perform in the same manner as the legs in EMC-1. However, the test cycle did cause the $\mathrm{P}$-leg power ratio to degrade rapidly with operating time in the bell jar, which would indicate that some other factor caused the EMC-1 performance anomaly.

K. The leg samples from the SNAP-21 program performed the same in the bell jar as legs made for the ten-couple modules and for EMC-1.

L. The performance of the sample legs from EMC-3 did not correlate well with performance of legs of the same type in other bell jar tests. The resistance ratio of both $\mathrm{N}$ - and $\mathrm{P}$-legs was significantly higher than other bell jar tests. The performance of the legs in EMC-3 did correlate well with the performance of those same legs in the bell jar.

M. The performance of the sample of legs from PMC-1 did correlate well with bell jar performance of legs of the same type. These legs did perform better than the sample of legs from EMC-3, which were made the same way, in the bell jar. This correlates with the better performance of PMC-1A when compared to EMC-3.

In summary, conclusions from the bell jar tests were used in several different ways.

- To plan the long-term ten-couple module tests.

- With other leg performance data to upgrade thermopile design.

- To verify the acceptability of technology for continued design application.

- To establish a correlation between leg performance in the bell jar and the converter.

Five additional bell jar tests were conducted during the program; these tests were associated directly with specific problems with converter development and are discussed as part of Converter Development. 


\subsubsection{Ten-Couple Modules}

The ten-couple modules were used as part of the technology improvement task for long-term evaluation, as compared to the bell jar which was used for shortterm evaluation.

The purpose was to test the long-term performance of both base line SNAP-23 technology and new concepts or design variations which appeared most promising for improving converter design.

The ten-couple modules have the capability of operating as a thermoelectric device for durations comparable to the converters. Ten-couple module testing was related to bell jar testing; design variations or concepts which performed well on a short-term basis in the bell jars were included for long-term evaluation in the ten-couple modules. In addition, variables were included in the ten-couple modules which could not be evaluated in the bell jar.

The ten-couple module, as shown in Figure 2-6, is in many respects a miniature converter. The thermoelectric couples use the same type of hardware at the hot and cold ends as a converter and are connected in series so the current flow is the same. The enclosure is sealed and backfilled with an inert backfill gas. The differences from SNAP-23 Converter construction are: the legs are mounted in a flat plate array; all legs are instrumented so that individual leg performance can be measured; and he at is supplied by heaters located within the sealed enclosure. Figure 2-7 shows the circuit layout and instrumentation locations for temperature and leg performance measurements.

\subsubsection{Ten-Couple Module Design}

The ten-couple module test fixture used for the SNAP-23A program was based on the design for the SNAP-27 program. Design changes were made so that legs of SNAP-23A configuration would fit in the fixture and the cold end could be controlled to the required lower SNAP-23A temperatures. In addition, changes were also made to improve the fixture and alleviate problems which had been encountered during fabrication and build for SNAP-27. The test panel shown in Figure 2-8 provides the means for controlling test conditions and for readout of performance data. 


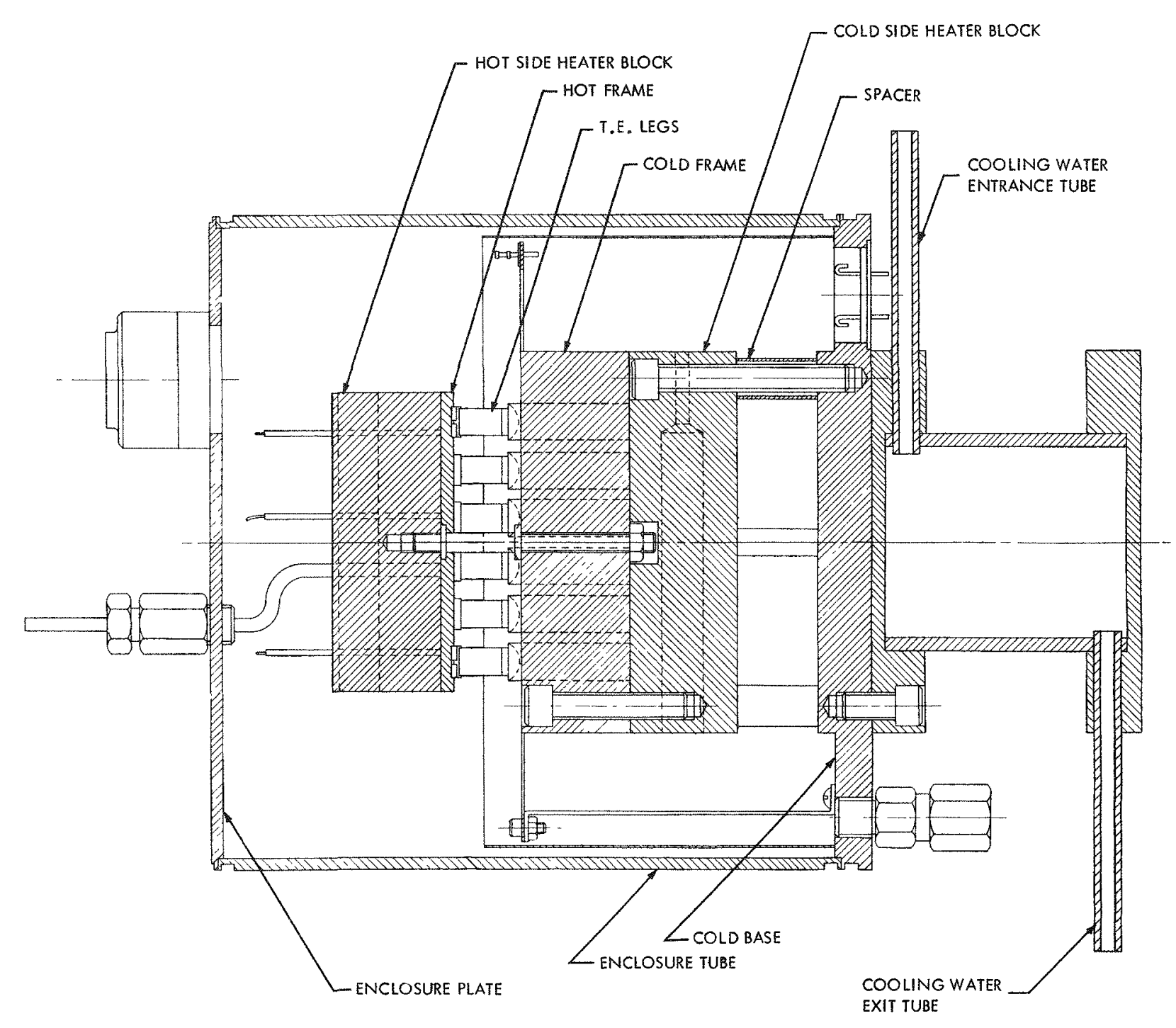

Figure 2-6

Design Configuration of the Ten-Couple Test Module 


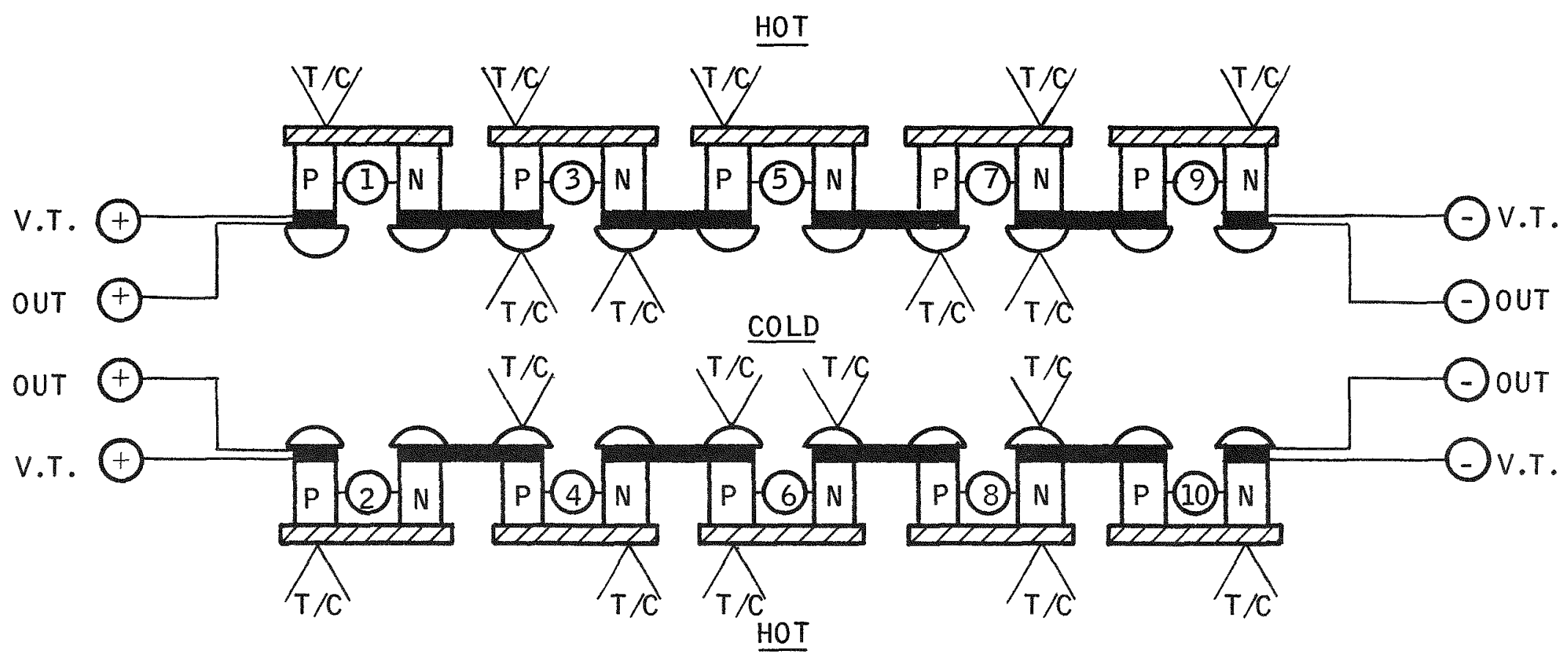

4 VOLTAGE TAPS 2P, IP, 9N, ION (4 LEADS)

3 HOT FRAME T/C RELATIVE POSITION 5P, 4N, 2P (6 LEADS)

1 COLD FRAME T/C

10 HOT SHOE (20 LEADS)

8 COLD CAP ( 16 LEADS)

Figure 2-7

Instrumentation Array, SNAP-23A Ten-Couple Module 


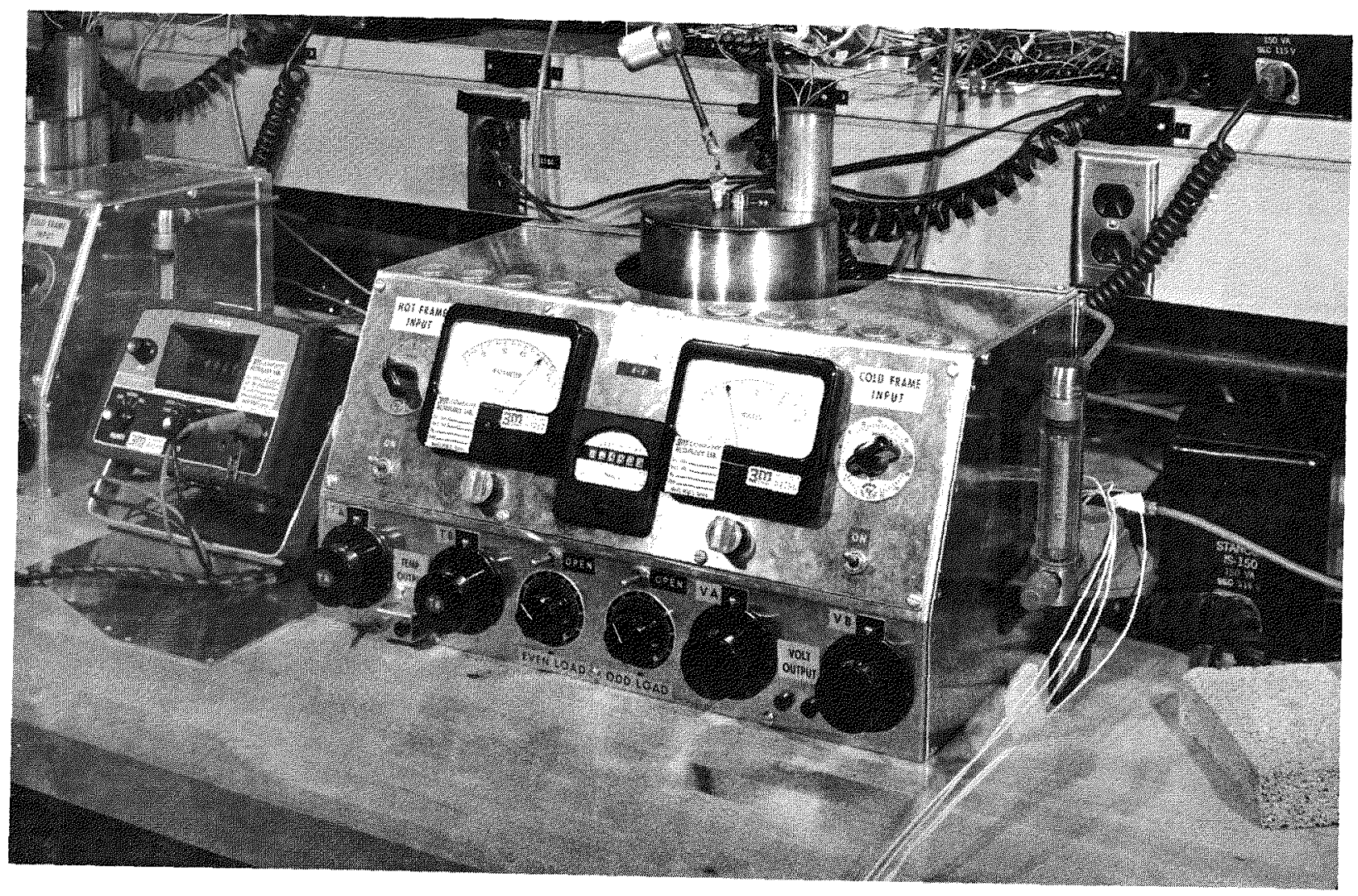

Figure 2-8

Ten-Couple Module Test Cabinet (With Module Installed) 
SNAP-23A Quarterly Report No, 1 describes in detail the ten-couple module design analysis and design changes.

\subsubsection{Tesí Variables}

A test plan was prepared to evaluate six different variables as follows:

- Leg fabrication method.

- P-leg hot end contact material.

- Thermal insulation.

- Hot junction button material.

- Leg contact pressure.

- Hot junction temperature.

Tests were planned for 12 ten-couple modules. The first four evaluated the base line design and alternate technology. The matrix of Table 2-2 established the build and test variables. The first four modules were built early in the program to develop long-term performance data which would be available as soon as possible for application to the full-sized converter design; Figure 2-9 shows these modules during operation in the laboratory.

Eight other bell jar tests with variations in technology were planned. A full factorial test design was used to determine the combinations of variables to be incorporated into the modules (see Table 2-2). Through analytical treatment of test results, this plan would eliminate unintentional biasing of results and aid in better, more complete evaluation of the variables under consideration. 
Table 2-2

10-Couple Modules Test Variable Matrix

\begin{tabular}{|c|c|c|c|c|c|c|c|c|}
\hline $\begin{array}{l}\text { Module } \\
\text { No. }\end{array}$ & $\begin{array}{c}\text { Couple } \\
\text { No. }\end{array}$ & $P-L e g$ & $N-L e g$ & $\begin{array}{l}\text { Thermal } \\
\text { Insulation }\end{array}$ & $\begin{array}{l}\text { Hot End } \\
\text { Contact } \\
\text { Material }\end{array}$ & $\begin{array}{l}\text { Contact } \\
\text { Pressure }\end{array}$ & $\begin{array}{l}\text { Hot } \\
\text { Junction } \\
\text { Temp F }\end{array}$ & Remarks \\
\hline 1 & $\begin{array}{l}1,3,5 \\
7 \& 9 \\
2,4,6 \\
8 \& 10\end{array}$ & $\begin{array}{l}\mathrm{SP}, \mathrm{N} \\
\mathrm{B}, \mathrm{N}\end{array}$ & SP & Min-K 1301 & Iron & $250 \mathrm{psi}$ & 1100 & $\begin{array}{l}\text { Odd couples SNAP- } 23 \\
\text { base line, even couples } \\
\text { were variation in leg } \\
\text { fabrication method. }\end{array}$ \\
\hline 2 & $\begin{array}{l}1,3,5 \\
7 \& 9 \\
2,4,6 \\
8 \& 10\end{array}$ & $\begin{array}{l}\mathrm{SP}, \mathrm{N} \\
\mathrm{B}, \mathrm{H}\end{array}$ & $\begin{array}{l}\mathrm{SP} \\
\mathrm{B}\end{array}$ & $\operatorname{Min}-\mathrm{K}-1999$ & Iron & $250 \mathrm{psi}$ & 1100 & $\begin{array}{l}\text { Odd couples SNAP }-23 \\
\text { base line, even coupses } \\
\text { were variation in leg } \\
\text { fabrication method, } \\
\text { Min-K } 1999 \text { thermat } \\
\text { insulation. }\end{array}$ \\
\hline 3 & $\begin{array}{l}1,3,5 \\
7 \& 9 \\
2,4,6 \\
8 \& 10\end{array}$ & $\begin{array}{l}\mathrm{SP}, \mathrm{H} \\
\mathrm{B}, \mathrm{H}\end{array}$ & $\begin{array}{l}\mathrm{SP} \\
\mathrm{B}\end{array}$ & Microquartz & Iron & $150 \mathrm{psi}$ & 1100 & $\begin{array}{l}\text { Both } N-\text { and P-legs } \\
\text { fabricated by different } \\
\text { methods, all P-legs } \\
\text { soft nose, Microquartz } \\
\text { insulation. }\end{array}$ \\
\hline
\end{tabular}

KEY:
SP - Simultaneously Pressed
B - Separately Pressed Segments and Bonded
N - Normal Hot Segment Material
H - Soft Nose at Hot End
MK - MIN-K 1301
MQ - Microquartz
$\mathrm{Fe}$ - Iron Hot Contact Material
Moly - Molybdenum Hot Contact Material 
Table 2-2

10-Couple Modules Test Variable Matrix (Continued)

\begin{tabular}{|c|c|c|c|c|c|c|c|c|}
\hline $\begin{array}{l}\text { Module } \\
\text { No. }\end{array}$ & $\begin{array}{l}\text { Couple } \\
\text { No. }\end{array}$ & P-Leg & N-Leg & $\begin{array}{l}\text { Thermal } \\
\text { Insulation }\end{array}$ & $\begin{array}{l}\text { Hot End } \\
\text { Contact } \\
\text { Material }\end{array}$ & $\begin{array}{c}\text { Contact } \\
\text { Pressure }\end{array}$ & $\begin{array}{c}\text { Hot } \\
\text { Junction } \\
\text { Temp }\end{array}$ & Remarks \\
\hline 4 & $\begin{array}{l}1,3,5, \\
7 \& 9 \\
2,4,6, \\
8 \& 10\end{array}$ & $\begin{array}{l}A P, H \\
B, H\end{array}$ & $\begin{array}{l}\mathrm{SP} \\
\mathrm{B}\end{array}$ & Min-K 1999 & Iron & $150 \mathrm{psi}$ & 1100 & $\begin{array}{l}\text { Both } N \text { - and P-legs } \\
\text { fabricated by different } \\
\text { methods, all P-legs } \\
\text { soft nose, Min-K } 1999 \\
\text { insulation. }\end{array}$ \\
\hline 5 & $\begin{array}{r}1 \\
2 \\
3 \\
4 \\
5 \\
6 \\
7 \\
8 \\
9 \\
10\end{array}$ & $\begin{array}{l}\mathrm{SP}, \mathrm{H} \\
\mathrm{B}, \mathrm{N} \\
\mathrm{B}, \mathrm{H} \\
\mathrm{B}, \mathrm{N} \\
\mathrm{SP}, \mathrm{N} \\
\mathrm{B}, \mathrm{H} \\
\mathrm{SP}, \mathrm{N} \\
\mathrm{B}, \mathrm{H} \\
\mathrm{B}, \mathrm{N} \\
\mathrm{SP}, \mathrm{H}\end{array}$ & $\begin{array}{l}\mathrm{SP}, \mathrm{H} \\
\mathrm{B}, \mathrm{N} \\
\mathrm{B}, \mathrm{N} \\
\mathrm{B}, \mathrm{N} \\
\mathrm{SP}, \mathrm{N} \\
\mathrm{B}, \mathrm{N} \\
\mathrm{SP}, \mathrm{N} \\
\mathrm{SP}, \mathrm{N} \\
\mathrm{SP}, \mathrm{N} \\
\mathrm{SP}, \mathrm{N}\end{array}$ & MQ & $\begin{array}{l}\text { Moly } \\
\mathrm{Fe} \\
\text { Moly } \\
\text { Moly } \\
\text { Moly } \\
\mathrm{Fe} \\
\mathrm{Fe} \\
\text { Moly } \\
\mathrm{Fe} \\
\mathrm{Fe}\end{array}$ & $150 \mathrm{psi}$ & 1000 & Factorial test design. \\
\hline 6 & $\begin{array}{r}1 \\
2 \\
3 \\
4 \\
5 \\
6 \\
7 \\
8 \\
9 \\
10\end{array}$ & $\begin{array}{l}\mathrm{SP}, \mathrm{N} \\
\mathrm{B}, \mathrm{H} \\
\mathrm{SP}, \mathrm{N} \\
\mathrm{B}, \mathrm{N} \\
\mathrm{B}, \mathrm{H} \\
\mathrm{B}, \mathrm{H} \\
\mathrm{B}, \mathrm{H} \\
\mathrm{SP}, \mathrm{N} \\
\mathrm{SP}, \mathrm{H} \\
\mathrm{SP}, \mathrm{H}\end{array}$ & $\begin{array}{l}\mathrm{SP}, \mathrm{N} \\
\mathrm{B}, \mathrm{N} \\
\mathrm{SP}, \mathrm{N} \\
\mathrm{B}, \mathrm{N} \\
\mathrm{B}, \mathrm{N} \\
\mathrm{B}, \mathrm{N} \\
\mathrm{B}, \mathrm{N} \\
\mathrm{SP}, \mathrm{N} \\
\mathrm{SP}, \mathrm{N} \\
\mathrm{SP}, \mathrm{N}\end{array}$ & $M Q$ & $\begin{array}{l}\text { Moly } \\
\text { Moly } \\
\mathrm{Fe} \\
\text { Moly } \\
\text { Moly } \\
\mathrm{Fe} \\
\mathrm{Fe} \\
\mathrm{Fe} \\
\mathrm{Fe} \\
\text { Moly }\end{array}$ & $150 \mathrm{psi}$ & 1100 & Factorial test design. \\
\hline
\end{tabular}


Table 2-2

10-Couple Module Variable Matrix (Continued)

\begin{tabular}{|c|c|c|c|c|c|c|c|c|}
\hline $\begin{array}{l}\text { Module } \\
\text { No. }\end{array}$ & $\begin{array}{l}\text { Couple } \\
\text { No. }\end{array}$ & P-Leg & N-Leg & $\begin{array}{l}\text { Thermal } \\
\text { Insulation }\end{array}$ & $\begin{array}{l}\text { Hot End } \\
\text { Contact } \\
\text { Material }\end{array}$ & $\begin{array}{l}\text { Contact } \\
\text { Pressure }\end{array}$ & $\begin{array}{l}\text { Hot } \\
\text { Junctign } \\
\text { Temp F }\end{array}$ & Remarks \\
\hline 7 & $\begin{array}{r}1 \\
2 \\
3 \\
4 \\
5 \\
6 \\
7 \\
8 \\
9 \\
10\end{array}$ & $\begin{array}{l}\mathrm{B}, \mathrm{H} \\
\mathrm{SP}, \mathrm{H} \\
\mathrm{SP}, \mathrm{N} \\
\mathrm{SP}, \mathrm{H} \\
\mathrm{B}, \mathrm{N} \\
\mathrm{B}, \mathrm{H} \\
\mathrm{B}, \mathrm{H} \\
\mathrm{SP}, \mathrm{N} \\
\mathrm{SP}, \mathrm{N} \\
\mathrm{B}, \mathrm{N}\end{array}$ & $\begin{array}{l}\mathrm{B}, \mathrm{N} \\
\mathrm{SP}, \mathrm{N} \\
\mathrm{SP}, \mathrm{N} \\
\mathrm{SP}, \mathrm{N} \\
\mathrm{B}, \mathrm{N} \\
\mathrm{B}, \mathrm{N} \\
\mathrm{B}, \mathrm{N} \\
\mathrm{SP}, \mathrm{N} \\
\mathrm{SP}, \mathrm{N} \\
\mathrm{B}, \mathrm{N}\end{array}$ & MQ & $\begin{array}{l}\mathrm{Fe} \\
\text { Moly } \\
\mathrm{Fe} \\
\mathrm{Fe} \\
\mathrm{Fe} \\
\text { Moly } \\
\text { Moly } \\
\mathrm{Fe} \\
\text { Moly } \\
\text { Moly }\end{array}$ & $250 \mathrm{psi}$ & 1000 & Factorial test design. \\
\hline 8 & $\begin{array}{r}1 \\
2 \\
3 \\
4 \\
5 \\
6 \\
7 \\
8 \\
9 \\
10\end{array}$ & $\begin{array}{l}\mathrm{SP}, \mathrm{N} \\
\mathrm{B}, \mathrm{H} \\
\mathrm{SP}, \mathrm{N} \\
\mathrm{B}, \mathrm{N} \\
\mathrm{SP}, \mathrm{N} \\
\mathrm{B}, \mathrm{H} \\
\mathrm{B}, \mathrm{H} \\
\mathrm{B}, \mathrm{N} \\
\mathrm{SP}, \mathrm{H} \\
\mathrm{SP}, \mathrm{H}\end{array}$ & $\begin{array}{l}\mathrm{SP}, \mathrm{N} \\
\mathrm{B}, \mathrm{N} \\
\mathrm{SP}, \mathrm{N} \\
\mathrm{B}, \mathrm{N} \\
\mathrm{SP}, \mathrm{N} \\
\mathrm{B}, \mathrm{N} \\
\mathrm{B}, \mathrm{N} \\
\mathrm{B}, \mathrm{N} \\
\mathrm{SP}, \mathrm{N} \\
\mathrm{SP}, \mathrm{N}\end{array}$ & $M Q$ & $\begin{array}{l}\mathrm{Fe} \\
\mathrm{Fe} \\
\text { Moly } \\
\mathrm{Fe} \\
\mathrm{Fe} \\
\text { Moly } \\
\text { Moly } \\
\text { Moly } \\
\text { Fe } \\
\text { Moly }\end{array}$ & 250 psi & 1100 & Factorial test design. \\
\hline 9 & $\begin{array}{r}1 \\
2 \\
3 \\
4 \\
5 \\
6 \\
7 \\
8 \\
9 \\
10\end{array}$ & $\begin{array}{l}\mathrm{B}, \mathrm{N} \\
\mathrm{SP}, \mathrm{H} \\
\mathrm{B}, \mathrm{H} \\
\mathrm{SP}, \mathrm{N} \\
\mathrm{B}, \mathrm{H} \\
\mathrm{SP}, \mathrm{N} \\
\mathrm{SP}, \mathrm{H} \\
\mathrm{B}, \mathrm{N} \\
\mathrm{SP}, \mathrm{N} \\
\mathrm{B}, \mathrm{H}\end{array}$ & $\begin{array}{l}\mathrm{B}, \mathrm{N} \\
\mathrm{SP}, \mathrm{N} \\
\mathrm{B}, \mathrm{N} \\
\mathrm{SP}, \mathrm{N} \\
\mathrm{B}, \mathrm{N} \\
\mathrm{SP}, \mathrm{N} \\
\mathrm{SP}, \mathrm{N} \\
\mathrm{B}, \mathrm{N} \\
\mathrm{SP}, \mathrm{N} \\
\mathrm{B}, \mathrm{N}\end{array}$ & MK & $\begin{array}{l}\mathrm{Fe} \\
\mathrm{Fe} \\
\mathrm{Fe} \\
\text { Moly } \\
\text { Moly } \\
\mathrm{Fe} \\
\text { Moly } \\
\text { Moly } \\
\mathrm{Fe} \\
\text { Moly }\end{array}$ & $150 \mathrm{psi}$ & 1000 & Factorial test design. \\
\hline
\end{tabular}


Table 2-2

10-Couple Module Variable Matrix (Continued)

\begin{tabular}{|c|c|c|c|c|c|c|c|c|}
\hline $\begin{array}{l}\text { Module } \\
\text { No. }\end{array}$ & $\begin{array}{c}\text { Couple } \\
\text { No. }\end{array}$ & P-Leg & N-Leg & $\begin{array}{l}\text { Thermal } \\
\text { Insulation }\end{array}$ & $\begin{array}{l}\text { Hot End } \\
\text { Contact } \\
\text { Material }\end{array}$ & $\begin{array}{l}\text { Contact } \\
\text { Pressure }\end{array}$ & $\begin{array}{l}\text { Hot } \\
\text { Junction } \\
\text { Temp }^{\circ}{ }_{F}\end{array}$ & Remarks \\
\hline 10 & $\begin{array}{r}1 \\
2 \\
3 \\
4 \\
5 \\
6 \\
7 \\
8 \\
9 \\
10\end{array}$ & $\begin{array}{l}\mathrm{SP}, \mathrm{N} \\
\mathrm{SP}, \mathrm{H} \\
\mathrm{B}, \mathrm{H} \\
\mathrm{B}, \mathrm{H} \\
\mathrm{B}, \mathrm{H} \\
\mathrm{B}, \mathrm{N} \\
\mathrm{SP}, \mathrm{N} \\
\mathrm{SP}, \mathrm{H} \\
\mathrm{B}, \mathrm{N} \\
\mathrm{SP}, \mathrm{N}\end{array}$ & $\begin{array}{l}\mathrm{SP}, \mathrm{N} \\
\mathrm{SP}, \mathrm{N} \\
\mathrm{B}, \mathrm{N} \\
\mathrm{B}, \mathrm{N} \\
\mathrm{B}, \mathrm{N} \\
\mathrm{B}, \mathrm{N} \\
\mathrm{SP}, \mathrm{N} \\
\mathrm{SP}, \mathrm{N} \\
\mathrm{B}, \mathrm{N} \\
\mathrm{SP}, \mathrm{N}\end{array}$ & MK & $\begin{array}{l}\mathrm{Fe} \\
\text { Moly } \\
\text { Moly } \\
\mathrm{Fe} \\
\text { Moly } \\
\text { Moly } \\
\mathrm{Fe} \\
\mathrm{Fe} \\
\mathrm{Fe} \\
\text { Moly }\end{array}$ & $150 \mathrm{psi}$ & 1100 & Factorial test design. \\
\hline 11 & $\begin{array}{r}1 \\
2 \\
3 \\
4 \\
5 \\
6 \\
7 \\
8 \\
9 \\
10\end{array}$ & $\begin{array}{l}\text { SP, N } \\
\text { B, H } \\
B, N \\
\text { SP, H } \\
\text { SP, N } \\
\text { SP, H } \\
\text { B, N } \\
\text { B, H } \\
\text { SP, N } \\
B, H\end{array}$ & $\begin{array}{l}\mathrm{SP}, \mathrm{N} \\
\mathrm{B}, \mathrm{N} \\
\mathrm{B}, \mathrm{N} \\
\mathrm{SP}, \mathrm{N} \\
\mathrm{SP}, \mathrm{N} \\
\mathrm{SP}, \mathrm{N} \\
\mathrm{B}, \mathrm{N} \\
\mathrm{B}, \mathrm{N} \\
\mathrm{SP}, \mathrm{N} \\
\mathrm{B}, \mathrm{N}\end{array}$ & MK & $\begin{array}{l}\text { Moly } \\
\text { Moly } \\
\mathrm{Fe} \\
\text { Moly } \\
\mathrm{Fe} \\
\mathrm{Fe} \\
\text { Moly } \\
\mathrm{Fe} \\
\mathrm{Fe} \\
\text { Moly }\end{array}$ & $250 \mathrm{psi}$ & 1000 & Factorial test design. \\
\hline 12 & $\begin{array}{r}1 \\
2 \\
3 \\
4 \\
5 \\
6 \\
7 \\
8 \\
9 \\
10\end{array}$ & $\begin{array}{l}\mathrm{SP}, \mathrm{N} \\
\mathrm{B}, \mathrm{H} \\
\mathrm{B}, \mathrm{N} \\
\mathrm{B}, \mathrm{H} \\
\mathrm{B}, \mathrm{N} \\
\mathrm{SP}, \mathrm{N} \\
\mathrm{SP}, \mathrm{N} \\
\mathrm{SP}, \mathrm{H} \\
\mathrm{B}, \mathrm{H} \\
\mathrm{SP}, \mathrm{H}\end{array}$ & $\begin{array}{l}\mathrm{SP}, \mathrm{N} \\
\mathrm{B}, \mathrm{N} \\
\mathrm{B}, \mathrm{N} \\
\mathrm{B}, \mathrm{N} \\
\mathrm{B}, \mathrm{N} \\
\mathrm{SP}, \mathrm{N} \\
\mathrm{SP}, \mathrm{N} \\
\mathrm{SP}, \mathrm{N} \\
\mathrm{B}, \mathrm{N} \\
\mathrm{SP}, \mathrm{N}\end{array}$ & MK & $\begin{array}{l}\text { Moly } \\
\mathrm{Fe} \\
\text { Moly } \\
\text { Moly } \\
\mathrm{Fe} \\
\mathrm{Fe} \\
\mathrm{Fe} \\
\mathrm{Fe} \\
\text { Moly } \\
\text { Moly }\end{array}$ & 250 psi & 1100 & Factorial test design. \\
\hline
\end{tabular}




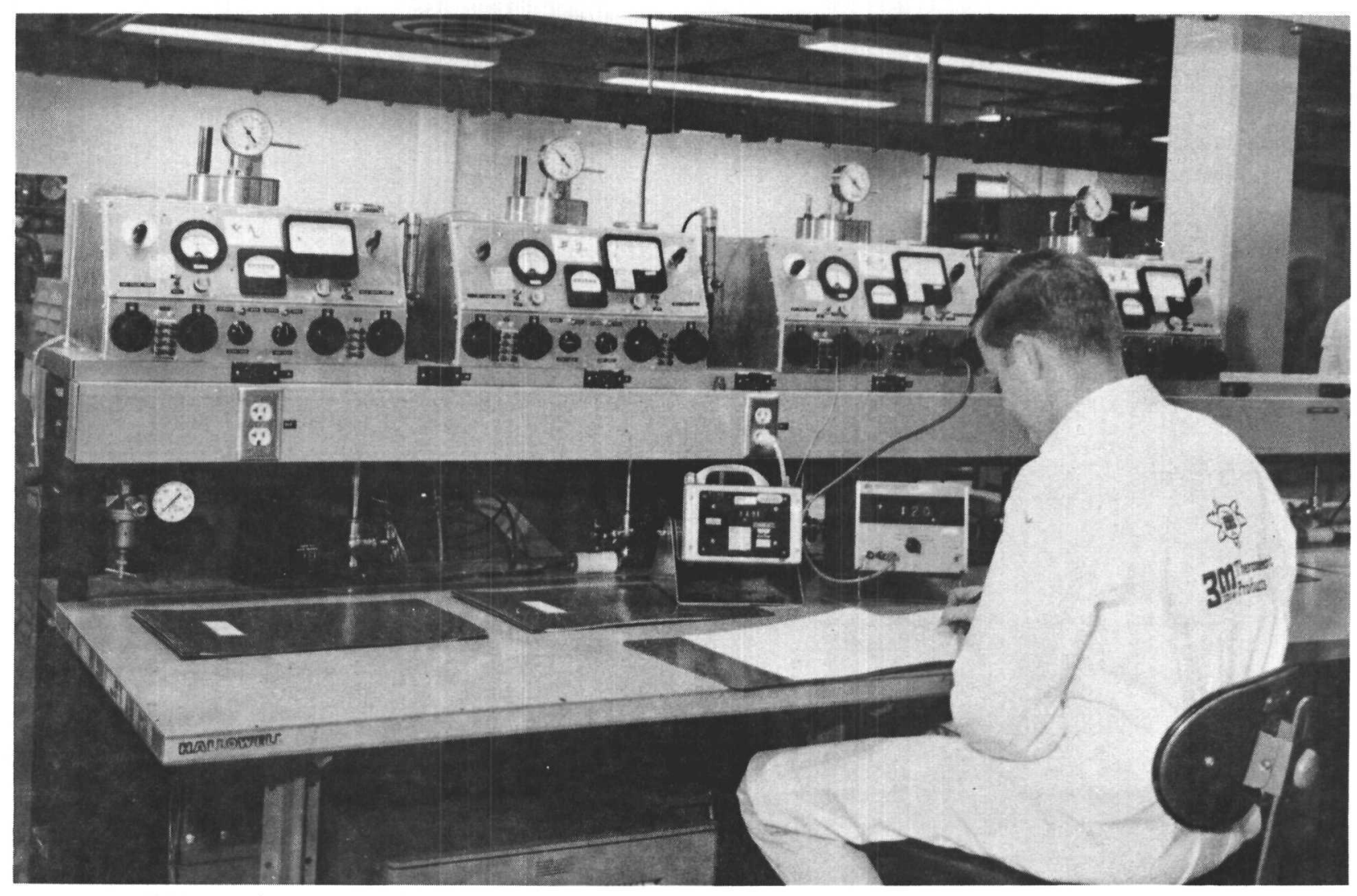

Figure 2-9

10-Couple Modules 1 through 4 on Long-Term Test 
During the period when the twelve 10-couple modules were on long-term test, data was recorded and reduced at 500 hour intervals. Modules 2 and 4 were removed from test after 8264 and 8242 hours respectively, due to a large change in resistance and power ratio. The remaining modules continued on operation for the duration of the program. Detailed data from the two discontinued modules is included in Section 5.0 .

The performance data from the first four 10-couple modules was a factor in making the change from the base-line technology used for EMC-1 and EMC-2. The data showed that P-legs fabricated of separately pressed and bonded segments performed better than simultaneous pressed P-legs. This was a long-term confirmation of the initial short-term observations in the bell jar tests. The change to the alternate $\mathrm{P}$-leg fabricating method was incorporated in all SNAP-23A converters starting with EMC-3. These first four 10-couple modules demonstrated that thermoelectric legs performed better when used with base-line Min-K 1301 thermal insulation than with the alternate thermal insulations, Min-K 1999 or Microquartz. The alternate insulations were considered for use on the basis that they would require less processing in preparation for use in converters. The 10-couple modules which used the alternate insulations were processed (after assembly) in the same manner as those with Min-K 1301.

The results of tests on Modules 5 through 12, which had the full factorial design of test variable described in Table 2-2, were evaluated at the end of the testing program. The conclusions from this evaluation are as follows:

A. Either of the two types of P-legs performs more stably and produce more power when operated in Min-K 1301 than in Microquartz thermal insulation.

B. All legs, both $N$ and $P$ type, which operated at the lower hot junction temperature of $1000^{\circ} \mathrm{F}$ outperformed those operated at the higher hot junction temperature of $1100^{\circ} \mathrm{F}$ from a relative power standpoint.

C. Legs with 250 psi contact pressure produced more power than those with the lower contact pressure of $150 \mathrm{psi}$. The $\mathrm{N}$-legs had better initial performance and greater long-term stability. The P-legs would seat-in 
better with the higher contact pressure resulting in lower contact resistance and greater power over the operating time span.

D. The P-legs fabricated of pressed and bonded segments would give better initial performance than the cimultaneously pressed P-legs. However, the relative improvement would decrease with time.

E. Compared with molybdenum contacts, iron contacts resulted in a slight power ratio decrease for the $\mathrm{N}-\mathrm{leg}$ but an increase in power ratio for the P-leg. The total effect of the differences was small but in favor of the iron contact material.

F. The N-leg fabricated of separately pressed and bonded segments demonstrated a slight power advantage over the simultaneously pressed $\mathrm{N}$-leg.

G. The advantage of the soft nose feature versus conventional P-leg was not resolved by these tests. This is probably due to the better leg alignment in the 10-couple module than is experienced in the converters. .

\subsubsection{Post-Test Analysis of SNAP-23 Devices}

As a portion of the thermoelectric couple improvement effort, a post-test analysis was conducted on SNAP-23 6-couple Module $23 \mathrm{~A}-2$ and the 256-couple converter $23 \mathrm{P}-1$. The examination identified certain mechanisms in the base line technology potential failure or degradation mechanisms. Pretest, test and posttest disassembly data were compiled and correlated for the thermoelectric couples and adjacent hardware. The principal areas of investigation included:

- Thermoelectric $\mathrm{N}$ and P-leg performance changes

- Leg hot junction electrical contact resistance

- Metallurgical changes within thermoelectric contact hardware

- Cold end thermal impedance

- Changes in backfill gas environment

- Chemical and physical changes in the thermal insulation 
The post-test analysis consisted of complete disassembly of both the converter and the 6-couple module. Samples of the internal gas were taken before the start of disassembly. After disassembly the following analyses were conducted:

- Visual of thermoelectric legs and related hardware

- Gas composition

- Extraneous electrical circuit resistance

- Leg alignment

- Thermal conductance

- Leg spring pressure

- Leg electrical resistivity

- Leg Seebeck voltage

- Dimensional

- Chemical composition of legs

In arriving at conclusions from these analyses the following difference in the converter and 6-couple module were considered.

- The physical configuration of the thermopile structure

- 6-couple module hot junction temperature $1100^{\circ} \mathrm{F}$; converter hot junction operating temperature $1035^{\circ}$ to $1085^{\circ} \mathrm{F}$

- 250.psi spring pressure for the converter; 150 psi spring pressure for the module

- Cold caps for the module were bare copper; cold caps for the converter were nickel plated

The following is a summary of the conclusions and their effect on SNAP-23A converter design and operating parameters. 
- Although some changes took place which shifted the thermoelectric characteristics of the N-legs, the net effect on device performance was small.

- The P-legs in the 6-couple module had considerable decrease in Seebeck voltage, caused by copper migration from the unplated copper cold caps. The cold caps for all the SNAP-23A converters were plated to prevent this effect.

- The apparent $\mathrm{N}$-leg hot contact resistance increased for the 6-couple module, caused by sublimation of the N-leg at the hot end decreaseing the cross-sectional area. This effect was insignificant for the converter which had higher leg spring pressure, $250 \mathrm{psi}$, and lower hot junction temperatures, $1035^{\circ} \mathrm{F}$ to $1085^{\circ} \mathrm{F}$. Spring pressure of 250 psi was used for all SNAP-23A converters and later in the program the average hot junction temperature was decreased from 1080 to $1011^{\circ} \mathrm{F}$.

- No significant change was observed in P-leg electrical contact resistance.

- The change in thermal impedance at the cold side of converter P-1 was at the cold cap-follower interface. The heat transfer grease in this interface had changed characteristics or had been withdrawn by some action. No grease was used at this interface for the early SNAP-23A converters and for the later units indium foil was used at this interface to decrease thermal impedance.

- Gas analysis showed little evidence of oxygen being present in either the converter or the 6-couple module.

- No evidence was found which would indicate compatibility problems with the Min-K 1301 thermal insulation.

- The boron nitride hot side insulation strips which align the legs at the hot end were broken in a number of places. This insulation strip was increased in cross-sectional area for all SNAP-23A converters to alleviate this problem.

\subsubsection{Cold End Temperature Drop Tests}

From the cold ends of the legs, the rejected heat is conducted to the converter outer case by a heat transfer system. Figure 2-10 shows the components and their 

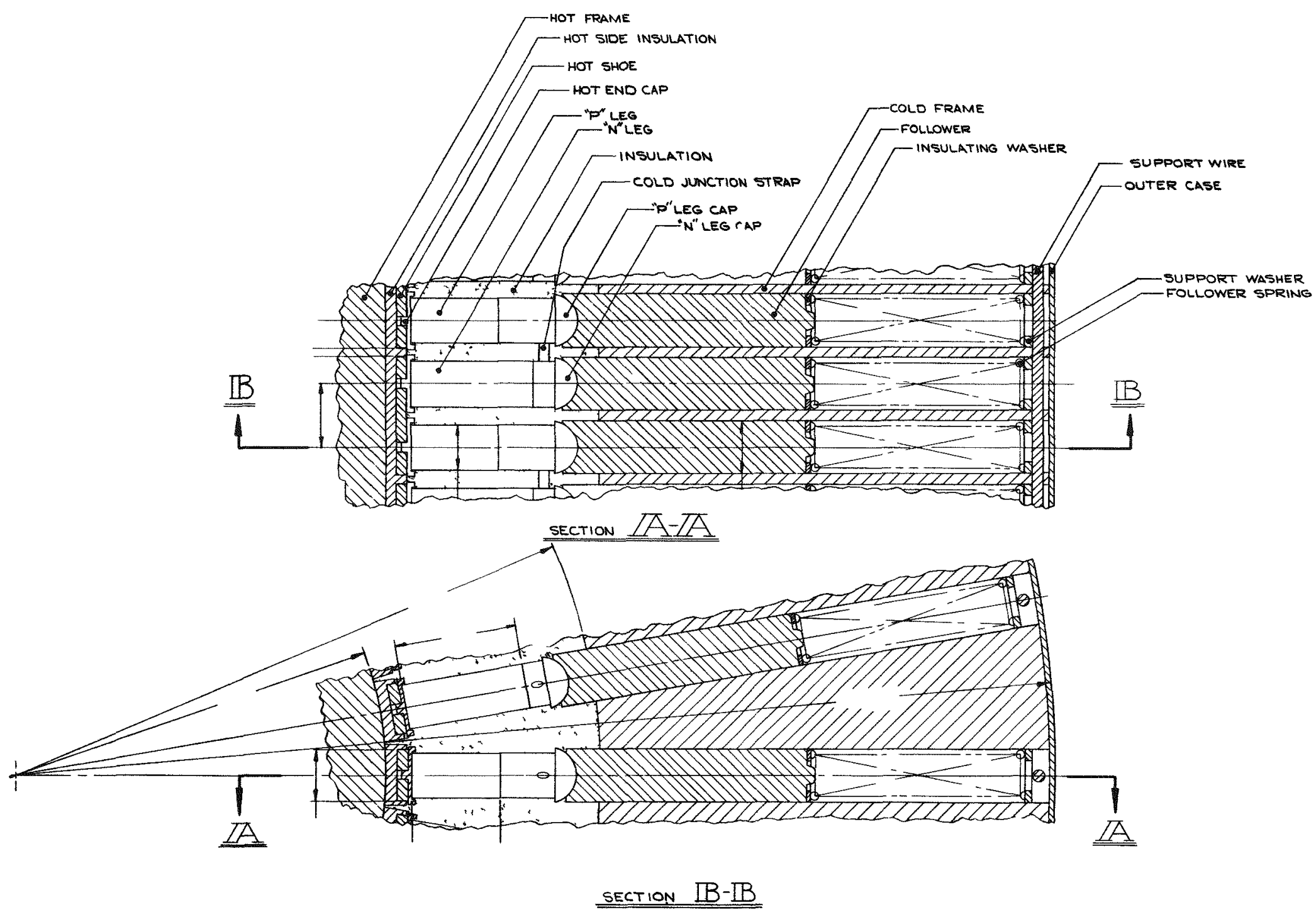

Figure 2-10

Detail - Thermoelectric Couple 
arrangement in this system. This heat transfer system also meets the additional requirements of positioning the legs at the cold end, providing force for contact pressure at both the hot and cold end of the leg, and electrically insulating the thermoelectric circuit from the structure. A high temperature drop through this heat transfer system increases the leg cold junction temperature and decreases power output and efficiency. The largest drop in temperature takes place at the mechanical interfaces where the cold cap mates with the follower and where the follower fits into the cold frame.

Data from tests conducted as part of the SNAP-21 program were used during the design of the converters. In addition, cold end heat transfer tests to evaluate beryllium oxide ( $\mathrm{BeO}$ ) followers on a 6 -couple bell jar module were conducted. Effects of both radial mismatch at the ball-socket interface and diametrical difference at the follower-cold frame interface were investigated. The difference in radii of the cold cap and follower socket was allowed to vary by as much as 0.005 inch with the cap both larger and smaller then the follower radii. Figure 2-11 shows how variation in these radii effects the heat transfer contacting area. Figure 2-12 presents the results of these tests. The solid line is the predicted temperature drop or average of the data. The broken line indicates the range through which most data deviated.

One test was run to determine effectiveness of opening tolerances on the cold frame hole diameter. A cold frame was constructed with holes of various sizes, and a standard BeO follower was used. The ball-socket mismatch was consistently 0.002 inch and ring contact was used so the temperature drop would be consistent. The range of difference between diameters tested was from 0.0015 to $0.0101 \mathrm{inch}$. The data from these tests is shown on Figure 2-13.

The data from these cold end heat transfer tests were used to determine the tolerance for the cold cap spherical radius, follower spherical socket, follower diameter, and cold frame follower hole diameters. 


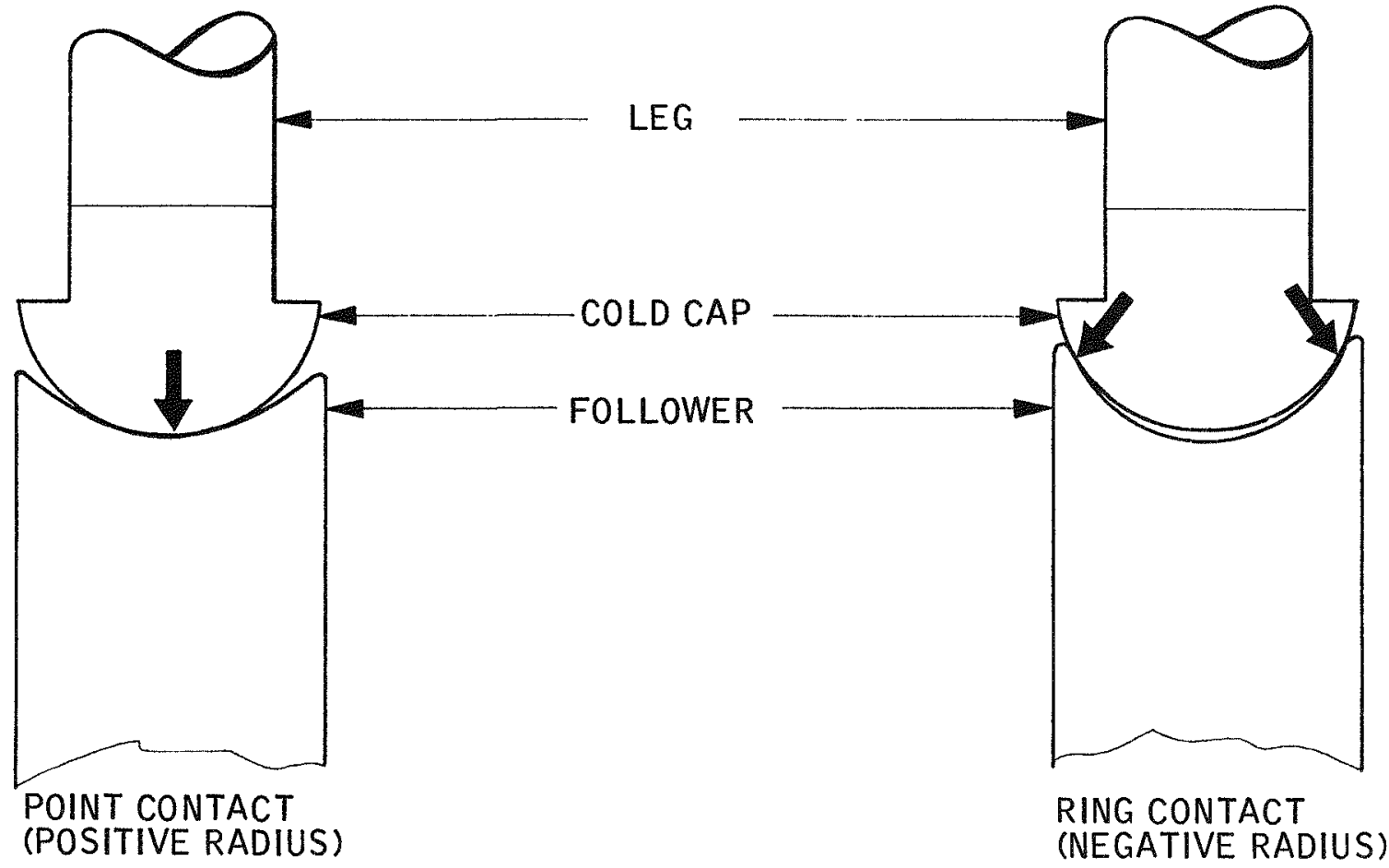

Figure 2-11

Follower/Cold Cap Contact Configurations 


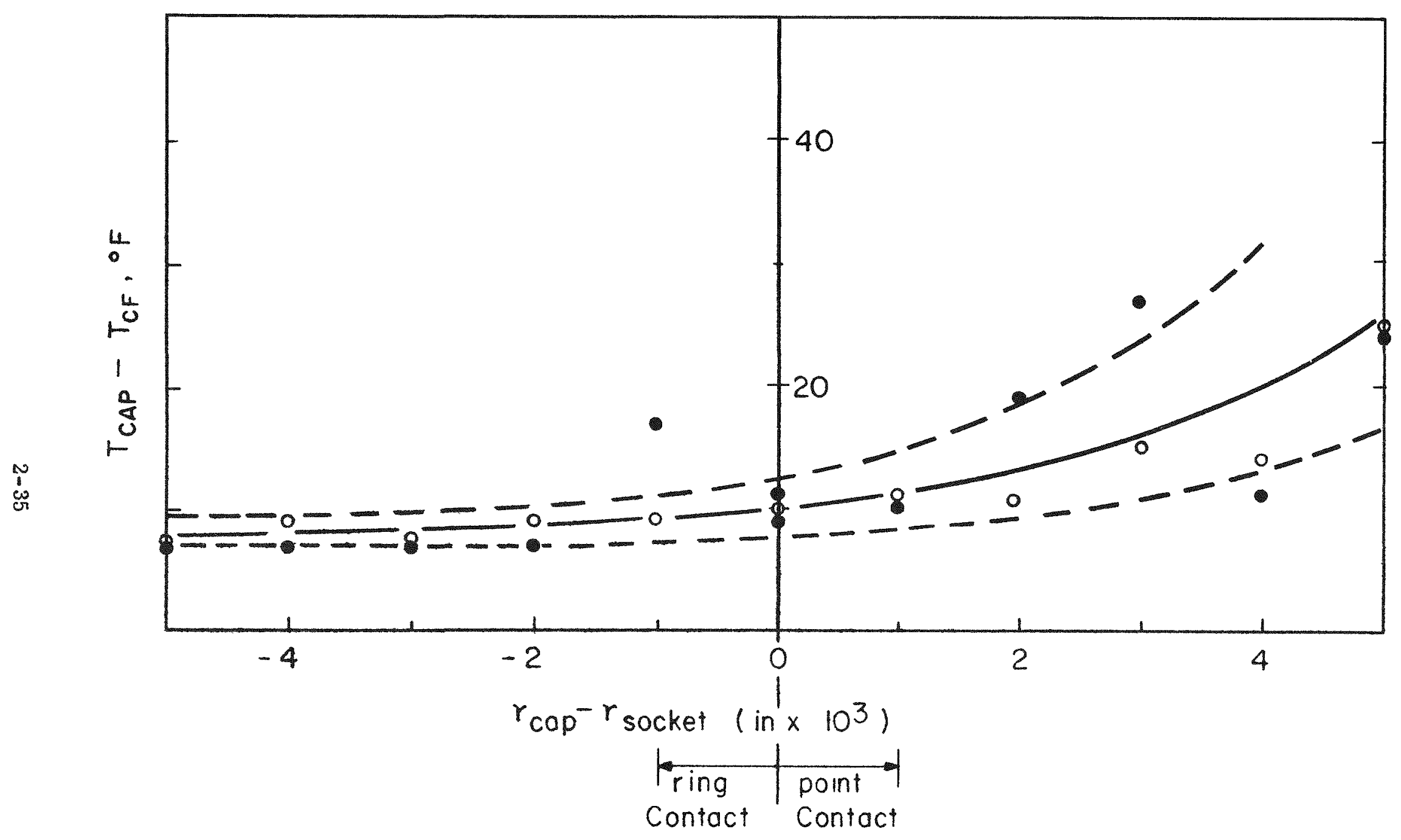

Figure 2-12

Cold End Temperature Drop versus Radial Mismatch 


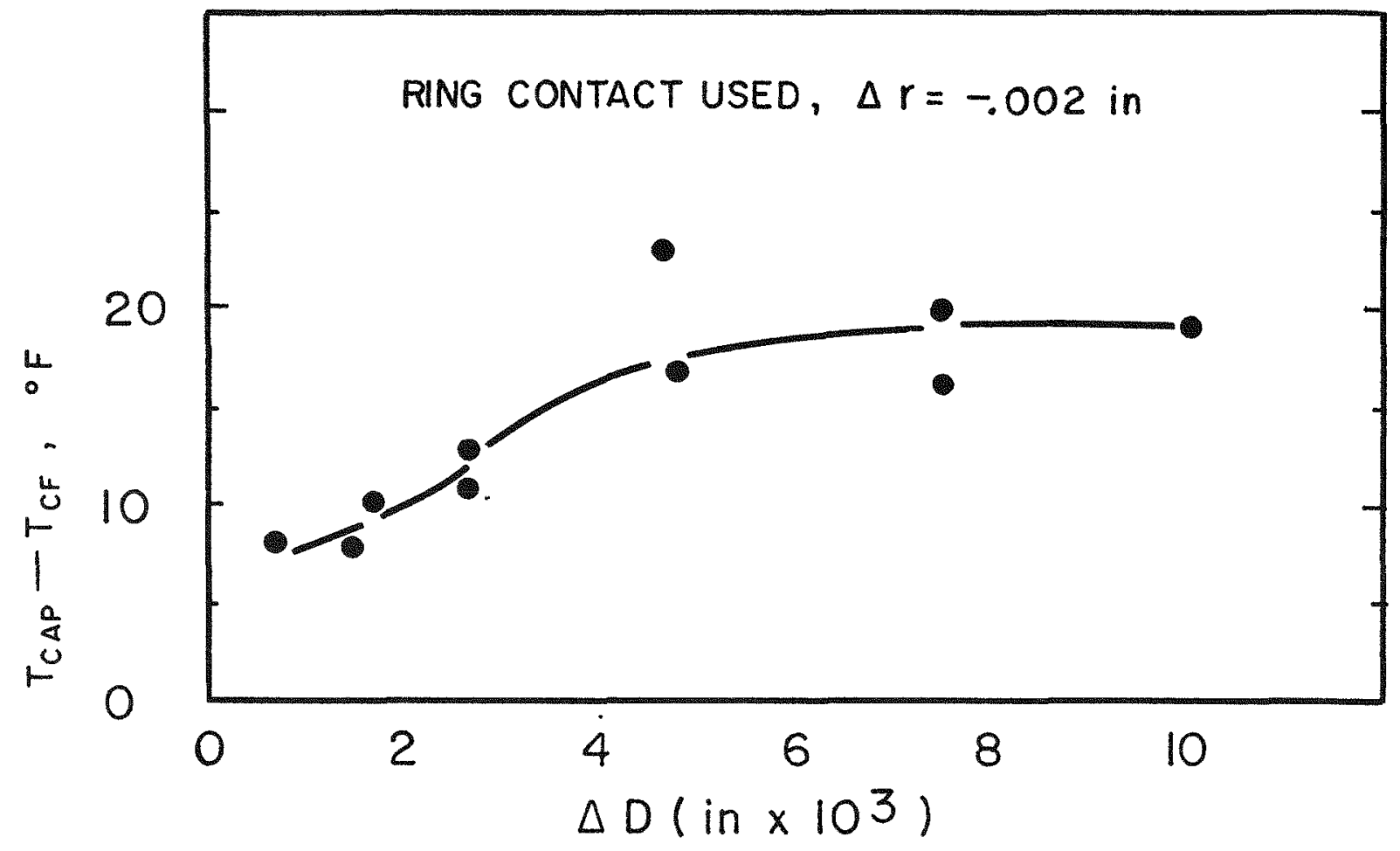

Figure 2-13

Cold End Temperature Drop versus Follower-to-Hole Clearance 


\subsection{CONVERTER DEVELOPMENT}

\subsubsection{Basic Configuration and Description}

The basic configuration and arrangement of components was the same for all seven converters built during the program. This basic cylindrical configuration was developed during the SNAP-23 Program. Figure 2-14 is a sectional view of the general configuration as adapted for EMC-1. Table 2-3 identifies the components and their materials. The hot frame, Item 3 , is a hollow cylinder which receives heat from the system stud. The thermoelectric legs surround the hot frame in a radial array of 40 rows with 7 couples per row. Between the thermoelectric circuit and the hot frame, boron nitride strips, Item 5, provide electrical insulation. One boron nitride strip is used for each axial row of legs and also provides the means for positioning the legs at the hot end. The legs are connected electrically at the hot end by hot junction electrodes, Item 13. The hot end of each leg contacts the hot junction button, Item 14, which fits on the hot junction electrode. The cold cap. Item 19, is attached to the cold end of the leg. The cold caps are connected electrically by cold junction electrodes, Item 17. The spherical surface of the cold cap fits into a socket in the follower. Item 20. This follower is part of the cold end heat rejection and leg contact force system. The springs, Item 22, force the follower against the cold cap to make thermal contact at the cold end and thermal and electrical contact at the hot end. The followers fit into holes in the cold frame, Item 12. The cold frame is a thick walled cylinder with holes for the individual leg followers. The cold frame is part of the cold side heat conductivity system and helps position the legs at the cold end. An outer case, Item 1, is a thin walled cylinder which is shrunk-fit over the cold frame. The system radiator, which dissipates converter rejected heat to ambient air, fits over the outer case. The support cone, Item 2; lower cover. Item 4; and hot frame with the outer case make up the hermetically sealed enclosure. The lower cover and support cone are the structural members which carry the loads induced by external shock and vibration. Microquartz pad, Items 8 and 10; block Min-K 1301, Item 7; and powdered Min-K 1301. Item 9 are thermal insulations which fill the void spaces in the converter enclosure to reduce extraneous heat losses. Wires come out through the power header. Item 11, to conduct the electrical power generated through the hermetic enclosure. 


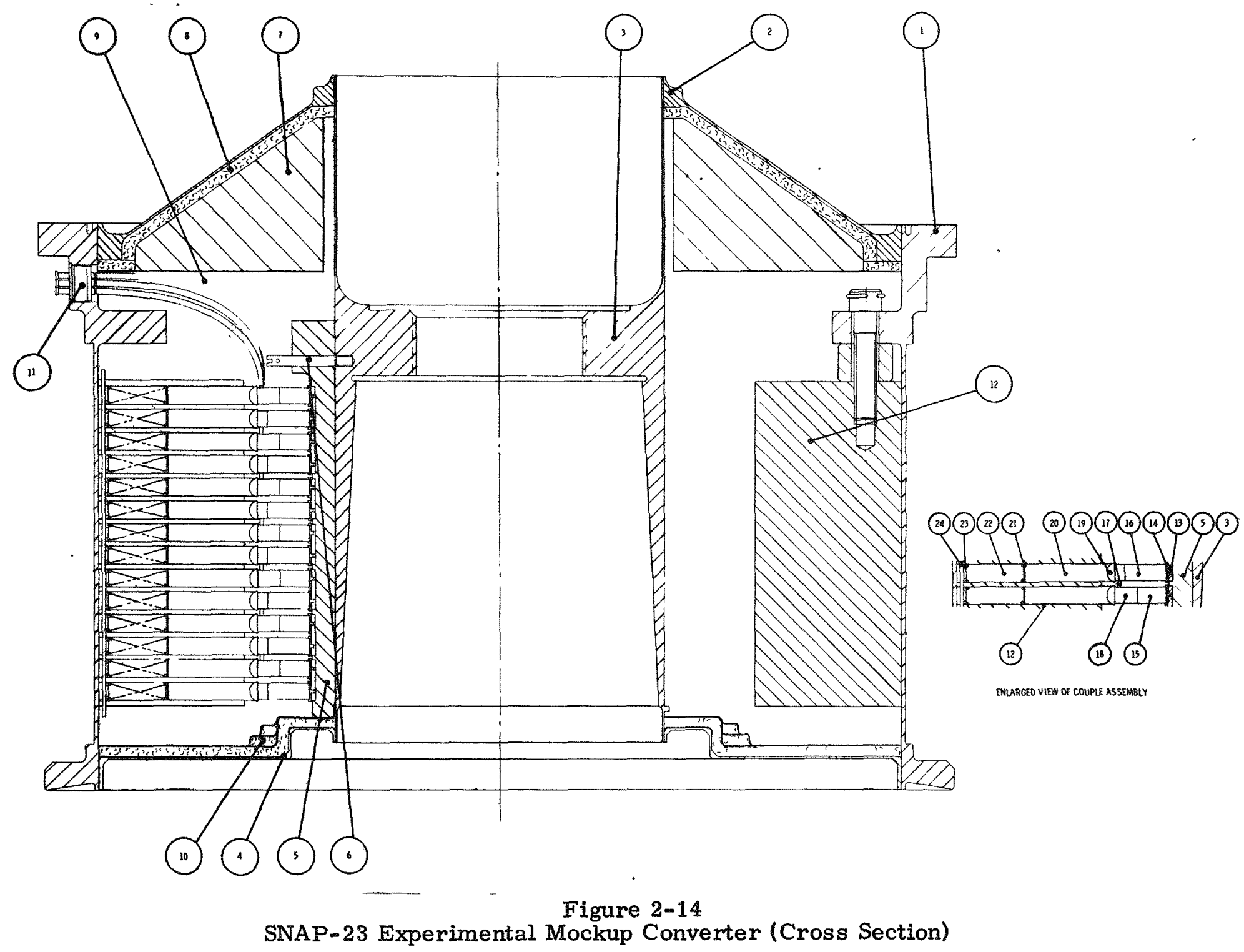


Table 2-3

SNAP-23A Experimental Mockup Converter Parts and Materials

\begin{tabular}{|c|c|c|c|}
\hline Item & Quantity & Part Title & Material \\
\hline 1 & 1 & Outer Case & Stainless Steel \\
\hline 2 & 1 & Support Cone & Stainless Steel \\
\hline 3 & 1 & Hot Frame & Stainless Steel \\
\hline 4 & 1 & Ring, Lower Rain Cover & Stainless Steel \\
\hline 5 & 40 & $\begin{array}{l}\text { Insulation Strip, } \\
\text { Electrical }\end{array}$ & Boron Nitride \\
\hline 6 & 40 & Pin, Anchor & Stainless Steel \\
\hline 7 & 1 & $\begin{array}{l}\text { Thermal Insulation } \\
\text { Block }\end{array}$ & $\begin{array}{l}\text { Johns-Manville Min-K } 1301 \\
\text { (Molded Form) }\end{array}$ \\
\hline 8 & 1 & $\begin{array}{l}\text { Thermal Insulation } \\
\text { for Support Cone }\end{array}$ & $\begin{array}{l}\text { Johns-Manville Micro } \\
\text { Quartz (formed at assembly) }\end{array}$ \\
\hline 9 & 1 & $\begin{array}{l}\text { Thermal Insulation } \\
\text { for Couples }\end{array}$ & $\begin{array}{l}\text { Johns-Manville Min-K } 1301 \\
\text { (Pow dered Form) }\end{array}$ \\
\hline 10 & 1 & $\begin{array}{l}\text { Min-K Thermal } \\
\text { Insulation for } \\
\text { Lower Cover }\end{array}$ & $\begin{array}{l}\text { Johns-Manville Micro } \\
\text { Quartz }\end{array}$ \\
\hline 11 & 1 & Power Output Header & Eimac Division of Varian \\
\hline 12 & 1 & Cold Frame & Aluminum \\
\hline 13 & 264 & Hot Junction Electrode & Copper \\
\hline 14 & 528 & Hot Junction Button & Mild Steel \\
\hline 15 & 264 & P-Leg & $(\mathrm{PbSn}) \mathrm{Te}-(\mathrm{BiSb}) \mathrm{Te} 3$ \\
\hline 16 & 264 & $N$-Leg & $\mathrm{PbTe}-\mathrm{PbTe}$ \\
\hline 17 & 264 & Jumper Wire & Copper \\
\hline 18 & 264 & Cold Cap, P-Leg & Copper \\
\hline 19 & 264 & Cold Cap, N-Leg & Copper \\
\hline 20 & 528 & Follower & Hardcoated Aluminum \\
\hline 21 & 528 & Insulating Washer & Mica \\
\hline 22 & 528 & Follower Spring & Stainless Steel \\
\hline 23 & 528 & Support Washer & Steel \\
\hline 24 & 40 & Support Wire & Steel \\
\hline
\end{tabular}


Both the $\mathrm{N}$ and $\mathrm{P}$ thermoelectric legs are segmented with different materials at the hot and cold ends to increase the conversion efficiency of the thermopile. The cold and hot segment materials are selected for optimum conversion efficiency over the operating temperature range.

The couples are connected in series electrically. The current flow through all couples is the same but the generated couple voltage is additive. In this way the required output power at 24 volts can be generated directly without the need for a $\mathrm{DC}$ to DC voltage converter.

\subsubsection{EMC (Engineering Mockup Converter) Series}

\subsubsection{Introduction}

While the converter designed and developed during the SNAP-23 program functioned properly, it was an experimental model built for laboratory testing. It did form a base line for the converter development of this program but required considerable design and development to meet SNAP-23A requirements and objectives. These requirements and objectives included:

- 10-year life

- Demonstrated reliability

- Field service capability

- Integration with heat source system

- Increased efficiency.

The EMC series were developmental units which were designed and built as part of a planned progression of events to meet these requirements and objectives. Initial EMC converters were designed to incorporate improvements in technology made since the end of the SNAP-23 program. It also incorporated rigorous design analysis in certain critical areas. As the program progressed the results of the technology development portion of the program were factored into the design. The techniques used for the as sembly of the first units was modified and improved for subsequent converters. The intent was to design and build three converters in the EMC series that would then lead to the design of a PMC (Prototype Mockup Converter) series. 


\section{3 .2 .2 EMC-1}

EMC-1 was the first converter to be designed and built during the SNAP-23A program. The objective was to design, develop, and test a thermoelectric converter that would interface with the SNAP-23A heat source system as well as contribute to a converter design to meet contractual requirements.

\subsection{Thermopile Design}

The design of the thermopile was based, to a large extent, on the geometry and technology used in the SNAP-23 converters. Many of the same $\mathrm{N}$ - and P-leg parameters were applied to this first converter. This included leg diameters, materials, ratios of the cold segment length to total leg length, and material characterization data. The SNAP -23 method of joining the cold segments to the hot segments was also used to manufacture the legs.

The thermopile for the EMC series of converters was designed to meet the following electrical performance requirements specified by the contract and $3 \mathrm{M}$-WANL interface document.

- Power Output - 60 watts at EOL

- Load Voltage - 24 volts

- Efficiency - 7.7\% at EOL.

The thermoelectric materials and related application technology imposed certain constraints on the design.

- Maximum Hot Junction Temperature $-1100^{\circ} \mathrm{F}$

- Maximum P-Leg Segment Temperature $-600^{\circ} \mathrm{F}$

The following input parameters were used for the design of the thermopile.

- Shunt heat loss as defined by adiabatic boundaries of drawing, Figure 2-15

- N- and P-leg diameter of 0.187 inch

- Extraneous electrical circuit resistance 6.33\% of total resistance

- N-leg hot segment material M-223 (ES 1103)

- N-leg cold segment material M-13 (ES 1104) 


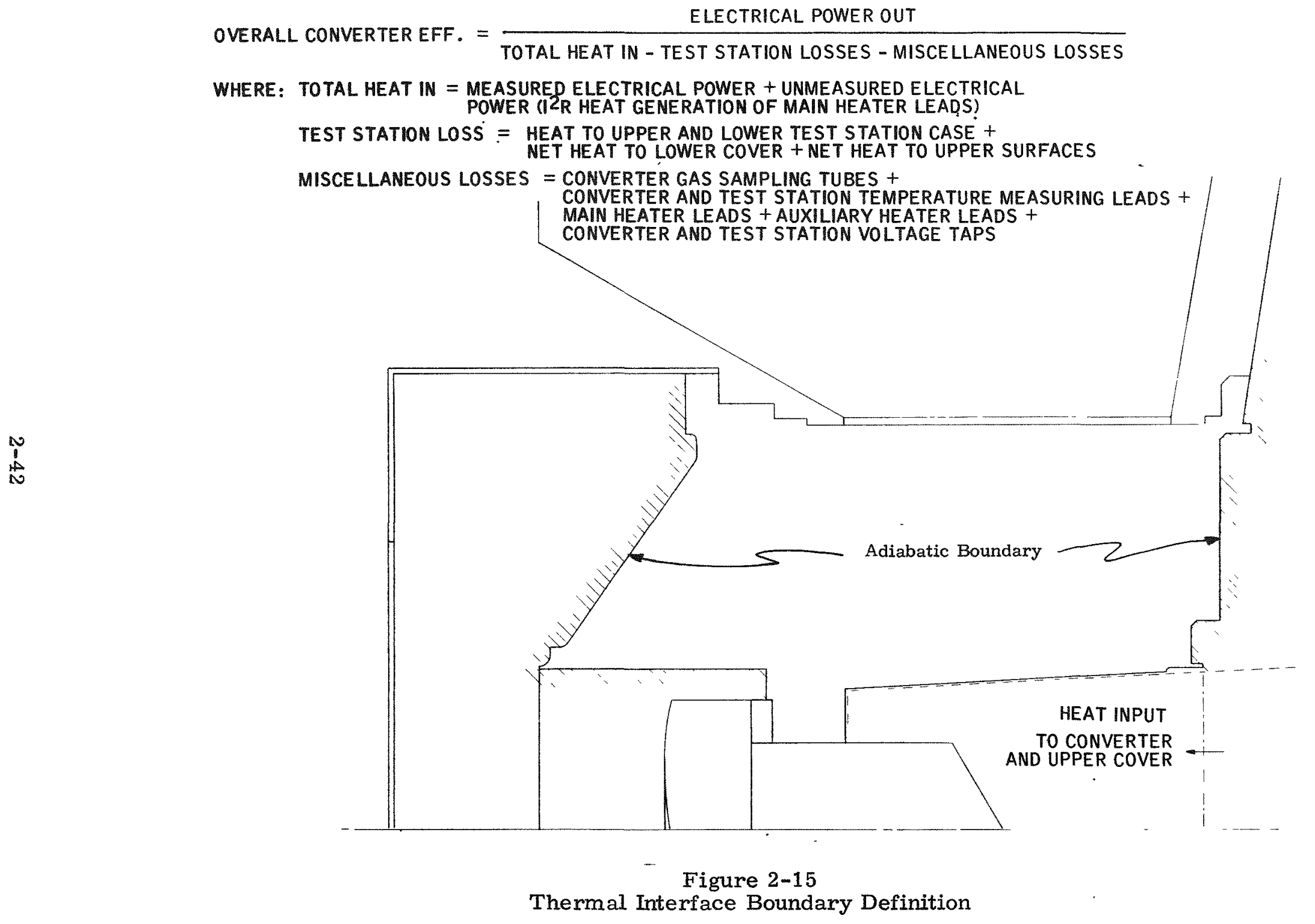


- P-leg hot segment material M-76 (ES 1113)

- P-leg cold segment material M-29 (ES 1116)

- Heat input at EOL was 78.2 percent of heat input at BOL.

Certain operating conditions were controlled by the system interface. These conditions were defined as:

- BOL cold junction temperature $-210^{\circ} \mathrm{F}$

- EOL cold junction temperature $-180^{\circ} \mathrm{F}$

- BOL average hot junction temperature $-1075^{\circ} \mathrm{F}$.

With these quantities defined, the analysis to determine the thermopile configuration was started; design analysis was directed to a thermopile which has maximum efficiency, as opposed to maximum power output. It was also established that the design would be based on a system which maintained the thermopile output voltage at a constant 24 volts. This had the advantage of reducing the hot junction temperature at BOL compared to an external load of fixed impedance. Hot junction temperature reduced by the Peltier heat pumping which is a function of current. This additional Peltier cooling effect was used at BOL conditions to permit higher operating temperatures at EOL with resultant improved efficiency.

The determination of couple number and leg length was calculated with a thermopile design computer program. Initial calculations were conducted for EOL conditions. With a cold junction temperature fixed at $180^{\circ} \mathrm{F}$ an EOL hot junction temperature was estimated. A thermopile configuration was then determined, which included leg lengths and number of couples. Using a thermopile analysis computer program calculations were then conducted to determine BOL conditions of heat input and cold junction temperature. The calculated EOL hot junction temperature was compared to the design goal of $1075^{\circ} \mathrm{F}$. The EOL hot junction was then adjusted to a new value and a new design for EOL conditions was prepared. With the revised design, the BOL hot junction temperature was determined. This iterative procedure was continued until a design configuration was arrived at which resulted in a $1075^{\circ} \mathrm{F}$ hot junction temperature at BOL heat input. Appendix $\mathrm{E}$ of SNAP-23A Quarterly Report Number 1 has a detailed description of this thermopile design procedure. This effort resulted in an initial thermopile design which is described in Table $2-4$. 
Table 2-4

Initial Converter Couple Geometry

$\begin{array}{ll}\text { Number of Couples }(N) & 280 \\ \text { Length of P-Leg }\left(L_{p}\right) & 0.327 \text { inch } \\ \text { Length of P-Leg Cold Segment }\left(L_{c p}\right) & 0.114 \mathrm{inch} \\ \text { Diameter of P-Leg }\left(D_{p}\right) & 0.187 \text { inch } \\ \text { Length of N-Leg }\left(L_{N}\right) & 0.429 \text { inch } \\ \text { Length of N-Leg Cold Segment }\left(L_{c N}\right) & 0.120 \text { inch } \\ \text { Diameter of N-Leg }\left(D_{N}\right) & 0.187 \text { inch }\end{array}$

Converter performance predictions were also calculated. To predict the performance, the shunt heat loss was calculated. The converter in this system was defined as having adiabatic boundaries where the converter top and bottom interfaces with the system; this means that no heat would be transferred through the lower cover or support cone to the system. This adiabatic interface boundary is defined by Figure 2-15. The shunt heat losses were calculated for both EOL and BOL temperature conditions. The shunt heat loss was the total of the heat losses through the following elements of the converter.

- Powdered thermal insulation packed around thermoelectric legs

- Powdered, block and pad thermal insulation at the ends of the thermpile

- Support cone

- Lower cover

A converter parametric study, which would serve as a basis for designing both the heat supply and heat rejection system, was conducted for Westinghouse. The relationship of fin base temperature and fin geometry to total heat input rate for 60 watts power at the EOL point were the primary parameters. Couple geometry and hot junction temperatures at BOL were also determined in the study.

\subsection{Converter Parametric Study Basis and Assumptions}

A. An optimum efficiency converter design would be prepared for five EOL fin base temperatures varying from $130^{\circ} \mathrm{F}$ to $200^{\circ} \mathrm{F}$ for a power output of 60 watts at 24 volts. 
B. Design computer program would establish couple geometry at EOL conditions.

C. The analysis computer program would evaluate performance of a given design for conformance to the given restraints at $\mathrm{BOL}$.

D. Simultaneously pressed $\mathrm{P}$ - and $\mathrm{N}$-leg materials were:

$$
\begin{array}{ll}
\text { N-leg hot segment } & M-223 \text { (ES 1103) } \\
\text { N-leg cold segment } & M-13 \text { (ES 1104) } \\
\text { P-leg hot segment } & M-76 \text { (ES 1113) } \\
\text { P-leg cold segment } & M-29 \text { (ES 1116) }
\end{array}
$$

E. Temperature difference between leg cold junction and fin base to be $30^{\circ} \mathrm{F}$ for both EOL and BOL conditions.

F. Average hot junction temperature at BOL shall not exceed $1075^{\circ} \mathrm{F}$.

G. Total heat input to converter at EOL is $78.2 \%$ of total heat input at BOL.

H. P- and N-leg diameters both 0,187 inch.

I. No heat loss in axial direction from upper and lower covers.

J. Shunt heat loss $\left(Q_{L}\right)$ at EOL and BOL are determined by use of the following equations:

$$
Q_{L}=0.1097(T h-T c-600)+46.11
$$

where

$$
Q_{L}=\text { converter shunt heat loss in watts }
$$

$T_{h}=$ couple hot junction temperature in degrees $\mathrm{F}$

$T_{c}=$ couple cold junction temperature in degrees $F$.

The parametric analysis was conducted and completed. The following terms are used in the next three tables to display the results.

$$
\begin{aligned}
L_{P} & =\text { length of } P-l e g \text { in inches } \\
L_{C P} & =\text { length of } P-l e g \text { cold segment in inches } \\
L_{N} & =\text { length of } N-\text { leg in inches }
\end{aligned}
$$




$$
\begin{aligned}
& \mathrm{L}_{\mathrm{CN}}=\text { length of } \mathrm{N} \text {-leg cold segment in inches } \\
& \mathrm{E}=\text { open circuit voltage in volts } \\
& \mathrm{V}=\text { load voltage in volts } \\
& \mathrm{Q}_{\mathrm{L}}=\text { shunt heat loss rate in watts } \\
& \mathrm{Q}_{\mathrm{T}}=\text { total heat input rate in watts } \\
& \mathrm{N}=\text { overall efficiency in percent } \\
& \mathrm{P} \quad=\quad \text { power output in watts } \\
& \text { I }=\text { current in amperes } \\
& \mathrm{N}=\text { number of couples }
\end{aligned}
$$

Table 2-5 lists the component geometries for five different EOL cold junction temperatures. Each temperature represents an optimized design.

Table 2-5

Component Geometries for Various EOL Cold Junction Temperatures

\begin{tabular}{|c|c|c|c|c|c|c|c|}
\hline$L_{\mathrm{P}}$ & $\mathrm{L}_{\mathrm{CP}}$ & $\mathrm{L}_{\mathrm{N}}$ & $\mathrm{L}_{\mathrm{CN}}$ & $\mathrm{N}$ & $\begin{array}{c}\mathrm{T}_{\mathrm{C}} \\
\text { EOL }\end{array}$ & $\begin{array}{c}\text { Cold Frame } \\
\text { O.D. }\end{array}$ & $\begin{array}{c}\text { Hot Frame I. D. } \\
\text { At Start of Taper } \\
\text { (Small End) }\end{array}$ \\
\hline \hline 0.336 & 0.118 & 0.481 & 0.144 & 263 & 160 & 8.716 & 2.767 \\
0.331 & 0.116 & 0.469 & 0.141 & 266 & 170 & 8.716 & 2.767 \\
0.319 & 0.112 & 0.446 & 0.134 & 272 & 190 & 8.843 & 2.894 \\
0.309 & 0.108 & 0.442 & 0.111 & 276 & 210 & 8.976 & 3.027 \\
0.297 & 0.104 & 0.420 & 0.105 & 283 & 230 & 9.116 & 3.167 \\
\hline
\end{tabular}

Table 2-6 lists performance characteristics at BOL conditions for the five converter designs.

Table $2-6$

SNAP-23A Experimental Mockup Converter Performance Characteristics at BOL

\begin{tabular}{|c|c|c|c|c|c|c|c|c|c|}
\hline $\mathrm{N}$ & $\mathrm{E}$ & $\mathrm{V}$ & $\mathrm{I}$ & $\mathrm{P}$ & $\mathrm{T}_{\mathrm{H}}$ & $\mathrm{T}_{\mathrm{C}}$ & $\mathrm{Q}_{\mathrm{L}}$ & $\mathrm{Q}_{\mathrm{T}}$ & $\eta$ \\
\hline \hline 263 & 53.31 & 24 & 3.226 & 77.42 & 1075 & 190 & 78 & 969.2 & 7.99 \\
266 & 53.51 & 24 & 3.23 & 77.64 & 1075 & 200 & 77 & 984.8 & 7.88 \\
272 & 53.82 & 24 & 3.26 & 78.26 & 1075 & 220 & 74 & 1018.9 & 7.68 \\
276 & 53.02 & 24 & 3.23 & 77.41 & 1075 & 240 & 72 & 1032.5 & 7.50 \\
283 & 52.26 & 24 & 3.18 & 76.35 & 1075 & 260 & 70 & 1043.1 & 7.32 \\
\hline
\end{tabular}


Table 2-7 lists performance characteristics at EOL conditions for the five converter designs.

Table $2-7$

SNAP-23A Experimental Mockup Converter

\begin{tabular}{|c|c|c|c|c|c|c|c|c|c|}
\hline $\mathrm{N}$ & $\mathrm{E}$ & $\mathrm{V}$ & $\mathrm{I}$ & $\mathrm{P}$ & $\mathrm{T}_{\mathrm{H}}$ & $\mathrm{T}_{\mathrm{C}}$ & $\mathrm{Q}_{\mathrm{L}}$ & $\mathrm{Q}_{\mathrm{T}}$ & $\eta$ \\
\hline \hline 263 & 41.48 & 24 & 2.5 & 60 & 890 & 160 & 61 & 759.6 & 7.89 \\
266 & 41.58 & 24 & 2.5 & 60 & 890 & 170 & 59 & 768.8 & 7.80 \\
272 & 41.67 & 24 & 2.5 & 60 & 890 & 190 & 57 & 790.6 & 7.58 \\
276 & 41.84 & 24 & 2.5 & 60 & 900 & 210 & 56 & 806.4 & 7.44 \\
283 & 41.74 & 24 & 2.5 & 60 & 900 & 230 & 55 & 833.4 & 7.19 \\
\hline
\end{tabular}

In selecting a design it is convenient to have three of the EOL parameters presented in curve form. Overall efficiency, total heat input rate, and number of couples are plotted against couple cold junction temperature and are shown in Figure 2-16, 2-17 and 2-18, respectively.

The initial SNAP-23A Experimental Mockup Converter (EMC) 280-couple design (Table 2-4) was based on the temperature and heat input data specified in the performance requirements for a SNAP $-23 A$ 60-watt thermoelectric converter. However, a subsequent heat source and radiator design and system thermal analyses by the system contractor in conjunction with the 3M converter parametric data showed that the heat rejection system could operate at a lower temperature. From the initial 280-couple design, the couple cold junction temperature was reduced from $180^{\circ} \mathrm{F}$ to $174^{\circ} \mathrm{F}$ at EOL and from $210^{\circ} \mathrm{F}$ to $191^{\circ} \mathrm{F}$ at BOL.

In addition, in the system contractor heat source design analyses the heat input spud diameter was increased which improved the temperature gradient along the heat spud; thereby, increasing the average couple hot junction temperature (the arithmetical average of the couple temperatures at the top and bottom of the converter) from a maximum of $1075^{\circ} \mathrm{F}$ to $1085^{\circ} \mathrm{F}$. 


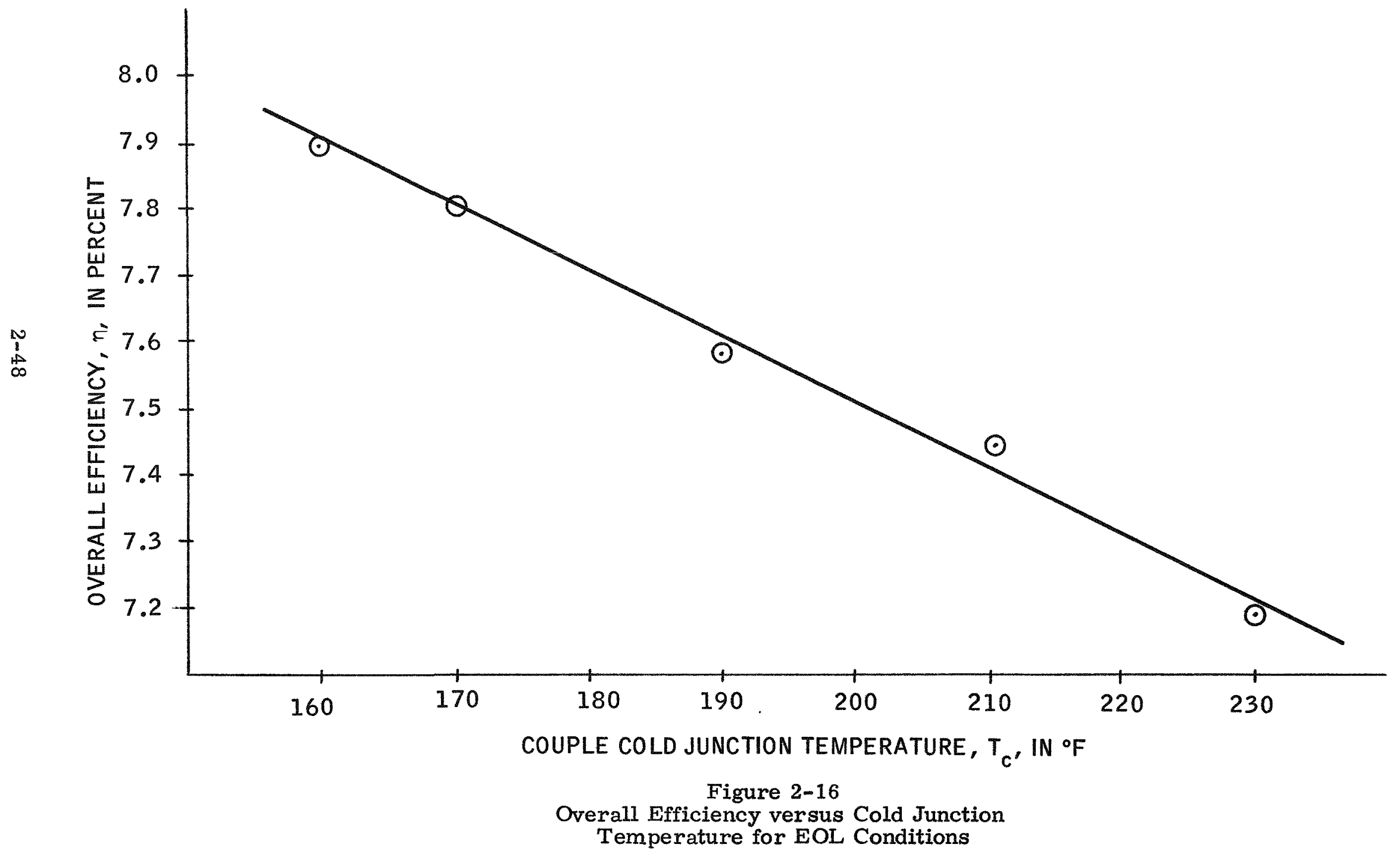




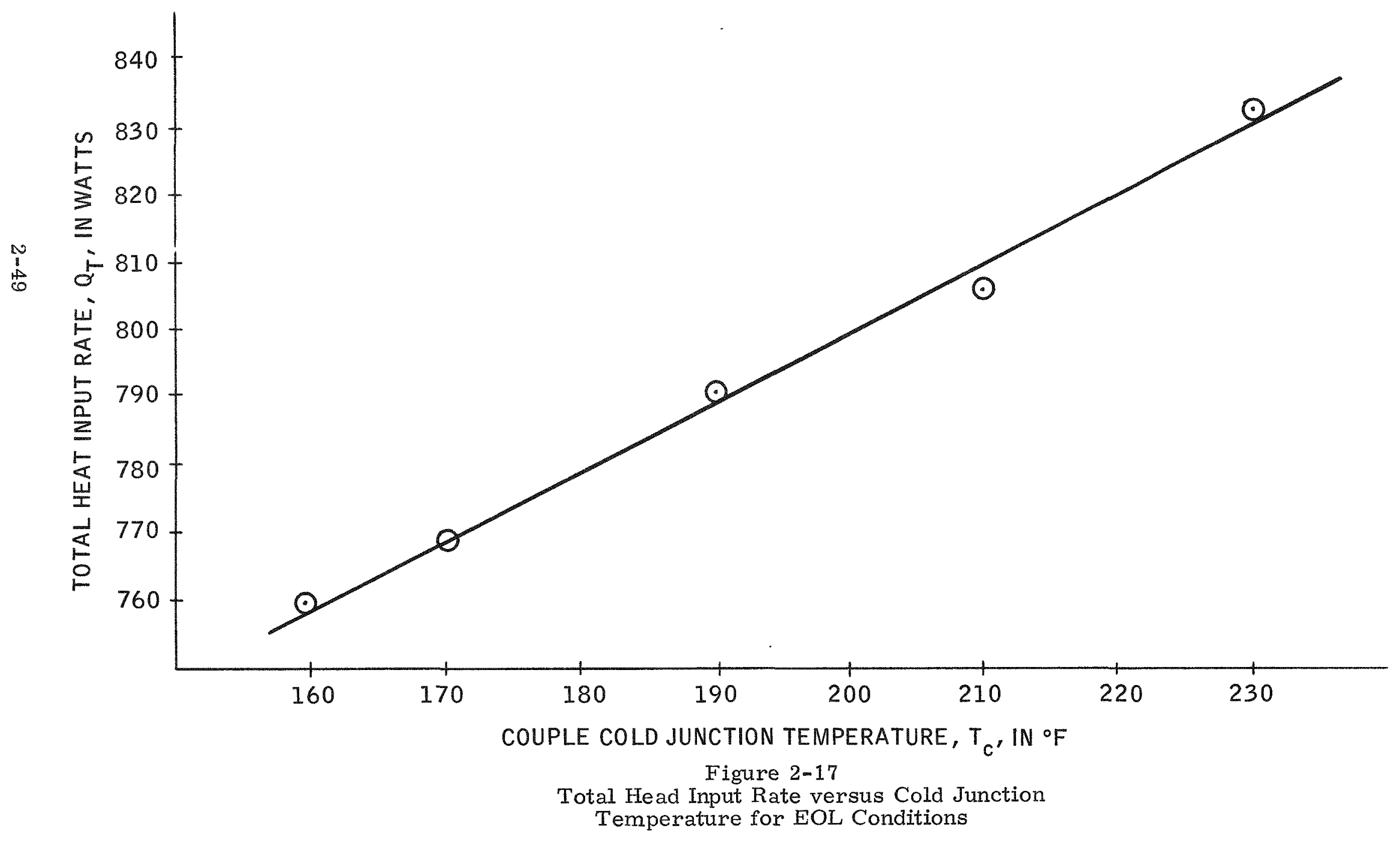




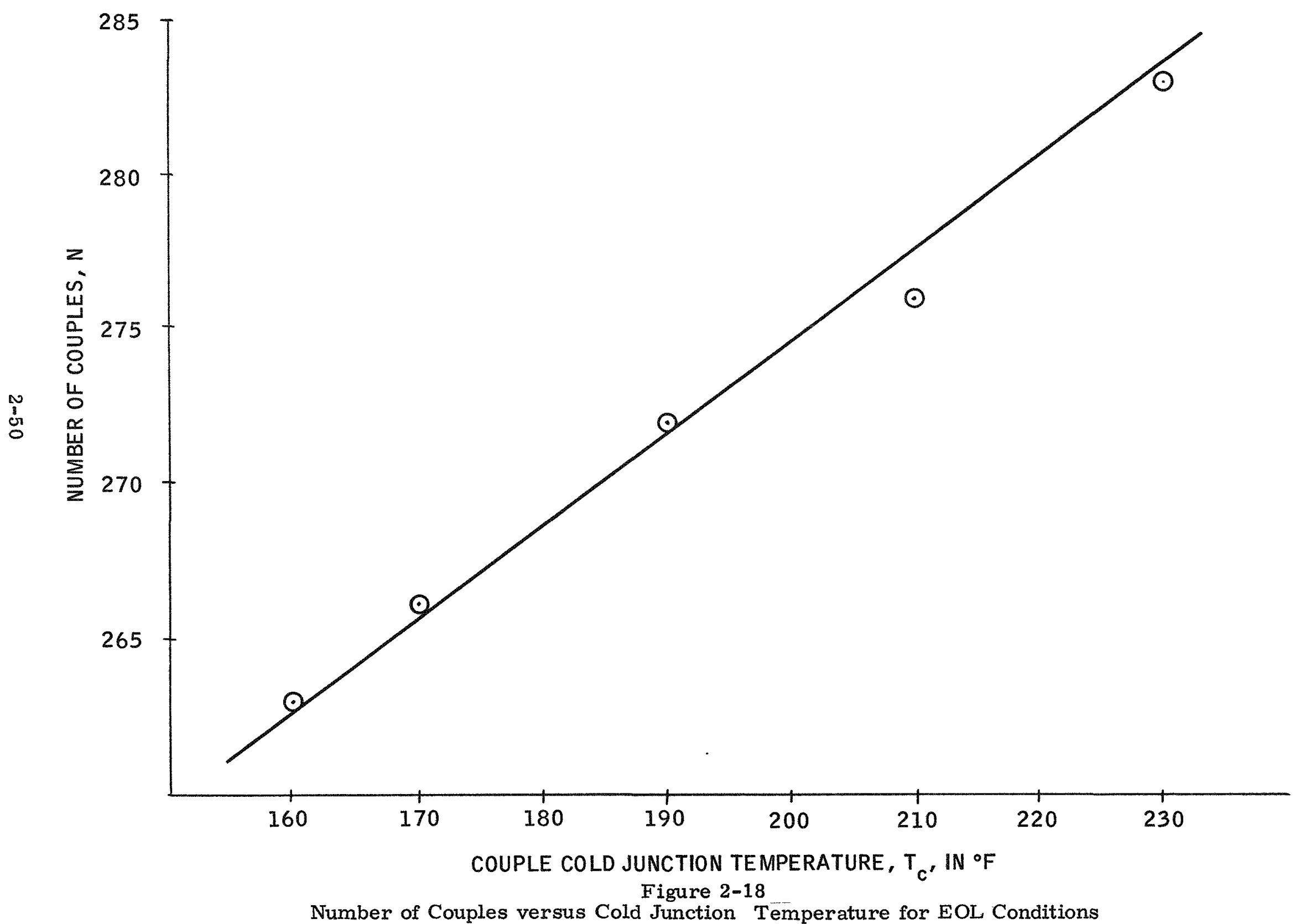

Number of Couples versus Cold Junction Temperature for EOL Conditions 
In view of the new temperature and heat input rate conditions established by the system contractor, the 280-couple design was adjusted to obtain a closer system thermal match and reduce fuel requirements. A summary of the operating parameters for the 280-couple (initial) design and the 264-couple (adjusted) design is presented in Tables 2-8 and 2-9. The procedure used to determine the 264-couple (adjusted) design is described in the following paragraphs.

From the converter parametric study, the corresponding heat input to the 264-couple experimental mockup converter for $174^{\circ} \mathrm{F}$ (EOL cold junction temperature) is 773 watts. The corresponding heat input to the 264-couple experimental mockup converter at BOL, as specified for the system is 1002 watts. In order to successfully integrate the converter into the system, it was requested that 3M reduce the number of couples without dimensionally changing other converter parts if the 60-watt power requirement at EOL could be met with the $773-$ watt heat input to the converter.

Two computer programs were used to arrive at the number of couples. The converter design computer program was used to calculate the number of couples and couple hot junction temperature at EOL for a maximum efficiency operating condition. The design was then evaluated at BOL by means of the converter parametric computer program, with critical parameters consisting of heat input to converter, couple hot junction temperature, and $\mathrm{P}$-leg cold segment temperature. $\mathrm{P}$-leg cold segment temperature is limited to a maximum value of $600^{\circ} \mathrm{F}$. To avoid exceeding this $600^{\circ} \mathrm{F}$ temperature as well as the maximum average hot junction temperature of $1085^{\circ} \mathrm{F}$, the converter must be able to absorb the heat input of 1002 watts which consists of he at input to couples plus converter heat losses. The converter was evaluated at a load voltage of 24 volts, the point at which the converter has its maximum heat absorption capacity under specified operating conditions.

The computer analysis showed that 16 couples should be removed from the 280-couple configuration to obtain a system heat balance at the specified temperatures. 
Table 2-8

SNAP-23A Experimental Mockup Converter EOL Operating Parameters

\begin{tabular}{|l|l|c|c|c|}
\hline \multirow{2}{*}{ EOL Conditions } & \multicolumn{2}{|c|}{ Initial Couple Design } & \multicolumn{2}{c|}{ Adjusted Couple Design } \\
\cline { 2 - 5 } & 280 -Couples & $\begin{array}{c}\text { System } \\
\text { Parameters** }\end{array}$ & 264 -Couples & $\begin{array}{c}\text { System } \\
\text { Parameters* }\end{array}$ \\
\hline \hline $\begin{array}{l}\text { Converter heat } \\
\text { losses } \\
\begin{array}{l}\text { Temperature cold } \\
\text { junction }\end{array}\end{array}$ & 58.2 watts & -- & 59.9 watts & -- \\
$\begin{array}{l}\text { Temperature hot } \\
\text { junction }\end{array}$ & $890^{\circ} \mathrm{F}$ & $180^{\circ} \mathrm{F}$ & $174^{\circ} \mathrm{F}$ & $174^{\circ} \mathrm{F}$ \\
$\begin{array}{l}\text { Total heat input } \\
\text { to converter } \\
\text { Overall efficiency }\end{array}$ & 796 watts & 781 watts & 771.5 watts & 773 watts \\
Load voltage & 24.7 & 7.7 percent & 7.8 percent & -- \\
$\begin{array}{l}\text { Open circuit } \\
\text { voltage } \\
\text { Power output }\end{array}$ & 42.8 & $24 \pm 1$ & 23.9 & $24 \pm 1$ \\
\hline
\end{tabular}

*Supplied by Westinghouse

**Listed in "Performance Requirements for SNAP-23A 60-Watt

Thermoelectric Converter", dated November 30, 1966 , incorporated in Contract A T(30-1)-3824, dated February 1, 1967. 
Table 2-9

SNAP-23A Experimental Mockup Converter BOL Operating Parameters

\begin{tabular}{|c|c|c|c|c|}
\hline \multirow{2}{*}{ EOL Conditions } & \multicolumn{2}{|c|}{ Initial Couple Design } & \multicolumn{2}{|c|}{ Adjusted Couple Design } \\
\hline & 280-Couples & $\begin{array}{c}\text { System } \\
\text { Parameters } * * *\end{array}$ & 264-Couples & $\begin{array}{c}\text { System } \\
\text { Parameters* }\end{array}$ \\
\hline $\begin{array}{l}\text { Converter heat } \\
\text { losses }\end{array}$ & 75.2 watts & -- & 78.4 watts & -- \\
\hline $\begin{array}{l}\text { Temperature cold } \\
\text { junction }\end{array}$ & $210^{\circ} \mathrm{F}$ & -- & $191^{\circ} \mathrm{F}$ & $191^{\circ} \mathrm{F}$ \\
\hline $\begin{array}{l}\text { Temperature hot } \\
\text { junction }\end{array}$ & $1075^{\circ} \mathrm{F}$ & $1075^{\circ} \mathrm{F}$ & $1085^{\circ} \mathrm{F}$ & $1085^{\circ} \mathrm{F}$ \\
\hline $\begin{array}{l}\text { Total heat input } \\
\text { to converter }\end{array}$ & 1030 watts & 989 watts & 1006 watts & 1002 watts \\
\hline Efficiency & 7.7 percent & -- & 8.0 percent & -- \\
\hline Load voltage & 24 & $24 \pm 1$ & 24 & $\begin{array}{l}\text { Re gulated } \\
\text { to } 24\end{array}$ \\
\hline $\begin{array}{l}\text { Open circuit } \\
\text { voltage }\end{array}$ & 55.2 & - & 53.5 & -- \\
\hline Power output & 79.3 watts & 60 watts min & 80.5 watts & 60 watts min \\
\hline $\begin{array}{l}\text { P-leg cold } \\
\text { segment } \\
\text { temperature }\end{array}$ & $573^{\circ} \mathrm{F}$ & -- & $586^{\circ} \mathrm{F}$ & -- \\
\hline
\end{tabular}

*Supplied by Westinghouse

** Listed in "Performance Requirements for SNAP-23A 60-Watt

Thermoelectric Converter", dated November 30, 1966 , incorporated in Contract A T $(30-1)-3824$, dated February 1, 1967. 
As shown in Table 2-9 using the 264-couple design, the P-leg cold segment temperature of $568^{\circ} \mathrm{F}$ is below the maximum allowable temperature of $600^{\circ} \mathrm{F}$. This tabulation also shows that the 264-couple design has the capacity to absorb 1006 watts total heat input rate, which is slightly greater than the system heat output rate of 1002 watts.

These analyses show that the 264-couple converter design should meet system specifications since the P-leg cold segment temperature and couple hot junction temperature are not expected to exceed the maximum allowable limits of $600^{\circ} \mathrm{F}$ and $1085^{\circ} \mathrm{F}$, respectively.

Leg geometry, the same for both the 264- and 280-couple design, is shown in Table 2-10. This is the couple configuration of the thermopiles built for both EMC-1 and EMC-2.

\subsection{Converter Structural Analysis}

The converter when integrated as a component into the SNAP-23A system must support itself in addition to the radiator and power conditioning apparatus. Figure 2-19 shows the converter weldment structure which must support these loads when mounted on the system stud. The 112 pounds of weight to be supported include portions of the converter, heat sink radiator, and power conditioner. The loads which are imposed on this weldment structure are shock and vibration inputs from the system. Because of the support structure, the shock and vibration input to the system are amplified to twice their input values to $10 \mathrm{~g}$.

The natural frequency and spring rate of the converter structure were analyzed in both axial and transverse directions. This analysis was conducted to determine to what extent vibration load inputs from the system would be magnified by the converter structure and to determine that the natural frequency of the converter structure was not within the range of input frequencies of 5 to 52 cycles per second.

The following items were evaluated in the determination of the spring rate and natural frequency of vibration. 
Table 2-10

SNAP-23A Experimental Mockup Converter

Thermoelectric Couple Parameters

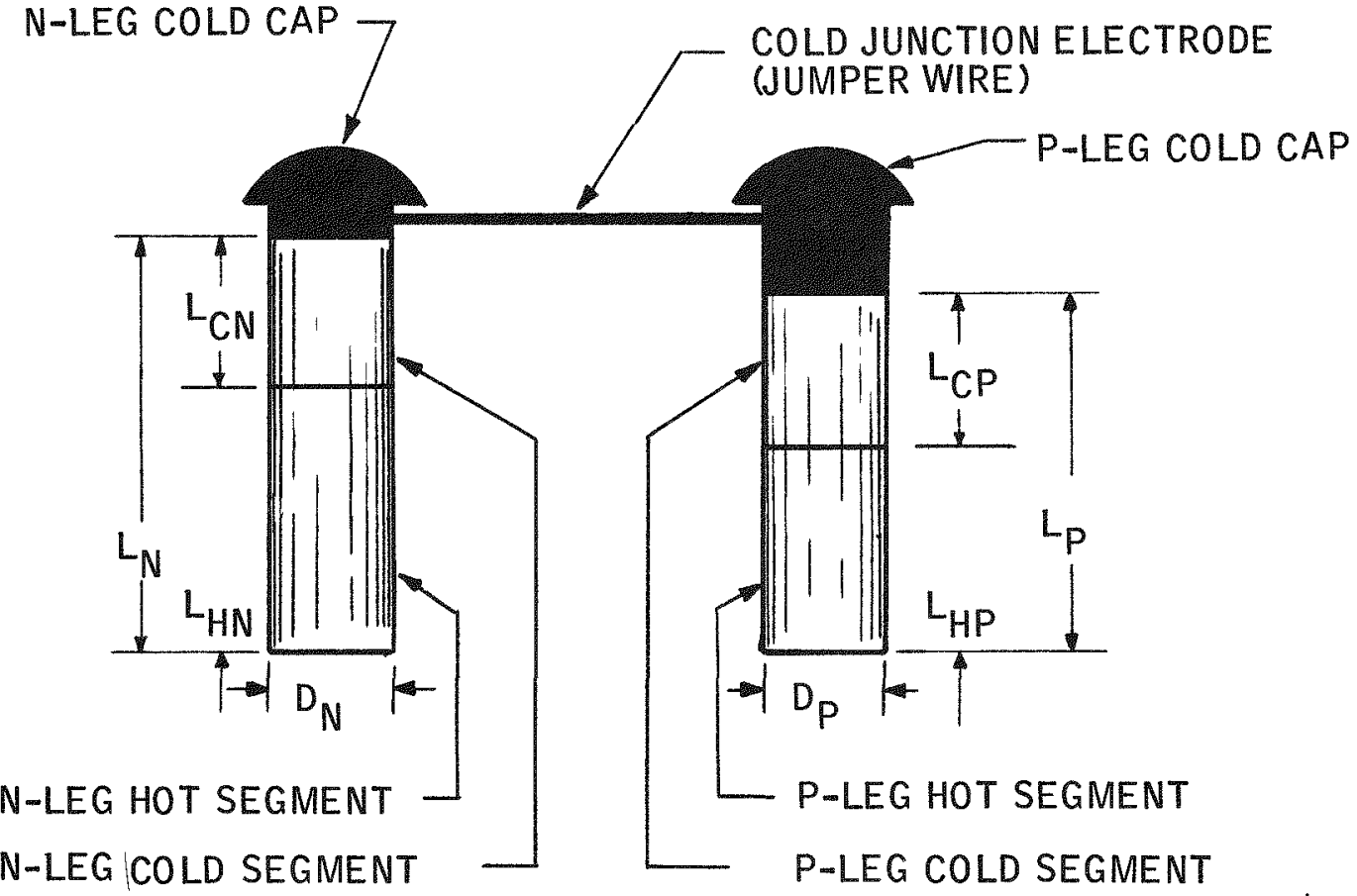

\begin{tabular}{|c|c|c|}
\hline Characteristic & P-Leg & N-Leg \\
\hline $\begin{array}{c}\text { Thermoelectric Material, } \\
\text { Hot Segment } \\
\text { Cold Segment }\end{array}$ & $\begin{array}{l}\mathrm{M}-76(\mathrm{PbSn}) \mathrm{Te} \\
\mathrm{M}-29(\mathrm{BiSb}) 2 \mathrm{Te} \\
3\end{array}$ & $\begin{array}{l}\mathrm{M}-223(\mathrm{PbTe}) \\
\mathrm{M}-13(\mathrm{PbTe})\end{array}$ \\
\hline $\begin{array}{l}\text { Leg Dimensions, inch } \\
\text { Hot Segment Length } \\
\text { Cold Segment Length } \\
\text { Total Leg Length } \\
\text { Diameter }\end{array}$ & $\begin{array}{l}\mathrm{L}_{\mathrm{HP}}=0.213 \\
\mathrm{~L}_{\mathrm{CP}}=0.114 \\
\mathrm{~L}_{\mathrm{P}}=0.327 \\
\mathrm{D}_{\mathrm{P}}=0.187\end{array}$ & $\begin{array}{l}\mathrm{L}_{\mathrm{HN}}=0.359 \\
\mathrm{~L}_{\mathrm{CN}}=0.120 \\
\mathrm{~L}_{\mathrm{N}}=0.479 \\
\mathrm{D}_{\mathrm{N}}=0.187\end{array}$ \\
\hline $\begin{array}{l}\text { Ratio } \\
\text { Cold Segment } \\
\text { Length to Total } \\
\text { Leg Length }\end{array}$ & $\frac{\mathrm{L}_{C P}}{\mathrm{~L}_{P}}=0.350$ & $\frac{{ }^{L_{C N}}}{\mathrm{~L}_{N}}=0.250$ \\
\hline $\begin{array}{l}\text { Ratio, } \text { inch }^{-1} \\
\text { Leg Length/Area }\end{array}$ & $\frac{L_{P}}{{ }^{A} P}=11.91$ & $\frac{\mathrm{L}_{\mathrm{N}}}{\mathrm{A}_{\mathrm{N}}}=17.44$ \\
\hline Fabrication Method & $\begin{array}{l}\text { Simultaneously } \\
\text { Powder-Pressed }\end{array}$ & $\begin{array}{l}\text { Simultaneously } \\
\text { Pow der-Pressed }\end{array}$ \\
\hline
\end{tabular}




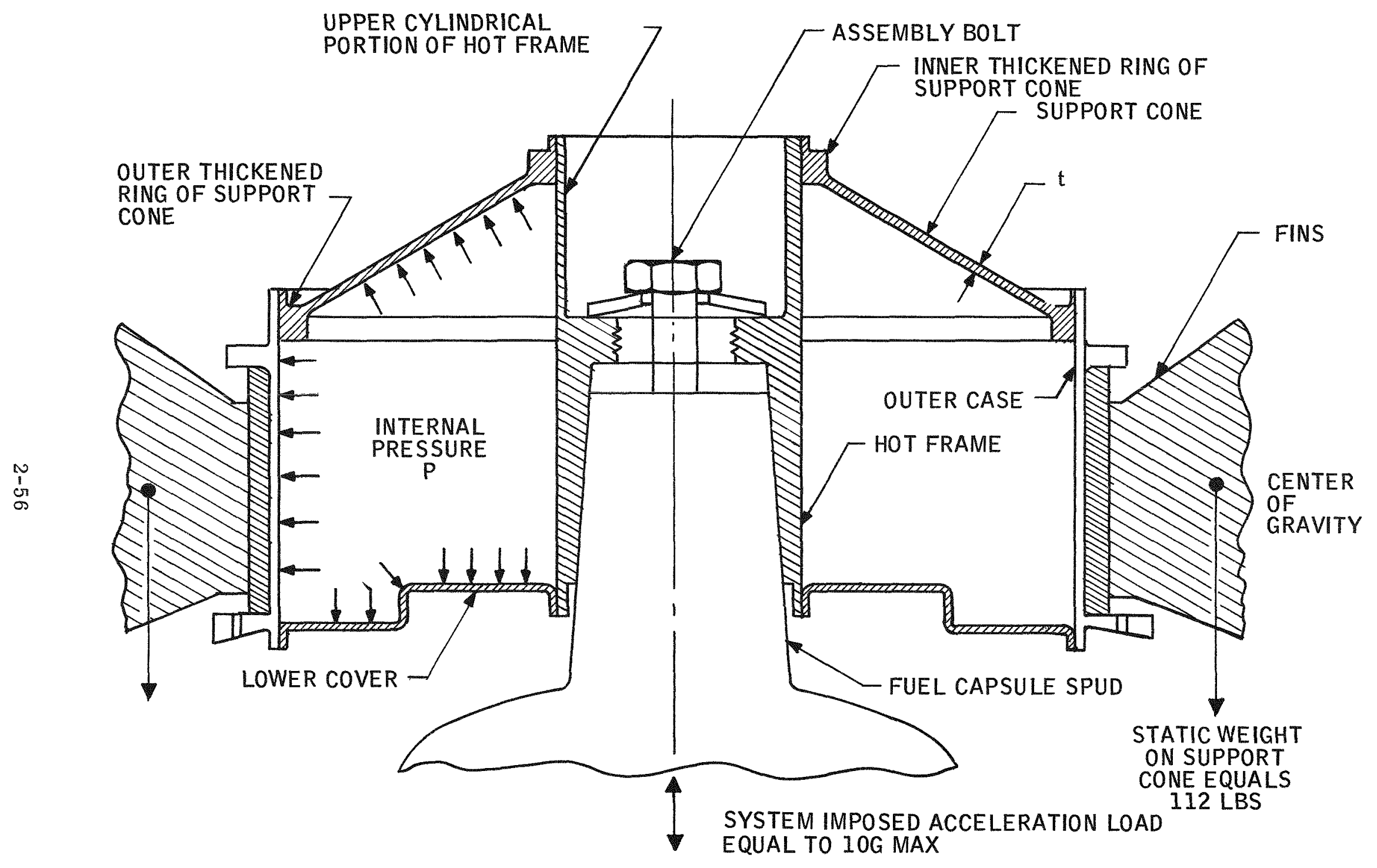

Figure 2-19. Converter-Fins-System Stud Assembly 
A. Bending deflection of upper cylindrical portion of hot frame as a cantilever beam.

B. Shear deflection of upper cylindrical portion of hot frame as a cantilever beam.

C. Rotation of free end of the upper cylindrical portion of the hot frame center line (due to bending).

D. Bending deflection of support cone.

E. Shear deflection of support cone.

F. Change in slope of support cone center line due to bending.

Spring rates, magnification factors, and natural vibration frequencies calculated for both the axial and transverse directions are listed in Table 2-11. The acceleration forces transmitted to the converter hot frame from the system, when multiplied by the magnification factors, yields the acceleration forces transmitted through the converter structure.

Table 2-11

Spring Rate Analysis Results

\begin{tabular}{|l|c|c|c|}
\hline \multicolumn{1}{|c|}{ Direction } & $\begin{array}{c}\text { Spring Rate } \\
\text { Lbs.Per Inch }\end{array}$ & $\begin{array}{c}\text { Natural Frequency } \\
\text { Cycles Per Second }\end{array}$ & $\begin{array}{c}\text { Magnification } \\
\text { Factor }\end{array}$ \\
\hline Axial & $4.97 \times 10^{5}$ & 215 & 1.062 \\
Transverse & $2.69 \times 10^{6}$ & 500 & 1.01 \\
\hline
\end{tabular}

The natural frequencies of vibration are well beyond the input frequencies so no difficulty would be encountered with resonance.

The structural design of the converter was analyzed for stress in critical areas. The stresses were determined on the basis of a design load factor made up of the following separate factors.

Magnification Factor

1.062

Safety Factor

1.5

Fatigue Factor

0.85

Calculated Design Load Factor $\frac{1.5 \times 1.062}{0.85}=1.875$

Analysis Load Factor 
The load imposed on the structure by shock and vibration would be:

$$
\text { Load }=\text { Load Factor } \times G \times W t=2.0 \times 10 \times 112 \mathrm{lbs} .=2240
$$

Stresses were calculated for those areas of the structure where it was obvious that the stresses would be the greatest. Those areas for which the stress was calculated were as follows:

- Support cone adjacent to its outer thickened ring

- Support cone adjacent to its inner thickened ring

- Outer thickened ring of support cone

- Inner thickened ring of support cone

- Upper cylindrical portion of hot frame

The results of these calculations are summarized in Table 2-12. The detailed calculations are included in Appendix A SNAP-23A Quarterly Report No. 1. The value of margin of safety (MS) is the indicator which shows if the design is adequate to withstand the loads. If the MS value is positive, as they all were for the structure, then the stresses are below the level which still allows for the safety factor, material fatigue, and load magnification.

\subsection{Outer Case and Cold Frame Analysis}

The outer case, which is a thin walled stainless steel cylinder, is assembled to the cold frame by means of a shrink fit, the cold frame being a thick sectioned aluminum cylinder which is inside the outer case. For the Experimental Mockup Converter the cold frame had 560 radially drilled holes which are subject to distortion when the radial band pressure, created by the stretching of the outer case, becomes excessive. Each radial hole contains a spring loaded follower which bears against a couple leg and establishes an electrical contact pressure at the hot and cold junction. Therefore, cold frame distortion is limited to approximately 0.0001 inch to avoid pinching the followers. The radial pressure exerted on the cold frame is limited by the thickness of the outer case wall and the yield point of the stainless steel as a result of the outer case being stretched beyond the yield point in the shrink fit assembly. Further stretching takes place in the heated condition when the aluminum cold frame expands more than the outer case due to the difference 
Table 2-12

Converter W eldment Stresses

\begin{tabular}{|c|c|c|c|c|c|c|c|c|c|}
\hline Item & \multicolumn{3}{|c|}{ Hoop Stress* } & \multicolumn{3}{|c|}{ Meridional Stress* } & $\begin{array}{c}\text { Combined } \\
\text { Stress } \\
*\end{array}$ & $\begin{array}{l}\text { Failure } \\
\text { Mode }\end{array}$ & $\underset{* *}{\text { M.S. }}$ \\
\hline \multirow{2}{*}{$\begin{array}{l}\text { Support cone adjacent to } \\
\text { its outer thickened ring }\end{array}$} & - & - & $+11,220$ & $+6,140$ & - & $+5,610$ & $+11,500$ & Tens. Yield & 1.19 \\
\hline & - & - & $+11,220$ & - & $-6,140$ & $+5,610$ & - & Tens. Yield & 1.20 \\
\hline $\begin{array}{l}\text { Support cone adjacent to } \\
\text { its inner thickened ring }\end{array}$ & - & - & $+4,520$ & $+15,280$ & - & $+2,260$ & $+15,750$ & Tens. Yield & 0.16 \\
\hline \multirow{2}{*}{$\begin{array}{l}\text { Outer thickened ring of support } \\
\text { cone }\end{array}$} & \multicolumn{4}{|c|}{ Up Load Not as Critical as Down Load } & & & & & \\
\hline & $-12,800$ & - & - & - & - & - & $-12,800$ & Buckling & 1.09 \\
\hline \multirow{2}{*}{$\begin{array}{l}\text { Inner thickened ring of } \\
\text { support cone }\end{array}$} & - & $-14,900$ & - & - & - & - & $-14,900$ & Comp. Yield $* * * *$ & 0.60 \\
\hline & $+17,050$ & - & - & - & - & - & $+17,050$ & Tens. Yield & 0.07 \\
\hline
\end{tabular}

* (+) Indicates tension, (-) indicates compression, all stresses in psi.

** M. S. = (allowable stress/design stress) -1 .

*** Not critical in buckling. 
in the thermal coefficient of expansion between the two metals. The system heat sink radiator changes on the converter outer case causing a load on the cold frame which adds to that caused by the outer case.

The holes in the cold frame have very little metal between them. There are fourteen 0.219 inch diameter holes in a span of 3.75 inches (cold frame height) which leaves a nominal web thickness between the holes of 0.0488 inch. Hole distortion is caused by the high stress in the thin webs. The stress in the webs is analyzed by equating the outer case hoop force to resisting web force. This loading is shown schematically in Figure 2-20. For simplification, only a diametrically opposite set of holes is shown in the cold frame sketch.

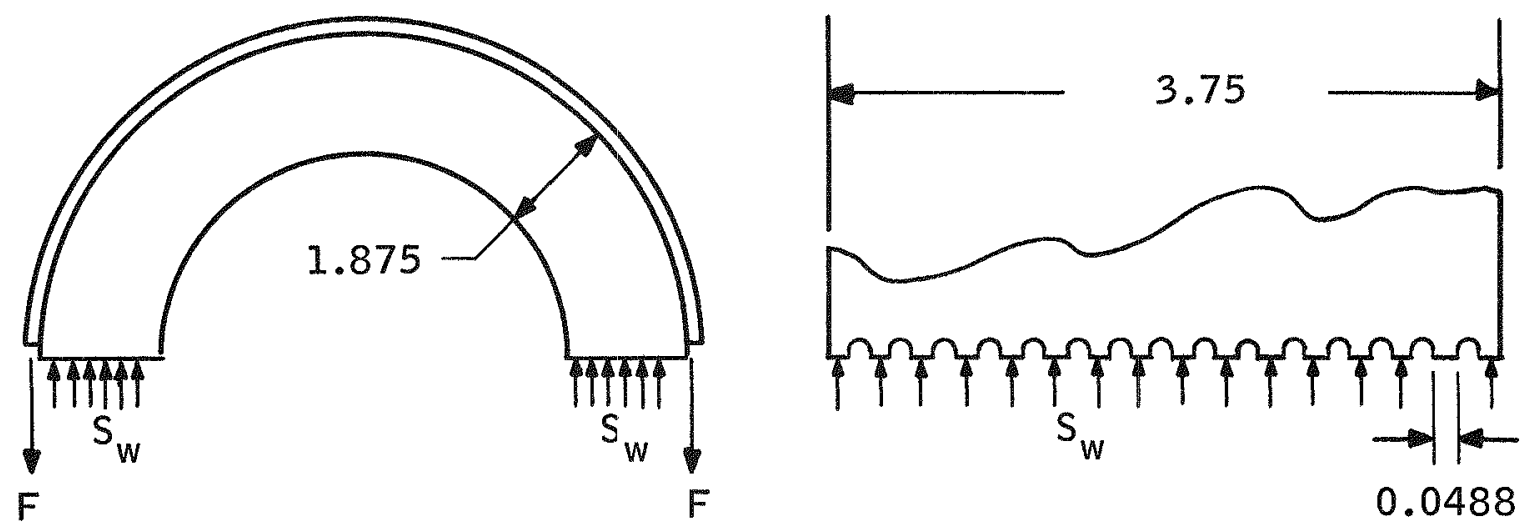

Figure 2-20

Cold Frame Force-Loading 
By equating the outer case hoop force $(F)$ to the total web forces $\left(S_{W}\right)$, allowing for variation in web stress for changing web thickness, calculation of hole distortion indicates that the hole diametral shrinkage is approximately 0.00007 inch. This value is within the desired limit of 0.0001 inch.

\subsection{Hot Frame Interface Analysis}

The hot frame system interface was analyzed from the standpoint of stress loads imposed duxing assembly and disassembly for 500 psi contact pressure, and for two separate cases of hot frame inside diameter taper (see Table 2-13). The two cases were a taper of two degrees and three degrees per side on the inside diameter that mates with system stud. To determine the stresses in the web of the hot frame, which would be subjected to the assembly and disassembly loads, it was first necessary to calculate the assembly and disassembly loads.

Figure 2-21 illustrates the engagement of the system stud with the converter hot frame. The fuel capsule stud is pulled into the converter hot frame by means of the assembly bolt. Taper dimensions are defined by the top and bottom engagement radii, $r_{1}$ and $r_{2}$; and the taper height, $h$. The maximum allowable contact pressure of 500 psi was used in the calculations. Forces acting on the system stud during engagement are shown in Figure 2-22.

For assembly, the coefficient of friction is assumed to be 0.10 for diassembly, the coefficient of friction is assumed to be 1.0 . This higher value for disassembly, though somewhat indeterminate, is based upon the probability of sticking after a long operating period at temperatures up to $1150^{\circ} \mathrm{F}$.

\begin{tabular}{|c|c|c|c|}
\hline $\begin{array}{c}\text { Taper, } \\
\text { Degrees }\end{array}$ & $\begin{array}{c}\text { Coefficient } \\
\text { Of Friction }\end{array}$ & $\begin{array}{c}\text { Assembly } \\
\text { Force, Lbs. }\end{array}$ & $\begin{array}{c}\text { Disassembly } \\
\text { Force, Lbs. }\end{array}$ \\
\hline 2 & 0.10 & 2840 & \\
3 & 0.10 & 3150 & \\
2 & 1.0 & & 20,200 \\
3 & 1.0 & & 19,460 \\
\hline
\end{tabular}




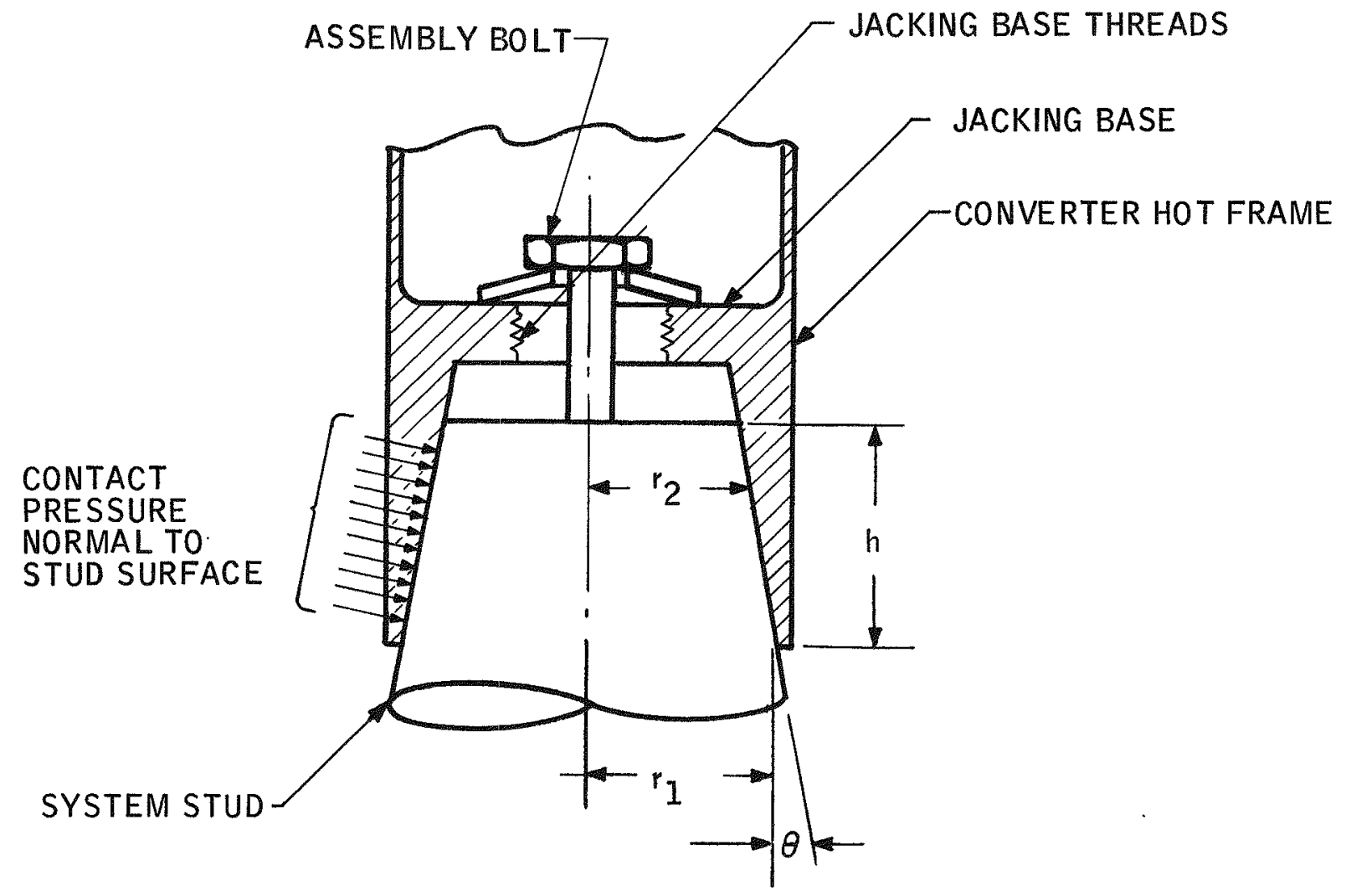

Figure 2-21. Converter Hot Frame - System Stud Interface

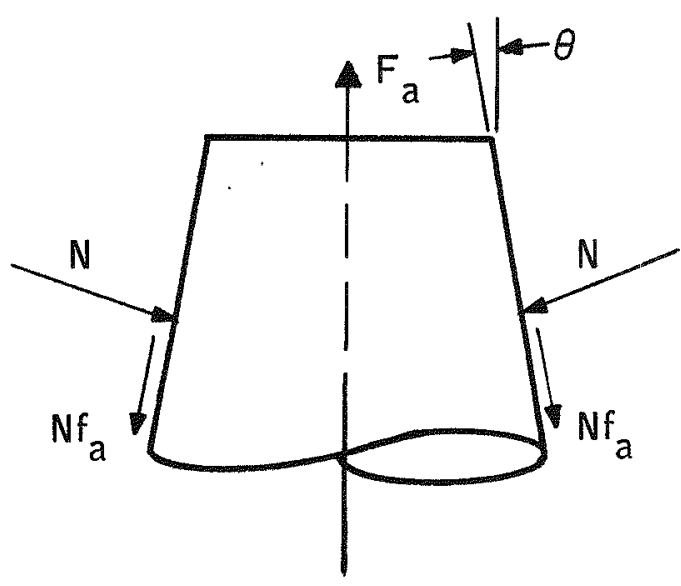

$\mathrm{F}_{\mathrm{a}} \sim$ ASSEMBLY FORCE

$\mathrm{f}_{\mathrm{a}} \sim$ COEFFICIENT OF FRICTION

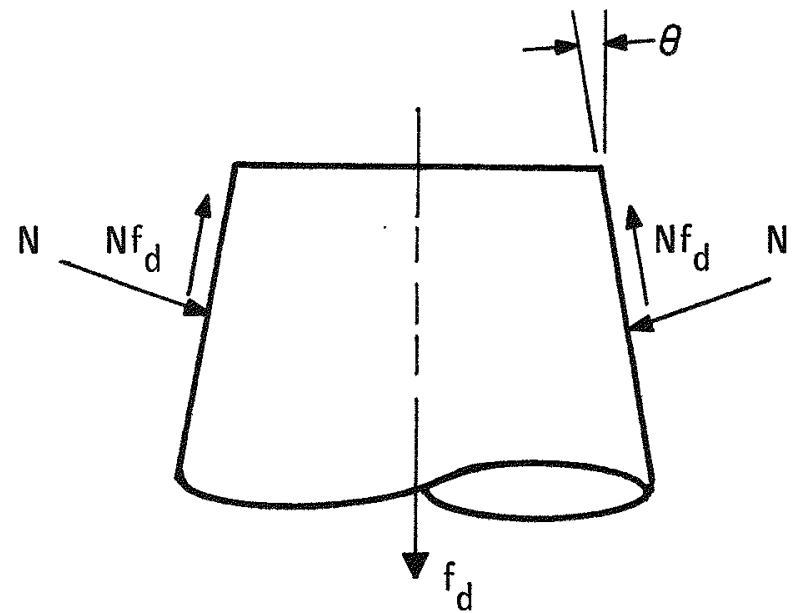

$F_{d} \sim$ DISASSEMBLY FORCE

$f_{d} \sim$ COEFFICIENT OF FRICTION

$$
\begin{aligned}
& \mathrm{N} \sim \text { NORMAL FORCE } \\
& \theta \sim \text { DEGREES TAPER }
\end{aligned}
$$

Figure 2-22. System Stud Force Diagrams 
The jacking base threads shown in Figure 2-21, have a pitch diameter of 1.75 inches and an engagement length of 0.500 inch which is the thickness of the jacking base. The number of threads per inch is 12. The disassembly technique involves screwing an internally threaded adapter into the jacking base. A long rod or bolt would then be screwed into the adapter until the bolt bears against the top of the system stud. Stud disengagement is effected by turning the bolt and holding the adapter with a separate wrench so that the jacking base threads are not exposed to dynamic loading.

The shear strength of 347 stainless steel at room temperature is approximately $20,000 \mathrm{psi}$. At $1150^{\circ} \mathrm{F}$, which is the approximate operating temperature, the shear strength is 47 percent of the room temperature value or 9400 psi.

For a calculated shear area of two square inches, the threads will theoretically shear when the disassembly force is 18,800 pounds. The web of the hot frame becomes the jacking base for removal of the converter from the system. The web is subjected to loading which will induce bending stresses. The jacking base can be analyzed as a disc with a fixed periphery and a uniform load around the edge of hole as shown in Figure 2-23.

By solution for the maximum bending stress which occurs at the outer edge of the disc, and relating this stress to the total edge load around the hole, it is found that, for the condition of the jacking base at a temperature of $1150^{\circ} \mathrm{F}$, the jacking base will yield when the disassembly force is approximately 7730 pounds. Since the theoretical disassembly force $(19,460$ pounds) is considerably greater, the jacking base must either be thickened or else another technique must be considered for separating the fuel capsule spud from the converter.

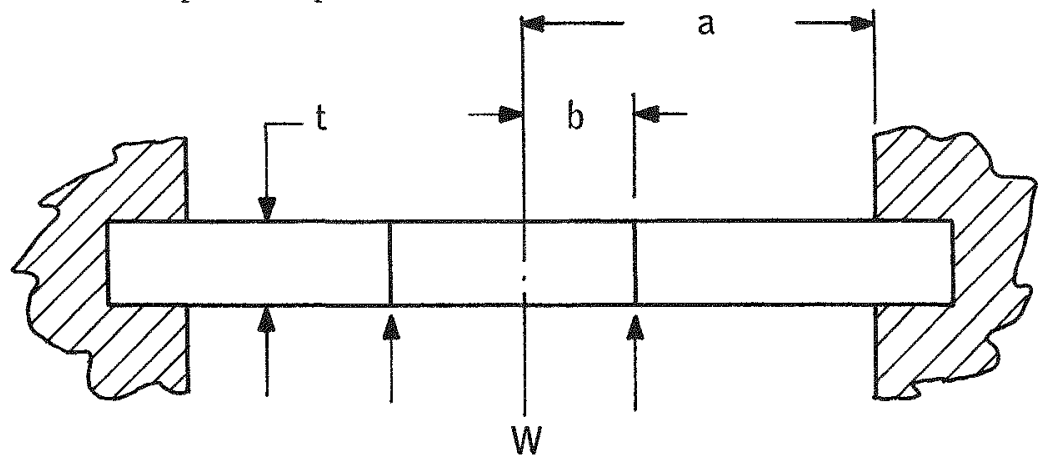

Figure 2-23

Jacking Base Loading Diagram 
The solution to this overstressing of the hot frame web or jacking base involved three factors.

- The thickness of the web was increased from . .500 to .750 .

- Mica sheet to be used between the hot frame and system stud to prevent seizure.

- The torque for removal of the coverter from the system was limited to $50 \mathrm{in}-\mathrm{lb}$.

\subsection{Upper and Lower Surface Temperature Analysis}

The SNAP-23A Experimental Mockup Converter was designed on the basis that all shunt heat losses are confined to a radial or horizontal direction with respect to the vertical axis of the converter. With the converter mounted on the heat spud, converter performance characteristics are based on an adiabatic (perfectly insulated) boundary for all exposed support cone, lower cover, hot frame, assembly bolt, and assembly washer surfaces. Surface temperatures at intermediate points along the exposed surfaces were calculated after the heat flow rates along the paths were determined. The intermediate temperatures must be known for estimating yield stresses and are also of value when estimated external converter heat flow in the vertical direction. Therefore, this analyses was concerned with the intermediate temperature calculations. Figure 2-24 shows the system interface temperature and the calculated intermediate temperatures. Also shown is the direction of heat flow in the upper and lower converter surfaces, the upper surface consisting of the upper hot frame cylinder and support cone.

\subsection{Couple Alignment Analysis}

Couple alignment was a major design consideration because proper operation of the thermoelectric legs and couples depends on the leg being positioned such that good contact is maintained at all times between the leg hot end and hot junction button. The couple hot junction is a flat, butt type joint and any loss of contact due to tilting would decrease the thermal heat transfer area and increase electrical contact resistance. The increase in electrical resistance by leg tilting was demonstrated during bell jar tests $8 / 18-10,9 / 18-12,11-4$ and $9-18$. 


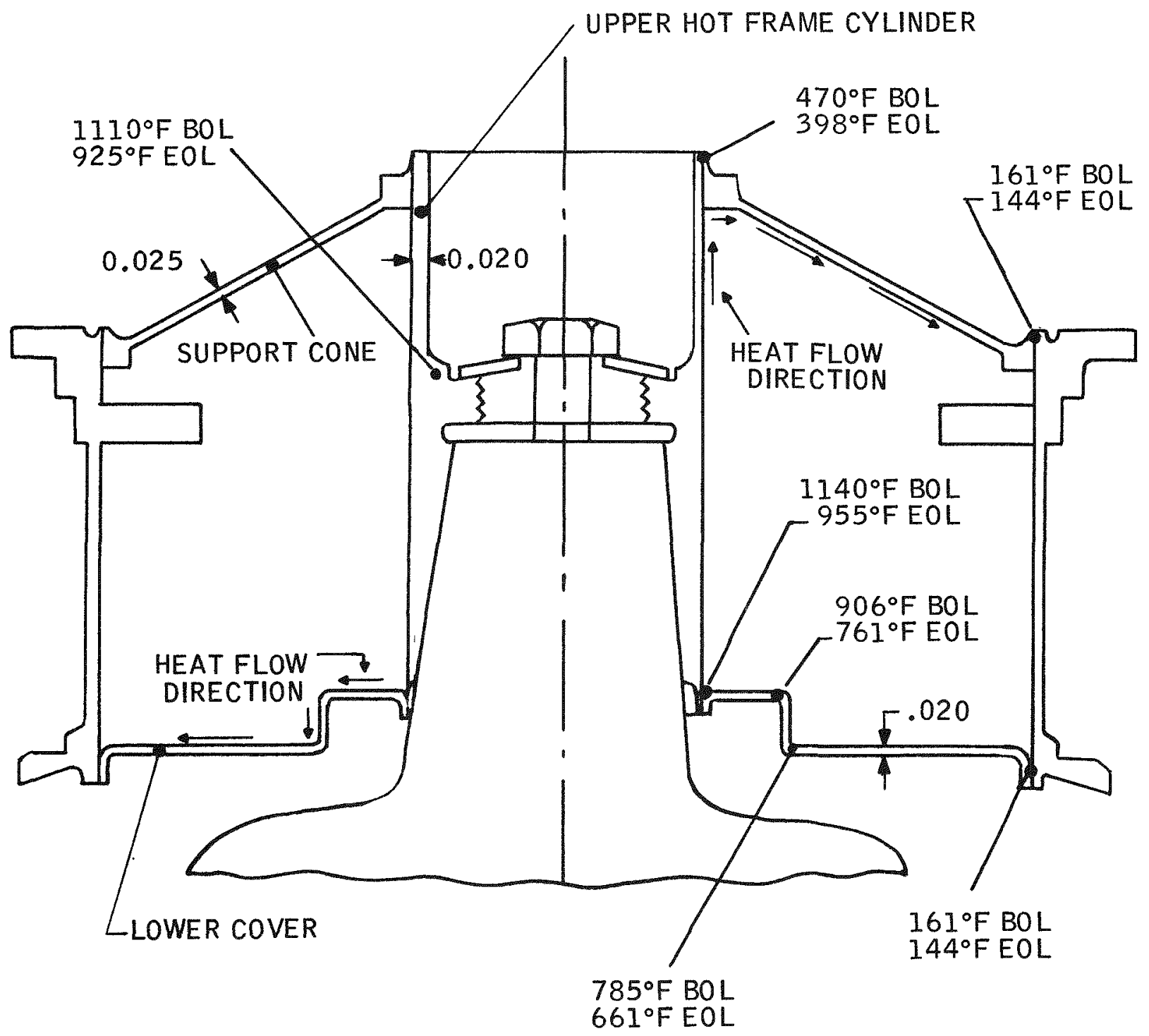

Figure 2-24. Experimental Mockup Converter Anticipated Surface Temperatures 
Proper contact, in turn, is dependent upon minimum misalignment in both the hot and cold contitions and minimum relative motion between the cold frame and the electrical insulation (boron nitride strips) during the initial heating period.

Thermal expansion of the boron nitride strips in the vertical (axial direction) is negligible compared to the hot frame expansion. Since the hot junction end of the legs must follow the boron nitride strips during thermal expansion, it is desirable that the strips be anchored to the hot frame at a point that has no relative motion with respect to the cold frame which positions the cold junction end of the legs. The cold frame expands a small amount in the vertical direction with respect to the boron nitride strips. To distribute the misalignment evenly between the upper and lower couples, the vertical midpoint of the cold frame (Figure 2-25) is the point selected as having zero relative motion with respect to the boron nitride anchoring point on the hot frame. The increase of length $a, b$, and $c$ due to thermal expansion should equal the increase in length of $d$ and e from thermal expansion. The linear thermal expansion of $b, c, d$, and e is calculated from the temperature increase, length, and coefficient of thermal expansion. The determination of the increase of a is more complicated and is done by breaking the support cone into three parts, calculating the individual expansions, and then adding the results together.

The boron nitride anchor point was found by iterative calculations. The calculated dimensions are shown by Table 2-14 for the structure as shown by Figure 2-25. These dimensions listed in Table 2-14 were used to dimension the components which make up the structure as shown by Figure $2-25$.

Table 2-14

Couple Alignment Hot and Cold Condition Dimensions

\begin{tabular}{|c|l|l|l|c|c|}
\hline Dimension & $\begin{array}{c}\text { Cold } \\
\text { Length }\end{array}$ & $\begin{array}{c}\text { Hot } \\
\text { Length }\end{array}$ & $\begin{array}{c}\text { Change } \\
\text { In Length }\end{array}$ & $\begin{array}{c}\text { Thermal } \\
\text { Average Hot } \\
\text { Temp ( F) }\end{array}$ & $\begin{array}{c}\text { Coefficient } \\
\text { of Expansion }\end{array}$ \\
\hline \hline $\mathrm{a}$ & 1.694 & 1.720 & 0.02632 & $*$ & $*$ \\
$\mathrm{~b}$ & 1.812 & 1.81248 & 0.00148 & 160 & $0.96 \times 10^{-5}$ \\
$\mathrm{c}$ & 1.876 & 1.87830 & 0.00230 & 170 & $1.29 \times 10^{-5}$ \\
$\mathrm{~d}$ & 2.687 & 2.70852 & 0.02152 & 845 & $1.04 \times 10^{-5}$ \\
$\mathrm{e}$ & 0.75 & 0.75807 & 0.00807 & 1110 & $1.04 \times 10^{-5}$ \\
\hline
\end{tabular}

*The average temperature and thermal coefficient of expansion are not directly applicable to calculating change in dimension $a_{\text {. }}$ 


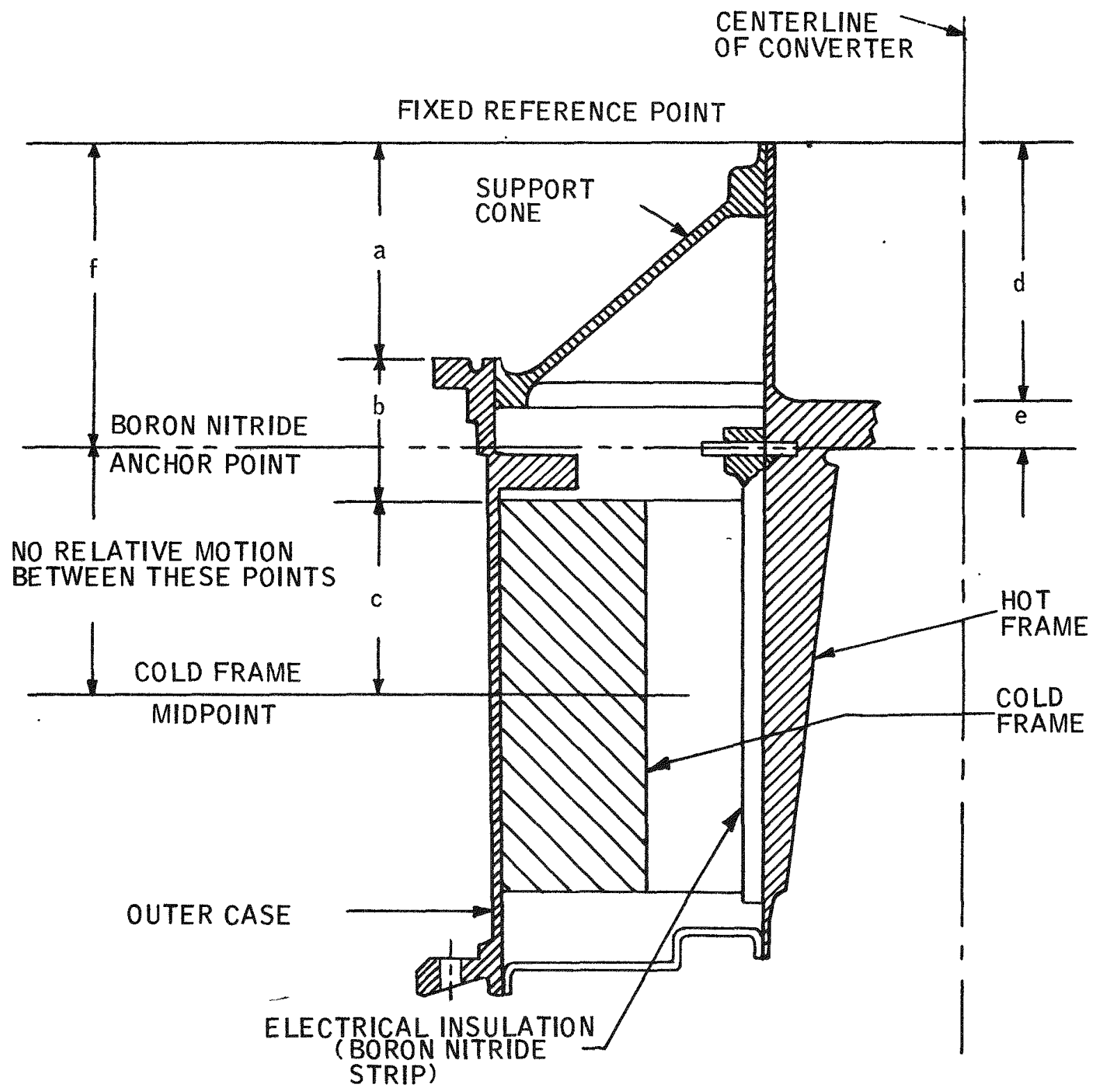

Figure 2-25. Sketch Showing Thermoelectric Couple Alignment Parameters 


\subsection{Hot Side Electrical Insulation Design}

The post-test analysis of the SNAP-23 converter $\mathrm{P}-1$ revealed that the electrical insulation (boron nitride strips) had cracked in many thin sections. Cracking is caused by high tensile stresses indirectly created by the difference in the thermal coefficient of expansion between the boron nitride and the stainless steel hot frame. Were it not for the high frictional force between the two parts, the hot frame would expand without causing a tensile load in the boron nitride strip which is anchored to the hot frame at one end. The combined force of 14 follower springs (each spring exerts a 7.1 pound force) acting on one boron nitride strip, when multiplied by the coefficient of friction for boron nitride against stainless steel at elevated temperatures, induces a high longitudinal tensile force in the strip. The method of anchoring the strip to the hot frame was changed from a short protrusion on the hot frame to a pin which extends all the way through the strip for EMC-1. The use of this pin eliminates the bending moment stress in the boron nitride which would add to the high tensile stress.

In addition to the change in pinning, the insulation strip was made thicker, both at the point of pinning to the hot frame and under the hot junction electrodes. Figure 2-26 shows this change in configuration. Revised and updated static coefficient of friction (Figure 2-27) and tensile strength (Table 2-15) data for boron nitride was used to calculate the necessary thickness as shown in Figure 2-26.

Table 2-15

Tensile Strength for Boron Nitride

At Various Temperatures

\begin{tabular}{|c|c|c|}
\hline $\begin{array}{c}\text { Temperature } \\
\text { (OF) }\end{array}$ & $\begin{array}{c}\text { Ultimate Tensile } \\
\text { Strength Parallel } \\
\text { To Press (psi) }\end{array}$ & $\begin{array}{c}\text { Ultimate Tensile } \\
\text { Strength Perpendicular } \\
\text { To Press (psi) }\end{array}$ \\
\hline \hline 75 & 5750 & 9000 \\
200 & 4800 & 6250 \\
400 & 3750 & 4600 \\
600 & 2900 & 3500 \\
800 & 2250 & 2650 \\
1000 & 1700 & 2000 \\
1200 & 1250 & 1450 \\
1400 & 900 & 1000 \\
1600 & 750 & 750 \\
2000 & 550 & 550 \\
\hline
\end{tabular}




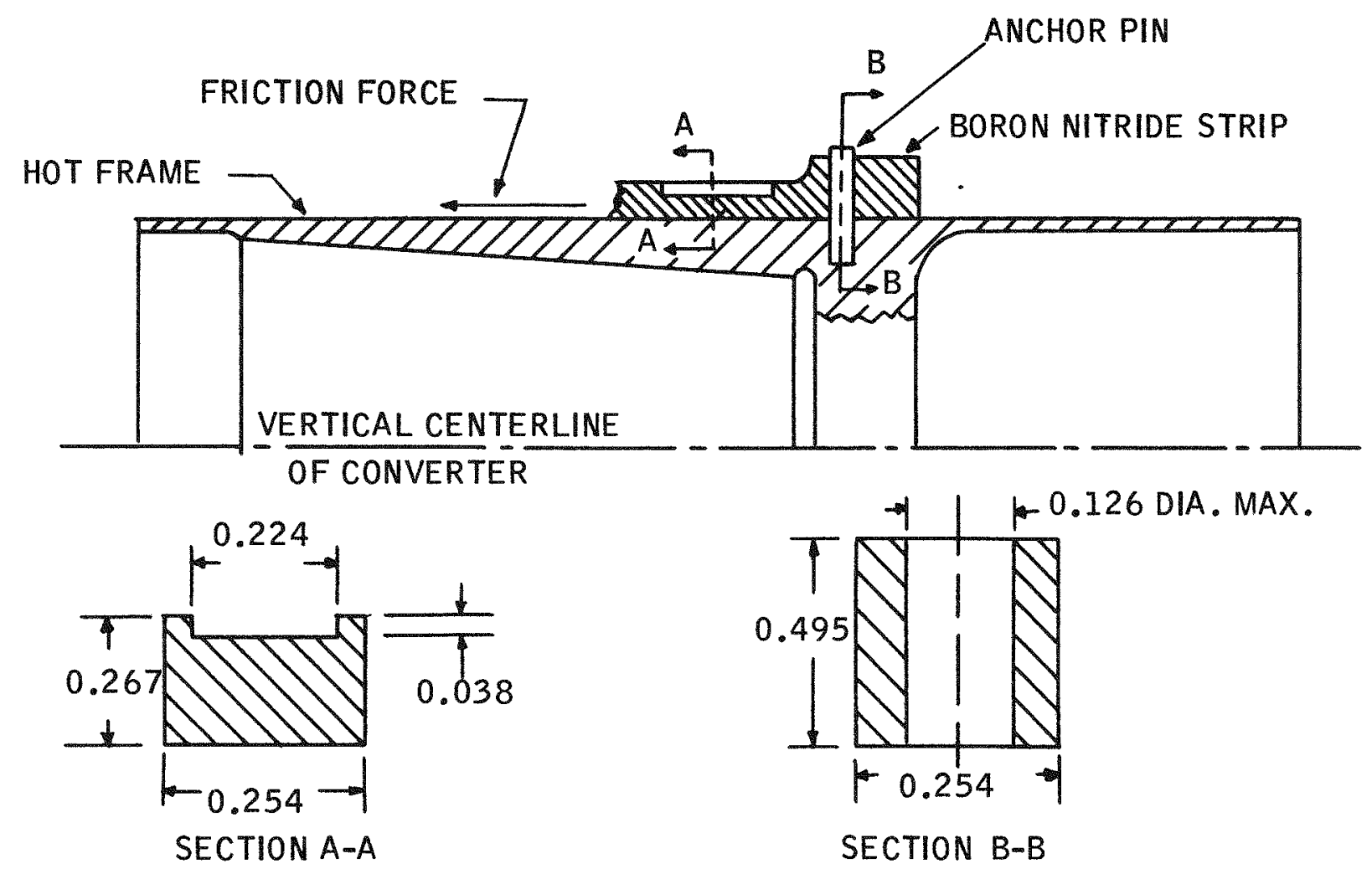

Figure 2-26. SNAP-23A Experimental Mockup Converter Electrical Insulation (Boron Nitride Strip) Anchoring Method 


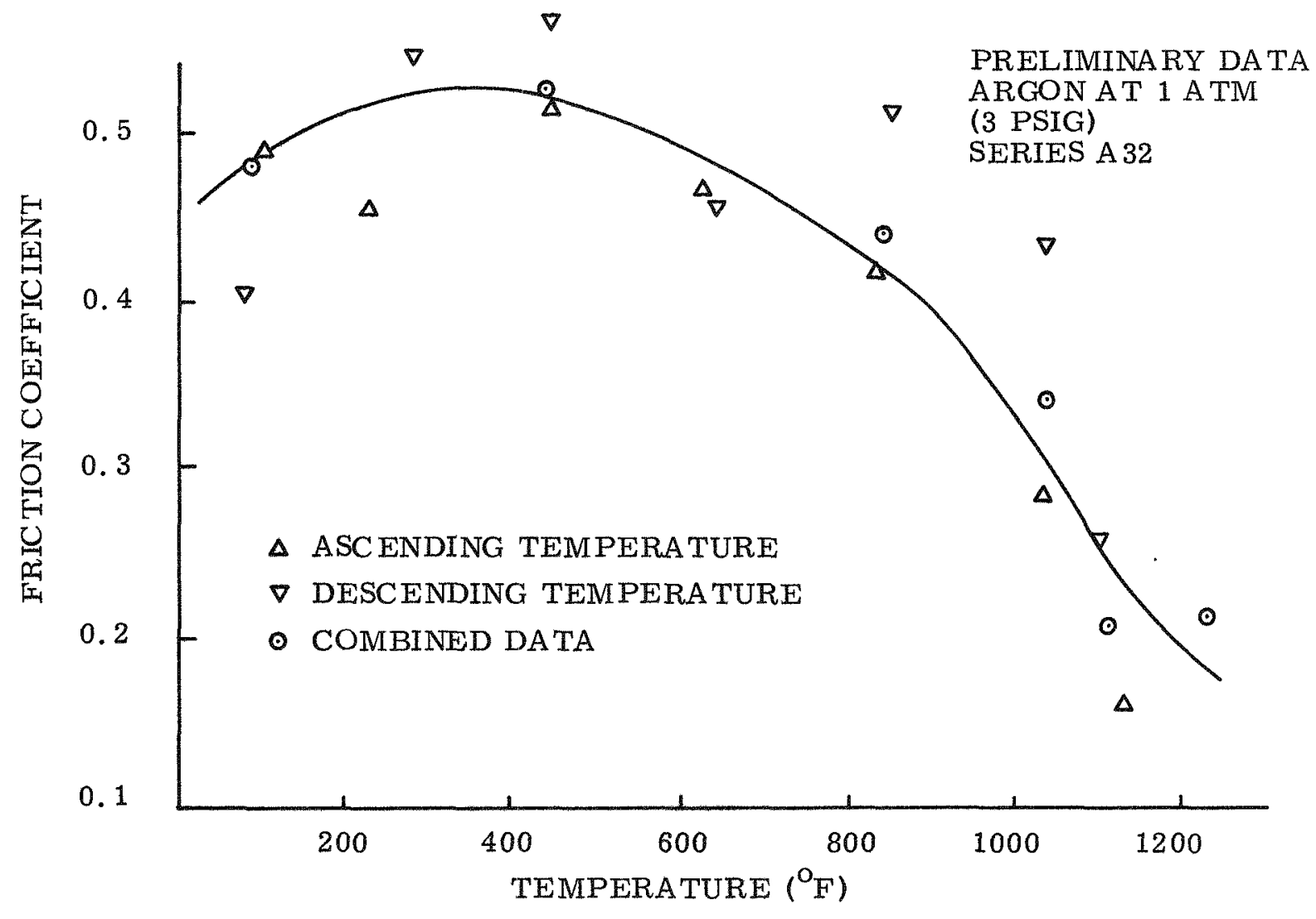

Figure 2-27

Static Friction Coefficient vs Temperature for Bor on Nitride on IN102 


\subsection{Cold Frame - Outer Case Attachment Design}

The bell jar tests demonstrated that leg misalignment would reduce thermopile output due to increased electrical resistance. If unattached, the converter cold frame could shift position within the outer case under two conditions: one, if the storage temperature dropped down to the low specification limit of $-65^{\circ} \mathrm{F}$; and two, if during thermal cycling the cold frame would creep longitudinally within the outer case. To preclude either of these two conditions from taking place, design configuration changes were made so the cold frame would be bolted to the outer case. This bolting would attach the cold frame to the outer case so no relative longitudinal movement could occur between the two parts.

\subsection{Leg Compression Spring Design}

The increase in hot side insulation strip thickness necessitated some other companion changes to the converter. Three choices were available.
A. Increase outer case diameter
B. Decrease follower length
C. Change leg compression spring design.

A change in outer case diameter would require a change in the interface dimension for mating with the system heat sink. A change in follower length would increase cold end temperature drop. It was decided to change the leg compression spring design. Although the new spring had less working length, an improvement in spring rate and working length ratio was realized by changing the spring material and using the maximum allowable stress recommended by Associated Spring Corporation for static spring application.

The actual working space was calculated from piece-part dimensions and their tolerances in both the cold and hot condition. This was done using the coefficient of thermal expansion and the part configuration. The spring design required several trial and error calculations with the final iteration establishing the following design: 


\author{
Maximum Allowable Stress \\ Total Coils \\ Active Coils \\ Mean Diameter \\ Wire Diameter \\ Load at 0.624 Inch
}
$167,000 \mathrm{psi}$
17
15
0.180 Inch
0.031 Inch
7. 1 Pounds

\subsection{Other Component Design}

The design of all other components of the converter was reviewed; some of the more significant changes are listed below:

Follower - The leg follower was subjected to detailed review primarily to aid in fabricating the part and to establish acceptance criteria.

Headers - The feedthrough headers are used to bring out the temperature instrumentation and power output wires and were changed from SNAP-23. The headers selected have hollow pins which are sealed in a ceramic insert. The instrumentation wires feed through these hollow pins and are then welded at the pin end. The power output wires feed through the hollow pins also, but are soldered to the pins at the inside diameter to effect a seal. The headers themselves are welded to the converter outer case. This type of metal to ceramic seal has greater reliability for long-term operation than the base line SNAP-23 compression-type seals.

Outer Case - The outer case changed considerably in configuration. In addition to the wall thickness change as determined by the cold frame-outer case stress calculations, flanges were added at both the top and bottom. The flange at the top was designed for attachment of a weather cover that would enclose the system thermal insulation that fits on top of the converter. The flange at the bottom was designed for attachment of the system rain shield. 
Converter Instrumentation - Converter temperature instrumentation was also updated. These changes were made to better evaluate the performance of the converter as a component on the test station and when integrated into the system. Some additional points of temperature instrumentation were added to aid in the evaluation of the overall system with converter instrumentation. The temperature instrumentation utilized wire thermocouples; iron-constantan being used except where the wire would be exposed to air at elevated temperatures, then chromel-alumel was used. The following is a summary tabulation of converter temperature instrumentation points.

$\begin{array}{lc}\begin{array}{lc}\text { Converter } \\ \text { Location }\end{array} & \begin{array}{c}\text { Number At } \\ \text { Location }\end{array} \\ \text { Inside } & 2 \\ \text { Inside } & 4 \\ \text { Inside } & 12 \\ \text { Inside } & 12 \\ \text { Outside } & 8 \\ \text { Outside } & 8 \\ \text { Outside } & 10\end{array}$

$$
\begin{gathered}
\text { Temperature } \\
\text { Measured } \\
\hline
\end{gathered}
$$

Hot Frame

Cold Frame

Leg Cold Junction

Leg Hot Junction

Outer Case

Hot Frame

Lower Cover

In addition to temperature instrumentation, a pressure transducer was included to measure converter internal gas pressure. A tube and valve arrangement was also incorporated so that gas samples could be taken from the interior of the converter.

\subsection{Summary of Converter Design}

EMC-1 incorporated numerous changes from the base line SNAP-23 converter design. These design changes were features which were intended to improve the performance and reliability of the converter. The converter was more than an operating device to produce electrical power; it was a laboratory device capable of generating data which would contribute to future converter development. The following is a summary listing of the most significant features and changes. 
A. Thermopile design, number of couples and leg geometry based on maximum use of Peltier cooling at BOL to improve efficiency at EOL.

B. Configuration changes for system integration.

C. Structural design changes for positive margin of safety based on rigorous stress analysis.

D. Strengthening of hot side insulation strip which also involved redesigning of leg compression spring.

E. Pinning location of hot side insulation strip so that thermoelectric leg tilt from thermal cycling was reduced.

F. Improved hermetically sealed enclosure by the use of metal to ceramic sealed headers rather than the compression type seal.

G. Outer case thickness sized to prevent cold frame follower hole distortion.

H. Cold frame attached rigidly to outer case so leg tilt will not be caused by cold frame shifting.

I. Revised instrumentation layout for better performance evaluation. 


\section{3 .2 .2 .13 Process and Test Station}

The object was to design a process and test station which would be used during the processing of the converter to measure and control temperatures. During test, the station would perform a similar function except it would be on a longterm basis while unattended and collect more detailed performance data.

The process and test staion was designed to incorporate the following required features:

- A controller was incorporated to insure constant temperature conditions; this controller was portable to facilitate its use on other test stations.

- Rotary switches with digital readout allowed temperatures to be read manually. Both I/C and C/A type thermocouple instrumentation outputs were read. These rotary switches allowed both open and closed circuit voltage measurements.

- The converter external load was electronic with high resolution.

- The load current was measured with a calibrated shunt having an accuracy of \pm 0.25 percent.

- All gas pressure readouts were in voltage via a pressure transducer.

- Input power was available for strip chart display filtered to 0.1 percent maximum ripple.

- A resetable hour meter was incorporated to record time.

- A water flow meter with line pressure regulation and in/out temperature measurement was used to control cold-side temperature.

- All connections to air and water services were of the quick disconnect type. 
- The test station was portable for use within the laboratory and at the dynamic testing facility.

- The test converter was mounted to the test station in such a way that it could be conveniently removed from the panel and mounted for dynamic testing.

- The cables were of sufficient length to permit mounting the converter on the dynamic testing station without disconnection.

- The thermoelectric converter leads allowed quick disconnect from the test station.

- Components were arranged and spaced to permit easy performance of processing operations.

- Long-term test temperature and power input were monitored on data acquisition system.

- The heat source provided simulation of the isotopic heat source thermal profile, minimum heat loss to the atmosphere to facilitate converter efficiency measurement, and a base which would act as a shock and vibration adapter.

The Process and Test Station design activity was concentrated in four main areas.

\section{A. Heat Source Simulator Design}

The heat source simulator was designed to provide 1000 watts to the converter with a temperature gradient along the converter hot frame of approximately $30^{\circ} \mathrm{F}$. The heat source simulator consisted primarily of a hot block containing six main heaters and two auxiliary heaters, the lower end attachment and the upper end attachment. 
The hot block mates with the converter hot frame taking into consideration the possibility of thermal stress and allowing a thermal gradient to be established. The six main heaters are uniformly spaced and inclined to the vertical axis. One auxiliary heater was placed on the top of the block and another on the bottom of the block to regulate variations in heat load thermal conductivity and heat losses from the hot block. The lower end attachment was bolted to the hot block to provide a mounting surface for the shock and vibration fixture and to hold in place the electrical insulation and bus bars which are required for connection of the electrical heater cartridges.

The upper end attachment was designed to provide a method of clamping the simulator to the hot frame without exceeding the maximum specified contact pressure on the hot frame.

\section{B. Water Jacket Design}

The water cooled jacket was designed to provide a heat sink which achieved a minimum of 1000 watts capacity at a temperature of approximately $180^{\circ} \mathrm{F}$.

C. Cabinet and Electrical Hardware

The process and test station cabinet and modular panel was designed to house all electrical hardware. The test station console (shown in Figure 2-28) consists of six modular panels mounted into a standard cabinet. The panels provide: the main power supply, the auxiliary power supply, two readout panels, load control and water jacket control. The temperature controller was added as a separate unit for temporary use.

D. Test Fixture Design

The test fixture was designed for mounting the SNAP-23A converter with simulator and water jacket to the test console. The fixture thermally insulates the simulator for effective 
efficiency measurements. The test fixture consists of a large tube with flange and mounting brackets. The converter with simulator and water jacket mounts on the brackets; the bottom of the tube is packed with thermal insulation and the flange attached. This assembly is shown by Figure 2-29.

An adaptor was designed for mounting the converter for shock and vibration testing. It was essentially a tube mounted between two plates. The design provides a dynamic mount which has structural rigidity for transmitting shock and vibration to the SNAP-23A converter when mated with system heat source simulator and water jacket. A sketch of the converter and fixture are shown in Figure 2-30。

The analytical approach used during design of the fixture considered hollow cylindrical shapes from the viewpoints of stiffness and small cross sectional area which will give the dynamic mount rigidity and minimum heat transfer area.

Thermal analyses were performed for the process and test station. The object of the analysis was to provide thermal characteristics of the test fixture which were required to evaluate performance of the converter when mounted on the test station.

The approach taken in design of the fixture was to thermally isolate the converter and the simulated heat source, and limit heat losses by use of thermal insulation. Heat flow from the simulator to points other than the converter hot frame is designated as heat loss. If this loss is zero, converter efficiency can be readily determined as converter power output divided by power input to the heat source. Perfect isolation of the converter and heat source, however, is impossible, first because of instrumentation, and secondly because of the conductivity of the insulating medium itself. Since a portion of the simulator power does not go into the converter hot frame, the magnitude of that portion must be determined and used in the efficiency calculation. If the losses are small in comparison to the input power, then a small error in loss calculation will have an insignificant influence on the efficiency determination. 


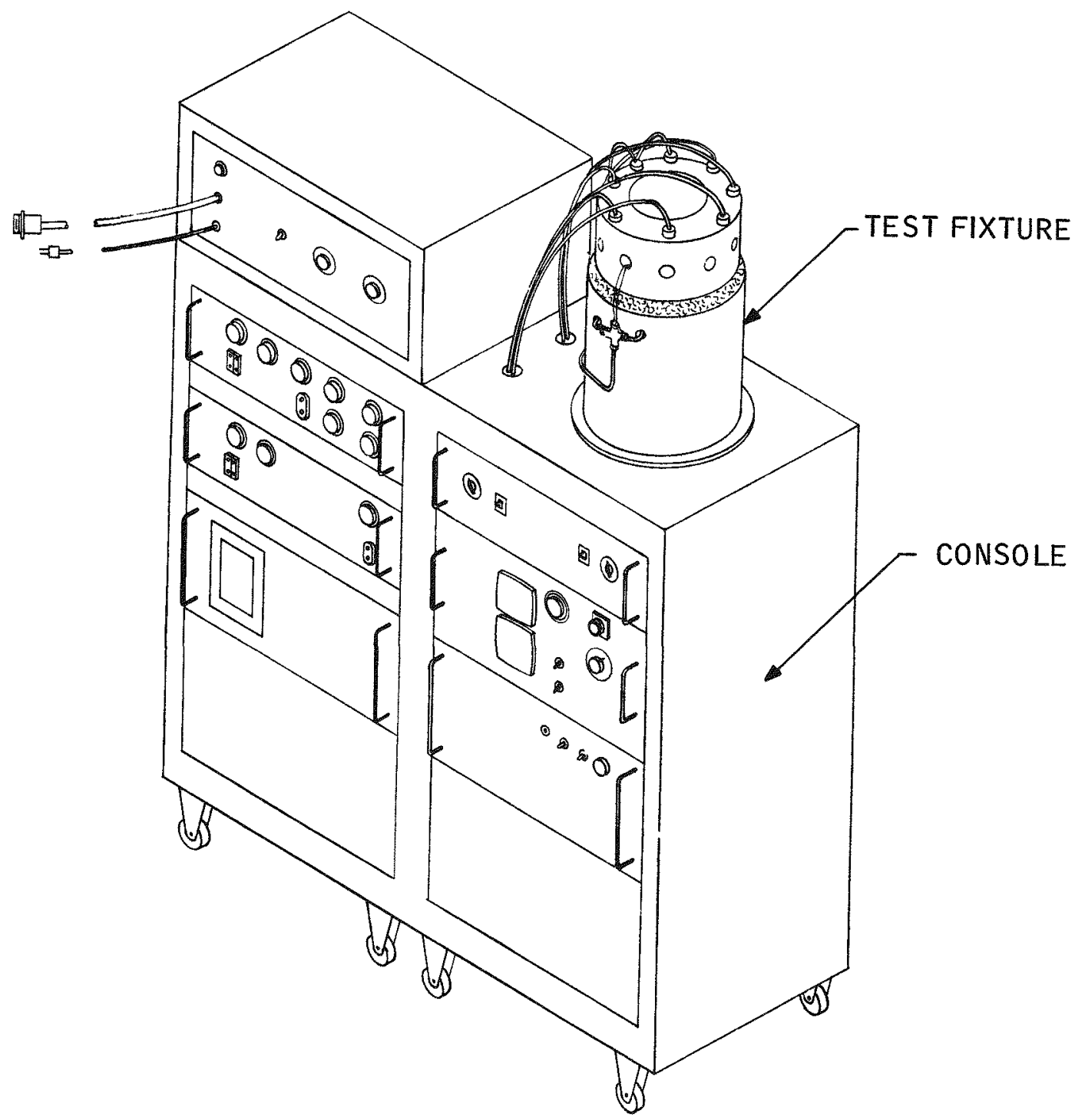

Figure 2-28. Process Test Station for SNAP-23A 


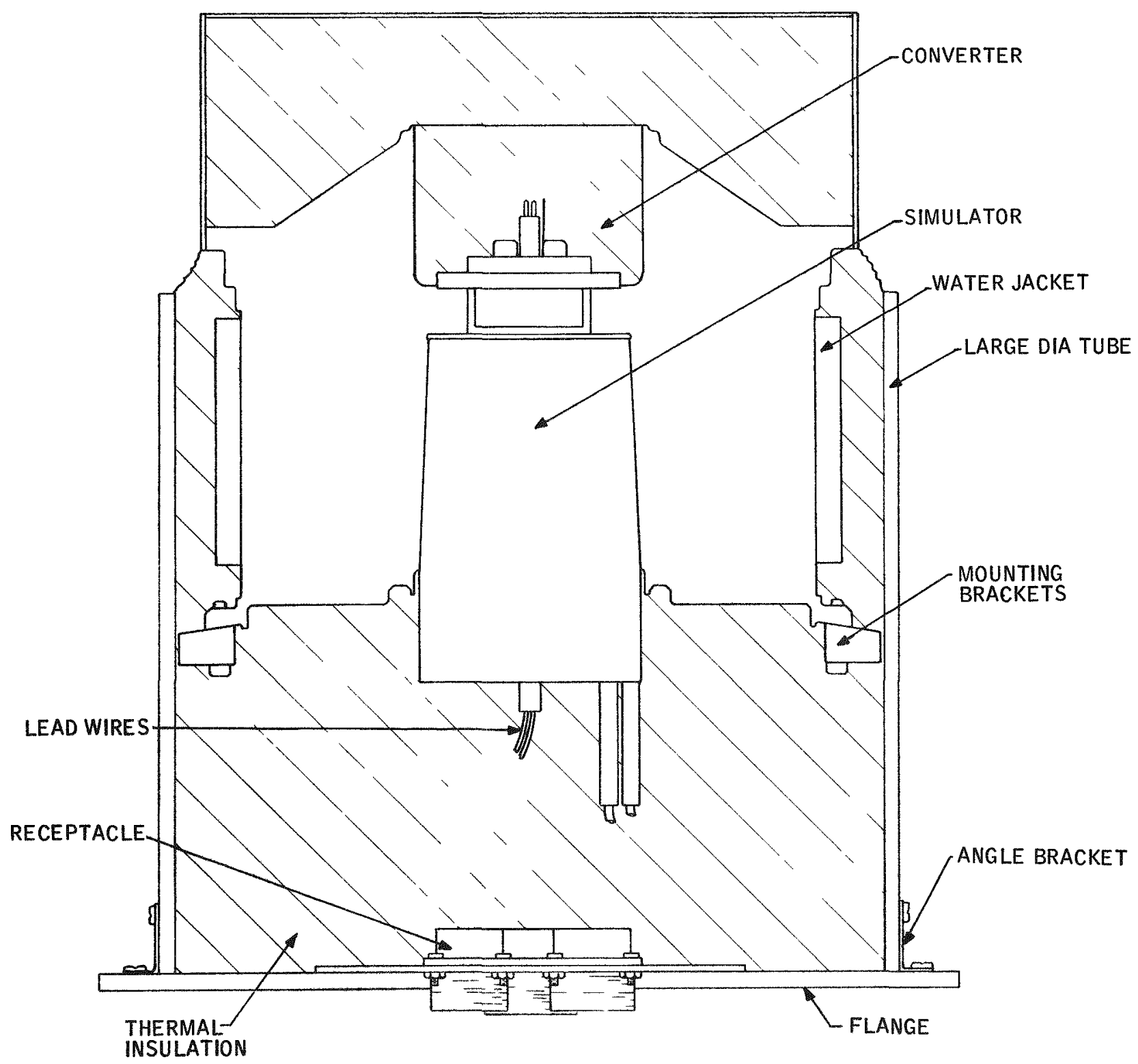

Figure 2-29. Converter with Simulator and Jacket Assembly Mounted in Test Fixture 


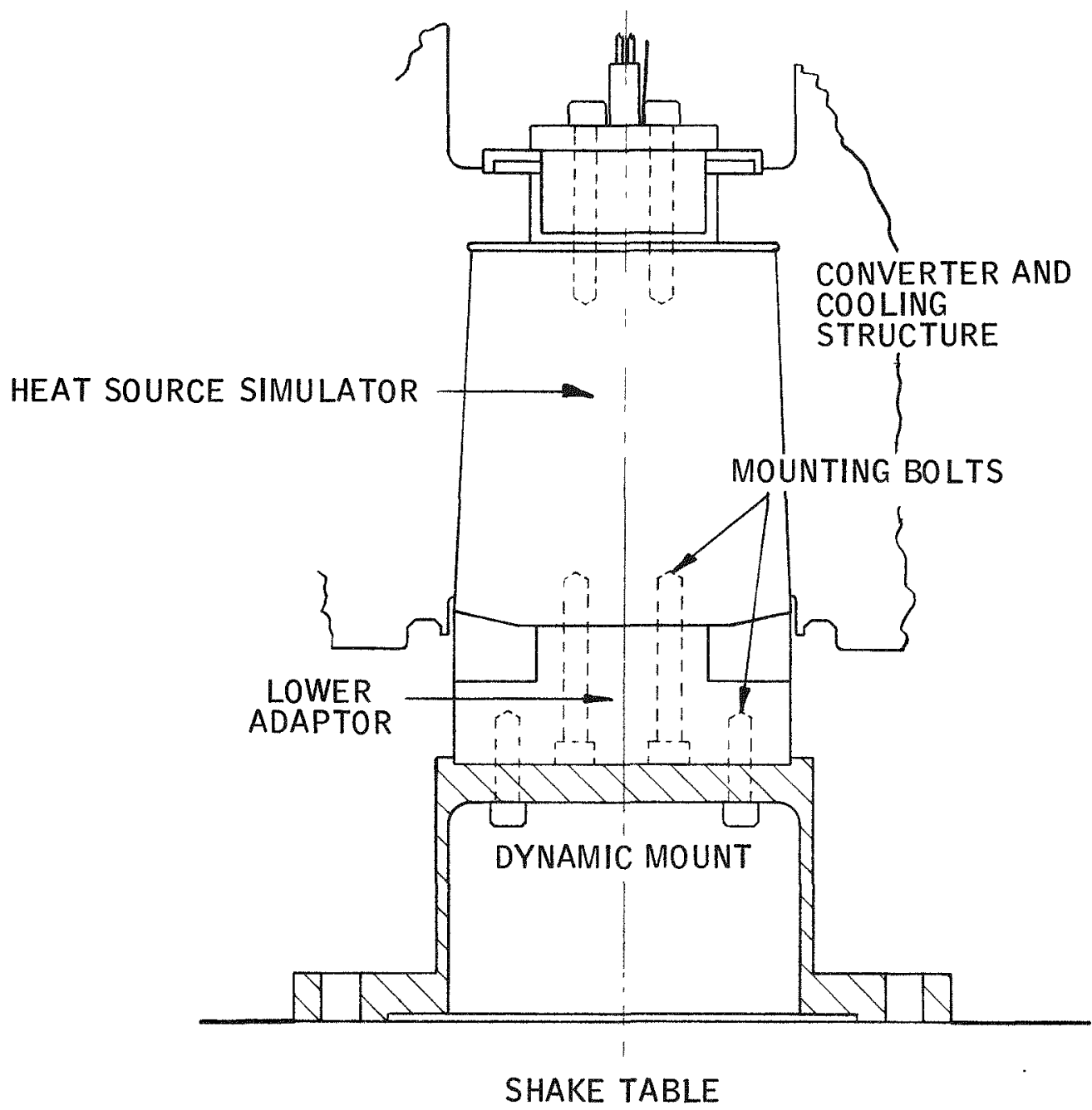

Figure 2-30. Converter Mounted in Shock and Vibration Fixture 
In the analysis, derivations were developed for calculating the heat loss from the lower, upper and midsection of the test fixture and from the power and instrumentation lead wires. With the derivations complete the efficiency of a converter could be determined from the recorded test data. Efficiency would be calculated with the following equation.

$$
\text { Efficiency }=\frac{\text { Converter Power Output }}{\text { Heater Power Input }- \text { Extraneous Heat Losses }}
$$

\section{3 .2 .2 .14 Converter Assembly}

A master fabrication flow plan was prepared for assembly of the unit. This plan was a block diagram which identified all component parts by name and identified the assembly and processing steps required.

Assembly development was conducted to develop techniques, tools, or equipment for assembly of the converter. The copper tube which is used to fill the converter enclosure with gas is pinched off to seal the enclosure after processing. A procedure and technique was developed for pinch-off sealing this tube. Sample parts of the weld areas were prepared and weld development conducted. Weld schedules for welding the enclosure were the result of this weld development.

Tools and fixtures for the assembly were also designed and built. These fixtures included those needed for thermal insulation processing, leak checking components, weld chill rings, pinch-off tool, and assembly fixtures for installing legs in the thermopile.

When all the parts were fabricated or procured assembly of the converter started. Figures 2-31,2-32, 2-33,2-34, and 2-35 show the assembly operations where couples are being installed between the hot and cold frame to build up the thermopile. The assembled converter is shown by Figure 2-36. After assembly in this configuration the upper brackets, MS connectors, instrumentation wires, and upper insulation were added to arrive at the test configuration as shown by Figure 2-37.

When phy sical assembly of the converter was complete, it was mounted on the process and test station for processing. After processing was completed the converter was moved to the Test laboratory for performance evaluation and operation. 


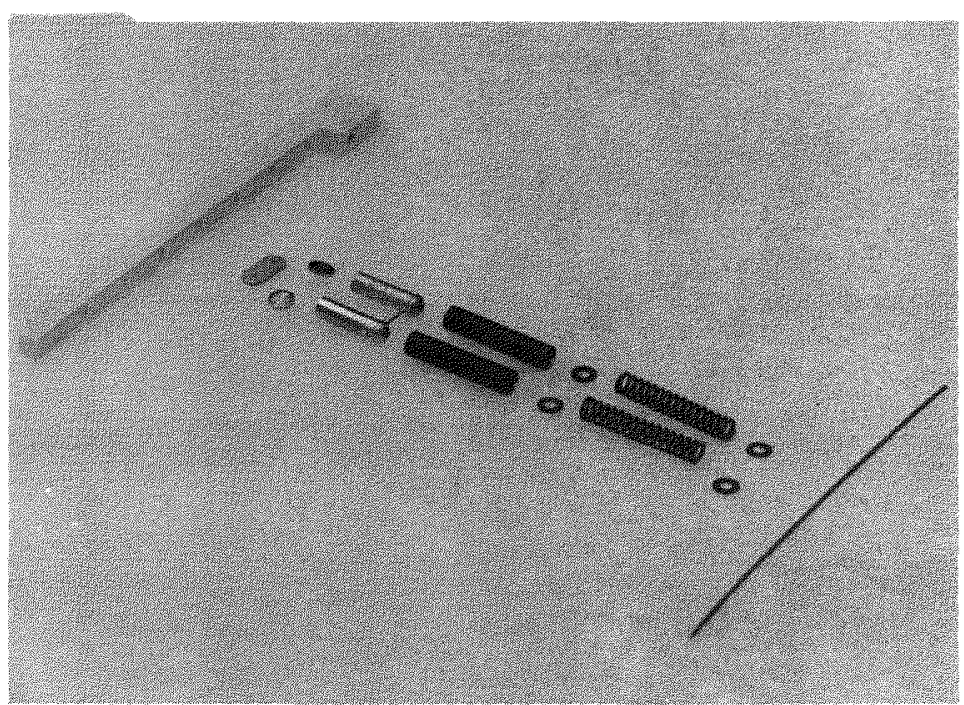

Figure 2-31. Thermoelectric Couples in Associated Hardware

Figure 2-32. Placement of Hot Junction Electrodes into Insulating Strip
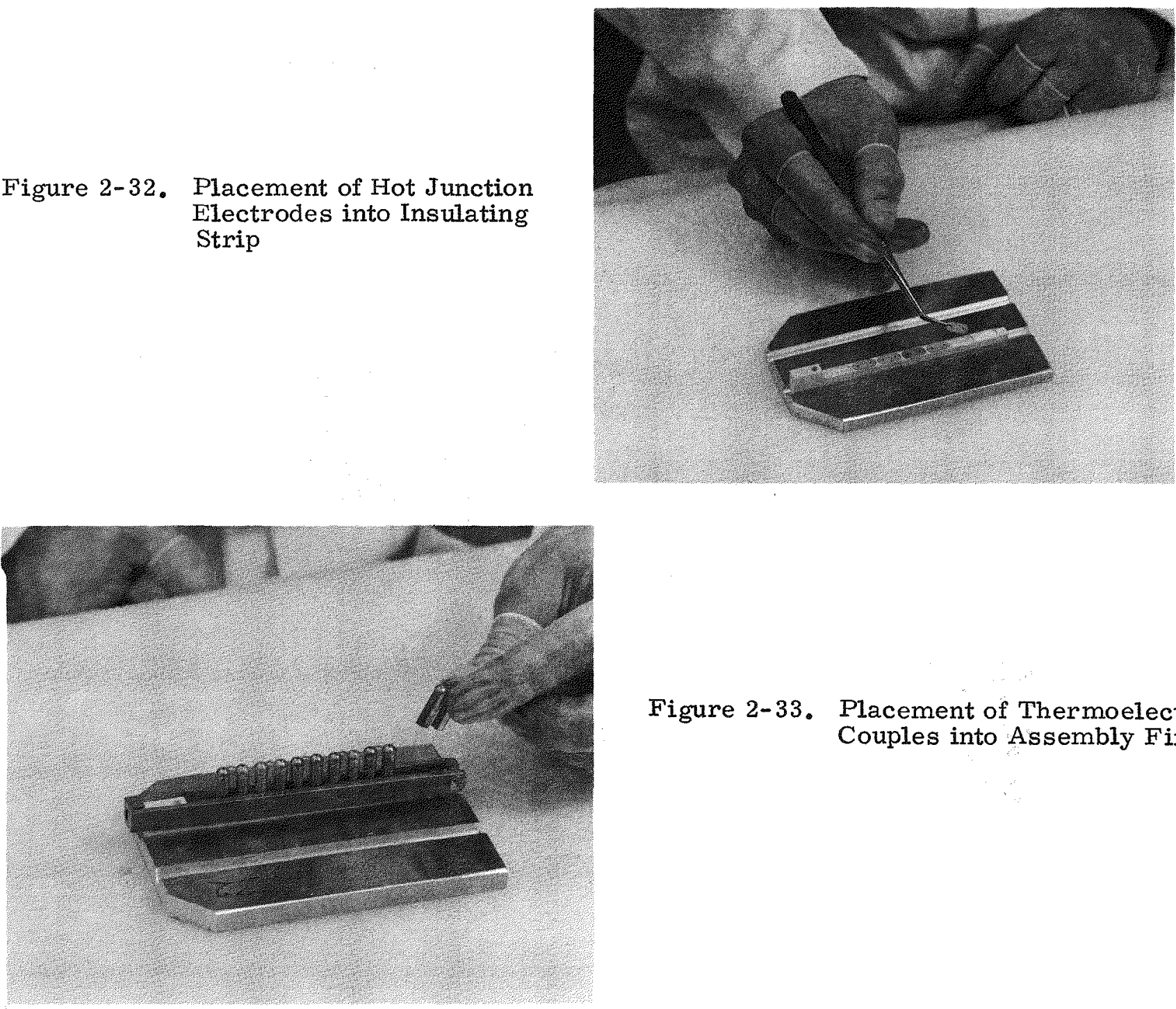

Figure 2-33. Placement of Thermoelectric Couples into Assembly Fixture 


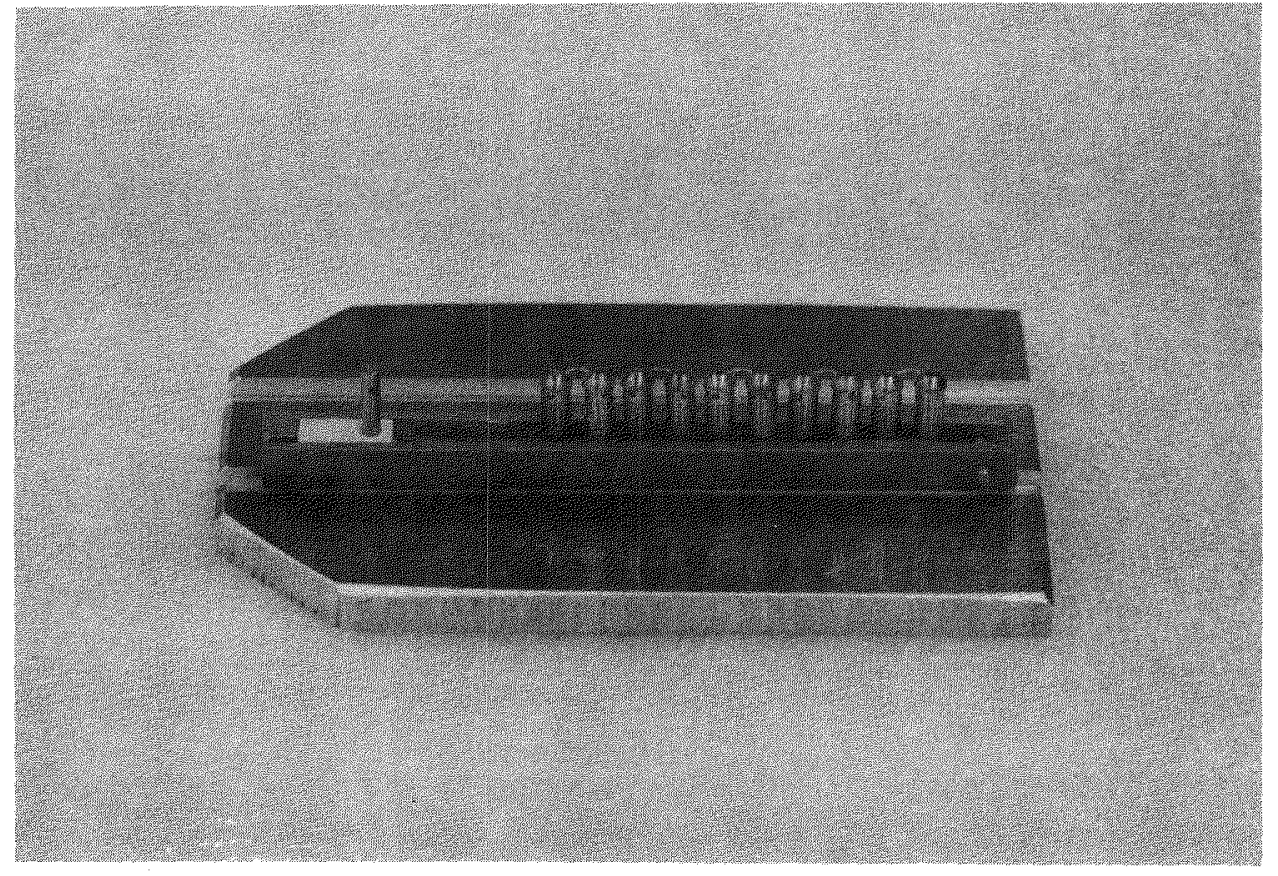

Figure 2-34. Thermoelectric Couple Assembly Fixture

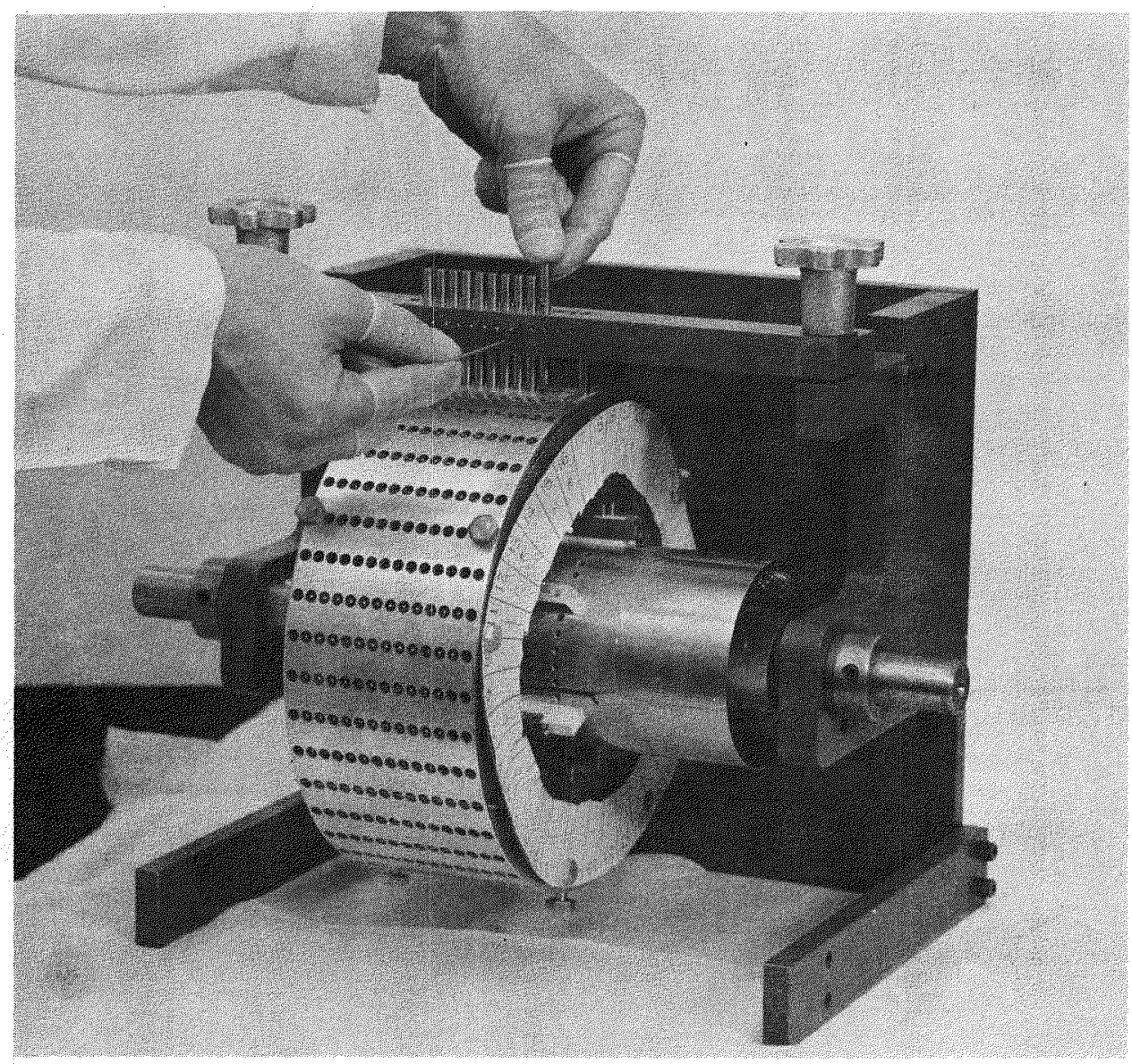

Figure 2-35. Locking Couples into Generator 


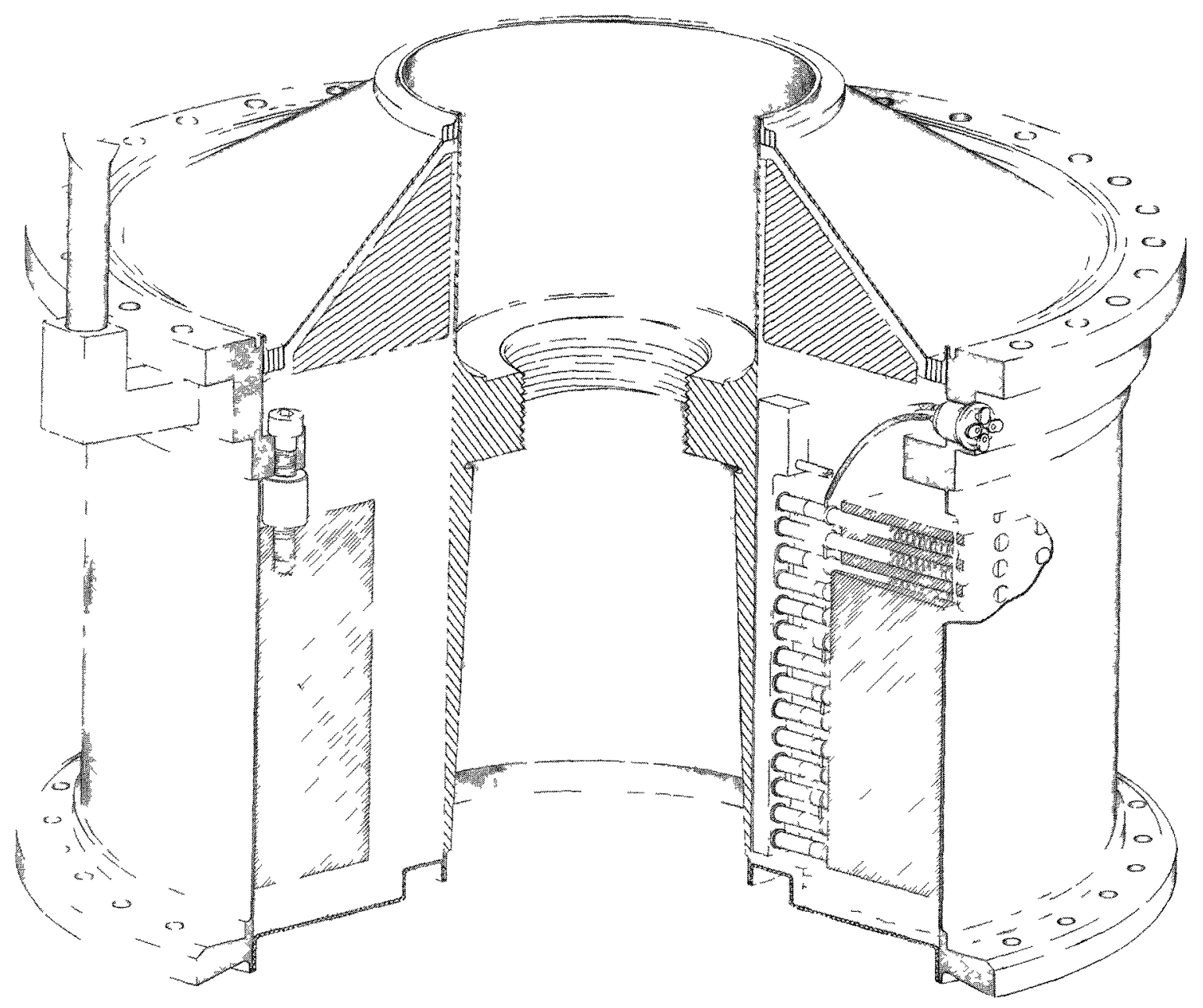

Figure 2-36. SNAP-23A 60-Watt Thermoelectric Converter 


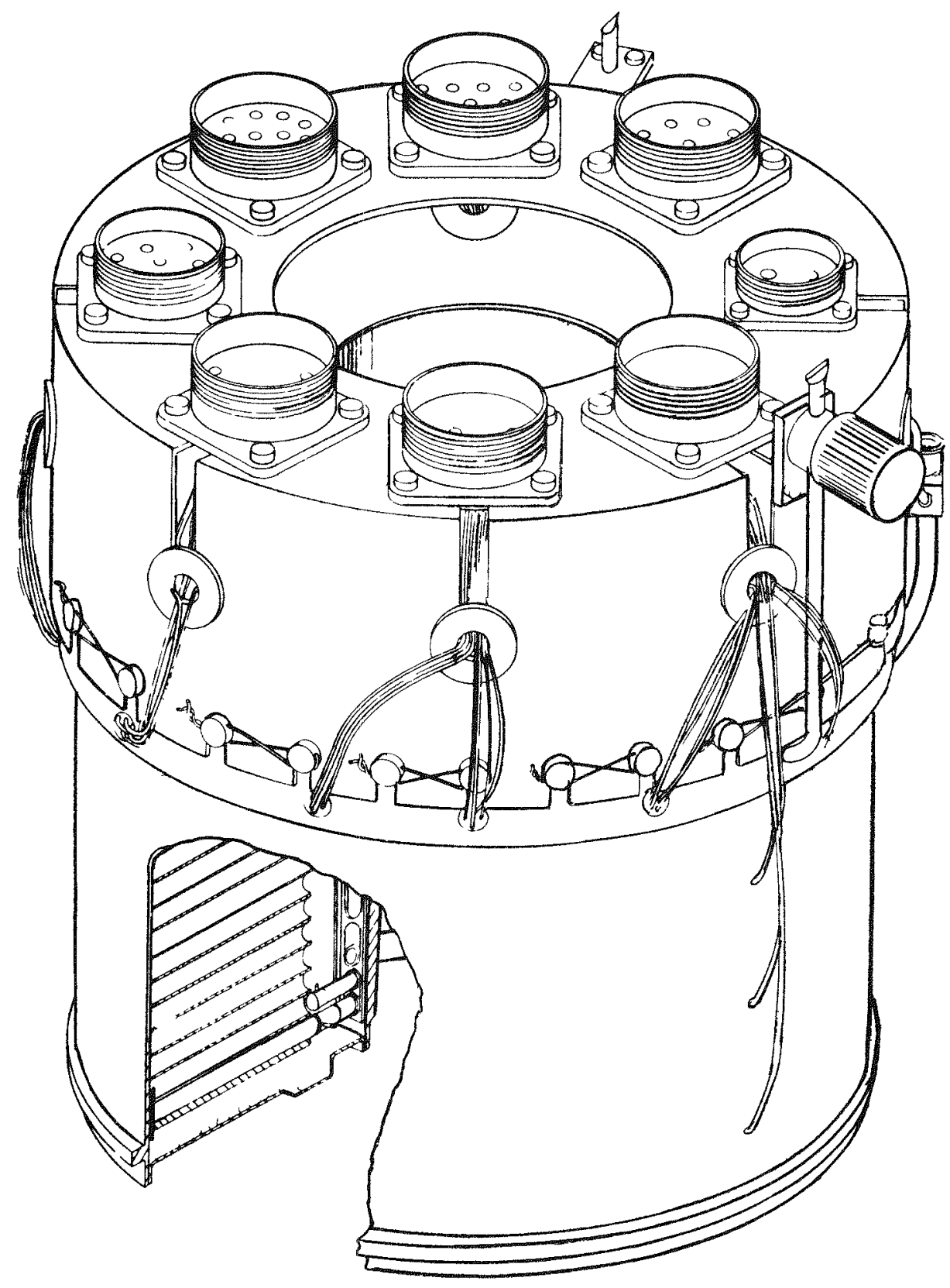

Figure 2-37. EMC Serıes Converter - Test Configuration 


\section{3 .2 .2 .15 Quality Control}

The objective of the quality control effort was to plan, implement, and conduct a quality control program in accordance with MIL-Q-9858A and consistent with the SNAP-23A program. The quality control plan was submitted to Westinghouse for concurrence. This plan outlined the procedures and documents to be used in assuring end-item acceptability. After Westinghouse review, the plan was published and submitted to the commission as part of the Quality Assurance Program Plan.

Two sequential sampling plans were prepared and implemented: QA-STD-48 for lot size 150 pieces minimum, and QA-STD-53 for small lot sizes.

Quality inputs to engineering documents were made during the design cycle and into manufacturing control programs. Quality inputs to all other disciplines were made at times when they were most effective. The quality program assured that all work affecting quality was prescribed in clear and complete documented instructions which were appropriate to a development effort.

Quality Control participated in the EMC reliability design review. Investigation of the necessary inspection points was conducted to assure proper alignment of parts after welding operations.

Surveys were conducted of prospective vendors. A report of condition was forwarded to vendors as a result of these surveys. The approved vendor list was continuously updated to reflect results of these surveys. Vendor inspection reports were evaluated for the purpose of reducing receiving inspection, resulting in time and cost savings.

The converter system interface dimensions were reviewed and classification of characteristics were identified. This facilitated the recording of required variable data and obtaining Westinghouse concurrence on deviated interface dimensions.

The subassembly and assembly manufacturing flow plans were reviewed for inclusion of the necessary inspection requirements. 
When fabricated or procured components were received they were inspected for compliance with design requirements. Those parts which were acceptable were placed in bonded stock. Those which had deviations from the specifications were held for action by a Material Review Board (MRB)。 MRB would examine and evaluate the condition of a part and take one of the following courses of action:
A. Reject the part.
B. Return part for corrective action rework.
C. Accept the part for conditional usage.
D. Accept the part for usage with recommendation the design be changed for subsequent converters.

During the assembly and subassembly operations, Quality performed the function of assuring that the proper parts went into the device. Quality also brought deviations from specification to the attention of the MRB, which would prescribe the proper action to be taken to correct the deviated condition.

\subsection{Initial Performance of EMC-1}

EMC-1 was placed on test while mounted on the same station which was used for processing. Measurements of converter initial performance were made to determine how well the converter measured up to design objectives and to establish a base line for future performance comparisons. The hot and cold side temperature as well as the power output were read out directly from the test station. Converter efficiency was calculated with the following equation.

$$
\text { Efficiency }=\frac{\text { Converter Power Output }}{\text { Converter Heat Input }}
$$

The heat input to the converter was determined by an analysis of test station heat losses and measured input to the electric heaters. These test station losses were calculated from temperatures measured on the converter and on the test station.

Nodal-point type heat loss analysis had been prepared as a computer code to performance the calculations. This calculation was made so that any heat 
transferred across the boundaries established at the top and bottom of the converter was corrected to an adiabatic condition.

SNAP-23A Converter EMC-1 initial performance is shown by Table 2-16.

Table 2-16

SNAP-23A Converter EMC-1 Initial Performance

\begin{tabular}{|l|c|c|}
\hline & \multicolumn{2}{|c|}{ Operating Conditions } \\
\cline { 2 - 3 } & BOL & EOL \\
\hline Hot Junction Temperature, ${ }^{\circ} \mathrm{F}$ & 1083 & 900 \\
Cold Junction Temperature, ${ }^{\circ} \mathrm{F}$ & 192 & 173 \\
Power Output, Watts & 72.5 & 50.9 \\
Converter Efficiency, $\%$ & 6.87 & 6.12 \\
Hot Frame - Hot Junction $\Delta t,{ }^{\circ} \mathrm{F}$ & 37 & 34 \\
Cold Junction - Outer Case $\Delta t,{ }^{\circ} \mathrm{F}$ & 56 & 47 \\
\hline
\end{tabular}

This initial performance of the converter was not up to design expectations. It did produce at EOL conditions 85 percent of required power output and 80 percent of desired efficiency. Table $2-17$ is a tabulation of the calculated Seebeck and resistance ratios for EMC-1.

Table 2-17

SNAP-23A Converter EMC-1 Initial Performance Ratios $\frac{\text { (Experimental Value) }}{\text { (Theoretical Value) }}$ at EOL and BOL Design Condition

\begin{tabular}{|l|c|c|c|c|}
\hline & \multicolumn{2}{|c|}{ Seebeck Ratio } & \multicolumn{2}{c|}{ Resistance Ratio* } \\
\cline { 2 - 5 } & EOL & BOL & EOL & BOL \\
\hline \hline Thermopile & 1.01 & 0.99 & 1.31 & 1.18 \\
Typical N-Leg & 1.00 & 0.99 & 1.00 & 0.97 \\
Typical P-Leg & 1.03 & 0.99 & 1.68 & 1.44 \\
\hline
\end{tabular}

*Theoretical resistance includes no extraneous resistance allowance.

The reason for the low power output and efficiency was attributed to the high resistance of the $\mathrm{P}-\mathrm{Leg}$. This $\mathrm{P}-\mathrm{Leg}$ resistance ratio is considerably higher than the resistance ratios of P-Legs of the same type which were operated in 
bell jars and 10-couple modules. Bell jar test 5-15 was conducted to determine if the time cycle during EMC-1 processing was the cause of the high resistance. Leg performance in this bell jar did not exhibit the same low performance as EMC-1. Another possible cause, which could not be verified, was the exposure of the thermopile to air by the crack in EMC-1 hot frame near the hot framelower case weld joint. While this crack was repaired as soon as its existence became known, air could have leaked in while the converter was at elevated temperatures causing a degrading oxidation to take place.

From a thermal standpoint, the heat required to keep EMC-1 at operating conditions was close to calculated. The temperature drop from the cold cap (leg cold junction) to the outer case exceeded the $30^{\circ} \mathrm{F} \Delta \mathrm{t}$ design base.

\section{3 .2 .2 .17 EMC-1 Disposition and Use}

EMC- 1 was operated on the test station at $3 M$ for 680 hours. This was a stability conditioning period during which thermoelectric performance was recorded and monitored. During this 680 hour period tests were conducted at off-design cold junction temperatures. The cold junction was adjusted to $20^{\circ} \mathrm{F}$ above and below normal at EOL conditions and $20^{\circ} \mathrm{F}$ and $40^{\circ} \mathrm{F}$ below normal at BOL conditions. The purpose was to develop converter performance data at thest off-design temperatures for system analysis. The results of these test with EMC-1 are listed in Tables $2-18$ and $2-19$.

At the end of this period EMC-1 was taken off the test station and packaged for shipment. It was shipped to Westinghouse where it was mated with EMS (Engineering Mockup System) for system testing. During heat up to operating temperatures the system heat source failed. Considerable rework was required to prepare the system for continued operation. Therefore, EMC-1 was removed from the system, shipped back to $3 \mathrm{M}$, and placed in storage. 
Table 2-18

SNAP-23A Converter EMC-1 Test Data for EOL Off-Design Cold Junction Temperatures (Nominal EOL $T_{C}=174^{\circ} \mathrm{F}$ )

\begin{tabular}{|c|c|c|}
\hline Parameter & $\begin{array}{c}\text { Cold } * * \\
\text { Junction Temperature } \\
\text { of } 153^{\circ} \mathrm{F}\end{array}$ & $\begin{array}{c}\text { Cold } * * \\
\text { Junction Temperature } \\
\text { of } 193^{\circ} \mathrm{F}\end{array}$ \\
\hline $\mathrm{T}_{\mathrm{oc}} \quad\left({ }^{\circ} \mathrm{F}\right)$ & 103 & 148 \\
\hline $\mathrm{T}_{\mathrm{hf}} \quad\left({ }^{\circ} \mathrm{F}\right)$ & 928 & 930 \\
\hline $\mathrm{T}_{\mathrm{C}} \quad\left({ }^{\circ} \mathrm{F}\right)$ & 153 & 193 \\
\hline $\mathrm{T}_{\mathrm{h}} \quad\left({ }^{\circ} \mathrm{F}\right)$ & 899 & 901 \\
\hline $\mathrm{V} \quad$ (volts) & 23.0 & 23.0 \\
\hline $\mathrm{E} \quad($ volts - Int $)$ & 41.4 & 40.3 \\
\hline I $\quad(a m p s)$ & 2.33 & 2.11 \\
\hline$P_{\text {output (watts) }}$ & 53.6 & 48.5 \\
\hline$P_{\text {in }} \quad$ (watts) & 880.0 & 840.0 \\
\hline$T_{h r}$ & 58.0 & 60.9 \\
\hline$\Delta \mathrm{T}^{*}$ & 24 & 20 \\
\hline
\end{tabular}

*Hot side axial differential

***Objective is to obtain performance data at two points approximately $\pm 20^{\circ} \mathrm{F}$ off nominal design point for system integration purposes. 
Table 2-19

SNAP-23A Converter EMC-1 Test Data for BOL Off-Design Cold Junction Temperatures (Nominal BOL $T_{c}=1910 \mathrm{~F}$ )

\begin{tabular}{|c|c|c|c|}
\hline Parameter & $\begin{array}{l}\text { Nominal } \\
\text { Cold Junction } \\
\text { Temperature }\end{array}$ & $\begin{array}{c}\text { Cold } * * \\
\text { Junction Temperature } \\
\text { of } 173^{\circ} \mathrm{F}\end{array}$ & $\begin{array}{c}\text { Cold } * * \\
\text { Junction Temperature } \\
\text { of } 154^{\circ} \mathrm{F}\end{array}$ \\
\hline$T_{\text {oc }} \quad\left({ }^{\circ} \mathrm{F}\right)$ & 138 & 115 & 92 \\
\hline $\mathrm{T}_{h f} \quad\left({ }^{\circ} \mathrm{F}\right)$ & 1118 & 1119 & 1120 \\
\hline $\mathrm{T}_{\mathrm{c}} \quad\left({ }^{\circ} \mathrm{F}\right)$ & 194 & 173 & 154 \\
\hline $\mathrm{T}_{\mathrm{h}} \quad\left({ }^{\circ} \mathrm{F}\right)$ & 1084 & 1085 & 1085 \\
\hline $\mathrm{V} \quad$ (volts) & 25 & 25 & 25 \\
\hline (volts-Int & 53.6 & 54.3 & 55.1 \\
\hline (amps) & 2.63 & 3.06 & 3. 18 \\
\hline$P_{\text {output (watts }}$ & 73.3 & 76.5 & 79.5 \\
\hline (watts & s) 1112 & 1136.0 & 1160.0 \\
\hline $\mathrm{T}_{\mathrm{hr}}$ & 128.5 & 130.5 & 135.0 \\
\hline$\Delta \mathrm{T}^{*}$ & 22 & 24 & 24 \\
\hline
\end{tabular}

*Hot side axial differential

**Objective is to obtain performance data at two points approximately $\pm 20^{\circ} \mathrm{F}$ off nominal design point for system integration purposes 


\section{3 .2 .3 EMC-2}

EMC-2 was the second converter to be built during the SNAP-23A program. While the design was basically the same as EMC-1 there were some changes in details. The purpose of building EMC-2 was to conduct shock and vibration tests and then place the converter of test for long-term performance evaluation.

\subsection{Design Activities}

The shunt heat loss through the converter included heat conducted through the Min-K 1301 thermal insulation. The initial shunt heat loss calculations for SNAP-23A converters were made with the best thermal conductivity values available at that time. This included using the published thermal conductivity values for Min-K 1301, since the thermal conductivity value for the powdered Min-K 1301 used in the converter had not been determined.

Thermal conductivity for powdered Min-K 1301 was later determined in an investigation conducted by $3 \mathrm{M}$ Central Research Laboratories. These values were determined for powdered Min-K 1301 with both argon and xenon backfill gas (Figure 2-38).

Using these values, the shunt heat loss for the converter was recalculated. The results of this calculation is shown by Table $2-20$.

Table 2-20

Converter Shunt Heat Loss, EOL

\begin{tabular}{|l|c|c|c|}
\hline \multirow{2}{*}{$\begin{array}{l}\text { Heat Loss } \\
\text { Location }\end{array}$} & \multicolumn{3}{|c|}{ Heat Loss, Watts } \\
\cline { 2 - 4 } & $\begin{array}{c}\text { Initial Value } \\
\text { With Xenon }\end{array}$ & Recalculated Values \\
\cline { 3 - 4 } & 23.9 & 35.1 & With Argon \\
\hline \hline Insulation & 23.9 & 23.9 & 41.2 \\
Lower Cover & 12.1 & 12.1 & 23.9 \\
Upper Cover & 59.9 & 71.1 & 12.1 \\
\hline Total & & 77.2 \\
\hline
\end{tabular}




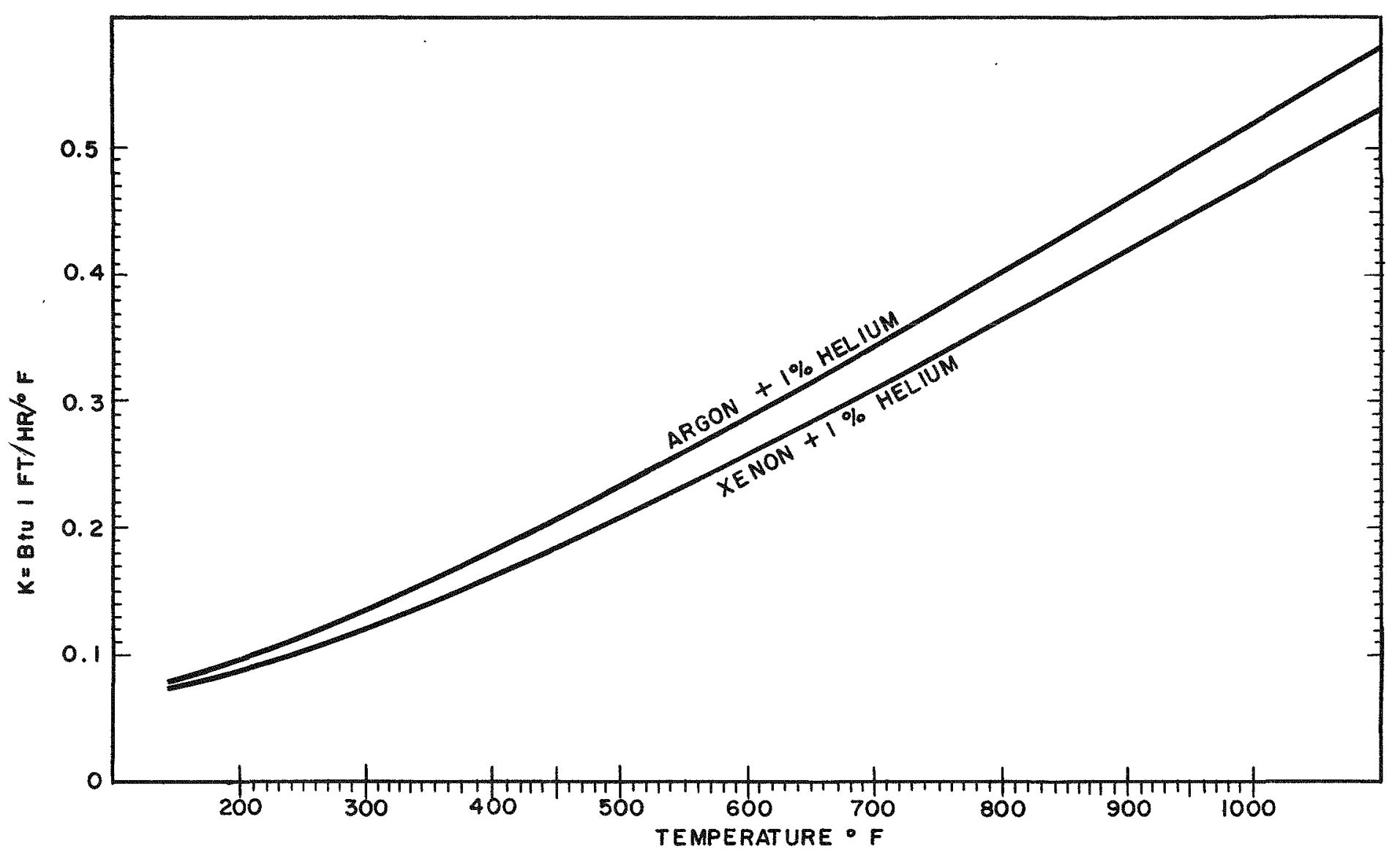

Figure 2-38. Conductivity versus Temperature for Powdered Min-K 1301, at $12.5 \mathrm{lbs} / \mathrm{cu}$. $\mathrm{ft}$. density 
The electrical insulation used on the temperature instrumentation wires within the converter enclosure was braided fiberglass. For EMC-1 this was single thickness braid. If the wire was bent over a sharp edge the wire could be exposed causing a short to ground. To prevent this from occurring double thickness fiberglass braid was used for EMC-2. The exterior temperature instrumentation wire insulation was changed from braided fiberglass to a nylon covering. This was done to alleviate a problem of moisture absorption and poor abrasion resistance of the fiberglass.

Changes were made to the details in the way the power output wires were brought out through the header. The copper wires from the thermopile feed through hollow pins in the header. The final seal between the wire and hollow pin is made by soldering. As the hollow pin is made of Kovar, the soldering can be done only if the inside of the hollow pin is pretinned. Initially this surface was tinned with soft solder. During the operation when the outer case is shrunk-fit over the cold frame, the soft solder oxidized so that it was difficult to obtain a seal that would not leak. Several changes were made to correct this condition.
A. The inside of the hollow pin was plated with nickel
B. The copper wire was annealed to provide more flexibility。
C. A flexible braided copper wire was spliced to the solid wire one-eighth inch out from the header.

The power output wires from EMC- 1 were attached to a terminal mounted on the outer case upper flange after leaving the header. This arrangement had the disadvantage that a cutout was required in the heat sink radiator to provide space for the terminal. This condition was corrected for EMC -2 by using a small clamp on the outer case flange to hold the wires after they exited from the power output header. This arrangement did not require any modifications to the heat sink radiator.

During assembly of EMC-1 difficulty was encountered in soldering the instrumentation wires to the exterior tabs on the instrumentation headers; therefore, a method of spot welding the instrumentation wires to the tabs was perfected. 
The sequence of attachment of the pressure transducer, gas sampling valve, and tabulation fitting was changed. It was observed during the assembly of EMC- 1 that these components were damaged to a certain degree when subjected to the temperatures of the shrink fit operation. For EMC-2 the scheduling of attachment of these parts to the outer case was changed to occur after shrink fit. The length of the gas sampling tube protrusion into the converter enclosure was shortened so it would clear the hot side insulation strips.

The most serious problem encountered during the assembly of EMC-1 was the weld burn-back and subsequent cracking in the area where the hot frame joins the lower cover. Weld development was conducted to solve this problem. Both the weld schedule, speed of rotation and heat input, and configuration of chill blocks were variables. Sample parts which duplicated the dimensions in the weld area were fabricated. From this development effort a weld schedule and chill block design resulted which corrected the welding problem in this area.

\subsection{Summary of Converter Design}

EMC-2 is basically the same design as EMC-1. A number of modifications were made based on the experience gained during the build and assembly of EMC-1. Some of these changes were made to simplify building, while others were made to solve problems which could result in minor defects in the converter.

\section{3 .2 .3 .3 Assembly}

Assembly of EMC-2 was very similar to that for EMC-1. Changes were made in those areas where improvements could be effected from development activities. The changes incorporated for welding the hot frame to the lower cover provided adequate control of the welding operation, no further cracks occurred.

Minor problems occurred during the sealoff of the instrumentation header pins. Two of the pins cracked and developed leaks after the weld-seal operation. One pin was repaired by rewelding without change to the wiring; the other was repaired by rerouting wire to an unused pin and welding the cracked pin closed. This repair was conducted so that the normal sequence of converter assembly was not affected. 


\section{3 .2 .3 .4 Quality Control}

The piece parts for EMC-2 were inspected per the Q.C. planning developed for EMIC-1. The assembly of the converter was also monitored in the same manner as was EMC-1. Discrepancies were of a minor nature and resolution was affected so that no delays occurred in the start or during the assembly operation.

\section{3 .2 .3 .5 Initial Performance}

EMC-2 was placed on test while mounted on the same station which was used for converter processing. Measurements of converter initial performance were made to determine how well the converter measured up to design objectives and to establish a base line with which future performance could be compared. The initial performance of EIMC-2 is displayed by Table 2-21.

Table 2-21

SNAP-23A Converter EMC-2 Initial Performance

\begin{tabular}{|l|c|c|}
\hline & \multicolumn{2}{|c|}{ Operating Conditions } \\
\cline { 2 - 3 } & BOL & EOL \\
\hline \hline Hot Junction Temperature, ${ }^{\circ} \mathrm{F}$ & 1081 & 898 \\
Cold Junction Temperature, ${ }^{\circ} \mathrm{F}$ & 190 & 172 \\
Power Output, Watts & 79.7 & 57.6 \\
Converter Efficiency, $\%$ & 7.33 & 6.76 \\
Hot Frame-Hot Junction $\Delta t,{ }^{\circ} \mathrm{F}$ & 35 & 30 \\
Cold Junction-Outer Case $\Delta t,{ }^{\circ} \mathrm{F}$ & 53 & 45 \\
\hline
\end{tabular}

The initial performance of EMC-2 as shown by Table 2-21 was below design objectives. However, its performance was a significant improvement over that of EMC-1.

The Seebeck voltage was two percent higher than the design base; but the internal resistance was 8.6 percent higher; this combined effect produced a power output level four percent lower. However, comparison of EMC-2 performance with that of EMC-1 indicated that P-leg resistance for EMC-2 was significantly lower by approximately 20 percent for EOL conditions than for EMC-1. From a thermal 
standpoint, EMC-2 was nearly a perfect match of EMC-1 thermal performance with respect to gross power input requirements and cold cap to outer case temperature drop. EMC-2 efficiency was markedly improved over EMC- 1. EMC- 1 test data showed an efficiency of 6.1 percent for EOL conditions, EMC-2 test data showed an efficiency of 6.7 percent for EOL conditions. EMC-2 measured efficiency was 87 percent of the desired goal of 7.7 at EOL conditions. At BOL operating conditions EMC-2 measured efficiency was 7.3 percent, also an improvement over EMC-1 BOL efficiency.

As no problems were encountered during the assembly of this converter which would have a detrimental influence on performance, EMC-2 was considered a true representation of how well a converter with this technology would perform. To evaluate the performance of the converter, the resistance and Seebeck ratios were calculated. The resistance ratio was defined by the following equation.

$$
R R \text { (Resistance Ratio) }=\frac{R_{x} \text { (Measured Experimental Resistance) }}{R_{m} \text { (Calculated Resistance) }}
$$

The Seebeck ratio is defined by the following equation.

$$
\mathrm{SR} \text { (Seebeck Ratio) } \quad=\frac{E_{x} \text { (Measured Experimental Seebeck) }}{E_{m} \text { (Calculated Seebeck) }}
$$

These two terms, $R R$ and $S R$, provided a method for evaluating converter performance. The resistance ratio gives a non-dimension measure of how actual converter resistance compares to theoretical resistance of the thermoelectric material. A value of greater than 1.000, means the measured resistance was greater than theoretical material resistance. The Seebeck ratio is also a non-dimensional term for comparing actual Seebeck with theoretical Seebeck voltage. The RR and SR for EMC-2 are shown by Table 2-22.

Examination of the data in Table 2-22 shows the reason for EMC-2 performance being less than design objective. The Seebeck ratios for both the $\mathrm{N}$ - and $\mathrm{P}$-legs were as good as theoretical or slightly better. The resistance ratios were higher than both theoretical and design values for the P-leg and somewhat lower for the $\mathrm{N}$-leg. A value greater than the theoretical or design value has a detrimental effect on the converter performance. This examination of SR and RR pinpoints the cause for performance being less than the design objective to the high resistance of the $\mathrm{P}-\mathrm{leg}$. 
Table 2-22

SNAP-23A Converter EMC-2 Initial Performance

Ratios $\frac{\text { (Experimental Value) }}{\text { (Theoretical Value ) }}$ at EOL and BOL Design Conditions

\begin{tabular}{|l|c|r|r|r|r|c|}
\hline & \multicolumn{4}{|c|}{ Seebeck Ratio } & \multicolumn{3}{c|}{ Resistance Ratio* } \\
\cline { 2 - 7 } & EOL & BOL & Design & EOL & BOL & Design \\
\hline \hline Thermopile & 1.02 & 1.01 & 1.00 & 1.16 & 1.10 & 1.068 \\
Typical N-Leg & 1.00 & 0.99 & 1.00 & 0.97 & 0.93 & 1.068 \\
Typical P-Leg & 1.04 & 1.03 & 1.00 & 1.34 & 1.28 & 1.068 \\
\hline
\end{tabular}

* Theoretical resistance includes no extraneous resistance allowance.

NOTE: Theoretical values are based on new material characteristics determined in the TELPS facility. 


\subsection{Disposition}

EMC-2 thermoelectric performance was evaluated on the test station; a complete data tabulation is included in Section 5.0. After the initial thermoelectric performance evaluation, off-design cold junction temperature testing was conducted; the results of these tests are tabulated in Tables $2-23$ and $2-24$. These tests were conducted with the cold junction temperature $20^{\circ} \mathrm{F}$ above and below normal EOL values and $20^{\circ} \mathrm{F}$ and $40^{\circ} \mathrm{F}$ below normal values at BOL. These tests were run to gather data for system integration.

After these thermoelectric performance tests were completed and a base line operating characteristic established, EMC-2 was prepared for dynamic testing. It was mounted to the test platform with the shock and vibration mounting adapter as shown in Figure 2-30. Figure 2-39 shows the converter mounted to the test fixture for dynamic testing.

EMC-2 was first subjected to vibration testing. It was vibrated from 8 to 26 cps a at $2.6 \mathrm{~g}^{\prime} \mathrm{s}$ peak acceleration and from 26 to $50 \mathrm{cps}$ at 0.072 inch displacement in the $Z$ axis (longitudinal axis). Next, it was subjected to the same levels of vibration in two transverse axes which were at right angles to each other. Upon completeion of these vibration cycles, which were consistent with interface requirements, the unit was visually examined and no damage was noted. Thermoelectric performance was also checked and the vibration of the converter did not cause a significant shift in performance as shown by Table 2-25.

Physical damage to the thermoelectric components would have been indicated by a significant change in hot or cold junction temperature and an increase in electrical circuit resistance.

EMC-2 was prepared for shock tests using the same mounting adaptor. EMC-2 was subjected to a $10 \mathrm{~g}$ shock of 10 milliseconds duration in each of the three orthogonal axes. No visual damage was incurred and the thermoelectric performance as displayed by Table 2-25 showed no significant change. 
Table $2-23$

SNAP-23A Converter EMC-2 Test Data for EOL Off-Design Cold Junction Temperatures

\begin{tabular}{|lc|c|c|c|}
\hline \multicolumn{1}{|c|}{ Parameter } & Units & $\begin{array}{c}\text { Nominal Cold } \\
\text { Junction } \\
\text { Temp. } \\
-20^{\circ} \mathrm{F}\end{array}$ & $\begin{array}{c}\text { Nominal Cold } \\
\text { Junction Temp. } \\
+20^{\circ} \mathrm{F}\end{array}$ \\
\hline Temperature Outer Case & $\mathrm{T}_{\mathrm{oc}}$ & ${ }^{\circ} \mathrm{F}$ & 108 & 150 \\
Temperature Hot Frame & $\mathrm{T}_{\mathrm{hf}}$ & ${ }^{\circ} \mathrm{F}$ & 929 & 932 \\
Temperature Cold Junction $\mathrm{T}_{\mathrm{c}}$ & ${ }^{\circ} \mathrm{F}$ & 155 & 193 \\
Temperature Hot Junction & $\mathrm{T}_{\mathrm{h}}$ & ${ }^{\circ} \mathrm{F}$ & 900 & 902 \\
Load Voltage & $\mathrm{V}$ & Volts & 23.0 & 23.0 \\
Open Circuit Voltage & $\mathrm{E}$ & Volts & 41.7 & 40.6 \\
Load Current & $\mathrm{I}$ & Amperes & 2.66 & 2.39 \\
Total Resistance & $\mathrm{R}$ & Ohms & 7.03 & 7.36 \\
Power Output & $\mathrm{P}$ & Watts $(\mathrm{e})$ & 61.2 & 55.0 \\
Gross Power Input & $\mathrm{P}_{\text {in }}$ & Watts(t) & 888 & 840 \\
\hline
\end{tabular}

Table 2-24

SNAP-23A Converter EMC-2 Test Data for BOL Off-Design Cold Junction Temperatures

\begin{tabular}{|lc|l|c|c|}
\hline \multicolumn{1}{|c|}{ Parameter } & Units & $\begin{array}{c}\text { Nominal Cold } \\
\text { Junction } \\
\text { Temp. } \\
-20^{\circ} \mathrm{F}\end{array}$ & $\begin{array}{c}\text { Nominal Cold } \\
\text { Junction Temp. } \\
-40^{\circ} \mathrm{F}\end{array}$ \\
\hline \hline Temperature Outer Case & $\mathrm{T}_{\mathrm{oc}}$ & ${ }^{\circ} \mathrm{F}$ & 116 & 90 \\
Temperature Hot Frame & $\mathrm{T}_{\mathrm{hf}}$ & ${ }^{\circ} \mathrm{F}$ & 1119 & 1121 \\
Temperature Cold Junction & $\mathrm{T}_{\mathrm{C}}$ & ${ }^{\circ} \mathrm{F}$ & 172 & 152 \\
Temperature Hot Junction & $\mathrm{T}_{\mathrm{h}}$ & ${ }^{\circ} \mathrm{F}$ & 1084 & 1085 \\
Load Voltage & $\mathrm{V}$ & $\mathrm{V}$ & 25.0 & 25.0 \\
Open Circuit Voltage & $\mathrm{E}$ & Volts & 54.4 & 55.2 \\
Load Current & $\mathrm{I}$ & Amperes & 3.33 & 3.48 \\
Total Resistance & $\mathrm{R}$ & Ohms & 8.83 & 8.68 \\
Power Output & $\mathrm{P}$ & Watts(e) & 83.2 & 87.0 \\
Gross Power Input & $\mathrm{P}_{\mathrm{in}}$ & Watts(t) & 1132 & 1156 \\
\hline
\end{tabular}




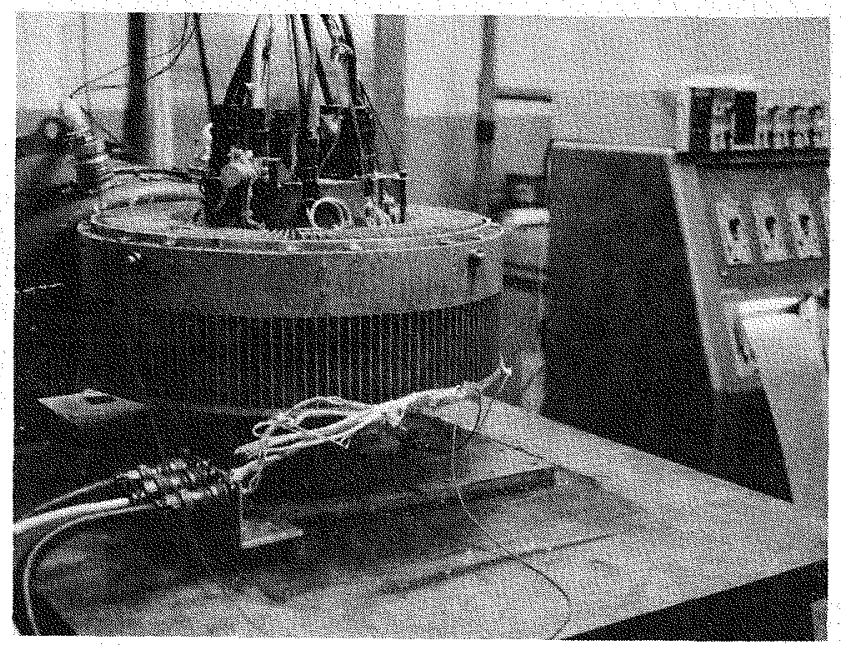

$\mathrm{X}$-Axis Vibration

ํㅗㅇ

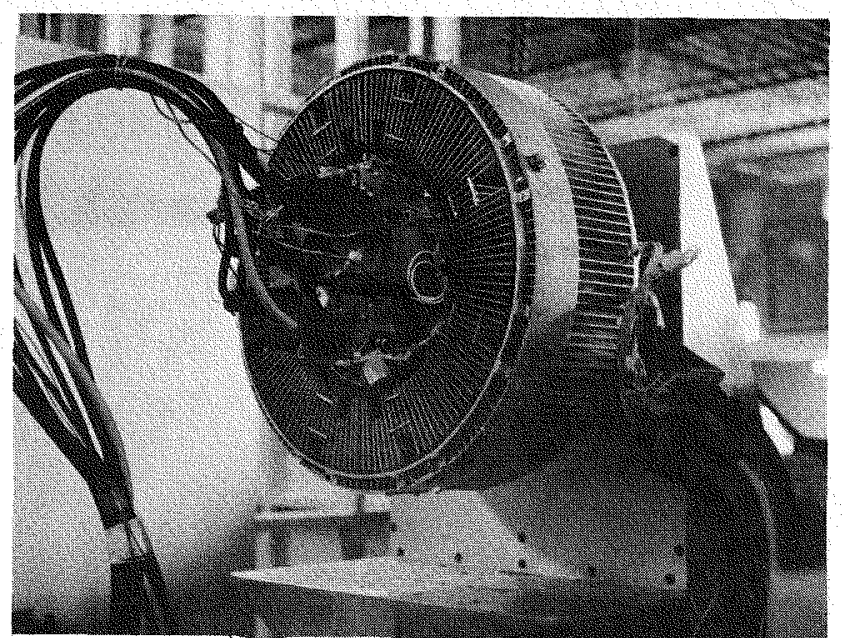

$\mathrm{X}$-Axis Shock

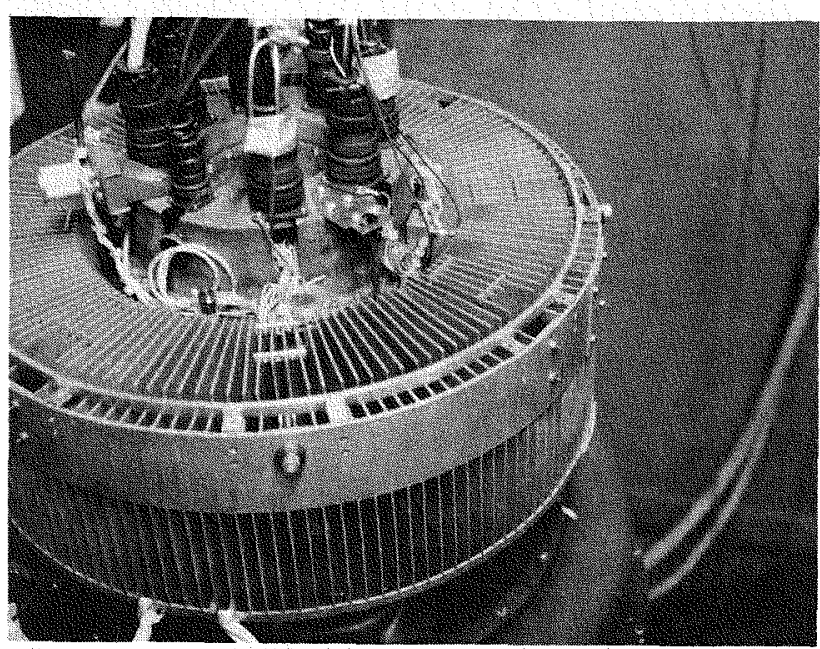

Z-Axis Vibration

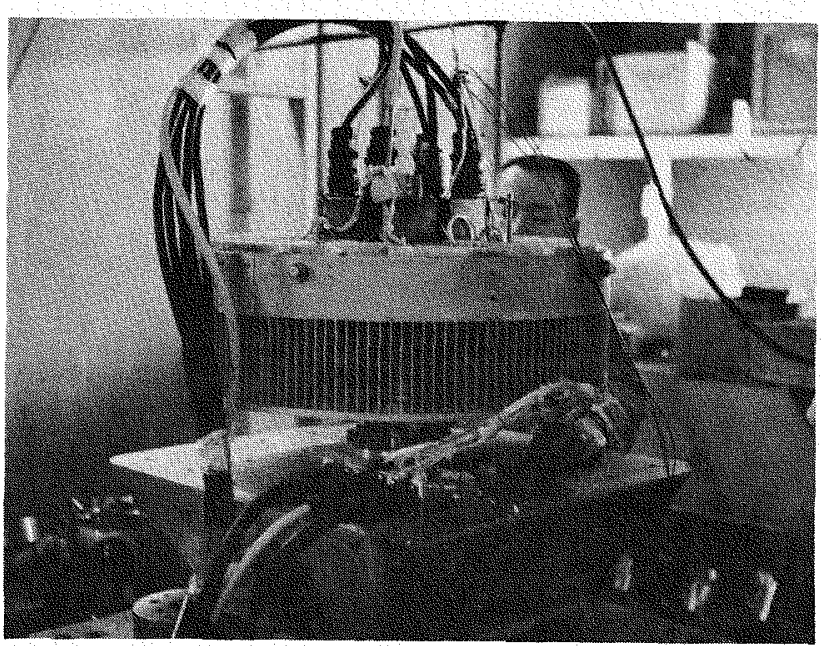

Z-Axis Shock

Figure 2-39. Dynamic Testing of SNAP-23A Converter EMC-2 
Table 2-25

Performance Data for SNAP-23A Converter EMC-2 Dynamic Test

\begin{tabular}{|l|c|c|c|c|c|c|l|l|}
\hline & $\mathrm{T}_{\mathrm{h}}{ }^{\circ}{ }_{\mathrm{F}}$ & $\mathrm{T}_{\mathrm{C}}{ }^{{ }_{\mathrm{F}}}$ & $\begin{array}{l}\mathrm{E}_{\mathrm{X}} \\
\text { Volts }\end{array}$ & $\begin{array}{l}\mathrm{E}_{\mathrm{C}} \\
\text { Volts }\end{array}$ & $\mathrm{E}_{\mathrm{X}} / \mathrm{E}_{\mathrm{C}}$ & $\begin{array}{l}\mathrm{R}_{\mathrm{X}} \\
\mathrm{Ohms}_{\mathrm{S}}\end{array}$ & $\begin{array}{l}\mathrm{R}_{\mathrm{C}} \\
\mathrm{Ohm}_{\mathrm{m}}\end{array}$ & $\mathrm{R}_{\mathrm{X}} / \mathrm{R}_{\mathrm{C}}$ \\
\hline $\begin{array}{l}\text { Pre-Vibration } \\
\text { Pre-Shock } \\
\text { Post-Shock }\end{array}$ & 1085 & 198 & 53.9 & 59.92 & 1.02 & 9.3 & 8.13 & 1.14 \\
\hline
\end{tabular}

Key: $\quad T_{h}$ Average hot junction temperature

$T_{c}$ Average cold junction temperature

$\mathrm{E}_{\mathrm{X}}$ Experimental Seebeck voltage

$\mathrm{E}_{\mathrm{C}}$ Theoretical Seebeck voltage

$R_{X}$ Experimental Internal resistance

$R_{C}$ Theoretical Internal resistance

The shock and vibration tests verified the capability of the converters to withstand the specified dynamic loading without damage or degradation of performance. After completion of the shock and vibration testing sequence, EMC-2 was placed on test in the laboratory for long-term performance evaluation. EMC-2 accumulated a total of 16,826 hours of operation in the laboratory. A complete data tabulation appears in Section 5. 0. 


\section{$2.3 .2 .4 \quad \mathrm{EMC}-3$}

EMC -3 was the third converter to be built during the SNAP-23A program. This converter incorporated the first design changes based on the thermoelectric technology improvement program. The purpose of $\mathrm{EMC}-3$ was to determine how well this improved thermoelectric technology would perform in a full scale converter.

\subsection{Design Activities}

Thermoelectric performance of both EMC-1 and EMC-2 did not meet program objectives. The EMC-1 failure in the hermetic seal during processing contributed to reduced power output and efficiency. EMC-2 did not have any known problems which would cause it to perform below the level of the technology capability. Therefore, to determine what corrective action could be taken, performance data from the 10-couple modules and the bell jars was evaluated; in addition, relevant performance data from the rmoelectric devices built for the SNAP-21, SNAP-23 and SNAP-27 were evaluated. A summary tabulation of the data examined is included in Table 2-26. In each case the devices which used P-legs fabricated of separately pressed and bonded segments performed better than theoretical calculated power. The same devices also out-performed those devices which used P-legs fabricated by simultaneously pressing. On this basis the decision was made to use P-legs fabricated of separately pressed and bonded segments. EMC-3 thermopile would contain 264 legs, with leg lengths and diameters being the same as for EMC-1 and EMC-2. In this way, the components already procured or fabricated for EMC-3 could be used. Even with this thermopile design, the reduction in performance would be slight from one of optimum configuration. Actual EMC-3 performance could be evaluated with the non-dimensional terms of Seebeck ratio, resistance ratio, and power ratio for comparison purposes without an optimum thermopile design.

Both EMC- 1 and EMC-2 had temperature drops greater than $30^{\circ} \mathrm{F}$ from cold cap to outer case at BOL and EOL conditions. Tests which were conducted on the SNAP-21 program and as part of technology improvement for SNAP-23A showed that an improvement could be made. These tests evaluated the drop in temperature across the cold cap-follower interface. During these tests, indium foil was 
placed between the follower and cold cap which resulted in a significant reduction in temperature drop. Indium foil between cold cap and follower was incorporated into EMC-3 design.

The pressure transducers which were used for both EMC-1 and EMC-2 did not function correctly. To alleviate this problem, a bourdon type pressure guage was used as a replacement on EMC-3.

\section{3 .2 .4 .2 Summary of Converter Design}

EMC-3 had the same basic configuration as its predecessors, EMC-1 and EMC-2. It incorporated the design and fabrication improvements used in EMC-2, and two other major changes which were made to improve thermoelectric performance:

A. The change from simultaneously pressed P-legs to separately pressed and bonded segments with soft nose at the hot end.

B. Inclusion of the indium foil between the cold cap and follower.

\section{3 .2 .4 .3 Assembly}

Only one change was required to assembly procedures and techniques which were used for the assembly of EMC-2. This change was made to incorporate indium foil between the cold cap and the follower. A development effort was conducted to determine the best method of installing the indium foil. The method developed was to cut the foil to size from the sheet stock. The foil was then formed over the cold cap spherical surface which was previously coated with vacuum grease; in this manner the foil would stay in place on the cold cap so that assembly of the couple could proceed as with EMC-2. The various steps in assembly with indium foil is shown by Figure 2-40. No other changes in procedure or methods were required because no design changes were made effecting assembly and because no problems were encountered during assembly of previous converter EMC-2. 
Table 2-26

Thermoelectric Generator Performance Comparison

\begin{tabular}{|c|c|c|c|}
\hline Unit & $\begin{array}{c}\text { Percent Over or } \\
\text { Under Theoretical } \\
\text { Power }\end{array}$ & $\begin{array}{c}\text { Extraneous } \\
\text { Resistance } \\
\text { in Percent of Total. } \\
\text { Resistance }\end{array}$ & $\begin{array}{l}\text { *P-Leg } \\
\text { Fabrication } \\
\text { Technique }\end{array}$ \\
\hline SNAP-23 Converter & +5.6 & +8.5 & $\mathrm{SP}, \mathrm{N}$ \\
\hline $\begin{array}{l}\text { SNAP-21 } \\
\text { P-6 Converter }\end{array}$ & -15.2 & +23.8 & $\mathrm{SP}, \mathrm{N}$ \\
\hline $\begin{array}{l}\text { SNAP-21 } \\
\text { 10D2 Converter }\end{array}$ & +5.8 & +1.8 & $\mathrm{~B}, \mathrm{H}$ \\
\hline $\begin{array}{l}\text { SNAP- } 27 \\
\text { Module \# } 10\end{array}$ & -6.0 & +6.0 & $\begin{array}{l}\text { Non-segmented } \\
\text { Conventional }\end{array}$ \\
\hline $\begin{array}{l}\text { SNAP- } 27 \\
\text { Module \# } 15\end{array}$ & -9.7 & +9.3 & $\begin{array}{l}\text { Non-segmented } \\
\text { Conventional }\end{array}$ \\
\hline $\begin{array}{l}\text { SNAP- } 23 \text { A } \\
\text { 10-Couple Module }\end{array}$ & -4.3 & +8.2 & $\mathrm{SP}, \mathrm{N}$ \\
\hline $\begin{array}{l}\text { SNAP-23A } \\
\text { 10-Couple Module }\end{array}$ & -8.3 & +9.3 & $\mathrm{SP}, \mathrm{H}$ \\
\hline $\begin{array}{l}\text { SNAP- } 23 A \\
10 \text {-Couple Module }\end{array}$ & +16.5 & -19.4 & $\mathrm{~B}, \mathrm{~N}$ \\
\hline $\begin{array}{l}\text { SNAP-23A } \\
\text { 10-Couple Module }\end{array}$ & +11.0 & -14.4 & $\mathrm{~B}, \mathrm{H}$ \\
\hline SNAP-23A Bell Jar & -1.2 & +0.93 & $\mathrm{SP}, \mathrm{N}$ \\
\hline SNAP-23A Bell Jar & -5.0 & +0.45 & $\mathrm{SP}, \mathrm{H}$ \\
\hline SNAP-23A Bell Jar & +16.5 & -26.6 & $\mathrm{~B}, \mathrm{~N}$ \\
\hline SNAP-23A Bell Jar & +11.3 & -17.3 & $\mathrm{~B}, \mathrm{H}$ \\
\hline
\end{tabular}

*SP: Simultaneously Pressed Segments

B: Individually Pressed and Bonded Segments

$\mathrm{N}$ : Conventional

$H$ : Soft Nose 


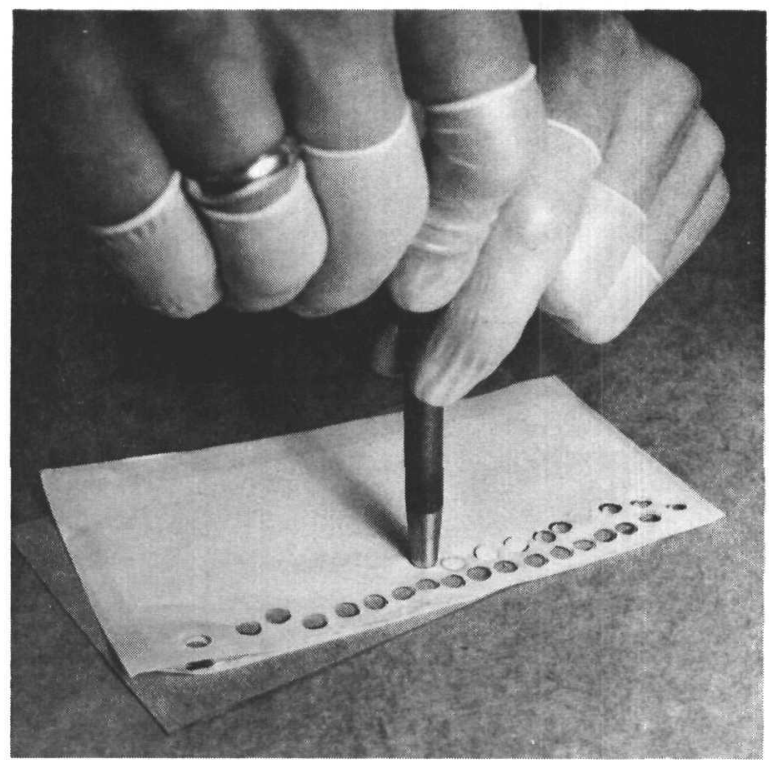

a. Cutting Indium Foil

b. Applying Vacuum Grease
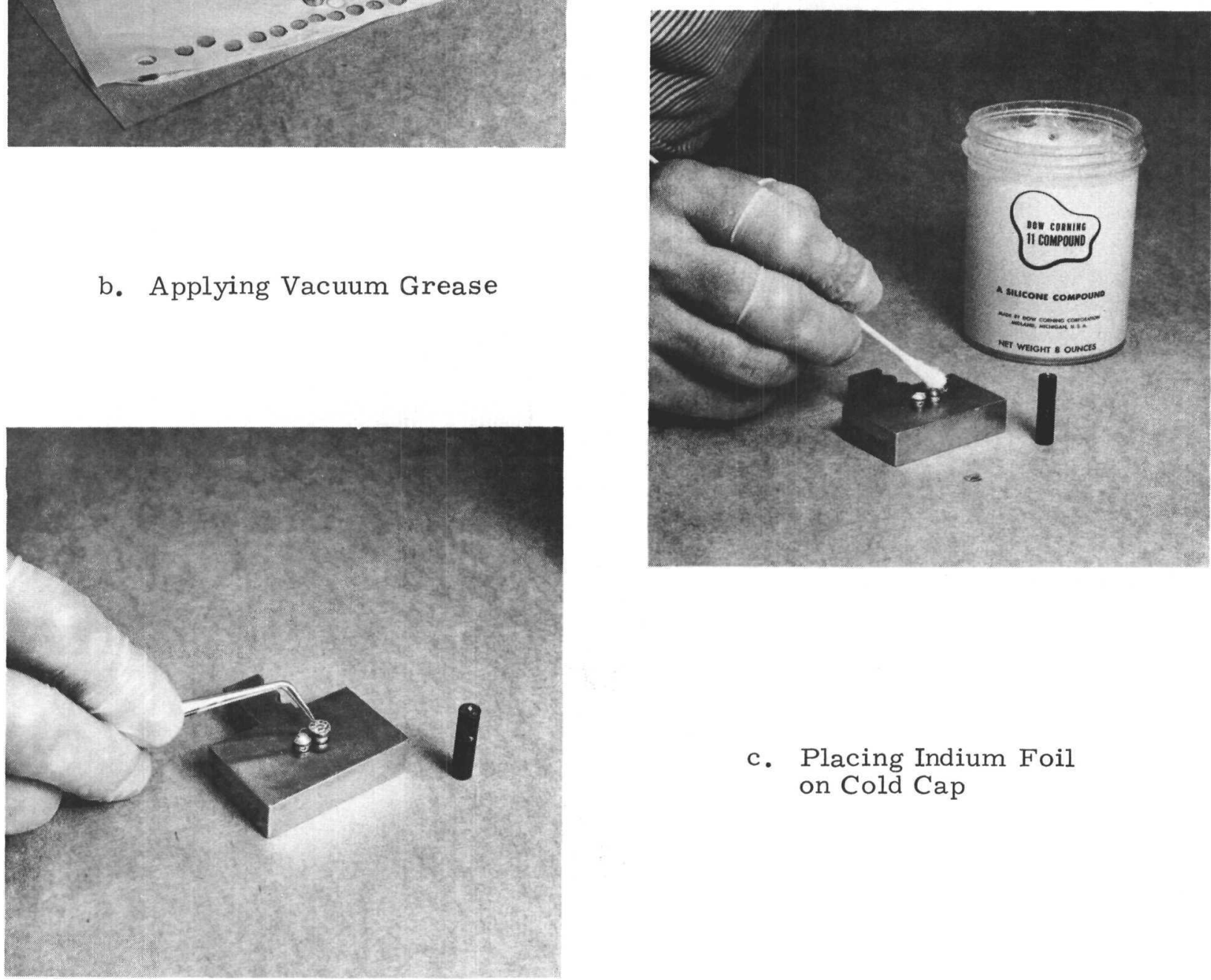

c. Placing Indium Foil on Cold Cap

Figure 2-40. Assembly Sequence of Fitting Indium Foil to Thermoelectric Couple Cold Caps 


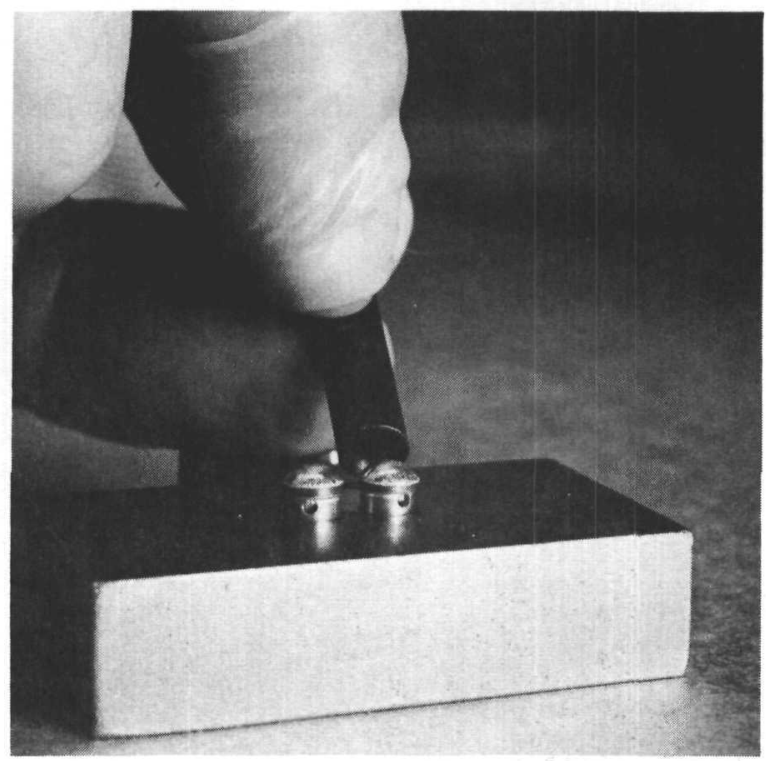

d. Forming Indium Foil

e. Placement of Thermoelectric Couples into Assembly Fixture

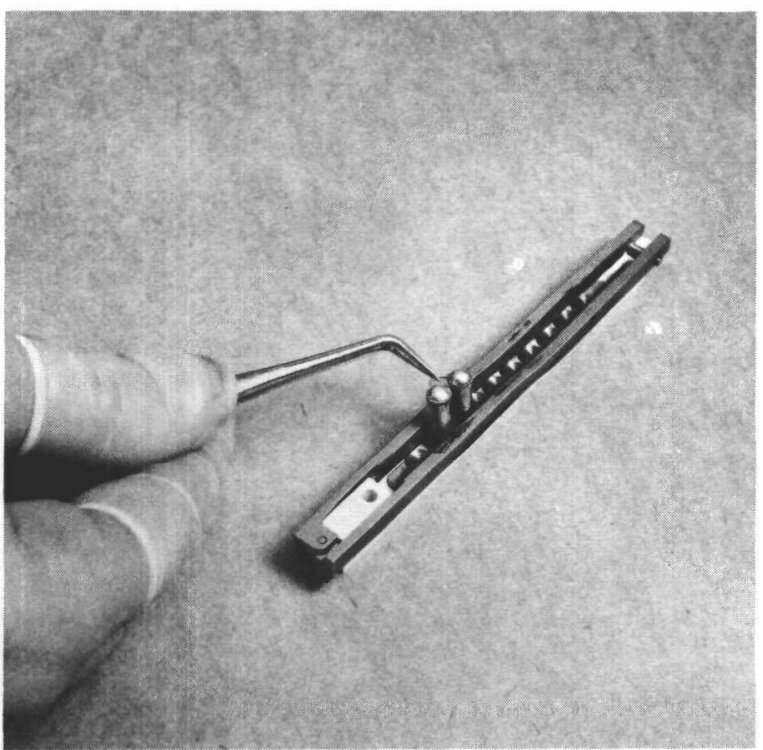

Figure 2-40. Assembly Sequence of Fitting Indium Foil to Thermoelectric Couple Cold Caps (Continued) 
Final assembly of EMC-3 proceeded without incident; upon completion of assembly the converter was mounted on the test station for processing in preparation for final seal off. The converter was then ready for initial performance evaluation.

\section{3 .2 .4 .4 Quality Control}

Quality control was maintained during the fabrication of parts and assembly of the converter by performing inspection per the plan developed for the two previous converters (EMC-1 and EMC-2). One additional step of inspection during thermopile assembly was initiated. A cystoscope was used to visually inspect along the rows of legs after assembly between the hot and cold frame. In this way the precise positioning of all parts could be assured. Of particular importance was the fit of the cold cap ball into the socket of the follower and the hot end of the thermoelectric leg into the recess of the hot junction button.

\subsection{Initial Performance}

EMC- 3 was placed on test while mounted on the same station which was used for converter processing. Initial performance measurements were made to determine how well the converter met design objectives and to establish a base line, to which future performance could be compared. Initial performance of EMC-3 is shown by Table $2-27$.

Table $2-27$

SNAP-23A Converter EMC-3 Initial Performance

\begin{tabular}{|l|c|c|}
\hline & \multicolumn{2}{|c|}{ Operating Conditions } \\
\cline { 2 - 3 } & BOL & EOL \\
\hline \hline Hot Junction Temperature, ${ }^{\circ} \mathrm{F}$ & 1077 & 900 \\
Cold Junction Temperature, ${ }^{\circ} \mathrm{F}$ & 191 & 172 \\
Power Output, Watts & 84.3 & 61.2 \\
Converter Efficiency, $\%$ & 8.23 & 7.43 \\
Hot Frame-Hot Junction $\Delta t,{ }^{\circ} \mathrm{F}$ & 34 & 28 \\
Cold Junction-Outer Case $\Delta t,{ }^{\circ} \mathrm{F}$ & 26 & 21 \\
\hline
\end{tabular}


The initial efficiency of EMC-3 as shown by Table 2-27 represented a 96 percent attainment of design goal and a significant improvement over EMC-1 and EMC-2. This efficiency measurement was taken only a few operating hours after completion of processing. As EMC-3 continued to operate on the test station its efficiency improved. This increased efficiency was primarily attributed to a decrease in electrical resistance. Table 2-28 shows how the resistance had decreased from initial value at time zero to values after operating 968 hours. At the 2782 hour operating time efficiency had increased to 7.7 percent and power output to 66.5 watts at EOL operating temperature conditions. This converter then met the design objectives for both efficiency and power output, and the temperature drop from cold junction to outer case was reduced to below the design value of $30^{\circ} \mathrm{F}$.

\section{3 .2 .4 .6 Disposition}

EMC-3 initial thermal and thermoelectric performance was evaluated on the test station with complete data tabulation included in SNAP-23A Quarterly Report No. 5. After initial thermoelectric performance evaluation, off-design cold junction temperature tests were conducted to gather data for system integration. These tests were conducted with the cold junction temperature $20^{\circ} \mathrm{F}$ above and below nominal EOL values and $20^{\circ} \mathrm{F}$ and $40^{\circ} \mathrm{F}$ below normal values at $B O L$; the test results are tabulated in Tables $2-29$ and 2-30.

EMC-3 was operated continuously on its test station at $3 \mathrm{M}$ for the balance of the program; at program termination the converter had accumulated 20,266 hours of running time at BOL conditions and was still functioning properly. 
Table 2-28

SNAP-23A Converter EMC-3 Initial Performance Ratios $\left(\frac{\text { Experimental value }}{\text { Theoretical value }}\right)$ at EOL and BOL Design Conditions

\begin{tabular}{|c|c|c|c|c|c|c|}
\hline \multirow[b]{3}{*}{ Thermopile } & \multicolumn{3}{|c|}{ Seebeck Ratio } & \multicolumn{3}{|c|}{ Resistance Ratio* } \\
\hline & EOL & $\mathrm{BOL}$ & Design & $\mathrm{EOL}$ & $\mathrm{BOL}$ & Design \\
\hline & 0.98 & $\begin{array}{l}0.98 \\
(1.00) * *\end{array}$ & 1.00 & 1.09 & $\begin{array}{l}1.07 \\
(1.00) * *\end{array}$ & 1.068 \\
\hline Typical N-leg & 1.01 & $\begin{array}{l}1.00 \\
(1.00) * *\end{array}$ & 1.00 & 1.05 & $\begin{array}{l}1.01 \\
(0.97) * * *\end{array}$ & 1.068 \\
\hline Typical P-leg & 0.96 & $\begin{array}{l}0.97 \\
(1.00) * *\end{array}$ & 1.00 & 1.13 & $\begin{array}{l}1.13 \\
(1.03) * * *\end{array}$ & 1.068 \\
\hline \multicolumn{7}{|c|}{$\begin{array}{l}\text { *Theoretical resistance includes no extraneous resistance allowance. } \\
\text { **Re-evaluation after } 968 \text { test hours. }\end{array}$} \\
\hline
\end{tabular}


Table $2-29$

SNAP-23A Converter EMC-3 Test Data for EOL Off-Design

Cold Junction Temperatures

\begin{tabular}{|c|c|c|c|c|}
\hline \multicolumn{2}{|l|}{ Parameter } & Units & $\begin{array}{c}\text { Nominal Cold } \\
\text { Junction Temp. } \\
-20^{\circ} \mathrm{F}\end{array}$ & $\begin{array}{l}\text { Nominal Cold } \\
\text { Junction Temp. } \\
+20^{\circ} \mathrm{F}\end{array}$ \\
\hline Temperature Outer Case & $\mathrm{T}_{\mathrm{oc}}$ & ${ }^{\circ} \mathrm{F}$ & 133 & 171 \\
\hline Temperature Hot Frame & $\mathrm{T}_{\mathrm{hf}}$ & ${ }^{\circ} \mathrm{F}$ & 927 & 931 \\
\hline Temperature Cold Junction & $\mathrm{T}_{\mathrm{c}}$ & ${ }^{\circ} \mathrm{F}$ & 154 & 192 \\
\hline Temperature Hot Junction & $\mathrm{T}_{\mathrm{h}}$ & ${ }^{\circ} \mathrm{F}$ & 900 & 903 \\
\hline Load Voltage & $\mathrm{V}$ & Volts & 23.0 & 23.0 \\
\hline Open Circuit Voltage & $\mathrm{E}$ & Volts & 41.4 & 40.6 \\
\hline Load Current & $I$ & Amperes & 2.85 & 2.60 \\
\hline Total Resistance & $\mathrm{R}$ & Ohms & 6.45 & 6.77 \\
\hline Power Output & $\mathrm{P}$ & Watts $(e)$ & 65.6 & 59.8 \\
\hline Gross Power Input & $P_{\text {in }}$ & Watts $(t)$ & 880 & 832 \\
\hline
\end{tabular}

Table $2-30$

SNAP-23A Converter EMIC-3 Test Data for BOL Off-Design

Cold Junction Temperatures

\begin{tabular}{|c|c|c|c|c|}
\hline \multicolumn{2}{|l|}{ Parameter } & Units & $\begin{array}{c}\text { Nominal Cold } \\
\text { Junction Temp. } \\
-20^{\circ} \mathrm{F}\end{array}$ & $\begin{array}{c}\text { Nominal Cold } \\
\text { Junction Temp. } \\
-40^{\circ} \mathrm{F}\end{array}$ \\
\hline Temperature Outer Case & $\mathrm{T}_{\mathrm{oc}}$ & ${ }^{\circ} \mathrm{F}$ & 144 & 125 \\
\hline Temperature Hot Frame & $\mathrm{T}_{\text {hf }}$ & ${ }^{\circ} \mathrm{F}$ & 1111 & 1109 \\
\hline Temperature Cold Junction & $\mathrm{T}_{\mathrm{c}}$ & ${ }^{\circ} \mathrm{F}$ & 170 & 152 \\
\hline Temperature Hot Junction & $\mathrm{T}_{\mathrm{h}}$ & ${ }^{\circ} \mathrm{F}$ & 1076 & 1073 \\
\hline Load Voltage & $\mathrm{V}$ & Volts & 25.0 & 25.0 \\
\hline Open Circuit Voltage & $\mathrm{E}$ & Volts & 54.5 & 54.9 \\
\hline Load Current & I & Amperes & 3.58 & 3.72 \\
\hline Total Resistance & $R$ & Ohms & 8.23 & 8.02 \\
\hline Power Output & $\mathrm{P}$ & Watts(e) & 89.6 & 92.9 \\
\hline Gross Power Input & $P_{\text {in }}$ & Watts $(t)$ & 1096 & 1120 \\
\hline
\end{tabular}




\subsubsection{PMC Series Converters}

\section{3 .3 .1 Introduction}

The Prototype Mockup Converters (PMC) were planned as the second series to be developed during thisprogram. The PMC series is a continuation of development from the EMC converters to meet the objectives of:

- 10-year life

- Demonstrated reliability

- Field service capability

- Integration with heat source system

- Increased efficiency

The purpose was to incorporate design changes based on the experience and technology gained during the build and test of the EMC converters. Inputs from the technology improvement program would also be incorporated into these converters as the data became available. Some of the design changes planned at the start of the program, such as those to further strengthen the mechanical structure if revealed during shock and vibration testing were not required because EMC-2 passed shock and vibration testing without difficulty. The emphasis was to design the PMC units to bridge the gap from a laboratory device to a device acceptable for field service. Some converters of the PMC series incorporated design features that would make these converters adaptable to field service as well as being useful laboratory test devices.

\subsubsection{PMC-1A and $1 \mathrm{~B}$ Converters}

These two converters were the first to be built as part of the PMC series. The design of these two converters was initially identical. Components were preferentially selected for PIC-1A because it was scheduled for integration with the system at Westinghouse. Changes were made in the final configuration of PMC-1B, prior to build, which were related to the specific condition of some of remaining components. 


\section{3 .3 .2 .1 Design Activities}

Design of these converters started before EMC-3 fabrication was completed. The initial step was an evaluation of the technical desirability and feasibility of change from the basic EMC design. The areas reviewed were the converter physical dimensions and operating temperatures. One of the questions which evolved from the review was - what is the probability that more than 280 couples will be required? This was important from the standpoint of need to update special tooling required to fabricate a cold frame with more than 280 couples and the possibility that the converter would need to be enlarged to accomodate a larger cold frame associated with a greater number of couples.

Figure 2-41 illustrates the dependency of the number of couples on the cold junction and hot junction temperatures and related heat input for EOL conditions as determined by a parametric study.

For example, EMC-3 264-couple converter was designed to provide 60 watts power output at EOL operating temperatures of $\mathrm{T}_{\mathrm{C}}=174^{\circ} \mathrm{F}$ and $\mathrm{T}_{\mathrm{h}}=900^{\circ} \mathrm{F}$. However, should the results of system and component testing show that the operating temperatures at EOL would be $T_{c}=180^{\circ} \mathrm{F}$ and $T_{h}=880^{\circ} \mathrm{F}, 280$ couples of the present configuration would be required to provide 60 watts minimum power output, as shown in Figure 2-41.

The design data base applied in the analysis included the following considerations:

- The couple geometry (leg diameters, lengths, L/A and $\mathrm{Lc} / \mathrm{L}$ ratios) was that of the EMC converter design.

- EOL conditions only are governing (with no consideration of BOL conditions), with the requirement to provide output power of 60 watts minimum for a 24 -volt load.

- The computer program employed for this analysis was the program used to evaluate converter performance of a given design and not that program normally employed for couple design (determining couple geometry and number of couples). Therefore, it was understood that the results 
Graphical representation of number of couples required to provide power output of 60 watts (minimum) for a 24-volt load, as related to various cold junction and hot junction temperatures (near EOL conditions), and related heat input to converter

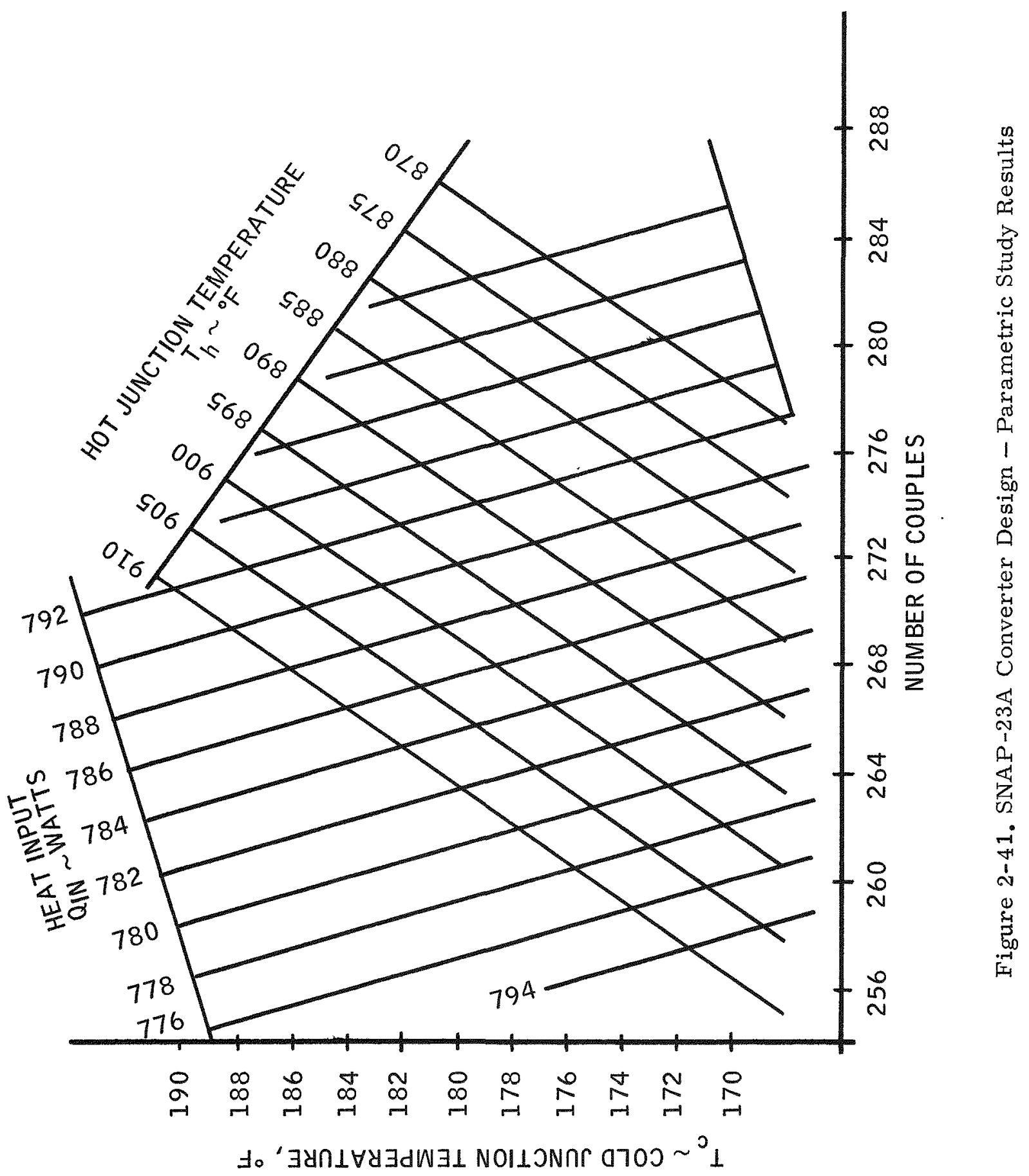


of this analysis would not be used to design another converter under operating temperature conditions different from the EMC design, but that the results illustrated a general "design margin" associated with the most current converter design.

Although the cold frame size used for the EMC series was large enough to allow an increase of 30 couples, special tooling would be required for a cold frame of 42 rows (294 couples). To resolve this, a heat loss analysis was performed to predict the shunt heat loss which would be incurred by using an oversized cold frame that would not require special tooling. The results of this analysis are shown in Table 2-31.

Table 2-31

Shunt Heat Loss - Cold Frame Size Comparison at EOL

\begin{tabular}{|l|c|c|}
\hline \multirow{2}{*}{$\begin{array}{l}\text { Heat Loss } \\
\text { Location }\end{array}$} & \begin{tabular}{c}
$|c|$ \\
Heat Loss, Watts \\
\cline { 2 - 3 }$(9.240$ Cold Frches Diameter $)$
\end{tabular} & $\begin{array}{c}\text { Couple Couple Capacity } \\
\text { Cold Frame }\end{array}$ \\
\hline \hline Insulation & 66.4 & 61.6 \\
Lower Cover & 22.1 & 20.0 \\
Upper Cover & 12.1 & 10.7 \\
Totals & 100.6 & 92.3 \\
\hline
\end{tabular}

Considering the magnitude of extra shunt heat loss of about eight watts, an oversized cold frame for greater number of couples would not be objectionable from a performance standpoint. However, before proceeding to order a cold frame for 294 couples, it was necessary to determine if a cold frame for 280 couples would be sufficient.

To simplify the parametric study, the critical number of 280 couples was examined for thermal compatibility with the fin-type rejection system at several cold junction temperatures. 
The following curves and tables show that an optimized, 280-couple converter can develop 60 watts at EOL without exceeding the heat rejection capacity of the available radiator. This also was true for a converter having a 13.3 percent extraneous resistance which has a higher heat rejection rate for the same power output. Checking each design at BOL conditions showed each P-leg segment temperature to be under $600^{\circ} \mathrm{F}$ and the heat absorption capacity to be greater than the available heat.

In Figure 2-42, cold junction temperatures of the 280-couple converter are plotted against heat rejected to the radiator fins for an extraneous resistance of both 6.33 percent and 13.3 percent ${ }^{1}$. Fin heat rejection capacity, corresponding to various cold junction temperatures, is also plotted so that the point at which converter heat rejection rate equals fin capacity can be determined. For 6.33 percent extraneous electrical resistance, the two curves intersect at a $\mathrm{T}_{\mathrm{c}}$ of $175^{\circ} \mathrm{F}$ and $\mathrm{Q}_{\mathrm{R}}$ of 728 watts for EOL conditions. Since the converter was optimized for each cold junction temperature, the $\mathrm{P}$ - and $\mathrm{N}-\mathrm{leg}$ geometry corresponding to $175^{\circ} \mathrm{F}$ can be determined from Figure 2-42. The corresponding hot junction temperature for each extraneous resistance is shown in Figure 2-43 and is $865^{\circ} \mathrm{F}$ for a converter having 6.33 percent extraneous resistance. Table 2-32 is a heat balance tabulation which also contains data pertaining to BOL conditions. The primary concern at BOL is that the converter can absorb the available heat without exceeding a hot junction temperature of $1085^{\circ} \mathrm{F}$ and that the fins have the capacity to absorb the converter rejection heat. For the balanced condition noted in Figure 2-42 where $T_{c}$ equaled $175^{\circ} \mathrm{F}$, the tabulation show shows that at $a \mathrm{~T}_{\mathrm{h}}$ of $1085^{\circ} \mathrm{F}$, the converter can absorb 1093 watts which is greater than the available heat of 1007.7 watts $^{2}$.

${ }^{1}$ Extraneous resistance value experienced with SNAP-23 converters.

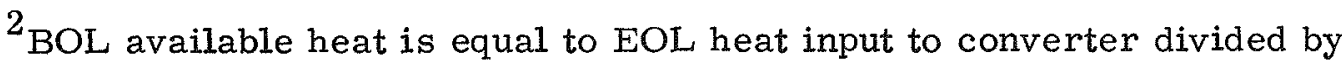
decay factor. 


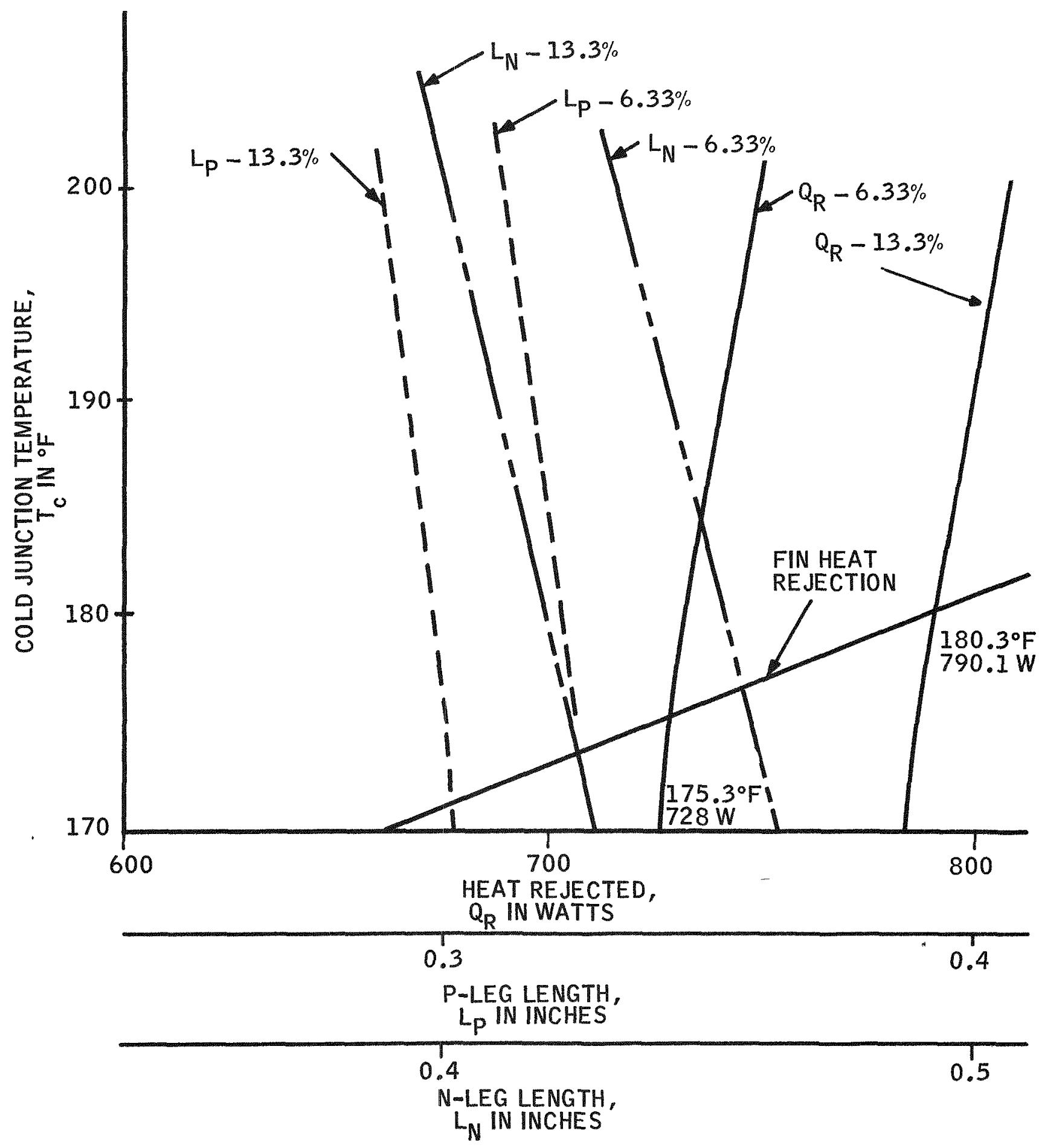

Figure 2-42. Heat Rejection and Leg Geometry Characteristics for Optimized, 280-Couple, 60Watt Converter at EOL 


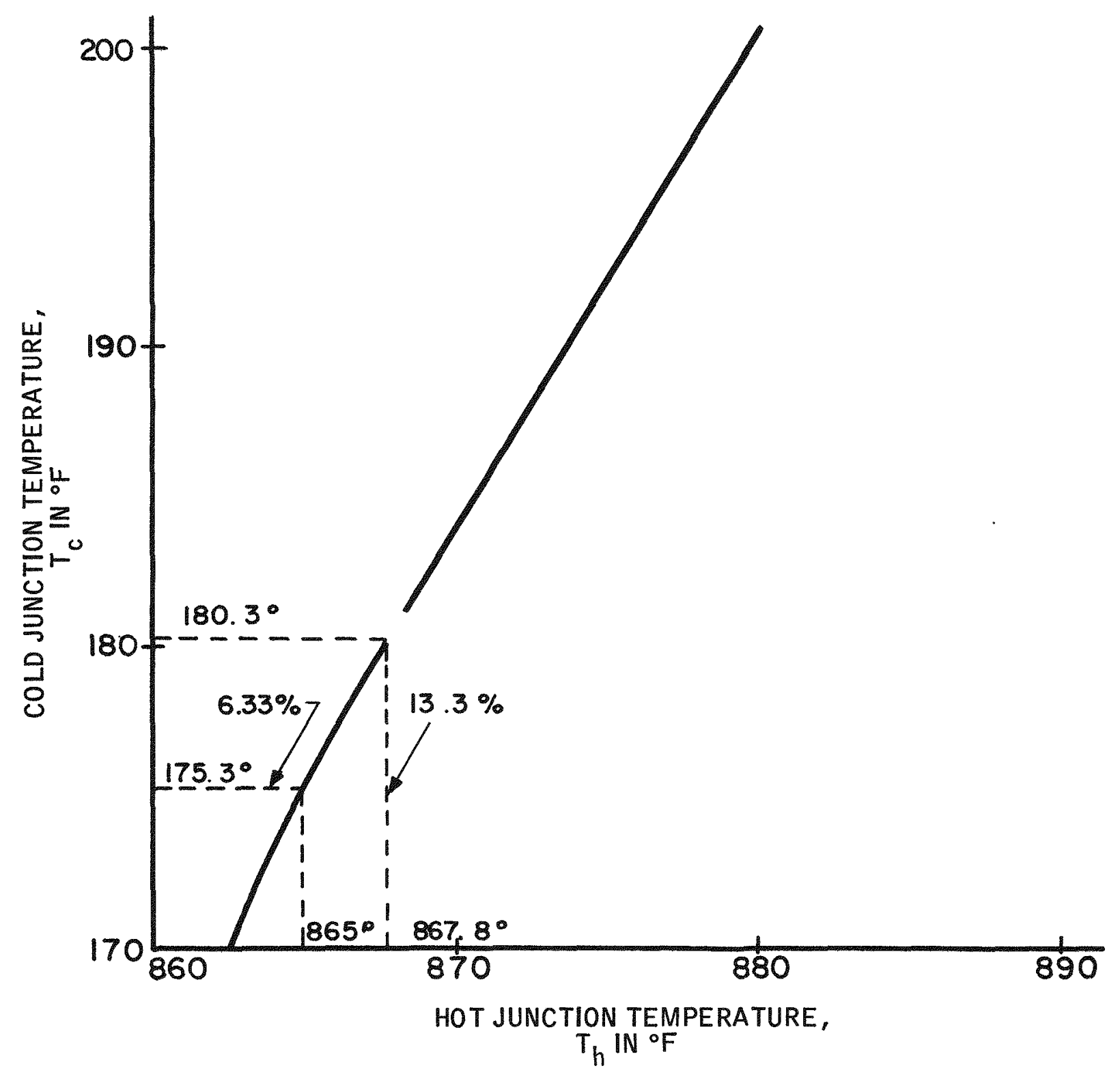

Figure 2-43. Couple Cold Junction Temperature versus Hot Junction Temperature at EOL 
Table 2-32

Heat Balance Tabulation

\begin{tabular}{|c|c|c|c|c|c|c|c|c|c|c|c|}
\hline$L_{P}$ & $\mathrm{~L}_{\mathrm{N}}$ & $\begin{array}{l}\text { Extraneous } \\
\text { Resistance }\end{array}$ & $\begin{array}{c}T_{c} \\
\text { EOL }\end{array}$ & $\begin{array}{l}\mathrm{T}_{\mathrm{h}} \\
\text { EOL }\end{array}$ & $\begin{array}{c}\text { Rejected } \\
\text { Heat, EOL }\end{array}$ & $\begin{array}{l}\text { Rejected } \\
\text { Heat BOL }\end{array}$ & $\begin{array}{c}\text { Total Heat Input } \\
\text { BOL (Ability to } \\
\text { Absorb Heat) } \\
\text { - }\end{array}$ & $\begin{array}{l}\text { Fin } \\
\text { Rejection } \\
\text { Rate EOL }\end{array}$ & $\begin{array}{c}\text { Fin } \\
\text { Rejection } \\
\text { Rate BOL }\end{array}$ & $\begin{array}{c}\text { Available } \\
\text { Heat at } \\
\text { BOL }\end{array}$ & $\begin{array}{l}\text { Power } \\
\text { Output } \\
\text { EOL }\end{array}$ \\
\hline 0.326 & 0.463 & 6.33 & 170 & 862.6 & 725.8 & 924.9 & 1094.1 & 662.2 & 872.3 & 1004.9 & 86.2 \\
\hline 0.302 & 0.429 & 13.3 & 170 & 862.6 & 784.1 & 999.5 & 1150.6 & 662.2 & 872.3 & 1079.5 & 86.1 \\
\hline 0.322 & 0.453 & 6.33 & 180 & 867.6 & 731.4 & 931.9 & 1095.6 & 785.8 & 1004.2 & 1011.9 & 85.5 \\
\hline 0.298 & 0.419 & 13.3 & 180 & 867.6 & 790.2 & 1007.1 & 1153.9 & 785.8 & 1004.2 & 1087.1 & 85.5 \\
\hline 0.316 & 0.443 & 6.33 & 190 & 873.8 & 739.4 & 942.2 & 1100.5 & 912.9 & 1138.4 & 1022.2 & 85.0 \\
\hline 0.293 & 0.410 & 13.3 & 190 & 873.8 & 798.9 & 1018.3 & 1158.1 & 912.9 & 1138.4 & 1098.3 & 85.0 \\
\hline 0.311 & 0.432 & 6.33 & 200 & 879.6 & 747.0 & 952.0 & 1105.3 & 1044.2 & 1275.8 & 1032.0 & 84.5 \\
\hline 0.288 & 0.400 & 13.3 & 200 & 879.6 & 807.1 & 1028.9 & 1163.9 & 1044.2 & 1275.8 & 1108.9 & 84.5 \\
\hline 0.325 & 0.458 & 6.33 & 175 & 865 & 728 & 927.2 & 1093.0 & 728 & 927.2 & 1007.7 & 85.7 \\
\hline 0.298 & 0.419 & 13.3 & 180 & 867.8 & 790.1 & 1007.3 & 1153.4 & 790.1 & 1007.3 & 1087.1 & 85.4 \\
\hline
\end{tabular}

BOL Temperatures $=1085^{\circ} \mathrm{T}_{\mathrm{h}}$ and $\mathrm{T}_{\mathrm{c}}=\mathrm{T}_{\mathrm{C}_{\mathrm{EOL}}}+17$ degrees

EOL Power $=60$ watts $(24$ volts at 2.5 amps $)$

BOL Voltage $=24$ volts 
The tabulation shows that fin capacity increases with temperature such that if EOL conditions were satisfied, BOL fin capacity would be adequate. The temperature rise of $17^{\circ} \mathrm{F}$ between EOL and BOL cold junction temperatures increases fin capacity at a rate equal to change in converter heat rejection rate between EOL and BOL. Therefore, an abbreviated tabulation concerning only EOL conditions is shown in Table 2-33.

Table 2-33

Abbreviated Heat Balance Tabulation for EOL Conditions

\begin{tabular}{ccc}
$\begin{array}{c}\text { Cold Junction } \\
\text { Temperature, }{ }^{\circ} \mathrm{F}\end{array}$ & $\begin{array}{c}\text { Extraneous } \\
\text { Resistance, }\end{array}$ & $\begin{array}{c}\text { Excess Fin } \\
\text { Capacity, watts }\end{array}$ \\
\cline { 2 - 3 } 170 & 6.33 & -63.6 \\
170 & 13.30 & -121.9 \\
175 & 6.33 & 0 \\
180 & 6.33 & 54.4 \\
180 & 13.30 & -4.4 \\
180 & 13.30 & 0 \\
190 & 6.33 & 173.5 \\
190 & 13.30 & 114.0 \\
200 & 6.33 & 297.2 \\
200 & 13.30 & 237.1
\end{tabular}

At $170^{\circ} \mathrm{F}$ and 6.33 percent extraneous resistance, the tabulation shows the fins are incapable of absorbing the converter rejected heat (shunt heat loss plus thermopile heat) by an amount equal to 63.6 watts. However, at $175^{\circ} \mathrm{F}$ the fin absorption rate exactly equals the converter heat rejection rate. At $190^{\circ} \mathrm{F}$ the fins have far more capacity than is required leaving allowance for converter variations such as increased extraneous resistance, increased thermal conductivity of leg material, and increased shunt heat loss. Each variation will be discussed separately. Couple number predictions are based on one variation occurring at a time. 
A. Converter Resistance

An increase in extraneous resistance and leg material resistance have the same effect on the converter. The tabulation shows that the large excess fin capacities at cold junction temperatures in excess of $190^{\circ} \mathrm{F}$ indicate that 280 couples will not be exceeded for reasons of increased resistance. The confidence level for this prediction, based on past material and extraneous resistance data is 100 percent.

B. Shunt Heat Loss

A considerable increase in shunt heat loss can be tolerated at cold junction temperatures in excess of $180^{\circ} \mathrm{F}$ for the 6.33 percent extraneous resistance. Therefore, the confidence level in not exceeding 280 couples, based on recent data for powdered Min-K thermal conductivity, is 100 percent.

C. Leg Material Thermal Conductivity

The large excess fin capacities at the higher cold junction temperatures indicate that a large change (approximately 50 percent since conducted heat is approximately 570 watts) in material thermal conductivity can be tolerated. The confidence level in not exceeding 280 couples is 100 percent.

D. Reduced Fin Performance

The excess fin capacity of 297 watts at the $200^{\circ} \mathrm{F}$ cold junction point represents approximately 29 percent of present fin capacity. Because of the difficulty in analyzing fin performance when air circulation through the fins is partially restricted by the enclosure, the confidence level in not exceeding 280 couples is

75 percent. 


\section{E. Reduced Seebeck Coefficient}

A five percent reduction in Seebeck coefficient was considered which would affect the reversible phenomena such as Peltier and Thompson heat values in addition to the Seebeck voltage. An approximate calculation indicated no excess couple problem. However, in view of possible calculation errors, the confidence level in not exceeding 280 couples is 75 percent.

Considering the probability of the foregoing variations happening and the compensating possibilities if they should occur, it was recommended that no tooling be ordered for a 294-couple cold frame.

The temperature drop from the leg cold junction to the outer case was greater than the $30^{\circ} \mathrm{F}$ design objective for the first two EMC units. The average temperature drops from cold junction to outer case are shown in Table 2-34 for all EMC units. EMC-3 had a lower temperature drop than EMC- 1 and EMC-2 because indium foil was used between the ball of the cold cap and the socket of the follower. A design change was considered in this area for PMC units because Xenon gas will be used as a backfill gas rather than Argon and the need to replace the hardcoated aluminum follower with a material that has greater reliability as an electrical insulator. The cold end temperature testing which was conducted as part of the technology improvement portion of the program provided inputs for a design change. This data showed that a follower made of beryllium oxide $(\mathrm{BeO})$ which made ring contact with the cold cap would be the best choice. Ring contact is achieved when the diameter of the cold cap ball is greater than the diameter of the follower socket. A BeO follower is solid electrical insulating material that does not depend upon a surface coating to obtain electrical insulation as with hardcoated aluminum followers.

Table 2-34

Temperature Drop From Leg Cold Junction to Outer Case

\begin{tabular}{ccc} 
Converter & BOL $\Delta t$ & $\frac{\text { EOL } \Delta t}{47}$ \\
\cline { 2 - 2 } & 56 & 45 \\
EMC-2 & 53 & 21 \\
EMC-3 & 26 &
\end{tabular}


With the selection of $\mathrm{BeO}$ as the follower material, specific design of the follower was initiated. A minimum clearance of .0007 inch between the follower and cold frame from the SNAP-27 program was used as a guide for determining follower diameter. The follower to cold cap temperature test data was used as a guide for dimensioning the follower socket. The specific dimension of the followers were also reviewed with potential vendors. A design configuration was established which could be fabricated to meet the functional requirements.

Several other converter design changes were made based on the experience gained during the fabrication, assembly, and use of the three EMC units.

a. The pressure transducer which had not been satisfactory was removed along with its receptacle and tubing. It was replaced with a pressure gauge. This design provided a rugged, more reliable and less costly sensing device. If the converter was to be subjected to shock and vibration, the pressure gauge would be removed.

b. The external power output wire stress relief junction was revised to incorporate provisions for potting the junction terminal in the event the system assembly and tests to be conducted by Westinghouse should require protection of the terminals. This change would improve system reliability.

c. The support wires which retain the leg compression springs of the thermopile assembly were simplified to reduce component complexity, assembly time, and yet maintain the same degree of inherent reliability as the previous design.

d. The routing of instrumentation wires to the headers and receptacles was changed to keep lead lengths to a minimum, and simplify the wire cable. 
e. The locations of the temperature sensing points internal of the thermopile at the hot and cold junctions were changed to get a better representation of the junction temperatures throughout the thermopile; the number of instrumented points was not changed.

f. The number and location of external temperature sensing thermocouples were changed to obtain a better temperature profile and to eliminate redundancy. These changes were made by $3 \mathrm{M}$ and Westinghouse agreement.

g. The method of attaching the external temperature sensing thermocouples was changed to reduce lead breakage. A method was developed to spot weld the wires in place rather than brazing them.

Prior to receipt of the PIC interface drawing, it was mutually agreed that 3MI would release all PMC component parts not related to couple geometry on the basis that PMC-1 nominal interface dimensions would not change from those identified on Westinghouse drawing 910E413D, the EMC interface drawing. This agreement was necessary so that long-lead time items could be procured to meet the fabrication schedule. However, upon receipt and inspection of the Westinghouse PMC interface drawing, the PIMC interface drawing contained dimensional tolerance requirements not specified before, in addition to previously agreed changes.

As a result of these drawing revisions, a review was made to determine applicability of the prior released converter drawings and usability of finished parts in stock, which were fabricated from these drawings, with the added interface requirements. A report was then submitted to Westinghouse giving data on the dimensions analyzed, location on the interface drawing, recommended change, and an alternate proposal where appropriate. Agreement was reached and a revised interface drawing was issued by Westinghouse. This drawing, plus several additions received by TWX, identified the final interface drawing for converter PMC-1. 
Piece-part dimensions that would affect the interface of the converter with respect to the heat rejection system and the heat source were reinspected if: (1) additional variable data was required, (2) measurement of additional dimensions was required, or (3) the dimensional tolerance was decreased. Prior to this time, fewer dimensions and a lesser amount of variable data was specified on the interface drawing and each part was either rejected or accepted based on the part tolerance, with no recording of variable data on acceptable parts. The additional variable data and additional required dimensional measurements were evaluated by $3 \mathrm{M}$, and a selection was made of the most suitable hot frame, cold frame, and outer case to be used on PMC-1. After completing this evaluation, all measurements on piece parts that would cause a deviation to the interface drawing were submitted to Westinghouse with a recommendation for disposition. Westinghouse concurred with all the recommendations and the parts were "used as deviated".

The thermopile of PMC- 1 was redesigned to incorporate improvements that were available from the technology improvement task and from fabrication and operation of the EMC converters. Material characterization data from the TELPS fixture was used for the first time to design the thermopile.

The couple design was started before performance data from EMC-3 was available. This was necessary because an approximate leg length had to be extablished so that other component designs could be completed and parts could be procured to meet the build schedule.

Westinghouse resolution of the converter-system thermal interface definition (interface temperatures and heat input rejected) was required before finalization of the couple design could be accomplished. Without this thermal definition, the following Design Approach and Design Summary was established for the couple design with recognition that integration of this design with the system would be necessary before the final design release of the thermoelectric couples and of the associated hardware could be completed. 
With the decision to use separately pressed and bonded P-Iegs in PMC-1, SNAP-2 1 devices were also examined for leg performance. It was noted that, in several instances, the measured Seebeck voltage was below theoretical voltage using the TELPS characterization data for the calculations. Since Seebeck voltage affects both the Peltier heat and the load power calculations, the individual leg computer program (in addition to the computer program for determining converter performance) was revised to accept a Seebeck voltage adjustment factor. To learn the effects of Seebeck voltage variation on performance, two converter designs were examined. One design was based on a 0.97 Seebeck ratio ${ }^{1}$ for $P$ - and $N-1$ eg and the other for a normal or 1.00 ratio for each leg; the geometry being optimized in each case. Performance calculations showed that anappreciable power difference may occur when a low Seebeck ratio is not factored into a design. Conversely, when a low Seebeck ratio is used in the design and the actual hardware has a normal Seebeck ratio, both efficiency and power will be higher for the design temperatures; and a fully optimized design is the result. An optimized design is needed when Seebeck ratios are considerably less then 1,00 . The same reasoning can be applied to resistance ratios ${ }^{2}$.

Preliminary designs involving both Seebeck and resistance adjustment factors indicated the leg lengths would not be appreciably longer than those used in the EMC converters. Since leg lengths shorter than those of EMC converters can be easily compensated for by lengthening the cold caps, it was possible to proceed with the design of other converter components.

The design approach used in determining PMC couple geometry, after EMC-3 and system test data became available, involved the worst-case adjustment ratios conditions noted in Table 2-35. These values corresponded to EMC-3 test data which, when compared to the SNAP-21 device data in Table 2-35, showed lower performance. The design conditions upon which PMC was based are listed as follows:

${ }^{1}$ Ratio of measured Seebeck voltage to theoretical voltage.

${ }^{2}$ Ratio of measured resistance including extraneous resistance to theoretical leg material resistance. Theoretical values are from TELPS material characterization data. 
a) $\left(\begin{array}{l}\text { Heat input rate to } \\ \text { converter at EOL }\end{array}\right)=0.782 \quad\left(\begin{array}{c}\text { Heat input rate to } \\ \text { converter at BOL }\end{array}\right)$

b) Hot frame to hot junction $\Delta \mathrm{T}=40^{\circ} \mathrm{F}$

c) Cold junction to fin base $\Delta T=30^{\circ} \mathrm{F}$

d) Minimum power output at $E O L=60.25$ watts at the converter power header

e) Fin heat rejection rate (given by System Contractor - WANL based upon radiator test data):

721 watts at $145^{\circ} \mathrm{F}$ (range $140-150^{\circ} \mathrm{F}$ )

926 watts at $160^{\circ} \mathrm{F}$ (range $155-165^{\circ} \mathrm{F}$ )

Straight lines through these points provide a valid temperature-heat load relationship between the temperatures of 130 and $180^{\circ} \mathrm{F}$. For this design the nominal values were used.

f) Load voltage $=24$ volts

g) Maximum average hot junction temperature $=1080^{\circ} \mathrm{F}$

h) Maximum hot junction temperature $=1100^{\circ} \mathrm{F}$

Design current for conditions other than EOL will be increased to control maximum hot junction temperature until limited by 24 -volt power voltage.

i) Maximum P-leg segment temperature $=600^{\circ} \mathrm{F}$

j) $\quad$ P- and N-leg diameters $=0.1875 \mathrm{inch}$

k) P-leg Seebeck ratio $=0.95$

1) $\quad \mathrm{N}-1$ eg Seebeck ratio $=1,00$ 
m) P-leg resistance ratio $=1.11$

n) $\quad N-1$ eg resistance ratio $=1.05$

o) Shunt heat loss curve with xenon backfill gas is

$$
Q_{L}=0.1714 \Delta T-53.31 \text { (watts) }
$$

The design characteristics for PMC-1 are listed in Tables 2-36 through 2-38. Table 2-36 contains the dimensional and material characteristics; Tables 2-37 and 2-38 contain the performance characteristics for nominal and design case values of Seebeck; resistance ratios are shown in Table 2-35. As noted in Table 2-37, the overall efficiency is 7.74 percent for nominal adjustment values, which are the arithmetical averages of the four thermoelectric devices in Table 2-35.

The total heat input parameter used in the overall efficiency calculation is dependent upon calculated shunt heat loss. A comparison is established between converter total heat input, as determined by a test station heat Ioss analysis and as determined theoretically. Total heat input values are shown in Table 2-39 for the three EMC converters. Shunt heat loss calculations for the EMC converters were based on argon backfill gas and measured hot frame and outer case temperatures. Heat input to each thermopile reflects measured Seebeck and resistance ratios. The differences between test station-determined and theoretical heat inputs ${ }^{1}$ are 21, 3 and 12 watts for converters EMC-1, EMC-2, and EMC-3, respectively.

The parametric performance characteristics of the PIMC design at fixed hot and cold junction temperatures are presented in Figure 2-44, where power output and thermopile efficiency are plotted against load voltage. The family of three curves represents converter performance for Seebeck voltage and resistance

${ }^{1}$ The input is theoretical to the extent that measured Seebeck ratios, resistance ratios, cold junction temperature, hot junction temperature, hot frame temperature, and outer case temperature from the test station were necessary for the theoretical calculation. 
Table 2-35

Seebeck Voltage and Resistance Ratios

\begin{tabular}{|c|c|c|}
\hline \multicolumn{3}{|c|}{ Bonded P-Leg } \\
\hline & Resistance Exp. & Seebeck Exp. \\
\hline & Resistance Calc. & Seebeck Calc. \\
\hline SNAP-21 A10D5 & 1.10 & 0.98 \\
\hline SNAP-21 A10D6 & 0.97 & 0.98 \\
\hline SNAP-21 A10D7 & 1.02 & 0.97 \\
\hline EMC No. 3 & 1.11 & 0.95 \\
\hline Nominal Factor (Avg.) & 1.06 & 0.97 \\
\hline Design Factor (Worst C & Case) 1.11 & 0.95 \\
\hline Best Case & .97 & .98 \\
\hline \multicolumn{3}{|c|}{ Simultaneously Pressed N-Leg } \\
\hline \multicolumn{2}{|r|}{ Resistance Exp. } & Seebeck Exp. \\
\hline & Resistance Calc. & Seebeck Calc. \\
\hline SNAP-23A Mod. 1 & 0.99 & 1.01 \\
\hline EMC No. 1 & 0.96 & 0.99 \\
\hline EMC No. 2 & 0.97 & 1.00 \\
\hline EMC No. 3 & 1.05 & 1.00 \\
\hline Nominal Factor (Avg.) & 0.99 & 1.00 \\
\hline \multicolumn{2}{|c|}{ Design Factor (Worst Case) 1.05} & 1.00 \\
\hline Best Case & .96 & 1.00 \\
\hline
\end{tabular}


Table 2-36. Dimensional and Material Leg Characteristics for 252-Couple PMC Converter

\begin{tabular}{|c|c|c|}
\hline Characteristics & P-Leg & N-Leg \\
\hline $\begin{array}{l}\text { Thermoelectric Material } \\
\text { Hot Segment } \\
\text { Cold Segment }\end{array}$ & $\begin{array}{l}\text { PbTe-SnTe (ES 1110)* } \\
(\mathrm{BiSb})_{2} \mathrm{Te}_{3}(\mathrm{ES} \mathrm{1116)}\end{array}$ & $\begin{array}{l}\mathrm{PbTe}(\mathrm{ES} \mathrm{1103)} \\
\mathrm{PbTe}(\mathrm{ES} \mathrm{1004)}\end{array}$ \\
\hline $\begin{array}{l}\text { Leg Dimensions, in. } \\
\text { Hot Segment Length } \\
\text { Cold Segment Length } \\
\text { Total Leg Length } \\
\text { Diameter }\end{array}$ & $\begin{aligned} \mathrm{L}_{\mathrm{HP}} & =0.198 \\
\mathrm{~L}_{\mathrm{CP}} & =0.127 \\
\mathrm{~L}_{\mathrm{P}} & =0.325 \\
\mathrm{D}_{\mathrm{P}} & =0.1875\end{aligned}$ & $\begin{aligned} \mathrm{L}_{\mathrm{HN}} & =0.299 \\
\mathrm{~L}_{\mathrm{CN}} & =0.161 \\
\mathrm{~L}_{\mathrm{N}} & =0.460 \\
\mathrm{D}_{\mathrm{N}} & =0.1875\end{aligned}$ \\
\hline $\begin{array}{l}\text { Ratio } \\
\text { Cold Segment } \\
\text { length to total } \\
\text { leg length }\end{array}$ & $\frac{\mathrm{L}_{\mathrm{CP}}}{\mathrm{L}_{\mathrm{P}}}=0.39$ & $\frac{\mathrm{L}_{\mathrm{CN}}}{\mathrm{L}_{\mathrm{N}}}=0.35$ \\
\hline $\begin{array}{l}\text { Ratio, in. }{ }^{-1} \\
\text { Leg length/Area }\end{array}$ & $\frac{\mathrm{L}_{\mathrm{P}}}{\mathrm{A}_{\mathrm{P}}}=11.77$ & $\frac{\mathrm{L}_{\mathrm{N}}}{\mathrm{A}_{\mathrm{N}}}=16.66$ \\
\hline Fabrication Method & $\begin{array}{l}\text { Separately pressed } \\
\text { and bonded }\end{array}$ & $\begin{array}{l}\text { Simultaneously } \\
\text { pressed }\end{array}$ \\
\hline
\end{tabular}

*3M material designation 
Table 2-37. Performance Characteristics for 252-Couple PMC Converter with Nominal Adjustment Factors

\begin{tabular}{|l|c|c|c|c|}
\hline \multicolumn{1}{|c|}{ Converter Parameter } & $\begin{array}{c}\text { Termi- } \\
\text { nology }\end{array}$ & Units & BOL & EOL \\
\hline Seebeck ratio, P-Leg & $\mathrm{SR}_{\mathrm{P}}$ & - & 0.97 & 0.97 \\
Seebeck ratio, N-Leg & $\mathrm{SR}_{\mathrm{N}}$ & - & 1.00 & 1.00 \\
Resistance ratio, P-Leg & $\mathrm{RR}_{\mathrm{P}}$ & - & 1.06 & 1.06 \\
Resistance ratio, N-Leg & $\mathrm{RR}_{\mathrm{N}}$ & - & 0.99 & 0.99 \\
Temperature, Cold Junction & $\mathrm{T}_{\mathrm{C}}$ & ${ }^{\circ} \mathrm{F}$ & 190 & 175 \\
Temperature, Hot Junction & $\mathrm{T}_{\mathrm{h}}$ & ${ }^{\circ} \mathrm{F}$ & 1040 & 890 \\
Shunt Heat Loss & $\mathrm{Q}_{\mathrm{L}}$ & Watts & 93 & 69 \\
Total Heat Input & $\mathrm{Q}_{\mathrm{T}}$ & Watts & 996 & 778 \\
Heat to Thermopile & $\mathrm{Q}_{\mathrm{S}}$ & Watts & 903 & 709 \\
Rejected Heat & $\mathrm{Q}_{\mathrm{R}}$ & Watts & 915 & 718 \\
Voltage, Open Circuit & $\mathrm{E}$ & Volts & 50.1 & 39.7 \\
Voltage, Load & $\mathrm{V}_{\mathrm{L}}$ & Volts & 24 & 24 \\
Power Output. & $\mathrm{P}$ & Watts & 80.4 & 60.3 \\
Overall Efficiency & $\mathrm{P}$ & Percent & 8.07 & 7.74 \\
\hline
\end{tabular}


Table 2-38. Performance Characteristics for 252-Couple PMC Converter With Design Case Adjustment Factors

\begin{tabular}{|l|c|c|c|c|}
\hline \multicolumn{1}{|c|}{ Converter Parameter } & $\begin{array}{l}\text { Termi- } \\
\text { nology }\end{array}$ & Units & BOL & EOL \\
\hline \hline Seebeck ratio, P-Leg & $\mathrm{SR}_{\mathrm{P}}$ & - & 0.95 & 0.95 \\
Seebeck ratio, N-Leg & $\mathrm{SR}_{\mathrm{N}}$ & - & 1.00 & 1.00 \\
Resistance ratio, P-Leg & $\mathrm{RR}_{\mathrm{P}}$ & - & 1.11 & 1.11 \\
Resistance ratio, N-Leg & $\mathrm{RR}_{\mathrm{N}}$ & - & 1.05 & 1.05 \\
Temperature, Cold Junction & $\mathrm{T}_{\mathrm{C}}$ & ${ }^{\circ} \mathrm{F}$ & 192 & 177 \\
Temperature, Hot Junction & $\mathrm{T}_{\mathrm{h}}$ & ${ }^{\circ} \mathrm{F}$ & 1080 & 920 \\
Shunt Heat Loss & $\mathrm{Q}_{\mathrm{L}}$ & Watts & 100 & 74 \\
Total Heat Input & $\mathrm{Q}_{\mathrm{T}}$ & Watts & 1034 & 733 \\
Heat to Thermopile & $\mathrm{Q}_{\mathrm{S}}$ & Watts & 934 & 807 \\
Rejected Heat & $\mathrm{Q}_{\mathrm{R}}$ & Watts & 956 & 747 \\
Voltage, Open Circuit & $\mathrm{E}$ & Volts & 52.4 & 41.5 \\
Voltage, Load & $\mathrm{V}_{\mathrm{L}}$ & Volts & 24 & 24 \\
Power Output & $\mathrm{P}$ & Watts & 78.5 & 60.5 \\
Overall Efficiency & $\mathrm{N}$ & Percent & 7.59 & 7.49 \\
\hline
\end{tabular}

Table 2-39. Total Converter Heat Input Comparison at EOL

\begin{tabular}{|c|c|c|c|}
\hline Heat Quantity, Watts & $\begin{array}{l}\text { EMC } \\
\text { No. } 1\end{array}$ & $\begin{array}{r}\text { EMC } \\
\text { No. } 2\end{array}$ & $\begin{array}{l}\text { EMC } \\
\text { No. } 3\end{array}$ \\
\hline A. Total heat to test station & 864 & 860 & 852 \\
\hline B. Test station and miscellaneous losses & 33 & 32 & 28 \\
\hline $\begin{array}{l}\text { C. Total heat to converter as determined } \\
\text { from test station analysis (Heat A - } \\
\text { Heat B) }\end{array}$ & 831 & 828 & 824 \\
\hline $\begin{array}{l}\text { D. Total heat to converter based on } \\
\text { theoretical calculations using } 1967 \\
\text { leg characterization data and latest } \\
\text { shunt heat calculations with argon } \\
\text { backfill gas. Measured temperatures } \\
\text { and adjustment ratios were used in } \\
\text { the calculations. }\end{array}$ & 810 & 831 & 836 \\
\hline
\end{tabular}




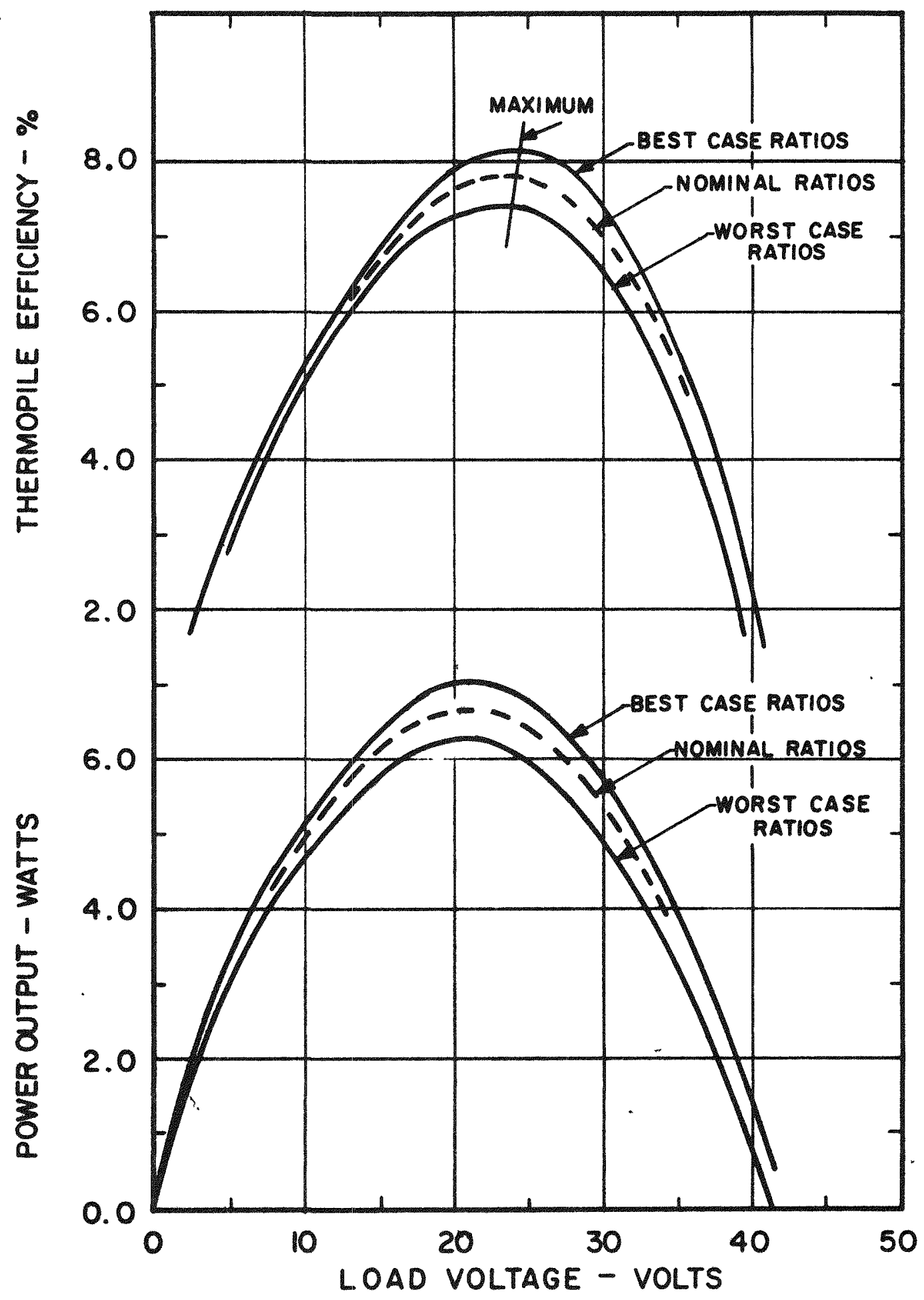

Figure 2-44

SNAP-23A PMC Theoretical Mapping

$$
\mathrm{T}_{\mathrm{c}}=177^{\circ} \mathrm{F}, \mathrm{T}_{\mathrm{h}}=920^{\circ} \mathrm{F}
$$


ratios of Design, Nominal and Best case, as defined in Table 2-35. As can be noted in Figure 2-44, the maximum efficiency ranges from 7.5 percent to 8.2 percent as the ratios range from Design to Best case. Figure 2-44 also shows that the load voltage at maximum efficiency is within the PIC operating band of $24 \pm 1$ volts over the full range of expected Seebeck voltage and resistance ratios.

The sensitivity of PMC performance to independent changes in Seebeck voltage and resistance ratios was also evaluated parametrically with the results shown in Tables 2-40 and 2-41. With design resistance, an improvement in Seebeck voltage is shown in Table 2-40 to increase the load voltage and current at maximum efficiency, which results in higher power output and efficiency at the fixed cold and hot junction temperatures. The effects of change in the resistance ratio are illustrated in Table 2-41 where the major effect is shown to be an increase in current, efficiency and power at maximum efficiency. In addition to illustrating the PMC sensitivity to resistance and Seebeck voltage ratios, Tables $2-40$ and 2-41 show that load voltage at peak efficiency can be expected to fall within the PMC operating band of $24 \pm 1$ volts for any anticipated set of resistance and Seebeck voltage ratios.

Shunt heat loss values for the three Experimental Mockup Converters were adjusted to incorporate measured test temperatures and updated thermal conductivity values for various thermal insulations. The Prototype Mockup Converter shung heat losses were based on both revised thermal conductivity values and operating temperatures. An investigation by $3 \mathrm{M}$, using a combination experimental-analytical procedure, established new thermal conductivity curves for powdered Min-K 1301, molded Min-K 1301, and Microquartz.

The shunt heat losses for the Experimental Mockup Converter series converters and Prototype Mockup Converter design are shown in Table 2-42. To compare the effects of different gases on shunt heat loss, EMC-3 and PMC losses are shown for both argon and xenon gas. EMC-3 used indium foil between the cold cap and follower, thereby enebling the converter to operate within the design temperature differential of $30^{\circ} \mathrm{F}$ maximum between the cold junction and converter outer case. EMC-1 and EMC-2, however, experienced temperature 
Table 2-40. PMC Sensitivity to Seebeck Voltage Ratio*

\begin{tabular}{|l|c|c|c|}
\hline Condition & $\begin{array}{c}\text { Worst Case } \\
\text { Seebeck }\end{array}$ & $\begin{array}{c}\text { Nominal } \\
\text { Seebeck }\end{array}$ & $\begin{array}{c}\text { Best Case } \\
\text { Seebeck }\end{array}$ \\
\hline \hline $\mathrm{T}_{\mathrm{h}}$ & 920 & 920 & 920 \\
$\mathrm{~T}_{\mathrm{C}}$ & 177 & 177 & 177 \\
Seebeck Voltage & 41.5 & 41.9 & 42.1 \\
Load Voltage (Max $\eta)$ & 24.0 & 24.3 & 24.4 \\
Current & 2.51 & 2.54 & 2.55 \\
Power Output & 60.46 & 61.6 & 62.1 \\
Q Input & 807 & 810 & 812 \\
Q Loss & 74 & 74 & 74 \\
Efficiency $(\eta)$ & 7.49 & 7.60 & 7.65 \\
\hline
\end{tabular}

*Design case resistance ratio assumed.

Table 2-41. PMC Sensitivity to Resistance Ratio*

\begin{tabular}{|l|c|c|c|}
\hline Condition & $\begin{array}{c}\text { Worst Case } \\
\text { Resistance }\end{array}$ & $\begin{array}{c}\text { Nominal } \\
\text { Resistance }\end{array}$ & $\begin{array}{c}\text { Best Case } \\
\text { Resistance }\end{array}$ \\
\hline \hline $\mathrm{T}_{\mathrm{h}}$ & 920 & 920 & 920 \\
$\mathrm{~T}_{\mathrm{c}}$ & 177 & 177 & 177 \\
Seebeck Voltage & 41.5 & 41.5 & 41.5 \\
Load Voltage (Max $\eta)$ & 24.0 & 24.1 & 24.2 \\
Current & 2.51 & 2.65 & 2.77 \\
Power Output & 60.46 & 63.7 & 66.7 \\
$Q_{\text {Input }}$ & 807 & 817 & 825 \\
Q $_{\text {Loss }}$ & 74 & 74 & 74 \\
Efficiency $(\eta)$ & 7.49 & 7.80 & 8.08 \\
\hline
\end{tabular}

*Design case Seebeck ratio assumed. 
differentials of $48^{\circ} \mathrm{F}$ at EOL and $57^{\circ} \mathrm{F}$ at BOL with argon gas. Consequently, shunt heat losses for these converters are slightly greater as a result of the lower outer case temperature necessary for establishing the design cold junction temperatures of $174^{\circ} \mathrm{F}$ EOL and $191^{\circ} \mathrm{F}$ BOL. The Prototype Mockup Converter, having been optimized for revised thermal and electrical characteristics, has different operating temperatures; therefore, shunt heat losses are unlike those of the Experimental Mockup Converter losses.

Table $2-42$

Shunt Heat Losses for EMC and PMC Converters

\begin{tabular}{|l|c|c|c|c|}
\hline Device & $\begin{array}{c}\text { BOL Loss } \\
\text { with Argon }\end{array}$ & $\begin{array}{c}\text { BOL Loss } \\
\text { with Xenon }\end{array}$ & $\begin{array}{c}\text { EOL Loss } \\
\text { with Argon }\end{array}$ & $\begin{array}{c}\text { EOL Los } \\
\text { with Xenon }\end{array}$ \\
\hline EMC Nos.1 and 2 & 110 & $\cdots-$ & 79.2 & $\cdots$ \\
EMC No.3 & 106.8 & 100 & 77.2 & 71.1 \\
PMC & 105.7 & 100 & 80.2 & 74.2 \\
\hline
\end{tabular}

As can be observed from Table $2-42$, xenon gas reduces the shunt losses by approximately 6 watts (or 7 percent). The higher cold end temperature differential in EMC-1 and EMC-2 resulted in shunt losses of two to three watts greater than the losses in EMC-3.

After the initial thermopile design for PMC- 1 was completed, parametric studies were made to evaluate the thermoelectric performance of several SNAP-23A PMC designs for several conditions af junction temperature and for a range of normalized thermoelectric performance. The studies included an evaluation of the effects of hot junction temperature at end-of-life to allow an assessment of the overall SNAP-23A system efficiency. The performance improvement resulting from a possibly lower $\Delta \mathrm{T}$ between the cold junction and the outer case through the use of BeO followers was studied. In addition the expected range in normalized thermoelectric performance as measured by 
Seebeck voltage and resistance ratio* observed in SNAP-21 and SNA P-23A units with simultaneously pressed N-legs and separately pressed and bonded P-legs was included in SNAP-23A PMC evaluation.

Three thermopile designs were prepared at end-of-life hot junction temperatures of 920,900 and $880^{\circ} \mathrm{F}$. The $920^{\circ} \mathrm{F}$ design was previously adopted as the SNAP-23 A PIC design since it offers the highest thermopile efficiency but does not exceed the maximum BOL average temperature of $1080^{\circ} \mathrm{F}$. The number of couples and leg geometries for the three designs are listed in Table 2-43.

Each of the three designs was required to produce a minimum of 60.25 watts EOL under Worst-case Seebeck voltage and resistance conditions. In designing the thermopiles, the leg geometry was optimized for maximum efficiency under Worst-case normalized thermopile performance conditions and a load voltage of 24 volts. This design philosophy has the advantage of maximizing thermopile efficiency when it is most needed.

Table $2-43$

SNAP-23A PMC Parametric Design Data Summary

$\begin{array}{lcccc} & & & & \text { Units } \\ \mathrm{T}_{\mathrm{h}}- & 880 & 900 & 920 & { }^{\circ} \mathrm{F} \\ \mathrm{T}_{\mathrm{C}}- & 178 & 177 & 177 & { }^{\circ} \mathrm{F} \\ \mathrm{Couples} & 270 & 260 & 252 & \\ \text { Diameter (N and P) } & 0.1875 & 0.1875 & 0.1875 & \text { inch } \\ \mathrm{N} \text { Total Length } & 0.454 & 0.458 & 0.460 & \text { inch } \\ \mathrm{N} \text { Cold Segment Length } & 0.159 & 0.160 & 0.161 & \text { inch } \\ \mathrm{P} \text { Total Length } & 0.319 & 0.322 & 0.325 & \text { inch } \\ \mathrm{P} \text { Cold Segment Length } & 0.137 & 0.132 & 0.127 & \text { inch }\end{array}$

* The experimental Seebeck voltage and resistances were normalized by comparison to calculated values as determined from TELPS measured characterization data for the same junction temperatures. The calculated value for resistance did not include resistance extraneous to the thermoelectric legs. 
The performance of the $920^{\circ} \mathrm{F}$ design was evaluated at the extreme conditions of normalized thermopile performance (Worst-case and Best-case) and at the Nominal condition. The results, Table 2-44, show the thermopile efficiency, power output, and load voltage at maximum efficiency under fixed hot and cold junction temperature*. Also shown is that the required heat input to maintain the $920^{\circ} \mathrm{F}$ hot junction temperature increases with improved thermoelectric material performance. This means that with a constant heat input, as is the case with an isotope fueled unit, the hot junction temperature would decrease at Nominal and Best-case conditions and would not, therefore exceed the BOL maximum of $1080^{\circ} \mathrm{F}$.

The performance of the $900^{\circ} \mathrm{F}$ hot junction design was also evaluated for the range in expected Seebeck voltage and resistance ratios versus load voltage. The results, presented in Table $2-45$, show a slightly lower converter efficiency than for the $920^{\circ} \mathrm{F}$ design as would be expected for the lower $\Delta \mathrm{T}$. The load voltage at maximum efficiency, Table $2-45$, remains in the $24 \pm 1$ volt operating band, and the heat required to maintain the hot junction temperature increases with improved thermoelectric material performance.

The performance of the $880^{\circ} \mathrm{F}$ hot junction design for the same range in condition is shown in Table 2-46. The comments made for the $900^{\circ} \mathrm{F}$ design apply.

The influence of various combinations of Seebeck voltage and resistance ratios was evaluated on the $920^{\circ} \mathrm{F}$ design. The performance results when Nominal and Best-case Seebeck voltage combine with Worst-case resistance and when Nominal and Best-case resistance combine with Worst-case Seebeck voltage are presented in Table 2-47. The results show that load voltage at maximum efficiency remains within $24 \pm 1$ volt for all conditions.

* The cold junction temperature is such that the heat rejected is matched to the fin capability when the $\Delta T$ between the cold junction and the fin base is $30^{\circ} \mathrm{F}$ and when the Seebeck and resistance ratios are Worst-case. 
Table 2-44

SNAP-23A Converter PMC Theoretical Design

for EOL Conditions of $T_{c}=1770 F$ and $T_{h}=9200 F$ (Worst Case)

MAXTMUM EFFICIENCY

\begin{tabular}{|c|c|c|c|c|}
\hline & Woret & Nominal & Best & Unit \\
\hline Seebeck & 41.5 & 41.9 & 42.1 & Volts \\
\hline Load Voltage & 24 & 24.4 & 24.6 & Volts \\
\hline Load Current & 2.51 & 2.67 & 2.80 & Amps \\
\hline Power Output & 60.46 & 64.8 & 68.5 & Watts \\
\hline Q Input & 807 & 819 & 830 & Watts \\
\hline Q Loss & 74 & 74 & 74 & Watts \\
\hline Efficiency & 7.49 & 7.91 & 8.25 & Perce \\
\hline
\end{tabular}

BOL CONDITION

\begin{tabular}{|c|c|c|}
\hline & Worst & \\
\hline $\mathrm{r}_{\mathrm{h}}$ & 1080 & ${ }^{\circ} \mathrm{F}$ \\
\hline$T_{2}$ & 192 & ${ }^{\circ} \mathrm{F}$ \\
\hline Secbock & 52.4 & Volts \\
\hline Load Voltage & 24 & Volts \\
\hline Power. Output & 78.5 & Watts \\
\hline Ampul & 1032 & Watts \\
\hline Q Loss & 100 & Watts \\
\hline Efficiency & 7.59 & Percen \\
\hline
\end{tabular}


Table $2-45$

SNAP-23A Converter Theoretical Performance for EOL Conditions of $\mathrm{T}_{\mathrm{c}}=1770 \mathrm{~F}$ and $\mathrm{T}_{\mathrm{h}}=9000 \mathrm{~F}$ (Worst Case)

\begin{tabular}{lccccc} 
& \multicolumn{5}{c}{ MAXIMUM EFFICIENCY } \\
& Worst & Nominal & Best & Units \\
Seebeck & 41.3 & & 41.7 & 41.9 & Volts \\
Maximum Load Voltage & 24 & 24.4 & 24.5 & Volts \\
Load Current & 2.51 & 2.66 & 2.80 & Amps \\
Power Output & 60.3 & 64.6 & 68.4 & Watts \\
Q Inputs & 811.6 & 823 & 835 & Watts \\
Q Loss & 70.6 & 70.6 & 70.6 & Watts \\
Efficiency & 7.43 & 784 & 8.19 & Percent
\end{tabular}

BOL CONDITION

Worst

$T_{h}$

$T_{\mathrm{c}}$

Seebeck

Load Voltage

Power Output

Q Input

Q Loss

Efficiency
1055

192

52.3

24

78. 7

1038

95

7. 58
Units

${ }^{\circ} \mathrm{F}$

${ }^{\circ} \mathrm{F}$

Volts

Volts

Watts

Watts

Watts

Percent 
Table 2-46

SNAP-23A Converter PMC Theoretical Performance for EOL Conditions of $T_{c}=178^{\circ} \mathrm{F}$ and $T_{h}=880^{\circ} \mathrm{F}$ (Worst Case)

MAXIMUM EFFICIENCY

Worst Nominal Best Units

Seebeck
Maximum Load Voltage
Load Current
Power Output
Q Input
Q Loss
Efficiency

4139

41. 80

$420 \quad$ Volts

24

24.36

$24.6 \quad$ Volts

2. 53

2. 67

2. 79 Amps

60.4

64. 7

68. 4

Watts

821

833.8

844

Watts

67

67

67

Watts

7. 35

7. 76

8. 10

Percent

\section{BOL CONDITION}

$\begin{array}{lcc} & \frac{\text { Worst }}{1030} & \frac{\text { Units }}{\mathrm{T}_{\mathrm{h}}} \\ \mathrm{o}_{\mathrm{C}} \mathrm{F} \\ \text { Seebeck } & 192 & { }^{\circ} \mathrm{F} \\ \text { Load Voltage } & 52.4 & \text { Volts } \\ \text { Power Output } & 24 & \text { Volts } \\ \text { Q Input } & 79 & \text { Watts } \\ \text { Q Loss } & 1050 & \text { Watts } \\ \text { Efficiency } & 91 & \text { Watts }\end{array}$


Table 2-47

Effect of Conditions on EOL Performance

$\left(\mathrm{T}_{\mathrm{c}}=1770 \mathrm{~F}\right.$ and $\left.\mathrm{T}_{\mathrm{h}}=920^{\circ} \mathrm{F}\right)$

SEEBECK VOLTAGE

\begin{tabular}{|c|c|c|c|c|}
\hline Condition & $\begin{array}{c}\text { Worst Seebeck } \\
\text { Worst Resistance }\end{array}$ & $\begin{array}{l}\text { Nominal Seebeck } \\
\text { Worst Resistance }\end{array}$ & $\begin{array}{c}\text { Best Seebeck } \\
\text { Worst Resistance }\end{array}$ & Units \\
\hline $\mathrm{T}_{\mathrm{h}}$ & 920 & 920 & 920 & ${ }^{\circ} \mathrm{F}$ \\
\hline $\mathrm{T}_{\mathrm{c}}$ & 177 & 177 & 177 & ${ }^{\circ} \mathrm{F}$ \\
\hline Seebeck & 41.5 & 41.9 & 42. 1 & Volts \\
\hline $\begin{array}{c}\text { Max. } \eta \text { Load } \\
\text { Voltage }\end{array}$ & 24 & 243 & 24.4 & Volts \\
\hline Load Current & 2.51 & 2. 54 & 2.55 & Amps \\
\hline Power Output & 60.46 & 61.6 & 62.1 & Watts \\
\hline Q Input & 807 & 810 & 812 & Watts \\
\hline Q. Loss & 74 & 74 & 74 & Watts \\
\hline Efficiency & 7.49 & 7. 60 & 7.65 & Percer \\
\hline
\end{tabular}

RESISTANCE

Condition

$\mathrm{T}_{\mathrm{h}}$

$\mathrm{T}_{\mathrm{c}}$

Seebeck

Max. $\eta$ Load Voltage

Load Current

Power Output

Q Input

Q Loss

Efficiency
Worst Seebeck Worst Resistance

920

177

41.5

24

2. 51

60.46

807

74

7. 49
Worst Seebeck Nominal Resistance

920

177

41. 5

24. 1

2. 65

63. 7

817

74

7. 80
Worst Seebeck

Best Resistance Units

920

${ }^{\circ} \mathrm{F}$

177

${ }^{\circ} \mathrm{F}$

41. 5

Volts

24. 2

Volts

2. 77

Amps

66. 7

Watts

825

Watts

74

Watts

8. 08

Percent 
Table 2-48 illustrates how thermopile performance can be expected to react to a lower cold end $\Delta T$. The condition selected was an assumed $\Delta T$ between the cold junction and fin base of $20^{\circ} \mathrm{F}$ rather than the present design value of $30^{\circ} \mathrm{F}$. The thermopile performance results show that both hot and cold junction temperatures would decrease by $10^{\circ} \mathrm{F}$ and the power output and thermopile efficiency would increase.

The results of these parametric studies were evaluated from a systems integration standpoint. While the results did provide a description of performance as a function of the variables studied, the design of the PMC-1 thermopile was not changed from the initial design described by Table $2-36$.

Table $2-48$

Influence of Cold End $\triangle T$ Between Cold Junction and Fin Base

(Fixed Design at Worst Case)

\begin{tabular}{lccc} 
Condition & $\Delta \mathrm{T}-30^{\circ} \mathrm{F}$ & $\Delta \mathrm{T}-20^{\circ} \mathrm{F}$ & Units \\
\cline { 2 - 4 } $\mathrm{T}_{\mathrm{h}}$ & 920 & 910 & ${ }^{\circ} \mathrm{F}$ \\
$\mathrm{T}_{\mathrm{c}}$ & 177 & 167 & ${ }^{\circ} \mathrm{F}$ \\
Seebeck & 41.5 & 41.1 & Volts \\
Max. $\eta$ Load Voltage & 24 & 23.8 & Volts \\
Load Current & 251 & 258 & Amps \\
Power Output & 6046 & 61.0 & Watts \\
Q Input & 807 & 808 & Watts \\
Q Loss & 74 & 74 & Watts \\
Efficiency & 7.49 & 7.55 & Percent
\end{tabular}




\subsection{Summary of Converter Design}

The PMC converter design was a continuation of EMC design. It incorporated many of the EMC design features which had contributed to the success of the EMC series. Changes were made to PMC from the EMC design to:

- Improve efficiency

- Increase reliability

- Incorporate field service capability

- Integrate with latest system interface definition

- Produce more useful performance data

To achieve these goals, the following specific design changes and features were incorporated into the design:

A. Thermoelectric P-leg was fabricated of separately pressed and bonded segments.

B. Thermopile was designed for maximum efficiency at EOL conditions.

C. Thermopile design was computed with use of Seebeck and resistance ratio which described Worse-case thermoelectric material characteristics to assure that the converter would produce a minimum rated power of 60.25 watts.

D. Parametric studies were conducted to integrate converter design with the system interface.

E. Incorporation of $\mathrm{BeO}$ followers.

F. Revised locations for both internal and external temperature instrumentation.

G. Power output terminal could be sealed by potting for weather proofing. 


\subsection{Fabrication}

Further weld development was required to improve the weld at the lower coverhot frame joint; specifically to assure a weld with minimum "roll over" toward the inside of hot frame and to produce a weld that would assure a structurally sound converter. The weld "roll over" on previous converters had violated the stud area interface boundary even when the as-machined piece parts met print dimensional tolerances. Also, the development was to determine if a tolerance of \pm .025 could be held on the diameter in the weld area.

Sample parts which duplicated the part configuration in the weld area were fabricated. The variables during this development were the part configuration, the chill block, weld speed, and heat input. The samples were welded and then subjected to annealing at converter operating temperatures. They were then measured for weld "roll over" and change in diameter. After these measurements were made the samples were sectioned to check weld penetration. A weld schedule and chill block design evolved from this development that met all requirements.

Components were procured for building two PMC units, PMC-1A and PMC-1B. Raw material was ordered from preliminary prints to reduce the procurement time. The final release of prints for the components with long-lead procurement times was accomplished on January 15, 1968, and all piece parts required for the start of subassembly work were completed on May 20, 1968. 
Assembly PIMC-1A

Assembly was started on PMC-1A first; as this converter was scheduled to be mated with the heat source system at Westinghouse, the best parts for system integration were selected for this unit. The cold frame and hot frame components were given particular attention during parts selection. The hot frame mates directly onto the stud of the system, so the hot frame which would result in the best fit was selected for PMC-1A; the cold frame outer diametrical surface has an influence on the physical dimensions of the shrunk-on outer case, thus the cold frame which would yield the best converter interface dimensions was used for PMC-1A.

PMC-1A subassembly work was completed without incident on May 25, 1968. Assembly of the unit proceeded according to plan without difficulties and was completed on June 24, 1968.

The weld of the hot frame to the lower cover was completed satisfactorily; a hermetic seal was achieved and the lower hot frame diameter was held to diametrical tolerance zone. Figure 2-45 shows PMC-1A after assembly was completed. Figure 2-46 shows PMC-1A on the station for leak checking prior to processing. After phy sical assembly the converter was completed and processing was started. During processing an electrical short developed between the thermoelectric circuit and ground. The short was isolated and identified as one of the diagnostic voltage tap wires which was in the area where the wire passed over an edge of the cold frame. For corrective action the short was burned open by $I^{2} R$ heating, and an external voltage tap wire was installed so that all diagnostic measurements could be made during testing.

\subsection{Quality Control PMC-1A}

Inspection of components to assure the quality of the device was conducted per the same basic plan as was used for previous converters. In addition, a plan was prepared for the inspection of all components which had an influence on the thermal-mechanical interface with the heat source system. There were two separate parts to this plan. 


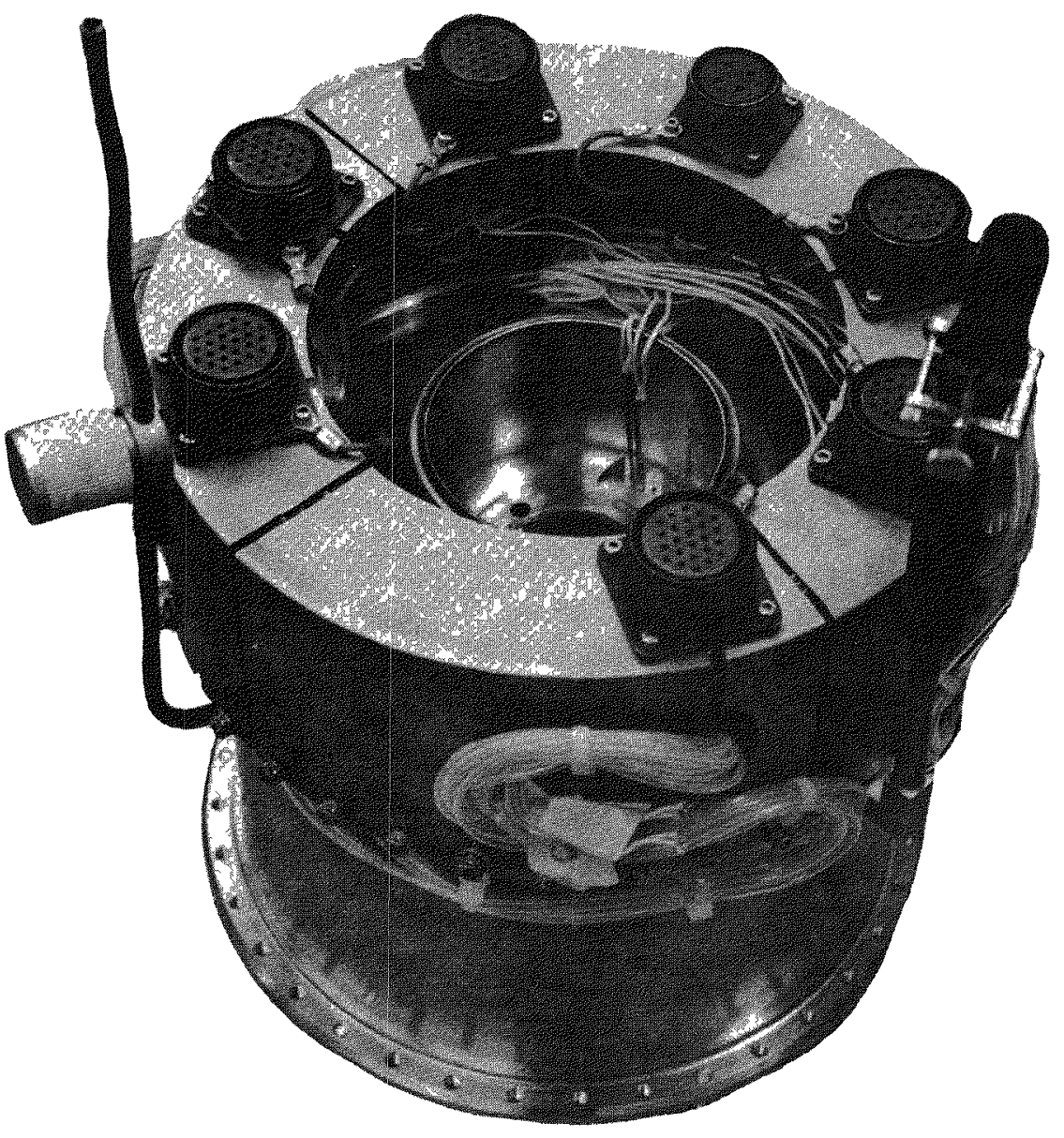

Figure 2-45

Top View of Assembled SNAP-23A Converter PMC-1A Showing Support Cone Weld 


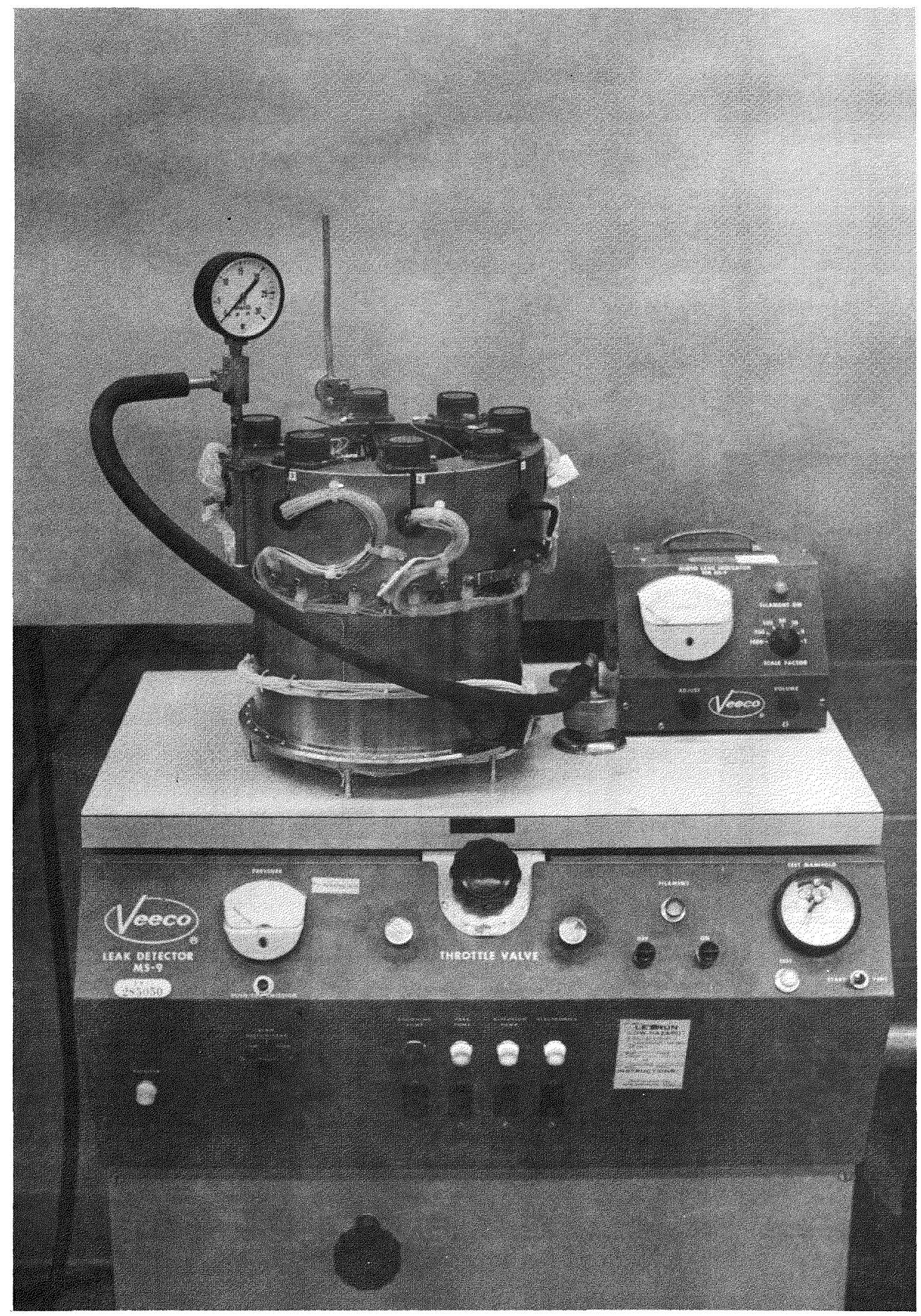

Figure 2-46

Assembled SNAP-23A PMC-1A Converter on Leak Detector Station 
A. Inspection to determine if any component dimensions were out-of-tolerance in areas that would cause the converter interface dimensions to be out-of-tolerance.

B. Inspection of components to determine the extent of component distortion in system interface zones during assembly, welding, and operation of the converter on the test station.

The first part of the plan was reviewed and accepted by Westinghouse. During the inspection of interface dimensions of components, the out-of-tolerance conditions were reviewed and accepted by Westinghouse before the component was used for device build. The second part of the plan was reviewed and approved by $3 \mathrm{M}$ Design Engineering. During the inspection of components, variable inspection data was recorded for those profiles which would affect converter interface dimensions. Converter interface dimensions were inspected and variable data recorded at several points during assembly. This data was turned over to Design Engineering for analysis.

\subsection{Initial Performance PMC-1A}

PMC-1A was placed on test while mounted on the converter process station. Initial performance measurements were made to determine how well the converter met design objectives and to establish a base line to which future performance could be compared. Initial performance of PIC-1A is shown by Table $2-49$.

\section{Table 2-49}

SNAP-23A Converter PMC-1A Initial Performance

\begin{tabular}{lrr} 
& \multicolumn{2}{c}{ Operating Conditions } \\
\cline { 2 - 2 } & $\underline{B O L}$ & $\underline{\text { EOL }}$ \\
Hot Junction Temperature, ${ }^{\circ} \mathrm{F}$ & 1081 & 922 \\
Cold Junction Temperature, ${ }^{\circ} \mathrm{F}$ & 190 & 177 \\
Power Output, Watts (e) & 90.5 & 67.2 \\
Converter Efficiency, $\%$ & 8.6 & 8.1 \\
Hot Frame-Hot Junction $\Delta t,{ }^{\circ} \mathrm{F}$ & 46 & 40 \\
Cold Junction-Outer Case $\Delta t,{ }^{\circ} \mathrm{F}$ & 40 & 35
\end{tabular}


The initial performance of PMC-1A as listed by Table $2-49$ shows that both the power output and efficiency met and exceeded design goals 60.25 watts power output and $7.7 \%$ efficiency). This was also a considerable improvement over the performance of the EMC series of converters. The improved initial performance was due to reduced electrical resistance and good Seebeck voltage characteristics. Table $2-50$ shows the Seebeck and resistance ratios; the Seebeck ratio was 0.98 , which was within the design range of 0.98 to 0.99 . The resistance ratio was 0.95 for BOL, which was below the design range of 0.97 to 1.08 ; this low resistance ratio contributed to increased power output and efficiency. As PMC-1A continued to operate on the test station during the stability conditioning period its performance improved due to decreasing circuit resistance. The temperature drop from leg cold junction to outer case was slightly greater than the design value of $30^{\circ} \mathrm{F}$. Detailed data on the initial performance of PIMC-1A is included in SNAP-23A Quarterly Report No. 7.

\subsection{Disposition - PIMC-1A}

Initial PMC-1A thermal and thermoelectric performance was evaluated on the test station at $3 \mathrm{M}$. After 508 hours of operation, PMC-1A was removed from the test station at $3 M$ and shipped to Westinghouse where the converter was mated with the SNAP23-A EMS (Engineering Mock-up System) for Iong-term evaluation. During this system evaluation testing PMC-1A performed without difficulties. A total of 14,778 operating hours was accumulated on PMC-1A while mated to the system. After PMC-1A was removed from the system, it was returned to $3 \mathrm{M}$ for post-system performance evaluation on the 3M test station, where it was operated up to the time of contract termination. PMC-1A operated for a total of 15,400 hours. Detailed long-term performance data is presented in Section 5.0 of this report. 
Table $2-50$

SNAP-23A Converter PMC-1A Performance Data

(Ratio of Experimental-to-Theoretical Values)

\begin{tabular}{|c|c|c|c|c|c|c|}
\hline \multirow{2}{*}{} & \multicolumn{3}{|c|}{ Seebeck Ratio } & \multicolumn{3}{c|}{ Resistance Ratio* } \\
\cline { 2 - 6 } & EOL & BOL & Design & EOL & BOL & Design \\
\hline \hline Couple - Initially at 195 hours & 0.98 & 0.98 & $0.98-0.99$ & 0.98 & 0.95 & $0.97-1.08$ \\
at 508 hours & $(0.99)$ & & & $(0.96)$ & \\
Typical N-Leg - Initially at 195 hours & 1.01 & 1.00 & 1.00 & 0.95 & 0.94 & $0.96-1.05$ \\
at 508 hours & $(1.01)$ & & & $(0.96)$ & & \\
Typical P-Leg - Initially at 195 hours & 0.96 & 0.97 & $0.95-0.98$ & 1.02 & 0.96 & $0.97-1.11$ \\
at 508 hours & $(0.98)$ & & & $(0.96)$ & & \\
\hline
\end{tabular}

*The theoretical resistance values include only $\mathrm{T} / \mathrm{E}$ material resistance. 


\subsection{Assembly - PMC-1B}

Manufacturing documentation was updated for PMC-1B after assembly of PMC-1A was completed. All the major components were fabricated as part of the two-sets for PMC-1 converters. The residual parts were evaluated to determine acceptability for build of PMC-1B. The requirements of PMC-1B were not as stringent as for PMC-1A as the unit did not have to meet the thermal and mechanical requirements for system interface. The components were accepted based on their suitability for a converter to be subjected to long-term performance evaluation in the $3 \mathrm{M}$ laboratory. The residual cold frame had a number of follower holes which were oversized, which would have the adverse effect of increasing the temperature drop from the cold junction to the outer case. To control this temperature drop, half of the thermopile was assembled with indium foil between the follower and cold cap as was done for EMC-3.

During the normal quality control inspection of the hot junction electrodes, it was observed that the plating had blistered which was cause for rejection. The subsequent investigation indicated that this blistering was caused by the oxygen content of the copper base material. Material was available from the SNAP-21 program which had a lower oxygen content and would not blister. New hot junction electrodes were made for PIMC-1B from this SNAP-21 copper.

Assembly of PMC-1B started on September 26, 1968, and proceeded without difficulty except during final closure welding. During this operation a small crack was discovered in the parent metal of the support cone near the outer flange. This crack was sealed by welding after the cone was welded in place. The crack apparently was in the part prior to welding so the inspection technique for leaks was revised for subsequent converters. After physical assembly was complete the converter was mounted on the test station for processing. Processing was completed on October 25, 1968, and the unit was delivered to test for initial performance evaluation. 


\section{3 .3 .2 .8 Quality Control - PMC-1B}

The updated manufacturing flow plan for PMC-1B was reviewed for changes and appropriate adjustments made to the inspection plan. The inspection for basic quality control was very similar to that conducted during the building of previous converters. Additional inspection was done in the following areas:

A. The cold frame follower holes were $100 \%$ inspected with an air gage and variable data was recorded on out-of-tolerance holes.

B. Variable data measurements were recorded on the cold caps and followers which were to be installed at the instrumented couple locations.

C. Variable data measurements were taken on components which contributed to interface dimensions. The interface dimensions were measured and data recorded between various steps of assembly.

The purpose of this increased inspection activity was to compliment the test data to provide engineering with a base for tolerance relaxation.

\subsection{Initial Performance - PMC-1B}

PMC-1B was placed on test while mounted on the converter processing test station. Initial performance measurements were made to determine how well the converter met performance objectives and to establish a base line to compare future performance. Initial performance of PMC-1B is shown by Table 2-51.

The initial performance of PMC-1B as listed in Table 2-51 shows that both power output and efficiency exceeded design objectives $(60.25$ watts power output and $7.7 \%$ efficiency). While the performance of PMC-1B was better than design objectives it did not perform as well as PIC-1A This is largely attributed to PMC-1A being made of selected parts and PMC-1B of residual parts. Table 2-52 is a tabulation of the resistance and Seebeck voltages for PMC-1B. From this table it can be seen that the resistance ratios were at the low end of the design 
Table $2-51$

SNAP-23A Converter PMC-1B Initial Performance

\begin{tabular}{rr}
\multicolumn{2}{c}{ Operating Conditions } \\
\hline BOL & EOL \\
1081 & 920 \\
192 & 176 \\
86.2 & 63.8 \\
8.27 & 7.74 \\
51 & 45 \\
37 & 31
\end{tabular}

Table 2-52

SNAP-23A Converter PMC-1B Initial Performance Data

(Ratio of Experimental-to-Theoretical Values)

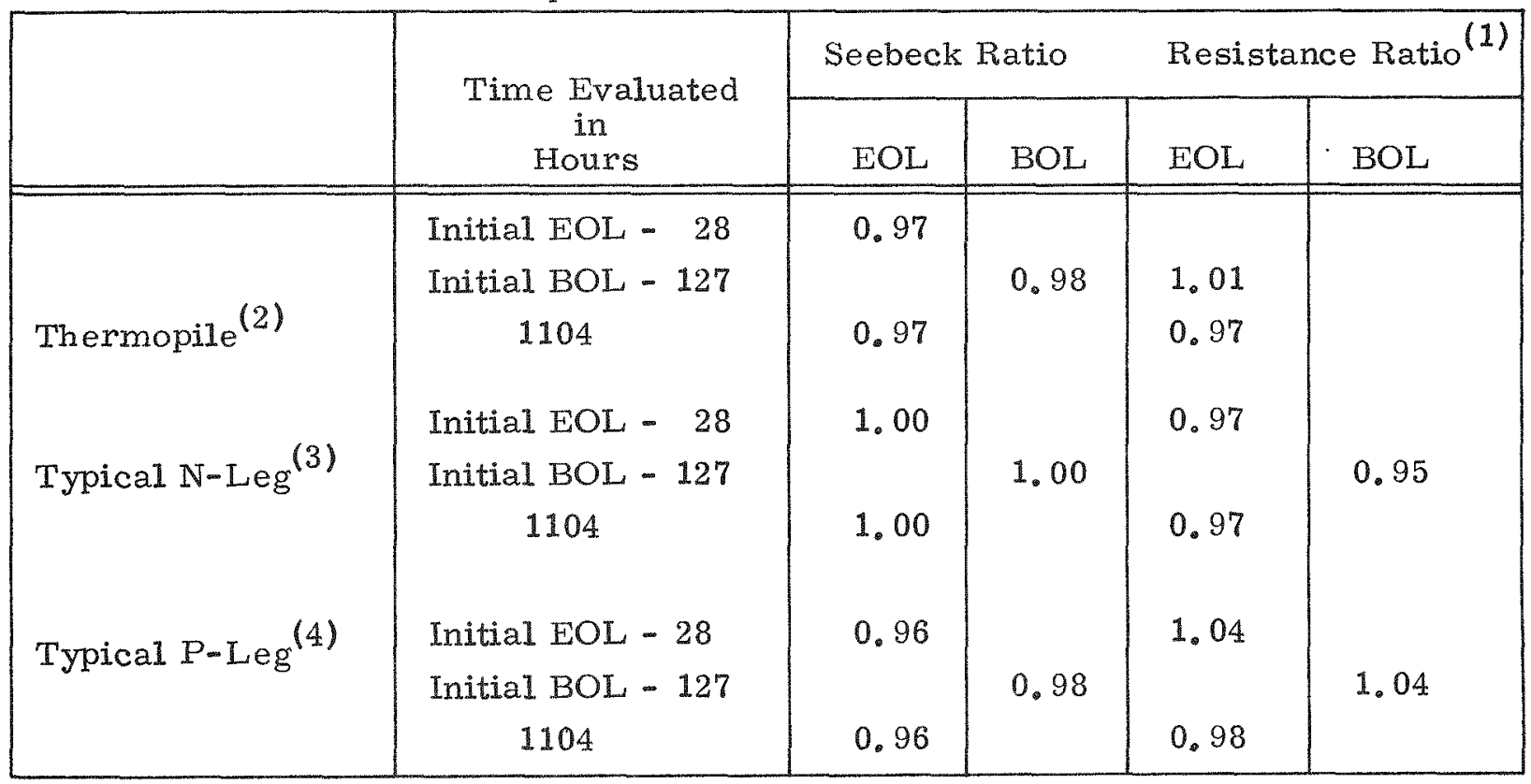

(1) The theoretical resistance values include only $\mathrm{T} / \mathrm{E}$ material resistance.

(2) Design Value

(3) Design Value

${ }^{(4)}$ Design Value
Seebeck Ratio

$0.98-0.99$

1.00

$0.95-0.98$
Resistance Ratio
$0.97-1.08$
$0.96-1.05$
$0.97-1.11$ 
range, improving performance. However, the Seebeck ratios were also at the low end, or below design values, which has the effect of reducing performance. Also included in Table 2-52 are resistance ratios after an operating period of 1104 hours. After this operating period the electrical resistance had decreased, further improving the performance. Detail and data on the initial performance of PMC-1B is included in SNAP-23A Quarterly Report No.8.

The cold junction to outer case (Tc-Toc) temperature drop data is summarized by Table 2-53. In addition to PMC-1B data, data is listed for PMC-1A and EMC-3 for comparative purposes. This data shows that the use of indium foil was effective in reducing the temperature drop at the cold end.

Off-design cold junction temperature tests were also conducted with PMC-1B. The cold junction temperature was both increased and decreased $20^{\circ} \mathrm{F}$ from the normal EOL temperatures. The data from these tests is listed in Table 2-54. The tests were conducted to determine how PMC-1B converter would perform at the different cold junction temperatures for system integration parametric studies.

\section{3 .3 .2 .10 Disposition - PMC-1B}

After initial performance evaluation, $P M C-1 B$ was kept on the test station at $3 \mathrm{M}$ for long-term thermal and thermoelectric performance evaluation. During this period data was recorded on a regular basis. A summary of long-term performance data is included in Section 5.0

After PMC-1B had been on test for 8842 hours it failed. The failure occurred suddenly without any advance warning. Early in the day of failure a complete set of performance data was taken which gave no indication of the impending failure; the performance appeared normal when compared to previous data. The failure was an open circuit in the thermopile electrical circuit. Tests made with a 100 volt Megger indicated no shorts to ground and an internal open circuit condition between Rows 4 and 8 of the thermopile. The resistance of the series circuit was greater than 20 megohms. 
Table 2-53

SNAP-23A Converter Cold End Heat Transfer Data

\begin{tabular}{|c|c|c|c|c|}
\hline $\begin{array}{c}\text { Converter } \\
\text { No. }\end{array}$ & Cold End Design & $\begin{array}{l}\text { Time } \\
\text { Evaluated } \\
\text { in Hours }\end{array}$ & $\begin{array}{c}\text { Test } \\
\text { Condition }\end{array}$ & 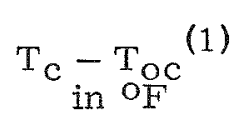 \\
\hline PMC-1B & $\begin{array}{l}\text { BeO Followers, Xenon Gas, } \\
\text { Indium Foil, and No Grease }\end{array}$ & $\begin{array}{c}28 \\
126.5 \\
1104 \\
1540 \\
\end{array}$ & $\begin{array}{c}\text { Initial EOL } \\
\text { Initial BOL } \\
\text { EOL } \\
\text { BOL }\end{array}$ & $\begin{array}{l}27 \pm 9 \\
30 \pm 11 \\
26 \pm 10 \\
32 \pm 13\end{array}$ \\
\hline PMC-1B & $\begin{array}{l}\text { BeO Followers, Xenon Gas, } \\
\text { and No Grease }\end{array}$ & $\begin{array}{c}28 \\
126.5 \\
1104 \\
1540\end{array}$ & $\begin{array}{c}\text { Initial EOL } \\
\text { Initial BOL } \\
\text { EOL } \\
\text { BOL }\end{array}$ & $\begin{array}{l}36 \pm 7 \\
42 \pm 7 \\
31 \pm 7 \\
37 \pm 10\end{array}$ \\
\hline$P M C-1 A$ & $\begin{array}{l}\text { BeO Followers, Xenon Gas, } \\
\text { and No Grease }\end{array}$ & $\begin{array}{l}47.5 \\
195 \\
750 \\
900\end{array}$ & $\begin{array}{c}\text { Initial EOL } \\
\text { Initial BOL } \\
\text { EOL } \\
\text { BOL }\end{array}$ & $\begin{array}{l}36 \pm 11 \\
40 \pm 14 \\
29 \pm 5 \\
36 \pm 7\end{array}$ \\
\hline $\mathrm{EMC}-3$ & $\begin{array}{l}\text { Aluminum Followers, Grease, } \\
\text { Argon Gas, and Indium Foil }\end{array}$ & $\begin{array}{c}11.5 \\
41 \\
6100 \\
6200\end{array}$ & $\begin{array}{c}\text { Initial EOL } \\
\text { Initial BOL } \\
\text { EOL } \\
\text { BOL }\end{array}$ & $\begin{array}{l}21 \pm 12 \\
26 \pm 16 \\
25 \pm 13 \\
29 \pm 15\end{array}$ \\
\hline
\end{tabular}

${ }^{(1)} T_{C}-T_{O C}=$ Average cold junction temperature minus average outer case temperature. 
Table 2-54

SNAP-23A Converter PMC-1B Performance Data

for

Off-Design Temperatures

(EOL Conditions)

\begin{tabular}{|c|c|c|c|c|c|}
\hline Parameter & Symbol & Units & $\begin{array}{l}\text { Cold Junction } \\
\text { Temperature } \\
\text { Reduced } 20^{\circ} \mathrm{F}\end{array}$ & $\begin{array}{l}\text { Cold Junction } \\
\text { Temperature } \\
\text { Increased } 20^{\circ} \mathrm{F}\end{array}$ & $\begin{array}{l}\text { Nominal } \\
\text { Cold Junction } \\
\text { Temperature }\end{array}$ \\
\hline Power Output & $P_{0}$ & Watts (e) & 69.6 & 61.4 & 65.8 \\
\hline Open Circuit Voltage & $\mathrm{E}$ & Volts & 41.9 & 40.8 & 41.2 \\
\hline Load Voltage & $\mathrm{V}_{1}$ & Volts & 24.0 & 24.0 & 24.0 \\
\hline Load Current & $I_{1}$ & Amperes & 2.90 & 2.56 & 2.74 \\
\hline Internal Resistance & $\mathrm{R}_{\mathrm{g}}$ & Ohms & 6.17 & 6.44 & 6.28 \\
\hline \multicolumn{6}{|l|}{ Temperatures } \\
\hline Hot Frame & $T_{h f}$ & ${ }^{\circ} \mathrm{F}$ & 964 & 962 & 965 \\
\hline Hot Junction & $\mathrm{T}_{\mathrm{h}}$ & ${ }^{\circ} \mathrm{F}$ & 920 & 920 & 922 \\
\hline Cold Junction & $\mathrm{T}_{\mathrm{C}}$ & ${ }^{\circ} \mathrm{F}$ & 157 & 197 & 178 \\
\hline Outer Case & $T_{\text {oc }}$ & ${ }^{o} F$ & 126 & 166 & 147 \\
\hline Gross Power Input & $P_{t}$ & Watts $(t)$ & 898 & 841 & 870 \\
\hline
\end{tabular}


The operating records of PMC-1B were examined and two over-termperature excursions had occurred.

A. At 1400 test hours, a cooling water blockage caused the cold electrode temperature to exceed $225^{\circ} \mathrm{F}$ for a period of approximately 40 minutes during which the cold electrode temperature reached a peak of $350^{\circ} \mathrm{F}$.

B. At 2200 test hours, a line voltage regulator malfunction caused a 25 percent increase in input power. As a result of this, the hot electrode temperature exceeded $1100^{\circ} \mathrm{F}$ for a period of 14 hours during which a maximum of approximately $1300^{\circ} \mathrm{F}$ was achieved.

While it is known that elevated temperature does accelerate certain types of reactions which could cause a failure, there is no way of determining to what extent the two over-temperature excursions contributed to the PMB-1B failure.

Radiographic analysis was conducted to gain additional information about the nature of the open circuit and its exact location. Radiographs were taken of Rows $3,4,5,6,7,8,9,20,30$, and 39. The top six legs in Row 5 had what appeared as a "halo" around the legs. All other rows appeared normal. It was concluded that failure was not of the type which could be alleviated by corrective action external to the converter.

The converter was disassembled for further analysis. From visual observation it was obvious that the legs from Rows 5 and 16 had been involved in a massive chemical reaction. Typical appearance can be seen in the photographs of Figures $2-47$ and $2-48$. The $N$-legs involved in the chemical reaction had a greatly increased diameter of copper colored residue at the middle of the leg. The hot ends were white with various degrees of distortion. The P-legs in the reaction zone appeared to have increased in diameter and had an orange colored ring at the cold end. The hot junction electrodes in the reaction zone had lost various amounts of the copper by the reaction. In the extreme cases sufficient copper was lost that only the protective plating remained. It was when this protective plating broke that the circuit opened in Row 5. 


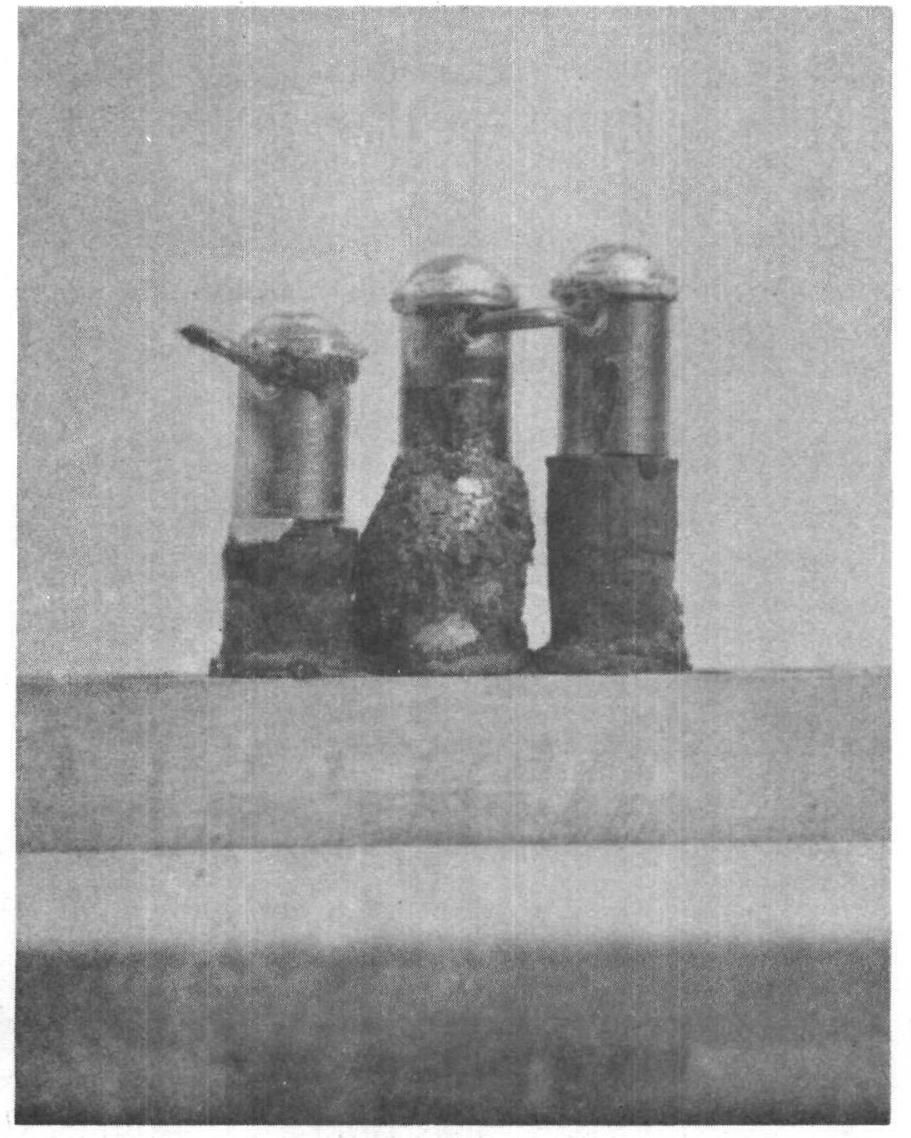

Figure 2-47

SNAP-23A Converter PMC-1B Thermoelectric Legs from Row 16 (Legs A8 through A10 from right to left) 


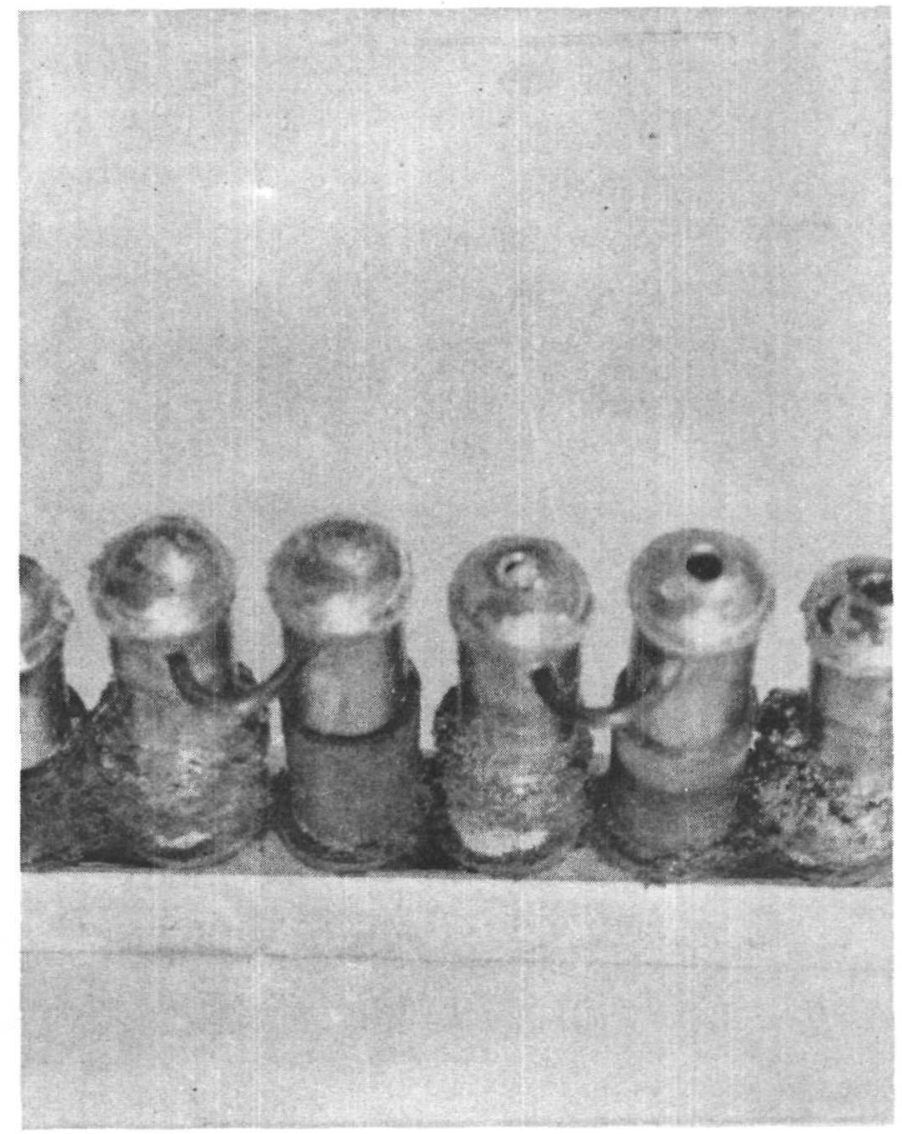

Figure 2-48

SNAP-23A Convert PMC-1B Thermoelectric Legs from Row 16 
A failure analysis was conducted. Each leg, hot junction electrode, and hot junction button was carefully examined to determine the cause of failure. Chemical analysis and sample mounting were conducted with components from critical areas. The chemical analysis verified that the reaction occurred between the copper of the hot junction electrodes and the thermoelectric materials. Some nodules were found on the hot segment of the N-legs. Analysis of a nodule gave no indication that these nodules were initiating the destructive chemical reaction. Two nodules were also found protruding up from the hot junction electrodes. Chemical analysis of these two nodules showed that they contained copper but no lead telluride. There was no evidence that these nodules did contribute to the failure. One inverted P-leg, (hot segment bonded to cold cap and cold segmented contact to the hot junction button) was found in Rows 5 and 16 in the reaction zone. Most of the cold segment thermoelectric material had melted causing the P-leg to be reduced in length. It has been established that this melted cold segment $P$ material would initiate the type of failure reaction observed in this converter. It was concluded that the failure of PIC-1B was caused by several P-legs being assembled in the inverted position in Rows 5 and 16. 


\subsubsection{PMC -2 Converter}

PMC -2 was the third major iteration in converter design configuration because of a change in requirements. PMC - 2 was required to be capable of, or be adaptable for, field service use. Changes needed to be made from PMC -1 design so that the converter could be operated under the service conditions of a salt water corrosive atmosphere (a possible field service condition). This converter would also incorporate the best converter design features and technology developed up to this time. As it was desirable to have PMC-2 usable as a laboratory test converter, it was designed to be convertible; initially to be built with diagnostic instrumentation required for laboratory testing, but the actual converter could be modified with a minimum of changes to prepare it for field service by removing the diagnostic instrumentation.

\subsection{Design Activities}

The initial step in the design of PMC - 2 was to determine what changes in physical configuration, if any, would be required. After a study of several different configurations, the one shown in part by Figure 2-49 appeared the most advantageous. The top portion of the converter would be covered by a weather tight enclosure. The power output leads would come out of the converter through hermetically-sealed headers into this top enclosure. The power output wires would exit from the top enclosure through a weather tight fitting. The entire converter structure-enclosure would be fabricated of Inconel j25. This material was selected because test data show ed it to have superior stress corrosion resistance when over 304 SS in a salt water atmosphere; however, a complete enclosure of Inconel 625 was not acceptable for system integration as the outer enclosure of the heat stud was 304 SS and there was no way that this stud could be mated to an Inconel 625 hot frame without excessive temperature drops occurring. 3M investigated the possibility of designing a converter enclosing case of composite materials with some portions made of 304 SS and others of Inconel 625. Initial calculations showed this was feasible and this approach was pursued.

The outside diamtere (dimension) of the converter at the system radiator interface became a concern when it was required to establish an upper limit on 
Figure 2-49

SNAP-23A Converter/System

Electrical Interface Concept

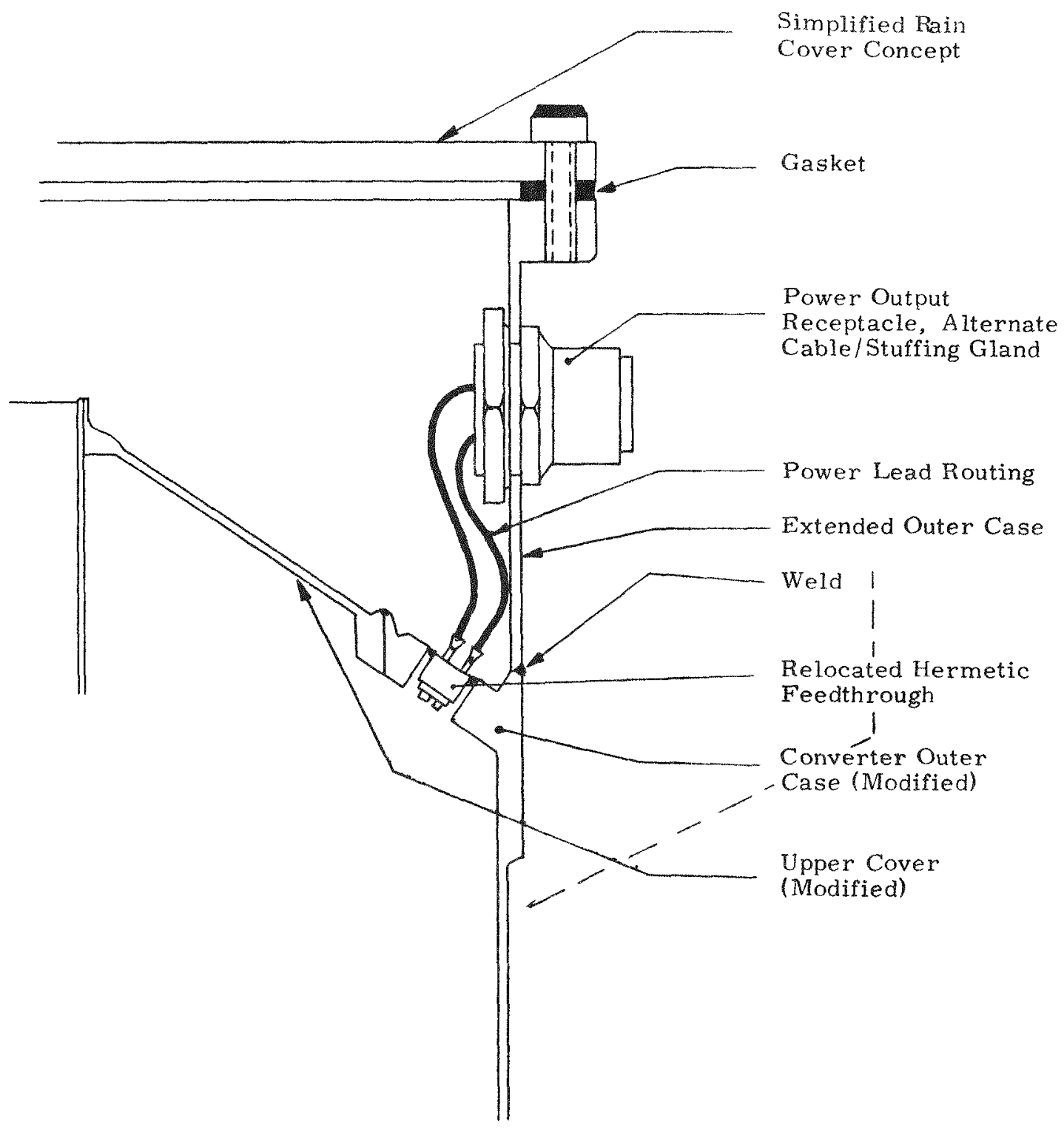


the hot junction temperature. This temperature limit would be selected to achieve maximum converter output at the end of ten years, with consideration for degradation of the thermoelectric materials. The current converter outer diameter was based on a 280 couple complement. Any restriction on the upper hot junction temperature may require additional couples, and thus an increase in cold frame diameter. The determination of design parameters for PMC - 2 required an extensive degradation analysis and parametric thermopile design study.

The thermopile design study was started with the determination of Seebeck and resistance ratios to be used for the calculations. The design ratios were determined from all thermoelectric converters which had operated with similar thermoelectric technology to that planned for PMC -2. The technology for PMC -2 would be the same as used for PMC -1; simultaneously pressed N-leg, separately pressed and bonded $\mathrm{P}-\mathrm{leg}, 250$ psi contact pressure, iron hot junction buttons, Xenon backfill gas, and Min-K-1301 thermal insulation. The applicable data used to establish design values for Seebeck and resistance ratios is shown by Table $2-55$. The design ratio values show $n$ on this table were selected such that if Seebeck and resistance of legs used to build PMC -2 would be the extreme adverse values, the converter would still produce rated power output (worst case design). Other design inputs were established as follows:

$\begin{array}{ll}\text { Power Output } & 61 \text { watts minimum at end of } \\ & 10 \text { years } \\ \text { Load Voltage } & 24 \\ \text { Load Current } & \begin{array}{l}\text { Variable so the load voltage is } \\ 24 \text { throughout operating life }\end{array} \\ \text { Maximum Number of Couples } & 280 \\ \text { Axial Temperature Gradient } & 30^{\circ} \mathrm{F} \\ \quad \text { of Heat Sink } & \text { As supplied by WA NL } \\ \text { Heat Source Change } & \\ \quad \text { with Time } & 35^{\circ} \mathrm{F@BOL} \\ \text { Cold End Temperature Drop } & 30^{\circ} \mathrm{F} @ \text { EOL } \\ \text { Heat Sink Characteristics } & \text { As supplied by WANL }\end{array}$


Table 2-55

SNAP -2 3A Converter PIMC -2 Thermopile Design

Adjustment Ratios

Design Values:*
N-Leg Simultaneously Pressed
$\frac{R_{x} / R_{c}}{1.00}$
$\mathrm{E}_{\mathrm{x}} / \mathrm{E}_{\mathrm{C}}$
P-Leg Bonded
1.03
1. 00
0.96

Data Base:

N-Leg Simultaneously Pressed

\begin{tabular}{|c|c|c|}
\hline Device & $\mathrm{R}_{\mathrm{x}} / \mathrm{R}_{\mathrm{c}}$ & $\mathrm{E}_{\mathrm{x}} / \mathrm{E}_{\mathrm{c}}$ \\
\hline SNAP-23A Moc. 1 & 0.99 & 1.00 \\
\hline EMC - 1 & 0.96 & 0.99 \\
\hline EMC -2 & 0.97 & 1.00 \\
\hline EMC -3 & 1.00 & 1.01 \\
\hline PMC - $1 \mathrm{~A}$ & 0.96 & 1. 01 \\
\hline Average & 0.98 & 1.00 \\
\hline Maximum & 1.00 & 1.01 \\
\hline Minimum & 0.96 & 0.99 \\
\hline \multicolumn{3}{|c|}{ P-Leg Bonded } \\
\hline$\underline{\text { Device }}$ & $\mathrm{R}_{\mathrm{x}} / \mathrm{R}_{\mathrm{c}}$ & $\mathrm{E}_{\mathrm{x}} / \mathrm{E}_{\mathrm{c}}$ \\
\hline EMC -3 & 1.03 & 0.96 \\
\hline$P M C-1 A$ & 0.96 & 0.98 \\
\hline SNAP -21 A 10D6 & 0.97 & 0.98 \\
\hline SNAP-21 A 10D8 & 1.00 & 0.96 \\
\hline Average & 0.99 & 0.97 \\
\hline Maximum & 1.03 & 0.98 \\
\hline Minimum & 0.96 & 0.96 \\
\hline
\end{tabular}

*Adjustment ratios are selected so that if variables which effect thermoelectric performance are pessimistic, the thermoelectric converter will produce the minimum required power output. 
The cold end temperature drop values of $35^{\circ} \mathrm{F}$ at BOL and $30^{\circ} \mathrm{F}$ at EOL are different from those values used for previous converter designs. The cold end heat transfer system was configured as follows:

- Nickel plated cold caps

- Indium foil between cold cap and follower

- BeO followers

- Aluminum cold frame

- No heat transfer grease at any interface

- Backfill gas of Xenon

The determination of the design temperature drop values was based on data recorded during the operation of previously built converters. This data is tabulated in Table $2-53$.

Design Parameters were determined for five different maximum hot junction temperatures ranging from $1020^{\circ} \mathrm{F}$ to $1100^{\circ} \mathrm{F}$. This range of hot junction temperatures was selected on the basis of initial degradation analysis results which indicated that maximum EOL power output would be associated with Th in this range. The tabulated data describing these five designs is shown by Table 2-56. This table shows the trends in performance as the hot junction temperature decreases. Table 2-57 displays supplementary data related to these five thermopile designs. One additional set of design parameters was prepared for the $1020^{\circ} \mathrm{F}$ maximum hot junction temperature case to determine to what extent efficiency was effected by limiting the number of couples to a maximum of 280. Maximum efficiency at this hot junction temperature would require 290 couples. Tabulated data in Table 2-58 shows that 290 couples would produce a predicted EOL efficiency of 7.63 percent compared to 7.61 percent for the design constrained to 280 couples. The small gain in efficiency for the 290-couple design confirm that the converter would not need to be increased in size to accommodate greater than 280 couples.

As part of parametric studies for system integration, the influence of ambient temperature on converter performance was calculated for PMC -2 Designs 4 and 5. The calculations were made at fixed EOL power output with the cold junction temperatures raised 10,20 and $30^{\circ} \mathrm{F}$ above the reference values. 
Table $2-56$

SNAP-23A Converter PMC-2 Thermopile

Design Characteristics

\begin{tabular}{|c|c|c|c|c|c|}
\hline \multirow{2}{*}{\multicolumn{6}{|c|}{ Geometry }} \\
\hline & & & & & \\
\hline Number of Couples & 258 & 266 & 274 & 280 & 280 \\
\hline N-Leg Length & 0.486 & 0.482 & 0.479 & 0.466 & 0.430 \\
\hline N-Leg Cold Segment Length & 0.170 & 0.169 & 0.168 & 0.163 & 0.150 \\
\hline P-Leg Length & 0.366 & 0.363 & 0.359 & 0.355 & 0.352 \\
\hline P-Leg Cold Segment Length & 0.143 & 0.142 & 0.140 & 0.138 & 0.137 \\
\hline
\end{tabular}

BOL Temperatures

Average Hot Frame

Maximum Hot Junction

Average Hot Junction

Average Cold Junction

Outer Case

EOL Temperatures

Average Hot Frame

Average Hot Junction

Average Cold Junction

Outer Case

BOL Performance

Efficiency

Power Output

Heat Input

Resistance

Open Circuit Voltage

Load Voltage

EOL Performance

Efficiency

Power Output

Heat Input

Resistance

Open Circuit Voltage

Load Voltage

$\begin{array}{rrrrr}1132 & 1112 & 1092 & 1072 & 1052 \\ 1100 & 1080 & 1060 & 1040 & 1020 \\ 1082 & 1062 & 1042 & 1022 & 1002 \\ 194 & 195 & 195 & 196 & 197 \\ 159 & 160 & 160 & 161 & 162\end{array}$

959

914

174

144

943

898

175

145

927

882

175

145

911

866

176

146
7. 86

78.9

78.3

994

9.20 1004

9.17

54.01

24

7.90
61.2
775
7.18
42.32
24

7.83

61.3

783

7.20

42.39

24
7. 81

79.2 1013

9. 14

54. 17

24

7. 76

61.4

790

7. 20

42.41

24

\section{84}

80.2 1022

8.90

53. 73

24

7. 69

61.3

797

7. 05

42.01

24
895

850

176

146

\section{2}


Table 2 -57

SNAP-23A Converter PMC-2 Thermopile Design

Supplemental Data

$\underline{\text { Design } 1} \quad \underline{\text { Design } 2} \quad$ Design $3 \quad$ Design $4 \quad$ Design 5

Shunt Heat Loss*
BOL - Watts
98.9
95.3
91.9
88.3
84.7
EOL - Watts
73.5
70.6
67.9
65.0
62.2

Computer Program Adjustments $* *$
Heat Input - Watts
12
12
14
14
13
Power Output - Watts
0.37
0.33
0.40
0.30
0.19

Leg Adjustment Factors

N-Leg Seebeck Voltage - 1.00

P-Leg Seebeck Voltage -......... 0.96

N-Leg Resistance -................ 1.00

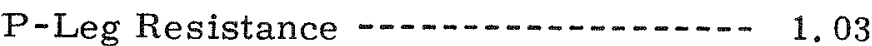

*Shunt Heat Loss $=0.1714 \times\left(\mathrm{T}_{\mathrm{h}}-\mathrm{T}_{\mathrm{c}}\right)-53.31$

** Listed Heat Input and Power Output values were subtracted from PRAM-01 computer program results to obtain PRAM-03 computer program results. 
Table 2-58

Modilied SNAP-23A Converter PMC-2

Thermopile Design

Geometry

Design 5a

Number of Couples

290

$\mathrm{N}$-Leg Length

0.442

$N$-Leg Cold Segment Length

0.155

P-Leg Length

0.376

P-Leg Cold Segment Length

0.147

BOL Temperatures

Average Hot Frame

1052

Maximum Hot Junction

1020

Average Hot Junction

1002

Average Cold Junction

197

Outer Case

162

EOL Temperatures

Average Hot Frame

895

Average Hot Junction

850

Average Cold Junction

176

Outer Case

146

BOL Performance

Efficiency

7. 77

Power Output

79.5

Heat Input

1023

Resistance

9.04

Open Circuit Voltage

54.0

Load Voltage

24

EOL Performance

Efficiency

7. 63

Power Output

61.2

Heat input

802

Resistance

7. 14

Open Circuit Voltage

42.2

Load Voltage

24 
The results are presented in Table 2-59 together with the reference-temperature results. It can be noted that the hot junction temperature increased 20 percent to 30 pexcent more than the cold junction temperatures when EOL power output is maintained. Even so, the conversion efficiency is only slightly lower at the increased ambient temperatures.

It was established that the maximum cold junction temperature at which the SNAP -23A converter can operate is $225^{\circ} \mathrm{F}$; this value is based on test data from converters 23P-1 and EMC -3, and from tests conducted to determine the $\mathrm{P}-\mathrm{leg}$ bond integrity. For converter $23 \mathrm{P}-1$, the hottest measured cold electrode had experienced a temperature of $210^{\circ} \mathrm{F}$ averaged over 9600 test hours, and had operated for short periods of up to $230^{\circ} \mathrm{F}$. During long-term testing, converter EMC -3 experienced a cold side temperature excursion during which the cold electrode temperature exceeded $225^{\circ} \mathrm{F}$ for less than onehalf hour. No noticeable effect on performance occurred as indicated by the test data. A review of prior related research data on cold end structures of similar configuration indicated that the $\mathrm{P}-\mathrm{leg}$ bond integrity is not impaired by exposure to temperatures above $225^{\circ} \mathrm{F}$ for short periods of time (approximately 200 hours). The test data was considered sufficient to support $225^{\circ} \mathrm{F}$ as an acceptable maximum cold electrode temperature, but not sufficient to establish a higher maximum temperature for extended periods of time.

Table 2-59 shows the cold junction temperature exceeds the maximum cold junction temperature limit of $225^{\circ} \mathrm{F}$ by a few degrees. Westinghouse indicated the new radiator design would perform more efficiently and thereby reduce the cold junction temperature by approximately $10^{\circ} \mathrm{F}$. This would prevent the cold junction temperature from exceeding $225^{\circ} \mathrm{F}$ under any circumstance in ambient temperatures up to $100^{\circ} \mathrm{F}$.

The degradation study was conducted after the thermopile designs for five different hot junction temperatures and the parametric thermopile studies were completed. The result of the study was a computer code which would calculate converter power output as a function of time in addition to a function of temperature. It was developed so that the thermoelectric leg thermal conductivity and electrical resistivity would change as a function of thermoelectric material sublimation which is a function of both time and temperature. The results of 
Table $2-59$

SNAP-23A Converter PMC-2

Increased Ambient Temperature Data

\begin{tabular}{|c|c|c|c|c|c|c|}
\hline $\begin{array}{c}\text { Ambient } \\
\text { Temp. } \\
\text { Rise } \\
\text { OF }\end{array}$ & $\begin{array}{c}T_{c j}^{(1)} \\
\text { Average } \\
\text { OF }\end{array}$ & $\begin{array}{c}\mathrm{T}_{\mathrm{hj}}^{(2)} \\
\text { Average } \\
\text { OF }\end{array}$ & $\begin{array}{c}\mathrm{T}_{\mathrm{hj}} \\
\text { Maximum } \\
\text { oF }\end{array}$ & $\begin{array}{l}\text { Heat } \\
\text { Input* } \\
\text { Watts }(t)\end{array}$ & $\begin{array}{l}\text { Output } \\
\text { Power** } \\
\text { Watts (e) }\end{array}$ & $\begin{array}{c}\text { Converter } \\
\text { Efficiency } \\
\text { Percent }\end{array}$ \\
\hline \multicolumn{7}{|c|}{ Design $4-$ EOL Conditions } \\
\hline 0 & 176 & 866 & 884 & 797 & 61.3 & 7.69 \\
\hline 10 & 186 & 878 & 896 & 801 & 61.3 & 7.65 \\
\hline 20 & 196 & 890 & 908 & 806 & 61.3 & 7.61 \\
\hline 30 & 206 & 902 & 920 & 810 & 61.3 & 7.57 \\
\hline \multicolumn{7}{|c|}{ Design $4-$ BOL Conditions } \\
\hline 0 & 196 & 1022 & 1040 & 1022 & 80.2 & 7.84 \\
\hline 10 & 206 & 1035 & 1053 & 1027 & 79.5 & 7.74 \\
\hline 20 & 216 & 1049 & 1067 & 1033 & 78.8 & 7.63 \\
\hline 30 & 226 & 1062 & 1080 & 1038 & 78.0 & 7.51 \\
\hline \multicolumn{7}{|c|}{ Design 5 - EOL Conditions } \\
\hline 0 & 176 & 850 & 863 & 803 & 61.1 & 7.61 \\
\hline 10 & 186 & 861 & 879 & 806 & 61.1 & 7.58 \\
\hline 20 & 196 & 873 & 891 & 810 & 61.2 & 7.56 \\
\hline 30 & 206 & 884 & 902 & 813 & 61.1 & 7.52 \\
\hline \multicolumn{7}{|c|}{ Design 5 - BOL Conditions } \\
\hline 0 & 197 & 1002 & 1020 & 1030 & 81.6 & 7. 92 \\
\hline 10 & 207 & 1015 & 1033 & 1033 & 81.0 & 7.84 \\
\hline 20 & 217 & 1027 & 1045 & 1038 & 80.2 & 7.73 \\
\hline 30 & 227 & 1040 & 1058 & 1042 & 79.5 & 7.63 \\
\hline
\end{tabular}

*Based on PRAM-03 Computer Program and the Added Correction Factor.

${ }^{(1)} \mathrm{T}_{\mathrm{cj}}=$ Cold junction temperature

${ }^{(2)} \mathrm{T}_{\mathrm{hj}}=$ Hot junction temperature 
this study as applied to PMC -2 is shown by Figure 2-50. From the curve of efficiency vs BOL maximum hot junction temperature, it can be seen that maximum efficiency (or maximum power output) would be achieved with an initial BOL maximum hot junction temperature between $1020^{\circ} \mathrm{F}$ and $1060^{\circ} \mathrm{F}$. Design 4 as listed in Table 2-56 was selected for PMC -2. This design was based on BOL maximum hot junction temperature of $1040^{\circ} \mathrm{F}$. With a specific thermopile design, number of couples and couple geometry, selected additional parametric studies were conducted for systems integration. The following variables were included in this study.
A. Ambient temperatures of $70^{\circ} \mathrm{F}$ and $100^{\circ} \mathrm{F}$.
B. Heat input variation of \pm 24 watts at EOL and \pm 31 watts at BOL.
C. Seebeck and resistance adjustment ratios for Design, Nominal and Best cases.

Two other changes were incorporated into the initial Design 4 study. These changes were a heat input bias of plus 20 watts and a system heat sink characteristics change based on radiator redesign. The revised heat sink characteristics and other input data for this parametric study is shown in Table 2-60. The parametric study was conducted $w i t h$ the thermopile analysis computer code and the results are shown by Tables 2-61,2-62 and 2-63.

The change to Inconel 625 outer case and change in detailed configuration of the structure required component design revision, stress analysis, and weld development. Figure 2-49 shows the preliminary configuration of the upper portion of the converter which was changed from PMC - 1 to PMC -2 design. This preliminary configuration was given careful study before the detail design of the individual components was initiated. There were several disadvantages or problems associated with the configuration shown by Figure $2-49$.

a. The outer case would be difficult and costly to machine with the upper conical section.

b. It would be difficult to attach the cold frame to the outer case. 
Figure 2-50

SNAP-23A Converter Long-Term Performance vs

Hot Junction Temperature

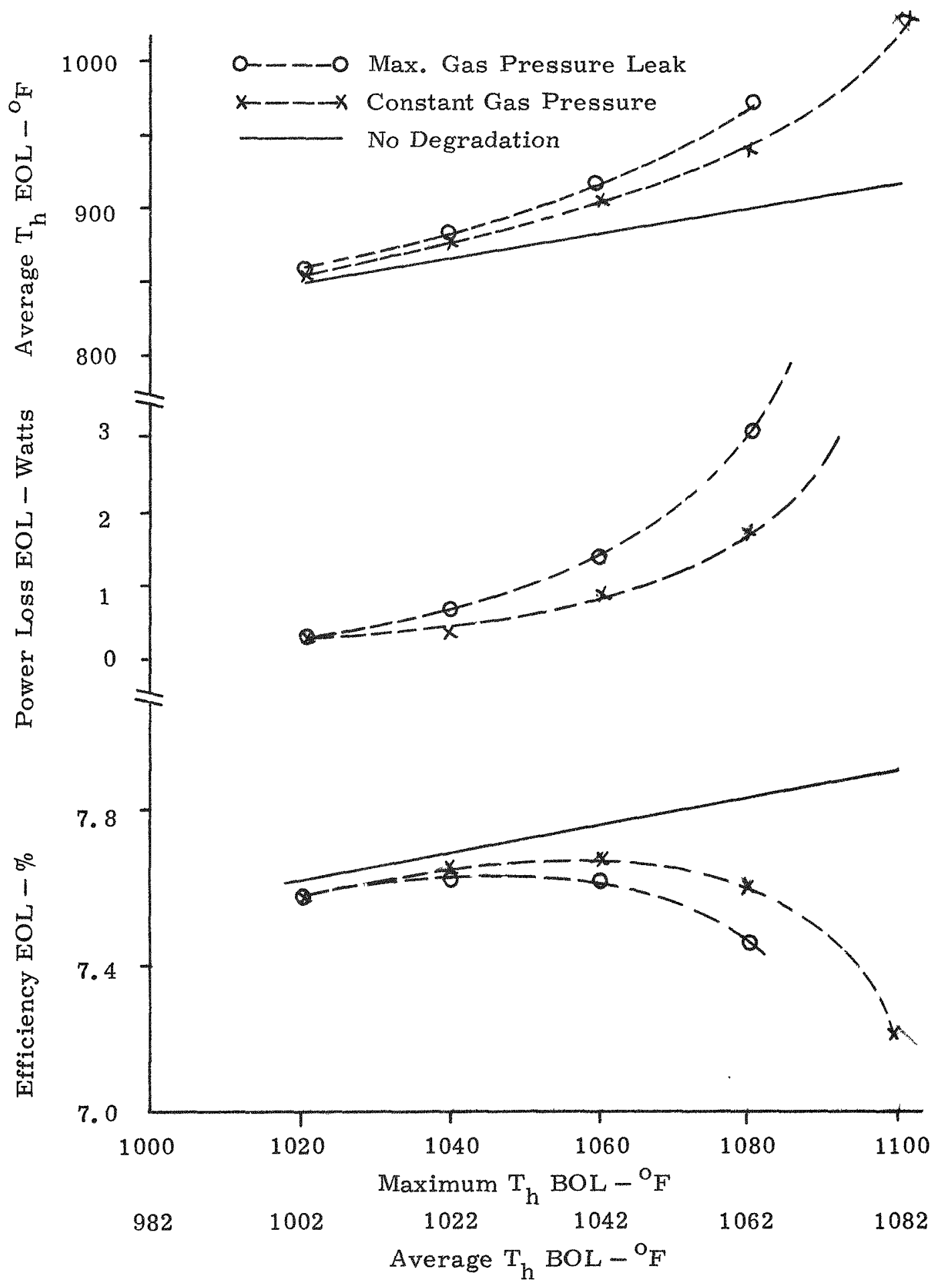


Table $2-60$

Thermoelectric Characteristics

THER MOELECTRIC ADJUSTMENT FACTORS

Resistance Ratios

$\begin{array}{lccc} & \text { Design } & \frac{\text { Nominal }}{0.98} & \frac{\text { Best }}{0.96} \\ \text { P-Leg } & 1.00 & 0.99 & 0.96\end{array}$

Seebeck Voltage Ratios

$\begin{array}{cccr} & \frac{\text { Design }}{1.00} & \frac{\text { Nominal }}{1.00} & \frac{\text { Best }}{1.00} \\ \text { N-Leg } & .96 & .97 & .98\end{array}$

SNAP -2 3A Converter PMC -2

Heat Sink Characteristics

Q Rejected

720 Watts

925 Watts
Fin Base Temperature

$\begin{array}{cc}\frac{70^{\circ} \mathrm{F} \text { Ambient }}{138^{\circ} \mathrm{F}} & \frac{100^{\circ} \mathrm{F} \text { Ambient }}{168^{\circ} \mathrm{F}} \\ 151^{\circ} \mathrm{F} & 181^{\circ} \mathrm{F}\end{array}$

SNAP -2 3A Converter PMC -2 Thermoelectric Couple Geometry
Number of Couples

N-Leg Length

N-Leg Cold Segment Length

P-Leg Length

P-Leg Cold Segment Length

$\mathrm{N}$ - and P-Leg Diameter
280

.466 Inches

.163 Inches

.355 Inches

.138 Inches

.1875 Inches 
Table 2-61

SNAP-23A Converter PIC -2 Parameter Study Minimum Heat Input $\mathrm{C}$ ase*
DESIGN ADJUSTMENT FACTORS $70^{\circ} \mathrm{F}$ Ambient $100^{\circ} \mathrm{F}$ Ambient

\section{BOL TEMPERATURES $\left({ }^{\circ} \mathrm{F}\right)$}

Average Hot Frame

Maximum Hot Junction

Avimum Hot Junction

Average Hot Junction

Outer Case

\section{EOL TEMPERATURES $\left({ }^{\circ} \mathrm{F}\right)$}

Average Hot Frame

Average Hot Junction

Average Cold Junction

Outer Case

1040
1008
990
185
150

1069

1037

1019

215
180

NOMINAL ADJUST MENT FACTORS $70^{\circ} \mathrm{F}$ A mbient $100^{\circ} \mathrm{F}$ Ambient

BEST ADJUSTMENT FACTORS

$70^{\circ} \mathrm{F}$ Ambient $100^{\circ} \mathrm{F}$ Ambient

\section{BOL PERFORMANCE}

Efficiency $(\eta)$

Power Output (watts, e)

Resistance (ohms)

Open Circuit Voltage (volts)

7. 74

78.4

8.47

886
841
168

168
138

914
869

869
198

168

1033
1001
983
185
150

1033
1001
983

185
150

1062

1030

1012

215
180

881

836

167
137

909
864

864
198

168

7. 95

7.95
80.5

80.5
8.16

51.4

7.64

7. 44

9.11
52.6

77.4

8.78
52.3

\section{EOL PERFORMANCE}

\section{Efficiency $(\eta)$}

Power Output (watts, e)

Resistance (ohms)

7. 39

58.4

6.73

40.4
7. 25
57. 3
7.26

7.26
41.3
7. 58

59.9

6.50

40.2
7.43
58.7

58.7
7.01

41.2

$877 \quad 905$

832

$\begin{array}{ll}167 & 197 \\ 137 & 167\end{array}$

8. 14

82.5

7. 89

7. 83

79.3

8. 49

52.1

7. 75

61.2
6.30

6.30
40.1

7. 61

60.1

6.80

41.0

$\begin{array}{rr}1027 & 1056 \\ 995 & 1024 \\ 977 & 1006 \\ 185 & 215 \\ 150 & 180\end{array}$

$*$ Load Voltage $=24 \mathrm{~V}, \mathrm{Q}$ Input BOL $=1013$ Watts $(t), \mathrm{Q}$ Input EOL $=790$ Watts $(t)$ 
Table 2-62

SNAP -23A Converter PMC -2 Parameter Study

Reference Heat Input Case*

DESIGN ADJUSTMENT FACTORS NOMTNAL ADJUSTMENT FACTORS

$100^{\circ} \mathrm{F}$ Ambient

$70^{\circ} \mathrm{F}$ A mbient

BOL TEMPERATURES $\left({ }^{\circ} \mathrm{F}\right)$

Average Hot Frame

Maximum Hot Junction

Average Hot Junction

Average Cold Junction

Outer Case

$\begin{array}{rr}1061 & 1090 \\ 1029 & 1058 \\ 1011 & 1040 \\ 187 & 217\end{array}$

1090
1058
1040
217

217
182

1054
1022
1004
187
152

$100^{\circ} \mathrm{F}$ Ambient

EOL TEMPERATURES $\left({ }^{\circ} \mathrm{F}\right)$

\section{Average Hot Frame}

Average Hot Junction

Average Cold Junction

Outer Case

902

802

169

139

930
885

885
199

169

7. 70

80.4

8. 74

53.3

7.39
77.2
9.39

9.39
54.2

7. 92

82.7
8.42

53.0

897

139

7.35
59.8
7.44
42.5

7.35
59.8

7.52

61.2

41. 6

42.5

\section{EOL PERFOR MANCE *}

Power Output (watts, e)

Resistance (ohms)
Open Circuit Voltage (volts)
BEST ADJUST MENT FACTORS

$70^{\circ} \mathrm{F}$ Ambient $100^{\circ} \mathrm{F}$ Ambient

$\begin{array}{rr}1048 & 1076 \\ 1016 & 1044 \\ 998 & 1026 \\ 187 & 217 \\ 152 & 182\end{array}$

*Load Voltage $=24 \mathrm{~V}, \mathrm{Q}$ Input BOL $=1044$ Watts $(t), Q$ Input EOL $=814$ Watts $(t)$ 
Table 2-63

SNAP-23A Converter PMC -2 Parameter Study Maximum Heat Input Case*

\section{BOL TEMPERATURES $\left({ }^{\circ}\right)$

(O) \\ Average Hot Frame \\ Maximum Hot Junction \\ Average Hot Junction \\ Average Cold Junction \\ Outer'Case \\ EOL TEMPERATURES $\left({ }^{\circ} \mathrm{F}\right)$}

DESIGN ADJUSTMENT FACTORS NOMTNAL ADJUSTMENT FACTORS $70^{\circ} \mathrm{F}$ Ambient $100^{\circ} \mathrm{F}$ Ambient

BEST ADJUST MENT FACTORS

$\begin{array}{rr}1082 & 1111 \\ 1050 & 1079 \\ 1032 & 1061 \\ 189 & 219 \\ 154 & 184\end{array}$
1075
1043
1025
188
153

$100^{\circ} \mathrm{F}$ Ambient

$70^{\circ} \mathrm{F}$ Ambient

$100^{\circ} \mathrm{F}$ Ambient

\section{Average Hot Frame \\ Average Hot Junction}

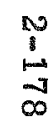

Average Cold Junction

Outer Case

$\begin{array}{ll}917 . & 945 \\ 872 & 900 \\ 170 & 200 \\ 140 & 170\end{array}$

912
867
170
140

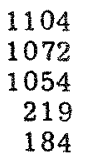

1068
1036

1036
1018

188

153

1097

1065
1047

219
184

\section{BOL PERFORMANCE *}

\section{Efficiency ( $\eta$ )}

Power Output (watts, e)

Resistance (ohms)

Open Circuit Voltage (volts)

\section{66}

82.3

9. 02

7.33
78.8
9.68
55.8

7. 87

84,6

8.68
54.6

7.54
81.1

9.32
55.5

940
895
200

200
170

\section{EOL PERFOR MANCE}

Efficiency $(\eta)$

Power Output (watts, e)

Resistance (ohms)

Open Circuit Voltage (volts)

$\begin{array}{cc}7.61 & 7.42 \\ 63.8 & 62.2 \\ 7.06 & 7.61 \\ 42.8 & 43.7\end{array}$

7.42
62.2
7.61

43. 7

7.80
65.4
6.81
42.6

7. 61

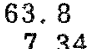

43.5

907

862

170

935

890

200
170

$*$ Load Voltage $=24 \mathrm{~V}, \mathrm{Q}$ Input BOL $=1075$ Watts $(t), Q \operatorname{Input} \mathrm{EOL}=838$ Watts $(t)$ 
c. The tubulation fitting would be difficult to position within the upper cover.

d. It would be difficult to encapsulate the power output wire feed-through fittings mounted on the conical portion of the outer case.

These difficulties were resolved and the revised configuration is shown by Figure 2-51. This figure shows in detail how the tubulation fitting would be positioned inside the upper cover to protect it from the environment. The outer case would be a cylindrical shell, and the header ring a flat ring which would contain the tubulation fitting and power output headers. The cold frame would be attached to header ring with bolts. The power output headers would be fitted into the header ring as shown by Figure 2-52 and be potted for protection from corrosive elements. The power output wires are routed from the power header to a terminal block at which point the junction would be made to the power cable. The power cable egresses through a stuffing gland to the power conditioner of the system. This arrangement is shown by Figure 2-53.

The outer case is shrunk fit over the cold frame. This shrink fit compression load, in addition to the compressive loading caused by the mounting of the heat sink on the outer case, is transferred to the cold frame. This is equivalent to an external compressive load on the cold frame; the critical compressive stresses are located between the follower holes as shown by Figures 2-54 and 2-55. The deformation of this web between follower holes must be limited to keep the cold frame deformation from binding the followers. To control this deformation the thickness of the outer case was reduced from $0.047^{\prime \prime}$ to $0.040^{\prime \prime}$ to reduce shrink fit loading. The I. D. of the cold frame was increased $0.007^{\prime \prime}$ so the same system interface dimensions were maintained.

A stress analysis of the enclosure weld areas was conducted to determine the best place to make the transition from Inconel 625 to 304 SS and to determine detail part configuration in the weld zone. The problem of high stress in the weld areas where $304 \mathrm{SS}$ is joined to Inconel 625 is related to the difference in thermal expansion rate of these two materials. The transition from Inconel 625 to $304 \mathrm{SS}$ could be made either at the hot or cold side of the converter. At the 
hot side the stresses would be higher than at the cold side because of the greater increase in temperature at operating conditions from when the welds were made. The decision was made to make the transition from Inconel 625 to $304 \mathrm{SS}$ at the points where the outer case joins the lower cover and the header ring.

The 304 SS has a higher rate of thermal expansion than Inconel 625. To keep the stresses in the weld joints to acceptable levels where the Inconel 625 outer case joins to the 304 SS lower cover and header ring, the 304 SS parts were dimensioned to press fit into the outer case. In this way the differential thermal expansion would not cause stress due to cantilevering in the weld areas.

Due to the change in converter enclosure configuration it was necessary to analyze the structure for its ability to $w$ ithstand externally applied shock and vibration loading. The configuration of the support cone had changed and the angle of the cone changed from $35^{\circ}$ to $45^{\circ}$. Figure $2-56$ defines the various types and locations of the stresses on the support cone from external loading. These stresses were calculated and the results are tabulated in Table 2-64. For these calculations a design factor $(D, F$,$) of 2.0$ was used. It was based on 1.5 safety factor, a 0.85 load carrying reduction factor to allow for fatigue, and 1.062 magnification factor for vibration. The actual loads which were used to calculate the stresses were determined as follows:

$$
\text { Stress Load }=\text { Weight } \times \text { G Load x D. F. (2.0) }
$$

The margin of safety was determined and is listed with the stresses in Table $2-64$. When the margin of safety has a value greater than zero (a positive number) the stress levels are not excessive. The cone as designed would be adequate since the margin of safety was positive in all cases. The other structural members were not analyzed as their configuration or loading had not changed since the structural analysis was made for EMC -1 .

PMC-2 structural analysis was based on load magnification of 2 to the converter through the system structure. During system support structure testing at WANL, lateral input $5 \mathrm{G}$ to the system resulted in a 15 load to the converter, a magnification factor of 3 . While the system support structure could be 


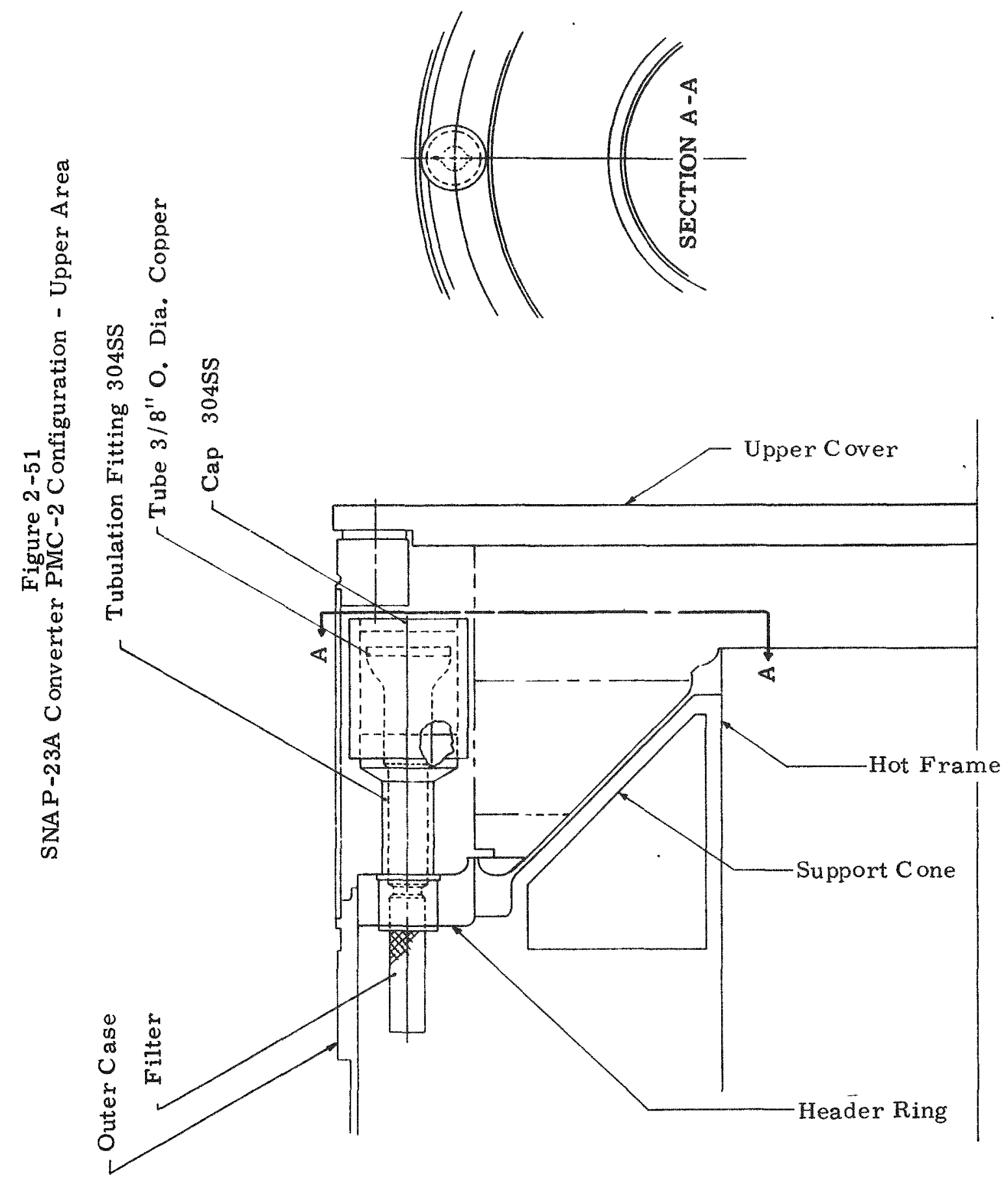


Figure 2-52

SNAP -23A C onverter PMC -2 Power Header Concept

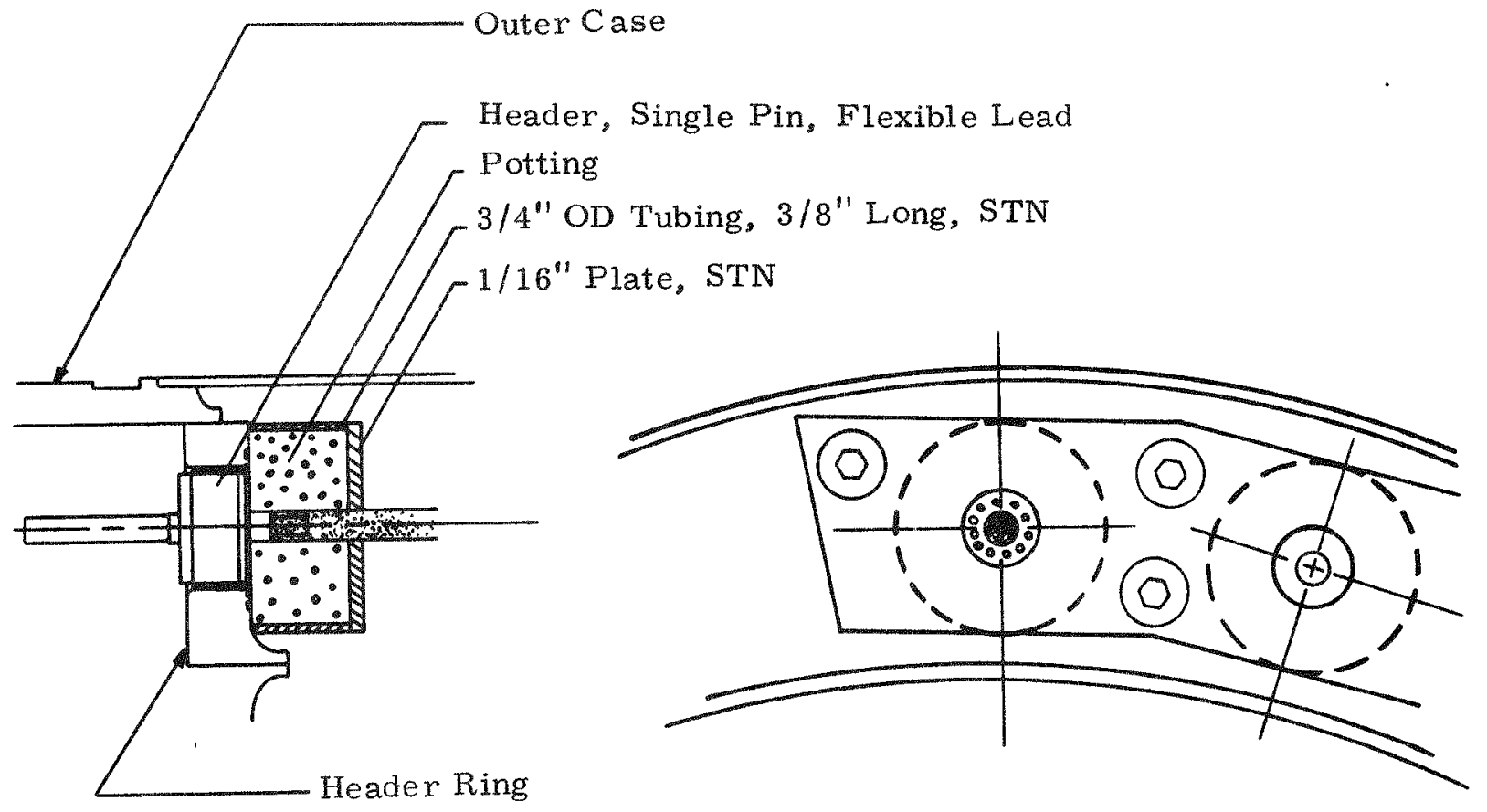


Figure 2-53

Cut-Away View of Power Output Termination for

SNAP -23A Converter PMC -2

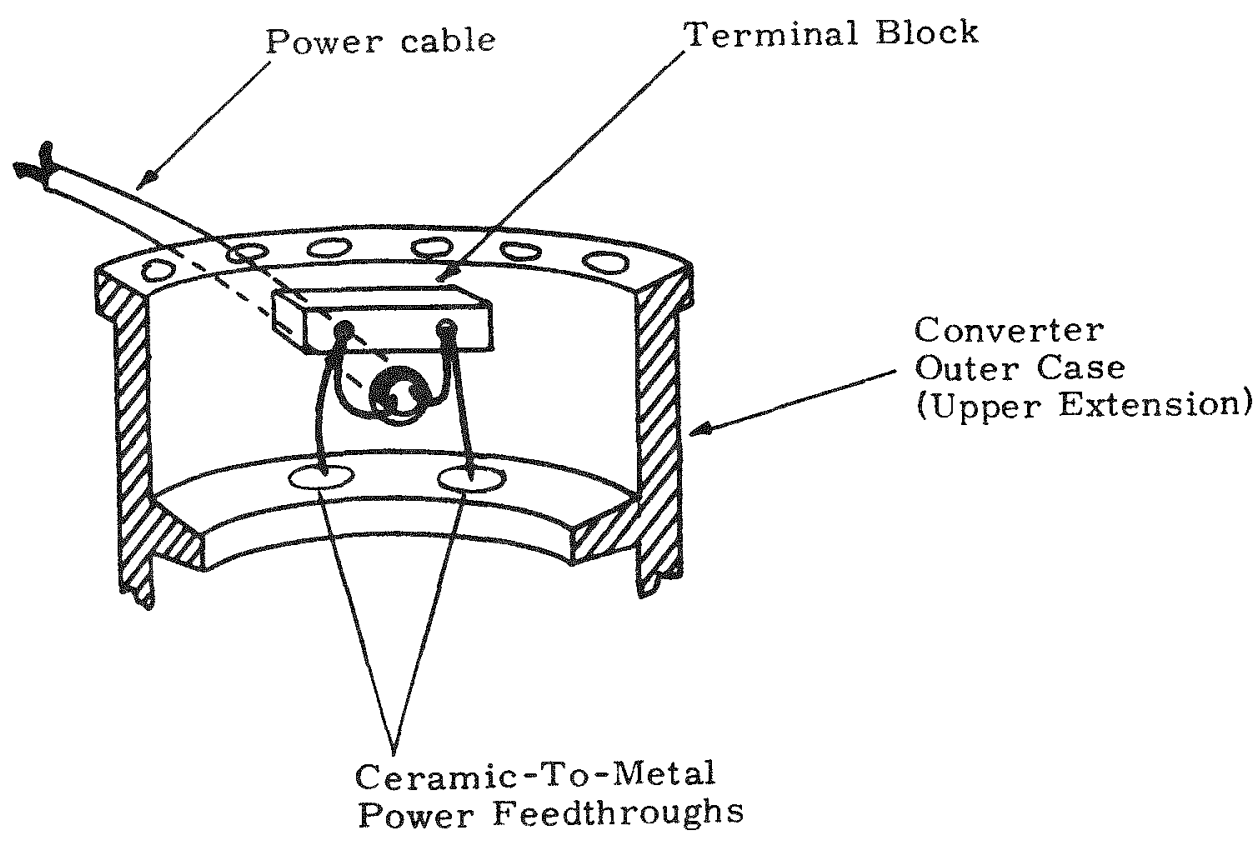


Figure 2-54

PMC -2 C old Frame Interface

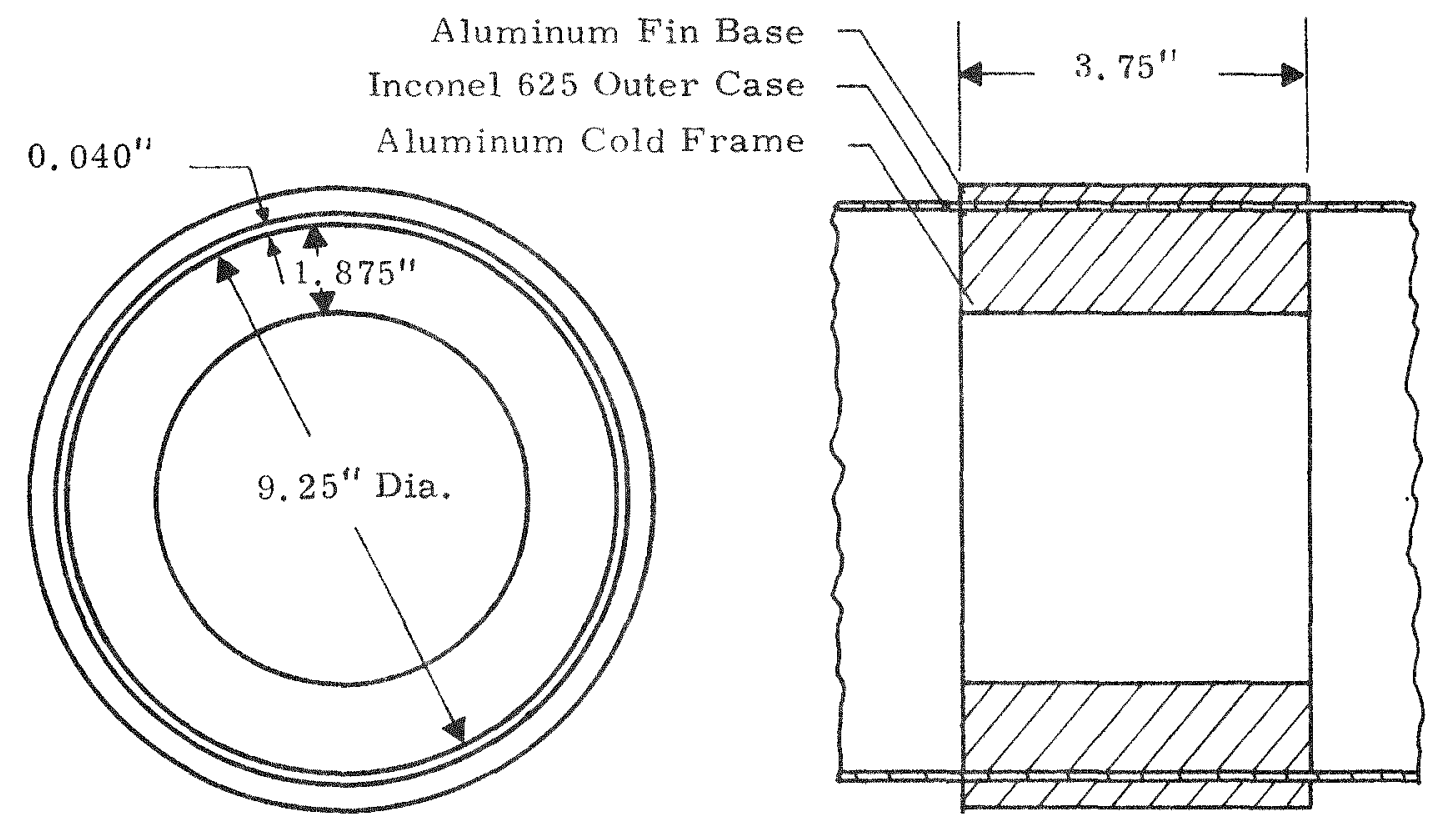

Figure 2-55

PMC -2 Cold Frame Force Loading
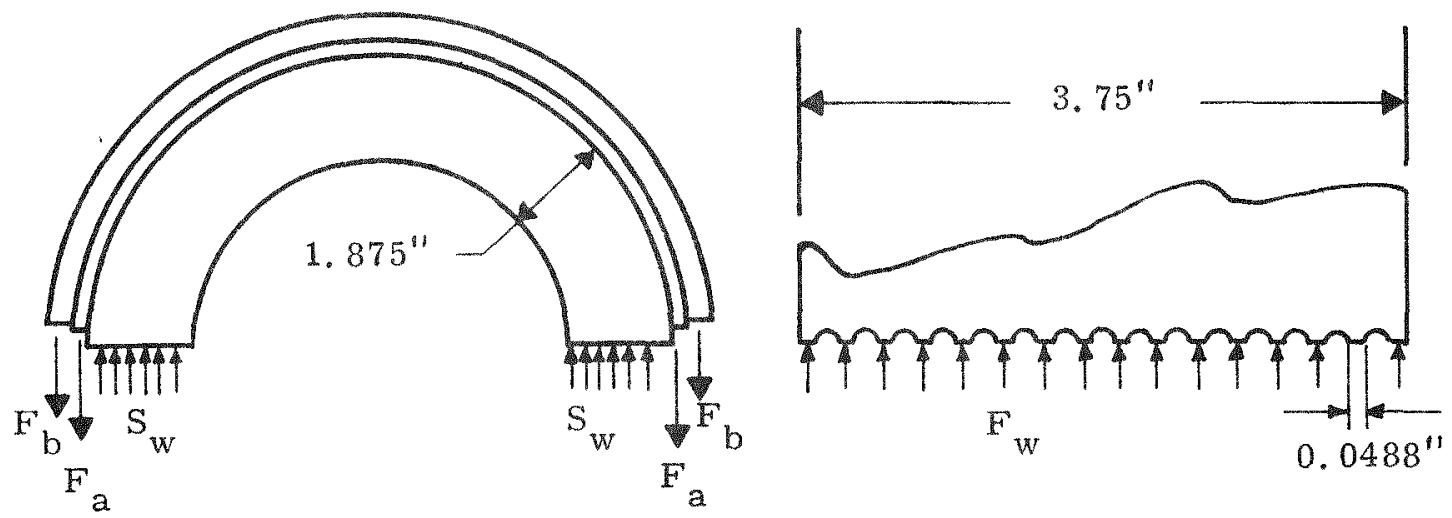
Figure 2-56

SNAP-23A Converter PIMC-2 Support Cone Stress Definition

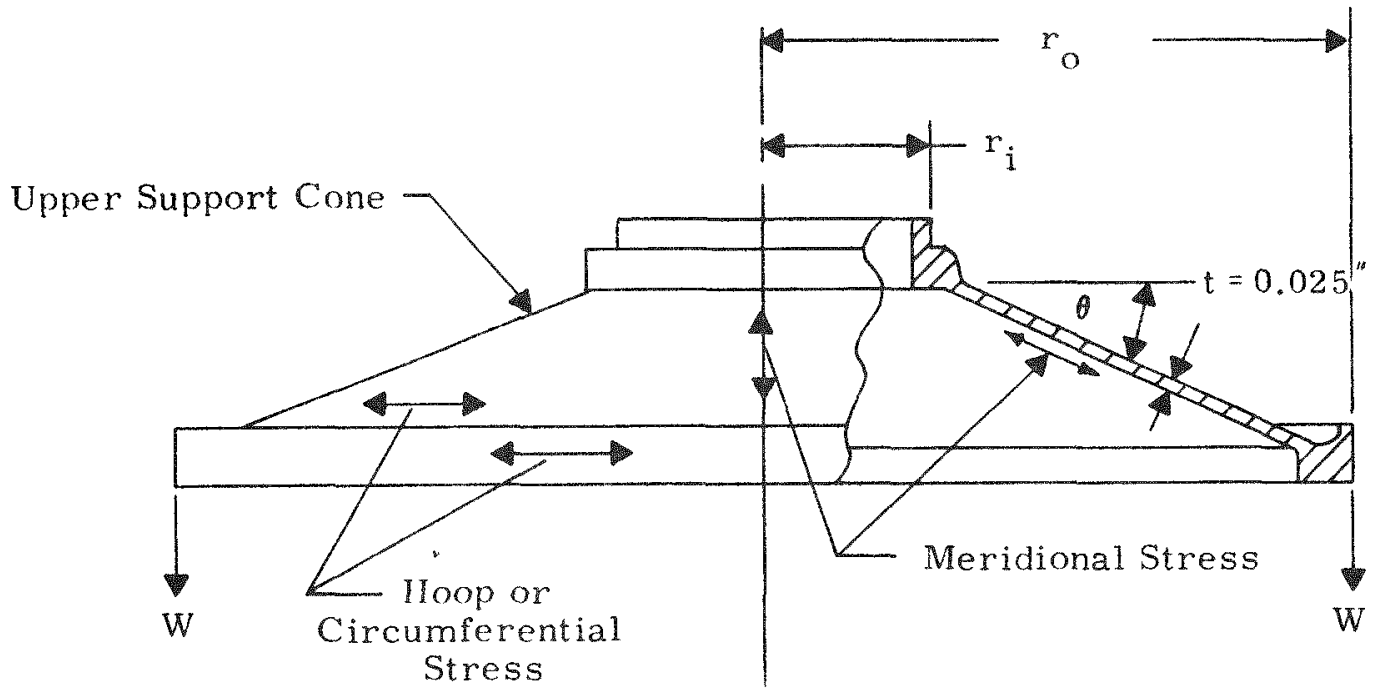


Table 2-64

SNAP-23A Converter Support Cone Stresses

\begin{tabular}{|c|c|c|c|c|c|c|c|c|c|}
\hline \multirow[b]{2}{*}{ Item } & \multicolumn{3}{|c|}{ Hoop Stress * } & \multicolumn{3}{|c|}{ Meridional Stress * } & \multirow[b]{2}{*}{$\begin{array}{l}\text { Combined } \\
\text { Stress** }\end{array}$} & \multirow[b]{2}{*}{ Failure Mode } & \multirow[b]{2}{*}{ M.S. } \\
\hline & $\begin{array}{l}\text { Down } \\
\text { Load }\end{array}$ & $\begin{array}{l}\text { Up } \\
\text { Load }\end{array}$ & $\begin{array}{l}\text { Pressure } \\
\text { Load }\end{array}$ & $\begin{array}{l}\text { Down } \\
\text { Load }\end{array}$ & $\begin{array}{c}\text { Up } \\
\text { Load }\end{array}$ & $\begin{array}{l}\text { Pressure } \\
\text { Load }\end{array}$ & & & \\
\hline $\begin{array}{l}\text { Support cone adjacent to } \\
\text { its outer thickened ring } \\
\text { Support cone adjacent to } \\
\text { its inner thickened ring }\end{array}$ & $\begin{array}{l}\cdots \\
\cdots \\
\cdots\end{array}$ & $\begin{array}{l}\cdots \\
\cdots \\
\cdots\end{array}$ & $\begin{array}{l}+\$ .530^{*} \\
+11,220 \\
+5,530^{*} \\
+11,220 \\
+3,880^{*} \\
+4,520 \\
+3.880^{*} \\
+4.520\end{array}$ & $\begin{array}{l}+6,000^{*} \\
+8.140 \\
+\ldots \\
+10.750 * \\
+15,280 \\
\ldots\end{array}$ & 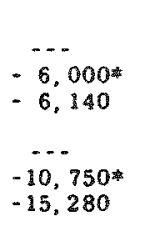 & $\begin{array}{l}+2,765 * \\
+5,610 \\
+2,765 \\
+5,610 \\
+1,940 * \\
+2,260 \\
+1,940 * \\
+2.260\end{array}$ & $\begin{array}{l}+8,200^{*} \\
+11,500 \\
+\ldots \\
+10,130^{*} \\
+15,750 \\
\ldots\end{array}$ & $\begin{array}{l}\text { Tens. Yield } \\
\text { Tens. Yield } \\
\text { Tens. Yield } \\
\text { Comp. Yield"* }\end{array}$ & $\begin{array}{l}2.00 * \\
1.19 \\
2.28 * \\
1.20 \\
0.925 * \\
0.16 \\
1.29 * \\
0.42\end{array}$ \\
\hline $\begin{array}{l}\text { Outer thickened ring of sup- } \\
\text { port cone } \\
\text { Inner thickened ring of } \\
\text { support cone }\end{array}$ & $\begin{array}{l}\text { U } \\
-6,220 \% \\
-12,800 \\
+\ldots \\
+9.650 \% \\
+17,050\end{array}$ & $\begin{array}{l}\text { Load Not a } \\
+-. \\
+7,900 \text { - } \\
-14,900 \\
\ldots\end{array}$ & $\begin{array}{c}\text { Critical a } \\
\ldots \\
\ldots \\
\ldots\end{array}$ & $\begin{array}{c}\text { Down Load } \\
\ldots \\
\ldots \\
\ldots\end{array}$ & $\begin{array}{l}\cdots \\
\cdots \\
\cdots\end{array}$ & $\cdots$ & $\begin{array}{l}-6,220 * \\
-12,800 \\
-7,900 * \\
-14,900 \\
+9,650 * \\
+17,050\end{array}$ & $\begin{array}{l}\text { Buckling } \\
\text { Comp. Yield } \\
\text { Tens. Yield }\end{array}$ & $\begin{array}{l}5.83^{*} \\
1.09 \\
2.20 * \\
0.80 \\
1.08 * \\
0.07\end{array}$ \\
\hline
\end{tabular}

*Values with support cone for PMC -2 at $45^{\circ}$ angle. All other values are for previous converters with a $35^{\circ}$ support cone angle

**( $(+)$ Indicates tension. $(-)$ indicates compression, all stresses in psi.

***M.S. (Margin of Safety) = (allowable stress/design stress) -1 ,

****Not critical in buckling.

NOTE: All stress values in psi. 
redesigned to control load magnification in the lateral direction it would result in a higher extraneous heat loss and lower system efficiency. 3M analyzed the PMC -2 structure for its capability of withstanding a 15 G lateral load. Results indicated that the structure would carry the $15 \mathrm{G}$ load with a positive margin of safety and that fatigue failure would not occur. This conclusion is based on the structural analysis only and does not include the thermoelectrics. For the converter to be qualified for $15 \mathrm{G}$ lateral loads, a unit should be dynamically tested. With the change in cone angle, it was necessary to analyze the location of where the boron nitride hot side insulation strips are pinned to the hot frame. This location of pinning is important so that couple misalignment is kept to a minimum during temperature cycling. Figure 2-57 shows the dimensional parameter which influences couple alignment during thermal cycling. The pinning point of the boron nitride strips on the hot frame is located so that the movement of the cold frame midpoint with reference to the boron nitride pinning point is zero during thermal cycling. With change in structure configuration and structural materials from PMC-1 to PMC-2, it was necessary to move the boron nitride pinning point 0.500 nearer the upper end of the hot frame.

PMC -2 configuration modifications have a small but significant effect on converter shunt heat losses. Design changes to the support cone, to accommodate the header ring, shortened the thin wall section and reduced the size of the insulation block between the hot frame and cone. Both increased the converter shunt heat losses.

A second design modification which increased shunt heat loss was a lengthening of the boron nitride insulation strips. These larger strips replace powdered thermal insulation (Min-K 1301) with a relatively high thermal conductivity material.

The shunt heat loss changes resulting from the design modifications are listed in Table 2-65. The results show that a larger change occurs at EOL than at BOL. This is not attributed to physical changes but rather to upgrading the calculational method. Table 2-65 also shows the revised shunt heat loss equation. 
Figure 2-57

Sketch Showing Thermoelectric Couple Alignment Parameters

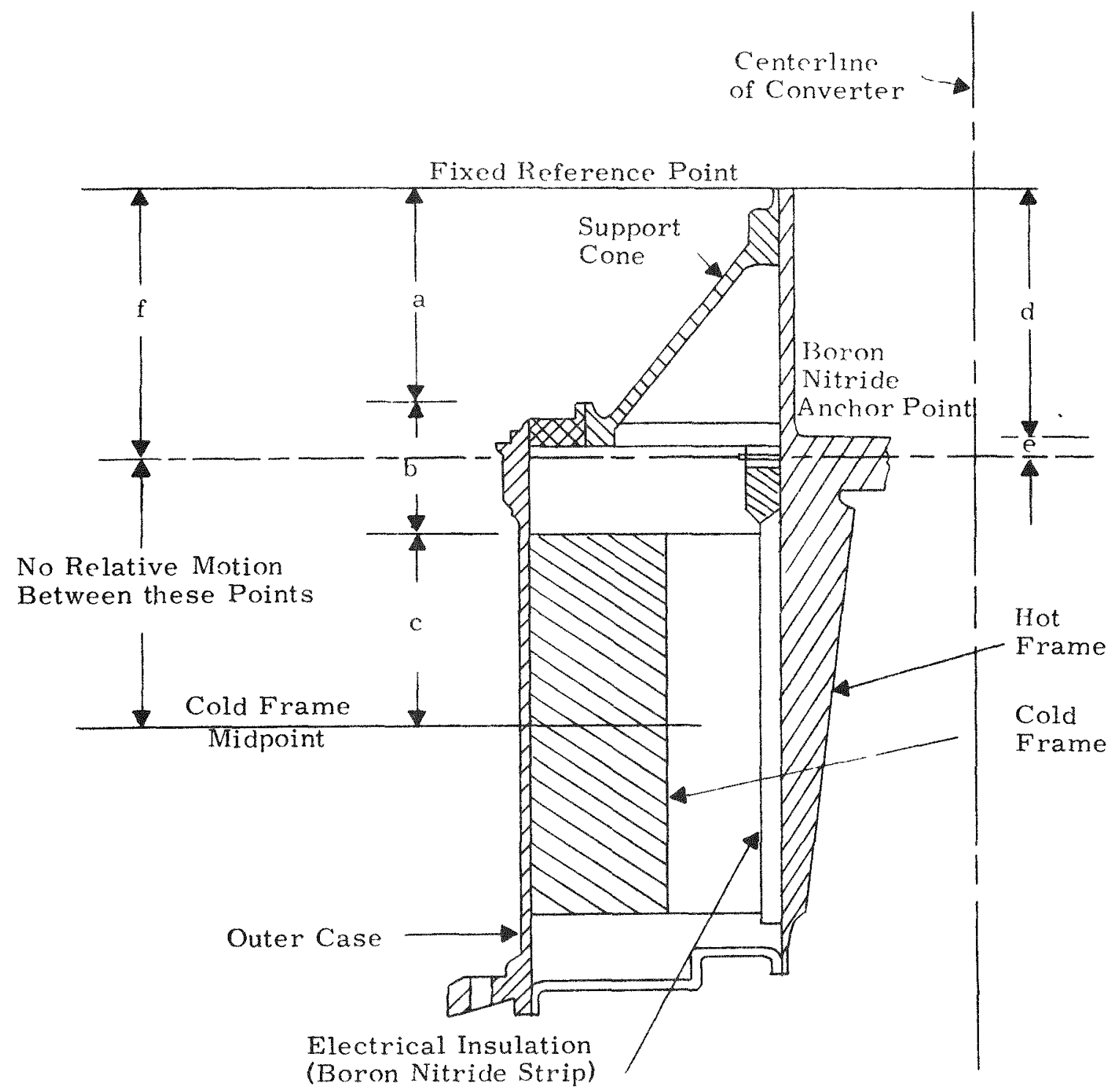


Table 2-65

Change in SNAP -23A Converter PMC -2 Shunt Heat Losses

BOL (PMC -2 MINUS PMC -1)

\begin{tabular}{ccccc} 
& $\begin{array}{c}\text { Physical } \\
\text { Changes }\end{array}$ & $\begin{array}{c}\text { Method } \\
\text { Upgraded }\end{array}$ & Net \\
\cline { 2 - 2 } Boron Nitride Strip & $0.26 \mathrm{~W}$ & & - & $0.26 \mathrm{~W}$ \\
Support Cone Insul. & $2.02 \mathrm{~W}$ & $-1.23 \mathrm{~W}$ & $0.79 \mathrm{~W}$ \\
Support C one Geometry & $\underline{1.16 \mathrm{~W}}$ & $\underline{1.20 \mathrm{~W}}$ & $\underline{2.36 \mathrm{~W}}$ \\
\multicolumn{1}{c}{ Totals } & $3.44 \mathrm{~W}$ & $-0.03 \mathrm{~W}$ & $3.41 \mathrm{~W}$
\end{tabular}

EOL (PMC -2 MINUS PMC -1)

\begin{tabular}{cccc} 
& $\begin{array}{c}\text { Physical } \\
\text { Changes }\end{array}$ & $\begin{array}{c}\text { Method } \\
\text { Upgraded }\end{array}$ & Net \\
\cline { 2 - 2 } Boron Nitride Strip & $0.20 \mathrm{~W}$ & - & $0.20 \mathrm{~W}$ \\
Support C one Insul & $1.64 \mathrm{~W}$ & - & $1.64 \mathrm{~W}$ \\
Support C one Geometry & $\underline{1.10 \mathrm{~W}}$ & $\underline{1.20 \mathrm{~W}}$ & $\underline{2.30 \mathrm{~W}}$ \\
\multicolumn{1}{c}{ Totals } & $2.94 \mathrm{~W}$ & $1.20 \mathrm{~W}$ & $4.14 \mathrm{~W}$
\end{tabular}

PMC -2 Shunt Heat Loss Equation (Revised)

Q Losses in Watts $=\left[0.1670 \times\left(T_{h}-T_{c}\right)\right]-45.97$ 
The revised shunt heat losses affect the amount of heat required by PIC -2 to operate at design junction temperatures. Table 2-66 lists the changes in shunt heat loss and revised PMC-2 converter heat requirements to meet design power output with $70^{\circ} \mathrm{F}$ ambient air.

A heat loss analysis of the PMC -2 top cover was completed which includes an evaluation of heat loss through the top cover insulation for EOL and BOL temperature conditions. In addition, the difference in heat loss with the laboratory test station top cover plate replaced by the system top cover plate was evaluated. Finally, the effects on top cover heat loss of ambient air temperature associated with fins and that with water cooling were determined.

For comparison, PMC $-1 \mathrm{~B}$ experienced upper cover heat losses of 3.65 watts at BOL and 3.1 watts at EOL. Lower heat losses were expected in PMC -2 because the microquartz in the upper cover of earlier units will be replaced by Min-K 2002 with a lower conductivity. The calculated results also show that top cover heat losses are not influended by top cover plate configuration. In addition, the top cover heat losses are not affected by the presence or absence of fins. The presence of the fins was simulated by increasing the temperature of air surrounding the top cover by $50^{\circ} \mathrm{F}$.

Table 2-66

Revised SNAP-23A C onverter PMC -2 Heat Requirements

$\begin{array}{lcc} & \text { EOL } & \text { BOL } \\ \begin{array}{lcc}\text { Converter Heat } \\ \text { Requirement (Reference) } \\ \text { Shunt Heat Loss }\end{array} & 818 \mathrm{Watts} & 1048 \mathrm{Watts} \\ \mathrm{T}_{\mathrm{h}} & 68.9 \mathrm{~W} \text { atts } & 91.6 \mathrm{Watts} \\ \mathrm{T}_{\mathrm{c}} & 857^{\circ} \mathrm{F} & 1011^{\circ} \mathrm{F} \\ \mathrm{T} \text { Ambient } & 169^{\circ} \mathrm{F} & 187^{\circ} \mathrm{F} \\ & 70^{\circ} \mathrm{F} & 70^{\circ} \mathrm{F}\end{array}$


It was concluded, based on these results, that PMC -2 did not need to be tested with fins to obtain top cover heat losses applicable to system conditions. Furthermore, the laboratory test station top cover plate does not perturb the top cover heat loss.

The detailed calculational results for the top cover are summarized in Table $2-67$. In examining the results, it can be noted that the changes in ambient temperature influence $Q$ case and $Q$ "adiabatic boundary" but does not affect $Q$ loss. This is because $Q$ loss, according to definition, includes only the heat transferred across the surface directly above the spud and not the so called "adiabatic boundary".

$$
\mathrm{Q} \text { Loss }=\mathrm{Q} \text { Case }-\mathrm{Q} \text { "Adiabatic Boundary" Net Out }
$$

The top cover heat losses were calculated with a nodal point heat transfer: computer program, that is a modification of the program used to analyze EMC and PMC -1 upper cover heat losses. The thermal conductivities for Min-K 2002 (top cover insulation) used in the analysis are based on Westinghouse measurements of the block form in air. Values for powder equal to twice the block conductivity values were assumed.

Data from EMC -1,2, 3 and PMC $-1 \mathrm{~A}$ and $1 \mathrm{~B}$ were statistically analyzed to determine how closely test station heat loss and hot junction temperature could be predicted from hot frame temperature. The analysis was made for two pairs of hot frame thermocouples; one pair internal of the converter at the center of the hot frame and the other pair external to the hot frame in the web. From the data analyzed and with the change in converter thermal impedance from configuration changes, it was concluded that both pairs of hot frame thermocouples should be installed on PMC -2. Data was also examined from the first five SNAP -23A converters to determine where temperature sensing thermocouples should be located at the cold side of the converter. It showed that the thermocouples on the cold frame had not given a good indication of cold junction temperature or cold junction to outer case temperature drop. Therefore, no thermocouples were installed on the cold frame, but thermocouples were placed at the leg cold junctions and on the outer case. Based on this instrumentation analysis and evaluation, instrumentation was included in PMC -2 as shown by Table 2-68. 
Table 2-67

SNA P-23A Converter PMC-2 Top Cover Heat Losses

(Preliminary)

\begin{tabular}{|c|c|c|c|}
\hline & \multicolumn{3}{|c|}{ BOL } \\
\hline & $\begin{array}{c}\text { Test Cover } \\
\text { W/O Pinch Off } \\
70^{\circ} \mathrm{F} \mathrm{Amb.} \mathrm{Air} \\
\end{array}$ & $\begin{array}{l}\text { System Cover } \\
\text { W/O Pinch Off } \\
70^{\circ} \mathrm{F} \mathrm{Amb.} \mathrm{Air} \\
\end{array}$ & $\begin{array}{l}\text { Test Cover } \\
\text { With Pinch Off } \\
70^{\circ} \mathrm{F} \mathrm{Amb.} \mathrm{Air} \\
\end{array}$ \\
\hline Q Out Case & $7.60 \mathrm{~W}$ & $7.54 \mathrm{~W}$ & $7.95 \mathrm{~W}$ \\
\hline $\begin{array}{l}\text { Q Out Support Cone (Net) } \\
\text { and Header Ring }\end{array}$ & $5.11 \mathrm{~W}$ & $5.08 \mathrm{~W}$ & $5.46 \mathrm{~W}$ \\
\hline Q Loss & $2.49 \mathrm{~W}$ & $2.46 \mathrm{~W}$ & $2.49 \mathrm{~W}$ \\
\hline
\end{tabular}

EOL

Test Cover Test Cover
W/O Pinch Off W/O Pinch Off $70^{\circ} \mathrm{F} \mathrm{Amb}$. Air $120^{\circ} \mathrm{F} \mathrm{Amb}$. Air

Q Out Case

Q Out Support Cone (Net) and Header Ring

Q Loss
$6.23 \mathrm{~W}$

4. $00 \mathrm{~W}$

$4.35 \mathrm{~W}$

$1.88 \mathrm{~W}$
2. $13 \mathrm{~W}$

$1.87 \mathrm{~W}$ 
Table $2-68$

SNA P-23A Converter PMC -2 Instrumentation

\begin{tabular}{|c|c|}
\hline Thermocouple* & Location \\
\hline $1,2,5,6,7,8$ & Hot Frame \\
\hline $\begin{array}{l}11,12,13,14,15,16 \\
17,18,19,20,21,22\end{array}$ & $\begin{array}{l}\text { Hot Junction } \\
\text { Hot Junction }\end{array}$ \\
\hline $\begin{array}{l}23,24,25,26,27,28 \\
29,30,31,32,33,34\end{array}$ & $\begin{array}{l}\text { Cold Junction } \\
\text { Cold Junction }\end{array}$ \\
\hline $\begin{array}{l}47,49 \\
48,50\end{array}$ & $\begin{array}{l}\text { Outer Case } \\
\text { Outer Case }\end{array}$ \\
\hline $39,40,41,42,43,44,45,46$ & Cone and Header Ring \\
\hline
\end{tabular}

In addition to this analysis to determine location of temperature indicating thermocouples, revisions were made in design details to reduce thermocouple failure rate. All corners around which the thermocouple wires are routed were radiused and microquartz insulation was placed between the wire and the location where the wire bent around the corner.

Several new components were designed or selected for the top cover area. Most of these components were routine to design but some of the special problems or features are worth noting.

The seal where the top cover fits to the top cover case had a design requirement to be moisture tight. To preclude extensive testing to qualify this seal design, the design was based on vacuum tight criteria for "o" ring seals. This seal design was considered adequate to keep moisture out and no qualification testing was conducted.

The power output cable was to be sealed where it exited from the top cover area with a stuffing tube. Stuffing tube designs to meet the requirements of MIL-S$19622 \mathrm{D}$ were used to establish critical dimensions for the stuffing tube design. Actual MIL-S-19622D stuffing tubes were not used because they were made of nylon material and the stuffing tube for PMC -2 had to be made of Inconel 625 . 
The power output cable had to be capable of withstanding exposure to the environment. It would be exposed to the atmosphere from where it left the stuffing tube to its termination at the system power conditioner. The end of cable within the top cover would need to be sealed to prevent moisture from entering. Initially, cable fabricated to meet the requirements of MIL-C-2194/ $2 \mathrm{E}$ DSGA was selected and a sample procured for evaluation. Various types of RTV (Room Temperature Vulcanizing) compounds were tried for sealing the cable end. The RTV would bond to the silicone rubber wire insulation, but not to the other layers of material used for construction. Additional contacts with cable vendors located a type of cable which was classified as being "blocked". It was fabricated to meet the requirements of MIL-C-915/8A D SS-2 which has the requirement that no moisture shall pass through the cable when mounted in a stuffing tube with hydrostatic pressure of 500 psi against the open end of the cable. The end of one sample of this cable was potted with GE RTV 108. This length of cable and one without potting were checked for moisture leak rate. Leakage rate for both lengths met PMC -2 requirements. On this basis the cable, MIL-S-915/8A D SS-2, was selected for PMC -2 and it was concluded that potting of the end of the cable was not required for moisture sealing.

An evaluation was made to develop a method of encapsulating the power output leads at the point where they come out of the converter power output headers. The details of design in this area are shown by Figure 2-58.

This development had two purposes.

A. To select the proper potting compound.

B. To develop the procedure and techniques for the potting operation.

A two-part potting compound was selected consisting of Dow Corning RTV encapsulant \#3120 and RTV Catalyst "S". A suitable technique was developed and a procedure was written for applying this encapsulant. 


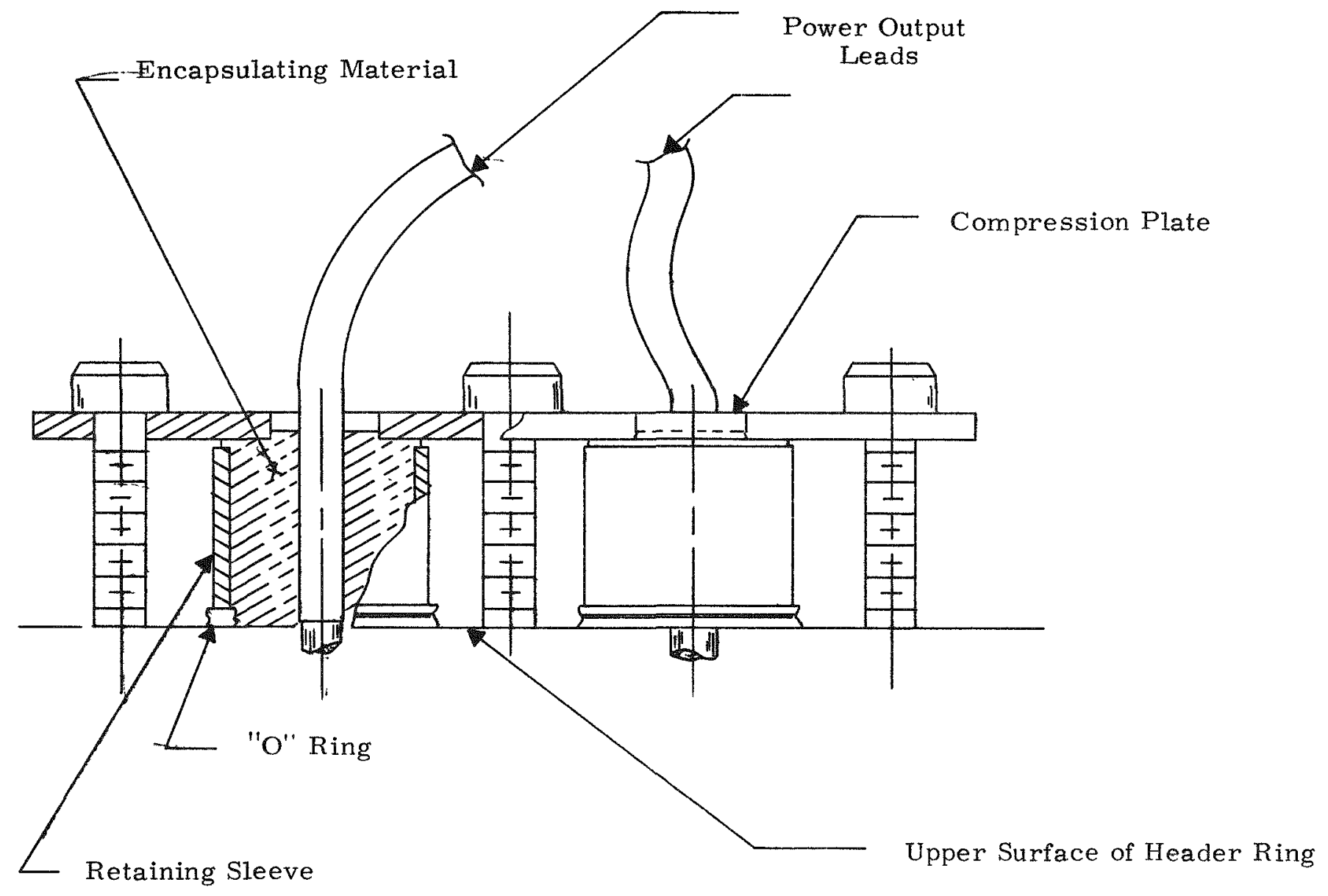

Figure 2-58

Converter Power Output Leads 
As the number of changes to PMC-2 from PMC-1B were extensive it was necessary for $W$ estinghouse to prepare a new interface drawing. First step was to obtain general agreement between WANL and 3M on the proposed configuration changes. After this agreement was reached, then the specific details of the drawing were resolved. Westinghouse then prepared an initial or preliminary drawing which included 3M inputs; after review, discrepancies were negotiated and agreement was reached on a final issue of the interface drawing for PMC -2 .

\section{3.3.3.2 Summary of Design}

PMC -2 incorporated extensive design changes from the previous five converters built on the SNAP-23A program. These changes were related to improvement of long-term performance and field service conditions rather than laboratory test conditions.

The outstanding features of the PMC -2 design are as follows:

A. Thermopile designed to produce maximum power at end of life with consideration for degradation of the thermoelectrics.

B. An outer case fabricated of Inconel 625 to improve corrosion resistance.

C. A change in configuration so tubulation fitting and power output terminals are not exposed to the atmosphere.

D. The top cover area included as an integral part of the converter.

E. Location of points of instrumentation changed and reduced based on previous test data to provide maximum useful information.

F. Instrumentation located and routed so that it could be removed and the "as built" laboratory test device could be converted to a field service device. 


\subsection{Fabrication}

The cold frame as machined had two deviations from specification. The first was the follower holes and the second was the outside diameter. The follower were elliptical at the cold frame inside diameter which caused some of the holes to be too large at their major diameter. Forty-two holes were inspected with an air gauge and variable data recorded. From this data it was calculated that increased thermal impedance could increase cold cap temperatures $5^{\circ} \mathrm{F}$ for EOL heat flux and $6^{\circ} \mathrm{F}$ for BOL heat flux from nominal hole size. Power output could decrease 0.23 watts at EOL conditions and 0.62 watts at BOL conditions. These values represent the worst-case effect on converter performance. Cost and schedule were considered in making the decision to use the cold frame as machined. The deviated follower holes were acceptable and their use in PMC -2 will develop data for dimensioning follower holes for future converters. The cold frame outside diameter was undersize by less than 0.001 inch. This diameter was acceptable based on the reduction of the outer case wall thickness tolerance from $0.038 / 0.042$ to $0.0385 / 0.042$ which was necessary to maintain the proper outer case interface dimension.

\subsection{Assembly}

After all the components had been fabricated or procured, assembly of PMC -2 started on September 20,1969. As there were considerable changes in piece parts and assemblies, some revision of assembly procedure description was required. The same tools and fixtures which had been used to assemble the previous five converters was useable without modification.

The assembly of the thermopile proceeded without difficulty. All thermocouple instrumentation wires were brought out through the top end of the thermopile as shown by Figure 2-59. Figure 2-60 shows the opposite, or bottom end, of the thermopile after assembly.

All welds were completed satisfactorily except where the 304 SS header ring was welded to the Inconel 625 outer case. For about $1 / 4$ of the length of this weld, which was done automatically, discontinuities existed. This discontinuity was caused by too large a gap where the parts fit together in this area. This 


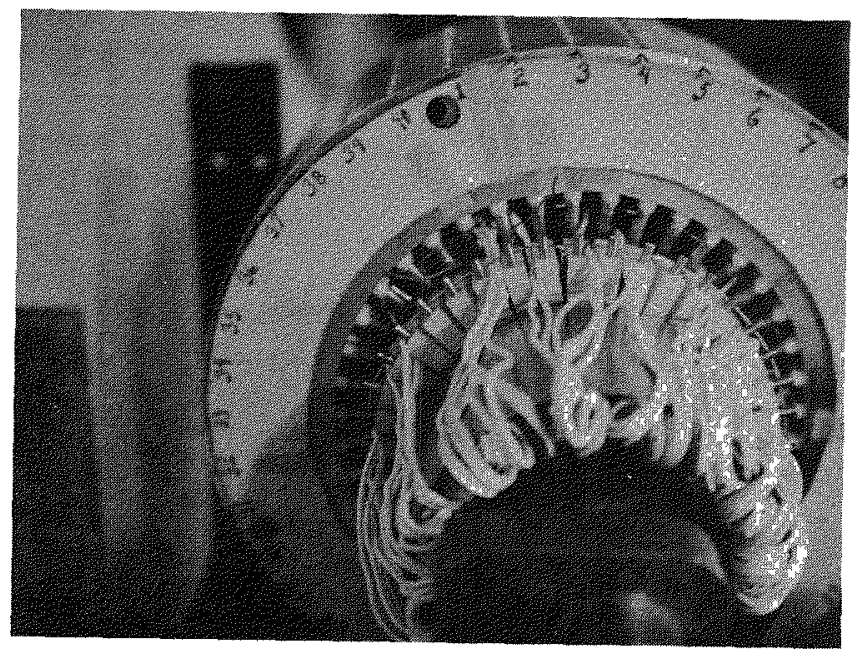

Figure 2-59

Top View of Cold Frame T/E Couples and Hot Frame Assy for SNA P-23A Converter PMC - 2

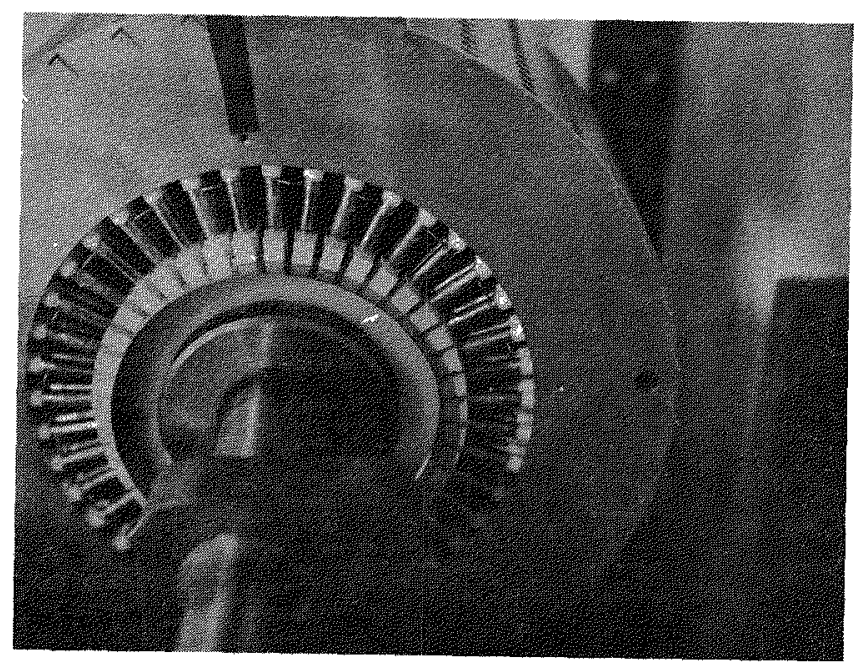

Figure 2-60

Bottom View of Cold Frame, T/E Couples and Hot Frame Assy for SNAP -2 3A Converter PIMC -2

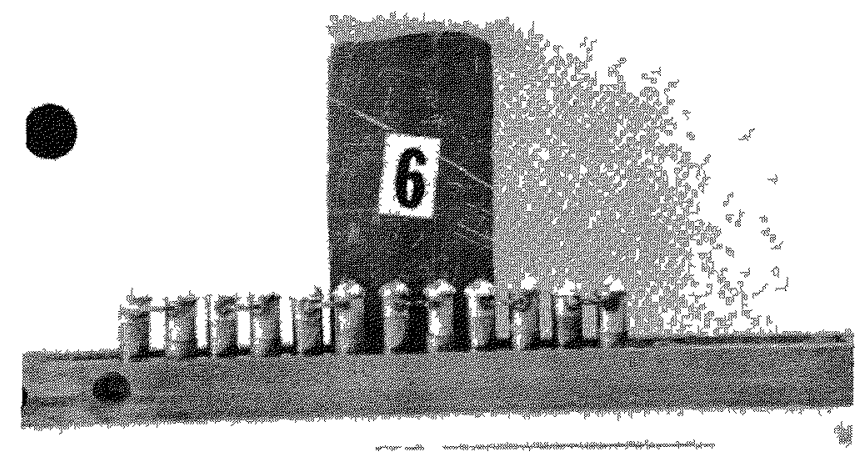

Figure 2-61

Assembled Row of $\mathrm{T} / \mathrm{E}$ Couples 
area was rewelded by a hand operation to obtain the necessary seal and structural joint. After assembly was completed, October 25, 1969, the converter was placed on the test station for processing.

\subsection{Quality Control}

Several additions were made to the quality control procedures during assembly to improve and assure a quality device. After each row of thermoelectric couples (with the exception of the end couples) were assembled onto the insulation strip, the assembly was photographed for a permanent record. Figure 2-61 shows a row of assembled thermoelectric couples. Note that the " $N$ " and " $\mathrm{P}$ " legs are very clearly defined. These assembled rows were identified according to the position they were installed in the converter.

Figure 2-62 shows the thermopile being visually inspected using a boroscope. The boroscope made it possible to inspect every couple for proper seating in the hot buttons, proper seating of the cold caps in the followers, cracked or broken jumper wires between cold caps, broken legs, or any foreign material in the thermopile.

\subsection{Initial Performance}

During the processing of PMC -2 several anomalies were observed. Early in the processing cycle an open was observed in the thermoelectric circuit in the region of Rows 36 to 40 . After several thermal cycles, the open circuit condition disappeared, but a short to ground appeared in the same area of the thermopile. This short circuit was found to be equivalent to six couples shorted out in Rows 36 to 40 . After several more thermal cycles the short to ground disappeared. However, the performance of Rows 36 to 40 was still below the remainder of the thermopile. The 28 couples for which performance could be measured produced a Seebeck voltage equivalent to only 26 couples. The apparent low Seebeck effect could be caused by one couple being reversed (position of $\mathrm{N}$ and $\mathrm{P}-\mathrm{leg}$ being reversed). This seemed very unlikely as the photographs taken of each row of couples during assembly did not show this condition. Previous investigation on the SNAP-21 program had demonstrated 

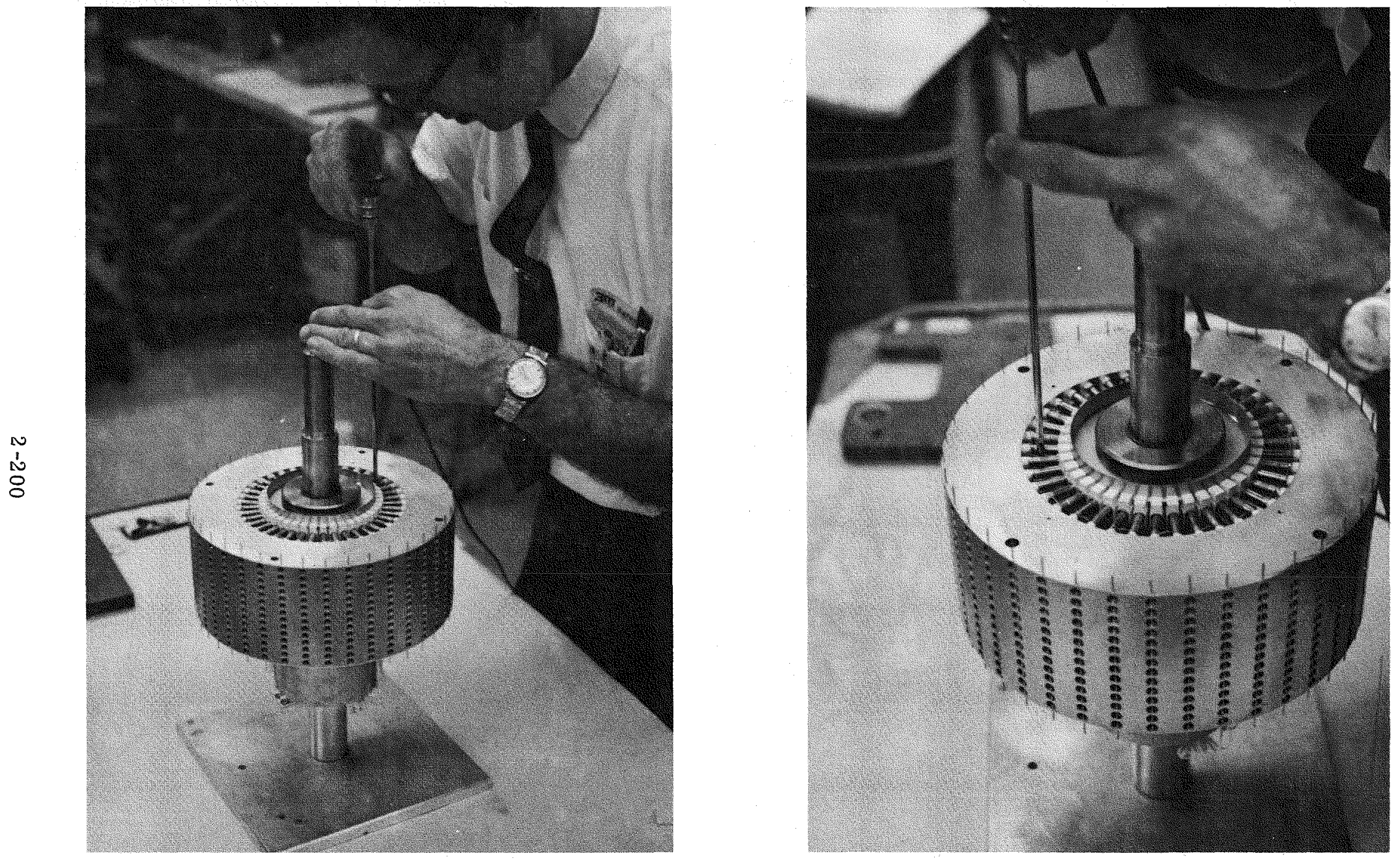

Figure 2-62

Visual Inspection of Thermopile

P 
that an $X$-ray of an assembled converter would reveal a reversed couple. PMC -2 was removed from the test station and subjected to radiographic examination. The results of the examination were:

A. No couples were reversed.

B. There was evidence of foreign material located between Rows 37 and 38, and extending over a length of approximately two hot electrodes.

A measurement of performance was made while PMC -2 was on the test station; Table 2-69 compares PMC -2 actual performance and ratios with design values, bell jar tests with couples from the same lot and batch as PMC-2 was built, and computed EOL values. By examining the values in Table $2-69$, it is apparent that the low power output is due to combined effects of high circuit resistance and low Seebeck voltage. The low Seebeck of the P-leg is the greatest contributing factor to the low power output. Table 2-70 is a summary of the Quality Control data used to determine the acceptability of the P-legs. This table compares the P-leg and material QC data of PMC -2 with that of PMC $-1 \mathrm{~A}$ and PMC -1B; the latter converters both had acceptable thermoelectric performance. From examination of the Seebeck data presented in Table 2-70, it was concluded that the QC measurements do not give a precise indication of in-pile thermoelectric leg performance to the degree required to meet the SNAP-23A converter performance specifications. Correlation exists between the QC thermoelectric data and thermopile performance, but the range of correlation is greater than the design Seebeck and resistance ratio range of values. This leads to the conclusion that either the design resistance and Seebeck ratio ranges need to be increased, or a more precise means is required to measure leg Seebeck and resistance prior to converter assembly.

It was determined that the as built PMC -2 was not acceptable for its intended purpose of mating with Fueled Prototype Mockup System (FPMS). This decision was based on several factors.

a. The thermoelectric performance was below design levels. 
b. The foreign object might contribute to shorting or open circuit condition as was observed during processing.

c. The foreign object might cause long-term degradation.

It was decided to attempt to repair PMC -2 by a partial disassembly and rebuild. This repair would cover removal of the foreign object which showed up between Rows 37 and 38 on the X-rays, and a visual examination of the failure zone.

To gain access to the thermopile area of the converter, the upper support cone was removed by machining. Special care was taken during this machining operation so the hot frame and header ring would not be damaged. The pad, block, and powdered thermal insulation in the upper portion of the converter and the powdered thermal insulation from between Rows 37 and 38 were carefully removed. An object was removed from between these two rows which was of irregular shape $3 / 16^{\prime \prime}$ to $1 / 4^{\prime \prime}$ long by $0.25^{\prime \prime}$ to $0.030^{\prime \prime}$ diameter. A nother small object was firmly attached to the hot frame between the boron nitride strips of Rows 37 and 38 but was not removed until later during rebuild of the converter. These objects had the appearance and texture of slag and chemical analysis was conducted to determine its composition. The result of the emission spectrographic analysis is shown in Table 2-71. A microprobe analysis was also conducted with results shown in Table 2-72. The results of these analyses indicated that the foreign object between Rows 37 and 38 was the product of a chemical reaction between copper and the thermoelectric leg material.

A boroscope was used to visually examine the condition of the legs, hot junction buttons, and hot junction electrodes in Rows 37 and 38. It was apparent that the hot junction buttons at Positions $A 7$ and A 8 of Row 37 and Positions A5, A6, $A 7, A 8, A 9$ and $A 10$ of Row 38 had been involved in a chemical reaction. The surface of these hot junction buttons was rough with a slag-like appearance while surfaces of the other hot junction electrodes were shiny in appearance. The " $P$ " type legs had a reddish brown ring on the surface part way up the leg. One " $P$ " type leg was shortened about $1 / 8$ " to $1 / 4$ ". None of the components in adjacent Rows 36 and 39 appeared to be involved in any chemical reaction. 
Table $2-69$

SNAP-23A Converter PMC-2 Performance versus Design Criteria

\begin{tabular}{|c|c|c|c|c|c|c|}
\hline & \multicolumn{2}{|c|}{ PMC-2 Data } & \multirow[b]{2}{*}{ Design } & \multicolumn{2}{|c|}{ Actual Bell Jar ${ }^{(2)}$} & \multirow{2}{*}{$\begin{array}{c}\text { Computed } \\
\text { EOL }\end{array}$} \\
\hline & EOL Actual & BOL, Actual & & EOL & $\mathrm{BOL}$ & \\
\hline$\frac{E_{x}}{E_{t}}$ & $\begin{array}{r}0.945 \\
(0.95)\end{array}$ & 0.945 & 0.98 & & & \\
\hline$\frac{R_{x}}{R_{t}}$ & $\begin{array}{l}1.02 \\
(1.05)\end{array}$ & 1.035 & 1.02 & & & \\
\hline$\frac{E n_{x}}{E n_{t}}$ & $\begin{array}{c}0.985 \\
(0.985)\end{array}$ & 0.99 & 1.00 & 0.99 & 1.00 & 0.985 \\
\hline$\frac{E p_{x}}{E p_{t}}$ & $\begin{array}{c}0.93 \\
(0.925)\end{array}$ & 0.95 & 0.96 & 0.945 & 0.955 & 0.93 \\
\hline$\frac{R n_{x}}{R n_{t}}$ & $\begin{array}{c}0.97 \\
(0.965)\end{array}$ & 0.96 & 1.0 & 0.95 & 0.96 & 0.97 \\
\hline$\frac{R p_{x}}{R p_{t}}$ & $\begin{array}{c}1.05 \\
(1.06)\end{array}$ & 1.14 & 1.03 & 1.05 & 1.035 & 0.93 \\
\hline $\begin{array}{l}P_{\text {in }} \\
\text { watts }\end{array}$ & 55.7 & 74.6 & $\begin{array}{l}61.2 \mathrm{EOL} \\
80.4 \mathrm{BOL}\end{array}$ & & & 61.7 \\
\hline Efficiency & 7.05 & $7.7^{(1)}$ & 7.52 & & & 7.55 \\
\hline
\end{tabular}

( ) - Data in brackets recorded 17 October 1969. Other data was recorded 20 October 1969.

(1) - Design value 7.7 percent

(2) - Data from 2 couples from same lot and batch as couples used for $\mathrm{PMC}-2$. 
Table 2-70

SNA P-23A Converter Q. C. Data Summary

\begin{tabular}{|c|c|c|c|c|c|c|c|c|c|}
\hline \multirow[b]{2}{*}{ Material } & \multirow[b]{2}{*}{ Converter } & \multicolumn{4}{|c|}{ Resistivity } & \multicolumn{4}{|c|}{ Seebeck (Millivolts) } \\
\hline & & Spec. & Max. & Min. & Avg. & Spec. & Max. & Min. & Avg. \\
\hline 3P Powder & PMC-1a \& $1 \mathrm{~b}$ & $450 \max$ & 395 & 373 & 382 & $58.0 \mathrm{~min}$ & 64.7 & 63.6 & 64.4 \\
\hline 3P Powder & PMC-2 & $450 \max$ & 355 & 333 & 342 & $58.0 \mathrm{~min}$ & 62.3 & 61.3 & 61.7 \\
\hline $\begin{array}{l}3 \mathrm{P}-4 \mathrm{P} \\
\text { Segment }\end{array}$ & PMC-1a & $450 \max$ & 384 & 346 & 362 & $56.0 \mathrm{~min}$ & 62.0 & 58.9 & 60.7 \\
\hline $\begin{array}{l}3 \mathrm{P}-4 \mathrm{P} \\
\text { Segment }\end{array}$ & PMC-1b & $450 \max$ & 369 & 352 & 358 & $56.0 \mathrm{~min}$ & 60.6 & 58.0 & 59.6 \\
\hline $\begin{array}{l}3 P-4 P \\
\text { Segment }\end{array}$ & PMC-2 & $450 \max$ & 342 & 315 & 331 & $56.0 \mathrm{~min}$ & 62.0 & 60.4 & 61.2 \\
\hline 10P Powder & PMC-1a \& 1b & $350 \max$ & 260 & 232 & 248 & $62.0 \mathrm{~min}$ & 69.5 & 68.7 & 69.0 \\
\hline 10P Powder & PMC-2 & $350 \max$ & 261 & 240 & 247 & $62.0 \mathrm{~min}$ & 68.7 & 67.8 & 68.0 \\
\hline
\end{tabular}


Table 2-71

Emission Spectrographic Analysis

of

Foreign Material in PMC -2

\begin{tabular}{|c|c|}
\hline Element & Percent Weight \\
\hline FE & 1 \\
CU & 30 \\
NI & 0.1 \\
CR & 0.1 \\
SN & 2 \\
TE & 10 \\
PB & 5 \\
MN & 0.3 \\
BI & 1 \\
SB & 5 \\
\hline
\end{tabular}

NOTE: The emission spectrographic data are semi-quantitative since corrections for quantitative analysis were not made. Consequently; the results are accurate to within a factor of $1 / 2$ to 2 times the amount present.

Table $2-72$

Microprobe Analysis of Foreign Material in PMC -2

\begin{tabular}{|l|c|c|c|c|}
\hline Element & Grey & Rose & White & Ridge-Like \\
\hline & & & & \\
CU & 53 & 58 & 3 & $34-58$ \\
SB & 45 & 30 & -- & $12-16$ \\
TE & 2 & 7 & 30 & --- \\
BI & -- & -- & 2 & -- \\
PB & -- & -- & 65 & -- \\
FE & -- & 2 & -- & $14-48$ \\
SN & -- & 3 & -- & $6-12$ \\
\hline
\end{tabular}

NOTE: Three phases were detected and arbitrarily designated as grey, rose and white. In addition, several areas with ridge-like structures were observed in the rose phase. Photomicrographs of the slag indicated eutectic alloys present in the slag.

Data are expressed in weight percent.

Data are within $\pm 15 \%$ of the amount present. 
The initial conclusion from the visual examination was that the low power output observed in Row 36 to 40 section was caused by a chemical reaction between the thermoelectric leg and the copper of the hot junction electrode. The reaction product had caused a short circuit path shorting out several couples and could easily have provided the short to ground. At this point in time the reaction had caused only a reduction in power output, but if the reaction would continue it could cause an open circuit by consuming the copper from the hot junction electrode.

Two parallel courses of action were pursued from this point forward: one was the rebuild of PMC -2 and the other was the failure analysis.

The repair would correct the faulty couples in Rows 37 and 38 , however, it did not correct for the low average $\mathrm{P}$-leg Seebeck ratio and hence the converter would not be expected to produce design power output. However, by adjusting the electrical current in the thermopile, the converter could be forced to match the thermal impedance of a converter that met design objectives. With this current adjustment, PMC -2 could be mated with the SNAP -23A FPMS and system thermal evaluation could proceed. It was on this basis that the repair of PMC -2 was undertaken.

The rebuild of PMC -2 started with an evaluation of the damage to PMC -2 . In addition to the damaged couples, hot junction buttons, and hot junction electrodes, the following additional damage was observed:
A) The fiberglass insulation was partly melted on four instrumenta- tion wires.
B) Six boron nitride insulation strips were broken at the thick section through the pinned area.

The upper eleven positions from Rows 37 and 38 were to be removed. To make room for removal and replacement of parts in these two rows, it was necessary to remove those instrumentation thermocouple wires which were routed between Rows 36 and 37 . The thermocouple wires which had melted insulation were also removed. It was necessary to cut away a portion of the boron nitride insulation strip as shown in Figure 2-63. 
Figure 2-63

Modified Boron Nitride Insulation Strip

for

SNAP-23A Converter PIMC -2 Rebuild

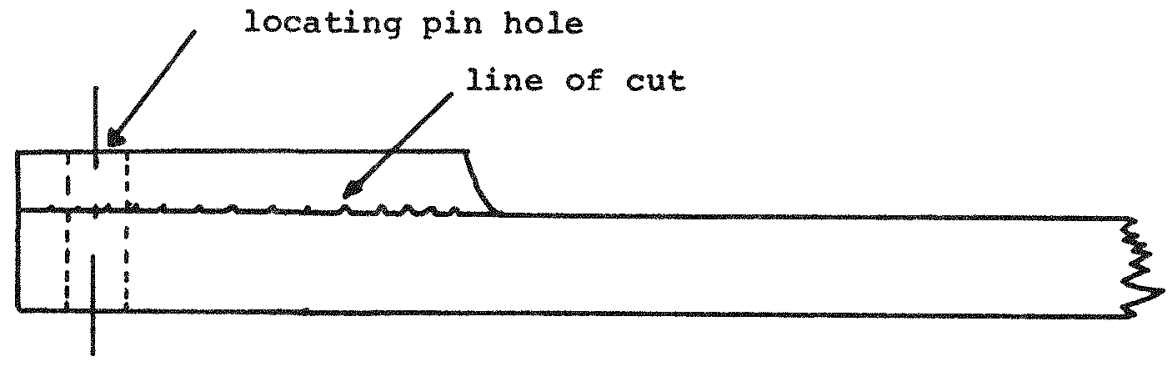

T-shaped channels were used to hold the followers up during removal of parts and $U$-shaped channel was used to hold the followers up during reassembly. This tooling required development because the followers could not be removed in the conventional way with the outer case in place and because of the limited space within the thermopile. The fixtures and procedures were developed after several trial runs on a mock-up, the parts were removed from Rows 37 and 38 of the thermopile; then the new couples, hot junction buttons and hot junction electrodes were installed into the thermopile. During re-assembly the spherical sockets of several of the followers received minor chips; while it was judged that this would have an insignificant effect on thermal performance, it was recommended that PMC -2 not be considered for shock and vibration testing. Temperature instrumentation wires were attached to the cold caps of the legs at the ends of Rows 37 and 38 to provide a means of measuring the cold junction temperature at these two points and monitoring the thermoelectric performance of the couples in Rows 37 and 38. A tabulation of instrumentation revisions was sent to Westinghouse for use in system integration.

With the replacement parts installed in Rows 37 and 38 , the rebuild proceeded up through converter processing configuration. The converter was processed again with just one change from the standard procedure. The maximum hot junction temperature for the seat-in operation was restricted to $1100^{\circ} \mathrm{F}$ maximum to reduce the possibility of initiating a failure mechanism. After processing was completed the top cover components were assembled to the unit and the converter was placed on the test station. Data taken during processing confirmed circuit continuity and the absence of shorts to ground. 
First step in the failure analysis was to examine the legs, hot junction buttons, and hot junction electrodes removed from PMC -2.

The "N" legs at Positions R38A5, R37A7, R37A8 and R38A9, showed evidence of chemical reaction by a copper colored band around the leg part way up from the hot end. The " $P$ " legs at Positions R38A6, R37A 7, R38A8 and R38A10, showed signs of being involved in a chemical reaction because of the dark grey layer of material on the surface of the leg. The "P" leg at Position R38A 10 was also only about one-half normal length. This can be seen in the photograph of this " $\mathrm{P}$ " leg at the lower position in Figure 2-64 compared to a normal " $P$ " leg in the upper position from location R38A 4 in the thermopile.

The exposed surfaces of the hot junction buttons at Positions R38A5, A6, A 7, A.8, $A 9$ and $A 10, R 37 A 7$ and $A 8$ were covered with a dark grey material with the appearance of slag. The hot junction electrodes at Positions R37A7-8, R38A 9-10 and R38A 7-8, had part of the copper material depleted by the chemical reaction. Figure 2-65 shows the extent that this hot junction electrode was depleted. After visual examination, these parts were identified and stored for further analysis. The conclusion from this visual examination was that a reaction had taken place between the copper of the hot junction electrodes and the thermoelectric leg material. The results of the chemical analysis verified that the thermoelectric material had reacted with the copper but what initiated this failure was not apparent from the visual examination. The shortened P-leg at Position R38A10 was unusual and was carefully analyzed; it was mounted and sectioned. The segment of the leg bonded to the cold cap had the same length as the hot segment, which suggested that this P-leg was inverted; chemical analysis verified this suspicion. The leg had been assembled into the converter inverted, with the cold segment at the hot end and the hot segment bonded to the cold cap. At the elevated operating temperatures, the cold end thermoelectric material melted and flowed down on the hot end hardware initiating the chemical reaction with the copper. The reaction spread to the couples in adjacent Rows 37 and 38 .

After the rebuild and processing of PMC -2 was completed initial performance evaluation was conducted. Measurements of converter initial performance were made to determine how converter performance compared to design objectives and to establish a base line with which future performance could be compared. 


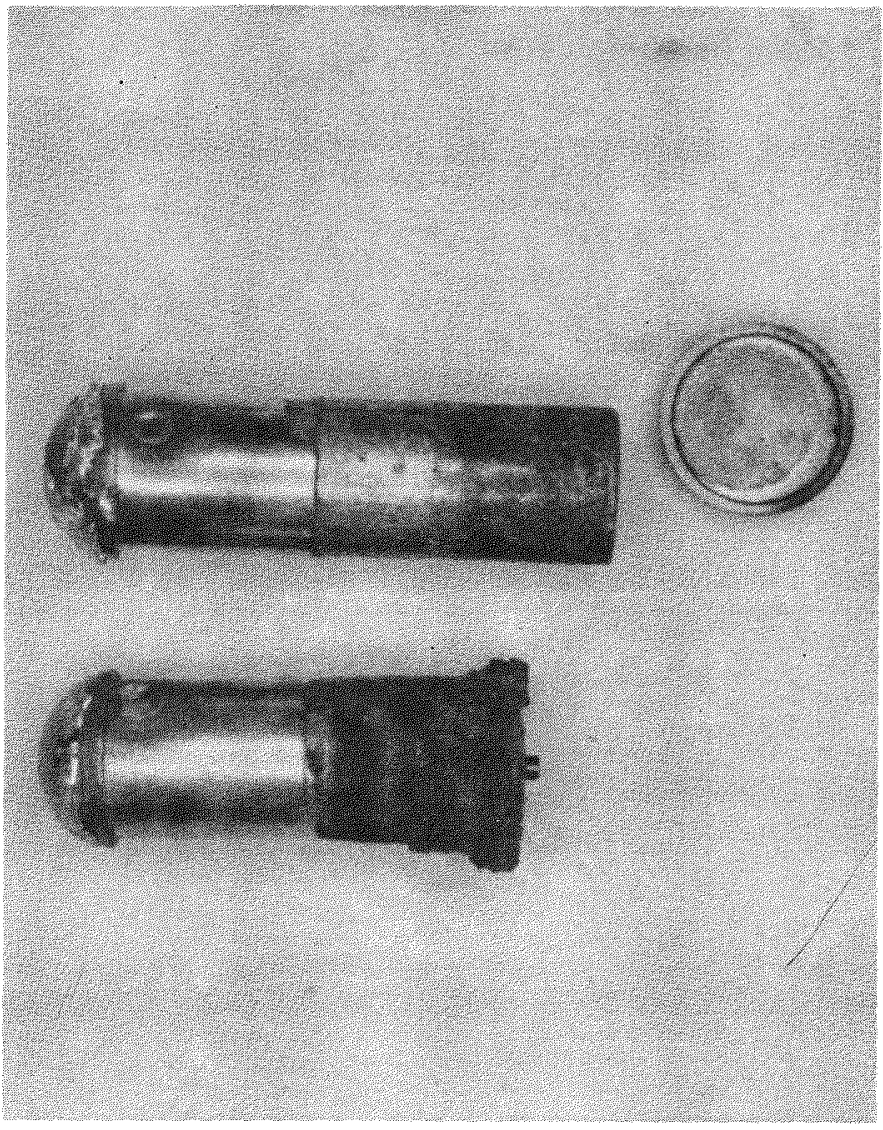

Figure 2-64

Comparison of P-Legs Removed From PIC -2 


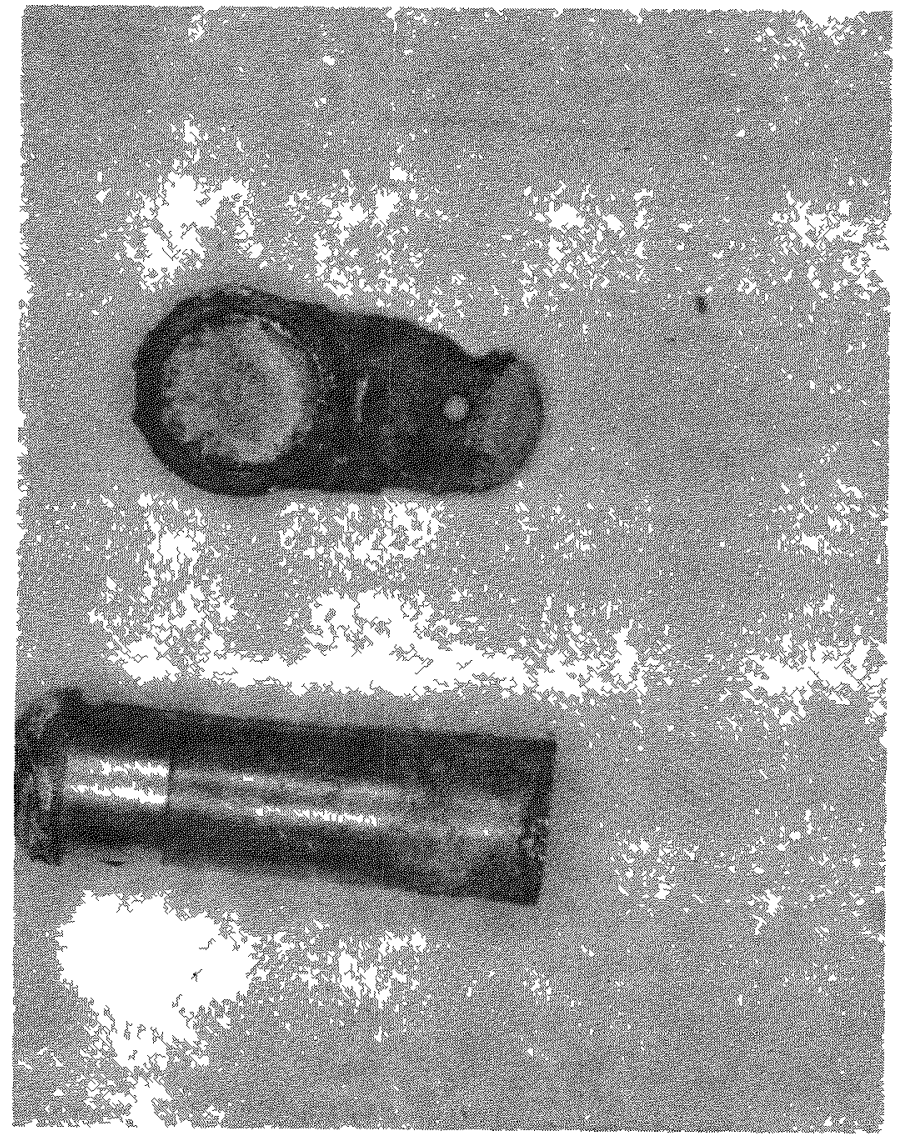

Figure 2-65

Erosion of Hot Junction Electrode Removed From PMC -2 
The initial performance of PMC -2 after stability conditioning is shown by Table 2-73. The complete listing of initial performance data is included in SNAP-23A Quarterly Report No. 13.

As predicted from data taken prior to PMC -2 rebuild, PMC -2 did not meet design objective power output. The cause for the low power output was high electrical resistance and low Seebeck voltage which is evident from a comparison of the actual Seebeck and resistance ratios listed in Table 2-74 with the listed design values.

Table $2-73$

SNAP-23A Converter PIMC -2 Initial Performance

\begin{tabular}{lccc} 
& \multicolumn{2}{c}{ Operating Conditions } \\
\cline { 2 - 3 } & $\underline{\text { BOL }}$ & $\underline{E}$ \\
Hot Junction Temperature, ${ }^{\circ}$ & 1010 & 858 \\
Cold Junction Temperature, ${ }^{\circ} \mathrm{F}$ & 190 & 169 \\
Power Output, Watts & 77.3 & 57.3 \\
Converter Efficiency, Percent & 7.99 & 7.31 \\
Hot Frame-Hot Junction $\Delta t,{ }^{\circ}{ }_{F}$ & 41 & 35 \\
Cold Junction-Outer Case $\Delta t,{ }^{\circ}{ }_{F}$ & 27 & 24
\end{tabular}

Even with this low power output, it was agreed by $3 M$ and Westinghouse that PMC -2 could perform a very useful function when mated to the FPMS. Therefore on the 3M test station, data would be taken so that PMC -2 would be calibrated for its function on FPMS as a thermal calorimeter.

On the nuclear fueled system, the current flow through the converter could be varied from open to short circuit condition to change the thermal impedance. With a variable thermal impedance, the operating temperature of the system could be varied. 
Table $2-74$

SNAP-23A Converter PMC-2 Initial Performance Data

(Ratio of Experimental-to-Theoretical Values)

\begin{tabular}{|c|c|c|c|c|c|}
\hline & \multirow{2}{*}{$\begin{array}{c}\text { Time Evaluated } \\
\text { in } \\
\text { Hours }\end{array}$} & \multicolumn{2}{|c|}{ Seebeck Ratio } & \multicolumn{2}{|c|}{ Resistance Ratio (1) } \\
\hline & & EOL & BOL & EOL & BOL \\
\hline Thermopile $^{(2)}$ & $\begin{array}{rl}\text { Initial EOL }- & 137.5 \\
\text { Initial BOL }- & 219.0 \\
356.0 & 476.0\end{array}$ & $\begin{array}{l}0.94 \\
0.95\end{array}$ & $\begin{array}{l}0.95 \\
0.96\end{array}$ & $\begin{array}{l}1.05 \\
1.01\end{array}$ & $\begin{array}{l}1.035 \\
1.01\end{array}$ \\
\hline Typical N-Leg ${ }^{(3)}$ & $\begin{aligned} & \text { Initial EOL }- 137.5 \\
& \text { Initial BOL }- 219.0 \\
& 356.0 \\
& 476.0\end{aligned}$ & $\begin{array}{l}0.97 \\
0.98\end{array}$ & $\begin{array}{l}0.98 \\
0.98\end{array}$ & $\begin{array}{l}1.00 \\
0.99\end{array}$ & $\begin{array}{l}0.99 \\
0.97\end{array}$ \\
\hline Typical P-Leg ${ }^{(4)}$ & $\begin{array}{r}\text { Initial EOL }-137.5 \\
\text { Initial BOL }-219.0 \\
356.0 \\
476.0\end{array}$ & $\begin{array}{l}0.92 \\
0.92\end{array}$ & $\begin{array}{l}0.94 \\
0.95\end{array}$ & $\begin{array}{l}1.11 \\
1.03\end{array}$ & $\begin{array}{l}1.08 \\
1.07\end{array}$ \\
\hline
\end{tabular}

${ }^{(1)}$ The theoretical resistance values include only $\mathrm{T} / \mathrm{E}$ material resistance.

$\begin{array}{lcc} & \text { Seebeck Ratio } & \text { Resistance Ratio } \\ { }^{(2)} \text { Design Value } & 0.98 & 1.02 \\ { }^{(3)} \text { Design Value } & 1.00 & 1.00 \\ { }^{(4)} \text { Design Value } & 0.96 & 1.03\end{array}$


3M and Westinghouse jointly defined the conditions at which PMC -2 would be tested on the $3 \mathrm{M}$ test station. To define the precise conditions of test, it was necessary to prepare a description of a nominal PMC -2 converter. The converter described would be the nominal device expected from a unit built per design specifications. This description of the nominal PMC -2 converter was a straight line connecting the two points in Table 2-75.

Table $2-75$

Nominal SNAP -23A C onverter PMC -2

Junction Temperature Versus Heat Input

$\begin{array}{lcc}\text { Q Input } & \frac{\mathrm{Th}}{\mathrm{TC}} \\ 1041 \text { Watts } & 1004^{\circ} \mathrm{F} & 187^{\circ} \mathrm{F} \\ 811 \text { Watts } & 852^{\circ} \mathrm{F} & 169^{\circ} \mathrm{F}\end{array}$

This PMC -2 test data was in addition to the normal data taken at; EOL, BOL, current-voltage mapping, and contract specification conditions. The number of additional conditions at which data would be taken was limited by time available in the schedule. Two additional conditions for which data was to be taken were as follows:

a) 940 watts heat input at a $\mathrm{Th}$ from the nominal PMC -2 curve $\left(938^{\circ} \mathrm{F}\right)$. This temperature would be achieved by adjusting the load current.

b) 960 watts heat input at a Th of $952^{\circ} \mathrm{F}$. This temperature would be achieved by adjusting the load current.

An evaluation of the error band associated with the calculated test station heat loss was conducted. The total error band was estimated to be \pm 7 watts. The correlation of station losses with hot frame temperature accounts for \pm 2 watts and the variation of insulation thermal conductivity accounts for the other \pm 5 watts. 
With the test station heat losses determined, the heat flow through PIMC -2 converter on the test station was determined for different current load conditions. This heat flow through the converter was compared with calculated values and the difference was the heat input bias. This heat input bias at different current flow conditions was required for systems evaluation at WANL. To evaluate FPMS characteristics it was necessary to operate at temperatures other than those achieved with the converter operating at 24 load voltage. The temperatures of the system were shifted by causing more or less current of flow through the converter. These heat flow bias values for PMC -2 were compared to different converter parameters. The best correlation between heat input bias was with thermopile electrical resistance. These values were plotted and are shown by the curve of Figure 2-66. Heat flow through the converter would be determined as follows:

$$
\mathrm{Q}_{\text {PMC -2 }}=\mathrm{Q}_{\text {PRAM }-01}+\mathrm{Q}_{\text {LOSS }}-\text { (Value from curve Figure 2-66) }
$$

where:

$$
\mathrm{Q}_{\mathrm{LOSS}}=0.1670 \times(\mathrm{Th}-\mathrm{Tc})-45.97
$$

The results of the long-term performance operation of PMC -2 are included in Section 5.0 .

\subsection{Disposition}

PMC -2 thermal and thermoelectric performance was evaluated on the $3 \mathrm{M}$ test station. Two special tests were run to provide data for Westinghouse to use for FPMS evaluation.

PMC - 2 was operated for 500 hours on the test station and shipped to Westinghouse.

The purpose of shipment of PMC -2 to Westinghouse was to mate PMC -2 with FPMS for system performance evaluation. In addition to the converter, the measured interface dimensions for PMC -2 and a procedure for mating PMC -2 to FPMS were prepared. The two previous converters had been mated to 
Figure 2-66

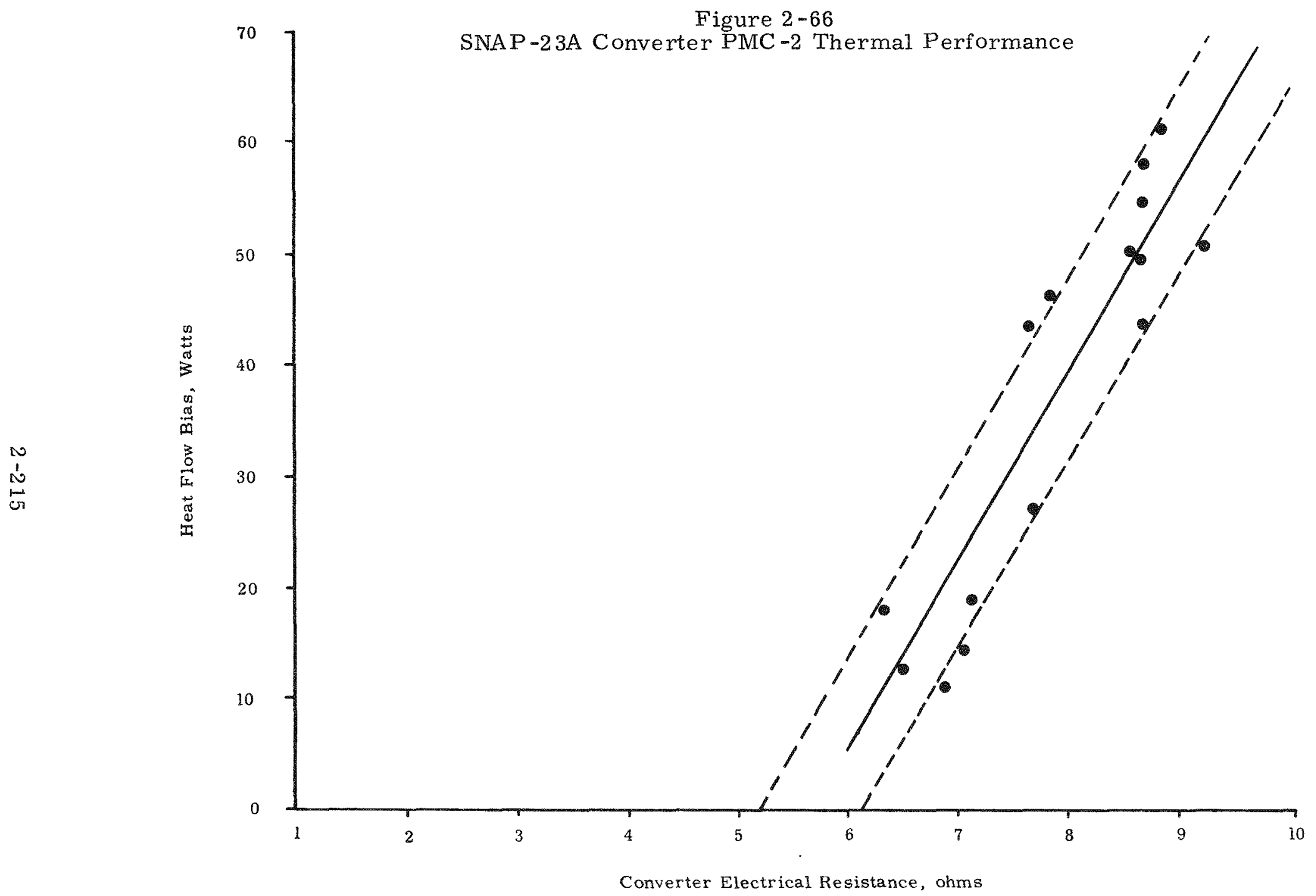

1
1
1
1 
electrically heated systems where the system heat source could be controlled so the cold converter could be mounted on a cold stud. With a nuclear heat source in the system, the stud would be at elevated temperatures at the time of mating. The procedure established the maximum rate of temperature rise of any thermoelectric hot junction. This rate of rise would be monitored and control would be achieved by the rate at which the converter was lowered into the stud.

PMC -2 was mated to FPMS on February 4, 1970, successfully. Converter and stud temperatures were monitored during the mating operation; this data was taken so the rate of converter heat up could be controlled and to establish a data base for an improved mating procedure. The recorded data for this operation is shown by Figure 2-67.

The thermoelectric performance of PMC -2 after mating with FPMS is shown in Table 2-76. PMC -2 was operated on FPMS at Westinghouse for a total of 1632 hours. During this operation period PMC -2 functioned properly without any difficulties.

A schedule was prepared for the removal of PMC -2 from FPMS. Normally when a converter is taken out of operation electric power is shut off and the unit slowly cools to room temperature. In this case PMC -2 would be removed from a heat source at elevated temperatures and the concern was that the rapid cooling could damage the converter. To preclude this kind of damage the following conditions and schedule for PMC -2 removal was prepared.

A. Prior to the start of physical removal of the converter from the hot system stud, the converter would be operated at short circuit electrical load conditions until the average hot junction temperature is down to $875^{\circ} \mathrm{F}$.

B. Then the converter should be removed from the stud in the following increments of distance in relation to time. 


\section{Figure 2-67}

Temperature Rise of Spud and Hot Frame versus

Position of Converter and Time

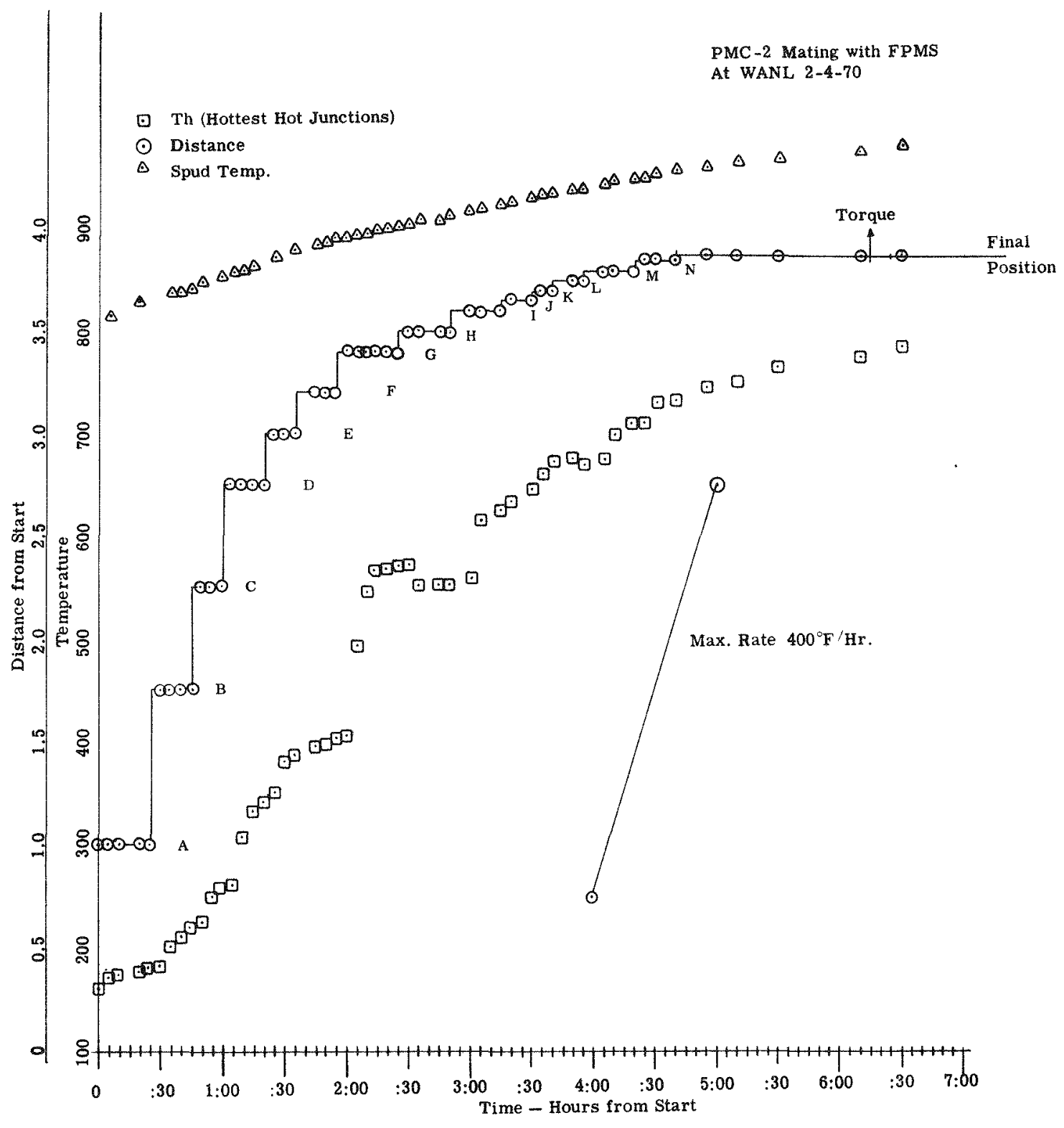


Table 2-76

SNAP-23A C onverter PMC -2 Electrical Performance at 3M and W estinghouse

\begin{tabular}{|l|c|c|c|c|}
\hline & \multicolumn{2}{|l|}{$\begin{array}{l}\text { Normal FPMS } \\
\text { Condition }\end{array}$} & \multicolumn{2}{c|}{$\begin{array}{l}\text { Short Circuit } \\
\text { Condition }\end{array}$} \\
\cline { 2 - 6 } Seebeck Ratio (Thermopile) & WANL & $3 \mathrm{M}$ & WANL & $3 \mathrm{M}$ \\
\cline { 2 - 6 } Resistance Ratio (Thermopile) & 1.06 & 1.03 & 1.07 & 1.06 \\
Hot Junction Temperature & 869.9 & 932 & 855 & 889 \\
Cold Junction Temperature & 180.1 & 175 & 186.6 & 184 \\
Load Voltage & 13.8 & 14.8 & 0.47 & 0 \\
Current & 3.77 & 4.02 & 5.32 & 5.59 \\
Seebeck Voltage & 42.9 & 46.2 & 39.8 & 42.7 \\
Resistance & 7.72 & 7.80 & 7.39 & 7.65 \\
Date & $2-23-70$ & $1-17-70$ & $3-4-70$ & $1-19-70$ \\
\hline
\end{tabular}


Time From Start

Of Removal (Minutes)

0

$0: 15$

$0: 30$

$0: 45$

$1: 00$

$1: 15$

$1: 30$

$1: 45$
Increments of Distance From Previous Position (Inches)

$1 / 8$

$1 / 4$

$1 / 4$

$1 / 4$

$1 / 2$

$1 / 2$

1

Off

On April 13, 1970, PMC -2 was successfully removed from FPMS following the prescribed procedure. The temperature, time, and movement data was recorded as shown in Table 2-77. This data verified that the removal procedure was proper for controlling temperature drop during removal of a converter from a fueled system.

After its removal from FPMS PMC -2 was packaged and returned to 3M where it was placed on a test station and operated to evaluate performance. The performance data is included in Section 5.0 . 
Table $2-77$

SNAP-23A Converter PMC-2 Removal From FPMS

\begin{tabular}{|c|c|c|c|c|c|c|c|c|c|c|c|c|c|c|}
\hline \multirow{2}{*}{\begin{tabular}{|l|} 
Date \\
$4-13-70$ \\
Time \\
\end{tabular}} & \multicolumn{2}{|c|}{ Stud $T_{C}{ }^{O_{F}}$} & \multicolumn{6}{|c|}{ Hot Cap $\mathrm{T}_{\mathrm{c}}{ }^{\mathrm{O}_{\mathrm{F}}}$} & \multicolumn{6}{|c|}{ Remarks } \\
\hline & 335 & 336 & 12 & 13 & 14 & 17 & 18 & 19 & & & & & & \\
\hline 1330 & 954 & 952 & 878 & 829 & 882 & 881 & 862 & 867 & Steady & $\begin{array}{l}\text { Sta } \\
\text { lold }\end{array}$ & Pr & ior & o Remov & \\
\hline 1352 & 960 & 960 & 865 & 792 & 862 & 875 & 837 & 870 & Prior & to 1 & aise & of & $\begin{array}{l}\text { Height } \\
.1125\end{array}$ & $\begin{array}{l}\text { Turns } \\
11 / 8\end{array}$ \\
\hline 1408 & 953 & 947 & 815 & 664 & 790 & 750 & 710 & 775 & $"$ & $"$ & $" 1$ & $n$ & .250 & $21 / 2$ \\
\hline 1422 & 980 & 976 & 685 & 590 & 695 & 715 & 600 & 735 & $"$ & $"$ & $"$ & $"$ & .250 & $21 / 2$ \\
\hline 1437 & 994 & 995 & 633 & 516 & 647 & 622 & 535 & 624 & $" 1$ & $"$ & $"$ & $"$ & .250 & $21 / 2$ \\
\hline 1452 & 1008 & 1006 & 550 & 471 & 559 & 576 & 485 & 580 & $" 1$ & 11 & $"$ & $n$ & .500 & 5 \\
\hline 1507 & 1020 & 1019 & 468 & 412 & 471 & 504 & 419 & 495 & $"$ & $"$ & $"$ & 11 & .500 & 5 \\
\hline 1522 & 1025 & 1022 & 414 & 353 & 417 & 441 & 359 & 433 & $" 1$ & $"$ & $" 1$ & 11 & 1.000 & 10 \\
\hline 1537 & 1022 & 1024 & 321 & 293 & 321 & 351 & 290 & 337 & $"$ & " & Com & ple & Removi & \\
\hline
\end{tabular}




\subsubsection{PMC-3 Converter}

PMC -3 converter was built as a replacement for PMC-2. The plans for building PMC-3 started after trouble was encountered with PIMC-2 during its initial processing cycle. It was built to mate with FPMS for long-term systen and converter evaluation.

\section{3 .3 .4 .1 Design Activities}

PMC-3 was of the same basic design as PMC-2. Some design modifications were made to make use of an existing cold frame, to control dimensions of the hot frame to mate with FPMS, and to avoid the type of themopile failure encountered with PMC-2.

The possibility of using the cold frame from disassembled PMC-1B was investigated. The most difficult problem was that the PMC-1B cold frame had a smaller outside diameter than PMC-2 design. With this smaller $\mathrm{O}_{0} \mathrm{D}$. , the outside interface diameter of PMC-3 would be smaller than interface drawing requirements. This problem was resolved when Westinghouse agreed to modify the system heat sink radiator to accept this smaller diameter. PMC-1B cold frame was also modified for the different method of attachment of the cold frame to the outer case. The drawing for the hot frame was also modified to the taper which would correspond to the heat stud taper of FPMS.

At the time of $\mathrm{PMC}-3$ design preparation the failure analysis of $\mathrm{PMC}-1 \mathrm{~B}$ and PMC-2 was not complete. It was evident that the failure of these two converters involved a reaction between the thermoelectric legs and the copper of the hot junction electrode. The decision was made to use a solid iron electrode as a replacement for the plated copper electrode. The long-term chemical compatibility of iron with thermoelectric materials had been demonstrated by SNAP-21, SNAP-23, SNAP-23A, and SNAP-27 thermoelectric devices on long-term operation. In these devices the hot junction button was made of iron which was in direct contact with the hot end of the legs. In addition, SNAP-21 six-couple module tests have demonstrated long-term performance stability with solid iron hot junction electrodes for continuous operation of over four years. What had not been evaluated with iron hot junction electrodes was the following: 
A. The seat-in characteristics of the legs with the existing procedures.

B. The actual increase in circuit electrical resistance.

The increase in electrode electrical resistance by changing from copper to iron was calculated as was the change in thermal impedance. A test in the bell jar was conducted to verify the effect on electrical resistance.

In parallel with the bell jar test, a design for a solid iron hot junction electrode was prepared so that parts could be procured to meet the assembly schedule. The hot junction electrode was made as thick as possible to reduce the electrical resistance. To accommodate the thicker hot junction electrode, the leg compression spring was redesigned to provide the 250 psi leg contact pressure. Figure 2-68 shows the relative dimension of the electrode designs. An iron electrode with the same overall dimension $(0.055)$ as the previous copper electrode and iron button was calculated to have an electrical resistance such that the circuit resistance of the thermopile would be increased 1.5 percent. The thicker iron electrode design (0.102 thick) prepared for PMC-3 was calculated to increase the thermopile electrical resistance only one percent. What could not be taken into account during these calculations was any influence on contact resistance between the electrode and the leg hot end.

Selection of thermoelectric material batch for PMC-3 was given special consideration in an attempt to improve PMC-3 electrical performance over that exhibited by PMC-2. In making this selection, the quality control measurements of electrical resistivity at room temperature and Seebeck voltage of various batches were examined and evaluated. This examination revealed the major variation occurred in the hot $\mathrm{P}$ segment material with only minor variation indicated for the other thermoelectric materials.

Thermoelectric material batch selection for PMC-3 was therefore confined to the hot $P$ segment material. Quality control measurements from all $P$ hot segment batches available at the time of selection are listed in Table 2-78. The data shows a variation of two $\mathrm{mv}$ in Seebeck voltage and 20 micro-ohm-inches in room temperature resistivity among the batches. In addition, the relative 
Figure 2-68

Hot Junction Electrode Comparison

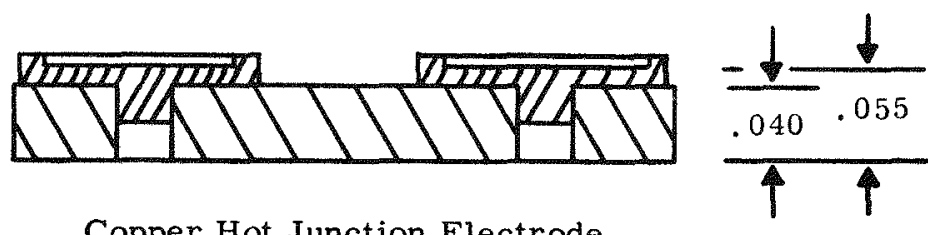

Copper Hot Junction Electrode

With Iron Hot Junction Buttons

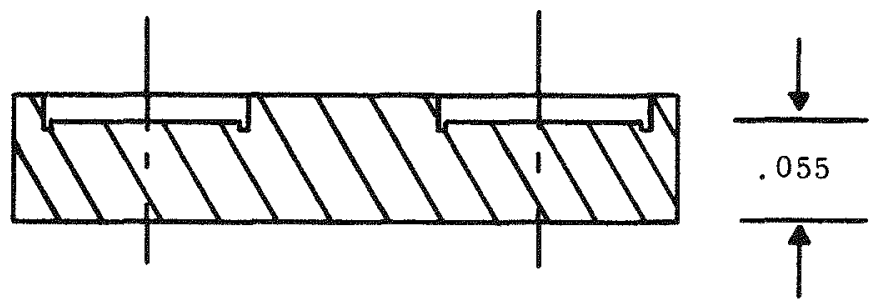

Iron Hot Junction Electrode Used For Bell Jar Tests

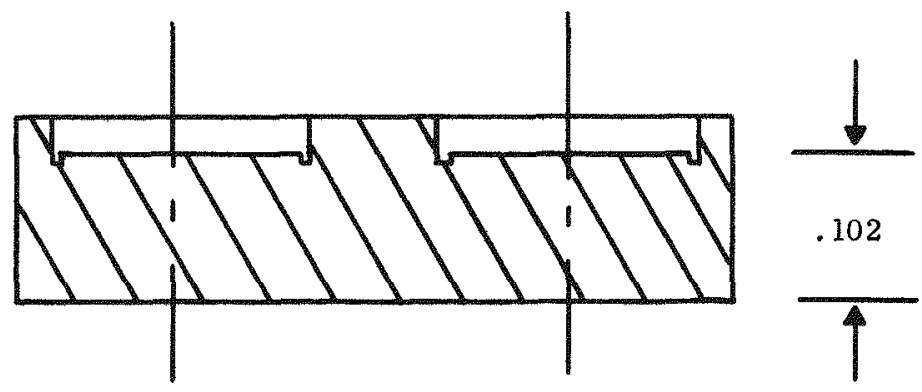

Iron Hot Junction Electrode

Designed For PMC-3 
Table 2-78

Selection of SNAP -23 A Converter PIMC-3

P-Leg Hot Segment Material

\begin{tabular}{cccc} 
Batch No. & $\mathrm{E} \mathrm{mV^{* }}$ & $\frac{\rho_{\mu} \Omega \mathrm{in}}{370.5}$ & $\frac{\mathrm{E}^{2} \rho_{\rho}}{10.5}$ \\
\cline { 2 - 3 } 77 & 62.4 & 376.0 & 10.2 \\
78 & 62.0 & 362.8 & 10.7 \\
79 & 62.2 & 365.0 & 11.0 \\
80 & 63.3 & 360.3 & 11.1 \\
81 & 63.2 & 368.8 & 10.9 \\
82 & 63.5 & 369.5 & 10.9 \\
83 & 63.4 & 357.3 & 11.2 \\
84 & 63.1 & 375.0 & 10.8 \\
85 & 63.6 & 372.5 & 11.0 \\
86 & 63.9 & 373.5 & 10.8 \\
87 & 63.6 & 375.8 & 10.9 \\
89 & 64.1 & 364.3 & 11.1 \\
$90 * * * *$ & 63.6 & 364.8 & 11.1 \\
91 & 63.6 & 353.8 & 11.0 \\
92 & 62.4 & 352.5 & 10.9 \\
93 & 62.0 & 354 & 11.0 \\
94 & 62.5 & &
\end{tabular}

$* \mathrm{Th}=875^{\circ} \mathrm{F}$; Average of four segments。

$* *$ Temperature $=75^{\circ} \mathrm{F}$; Average of four segments

****Batch selected for PMC-3 
power number, $\mathrm{E}^{2} / \rho$, indicates a variation of 10 percent. Based on the Seebeck voltage and the relative power number, batch $\mathrm{B}-90$ was selected for PMC -3 .

This selection technique did not assure that converter performance would fall in the design range established for SNAP-23A. Only an ingradient test performed at or near the SNAP-23A cold and hot junction temperatures can be used to predict expected couple performance in a converter.

Two bell jar tests were conducted with leg performance measure at converter operating temperatures. In these same two bell jar tests the iron hot junction electrode was evaluated for use in PMC-3. Both bell jars were extensively instrumented to measure hot and cold junction temperatures, Seebeck voltage and resistance of individual legs, and resistance of the hot junction electrodes. Thermoelectric couples used in these bell jar tests were samples from the production lot and batch proposed for use in PMC-3. The hot segment material of the P-leg was from material batch number 90 .

Bell Jar Test Conclusions:

- Initial Seebeck ratios met the PMC-3 design requirements.

- Initial resistance ratios were one to three percent greater than the design value.

- Post-stability resistance ratios showed a six percent reduction in Seebeck ratio.

- The thermopile resistance decreased during the stability conditioning period which was due mainly to an improvement in the $\mathrm{P}-\mathrm{leg}$ resistance. The Seebeck ratio decreased resulting in a net power output improvement.

- The solid iron hot junction electrode designed for PMC-3 increased the electrical resistance only one percent.

- The legs would "seat-in" as well to the iron as to the copper hot junction electrodes. 
PMC-3 thermoelectric performance was predicted based on the results of these two bell jar tests. The purpose of the prediction based on these ingradient tests of thermoelectric legs was to determine if these same legs in PMC-3 would produce design objective power output. The bell jar test data used in these predictions is displayed by Table 2-79. These Seebeck and resistance ratios were all normalized to thermopile design temperatures.

Table 2-79

SNAP-23A Converter PIC-3 Pre-Build Bell Jar Test Data

\begin{tabular}{|c|c|c|c|c|}
\hline Operating Conditions & $\begin{array}{c}\text { Bell Jar } \\
\text { Test *1 }\end{array}$ & $\begin{array}{c}\text { Bell Jar } \\
\text { Test \#2 }\end{array}$ & $\begin{array}{c}\text { Bell Jar } \\
\text { Test \#2 }\end{array}$ & $\begin{array}{c}\text { Thermopile } \\
\text { Design Values }\end{array}$ \\
\hline Hours of Operation & 50 & 262 & 1214 & \\
Temp. Hot Junction & 861 & 860 & 860 & \\
Temp. Cold Junction & 167 & 169 & 169 & \\
Characteristic & & & & \\
Seebeck Ratio & & 0.97 & 0.97 & 0.98 \\
Thermopile & 0.98 & 0.99 & 1.00 & 1.00 \\
N-Leg & 1.00 & 0.95 & 0.95 & 0.96 \\
P-Leg & 0.96 & & & \\
Resistance Ratio & & 1.00 & 0.96 & 1.02 \\
Thermopile & 1.00 & 0.97 & 0.96 & 1.00 \\
N-Leg & 0.96 & 1.03 & 0.95 & 1.03 \\
P-Leg & 1.05 & & & \\
\hline
\end{tabular}

In addition to data on Seebeck and resistance ratios from the bell jar tests, the effects of the following factors were included:

a. A one percent resistance increase for the inclusion of the solid iron hot junction electrodes in PMC-3 converter.

b. Difference between bell jar and converter performance with legs from same batch and lot.

c. The decrease of electrical resistance during stability conditioning period. 
These factors were used to predict PMC-3 power output in the manner shown by the equation of Table 2-80. The design power output was adjusted by the addition or subtraction of the effect of five factors. The EOL predicted power output based on the initial performance of couples in bell jar No. 1 and No. 2 was 61.3 watts. In addition, a prediction was made based on the performance of couples in No. 2 bell jar which had operated through the stability conditioning period up to 1214 hours; this prediction was 61.7 watts EOL power output. On the basis of both these power output predictions, legs from the same lot and batch as those tested in the bell jar were accepted for assembly into PMC -3 . These test also verified the acceptability of using the all-iron electrode in PIMC-3.

Table $2-80$

SNAP-23A Converter PMC-3 Power Output Predictions

Predicted Power Output $=$ Design Power + Iron Electrode Resistance Adjustment + Bell Jar to Converter Correlation \$ Stability Condition Change + Seebeck Difference $\mp$ Resistance Difference

Design Power

Iron Electrode

Resistance Adjustment

Bell Jar to Converter

Cor relation

Stability Conditioning

Change

Seebeck Difference

Resistance Difference

Predicted PMC-3 Power
Based on Initial

No, 1 and No, 2

Bell Jar Data

Watts $\%$

61

$-0.6$

$-1.2$

$+1.5$

$-0.6$

$+1.2$

61.3

$-2$

$-1$

$+2$
Based on Stability Conditioned No. 2 Bell Jar

Watts $\%$

61

$-0.6$

$-1$

$-1.2$

$-2$

$+2.5$

N. A。

N. A。

$-1.2$

$-2$

$+3.7$

$+6$

N. A. - Not Applicable 
In summary the following component design changes were made in $\mathrm{PIMC}-2$ design for PMC-3:
A) A nominal hot frame taper of 1.246 instead of 1.250 inches/foot.
B) The use of PMC-1B cold frame which caused the converter to have a smaller outside diameter.
C) An iron hot junction electrode instead of a copper plated part.
D) A decrease in the diameter of indium foil used between the follower and cold cap from $0.25^{\prime \prime}$ to $0.219^{\prime \prime}$.
E) Leg compression spring redesigned to provide $250 \mathrm{psi}$ leg contact pressure with the thicker iron electrode.

Data from the stability conditioning periods of all previous converters was reviewed. The effect of electrical resistance with time and temperature was studied to determine the stability conditioning operating temperatures and time for PMC-3. The typical change in both Seebeck and resistance during the initial operation of the thermopile is illustrated by the No. 2 bell jar test data in Figure 2-69. This study established a stability conditioning period of 500 hours at a hot junction temperature $1080^{\circ} \mathrm{F}$ for $\mathrm{PMC}-3$.

\section{3 .3 .4 .2 Summary of Converter Design}

PMC-3 converter was built as a replacement for PMC-2 and was of the same basic design. Several modifications were made to the design based on inputs from assembly, disassembly, rebuild, and performance of PMC-2. The purpose of these changes was as follows:

- To prevent potential reaction between the thermoelectric legs and the copper of the hot junction electrode.

- To make use of a salvaged cold frame from PMC-1B.

- To control dimensions of the hot frame for mating with FPMS. 
Figure 2-69

Performance During Stability Conditioning PMC-3 Couples in Bell Jar Test No. 2

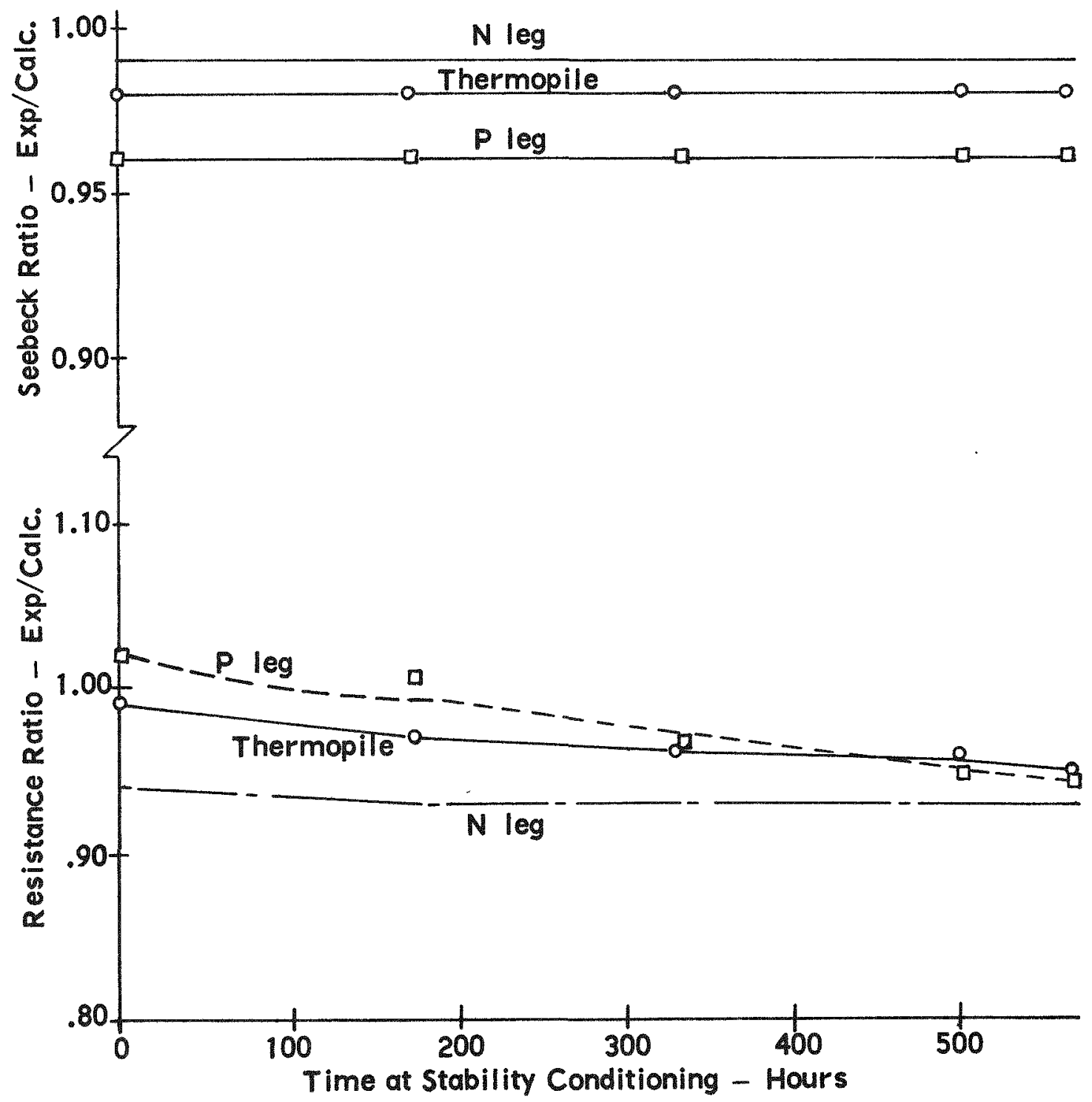


To achieve these objectives, the following specific changes or features were incorporated

- The taper of the hot frame was machined to fit the system stud.

- The outside diameter of the converter was reduced so the cold frame from PMC-1B could be used.

- The hot junction electrodes were made from iron.

- Satisfactory performance of the couples was verified by ingradient tests in bell jars before thermopile assembly.

\section{3 .3 .4 .3 Assembly}

Assembly of PMC-3 was identical to that for PMC-2. However, several incidents were noted as they would influence component design of future converters.

A. Chipping occurred on the boron nitride hot side insulation strips in the area of the hot junction electrode.

B. Follower spring back-up washer diameter was so large causing a tendency to bend in the hole.

C. The inside diameter of the header ring decreased as a result of welding to the outer case causing a misfit with the support cone.

D. The seal material at the open end of the sheathed thermocouples reacted to cause an error in temperature read-out.

E. The gas pinch-off tube did not seal and required rework. The defect was caused by pinching the tube too close to where it was brazed to the stainless steel part.

Assembly of PMC-3 was completed on March 21, 1970.

\section{3 .3 .4 .4 Quality Control}

Quality Control was the same for PMC-3 as was for PMC-2 except for one additional inspection step. All $\mathrm{P}$-legs were examined for excessive flash where the leg attaches to the cold cap. The flash was BiSbTe cold segment material which had melted and 
flowed down the leg. This flash was caused by wear in the mold used for bonding the leg to the cold cap.

\section{3 .3 .4 .5 Initial Performance}

PMC-3 was placed on test while mounted to the process-test station. Initial performance measurements were made to determine how well the converter met design objectives and to establish a base line for comparison with long-term performance. Initial performance of PMC-3 after stability conditioning is shown by Table 2-81. The complete listing of initial performance data ia included in SNAP-23A Quarterly Report No. 13.

The initial power output of stabilized PMC-3 converter was almost identical to the pre-build predictions in Table 2-80. This correlation demonstrates that bell jar test data can contribute to an accurate prediction of converter performance.

Table 2-81

SNAP-23A Converter PMC-3 Initial Performance

\begin{tabular}{lcr} 
& \multicolumn{2}{c}{ Operating Conditions } \\
Hot Junction Temperature ${ }^{\circ}{ }_{F}$ & $\underline{B O L}$ & $\underline{E O L}$ \\
Cold Junction Temperature, ${ }^{\circ} \mathrm{F}$ & 1011 & 860 \\
Power Output, Watts & 186 & 165 \\
Converter Efficiency, percent & 82.1 & 61.2 \\
Hot Frame-Hot Junction $\Delta t,{ }^{\circ} \mathrm{F}$ & 8.18 & 7.57 \\
Cold Junction-Outer Case $\Delta t,{ }^{\circ} \mathrm{F}$ & 32 & 25 \\
\end{tabular}

\section{3 .3 .4 .7 Disposition}

After assembly and processing of PMC-3 was complete, initial performance was evaluated and stability conditioning conducted on the test station. After operating for 672 hours on the $3 \mathrm{M}$ test station the converter was removed, packaged, and shipped to Westinghouse for mating with FPMS. 
A new schedule for mating converters onto isotopic fueled systems was prepared for PMC-3. The objective was to develop a schedule that did not depend on temperature measurements for determination of the rate of engagement. This type of schedule would be necessary for the APC (Advanced Prototype Converters) units that do not have internal temperature instrumentation. The data that was recorded during the mating of $\mathrm{PMC}-2$ to the fueled system was used to develop the following schedule:

A. Lowex the converter to a position where the lower cover hot frame weld is $1 / 4$ inch above the top of the stud. Hold the converter in this position until the temperature of the lower instrumented hot junction button is $150^{\circ} \mathrm{F}$.

B. Proceed to lower the converter in steps of distance per time interval as defined by Table 2-82.

Table 2-82

Mating Schedule of

SNAP-23A Converter PMC-3 to Fueled System

\begin{tabular}{|c|c|c|}
\hline $\begin{array}{c}\text { Time from Start } \\
\text { (hours/minutes) }\end{array}$ & $\begin{array}{c}\text { Movement Increment } \\
\text { (Inches) }\end{array}$ & $\begin{array}{c}\text { Total Movement } \\
\text { from Start } \\
\text { (Inches) }\end{array}$ \\
\hline 0 & $0.70^{\prime \prime}$ & $0.70^{\prime \prime}$ \\
$0 / 15$ & 0.60 & 1.30 \\
$0 / 30$ & 0.50 & 1.80 \\
$0 / 45$ & 0.35 & 2.15 \\
$1 / 00$ & 0.30 & 2.45 \\
$1 / 15$ & 0.25 & 2.70 \\
$1 / 30$ & 0.20 & 2.90 \\
$1 / 45$ & 0.20 & 3.10 \\
$2 / 00$ & 0.15 & 3.25 \\
$2 / 15$ & 0.15 & 3.40 \\
$2 / 30$ & 0.10 & 3.50 \\
\hline
\end{tabular}


C. From the last step of Table 2-82, lower the converter 0.10 inch every fifteen minutes until the hot frame is mated with the system stud.

D. During the mating operation, the power output leads of the converter must be shorted for maximum current flow.

On May 12, 1970, PMC-3 was mated to FPMS at Westinghouse. The mating procedure prescribed was followed and no difficulties occurred. During the mating operation temperatures and converter lowering position were recorded as a function of time. A summary of this data is shown by Figure 2-70. As can be seen by the curves of Figure 2-70, the converter hot junction temperature and system spud temperatures did converge. Also the rate of temperature rise of the hottest hot junction was below the desired maximum of $400^{\circ} \mathrm{F}$ per hour.

The performance of PMC-3 on FPMS was monitored and recorded. As the heat input to the converter could not be varied in this fueled system, it was not possible to take data to compare with 3M-measured EOL and BOL test data. PMC-3 performed properly throughout its period of testing; Table 2-83 is a summary of data read-out from the system test which shows PMC-3 performance. PMC-3 was still operating on FPMS when the contract was completed at the end of June 1970. 


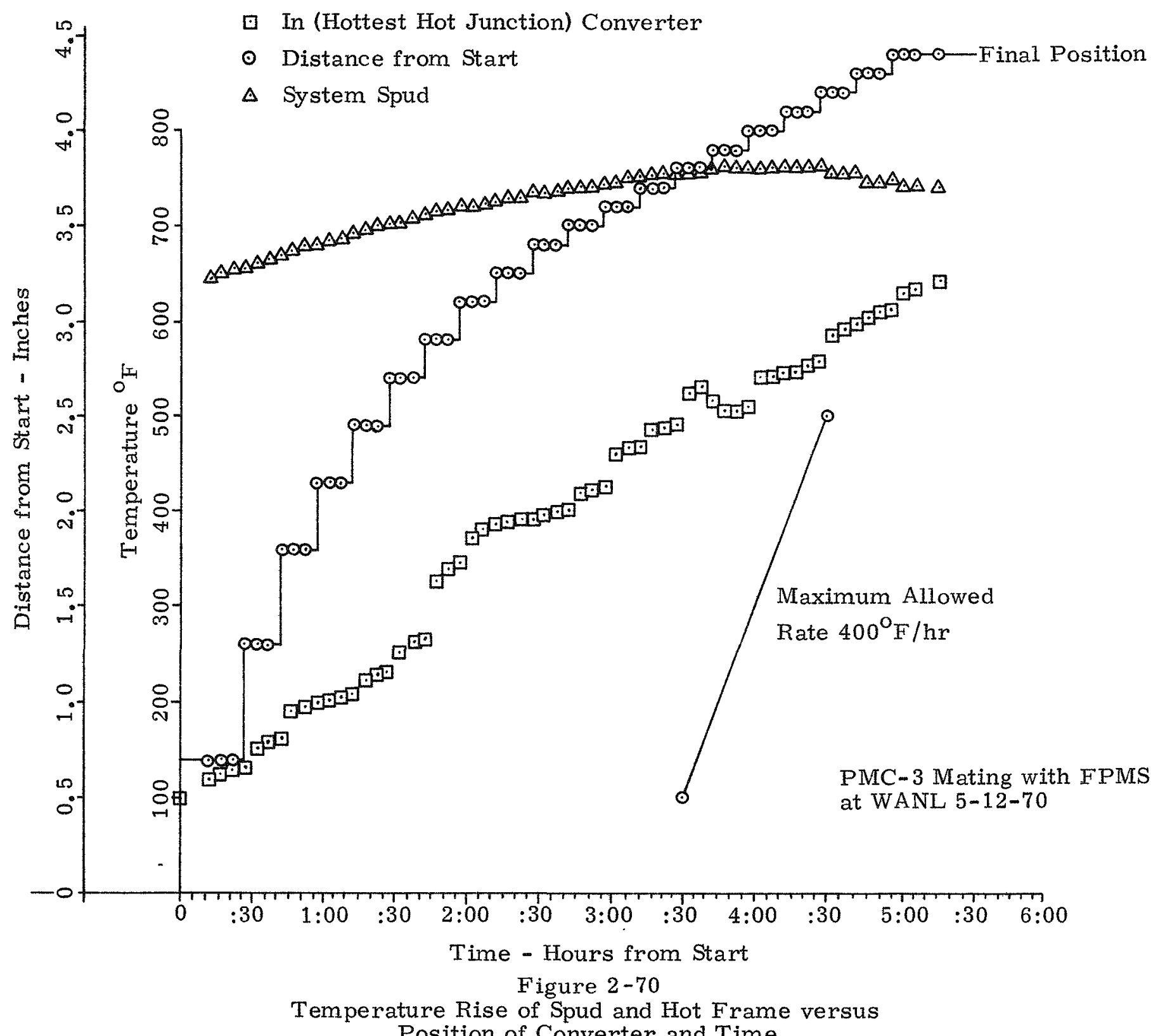


Table 2-83

SNAP-23A Converter PMC-3/FPIS

TEST POINT SUMMARY

Description

A. Converter Performance

Voltage - volts

Current - amps

Power output - watts

Open circuit voltage - volts

Internal resistance - ohms

B. System Output (P.C. out)

Load voltage - volts

Load current - amps

Net power output - watts

C. Converter Temperatures ${ }^{\circ} \mathrm{F}$

$T$ hot frame web
$\bar{T}$ hot cap
$\bar{T}$ cold cap
$\bar{T}$ outer case

D. Base Assembly Temperatures

$\bar{T}$ external bottom

$\bar{T}$ external side

$\overline{\mathrm{T}}$ bucket bottom

T bucket support ring

$\overline{\mathrm{T}}$ inner ring-seal

E. Radiator/Ambient Temperatures ${ }^{\circ} \mathrm{F}$

T radiator fin base

T shroud

T power transistor cover

$T$ ambient

F. Heat Source Temperatures ${ }^{\circ} \mathrm{F}$

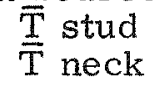

G. Date

H. FPMS Test Time
Krypton Filled Base Assembly (1.5 psig)
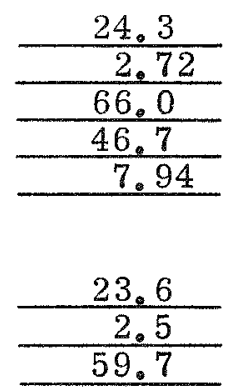

$\begin{array}{r}937 \\ \hline 932 \\ \hline 171 \\ \hline 153 \\ \hline\end{array}$

135

122

1221

1206

1182

$\begin{array}{r}\frac{143}{122} \\ \hline 122 \\ \hline 80 \\ \hline\end{array}$

1028

1173

$5-21-70$

216 


\subsection{PHASE II, ADVANCED PROTOTYPE CONVERTERS (APC)}

\subsection{INTRODUCTION}

Phase II of the SNAP-23A program was initiated in February of 1970. In Phase II, plans were made to build four APC units; one for laboratory testing and three for field trial. Design of the $A P C$ units was initiated based on PMC-2 with changes incorporated to improve reliability and reduce costs. A quality control program for thermoelectric materials, leg and couples using the 3M TEMPS facility was initiated with the objective to provide as surance that SNAP-23A performance requirements would be met. Fabrication of long-lead time components was initiated to meet the tight Phase II procurement schedule.

The objective of the Phase II program was to demonstrate field service capability of the SNAP-23A systems in various terrestrial environments. To accomplish this goal, three SNAP-23A isotope fueled systems would be operated at remote sites which require a continuous, unattended electrical power supply. A fourth SNAP-23A system with internal instrumentation for diagnosis of temperature distributions and individual thermoelectric leg performance was to be tested in the laboratory. The field service systems would be monitored periodically to confirm expected performance as measured on the laboratory system. 


\subsection{CONVERTER DEVELOPMENT}

\subsubsection{Design Changes}

A review of all thermoelectric converter piece-part drawings was conducted. The objective of this review was to simplify the design of all components where possible and to correct any deficiencies that were identified during fabrication of PMC-2 and PMC-3. These changes would result in a less costly converter with greater reliability.

As a result of the design review, changes were made to the piece-part drawings which can be categorized as follows:

- Simplify the component by relaxing tolerances, changing materials or re-dimensioning to facilitate machining and inspection.

- Specify additional non-destructive tests to detect flaws that could be potential failure modes.

- Re-dimension components that were previously match-drilled to achieve interchangeability.

A detailed discussion of design changes is presented in SNAP-23A Quarterly Report No. 13.

3.2.2 Development of Thermoelectric Leg and Couple Acceptance Test Methods

\subsubsection{Introduction}

Thermoelectric materials acceptance test methods used for PMC-2 and earlier converter couples did not provide adequate assurance that the stringent performance requirements of SNAP-23A converters would be met. Studies have shown that correlation exists between the $Q C$ acceptance test results ${ }^{(1)}$ and thermoelectric

(1) Acceptance is based on room temperature resistivity and Seebeck voltage measured over the temperature interval of $75^{\circ} \mathrm{F}$ to $675^{\circ} \mathrm{F}$ or $75^{\circ} \mathrm{F}$ to $875^{\circ} \mathrm{F}$. 
performance at the operating temperature interval in the converter. However, the correlations have a wide band of variance such that thermoelectric materials with equal acceptance test results may result in acceptable converter performance in one case and unacceptable performance in another.

An improved approach to acceptance testing is to measure thermoelectric properties in the temperature interval experienced in the SNAP-23A converters. This realistic ingradient acceptance test offers the potential for being the most accurate prediction of converter thermoelectric performance since extrapolation from room temperature to converter operating temperature conditions is not required. Two test fixtures are available for ingradient testing; bell jars and the $3 \mathrm{M}$ TEMP ${ }^{(2)}$ facility. In bell jar tests, the resistance and Seebeck voltage of the $\mathrm{N}$ - and $\mathrm{P}$-legs of a couple can be measured. In TEMP fixtures, the thermal conductance can also be measured. TEMP has the added advantage of being significantly faster than a bell jar and therefore is preferable for acceptance testing.

\subsubsection{Qualification of TEMP for Acceptance Testing}

A series of ingradient measurements was planned to qualify TEMP for quality control acceptance testing. The planning, described in SNAP-23A Quarterly Report No. 13, included measurements of the point function properties $\mathrm{S}, \mathrm{k}$ and $\mathrm{ok}$ of homogeneous samples and measurements of the integrated performance parameters $\mathrm{E}, \mathrm{R} \mathrm{A/L}$ and $\mathrm{Q} L / \mathrm{A}$ of segmented legs and leg-cap assemblies at typical SNAP-23A junction temperatures. Qualification would be made through comparison of TEMP results to converter and bell jar results.

The qualification effort was completed to the stage of measuring point funtion properties of the homogeneous samples and comparing the results to bell jar measurements. The remaining planned effort was not completed by the end of SNAP-23A program.

(2) TEMP stands for Thermo Electric Material Properties. TEMP refers to a $3 \mathrm{M}$ facility for measurement of thermoelectric material properties as a function of temperature. 
The TEMP point function measurements were made on eight lots of thermoelectric materials which were selected as prime candidates for APC couples. The measurements were made on at least three samples from each lot with the results averaged to obtain properties assigned to that lot. Segmented leg performance was then predicted by integrating point function properties from the cold junction to the segment point and from the segment point to the hot junction.

Results from the TEMP measurements are presented in Table 3-1 together with bell jar test results. The TEMP predictions of resistance and Seebeck voltage were made using average properties for the cold segment lot and hot segment lot in each $\mathrm{N}-\mathrm{leg}$ and $\mathrm{P}-\mathrm{leg}$.

Bell jar to TEMP correlations are shown in Table 3-2. It can be noted that the Seebeck voltage of the four lots of material can be predicted to within $1 \%$. The resistance predicted by TEMP is, however, 12-20\% less than bell jar resistance. Part of this difference may be attributed to measurement technique. The bell jar uses the hot junction electrode, which introduces contact resistance at the hot junction, while the TEMP requires no electrode. A further cause of the difference may be attributed to end effects in the TEMP measurements which would yield a low resistivity value. This has been observed on other TEMP measurements.

Lot-to-lot comparisons as measured in the bell jars and TEMP are presented in Table 3-3. Both bell jar results predict a difference in P-leg resistance in Lot 13 and Lot 14 of $6 \%$. In addition, both test methods predict a small difference in Seebeck voltage between the two lots of $\mathrm{N}$-legs and essentially no difference in Seebeck voltage between the two lots of P-legs. The bell jar results, however, indicate an $8 \%$ difference resistance between $\mathrm{N}-$ Leg Lots 15 and 16 whereas the TEMP results show only a $1 \%$ difference.

In conclusion, TEMP results can be used to closely predict Seebeck voltage of a segmented leg. However, TEMP prediction of resistance must be increased by $10-20 \%$ to correlate with bell jar resistance. The cause for this difference is suspected to be inordinately low TEMP resistivity values. Further testing would be required to define the differences and provide the proper factors for correction and correlation. 
Table 3-1

Bell Jar And TEMP Results APC Couple Materials

\begin{tabular}{|c|c|c|c|c|c|c|}
\hline$\underline{\mathrm{LEG}}$ & $\underline{\text { LOT }}$ & TEST & 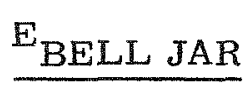 & $\mathrm{R}_{\mathrm{BELL}} \mathrm{JAR}$ & $\mathrm{E}_{\text {TEMP }}$ & $\mathrm{R}_{\mathrm{TEMP}}$ \\
\hline$N$ & 15 & $\frac{1}{2}$ & $\begin{array}{l}82.9 \mathrm{mv} \\
84.5 \mathrm{mv}\end{array}$ & $\begin{array}{l}14.16 \mathrm{~m} \Omega \\
14.32 \mathrm{~m} \Omega\end{array}$ & $\begin{array}{l}83.2 \mathrm{mv} \\
83.2 \mathrm{mv}\end{array}$ & $\begin{array}{l}11.87 \mathrm{~m} \Omega \\
11.87 \mathrm{~m} \Omega\end{array}$ \\
\hline $\mathrm{N}$ & & Ave. & $83.7 \mathrm{mv}$ & $14.24 \mathrm{~m} \Omega$ & $83.2 \mathrm{mv}$ & $11.87 \mathrm{~m}^{\Omega}$ \\
\hline \multirow[t]{2}{*}{$\begin{array}{l}\mathbf{N} \\
\mathbf{N}\end{array}$} & $\begin{array}{l}16 \\
16\end{array}$ & $\begin{array}{l}1 \\
2 \\
\end{array}$ & $\begin{array}{l}82.1 \mathrm{mv} \\
81.6 \mathrm{mv} \\
\end{array}$ & $\begin{array}{l}12.94 \mathrm{~m} \Omega \\
13.38 \mathrm{~m} \Omega \\
\end{array}$ & $\begin{array}{l}82.7 \mathrm{mv} \\
82.7 \mathrm{mv} \\
\end{array}$ & $\begin{array}{l}11.70 \mathrm{~m} \Omega \\
11.70 \mathrm{~m} \Omega\end{array}$ \\
\hline & & Ave. & $81.8 \mathrm{mv}$ & $13.16 \mathrm{~m} \Omega$ & $82.7 \mathrm{mv}$ & $11.70 \mathrm{~m} \Omega$ \\
\hline \multirow[t]{2}{*}{$\begin{array}{l}\mathrm{P} \\
\mathrm{P}\end{array}$} & $\begin{array}{l}13 \\
13\end{array}$ & $\begin{array}{l}1 \\
2 \\
\end{array}$ & $\begin{array}{l}66.7 \mathrm{mv} \\
67.3 \mathrm{mv} \\
\end{array}$ & $\begin{array}{l}11.76 \mathrm{~m} \Omega \\
10.29 \mathrm{~m} \Omega\end{array}$ & $\begin{array}{r}66.7 \mathrm{mv} \\
66.7 \mathrm{mv} \\
\end{array}$ & $\begin{array}{l}9.84 \mathrm{~m} \Omega \\
9.84 \mathrm{~m} \Omega \\
\end{array}$ \\
\hline & & Ave. & $67.0 \mathrm{mv}$ & $11.02 \mathrm{~m} \Omega$ & $66.7 \mathrm{mv}$ & $9.84 \mathrm{~m} \Omega$ \\
\hline \multirow[t]{2}{*}{$\begin{array}{l}\mathrm{P} \\
\mathrm{P}\end{array}$} & $\begin{array}{l}14 \\
14\end{array}$ & $\begin{array}{l}1 \\
2\end{array}$ & $\begin{array}{l}68.0 \mathrm{mv} \\
66.5 \mathrm{mv}\end{array}$ & $\begin{array}{l}10.78 \mathrm{~m} \Omega \\
12.65 \mathrm{~m} \Omega\end{array}$ & $\begin{array}{l}67.3 \mathrm{mv} \\
67.3 \mathrm{mv}\end{array}$ & $\begin{array}{l}10.46 \mathrm{~m}^{\Omega} \\
10.46 \mathrm{~m}^{\Omega}\end{array}$ \\
\hline & & Ave. & $67.25 \mathrm{mv}$ & $11.72 \mathrm{~m} \Omega$ & $67.3 \mathrm{mv}$ & $10.46 \mathrm{~m} \Omega$ \\
\hline
\end{tabular}

EOL temperatures of $\mathrm{Tc}=169^{\circ} \mathrm{F}, \mathrm{Th}=856^{\circ} \mathrm{F}$

Test time $=47$ hours for Test 1

Test time $=49$ hours for Test 2 
Table 3-2

Bell Jar - TEMP Correlations

\begin{tabular}{|c|c|c|c|c|}
\hline & & & $\frac{\mathrm{E}_{\mathrm{BELL} \mathrm{JAR}}}{\mathrm{F}}$ & $\frac{\mathrm{R}_{\text {BELL JAR }}}{\mathrm{R}}$ \\
\hline LEG & LOT & TEST & $\mathrm{E}_{\mathrm{TEMP}}$ & $\mathrm{R}_{\text {TEMP }}$ \\
\hline \multirow{3}{*}{$\begin{array}{l}\mathrm{N} \\
\mathrm{N}\end{array}$} & 15 & 1 & 1.00 & 1.19 \\
\hline & 15 & 2 & 1.02 & 1.21 \\
\hline & & Ave. & 1.01 & 1.20 \\
\hline \multirow{3}{*}{$\begin{array}{l}N \\
N\end{array}$} & 16 & 1 & .99 & 1.11 \\
\hline & 16 & 2 & .99 & 1.14 \\
\hline & & Ave. & .99 & 1.12 \\
\hline \multirow{3}{*}{$\begin{array}{l}\mathrm{P} \\
\mathrm{P}\end{array}$} & 13 & 1 & 1.00 & 1.20 \\
\hline & 13 & 2 & 1.01 & 1.05 \\
\hline & & Ave. & 1.00 & 1.12 \\
\hline \multirow{3}{*}{$\begin{array}{l}\mathrm{P} \\
\mathrm{P}\end{array}$} & 14 & 1 & 1.01 & 1.03 \\
\hline & 14 & 2 & 0.99 & 1.21 \\
\hline & & Ave. & 1.00 & 1.12 \\
\hline
\end{tabular}

*EOL temperatures of $\mathrm{Tc}=169^{\circ} \mathrm{F}, \mathrm{Th}=856^{\circ} \mathrm{F}$ Test time $=47$ hours for Test 1

Test time $=49$ hours for Test 2 
Table 3-3

Lot To Lot Comparison APC Couple Materials

\begin{tabular}{|c|c|c|c|}
\hline$\underline{L E G}$ & RATIO & BELL JAR & TEMP \\
\hline $\mathrm{N}$ & $\frac{E_{\text {LOT } 15}}{E_{\text {LOT } 16}}$ & 1.02 & 1. 01 \\
\hline $\mathrm{N}$ & $\frac{\mathrm{R}_{\text {LOT }} 15}{\mathrm{R}_{\text {LOT } 16}}$ & 1.08 & 1.01 \\
\hline $\mathrm{P}$ & $\frac{E_{\text {LOT } 13}}{E_{\text {LOT } 14}}$ & 1.00 & 0.99 \\
\hline$P$ & $\frac{\mathrm{R}_{\text {LOT }} 13}{\mathrm{R}_{\text {LOT } 14} 14}$ & 0.94 & 0.94 \\
\hline
\end{tabular}




\subsubsection{Procurement and Fabrication}

Procurement of long-lead time items needed to meet assembly schedules was initiated early in the Phase II program.

Fabrication of several components such as leg caps, header rings, insulation strips, hot junction electrodes and insulation blocks was completed. Orders for other components such as followers, cold frame, hot frame, support cone, headers and thermoelectric couples were partially completed before termination of the contract. 


\section{0 WANL -3M INTERFACE AC TIVITIES}

3M Company and Westinghouse Astronuclear Laboratory (WANL) conducted extensive interface activities, both formal and informal, in order to insure the orderly integration of the 3M converter and WANL heat source into the SNAP-23A System. These activities can be broken into three categories consisting of documents, drawings and meetings.

\section{1 INTERFACE DOCUMENTS}

The prime means of identifying the mutual interfaces of the co-prime contractors was established through the WANL-3M Interface Document (WANL-SS-001). This document, as approved by the Commission, formed the broad basis for all interface activities. Detailed dimensional interfaces were defined in the interface drawings and technical interfaces were established in writing through the minutes of the interface meetings.

The broad areas of responsibility as stated in the above interface document were as follows:

a. WANL is responsible for the design and development of the overall SNAP-23A system. This system included the heat source assembly, $3 \mathrm{M}$ 's converter assembly, the heat rejection assembly, the insulation and support assembly, and the electrical power conditioning and control assembly. 
b. 3M Company is specifically responsible for the detailed design, development, fabrication, assembly, acceptance testing, and delivery of the converter assembly which is used in the SNAP-23A system. The converter assembly shall be a hermetically sealed unit containing a number of thermoelectric couples located between an inner hot frame and a cold frame. It will contain the required the rmal insulation, instrumentation, and electrical connections. The hot frame will provide an interface for attachment to the heat source assembly (stud). The outer case will be an integral part of the converter assembly and will provide an interface to which the SNAP -23A heat rejection assembly may be attached. Electrical connection points between the converter and the electrical control and conditioning subsystem will be at a mutually defined location on the converter.

c. WANL shall have responsibility for the top assembly drawing of the SNAP-23A power system. This drawing is the assembly of the overall power system, defining the layout and arrangement of all component assemblies. It shall reference all component assembly drawings, including the assemblies defined in Section 4.2.a. The referenced 3M drawings shall serve as control drawings for the procurement, installation, checkout, and acceptance of the 3MI supplied components.

d. WANL and 3M shall mutually define the requirements for sensing devices which will be attached to or incorporated into the converter assembly for diagnostic, measurement, and control purposes. The instrumentation shall be supplied and installed by $3 \mathrm{M}$.

\subsection{INTERFACE DRAWINGS}

As defined in section 4.1 the responsibility for the preparation and maintenance of the interface drawing was vested with WANL. This drawing (WANL 914E462) describes the converter mechanical interfaces at the hot spud, outercase, upper and lower cover and the electrical output and diagnostic instrumentation necessary to attach the converter to the heat source during system assembly. The drawing was developed by joint WANL-3M effort. 


\section{3 INTERFACE MEETINGS}

The day -to-day definition of the detailed interfaces was established through formal monthly interface meetings and informal technical working meetings and correspondence.

The formal monthly interface meetings were attended by the Commission and coprime contractor representatives. Agreements and action items resulting from these meetings were documented in the meeting minutes. These minutes and the responses to the action items contained therein then formed an extension to the interface document. Thus, as the program progressed, a continual updating of the interface document was effected and the necessary details were continually being added.

Informal meetings and correspondence between WANL and 3M were engaged in at all levels throughout the program to effect the necessary technical and administrative interchanges necessary to a successful program involving two contractors. These meetings and correspondence established the agendas for the formal interface meetings and provide means for day-to-day solutions to mutual programs. 


\section{0 THERMOELEC TRIC COUPLE DEVELOPMENT}

\subsection{INTRODUCTION}

The major objective of the thermoelectric couple development task was to identify and provide solutions for problem areas related to 10-year life thermoelectric leg stability. This effort was conducted in support of the 60 -watt converter development program through the five distinct approaches listed below.

- Bell jar testing to verify ing radient thermoelectric performance with respect to design objectives and specifications, and to qualify new concepts for longterm performance evaluation.

- 10-couple module testing for long-term performance evaluation of promising variables investigated in the bell jar tests.

- Converter testing for long term and specification performance evaluation.

- Material characterization testing to establish a design base for thermoelectric properties.

- Continuation testing of related devices 


\subsection{BELL JAR TESTS}

The SNAP-23A bell jar test effort was extensive in both scope and number of tests. The tests were conducted in two phases. The first phase was a series of technology improvement tests run early in the program to determine the effects of changes in thermoelectric materials, hot and cold contact materials, leg alignment, processing schedules and operating temperature. A discussion of the technology improvement tests is presented in Section 2.2.2.

The second phase of bell jar testing was conducted primarily to upgrade the quality control of thermoelectric materials and thereby assure that the converter would meet performance requirements. The second phase tests were conducted on PMC -2, PMC -3 and APC couples. The PMC -2 tests were run to confirm the correlation between bell jar and converter results observed during the Phase I testing. The PMC -3 and APC couple tests were used to accept materials for these respective converters.

\subsubsection{PMC -2 Couples: Test 20}

Seebeck voltage and resistance of the $\mathrm{N}$ - and $\mathrm{P}$-legs measured in the bell jar were in close agreement with values measured in converter PMC -2 except the BOL $\mathrm{P}-\mathrm{leg}$ resistance ratio. The correspondence can be noted by comparing the bell jar ratios with the PMC -2 converter Seebeck and resistance ratios in Table $5-1$. These results demonstrated that converter power output could be predicted with a high degree of confidence from ingradient tests run in a bell jar.

\subsubsection{PMC -3 Couples: Tests 21 and 22}

Thermoelectric material batches selected for PMC -3 were operated in two bell jar tests prior to assembly of the converter. The purposes of these tests were: (1) to determine if couples made from these batches of thermoelectric materials would result in acceptable converter performance; and (2) to evaluate the effects of a one-piece iron hot junction electrode.

In the first test, both the conventional iron button-copper electrode configuration and the one-piece ir on hot junction electrode were incorporated. The test was run 
Table $5-1$

SNA P-23A

Converter PIMC-2 Performance

versus Design Criteria

\begin{tabular}{|c|c|c|c|c|c|c|}
\hline & \multicolumn{2}{|c|}{ PMC-2 Data } & \multirow{2}{*}{ Design } & \multicolumn{2}{|c|}{ Actual Bell Jar* } & \multirow{2}{*}{$\begin{array}{c}\text { Computed } \\
\text { EOL }\end{array}$} \\
\hline & EOL Actual & BOL Actual & & EOL & BOL & \\
\hline$\frac{E_{x}}{E_{t}}$ & 0.945 & 0.945 & 0.98 & & & \\
\hline$\frac{R_{x}}{R_{t}}$ & 1.02 & 1.035 & 1.02 & & & \\
\hline$\frac{E n_{x}}{E n_{t}}$ & 0.985 & 0.99 & 1.00 & 0.99 & 1.00 & 0.985 \\
\hline$\frac{E p_{x}}{E p_{t}}$ & 0.93 & 0.95 & 0.96 & 0.945 & 0.955 & 0.93 \\
\hline$\frac{R n_{x}}{R n_{t}}$ & 0.97 & 0.96 & 1.0 & 0.95 & 0.96 & 0.97 \\
\hline$\frac{R p_{x}}{R p_{t}}$ & 1.05 & 1.14 & 1.03 & 1.05 & 1.035 & 0.93 \\
\hline $\begin{array}{l}P_{\text {in }} \\
\text { watts }\end{array}$ & 55.7 & 74.6 & $\begin{array}{l}61.2 \text { EOL } \\
80.4 \text { BOL } \\
\end{array}$ & & & 61.7 \\
\hline Efficiency & 7.05 & 7.7 & 7.52 & & & 7.55 \\
\hline
\end{tabular}

* - Data from 2 couples from same lot and batch as couples used for PMC-2. 
for 50 hours and then replaced by the second pair of PMC -3 couples. The second bell jar test used only one-piece iron hot junction electrodes and was operated at the stability conditioning time-temperature cycle planned for PMC -3 . A total operating time of 1214 hours was accumulated during the second bell jar test.

Results from the first PMC -3 couple test showed that initial leg seat-in for the one-piece iron hot junction electrode was comparable to that with the iron buttoncopper electrode configuration. Results from both bell jar tests 21 and 22 indicated that couple power output following the period of stability conditioning would be adequate to meet the design requirements. Two EOL predictions of PMC -3 power output were prepared on basis of bell jar test data. They were 61.3 and 61.7 watts (See Table 5-27 on page 5-75). Based on these results, the assembly of PIMC -3 was initiated with confidence that performance requirements would be met. The actual power output of PMC -3 was 61.2 watts.

\subsubsection{APC Couples: Tests 23 and 24}

Thermoelectric couples from material lots selected for the Advanced Prototype Converters were operated in two bell jar tests to determine if power output characteristics were sufficient to meet APC requirements. The testing involved couples from two thermoelectric material lots with all couples pressure contacted to one-piece iron hot junction electrodes. Each two-couple test contained couples from both lots to eliminate the effects of test-to-test variables. The position of each lot in the bell jar was also altered so that the $\mathrm{N}-\mathrm{leg}$ and $\mathrm{P}-\mathrm{leg}$ lots in the couple position in Test 23 were located in the output positions in Test 24. During bell jar testing, the time-temperature cycle planned for the converters was duplicated to evaluate the effects of stability conditioning on power output.

Results from the tests indicated that one $\mathrm{N}-\mathrm{leg}$ lot (Lot 16) and both P-leg lots would meet the APC power output requirements. The assessment was made by comparing the Seebeck voltage and resistance ratios determined from bell jar test results to the design ratios. A $2 \%$ increase in resistance per couple was as sumed when these couples are placed in a generator with the increase probably due to a change in leg alignment in the generator when hot. The magnitude of the difference as determined from bell jar results are as follows: 
N-leg results from the APC couple tests are plotted as a function of time during the 500-hour stability conditioning period in Figure 5-1. The N-leg Seebeck voltage increased approximately $1 \%$ during the first 100 hours and then remained constant. Resistance remained constant during the stability conditioning period. The performance level at EOL, Table 5-2, shows that Lot 16 performed at a power ratio* of greater than 1.02 after stability conditioning. Lot 15 was rejected for use in the APC converter because of high Seebeck voltage and resistance ratios. The design power ratio for A PC converter $\mathrm{N}$-legs was 1.00 .

$\mathrm{P}-\mathrm{leg}$ results measured during the stability conditioning period are plotted in Figure 5-2. A significant difference can be noted between results from bell jar Test 23 and Test 24. The differences were caused by an air leak in Test 24 with resultant oxidation of the $\mathrm{P}-\mathrm{leg}$ and decrease in Seebeck voltage and resistivity; therefore, the post-stability conditioning data was not considered valid.

Results from Test $23 \mathrm{P}$-leg were more consistent with time trends observed in units with hermetic seal integrity, i. e., a reduction of resistance to a value nearly equal to the calculated material resistance and a nearly stable Seebeck voltage.

Performance results at EOL temperature conditions are listed for the $\mathrm{P}$-legs in Table 5-2. The post-stability conditioning $P-1$ g power ratios from Test 23 were 0.94 and 0.97 for Lots 13 and 14, respectively. This performance exceeded the design power ratio of 0.89 by greater than $2 \%$, therefore, both lots were accepted for $\mathrm{APC}$ converters.

*Power Ratio $=\frac{(\text { Seebeck Voltage Ratio })^{2}}{\text { Resistance Ratio }}$ 


\section{Foura b 1}

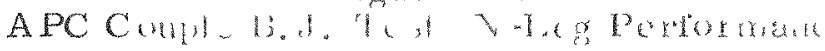

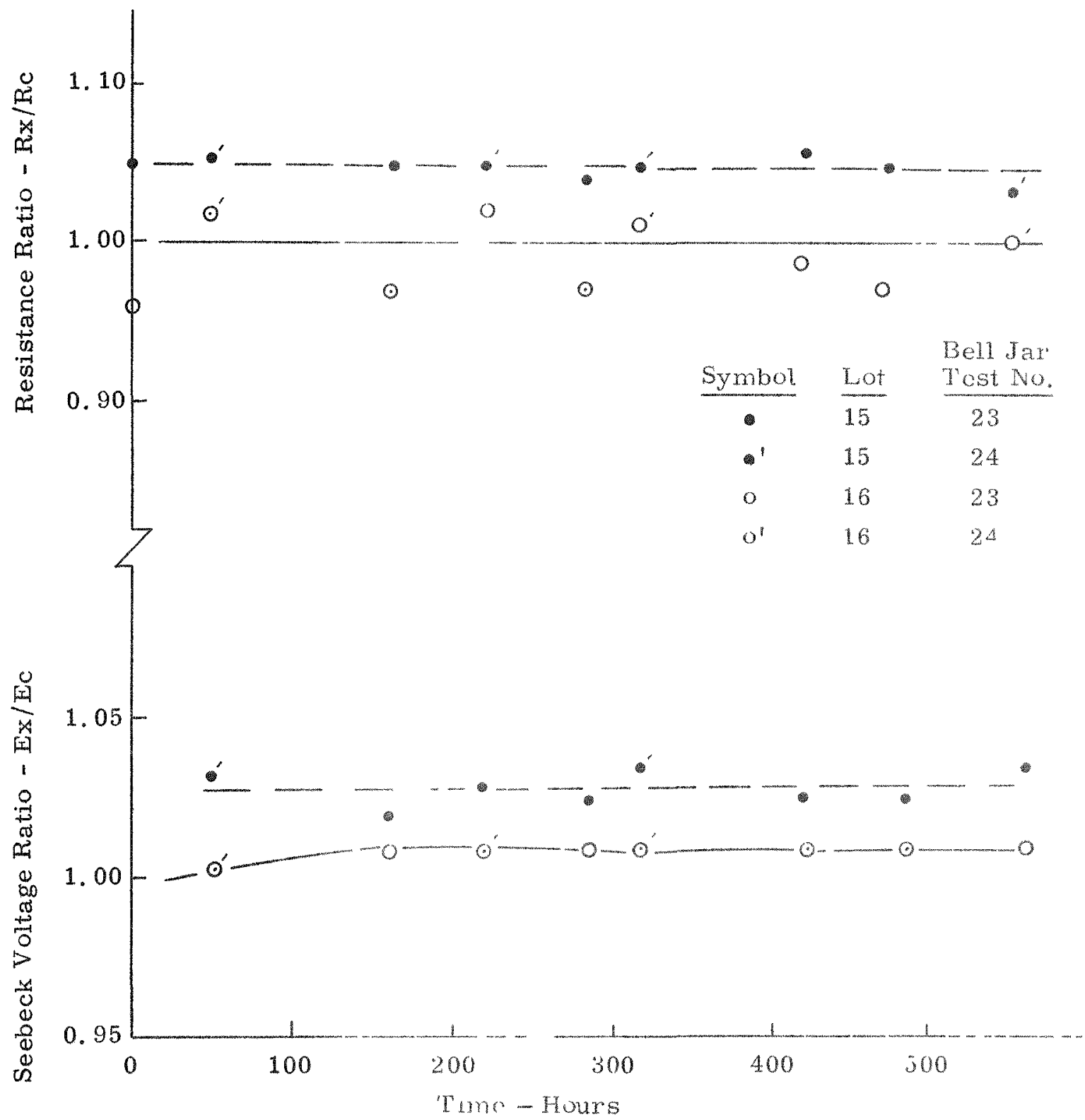


Figure 5-2

A PC Couple B.J. Tests P-Leg Performance

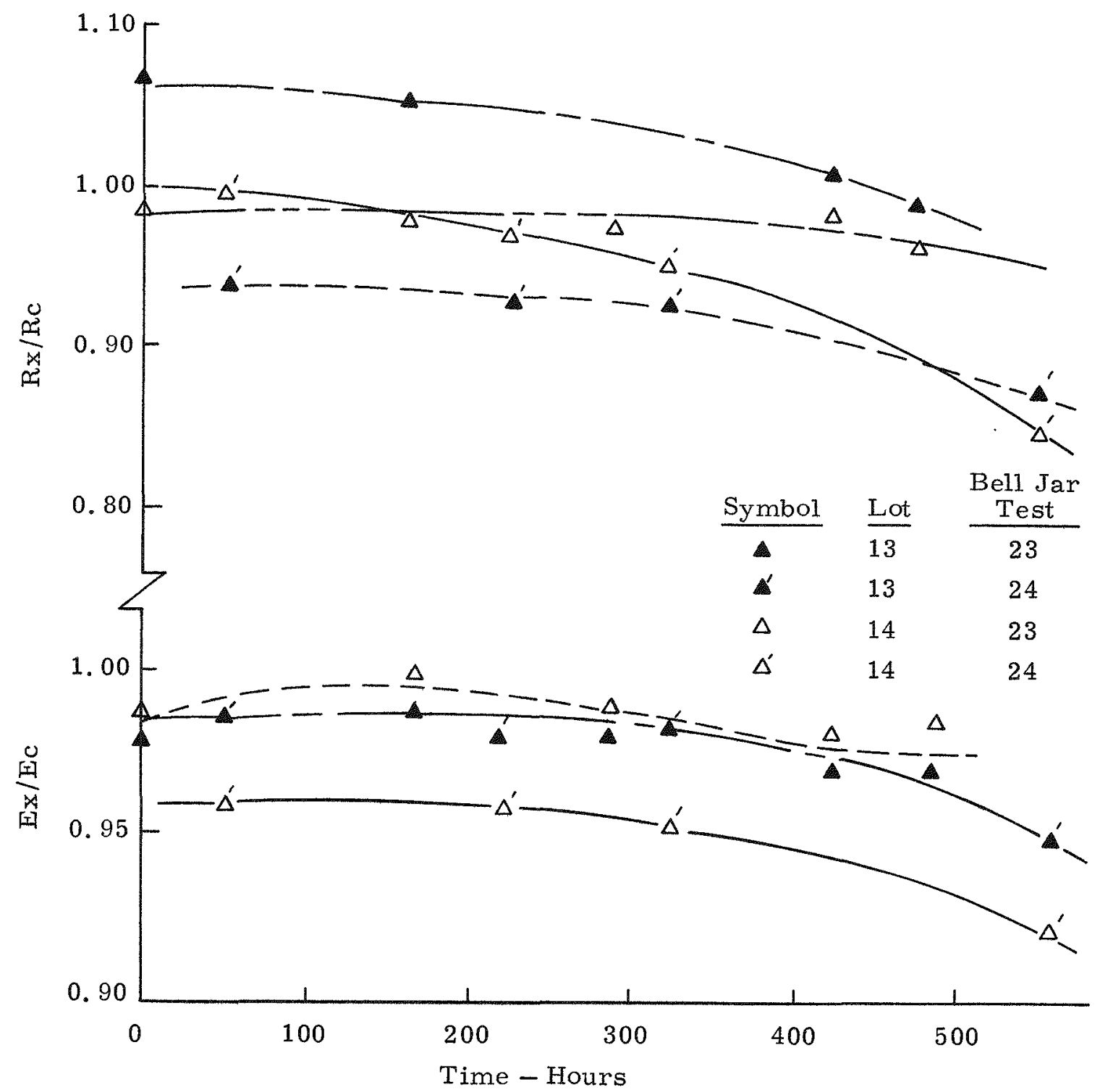


Table 5-2

APC Bell Jar Test Results

EOL Temperature Conditions

TEST 23

Pre-Stability Post-Stability Conditioning

\section{THERMOPILE}

Seebeck Voltage Ratio

Resistance Ratio

\section{N-LEG LOT 16}

Seebeck Voltage Ratio

Resistance Ratio

\section{N-LEG LOT 15}

Seebeck Voltage Ratio

Resistance Ratio

P-LEG LOT 13

Seebeck Voltage Ratio

Resistance Ratio

P-LEG LOT 14

Seebeck Voltage Ratio

Resistance Ratio

$\begin{array}{llll}0.99 & 0.99 & 0.99 & 0.97 \\ 1.04 & 1.00 & 1.06 & 0.96\end{array}$

1.01

1.02

1. 00

1.02

0.97

0.99

1. 01

1.02

1. 02

1. 04

1. 03

1. 05

1. 06

1. 06

1. 08

1.05

0.96

0.95

0.97

0.92

1.08

0.96

0.94

0.86

0.98

0.97

0.96

0.89

0.99

0.97

0.84 


\section{3 TEN COUPLE MODULES}

\section{3. 1 History}

Early in the SNAP-23A program, twelve 10-couple modules were built to determine the stability characteristics of the SNAP-23A baseline design and evaluate alternate design concepts. (See Table 2-2 for test variable matrix.) Of these original twelve 10-couple modules, two (No. 2 and No.4) were torn down for post-test analysis after about 8,000 hours of operation; the ten remaining modules continued on test until June, 1970 , accumulating a minimum of 21,000 hours of operation per module.

\subsubsection{Modules No. 2 and 4}

Both Modules No. 2 and No. 4 differed from the other 10-couple modules in that they were built using Min-K 1999 thermal insulation instead of Min-K 1301 or microquartz.

These two modules were given a post test evaluation due to a $60 \%$ or greater power degradation in the $\mathrm{P}$-legs.

The conclusions reached during the post-test evaluation were:

\section{- Thermal}

There was an increase of five percent in the thermal input required to maintain constant temperatures during the first 1, 000 hours of operation. This additional extraneous heat loss was due to a five to six and one half percent build -up of hydrogen within the modules. The hydrogen was entrapped in the porous regions of Min-K 1999 during the module processing operation, and released during the first 1,000 hours of operation.

- Electrical

P-Leg Electrical Performance: The bonded P-legs had a significantly lower resistance and Seebeck voltage than the simultaneously pressed $\mathrm{P}$-legs at the start of test operation. This is believed to be 
due to a reduction in Seebeck coefficient and resistivity for the hot bonded P-segments during the modules' processing operation. The simultaneously pressed $P$-legs were not affected in the same way, but had an initial power output which was $20 \%$ less than the bonded P-legs.

The performance-time characteristics for the two types of $\mathrm{P}$-legs were also markedly different. The bonded $P$-legs we re initially more stable; however, after 4,000 hours their power output degraded to a level near that of the simultaneously pressed P-leg at the time of module tear-down (approximately 60 percent of theoretical power values). The Seebeck voltage was stable for both types of P-legs. The resistance increase was the cause of the power degradation.

All evidence indicates that the increase in resistance was due to a chemical deposit which formed at the hot button-hot segment interface. The deposit was a white complex compound with principal constituents of manganese, boron, iron, and antimony. All four elements are present in both Min-K 1301 and Min-K 1999 modules, however, this compound has been observed only in devices which contain Min-K-1999.

It is believed that Min-K 1301 suppresses the formation of this deposit because of the presence of certain additional constituents. For example, from prior analyses of Min-K 1301 devices, $\alpha$-MnS has always been present at the hot junction. Sulfur is not present in Min-K 1999, and could not react with the manganese in Modules No. 2 and No. 4; however, it is apparent that a different set of reactions, not all of which are known, were occurring.

N-Leg Electrical Performance: The N-leg electrical performance also degraded during operation. The degradation was due to an increase in contact resistance at the leg-hot button interfaces, which was the result of two factors:

1) Sublimation - The N-legs were rounded off at the hot end from sublimation, producing a reduced hot end contact area and a corresponding large contact resistance. 
2) Chemical Deposit - A chemical deposit formed on the periphery of the hot buttons, similar to that observed on the $P$-buttons. It is suspected that this deposit also contributed to a reduced contact area. The $\mathrm{N}-\mathrm{leg}$ resistances in both modules increased at a rate of approximately $1.4 \% / 1000$ hours greater than the Min-K 1301 modules.

- Differences between Modules No. 2 and No. 4 Both modules were designed and built to be identical, except in the following two areas:

1) Spring Pressure - 250 psi for Module No, 2, 150 psi for Module No. 4.

2) Conventional P-legs in Module No, 2, soft nose P-legs in Module No. 4.

Material creep was greater for the N-legs with 250 psi compressive loading as compared to $\mathrm{N}$-legs operated at the lower pressure; the 250 psi $\mathrm{N}$-legs had larger cross sectional areas near the hot junction, lower contact resistances, and better electrical power performance after 8,000 hours of operation.

Neither the magnitude of the compression loading, nor the type of $\mathrm{P}-\mathrm{leg}$ (conventional or soft nose) significantly affected the electrical performance of the $\mathrm{P}$-legs.

\subsubsection{Modules No. 1 and No. 3}

Plots showing the average performance (experimental/theoretical values) versus time for Modules No. 1 and No. 3 are presented in Figures 5-3 through 5-8. This performance data is summarized in Table 5-3 for the last 20,000 hours of operation.

As indicated by the data analysis, Module No. 1 (Min-K 1301 thermal insulation and 250 psi contact pressure) consistently out performs Module No. 3 (microquartz insulation and 150 psi contact pressure) from a power standpoint. Neither microquartz nor the lower contact pressure appear to be suitable alternates for the baseline (converter) program. 
Table 5-3

SNAP-23A Ten Couple Modules No. 1 and No. 3

Final Performance Analysis

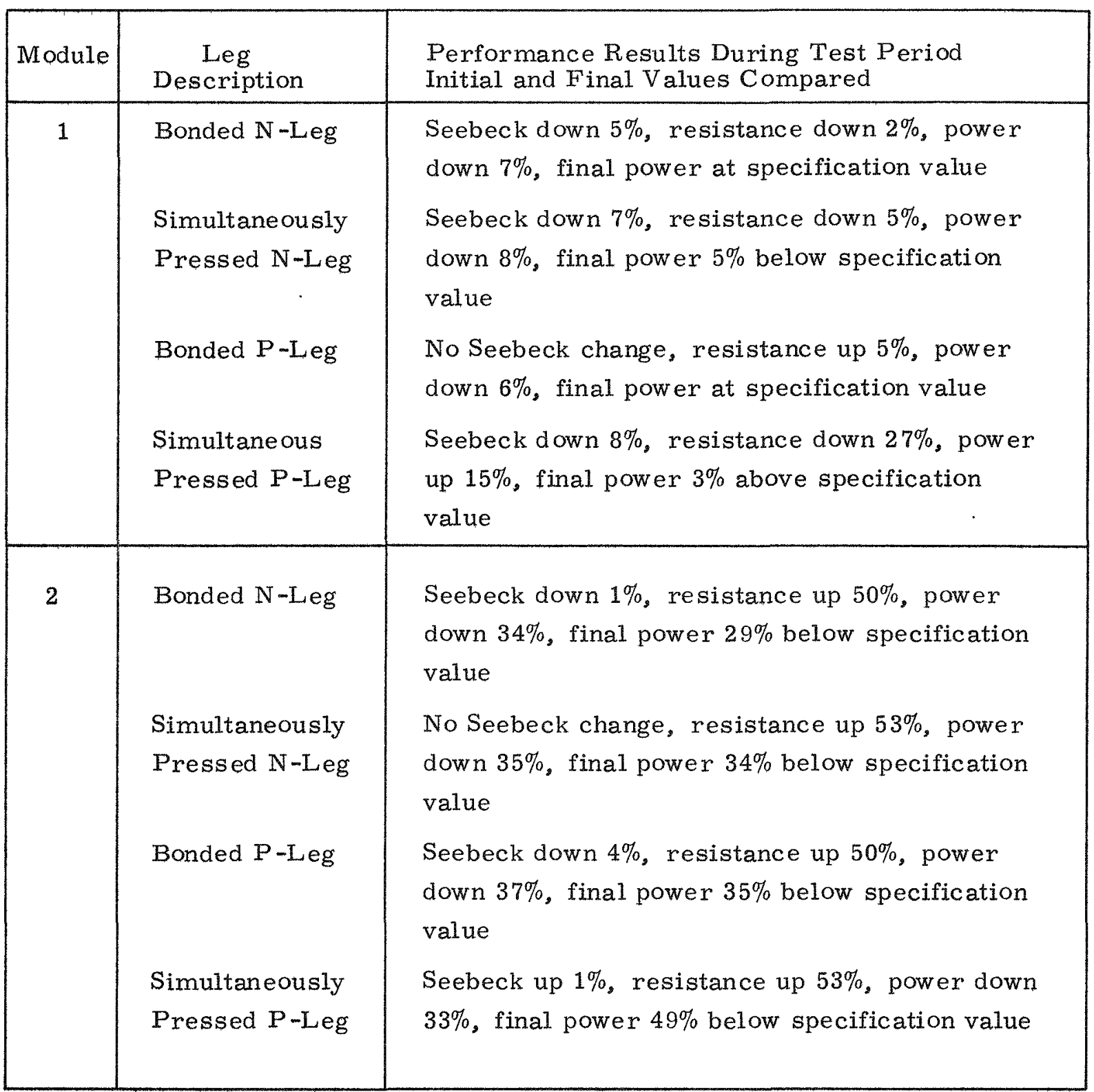




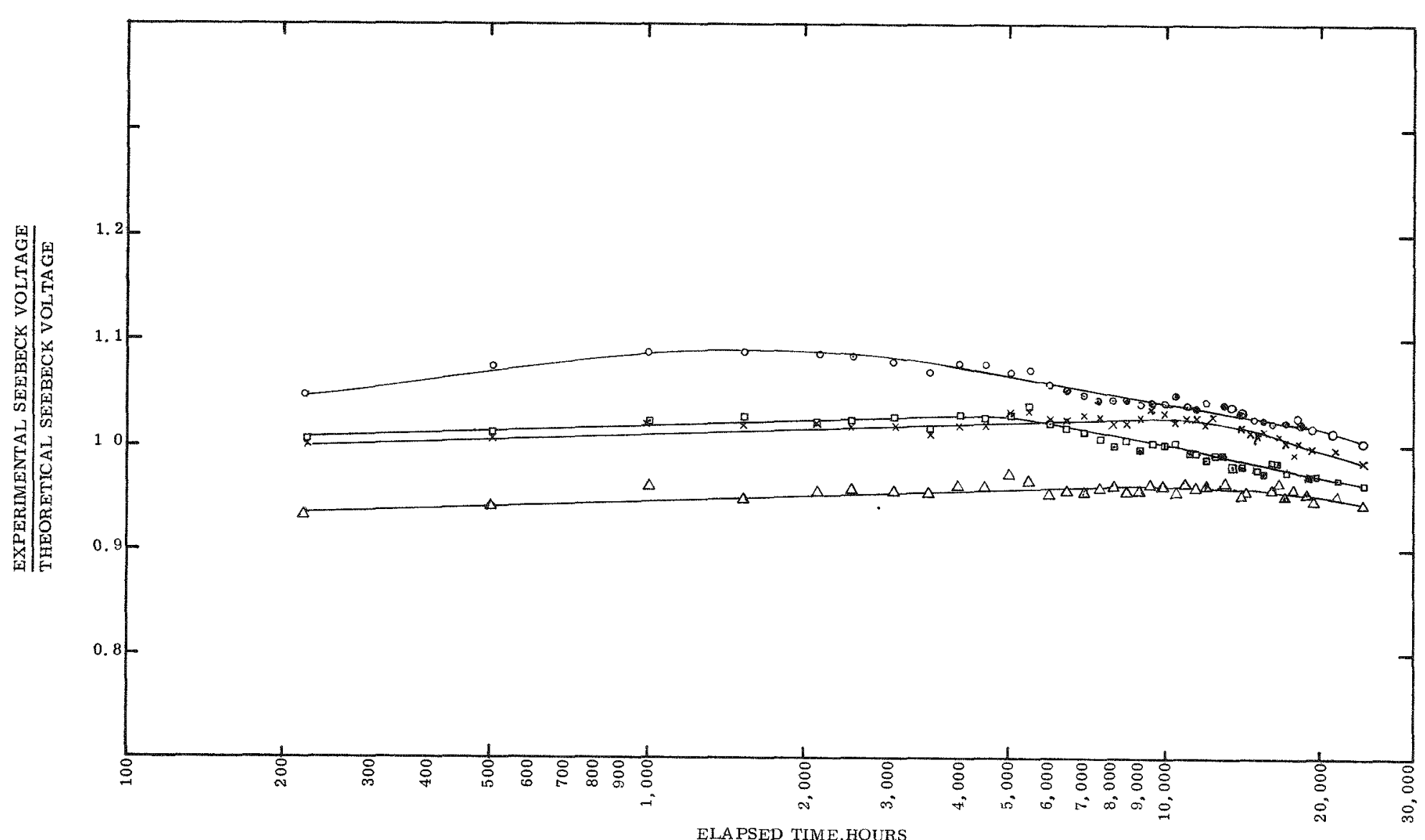

Thermal insulation $=$ Min $-\mathrm{K} 1301$ Contact pressure $=250 \mathrm{pS}$
Hot electrode $\begin{array}{ll}\text { Hot electrode } & =1100^{\circ} \\ \text { Cold electrode } & =190^{\circ} \mathrm{F}\end{array}$ P-Leg, odd, simul pressed, hard nose
$\square$ N-Leg, odd, simul pressed, hard nose N-Leg, even, bonded, hard nose

Figure 5-3

SNAP-23A Ten Couple Module No. 1 - Seebeck Ratio vs Time 


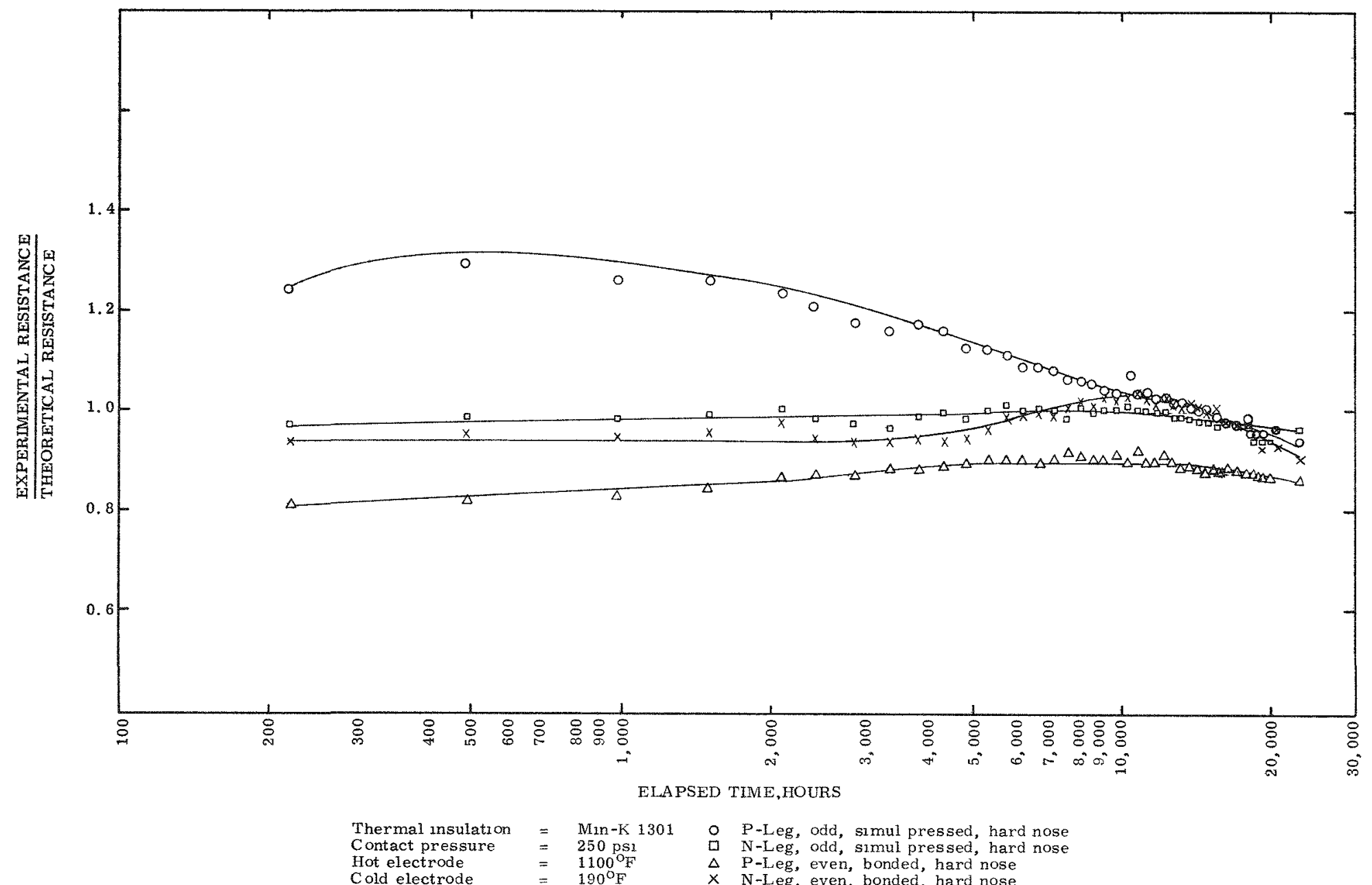

Figure 5-4

SNAP-23A Ten Couple Module No. 1 - Resistance Ratio vs Time 


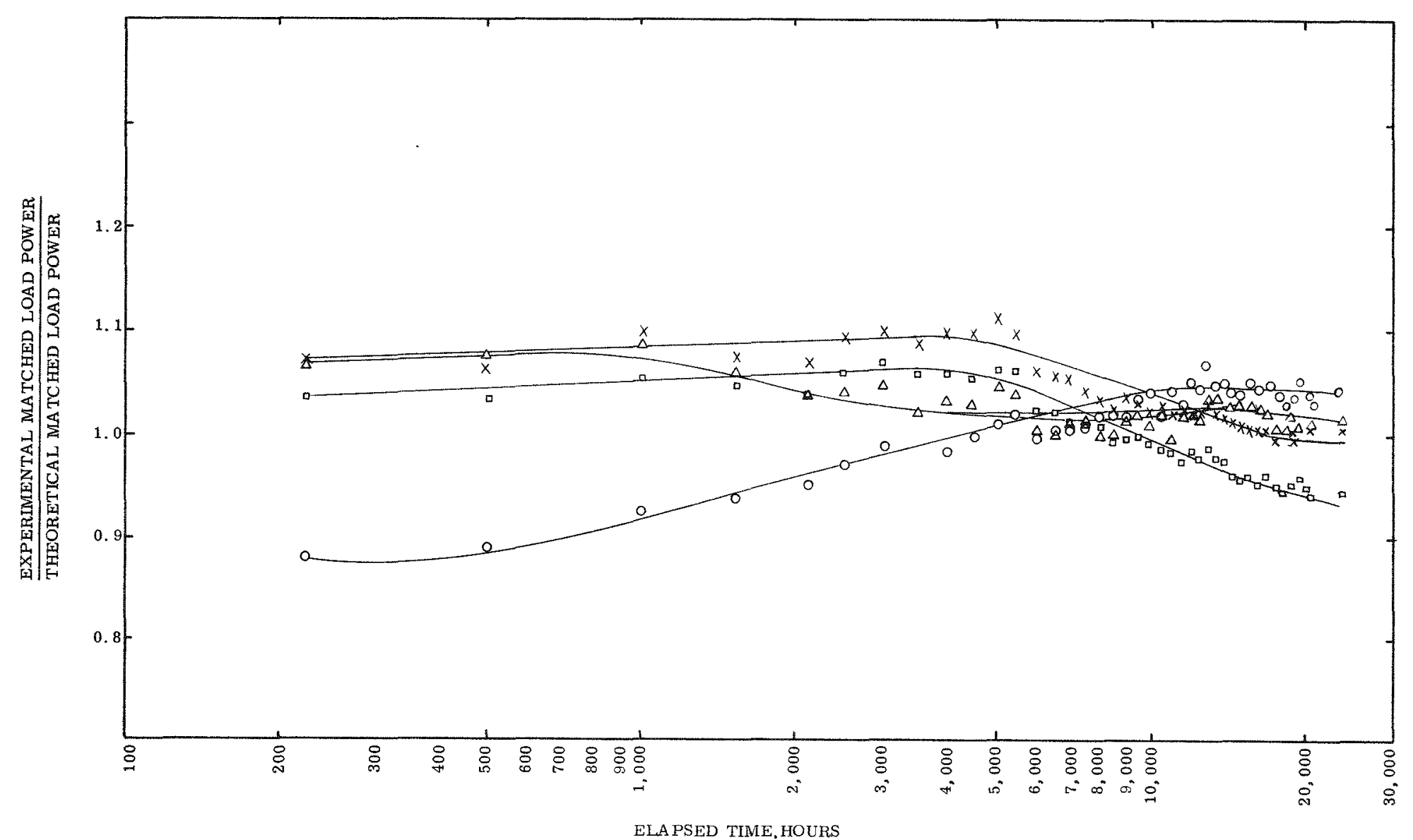

$\begin{array}{llll}\text { Thermal insulation } & =\text { Min-K } 1301 & \circ \text { P-Leg, odd, simul pressed, hard nose } \\ \text { Contact pressure } & =250 \mathrm{pS} & \mathrm{a} \text { N-Leg, odd, simul pressed, hard nose } \\ \text { Hot electrode } & =1100^{\circ} \mathrm{F} & \Delta \text { P-Leg, even, bonded, hard nose } \\ \text { Cold electrode } & =190^{\circ} \mathrm{F} & \times \text { N-Leg, even, bonded, hard nose }\end{array}$

Figure 5-5

SNAP -23A Ten Couple Module No. 1 - Power Ratio vs Time 


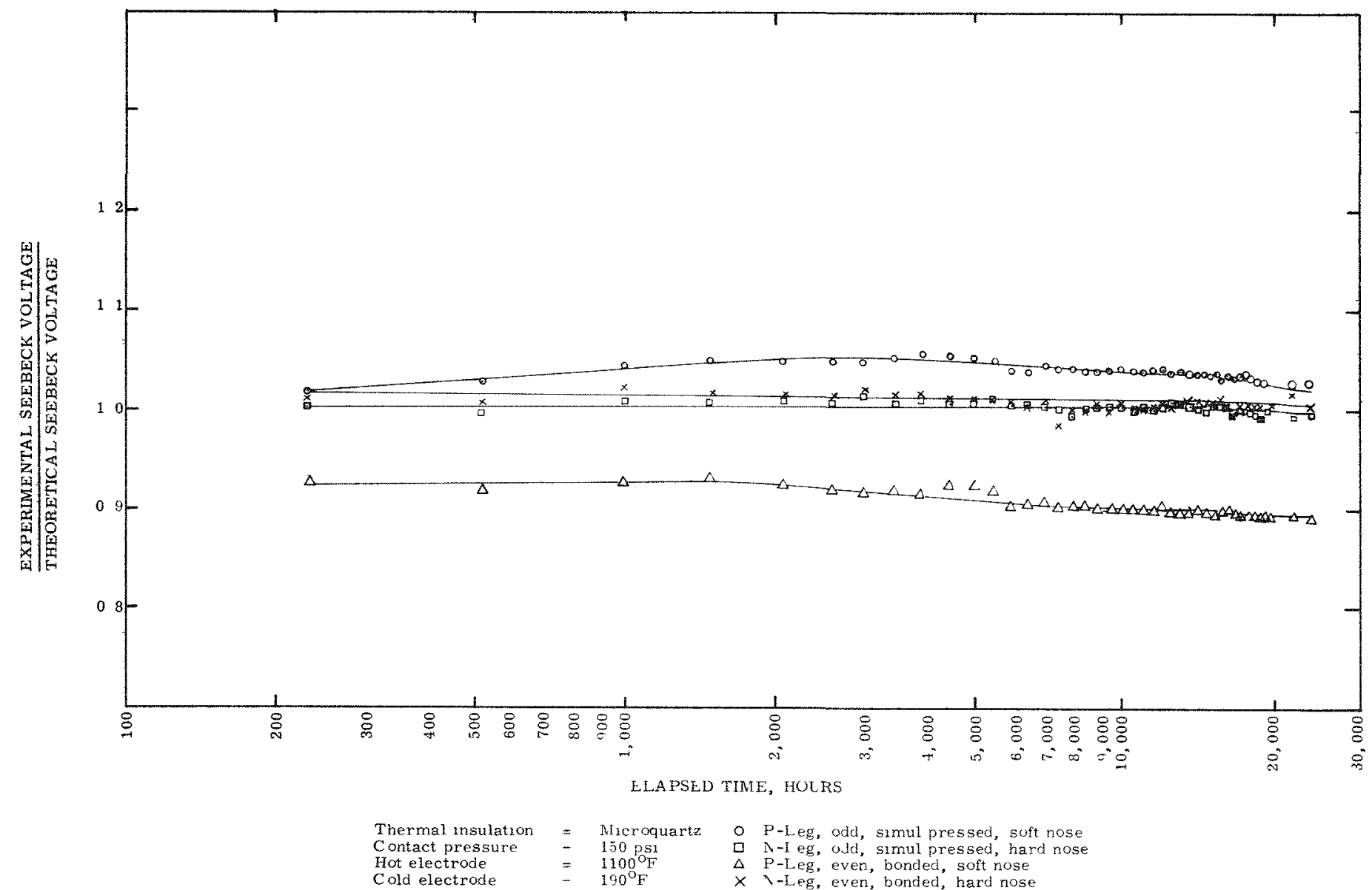

Figure 5-6

SNAP-23A Ten Couple Module No. 3 - Seebeck Ratio vs Time 


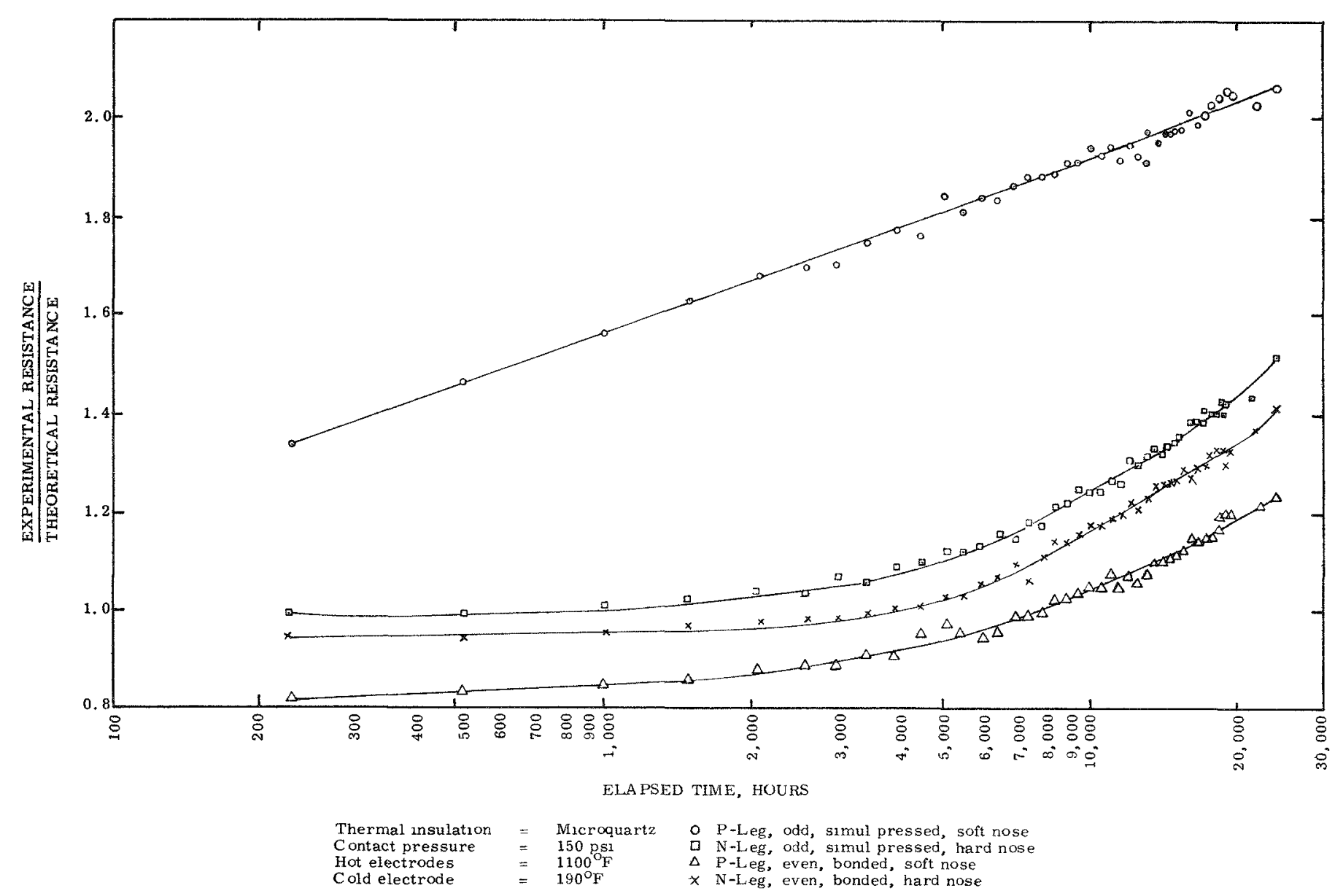

Figure 5-7

SNAP-23A Ten Couple Module No. 4 - Resistance Ratio vs Time 


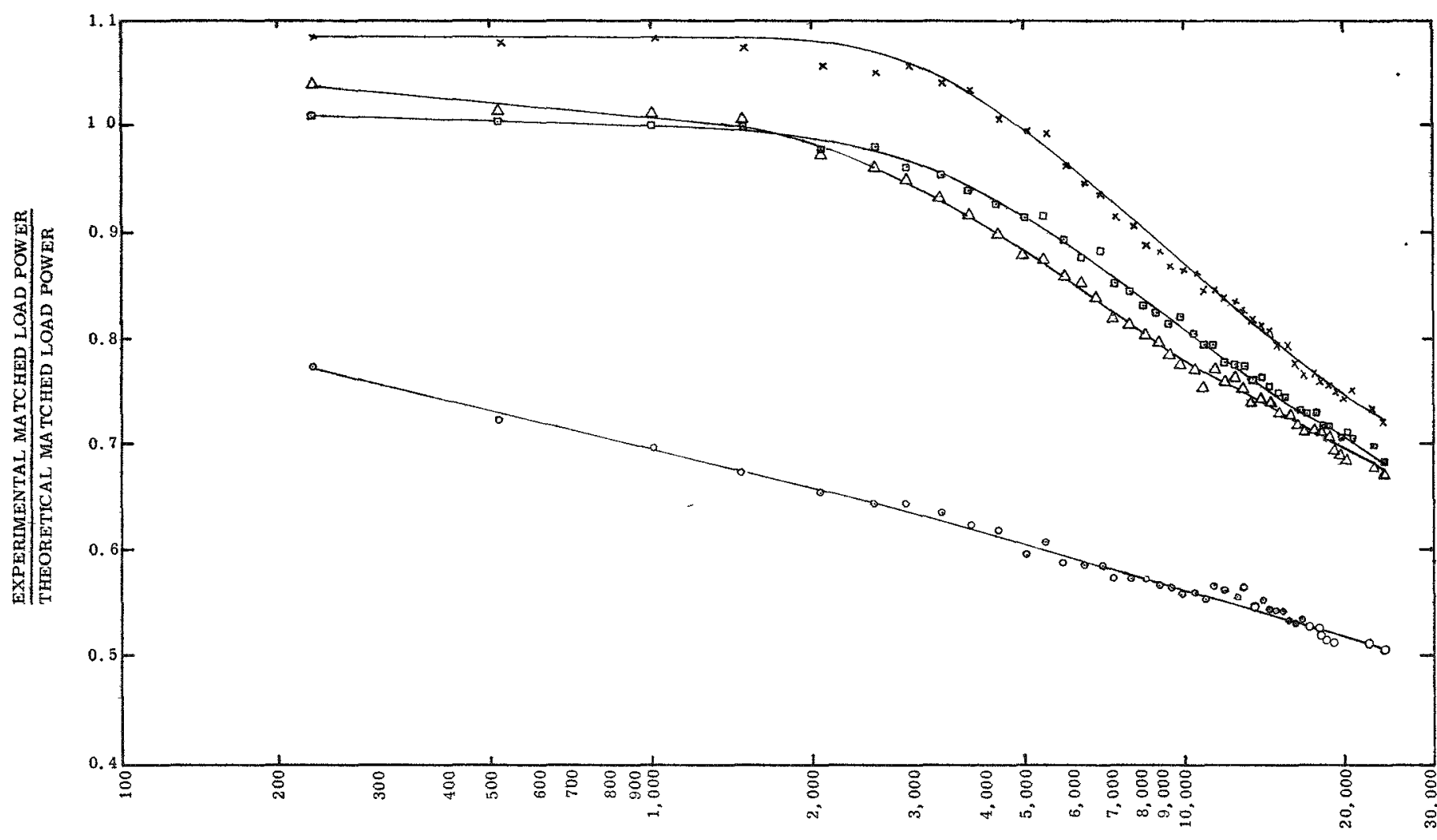

ELA PSED TIME, HOURS

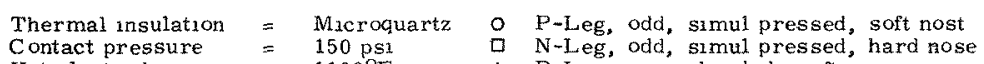

$\begin{array}{llll}\text { Contact pressure } & =150 \mathrm{pSI} & \square \mathrm{N}-\mathrm{L} \text { eg, odd, simul pressed, hard nos } \\ \text { Hot electrode } & =1100^{\circ} \mathrm{F} & \triangle & \mathrm{P}-\mathrm{L} e g, \text { even, bonded, soft nose } \\ \text { C old electrode } & =190^{\circ} \mathrm{F} & \times \mathrm{N}-\mathrm{Leg} \text {, even, bonded, hard nose }\end{array}$

Figure 5-8

SNAP-23A Ten Couple Module No. 3 - Power Ratio vs Time 


\subsubsection{Modules 5 through 12 (Factorial Test Modules)}

Modules 5 through 12 consisted of a full factorial design including two levels of each variable:

- Hot contacts, iron or molybdenum

- Hot junction temperature, $1000^{\circ} \mathrm{F}$ or $1100^{\circ} \mathrm{F}$

- Insulation, Min-K 1301 or microquartz

- Contact pressure, 150 psi or 250 psi

- P-leg construction, bonded or simultaneously pressed

- N-leg construction, bonded or simultaneously pressed

The construction of each module and operating conditions are given in Table 5-3.

All eight of these modules had been operated for at least 21,000 hours at the end of June, 1970. The performance averages for this period are presented in Figures 5-9 through 5-22. The se figures graphically present the $N$ - and $P-1$ eg average Seebeck, resistance, and power ratios versus time for both the microquartz modules and the Min-K 1301 modules; significant effects are shown on a second scale. Analysis of these data indicate the following:

- N-Leg Seebeck Voltage - Microquartz Modules (Figure 5-9)

The average Seebeck ratio remained stable, and none of the variables had a significant effect on this parameter.

- N-Leg Resistance - Microquartz Modules (Figure 5-10)

Those legs with iron hot buttons (factor $\mathrm{B}+$ ) exhibited a resistance ratio 0.030 higher than those with molybdenum buttons (factor B-). As a result of the first and second order interactions of hot junction temperature and hot contact pressure (factors C, D, and DC), the various combinations resulted in the following resistance ratios after 20,000 hours of operation. (Data not valid at 21,000 hours due to bad data point). 


\begin{tabular}{|c|c|c|}
\hline $\begin{array}{c}\text { Hot Junction } \\
\text { Temperature, }\end{array}$ & $\begin{array}{c}\text { Contact } \\
\text { Pressure, psi }\end{array}$ & $\begin{array}{c}\text { Resistance } \\
\text { Ratio }\end{array}$ \\
\hline $1000(\mathrm{C}-)$ & $150(\mathrm{D}+)$ & 1.47 \\
$1000(\mathrm{C}-)$ & $250(\mathrm{D}+)$ & 1.12 \\
$1100(\mathrm{C}+)$ & $150(\mathrm{D}-)$ & 1.67 \\
$1100(\mathrm{C}+)$ & $250(\mathrm{D}+)$ & 1.23 \\
\hline
\end{tabular}

Differences between the lower $(-)$ and upper $(t)$ levels of each of the significant effects increased with time, thus increasing their significance.

- N-Ieg Power - Microquarts Modules (Figure 5-11)

Those legs with iron hot buttons (factor $\mathrm{B}+$ ) exhibited a power ratio 0.053 lower than those with molybdenum buttons (factor $\mathrm{B}-$ ). The various combinations of hot junction temperature (factor $C$ ) and hot contact pressure (factor D) resulted in the following power ratios after 21,000 hours of operation:

\begin{tabular}{|c|c|l|}
\hline $\begin{array}{c}\text { Hot Junction } \\
\text { Temperature, }\end{array}$ & $\begin{array}{c}\text { Contact } \\
\text { Pressure, psi }\end{array}$ & $\begin{array}{c}\text { Power } \\
\text { Ratio }\end{array}$ \\
\hline $1000(\mathrm{C}-)$ & $150(\mathrm{D}-)$ & 0.76 \\
$1000(\mathrm{C}-)$ & $250(\mathrm{D}+)$ & 1.00 \\
$1100(\mathrm{C}+)$ & $150(\mathrm{D}-)$ & 0.62 \\
$1100(\mathrm{C}+)$ & $250(\mathrm{D}+)$ & 0.86 \\
\hline
\end{tabular}

Differences between the lower $(-)$ and upper $(+)$ levels of each of the significant effects increased with time, thus increasing their significane.

- N-Leg Seebeck Voltage - Min-K 1301 Modules (Figure 5-12) The Seebeck ratio of those legs with an $1100^{\circ} \mathrm{F}$ hot junction temperature decreased to a level 0.07 lower than that legs with a $1000^{\circ} \mathrm{F}$ hot junction temperature (whose voltage remained relatively stable). 
- N-Leg Resistance - Min-K 1301 Modules (Figure 5-13)

As a result of the first and second order interactions of hot junction temperature and hot contact pressure (factors $\mathrm{C}$ and $D$ ) the various combinations resulted in the following resistance ratios after 21,000 hours of operation.

\begin{tabular}{|c|c|c|}
\hline $\begin{array}{c}\text { Hot Junction } \\
\text { Temperature, }\end{array}$ & $\begin{array}{c}\text { Contact } \\
\text { Pressure, psi }\end{array}$ & $\begin{array}{c}\text { Resistance } \\
\text { Ratio }\end{array}$ \\
\hline $1000(\mathrm{C}-)$ & $150(\mathrm{D}-)$ & 1.10 \\
$1000(\mathrm{C}-)$ & $250(\mathrm{D}+)$ & 0.96 \\
$1100(\mathrm{C}+)$ & $150(\mathrm{D}-)$ & 1.06 \\
$1100(\mathrm{C}+)$ & $250(\mathrm{D}+)$ & 0.92 \\
\hline
\end{tabular}

- N-Leg Power - Min-K 1301 Modules (Figure 5-14)

Those legs with iron hot buttons (factor $\mathrm{B}+$ ) exhibited a power ratio 0.008 lower than those with molybdenum (factor $\mathrm{B}-$ ).

The various combinations of hot junction temperature (factor $\mathrm{C}$ ) and hot contact pressure (factor D) resulted in the following power ratios after 21,000 hours of operation:

\begin{tabular}{|c|c|c|}
\hline $\begin{array}{c}\text { Hot Junction } \\
\text { Temperature, }\end{array}$ & $\begin{array}{c}\text { Contact } \\
\text { Pressure, psi }\end{array}$ & $\begin{array}{l}\text { Power } \\
\text { Ratio }\end{array}$ \\
\hline $1000(\mathrm{C}-)$ & $150(\mathrm{D}-)$ & 0.97 \\
$1000(\mathrm{C}-)$ & $250(\mathrm{D}+)$ & 1.09 \\
$1100(\mathrm{C}+)$ & $150(\mathrm{D}-)$ & 0.89 \\
$1100(\mathrm{C}+)$ & $250(\mathrm{D}+)$ & 1.01 \\
\hline
\end{tabular}

Differences between the lower $(-)$ and upper $(+)$ level of each of the significant effects increased slightly with time.

- P-Leg Seebeck Voltage - Microquartz Modules (Figure 5-15) The average Seebeck voltage ratio was on a mild decreasing trend with simultaneously-pressed P-legs exhibiting a 0.17 higher ratio than thei $\mathrm{r}$ bonded counterparts. 
- P-Leg Resistance - Microquartz Modules (Figure 5-16) The resistance of the bonded type $P-1$ eg was on an increasing trend while that of the simultaneously-pressed type stabilized. However, the final resistance ratio of the bonded type was 0,28 lower than that of the simultaneously pressed variety.

- P-Leg Power - Microquartz Modules (Figure 5-17)

The power ratio of the simultane ously-pressed P-legs stabilized while that of the bonded type was on a decreasing trend. However, the final power ratio of the bonded type was 0.06 higher than that of the simultaneously-pressed variety.

- P-Leg Seebeck Voltage - Min-K 1301 Modules (Figure 5-18) The simultaneously-pressed legs exhibited a Seebeck ratio approximately 0.11 higher than their bonded counterparts. The Seebeck ratio of legs with an $1100^{\circ} \mathrm{F}$ hot junction temperature continued to decrease more rapidly than the ratio for $1000^{\circ} \mathrm{F}$ legs (the lower temperature legs exhibited a final Seebeck ratio 0.10 higher than the $1100^{\circ} \mathrm{F}$ legs).

- P-Leg Resistance - Min-K 1301 Modules (Figure 5-19) The resistance of the simultaneously-pressed legs decreased while that of the bonded type remained stable. However, the final resistance ratio of the simultaneously-pressed type was still 0.24 higher than that of the bonded type legs. The $1000^{\circ} \mathrm{F}$ legs exhibited a 0.08 higher resistance ratio than those with an $1100^{\circ} \mathrm{F}$ hot junction temperature. The resistance ratio of legs with a 250*psi contact pressure remained approximately 0.11 lower than that of the $150 \mathrm{psi}$ legs. Those legs with iron hot buttons (factor $\mathrm{BH}$ ) exhibited a resistance ratio 0.06 lower than those with molybdenum buttons (factor $\mathrm{B}-$ ).

- P-Leg Power - Min-K 1301 Modules (Figure 5-20) The various combinations of leg manufacturing technique (factor $A$ ) and hot junction temperature (factor $C$ ) resulted in the following power ratios after 21,000 hours of operation: 


\begin{tabular}{|l|c|c|}
\hline \multicolumn{1}{|c|}{ P-Leg Type } & $\begin{array}{c}\text { Hot Junction } \\
\text { Temperature, }\end{array}$ & $\begin{array}{c}\text { Power } \\
\text { Ratio }\end{array}$ \\
\hline Simultaneously Pressed (A+) & $1000(\mathrm{C}-)$ & 0.94 \\
Simultaneously Pressed (A+) & $1100(\mathrm{C}+)$ & 0.82 \\
Bonded (A-) & $1000(\mathrm{C}-)$ & 0.94 \\
Bonded (A-) & $1100(\mathrm{C}+)$ & 0.82 \\
\hline
\end{tabular}

The power ratios of bonded legs at $1000^{\circ} \mathrm{F}$ and simultaneously pressed legs at $1100^{\circ} \mathrm{F}$ tended to be fairly stable, while those associated with bonded legs at $1100^{\circ} \mathrm{F}$ and simultaneously pressed legs at $1000^{\circ} \mathrm{F}$ were decreasing and leveling-off respectively (see Figure 5-21). The power ratio of legs with a 250 psi contact pressure remained approximately 0.08 higher than that of the 150 psi legs. Those legs with iron hot buttons exhibited a power ratio 0.07 higher than those with molybdenum buttons.

Based on the foregoing analysis, the following conclusions may be drawn:

A. On the basis of test results from Modules 1 and $3, \mathrm{~N}$ - and particularly $\mathrm{P}$-legs are more stable and produce more power when operated in a Min-K 1301 as opposed to a microquartz environment (see Figures 5-11, 5-14 and 5-22).

B. Those legs (both $\mathrm{P}$ and $\mathrm{N}$ ) operated at the lower hot junction temperature $\left(1000^{\circ} \mathrm{F}\right)$ outperformed their $1100^{\circ} \mathrm{F}$ counterparts from a relative power standpoint (see Figures 5-11, 5-14, and 5-21).

C. On the basis of test results from Modules 1 and 3, legs with 250 psi contact pressure produce more power than comparable legs with 150 psi contact pressure. In the case of the N-legs the higher pressure resulted in greater initial performance and more stability. The primary difference in $\mathrm{P}$-leg performance with 250 psi appears to be better seat-in and thus greater initial power output than the 150 psi P-legs. 
D. While initial performance of the bonded P-leg construction was superior to that of simultaneously pressed construction, the difference decreased with time (see Figure 5-22) but the bonded $\mathrm{P}-\mathrm{leg}$ performance was slightly better from a power standpoint.

E. As compared to molybdenum hot junction contacts the iron contact causes a slight power ratio decrease in the $N-1$ eg, the use of iron results in a power increase in the P-leg. (Both materials exhibit only slight influence on power).

F. The bonded $\mathrm{N}$-leg demonstrated a slight power advantage ( five percent) over the simultaneously pressed $\mathrm{N}-1$ leg.

G. The advantage of soft nosed versus conventional P-leg was not fully resolved in these tests. This is perhaps due to the better leg alignment attainable in these modules nullifying any benefit which would result if soft nosed $\mathrm{P}$-legs were used in a device (i.e., generator) where the legs may not be as well aligned. 


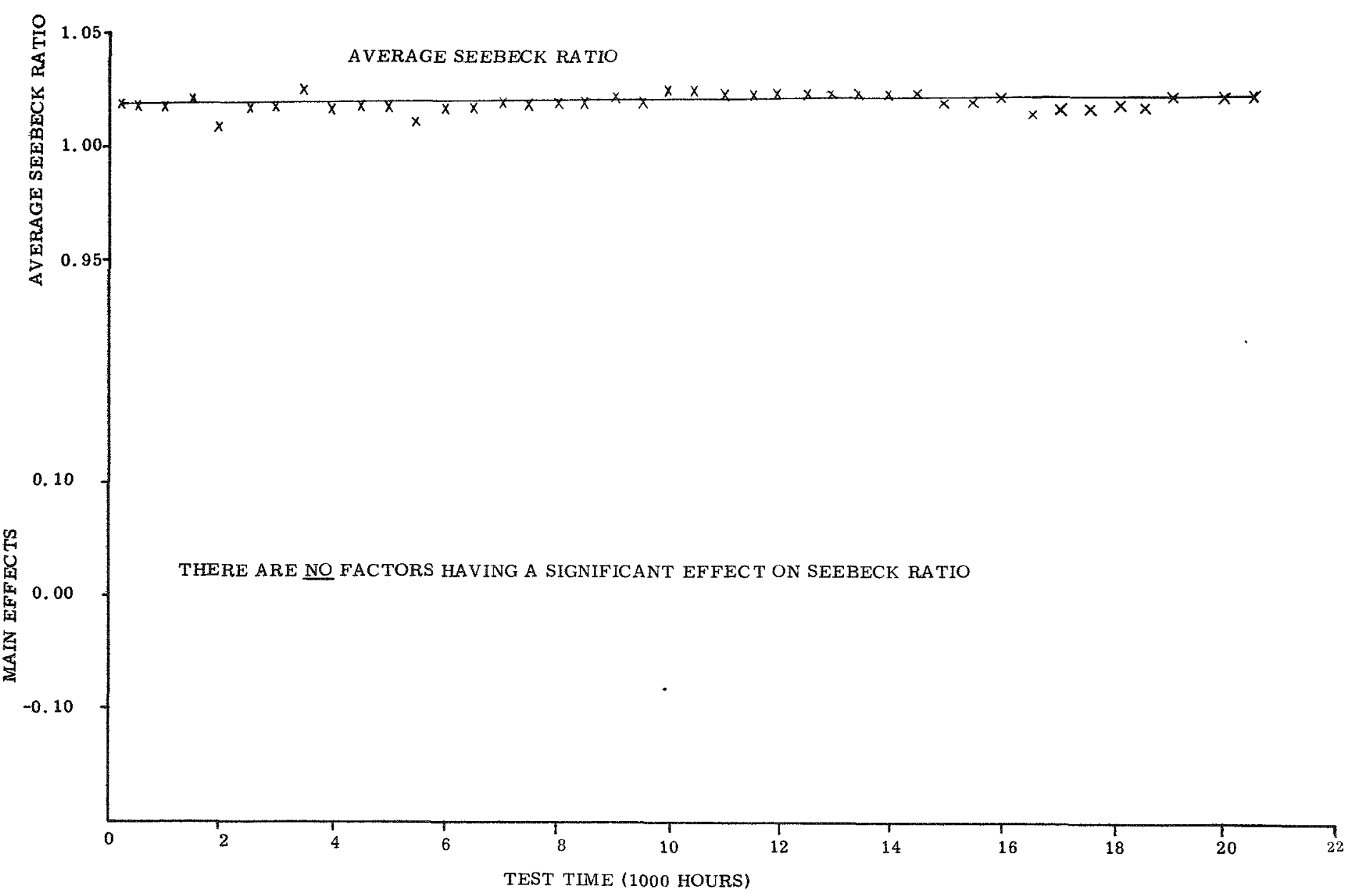

Figure 5-9

N-Leg Statistical Analysis (Microquartz Modules)

Average and Main Effects for Seebeck Ratio 


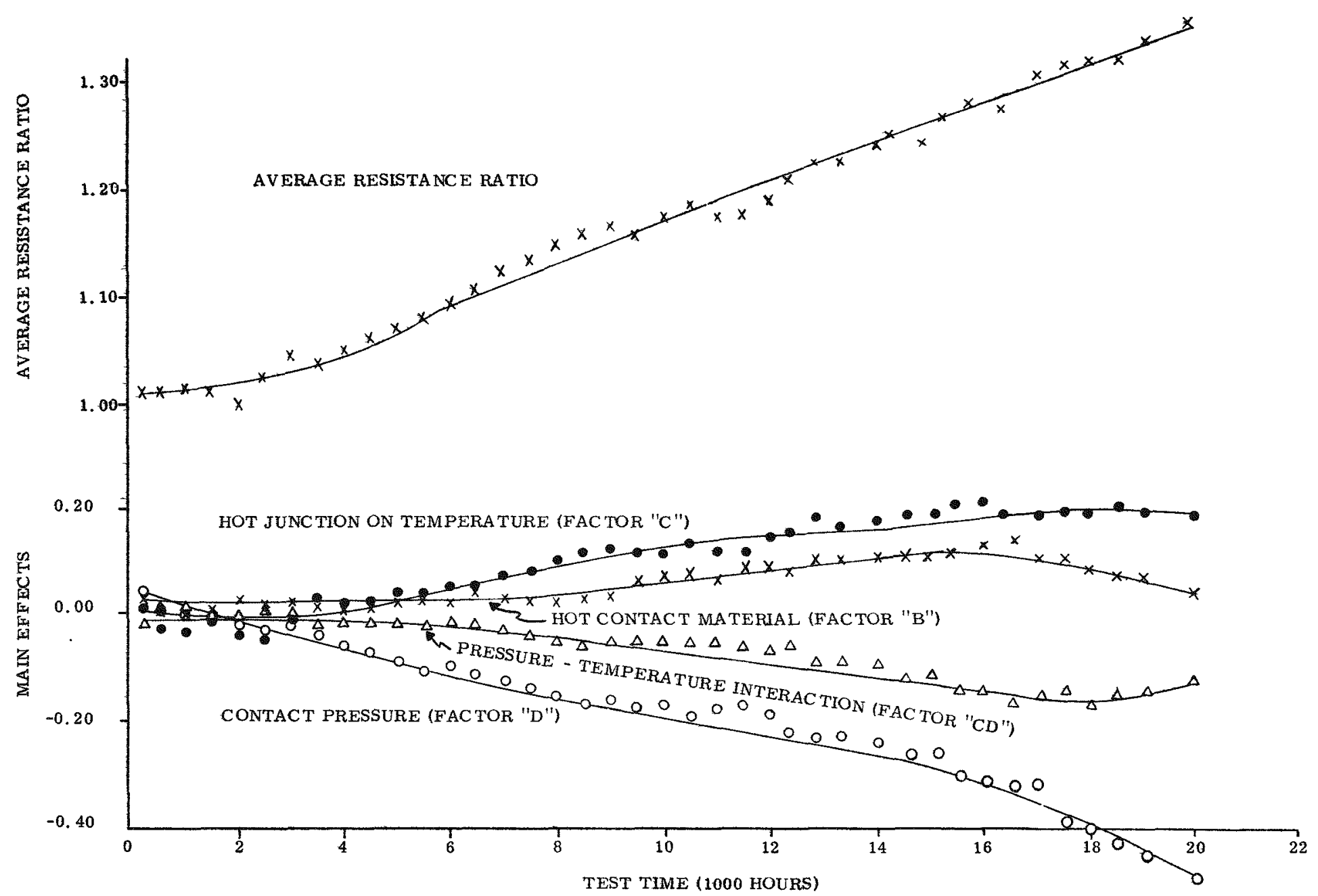

Figure 5-10

$\mathrm{N}$-Leg Statistical Analysis (Microquartz Modules) Average and Main Effects for Resistance Ratio 


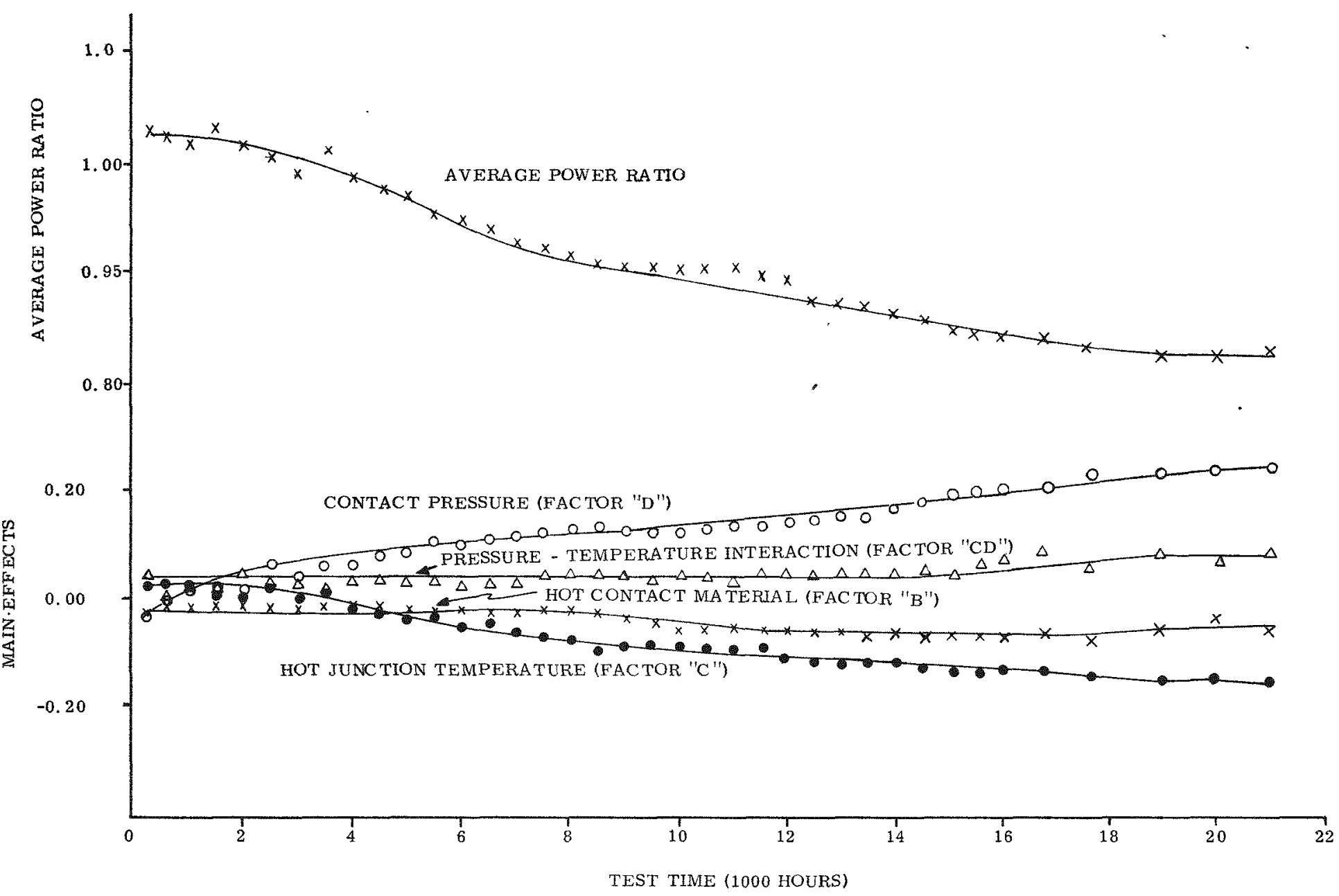

Figure 5-11

N-Leg Statistical Analysis (Microquartz Modules)

Average and Main Effects for Power Ratio 


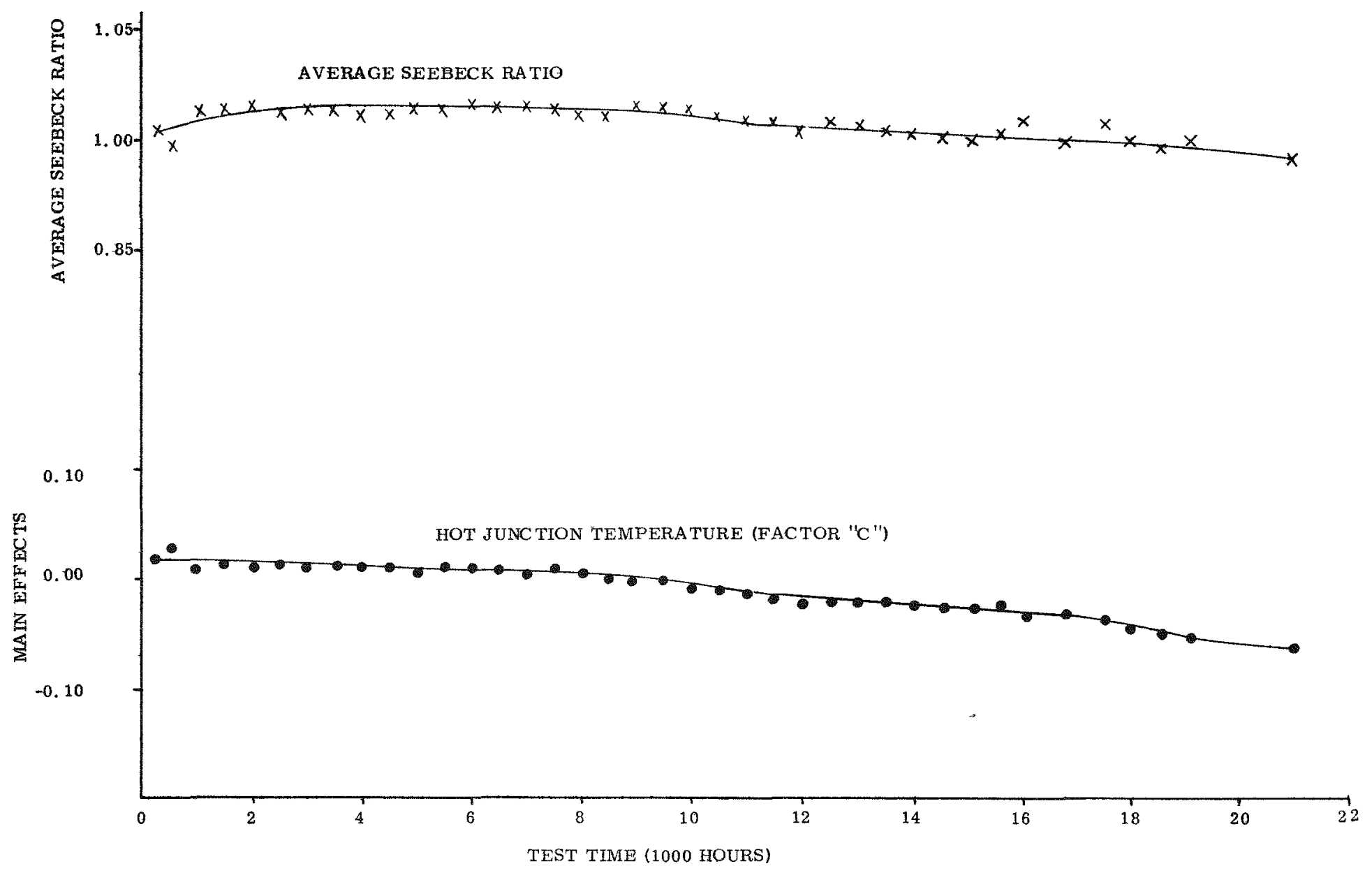

Figure 5-12

N-Leg Statistical Analysis (Min-K 1301 Modules)

Average and Main Effects for Seebeck Ratio 


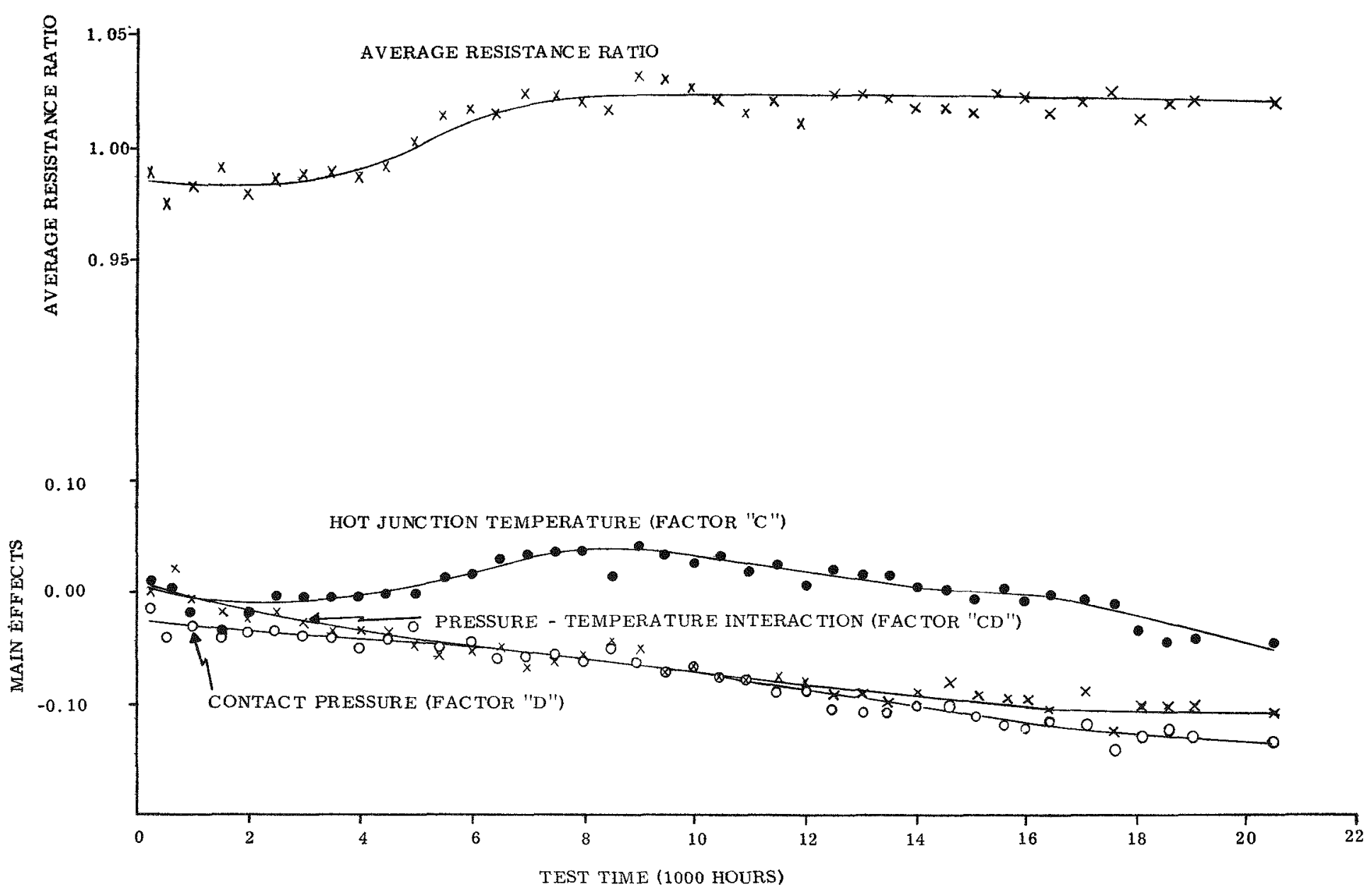

Figure 5-13

N-Leg Statistical Analysis (Min-K 1301 Modules) Average and Main Effects for Resistance Ratio 


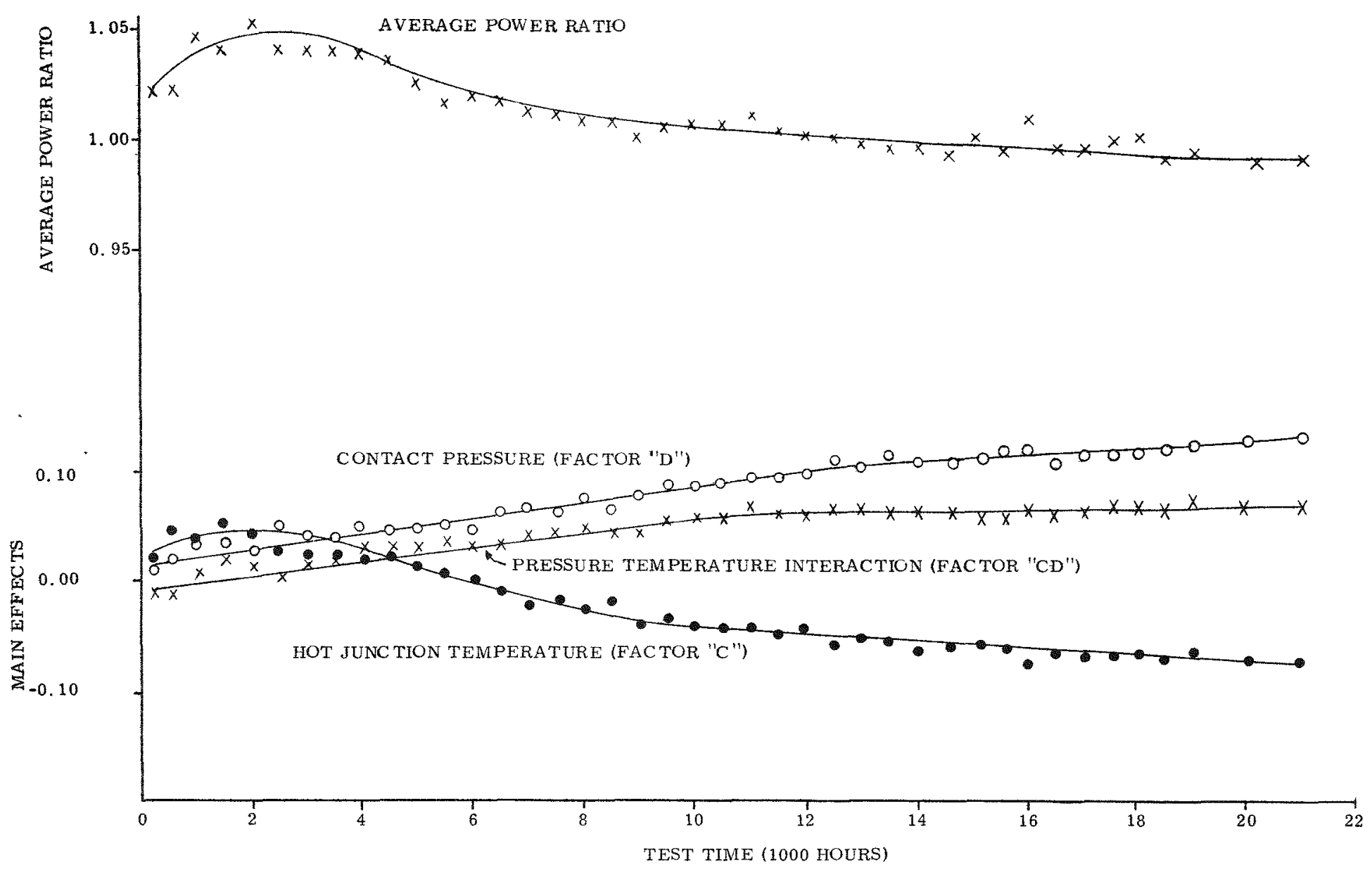

Figure 5-14

N-Leg Statistical Analysis (Min-K 1301 Modules) Average and Main Effects for Power Ratio 


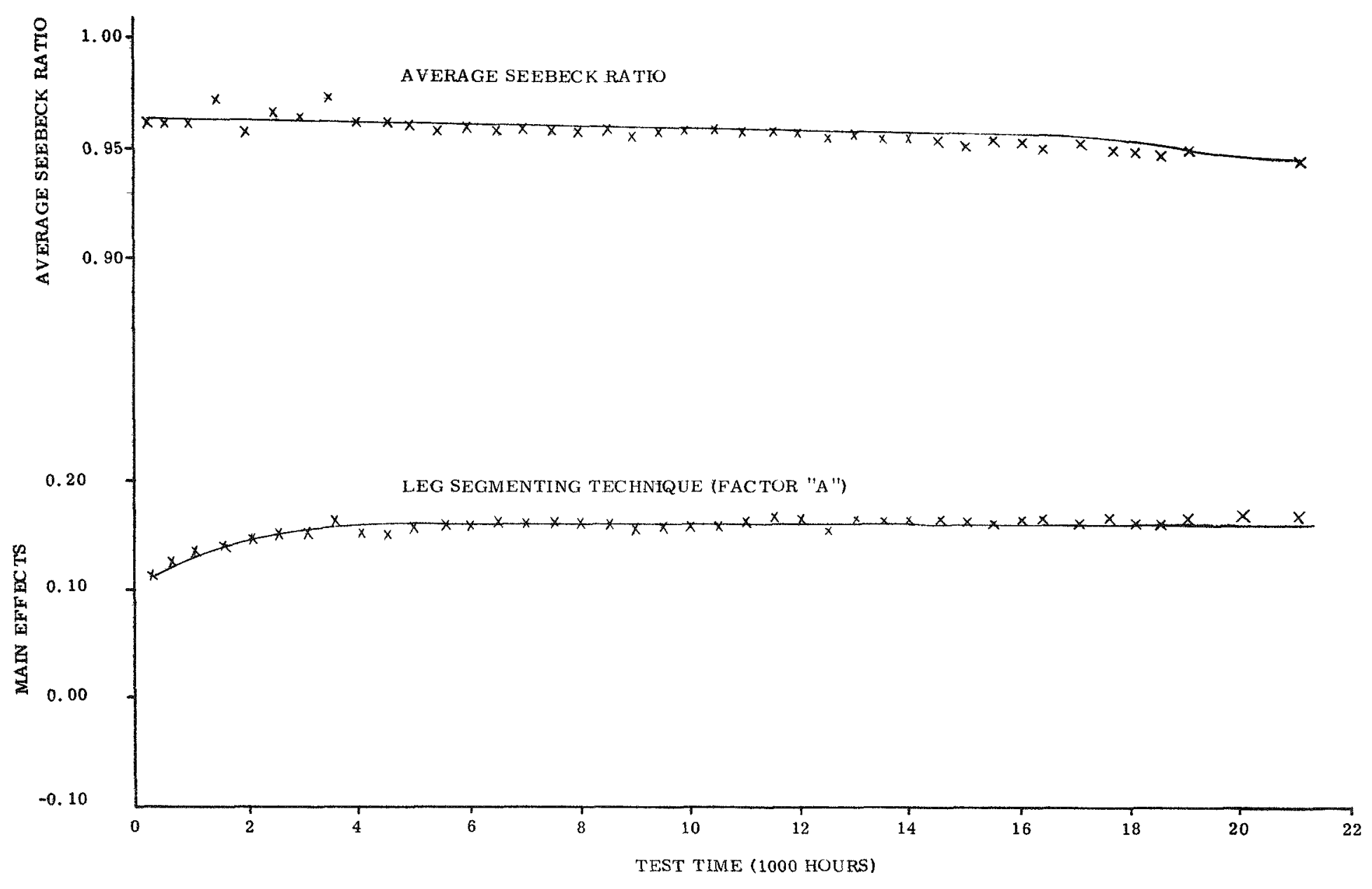

Figure 5-15

P-Leg Statistical Analysis (Microquartz Modules) Average and Main Effects for Seebeck Ratio 


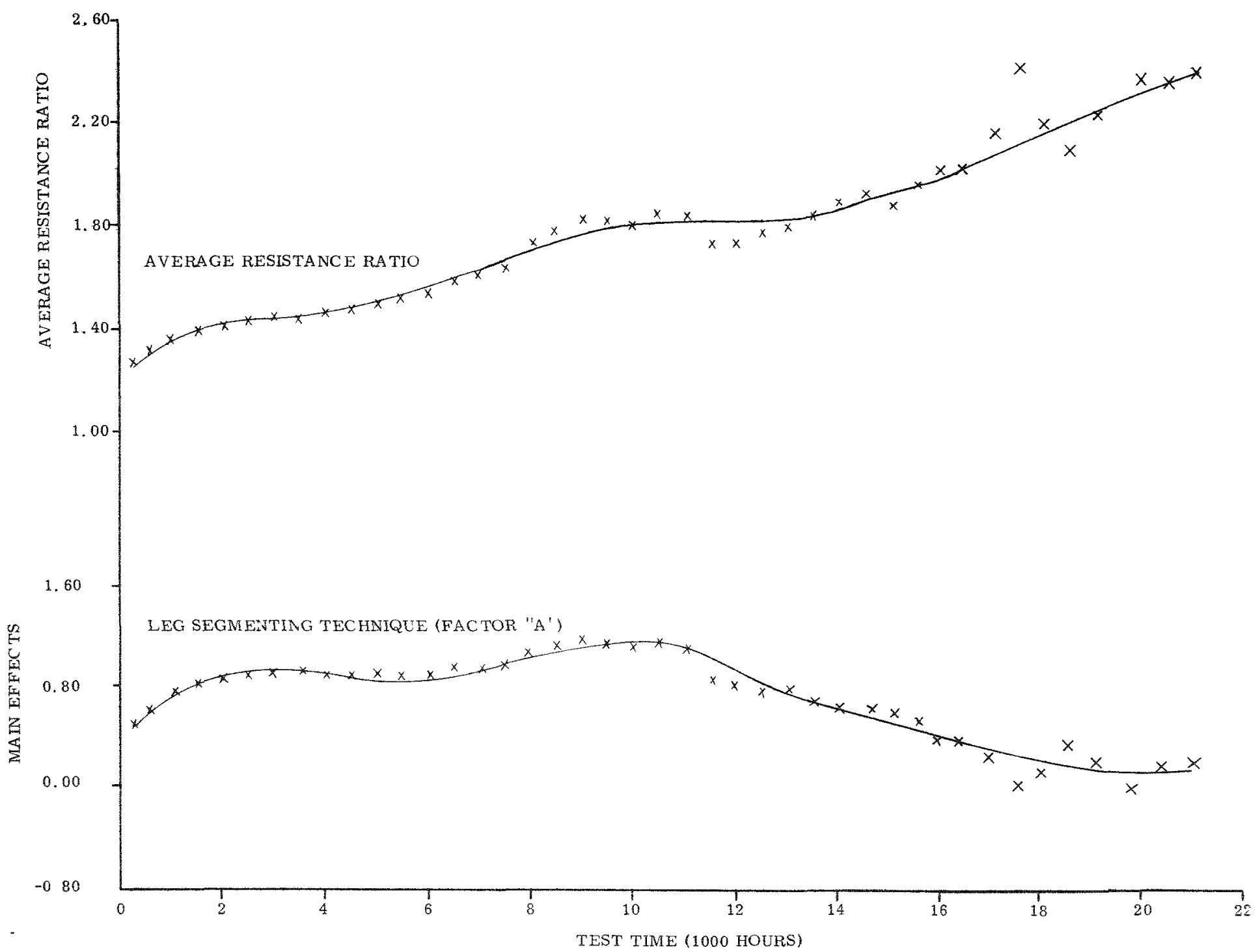

Figure 5-16

P-Leg Statistical Analysis (Microquartz Modules) Average and Main Effects for Resistance Ratio 


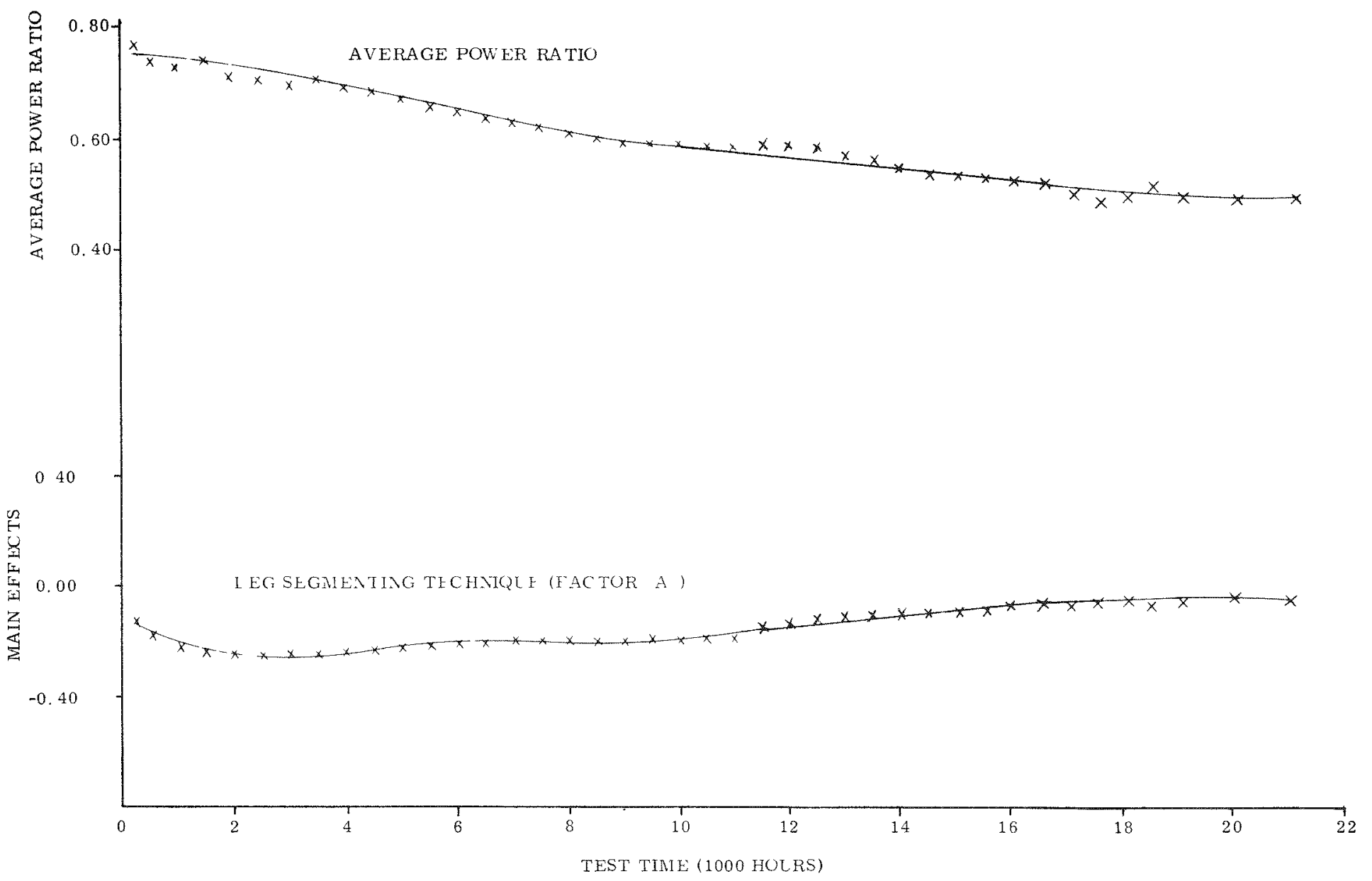

Figure 5-17

P-Leg Statistical Analysis (Microquartz Modules)

Average and Main Effects for Power Ratio 


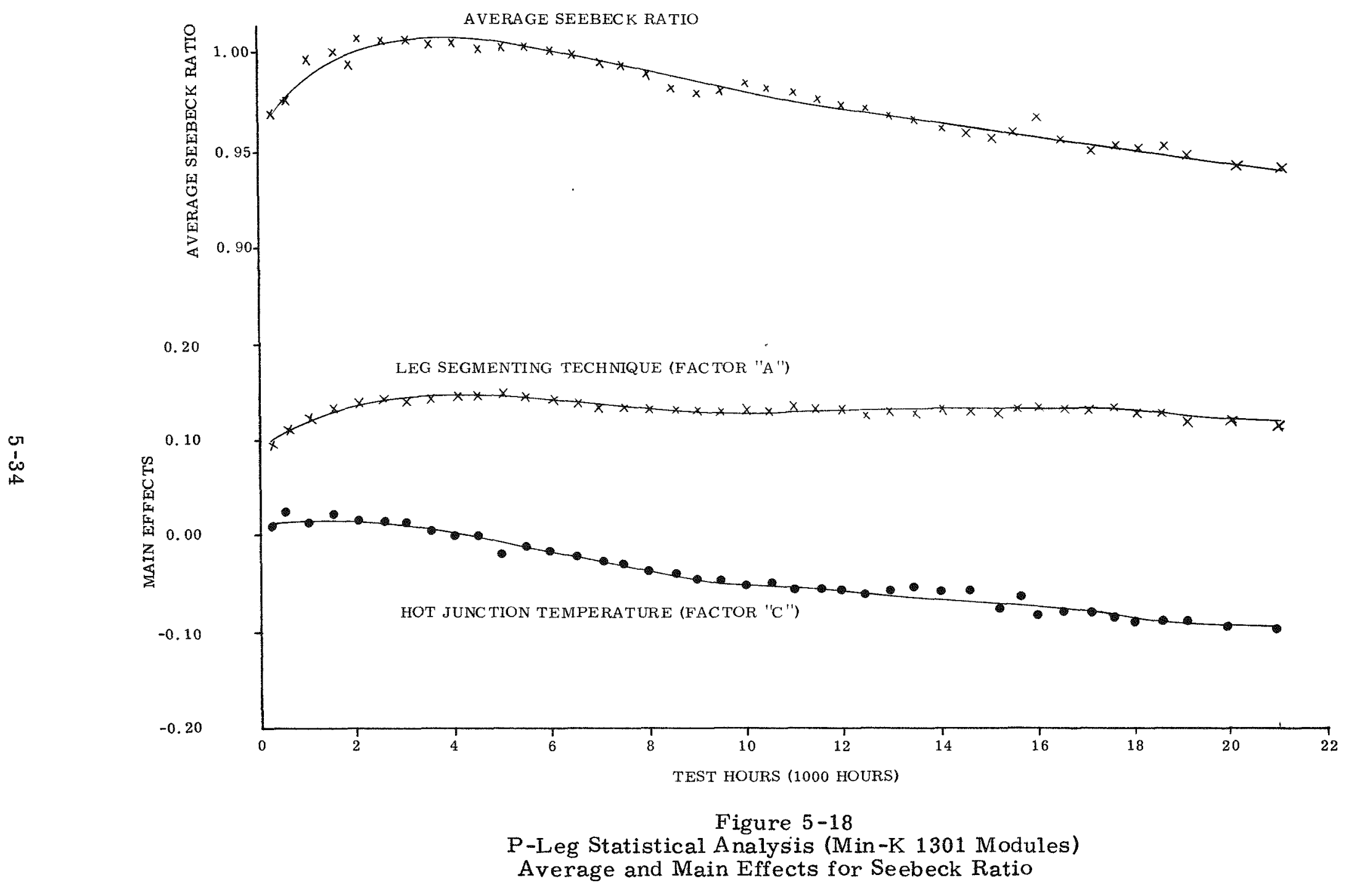




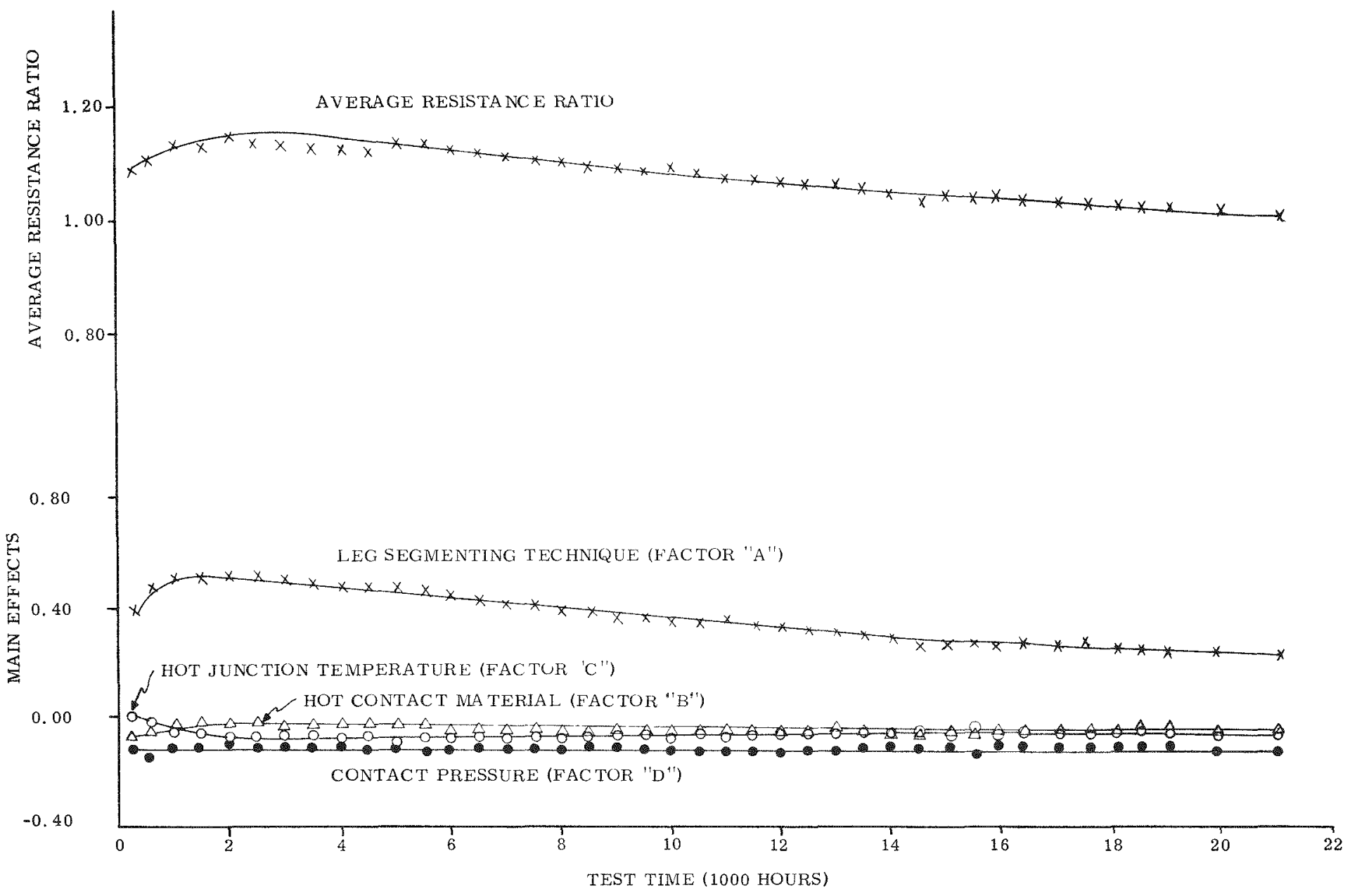

Figure 5-19

P-Leg Statistical Analysis (Min-K 1301 Modules) Average and Main Effects for Resistance Ratio 


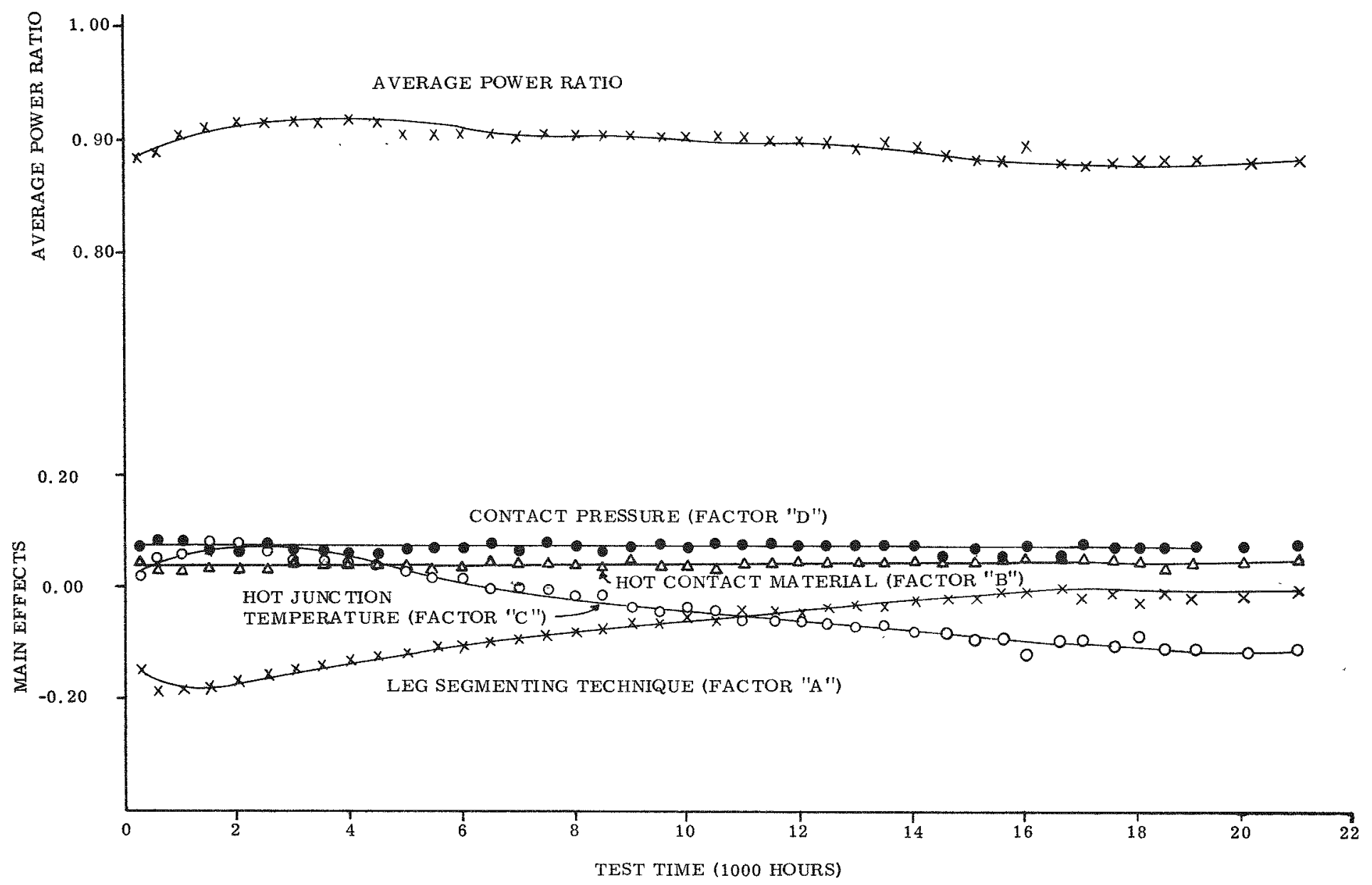

Figure 5-20

P-Leg Statistical Análysis (Min-K 1301 Modules)

Average and Main Effects for Power Ratio 


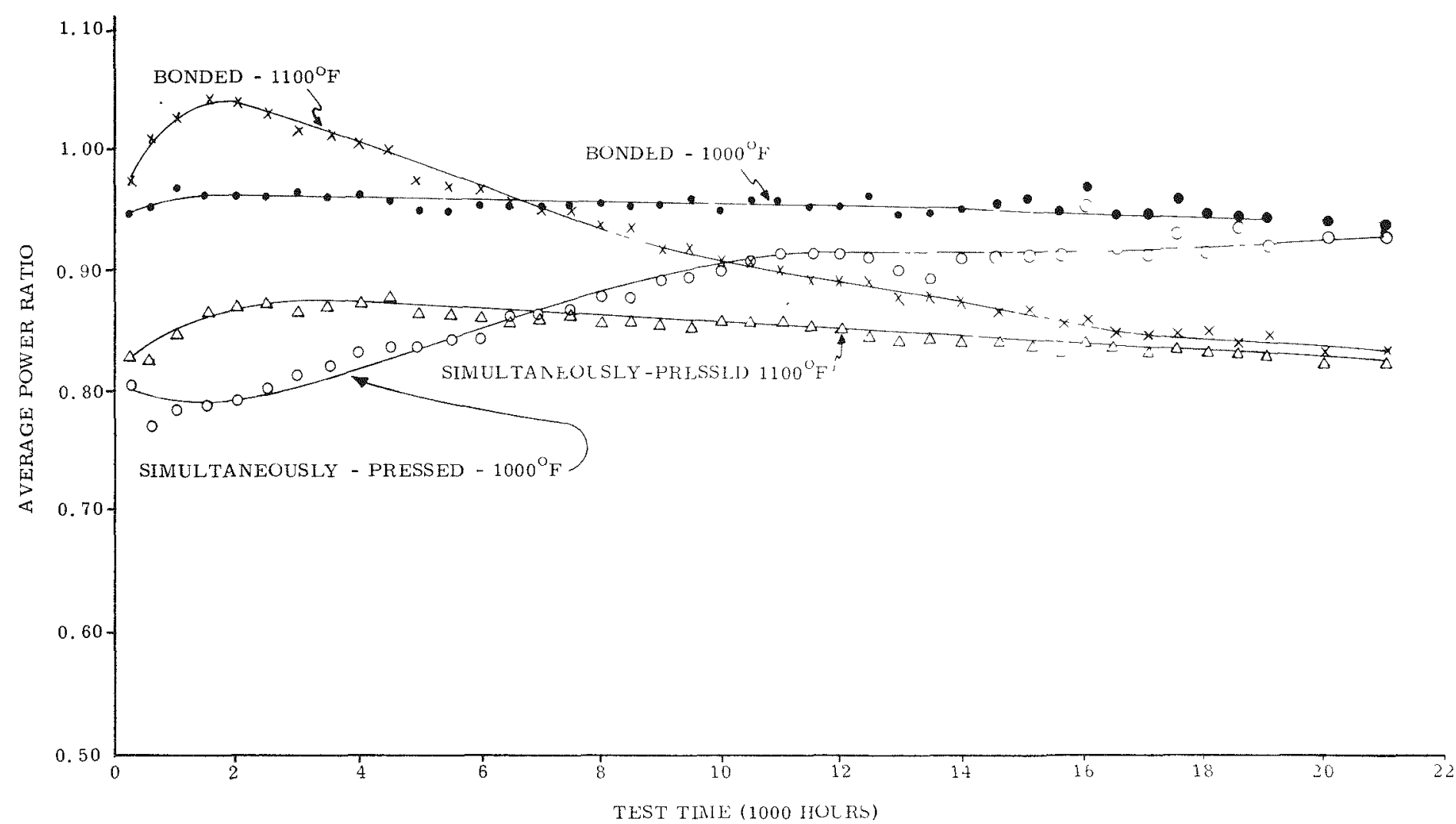

Figure 5-21

Comparison of Average Power Ratio for Various

Combinations of P-Legs and Hot Junction Temperatures (Min-K 1301 Modules) 


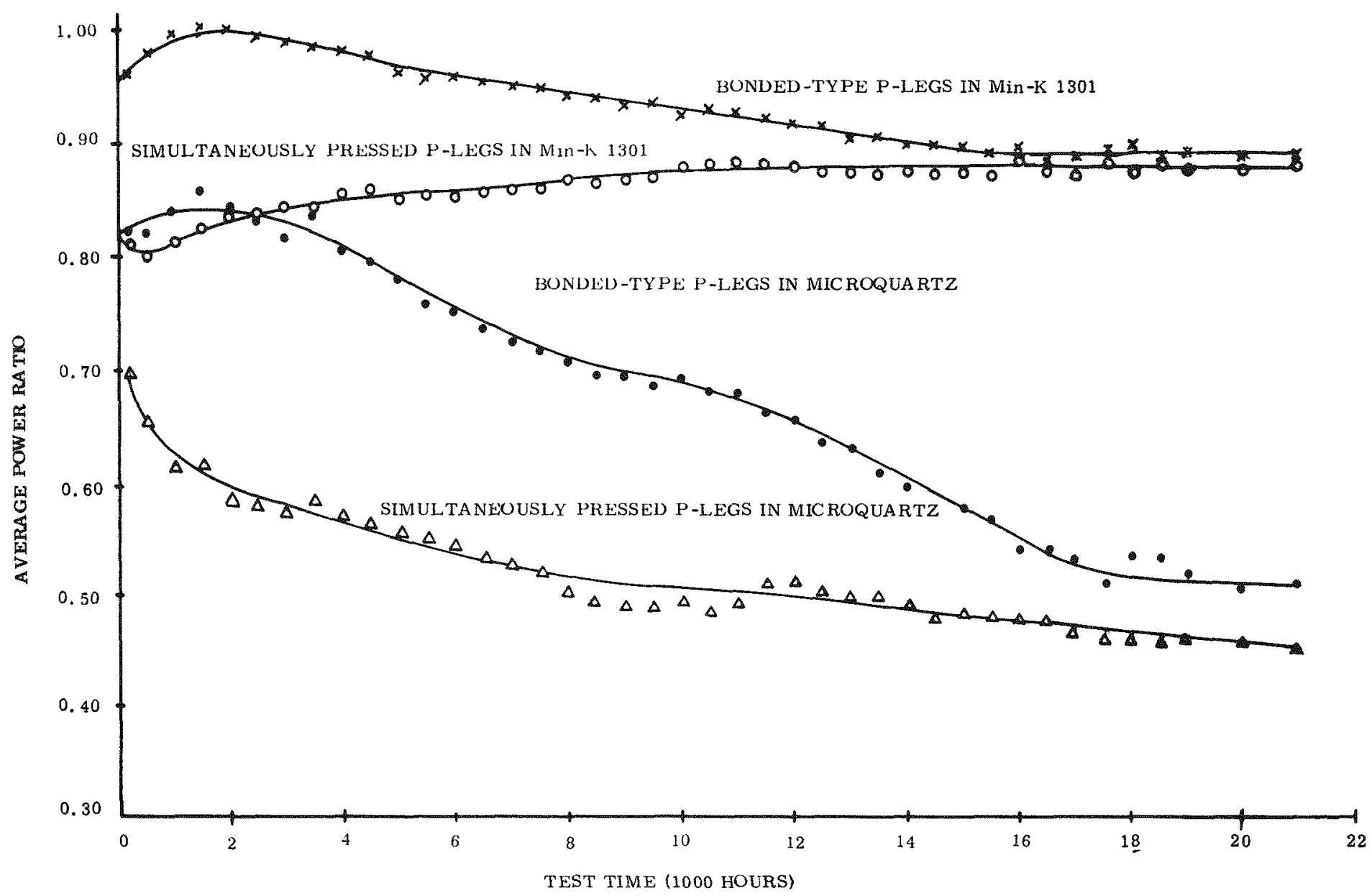

Figure 5-22

Comparison of Average Power Ratio for Various Combinations of P-Legs and Thermal Insulations 


\subsection{SNAP-23A CONVERTER PERFORMANCE SUMMARY}

The SNAP-23A converters, in general, exhibited performance that was consistent from unit to unit and stable over the period of long-term testing. This consistent and stable performance is illustrated in Figure 5-23 where converter efficiency is plotted as a function of time. All converters built after EMC-2 operated in an efficiency band of $8.0 \pm 0.4$ percent over the entire life test period. PMC-la exhibited the greatest performance stability with an efficiency decrease of only 0.07 percent in 16,000 hours. Details of performance of each converter are presented in the following sections.

Conversion efficiency is the single, most important factor in characterizing performance. This is especially true in an isotope fueled system where heat to the converter is a predictable and invariant function of time. Variation in the thermal characteristics of a converter can change hot junction temperature. In the case of the SNAP-23A, however, the efficiency is a very weak function of hot junction temperature and power output is dependent primarily on conversion efficiency.

\subsubsection{EMC-1}

\subsubsection{EMC-1 Thermal and Thermoelectric Description Summary}

This section summarizes the thermal and thermoelectric characteristics of EMC- 1 with only sufficient detail to define the thermal and electrical functions of . each component in the thermopile. A complete description of EMC-1 is presented in Section 2.3 .2 .2 .

Heat from the stud is conducted through the hot frame, electrical insulation strips, hot junction electrodes and buttons to the thermoelectric elements. The thermoelectric elements are arranged thermally in parallel with one another and with the shunt heat loss paths of the lower conver, support cone and thermal insulation. Rejected heat from the thermoelectric elements is transferred to the cold caps, through the followers to the cold frame, outer case and fins. 
Figure 5-23

SNAP-23A Converter - Efficiency vs Time

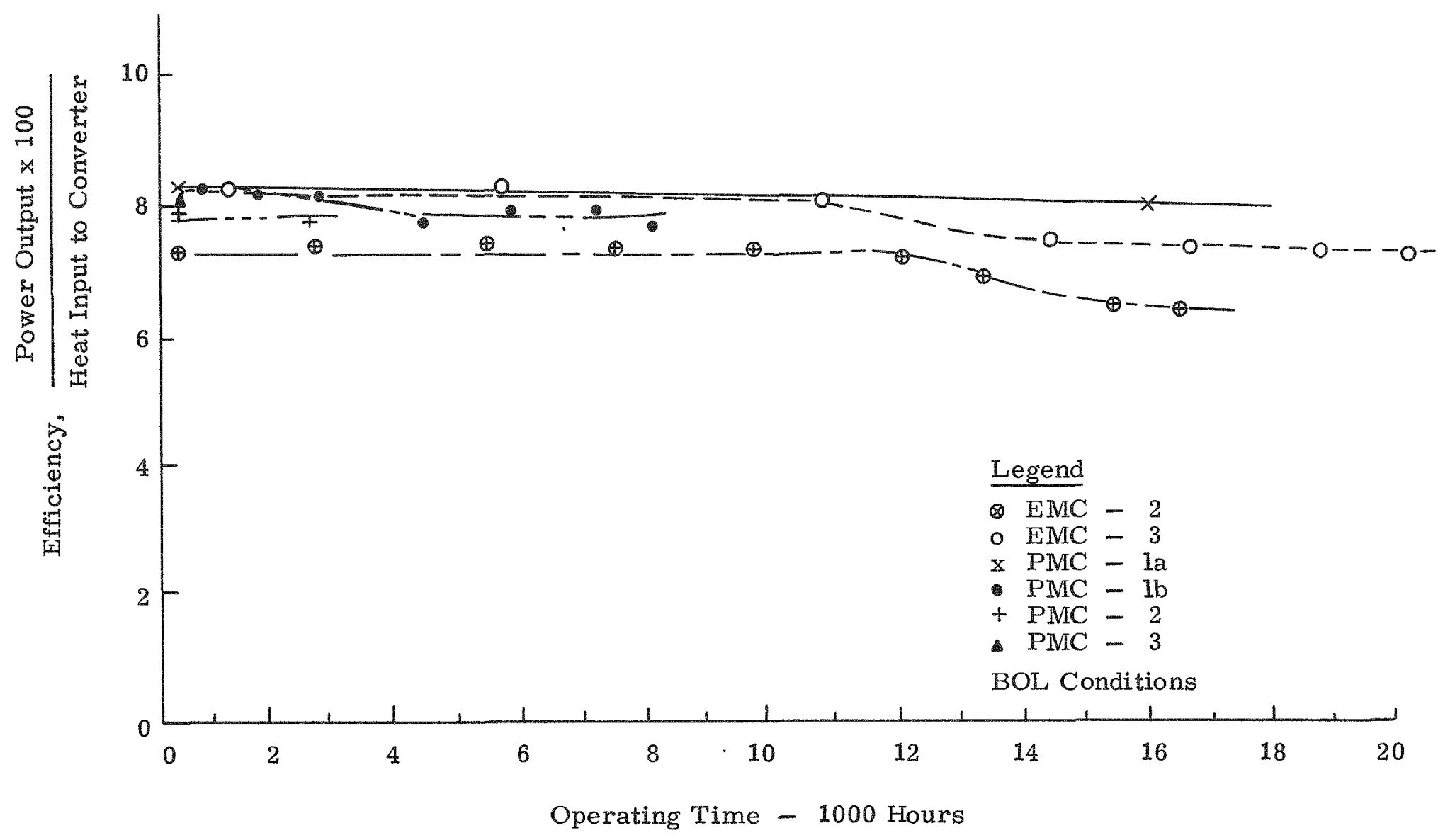


The electric current generated in the thermoelectric elements is transferred in a series path from one element to the next through hot junction and cold junction electrodes. Electrical insulation is provided at the hot end by the boron nitride electrical insulating strip. At the cold side electrical insulation is provided by an aluminum oxide coating on the aluminum followers.

Some component material changes were made in later converters. These changes involved the P-leg, hot junction electrodes and followers. EMC-1 was built with $\mathrm{P}-\mathrm{leg}$ fabricated by simultaneously pressing, copper hot junction electrodes and anodized aluminum followers. Table 5-4 lists follower, electrode, N-leg and $\mathrm{P}-\mathrm{leg}$ materials for each converter including thermoelectric element dimensions and number of couples.

\subsubsection{EMC-1 History}

EMC-1 was tested at $3 \mathrm{M}$ for a total of 680 hours and then delivered to Westinghouse for testing with the SNAP-23A electrically heated mockup system (EMS). During the $3 M$ testing the converter was operated at design EOL and BOL junction temperatures and load voltage. In addition, converter performance was measured at the following off-design conditions:

- EOL Mapping (Fixed Heat Input, Variable Load Voltage)

- BOL Mapping (Fixed Heat Input, Variable Load Voltage)

- EOL Increased Cold Junction Temperature

- BOL Reduced Cold Junction Temperature.

The converter was placed in storage at $3 \mathrm{M}$ after completion of EMC-1/EMS testing.

\subsubsection{EMC-1 Performance Predictions}

Performance predictions were made for all SNAP-23A converters at EOL and BOL temperature and load voltage conditions. The predictions consisted of a thermoelectric analysis to define performance of the thermoelectric couples and a thermal analysis of the parallel structural and insulation shunt heat losses. 
Table 5-4

SNAP -23A Converter Description Summary

\begin{tabular}{|c|c|c|c|c|c|c|c|}
\hline Converter & EMC-1 & EMC-2 & EMC -3 & PMC-la & PMC-1b & PMC-2 & PMC-3 \\
\hline \multicolumn{8}{|l|}{ Thermopile Design } \\
\hline Number of Couples & 264 & 264 & 264 & 252 & 252 & 280 & 280 \\
\hline \multicolumn{8}{|l|}{ N-Leg } \\
\hline Diameter & .1875 & .1875 & .1875 & .1875 & .1875 & .1875 & .1875 \\
\hline Length Total & .479 & .479 & .479 & .460 & .460 & .466 & .466 \\
\hline Length Cold Segment & .120 & .120 & .120 & .161 & .161 & .163 & .163 \\
\hline Length Hot Segment & .359 & .359 & .359 & .299 & .299 & .303 & .303 \\
\hline \multicolumn{8}{|l|}{ P-Leg } \\
\hline Diameter & .1875 & .1875 & .1875 & .1875 & .1875 & .1875 & .1875 \\
\hline Length Total & .327 & .327 & .327 & .325 & .325 & .355 & .355 \\
\hline Length Cold Segment & .114 & .114 & .114 & .127 & .127 & .138 & .138 \\
\hline Length Hot Segment & .213 & .213 & .213 & .198 & .197 & .217 & .217 \\
\hline \multicolumn{8}{|l|}{ Thermoelectric Materials } \\
\hline N-Leg Cold Segment - Pb Te & ES- 1104 & ES- 1104 & ES-1104 & ES- 1104 & ES-1104 & ES- 1104 & ES-1104 \\
\hline N-Leg Hot Segment $-\mathrm{PbTe}$ & ES- 1103 & ES- 1103 & $E S-1103$ & ES- 1103 & ES- 1103 & ES- 1103 & ES- 1103 \\
\hline P-Leg Cold Segment $-\left(\mathrm{BiSb}_{2} \mathrm{Te}_{3}\right.$ & $\mathrm{ES}-1116$ & ES- 1116 & ES- 1116 & ES- 1116 & ES- 1116 & ES- 1116 & ES- 1116 \\
\hline P-Leg Hot Segment $-(\mathrm{PbSn}){ }^{2} \mathrm{e}^{\circ}$ & ES- 1113 & ES- 1113 & ES- 1110 & ES- 1110 & ES- 1110 & ES- 1110 & ES-1110 \\
\hline P-Leg Soft Nose $\quad-(\mathrm{PbSn}) \mathrm{Te}$ & - & - & ES- 1111 & ES- 1111 & ES-1111 & $\mathrm{ES}-1111$ & $\mathrm{ES}-1111$ \\
\hline \multicolumn{8}{|l|}{ Hardware Material } \\
\hline Hot Electrode & $\mathrm{Cu}+\mathrm{Fe}$ Plating & $\mathrm{Cu}+\mathrm{Fe}$ Plating & $\mathrm{Cu}+\mathrm{Fe}$ Plating & $\mathrm{Cu}+\mathrm{Fe}$ Plating & $\mathrm{Cu}+\mathrm{Fe}$ Plating & $\mathrm{Cu}+\mathrm{Fe}$ Plating & $\mathrm{Fe}$ \\
\hline Cold Cap & $\mathrm{Cu}+\mathrm{Ni}$ Plating & $\mathrm{Cu}+\mathrm{Ni}$ Plating & $\mathrm{Cu}+\mathrm{Ni}$ Plating & $\mathrm{Cu}+\mathrm{Ni}$ Plating & $\mathrm{Cu}+\mathrm{Ni}$ Plating & $\mathrm{Cu}+\mathrm{Ni}$ Plating & $\mathrm{Cu}+\mathrm{Ni}$ Plating \\
\hline Follower & Aluminum & Aluminum & Aluminum & Beryllium Oxide & Beryllium Oxide & Beryllium Oxide & Beryllium Oxide \\
\hline Follower-Cold Cap Interface & - & - & Indium & - & Partial Indium & Indium & Indium \\
\hline Cover Gas & Argon & Argon & Argon & Xenon & Xenon & Xenon & Xenon \\
\hline Follower Cylinder & Greased & Greased & Greased & Dry & Dry & Dry & Dry \\
\hline
\end{tabular}

Note: All Measurement in Inches 
The thermoelectric analysis was made using the material properties $S, \rho$ and $K$ for each of the four thermoelectric materials in the couple. These point function properties are integrated over the cold junction to hot junction temperature interval to determine couple performance, heat requirement at the hot junction and heat rejected from the cold junction. The calculational model is described in Appendix $\mathrm{F}$ of SNAP-23A Quarterly Report No. 1.

Thermal analysis of the shunt heat losses through the insulation and structure parallel to the thermoelectric elements was made for each basic converter design. The shunt heat losses vary with gas type, number of couples, structural configuration and structural materials. The shunt heat losses were calculated as a function of hot junction and cold junction temperature for each converter design configuration.

Results from the thermoelectric and shunt heat loss analysis are presented in Table 5-5. The point function properties $S, \rho$ and $K$ are designated original values which were those available when the design analysis was first made. Later in the SNAP-23A program the materials were recharacterized in the TELPS facility. These recharacterized values were used in all analysis reported herein except those in Table 5-6. The extraneous resistance was assumed to be 6.8 percent of the thermoelectric material resistance for these calculations. Converter shunt heat losses were determined from SNAP-23 parametric studies. These were upgraded later in the program.

The hot junction temperature was limited to a maximum of $1100^{\circ} \mathrm{F}$ to reduce sublimation to an estimated reasonable level. 
Table 5-5

Summary: Predictions of SNAP-23A Converter Performance

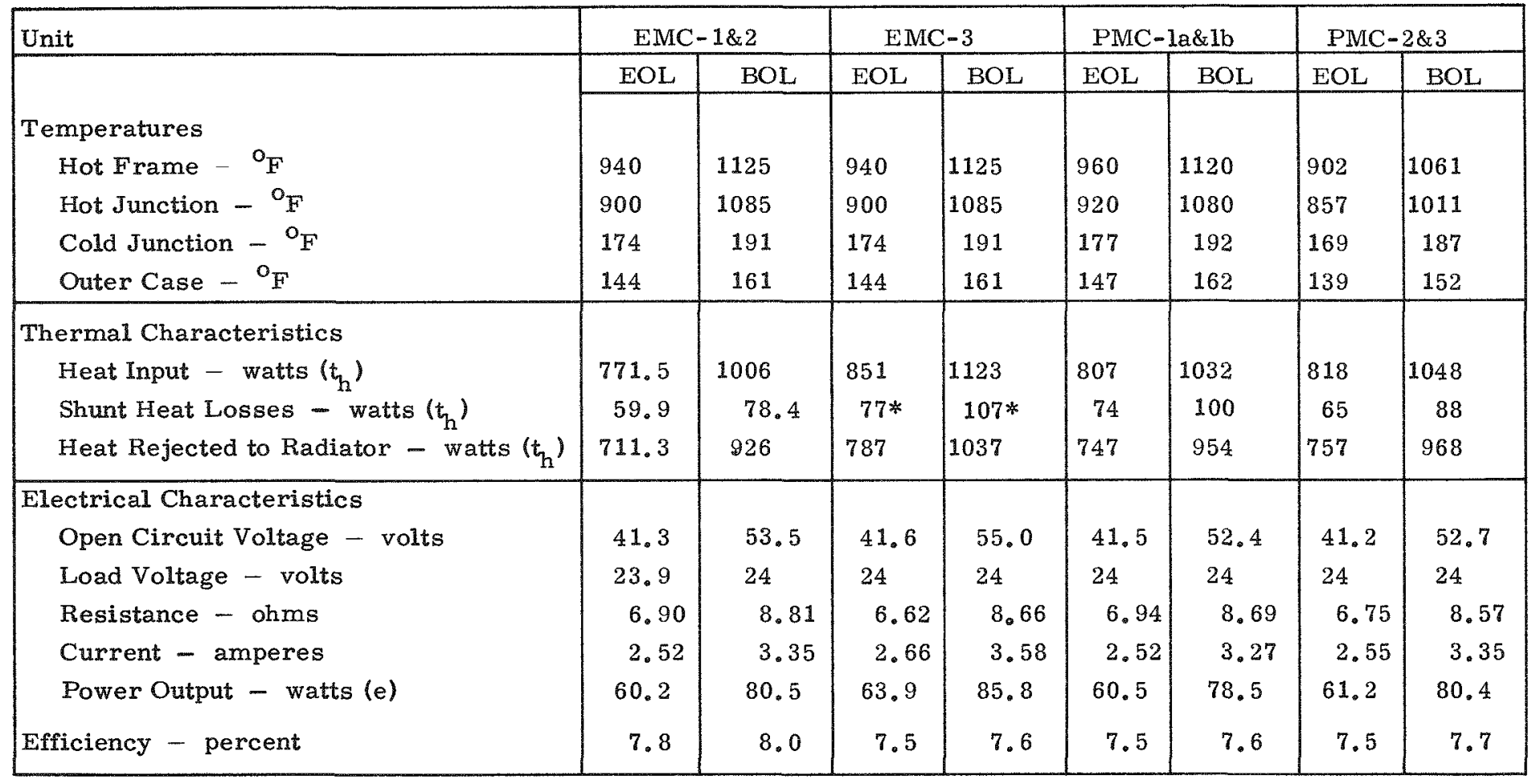

* These values increased because of updated thermal conductivity data for powdered Mink-1301. 
Table 5-6

Original SNAP-23A Converter EMC-1 and EMC-2

Performance Predictions

\begin{tabular}{|l|c|c|}
\hline & $\begin{array}{c}\text { EOL } \\
\text { Conditions }\end{array}$ & $\begin{array}{c}\text { BOL } \\
\text { Conditions }\end{array}$ \\
\hline Cold Junction Temperature & $174^{\circ} \mathrm{F}$ & $191^{\circ} \mathrm{F}$ \\
Hot Junction Temperature & $900^{\circ} \mathrm{F}$ & $1085^{\circ} \mathrm{F}$ \\
Converter Heat Losses - Watts (t) & 59.9 & 78.4 \\
Total Heat Input & 771.5 & 1006 \\
$\quad$ to Converter - Watts (t) & 23.9 & 24 \\
Load Voltage - Volts & 41.3 & 53.5 \\
Open Circuit Voltage - Volts & 60.2 & 80.5 \\
Power Output - Watts (e) & 7.8 & 8.0 \\
Efficiency - Percent & & \\
\hline
\end{tabular}

\subsubsection{EMC-1 Performance Data}

A summary of performance data from EMC-1 testing is presented in Table 5-7. A complete listing of EMC- 1 performance data is included in SNAP-23A Quarterly Report No. 4. The conversion efficiency is shown to be below expectation, due in part, to a leak in the hermetic enclosure during final processing and the resultant oxidation of components. In comparing the measured to the predicted performance results of Table 5-6, the converter is deficient in all performance parameters. Seebeck voltage is slightly below predicted. The electrical resistance is greater than predicted as are the heat input requirements. The total result of these adverse effects is to lower EOL converter efficiency from a predicted value of 7.8 percent to an actual conversion efficiency of 6.1 percent.

The thermopile, typical $\mathrm{N}$-leg and typical P-leg resistance and Seebeck voltage are divided by theoretical values and presented in Table 5-8. These ratios show the primary deviation from theoretical is the resistance of the P-leg. At EOL conditions the P-leg resistance was 68 percent greater than theoretical. This caused the thermopile resistance to be 31 percent greater than theoretical which in turn reduced power output and efficiency. The $\mathrm{N}-1$ eg performed very close to the theoretical level and as such did not contribute to performance deviation. 
Table $5-7$

SNAP-23A Converter EIMC-1 Performance Data

\begin{tabular}{|c|c|c|c|c|}
\hline Parameter & Symbol & Units & $\begin{array}{c}\text { EOL } \\
(43.4 \mathrm{Hrs})\end{array}$ & $\begin{array}{c}\text { BOL } \\
(66.5 \mathrm{Hrs})\end{array}$ \\
\hline Net Power Input & $P_{\text {in }}$ & Watts (e) & 831 & 1055 \\
\hline Power Output & $P_{0}$ & Watts (e) & 50.9 & 72.5 \\
\hline Efficiency & $\eta$ & Percent & 6.12 & 6.87 \\
\hline Open Circuit VoItage & $\mathrm{E}$ & Volts & 40.9 & 52.5 \\
\hline Load Voltage & $V_{1}$ & Volts & 23.0 & 25.0 \\
\hline Load Current & $\mathrm{I}_{1}$ & Amps & 2.21 & 2.90 \\
\hline Internal Resistance & $R_{g}$ & Ohms & 8.10 & 9.48 \\
\hline \multicolumn{5}{|l|}{ Temperatures } \\
\hline Hot Frame & $T_{h f}$ & $o_{F}$ & 934 & 1120 \\
\hline Hot Junction & $\mathrm{T}_{\mathrm{h}}$ & ${ }^{\circ} F$ & 900 & 1083 \\
\hline Cold Junction & $T_{c}$ & ${ }^{o} \mathrm{~F}$ & 173 & 192 \\
\hline Outer Case & $\mathrm{T}_{\mathrm{OC}}$ & ${ }^{\circ} \mathrm{F}$ & 126 & 136 \\
\hline Gross Power Input & $P_{t}$ & Watts $(t)$ & 864 & 1100 \\
\hline Test Station Losses & $P_{1}$ & Watts (t) & 33 & $45^{\circ}$ \\
\hline
\end{tabular}

Table 5-8

SNAP-23A EMC-1 Initial Performance Ratios Experimental Value Theoretical Value At EOL and BOL Design Conditions

\begin{tabular}{|l|l|l|l|l|}
\hline & \multicolumn{2}{|c|}{ Seebeck Ratio } & \multicolumn{2}{c|}{ Resistance Ratio* } \\
\cline { 2 - 5 } & EOL & BOL & EOL & BOL \\
\hline Thermopile & 1.01 & 0.99 & 1.31 & 1.18 \\
Typical N-leg & 1.00 & 0.99 & 1.00 & 0.97 \\
Typical P-leg & 1.03 & 0.99 & 1.68 & 1.44 \\
\hline
\end{tabular}

* Theoretical resistance includes no extraneous resistance allowance.

Note: Theoretical values are based on the new material characteristics discussed in Section 5.3.1.3. 
5.4 .2 EMC-2

5.4.2.1 EMC-2 Thermal and Thermoelectric Description Summary

EMC - 2 was built to design specifications which were identical to EMC-1 from thermal and thermoelectric performance considerations. However, there was no breach in the EMC-2 hermetic seal after initiation of processing as occurred with EMC-1. This was considered to be a major factor in the improved performance exhibited by EMC-2。

\subsubsection{EMC-2 History}

EIMC-2 was operated for a total period of 16,826 hours primarily at beginningof-life temperature and electrical loading conditions. Dynamic testing was conducted with the converter subjected to design shock $(10 \mathrm{~g})$ and vibration at BOL thermal conditions. Early in the testing, converter performance was measured at EOL and several off-design conditions which included the following:

- EOL Mapping (Fixed Heat Input, Variable Load Voltage)

- BOL Mapping (Fixed lleat Input, Variable Load Voltage)

- EOL Variable Cold Junction Temperature

- BOL Reduced Cold Junction Temperature.

The testing termination date coincided with the SNAP-23A program termination. At the time of shut down, converter performance was satisfactory.

\subsubsection{EIMC-2 Performance Predictions}

Performance predictions for EMC-2 were identical to EMC-1. The results are shown in Table 5-5.

\subsubsection{EMC-2 Performance Data}

EMC-2 performance data at BOL and EOL conditions is presented in Tables 5-9 and 5-10, respectively. A complete listing of EMC-2 initial performance 
evaluation data is included in SNAP-23A Quarterly Report No. 5. The testing covered a time span of 16,825 hours and included a dynamic test to demonstrate capability of the converter to sustain shock and vibration loads. Results show that the dynamic testing caused a small, temporary increase in internal resistance of 2.5 percent. Examination of the data revealed that the resistance returned to the predynamic testing level within the 200-hour period between the postdynamic test measurement and the next measurement.

Comparing observed performance with the predictions listed in Table $5-5$, shows EMC-2 approached the EOL and BOL performance predictions much closer than EMC-1. The power output initially was within three watts of predictions at EOL temperature condition and exceeding the prediction at ROL. The observed efficiency was initially less than predicted at both EOL and BOL temperature conditions.

Normalized performance data presented in Table 5-11 show the thermopile Seebeck voltage is 3 percent greater than anticipated due to higher Seebeck voltage of the $P-l e g$ and that the thermopile resistance ratio is 16 percent above theoretical due also to the P-leg. Comparison of power ratio shows the $\mathrm{N}-1 \mathrm{eg}$ is performing very close to theoretical, whereas the P-leg is initially 19 percent below theoretical. During operation, the P-1eg power output showed considerable improvement until 10,000 hours and then began to degrade significantly. The $\mathrm{N}$-leg shows a degradation of over 10 percent in power output due to an increasing resistance and decreasing Seebeck voltage over the 3,000 to 16,000 -hour period.

Converter EMC-2 efficiency at BOL temperatures versus operating time, (see Figure 5-23) indicates how power output will vary. This relationship holds because efficiency of a SNAP-23A converter operating at a load voltage of $25 \mathrm{v}$ is nearly constant for hot junction temperature over the range from $1000^{\circ} \mathrm{F}$ to $1080^{\circ} \mathrm{F}$. As can be noted, efficiency remained at about 7.5 percent until 12,000 hours, dropped to 6.8 percent at 15,000 hours and remained constant until the end of testing. 
Table 5-9

SNAP-23A Converter EMC -2 Performance Data (BOL Conditions)

\begin{tabular}{|c|c|c|c|c|c|c|c|c|c|c|c|c|c|c|c|c|c|c|c|}
\hline Parameter & symbol & Units & \multicolumn{17}{|c|}{ Measured Values at Spec fied Hours } \\
\hline Normalized Power Output & $\mathrm{P}_{\mathrm{N}}{ }^{*}$ & Watts (e) & 796 & 791 & 799 & 789 & $80 ?$ & 838 & 841 & $84 \mathrm{r}$ & $84 \mathrm{f}$ & 842 & 829 & 847 & 832 & 768 & $i+0$ & 739 & - \\
\hline Open Circurt Voltage & E & Voits & 537 & 542 & 545 & 541 & 542 & 532 & $\Rightarrow$ &, 3 & $\Rightarrow 3$ & 243 & 240 & 334 & 498 & 320 & s1 9 & 024 & 52.4 \\
\hline Internal Resistance & $R_{g}$ & Ohms & 903 & 924 & 926 & 930 & 927 & 899 & 899 & 879 & 877 & 873 & 867 & 859 & $? 9_{3}$ & 881 & 900 & $92^{n}$ & 9.29 \\
\hline Norm Int Resistance & $\mathrm{B}_{\mathrm{N}^{*}}$ & Ohms & 304 & 925 & 931 & 942 & 933 & $9+2$ & 898 & $8 \$ 3$ & 881 & 877 & 867 & 859 & в 72 & 8 80 & 324 & 931 & - \\
\hline Load Voltage & $\mathrm{v}_{1}$ & Volts & 250 & 250 & 250 & 250 & 250 & 250 & 200 & 200 & 250 & $2\urcorner 0$ & 250 & $2 \ni 0$ & 200 & 200 & 200 & & 25.0 \\
\hline Cold Junction & $T_{c}$ & of & 191 & 191 & 190 & 189 & 195 & 186 & 188 & 187 & 185 & 190 & 189 & 187 & 180 & 192 & 183 & 189 & 188 \\
\hline Gross Power Input & $P_{t}$ & Watts $(t)$ & 1104 & 1112 & 1120 & 1132 & 1128 & $112 x$ & $\$ 179$ & 1175 & 1153 & 1140 & 1150 & 1144 & 109 & 1129 & 1118 & 1.124 & 1121 \\
\hline
\end{tabular}

Data normalized to $T_{h} \quad 1085^{\circ} \mathrm{F}$ and $T_{c} \quad 191{ }^{\circ} F$ 
Table 5-10

SNAP -23A Converter EMC -2 Performance Data (EOL C onditions)

\begin{tabular}{|c|c|c|c|c|c|c|c|c|c|c|c|c|}
\hline \multirow[b]{2}{*}{ Parameter } & \multirow[b]{2}{*}{ Symbol } & \multirow[b]{2}{*}{ Units } & \multicolumn{10}{|c|}{ Measured Values at Specified Heurs } \\
\hline & & & 35 & $\begin{array}{c}508 \\
\text { (Pre } \\
\text { dynamic } \\
\text { Test) }\end{array}$ & $\begin{array}{c}628 \\
\text { (Post } \\
\text { dynamic } \\
\text { Test) }\end{array}$ & 3683 & 7142 & 9488 & 11810 & 12909 & 14,953 & 16,825 \\
\hline Net Power Input & $P_{\text {in }}$ & Watts (t) & 832 & 852 & 860 & 896 & 891 & 881 & 873 & 860 & 866 & 870 \\
\hline Power Output & $P_{0}$ & Watts (e) & 576 & 576 & 571 & 632 & 136 & 112 & 602 & 071 & 547 & $54 \mathrm{~s}$ \\
\hline Efficiency & $\eta$ & Percent & 692 & 6.76 & 664 & 705 & 714 & f. 95 & 690 & 664 & 632 & 626 \\
\hline Open Circuit Voitage & E & Volts & 411 & 424 & 429 & 432 & 428 & 419 & 411 & 409 & 411 & 408 \\
\hline Load Voltage & $v_{1}$ & Volts & 230 & 230 & 240 & 240 & 240 & 240 & 240 & 240 & 240 & 240 \\
\hline Load Current & $\mathrm{I}_{1}$ & Amps & 2 э0 & 250 & 238 & 263 & 2 6 & 205 & 251 & 238 & 228 & 227 \\
\hline Internal Resistance & $\mathrm{R}_{\mathrm{g}}$ & Ohms & 723 & 776 & 794 & 728 & 708 & 700 & 680 & 712 & 751 & 741 \\
\hline Temperatures & & & & & & & & & & & & \\
\hline Hot Frame & $\mathrm{T}_{\mathrm{hf}}$ & ${ }^{\circ} \mathbf{F}$ & 931 & 926 & 934 & 933 & 935 & 932 & 930 & 928 & 934 & 931 \\
\hline Hot Junction & $\mathrm{T}_{\mathrm{h}}$ & ${ }^{\circ} \mathrm{F}$ & 901 & 898 & 904 & 903 & 905 & 902 & 900 & 898 & 904 & 901 \\
\hline Cold Junction & $\mathrm{T}_{\mathrm{c}}$ & ${ }^{\circ} \mathrm{F}$ & 173 & 172 & 176 & 171 & 175 & 174 & 172 & 171 & 173 & 172 \\
\hline Outer Case & $\mathrm{T}_{\text {oc }}$ & ${ }^{\circ} \mathbf{F}$ & 128 & 129 & 125 & 119 & 119 & 11 ก & 114 & 117 & 118 & 116 \\
\hline Gross Power Input & $P_{t}$ & Watts $(t)$ & 860 & 880 & 888 & 924 & 919 & 909 & 901 & 888 & 894 & 898 \\
\hline
\end{tabular}


Table 5-11

SNAP -23A Converter EMC -2 Performance Data - BOL Conditions (Ratio of Experimental-to-Theoretical Values)

\begin{tabular}{|c|c|c|c|c|c|c|c|c|c|c|}
\hline \multirow{2}{*}{$\begin{array}{l}\text { Test } \\
\text { Hours }\end{array}$} & \multicolumn{3}{|c|}{ Seebeck Ratio } & \multicolumn{3}{|c|}{ Resistance Ratio (1) } & \multicolumn{3}{|c|}{ Fouer Ratio (2) } & \multirow{2}{*}{$\begin{array}{l}\text { Power Input hias } \\
\text { Lxpecument- } \\
\text { Calculated }\end{array}$} \\
\hline & $\begin{array}{c}\text { Thermo- } \\
\text { pile }\end{array}$ & $\begin{array}{c}\text { N-Leg } \\
\text { (Typrcal) }\end{array}$ & $\begin{array}{c}\text { P-Leg } \\
\text { (Typical) }\end{array}$ & $\begin{array}{c}\text { Thermo- } \\
\text { pile }\end{array}$ & $\begin{array}{c}\text { N-Lefi } \\
\text { (I ipcal) }\end{array}$ & $\begin{array}{c}P>I \mathrm{eg} \\
\text { (T)pical) }\end{array}$ & $\begin{array}{c}\text { Thermo- } \\
\text { prle }\end{array}$ & $\begin{array}{c}\text { N-Leg } \\
\text { (Frpical) }\end{array}$ & $\begin{array}{c}\text { P'ieg } \\
\text { (Typical) }\end{array}$ & \\
\hline 483 & 1.03 & 0.98 & 1.07 & 1.16 & 0.94 & 1.42 & 0.31 & 1.02 & 0.81 & -3 \\
\hline 3009 & 1.04 & 0.98 & 1.08 & 1.13 & 0.90 & 1.32 & 0.96 & 1.06 & 0.88 & 17 \\
\hline 5288 & 1.03 & 1.00 & 1.06 & 1.10 & 0.94 & 1.34 & 0.98 & 1.06 & 0.31 & 24 \\
\hline 7349 & 1.03 & 1.00 & 1.05 & 1,09 & 0.96 & 1.21 & 0.98 & 1.04 & 0.92 & -2 \\
\hline 9559 & 1.01 & 0.98 & 1.03 & 1.06 & 0.96 & 1.16 & 0.90 & 1.00 & 0.90 & 10 \\
\hline 11840 & 1.00 & 0,98 & 1.01 & 1.06 & 0.97 & 1.16 & 0.94 & 0.99 & 0.88 & 9 \\
\hline 13133 & 0.99 & 0,97 & 1.01 & 1.12 & 0.97 & 1.39 & 0.88 & 0.97 & 0.79 & 8 \\
\hline 15268 & 0.99 & 0.97 & 1.01 & 1,16 & 0.98 & 1.34 & 0.34 & 0.95 & 0.76 & 28 \\
\hline 16657 & 0.98 & 0.96 & 1.01 & 1.16 & 0.98 & 1.34 & 0.83 & 0.94 & 0.76 & 23 \\
\hline
\end{tabular}

(1) Theoretical resistance includes no extraneous resistance allowance

(2) Matched load power ratıo $=\frac{(\text { Seebeck Rat1o })^{2}}{\text { Resistance Ratso }}$ 
5.4.3 EMC-3

5.4.3.1 EMC-3 Thermal and Thermoelectric Description Summary

In EMC-3, the simultaneously pressed P-leg was replaced by separately pressed and bonded hot and cold P-leg segments. This was expected to improve thermoelectric performance. The second change which effected the thermal and thermoelectric performance was the addition of indium foil between the copper cold cap and the aluminum follower to reduce the interface temperature drop.

No other changes were made to EMC-3 from EMC-2 which effected thermal and thermoelectric performance. Number of couples, leg geometries and couple hardware was identical to EMC-2 as shown in Table 5-4.

\subsubsection{EMC-3 History}

EMC-3 operated for 20,249 hours by the end of the SNAP-23A program. During this testing, performance was measured at essentially the same conditions as EMC-2 with the exception of the dynamic testing which was not repeated for EMC-3. The test conditions include:

- EOL And BOL Mapping (Fixed Heat Input, Variable Load Voltage)

- EOL And BOL Variable Cold Junction Temperature

- EOL And BOL Design Conditions.

\subsubsection{EMC-3 Performance Predictions}

Performance predictions were made for EMC-3 using updated material property data. Thermoelectric material characteristics $S$, $\rho$ and $K$ for the four thermoelectric materials in the EMC-3 couple were remeasured in the TELPS facility and incorporated in the calculations. In addition, shunt heat losses were revised based on updated thermal conductivity data for powdered Min-K 1301 as per the discussion in paragraph 3.2.1.2 of SNAP-23A Quarterly Report No. 4. 
Results from EMC-3 performance predictions are listed in Table 5-12. These values are based on an extraneous resistance ratio of 1.068 and a Seebeck voltage ratio of 1.00 。

Table $5-12$

SNA P-23A Converter EMC-3 Performance Predictions

\begin{tabular}{|l|c|c|}
\hline & $\begin{array}{c}\text { EOL } \\
\text { Conditions }\end{array}$ & $\begin{array}{c}\text { BOL } \\
\text { Conditions }\end{array}$ \\
\hline Cold Junction Temperature - $o_{\mathrm{F}}$ & 174 & 191 \\
Hot Junction Temperature - ${ }_{\mathrm{F}}$ & 900 & 1085 \\
Converter Heat Losses - Watts $(\mathrm{t})$ & 77 & 107 \\
Total Heat Input to Converter - Watts (t) & 851 & 1123 \\
Load Voltage - Volts & 24 & 24 \\
Open Circuit Voltage - Volts & 41.6 & 55.0 \\
Power Output - Watts (e) & 63.9 & 85.8 \\
Ffficiency - Percent & 7.5 & 7.6 \\
\hline
\end{tabular}

5.4.3.4 EMC-3 Performance Data

Tables 5-13 and 5-14 list FMC - 3 thermopile performance data over the 20,140 hour test period. A complete listing of EMC-3 initial performance data is included in SNA P-23A Quarterly Report No. 5. Comparison of early data with performance predictions show s that EMC- 3 exceeded predicted performance and exceeded the 7.7 percent efficiency goal at EOL temperature conditions after 2783 hours of operation.

Normalized thermoelectric performance at BOL temperature conditions is presented in Table 5-15. The results show that the Seebeck voltage and resistance of the thermopile is nearly identical to theoretical values. During operation a one percent decrease in Seebeck voltage and four percent increase in resistance occurred which reduced power output by six percent. The heat required increased during the operating time by four percent. These changes combine to degrade conversion efficiency by ten percent.

EMC-3 BOL efficiency, plotted in Figure 5-23, exhibited an abrupt reduction after 11,000 hours of operation taking place over a 1500 hour period. A steady efficiency of 7.7 percent was exhibited from 12,000 hours to 20,000 hours at the end of testing. 
Table $5-13$

SNAP-23A Converter EMC-3 Performance History (BOL Conditions)

\begin{tabular}{|c|c|c|c|c|c|c|c|c|c|c|c|c|c|c|c|c|c|}
\hline & & & & & suret & Thile & $F_{p p}$ & CDIn: & & & & & & & & & \\
\hline Parameter & Symbol & Units & 123 & 681 & 1107 & 1800 & 4014 & 4223 & 8407 & 10563 & $\begin{array}{ll}12765 \\
\end{array}$ & 14237 & 14981 & 10605 & $17 \quad 22$ & 18584 & 1370 \\
\hline Power Output & $\mathrm{P}_{\mathrm{o}}$ & Watts $(e)$ & 880 & 393 & 910 & 11 & 23 & 121 & on 8 & 102 & 878 & 875 & 877 & 871 & 870 & 868 & 862 \\
\hline Normalized Power Output & $\mathrm{P}_{\mathrm{N}}$ & Watts (c) & 882 & 912 & $92 \mathrm{c}$ & 12 & $\because$ & 117 & 110 & 889 & 881 & 874 & 874 & 872 & 879 & 873 & \\
\hline Open Circult Voltage & $\mathrm{E}$ & volts & 41 & 537 & 541 & 23 & +3 & it? & 242 & 244 & 537 & 539 & 37 & 537 & 039 & 534 & $53 \mathrm{~s}$ \\
\hline Normahzed O C Voltage & $\mathrm{E}_{\mathrm{N}}$ & volts & 544 & $24 \mathrm{c}$ & $54 \mathrm{f}$ & 47 & 1,4 & \& & 147 & 042 & 540 & 538 & 338 & 038 & 540 & 538 & \\
\hline Internal Resistance & $\mathrm{r}_{\mathrm{g}}$ & Ohms & 827 & 804 & $7 n$ & $7 \mathrm{~m}$ & 714 & 802 & 811 & 815 & 817 & 826 & 817 & 825 & 830 & 820 & 826 \\
\hline Norm Int Resistance & $\begin{aligned} \mathrm{R}_{\mathrm{N}} \\
\mathrm{R}^{2}\end{aligned}$ & Ohms & 834 & 814 & 801 & 802 & 803 & 803 & 814 & 820 & 822 & 825 & 825 & 826 & 826 & 830 & \\
\hline Load Voltage & $v_{1}$ & volts & 250 & 250 & 2,0 & 2,0 & $2>0$ & 2,0 & $2>0$ & 200 & 250 & 250 & 2,0 & 250 & $2 \supset 0$ & 250 & 250 \\
\hline Load Current & $I_{1}$ & Amps & 3.2 & 33 & $3: 4$ & 316 & $\cdots$ & 371 & 363 & 361 & $3>1$ & 349 & 351 & 348 & 348 & 348 & $34 \hat{s}$ \\
\hline $\begin{array}{l}\text { Temperature } \\
\text { Hot Junction }\end{array}$ & $T_{h}$ & $\Gamma$ & $108 n$ & 1074 & 1780 & 1074 & 1077 & 1087 & 1083 & 108? & 1081 & 1086 & 1081 & 1084 & 1080 & 1078 & 1080 \\
\hline Cold Junction & $r_{c}$ & r & 181 & 193 & 11 & 111 & 11 & 187 & $1^{191}$ & $18 \mathrm{r}$ & 190 & 191 & 187 & 191 & 195 & 189 & 190 \\
\hline Gross Power Input & $P_{t}$ & watts(t) & 1096 & 1108 & 1120 & 1124 & 1112 & 1140 & 1122 & 1123 & 1161 & 1161 & $11>8$ & 1160 & 1162 & 1156 & 154 \\
\hline Internal Gas Pressure & $P_{g}$ & PSIG & 104 & 112 & 111 & 110 & 110 & 109 & 103 & 102 & 102 & 103 & 102 & 100 & 102 & 100 & 101 \\
\hline
\end{tabular}

Data normalized to $T_{h} \quad 1080 \mathrm{~F}$ and $T_{G} \quad 191$ ग 
Table 5-14

SNAP -23A Converter EMC -3 Performance Data (EOL Conditions)

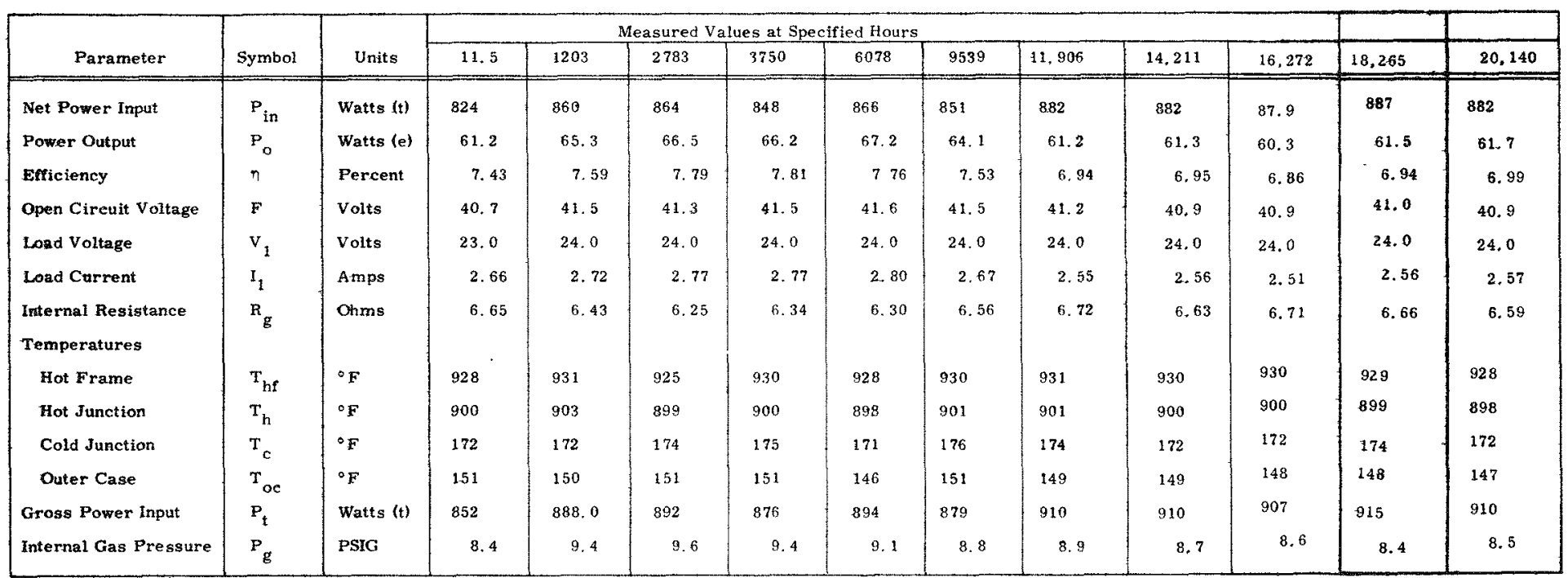


Table $5-15$

SNAP-2 3A Converter EMC-3 Performance Data BOL C onditions

(Ratio of Experimental-to-Theoretical Values)

\begin{tabular}{|c|c|c|c|c|c|c|c|c|c|c|}
\hline \multirow{2}{*}{$\begin{array}{l}\text { Test } \\
\text { Hours }\end{array}$} & \multicolumn{3}{|c|}{ Seebeck Ratio } & \multicolumn{3}{|c|}{ Resistance Ratio (1) } & \multicolumn{3}{|c|}{ Power Ratio (2) } & \multirow[b]{2}{*}{$\begin{array}{c}\text { Power Input Bias } \\
\text { Experiment - Calculated }\end{array}$} \\
\hline & \begin{tabular}{|c}
$\begin{array}{c}\text { Thermo- } \\
\text { p1le }\end{array}$ \\
\end{tabular} & $\begin{array}{c}\text { N-Leg } \\
\text { (Typical) }\end{array}$ & $\begin{array}{c}\text { P-Leg } \\
\text { (Typical) }\end{array}$ & $\begin{array}{l}\text { Thermo- } \\
\text { plle }\end{array}$ & $\begin{array}{c}\text { N-Leg } \\
\text { (Typical) }\end{array}$ & $\begin{array}{c}\text { P-Leg } \\
\text { (Typical) }\end{array}$ & $\begin{array}{l}\text { Thermo- } \\
\text { plle }\end{array}$ & $\begin{array}{l}\text { N-Leg } \\
\text { (Typicai) }\end{array}$ & $\begin{array}{l}\text { P-Leg } \\
\text { (Typical) }\end{array}$ & \\
\hline 1,107 & 0.99 & 1.00 & 0.98 & 0.985 & 0.99 & 0.98 & 1.00 & 1.01 & 1.02 & -32 \\
\hline 5,500 & 0.99 & 1.00 & 0.97 & 0.99 & 0.96 & 1.02 & 0.99 & 1.04 & 0.92 & -46 \\
\hline 10,563 & 0.98 & 0.99 & 0.97 & 1.00 & 1.00 & 1.00 & 0.96 & 0.98 & 0.94 & -34 \\
\hline 14,237 & 0.98 & 0.99 & 0.96 & 1.02 & 1.06 & 0.96 & 0.94 & 0.92 & 0.96 & 19 \\
\hline 16,446 & 0.97 & 0.98 & 0.96 & 1.02 & 1.06 & 0.96 & 0.93 & 0.90 & 0.96 & 19 \\
\hline 18,584 & 0.98 & 0.99 & 0.96 & 1.02 & 1.06 & 0.96 & 0.94 & 0.90 & 0.96 & 23 \\
\hline 19,970 & 0.98 & 0.99 & 0.96 & 1.02 & 1.06 & 0.96 & 0.94 & 0.90 & 0.96 & 24 \\
\hline
\end{tabular}

(1) Theoretical resistance includes no extraneous resistance allowance

(2) Matched load power ratio $=\frac{(\text { Seebeck Ratio })^{2}}{\text { Resistance Ratio }}$ 


\subsubsection{PMC-1A}

\subsubsection{PMC-1A Thermal and Thermoelectric Description Summary}

In PMC-1A, the number of couples was reduced from 264 to 252 , the leg lengths were decreased and the EOL average hot junction temperature was increased from $900^{\circ} \mathrm{F}$ to $920^{\circ} \mathrm{F}$. Beryllium oxide replaced aluminum as the follower material and the indium foil at the cold cap-followeriinterface of EMC-3 was eliminated. Other parts of the thermopile configuration remained the same as EMC-3.

\subsubsection{PMC-1A History}

After completion of short-term testing at 3M PMC-1A was delivered to Westinghouse for operation with EMS. EMS was shut down near the end of the SNAP-23A program and PMC - 1A was returned to $3 M$ for testing to define performance changes which occurred during the extended EMS operation. Total test time accumulated during $3 \mathrm{M}$ and Westinghouse testing was 15483 hours as of June 30,1970 .

Converter performance was measured at the following conditions during initial $3 \mathrm{M}$ testing.

- EOL and BOL Design Hot Junction Temperatures, Cold Junction Temperatures and Load Voltage

- EOL Variable Cold Junction Temperature

- EOL Mapping (Fixed Heat Input, Variable Load Voltage)

- Contract Specification Boundary Conditions

\subsubsection{PMC-1A Performance Predictions}

Performance predictions for PMC-1A are presented in Table 5-16 for EOL and BOL conditions. The end-of-life predictions include the expected range in thermoelectric performance based on variations in $\mathrm{N}-\mathrm{leg}$ and $\mathrm{P}-\mathrm{leg}$ performance measured in earlier converters andmmodules. The listed BOL predictions represent only the minimum expected performace. 
The design approach used for PMC-1A was a departure from that applied to earlier designs. In the PMC-1A design approach, the ratio of experimental Seebeck voltage to theoretical Seebeck voltage and the ratio of experimental resistance to theoretical material resistance determined from instrumented $\mathrm{N}$-legs and P-legs manufactured with the fabrication method used for PMC-1A elements were collected. This data base as presented in Table 5-17 was used to define the minimum, nominal and expected converter performance. The thermopile was designed at minimum expected converter performance conditions to be assured of meeting power output requirements. The operating conditions were defined so that the maximum hot junction temperature would not exceed $1100^{\circ} \mathrm{F}$ during the ten-year design life.

Table $5-16$

SNAP-23A Converter PMC-1A and PMC-1B Performance Predictions

\begin{tabular}{|c|c|c|}
\hline & $\mathrm{EOL}$ & $\mathrm{BOL*}$ \\
\hline Cold Junction Temperature $-{ }^{\circ} F$ & 177 & 192 \\
\hline Hot Junction Temperature $-{ }^{\circ} F$ & 920 & 1080 \\
\hline Converter Heat Losses - Watts ( $t)$ & 74 & 100 \\
\hline Total Heat Input to Converter - Watts $(t)$ & $\frac{+11}{-12}$ & 1032 \\
\hline Load Voltage - Volts & $24.4 \quad \frac{+0.2}{-0.4}$ & 24 \\
\hline Open Circuit Voltage - Volts & $41.9 \frac{+0.2}{-0.4}$ & 52.4 \\
\hline Power Output - Watts (e) & $64.8 \frac{ \pm 3.7}{-4.3}$ & 78.5 \\
\hline Efficiency - Percent & $7.91 \frac{+0.34}{-0.42}$ & 7.59 \\
\hline
\end{tabular}

*Minimum performance conditions 
Table 5-17

Seebeck Voltage and Resistance Ratios for PMC-1A Design

\begin{tabular}{|c|c|c|}
\hline \multicolumn{3}{|c|}{ Bonded P-Leg } \\
\hline & Resistance Exp. & Seebeck Exp. \\
\hline & $\overline{\text { Resistance Calc. }}$ & $\overline{\text { Seebeck Calc. }}$ \\
\hline SNAP-21 A10D5 & 1.10 & 0.98 \\
\hline SNAP-21 A10D6 & 0.97 & 0.98 \\
\hline SNAP-21 A10D7 & 1.02 & 0.97 \\
\hline EMC No. 3 & 1.11 & 0.95 \\
\hline Nominal Factor (Avg.) & 1.06 & 0.97 \\
\hline Design Factor (Worst Case) & 1.11 & 0.95 \\
\hline \multicolumn{3}{|c|}{ Simultaneously Pressed N-Leg } \\
\hline & Resistance Exp. & Seebeck Exp. \\
\hline & $\overline{\text { Resistance Calc. }}$ & $\overline{\text { Seebeck Calc. }}$ \\
\hline SNAP-23 Mod. 1 & 0.99 & 1.01 \\
\hline EMC No. 1 & 0.96 & 0.99 \\
\hline EMP No. 2 & 0.97 & 1.00 \\
\hline EMC No. 3 & 1.05 & 1.00 \\
\hline Nominal Factor (Avg.) & 0.99 & 1.00 \\
\hline Design Factor (Worst Case) & 1.05 & 1.00 \\
\hline
\end{tabular}




\subsubsection{PMC-1A Performance Data}

Initial performance of $\mathrm{PMC}-1 \mathrm{~A}$ exceeded design predictions and performance requirements specified in the SNAP-23A contract. The results, Table 5-17, show the initial efficiency was $8.14 \%$ and $8.42 \%$ at EOL and BOL conditions respectively. A complete listing of PMC-1A initial performance evaluation data is included in SNAP-23A Quarterly Report No.7.

The performance before and after system testing was nearly stable as shown by the data in Table 5-18. The efficiency at BOL conditions remained essentially constant whereas the efficiency at EOL conditions decreased slightly. The converter operated at approximately $1000^{\circ} \mathrm{F}$ hot junction temperature during long-term testing on the EMS system at WANL. This relatively low hot junction temperature is considered to be a significant contributor to the stable operation of $\mathrm{PMC}-1 \mathrm{~A}$.

Normalized PMC-1A data is presented in Table 5-19. The ratios of experimental to theoretical Seebeck voltage and resistance show both quantities decreased during the long-term test with changes due primarily to the P-leg. The heat input bias was nearly constant over the test period.

\subsubsection{PMC-1B}

\subsubsection{PMC-1B Thermal and Thermoelectric Description Summary}

PMC-1B was built to PMC-1A specifications using spare parts. The cold frame contained several out-of-tolerance follower holes. In the out-of-tolerance hole positions, indium foil was placed between the follower and cold cap to compensate for the increased thermal resistance of the follower-to-hole interface. 
Table 5-18

SNAP-23A Converter PMC-1A Performance Data

\begin{tabular}{|c|c|c|c|c|c|c|}
\hline \multirow[b]{2}{*}{ Parameter } & \multirow[b]{2}{*}{ Symbol } & \multirow[b]{2}{*}{ Units } & \multicolumn{2}{|c|}{ EOL Conditions } & \multicolumn{2}{|c|}{ BOL Condrtions } \\
\hline & & & Initial (508 Hrs) & Final $(15,808 \mathrm{Hrs})$ & Initial (484 Hrs) & Final $(15,785 \mathrm{Hrs})$ \\
\hline Net Power Input & $\mathrm{Pm}$ & Watts $(t)$ & 852 & 852 & 1055 & 1066 \\
\hline Power Output & Po & Watts (e) & 69.4 & 66.5 & 88.8 & 89.0 \\
\hline Efficiency & $\eta$ & Percent & 8.14 & 7.82 & 8.42 & 8.35 \\
\hline Open Circuit Voltage & E & Volts & 41.8 & 40.8 & 52.6 & 51.7 \\
\hline Load Voltage & $\mathrm{V} 1$ & Volts & 24.0 & 24.0 & 24.0 & 24.0 \\
\hline Load Current & II & Amps & 2.89 & 2.77 & 3.70 & 3.71 \\
\hline Internal Resistance & $\mathrm{Rg}$ & Ohms & 6.16 & 6.06 & 7.73 & 7.46 \\
\hline Hot Junction Temperature & Th & ${ }^{\circ} \mathrm{F}$ & 919 & 919 & 1079 & 1078 \\
\hline Cold Junction Temperature & $\mathrm{Tc}$ & ${ }^{\circ} \mathrm{F}$ & 177 & 174 & 199 & 191 \\
\hline Gross Power Input & $P t$ & Watts(t) & 880 & 880 & 1088 & 1100 \\
\hline
\end{tabular}


Table 5-19

SNAP-23A C onverter PMC -1A Performance Data - BOL Conditions

(Ratio of Experimental-to-Theoretical Values

\begin{tabular}{|c|c|c|c|c|c|c|c|c|c|c|}
\hline \multirow{2}{*}{$\begin{array}{l}\text { Test } \\
\text { Hours }\end{array}$} & \multicolumn{3}{|c|}{ Seebeck Ratio } & \multicolumn{3}{|c|}{ Resistance Ratio (1) } & \multicolumn{3}{|c|}{ Power Ratio (2) } & \multirow[b]{2}{*}{$\begin{array}{l}\text { Power Input Bias } \\
\text { Experiment - Calculated }\end{array}$} \\
\hline & $\begin{array}{l}\text { Thermo- } \\
\text { pile }\end{array}$ & $\begin{array}{c}\text { N-Leg } \\
\text { (Typical) }\end{array}$ & $\begin{array}{c}\text { P-Leg } \\
\text { (Typical) }\end{array}$ & $\begin{array}{l}\text { Thermo- } \\
\text { pile }\end{array}$ & $\begin{array}{c}\text { N-Leg } \\
\text { (Typica1) }\end{array}$ & $\begin{array}{c}\text { P-Leg } \\
\text { (Typical) }\end{array}$ & $\begin{array}{l}\text { Thermo- } \\
\text { pile }\end{array}$ & $\begin{array}{c}\text { N-Leg } \\
\text { (Typical) }\end{array}$ & $\begin{array}{c}\text { P-Leg } \\
\text { (Typical) }\end{array}$ & \\
\hline 484 & 0.986 & 1.00 & 0.97 & 0.95 & 0.94 & 0.96 & 1.02 & 1.06 & 0.98 & -17 \\
\hline 1,782 & 0.98 & & & 0.96 & & & 1.00 & & & \\
\hline 3,798 & 0.98 & & & 0.94 & & & 1.02 & & & \\
\hline 7,758 & 0.99 & & & 0.95 & & & 1.03 & & & \\
\hline 10,326 & 0.99 & & & 0.98 & & & 1.00 & & & \\
\hline 15,785 & 0.965 & 0.99 & 0.93 & 0.925 & 0.96 & 0.89 & 1,01 & 1.02 & 0.97 & -7 \\
\hline
\end{tabular}

(1) Theoretical resistance includes no extraneous resistance allowance

(2) Matched load power ratio $=\frac{(\text { Seebeck Ratio })^{2}}{\text { Resistance Ratio }}$ 


\subsubsection{PMC-1B History}

Following initial short-term testing, PMC-1B was placed on long-term test in the $3 \mathrm{M}$ test facility. After 8836 hours of operation, the test was prematurely terminated due to an open circuit internal to the converter. Discussion of the cause of this failure is presented in Section 2.3 .3 .2 .

During short-term and subsequent testing, performance was measured at the following conditions:

- EOL Mapping (Fixed Input Heat, Variable Load Voltage)

- EOL Variable Cold Junction Temperature

- EOL and BOL Design Conditions

\subsubsection{PMC-1B Performance Predictions}

PMC-1B operating conditions and design specifications are identical to PMC-1A. Predictions presented in Table 5-16 and the discussion in Section 5.4.4.3 for PMC-1A are applicable to PMC-1B.

\subsubsection{PMC-1B Performance Data}

Initial performance of PMC-1B was similar to PMC-1A except for heat input characteristics. As shown in Tables 5-20 and 5-21, PMC-1B initially exceeded design and contractual efficiency requirements at EOL conditions. However, because of the greater heat input requirement, PIMC-1B efficiency was less than PMC-1A. A complete listing of PMC-1B initial performance evaluation data is included in SNAP-23A Quarterly Report No. 8.

Normalized PMC-1B data is presented in Table 5-22 and Figure 5-23. Results show the electrical performance degraded six percent during the 8800 hours of testing while the heat input bias remained relatively stable. Testing was terminated by the open circuit condition. 
Table 5-20

SNAP-23A Converter PMC-1B Performance Data

BOL Conditions

\begin{tabular}{|c|c|c|c|c|c|c|c|c|c|c|c|c|c|c|c|c|c|}
\hline \multirow[b]{2}{*}{ Parameter } & \multirow[b]{2}{*}{ Symbol } & \multirow[b]{2}{*}{ Units } & \multicolumn{15}{|c|}{ Measired Values at Specified Hours } \\
\hline & & & 126 & 267 & 558 & 1059 & 1540 & 2285 & 2906 & 3722 & 4426 & 5169 & 5810 & 6626 & 7270 & 8091 & 8836 \\
\hline Power Output & $P_{0}$ & Watts $\{e\}$ & 86.2 & 89.0 & 90.2 & 90.0 & 91.5 & 91.2 & 91.2 & 89.2 & 80.0 & 79.5 & 79.6 & 79.6 & 79.2 & 78. 3 & 77.3 \\
\hline Normalized Power Output & $P_{N^{*}}$ & watts $(e)$ & 86.1 & 88.7 & 90.3 & 89.2 & 91.1 & 30.7 & 91.1 & 90.0 & 87.3 & 87.7 & 86.6 & 86.7 & 86.7 & 85.7 & 83.5 \\
\hline Open Circuit Voltage & $E$ & Volts & 52.4 & 52.6 & 32.6 & 52.3 & 52.7 & 526 & 52.5 & 48.2 & 47.9 & 47.5 & 47.4 & 47.5 & 47.4 & 47.3 & 47.3 \\
\hline Normalized O.C. Voltage & $\mathrm{E}_{\mathrm{N}} *$ & Volts & 52.4 & 52.4 & 52.7 & 52.2 & 52.8 & 52.3 & 52.7 & 52.6 & 52.4 & 52.4 & 52.0 & 52.0 & 52.0 & 51.8 & 51.7 \\
\hline Internal Resistance & $R_{g}$ & Ohms & 7. 94 & 7. 76 & 7.66 & 7.58 & 7. 64 & 7. 55 & 7. 54 & 6.96 & 7. 15 & 7.07 & 7.04 & 7.06 & 7. 08 & 7.12 & 7.22 \\
\hline Norm. Int. Resistance & $\mathrm{F}_{\mathrm{N}}^{*}$ & Ohms & 7.93 & 7. 79 & 7.67 & 7. 63 & 7.53 & 7. 51 & 7. 53 & 7. 66 & 7. 86 & 7.81 & 7. 78 & 7. 75 & $7.75^{\circ}$ & 7. 79 & 7.98 \\
\hline Load Voltage & $v_{1}$ & Volts & 25.0 & 25.0 & 25.0 & 25.0 & 25.0 & 25.0 & 25.0 & 25.0 & 25.0 & 25.0 & 25.0 & 25.0 & 25.0 & 25.0 & 25.0 \\
\hline $\begin{array}{l}\text { Load Current } \\
\text { Temperatures }\end{array}$ & $I_{1}$ & Amps & 3.45 & 3.56 & 3.61 & 3.60 & 3.62 & 3.65 & 3.65 & 3.33 & 3.20 & 3. 18 & 3.18 & 3. 18 & 3.17 & 3.13 & 3.09 \\
\hline Hot Junction & $T_{h}$ & $o_{F}$ & 1081 & 1079 & 1079 & 1079 & 1079 & 1084 & 1075 & 1014 & 1014 & 1009 & 1012 & 1015 & 1015 & 1015 & 1013 \\
\hline Cold Junction & $T_{c}$ & oF & 192 & 190 & 192 & 188 & 194 & 192 & 189 & 184 & 187 & 188 & 185 & 187 & 189 & 189 & 183 \\
\hline Gross Power Input & $P_{t}$ & Watts (s) & 1076 & 1105 & 1116 & 1118 & 1124 & 1139 & 1138 & 1038 & 1034 & 1028 & 1022 & 1022 & 1022 & 1014 & 1011 \\
\hline Internal Gas Pressure & $\mathrm{P}_{\mathrm{g}}$ & PSIG & 11.1 & 11.9 & 12.7 & 13.0 & 12.7 & 13.0 & 12.5 & 11.8 & 11.6 & 11.7 & 11.7 & 11.4 & 11.4 & 11.3 & 11.2 \\
\hline
\end{tabular}

${ }^{*}$ Data normalized to $\mathrm{T}_{\mathrm{h}} 10800 \mathrm{~F}$ and $\mathrm{T}_{\mathrm{c}}=192^{\circ} \mathrm{F}$ 
Table 5-21

SNAP-23A Converter PMC-1B Performance Data

(EOL Conditions)

\begin{tabular}{|c|c|c|c|c|c|c|c|}
\hline \multirow[b]{2}{*}{ Parameter } & \multirow[b]{2}{*}{ Symbol } & \multirow[b]{2}{*}{ Units } & \multicolumn{5}{|c|}{$\begin{array}{c}\text { Measured Value at } \\
\text { Specified Hours }\end{array}$} \\
\hline & & & 28 & 1104 & 3457 & 5644 & 8061 \\
\hline Net Power Input* & $P_{\text {in }}$ & Watts & 824 & 870 & 893 & 884 & 87.4 \\
\hline Power Output & $P_{0}$ & Watts & 63.8 & 67.2 & 70.1 & 68.4 & 65.9 \\
\hline Efficiency & $\eta$ & Percent & 7. 74 & 7.72 & 7.85 & 7. 74 & 7.54 \\
\hline Open Circuit Voltage & $\mathrm{E}$ & Volts & 41.2 & 41.4 & 41.9 & 41.6 & 41.3 \\
\hline Load Voltage & $\mathrm{v}_{1}$ & Volts & 24.0 & 24.0 & 24.0 & 24.0 & 24.0 \\
\hline Load Current & $I_{1}$ & Amps & 2.66 & 2.80 & 2.92 & 2.85 & 2.75 \\
\hline Internal Resistance & $R_{g}$ & Ohms & 6.47 & 6.21 & 6.14 & 6.18 & 6.29 \\
\hline \multicolumn{8}{|l|}{ Temperatures } \\
\hline Hot Frame & $\mathrm{T}_{\mathrm{hf}}$ & ${ }^{\circ} \mathrm{F}$ & 965 & 961 & 962 & 960 & 961 \\
\hline Hot Junction & $T_{h}$ & ${ }^{\circ} \mathrm{F}$ & 920 & 921 & 922 & 920 & 921 \\
\hline Cold Junction & $T_{c}$ & ${ }^{\circ} \mathrm{F}$ & 176 & 177 & 175 & 174 & 176 \\
\hline Outer Case & $T_{\text {oc }}$ & ${ }^{\circ} \mathrm{F}$ & 145 & 149 & 148 & 142 & 146 \\
\hline Gross Power Input & $P_{t}$ & Watts & 852 & 898 & 921 & 912 & 902 \\
\hline Internal Gas Pressure & $\mathrm{P}_{\mathrm{g}}^{2}$ & PSIG & 9.6 & 11.3 & 10.9 & 10.4 & 10.4 \\
\hline
\end{tabular}

*Estimated values based on PMC-1A test station losses. 
Table 5-22

SNAP-2 3A Converter PMC-1B Performance Data - BOL C onditions

(Ratio of Experimental-to-Theoretical Values)

\begin{tabular}{|c|c|c|c|c|c|c|c|c|c|c|}
\hline \multirow{2}{*}{$\begin{array}{l}\text { Test } \\
\text { Hours }\end{array}$} & \multicolumn{3}{|c|}{ Seebeck Ratıo } & \multicolumn{3}{|c|}{ Resistance Ratio (1) } & \multicolumn{3}{|c|}{ Power Ratio (2) } & \multirow[b]{2}{*}{$\begin{array}{l}\text { Power Input Bias } \\
\text { Experment - Calculated }\end{array}$} \\
\hline & $\begin{array}{l}\text { Thermo- } \\
\text { pile }\end{array}$ & $\begin{array}{l}\text { N-Leg } \\
\text { (Typical) }\end{array}$ & $\begin{array}{l}\text { P-Leg } \\
\text { (Typical) }\end{array}$ & $\begin{array}{c}\text { Thermo- } \\
\text { plle }\end{array}$ & $\begin{array}{c}\text { N-Leg } \\
\text { (Typical) }\end{array}$ & $\begin{array}{l}\text { F-Leg } \\
\text { (Typical) }\end{array}$ & $\begin{array}{c}\text { Thermo- } \\
\text { pile }\end{array}$ & $\begin{array}{l}\mathrm{N}-\mathrm{Leg} \\
\text { (Typical) }\end{array}$ & $\begin{array}{l}\text { P-Leg } \\
\text { (Typical) }\end{array}$ & \\
\hline 772 & .985 $.985 \mathrm{r}$ & 1.00 & 0.97 & 0.95 & 0.94 & 0.96 & 1.02 & 1.06 & .98 & 16 \\
\hline 1540 & .98 & 1.00 & 0.96 & .94 & 0.93 & 0.95 & 1.02 & 1.08 & .97 & 22 \\
\hline 2906 & .98 & 1.00 & 0.96 & .94 & 0.96 & 0.92 & 1.02 & 1.04 & 1.00 & 33 \\
\hline 4426 & .98 & 1.00 & 0.96 & .97 & 0.99 & 0.95 & .99 & 1.01 & .97 & 37 \\
\hline 5810 & 0.97 & 1.00 & 0.95 & .96 & .99 & 0.93 & .98 & 1.01 & .97 & 30 \\
\hline 7270 & .97 & 1.00 & 0.95 & .96 & .99 & 0.93 & .98 & 1.01 & .97 & 31 \\
\hline 8091 & 0.96 & 0.98 & 0.94 & 0.96 & 0.98 & 0.94 & .96 & .98 & .94 & 24 \\
\hline
\end{tabular}

(1) Theoretical resistance includes no extraneous resistance allowance

(2) Matched load power ratio $=\frac{(\text { Seebeck Ratıo })^{2}}{\text { Resistance Ratio }}$ 


\subsubsection{PMC-2}

\subsubsection{PMC-2 Description}

The thermoelectric degradation model, described in Section 2.3.3.3, was utilized for the first time in the design of the PMC-2 thermopile. This marked a milestone in the program by defining a hot junction temperature and thermopile configuration which would maximize system efficiency by considering thermoelectric degradation at the end of a ten-year operating lifetime. Results from thest studies showed that the hot junction should be reduced $60^{\circ} \mathrm{F}$ to $1020^{\circ} \mathrm{F}$ at BOL for maximum system efficiency at end of life.

The thermopile was redesigned to provide the required 61 watts power output at the reduced hot junction temperatures. This design consisted of 280 couples with slightly longer thermoelectric elements than PMC-1A. Indium foil was incorporated at all cap-follower interfaces. Details of the leg lengths and electrode hardware are listed in table 5-4.

Several modifications were made to the converter design to make the unit weatherproof. Some of these modifications affected the thermopile performance and were thereby factored into the thermoelectric design. The instrumentation header ring was moved to the top cover area which resulted in a shortened heat conduction path from the hot frame through the upper support cone to the outer case. This together with changes to the hot frame electrical insulation strips increased shunt heat losses. Another modification was the substitution of Min K-2002 insulation for Microquartz inside the top cover. The lower conductance of Min k-2002 reduced top cover heat losses.

\subsubsection{PMC-2 History}

PMC-2 was shut down after initial processing and partially disassembled to replace couples involved in a chemical reaction with the hot end hardware. After repair, the unit was placed on short-term test where performance was measured at the following conditions: 
- EOL Mapping

- EOL Variable Cold Junction Temperature

- EOL and BOL Design Conditions

- FPMS Mapping (Conditions expected to match the thermal characteristics characteristics of the Fueled Prototype Mockup System.)

The converter was then delivered to Westinghouse for mating to the Fueled Prototype Mockup System (FPMS).

Folowing FPMS testing, PMC-2 was returned to 3M for further testing to reconfirm the thermal characteristics of $\mathrm{PMC}-2$ which were measured before delivery to WANL. The test conditions consisted of EOL and BOL design conditions and the FPMS mapping conditions.

\subsubsection{PMC-2 Performance Predictions}

With PMC-2 slated for mating with a fueled system, the performance predictions were made for a range in fuel loading and thermoelectric performance. Predictions were made at three heat inputs representing minimum, nominal and maximum fuel loading. Results from the predictions at the nominal fuel loading case are listed in Table 5-23.

The expected variation in thermoelectric performance was determined from analysis of earlier generators and modules performance. The data available at the time when this variability was defined is listed in Table 5-24. In comparing this data base to that presented for PMC-1A, (see Table 5-17) it can be noted that EMC-3 resistance ratios are significantly lower in Table 5-24. Resistance ratios in $E M C-3$ showed a dramatic improvement over the first 1000 hours and the improved values were included in the data base for PMC-2 analysis. 
Table 5-23

SNAP-23A Converter PIC-2 Performance Predictions

Nominal Fuel Loading Conditions

\begin{tabular}{|l|r|r|}
\hline & EOL & BOL \\
\hline Colt Junction Temperature - ${ }^{\circ} F$ & 169 & 187 \\
Hot Junction Temperature - ${ }^{\circ} F$ & $852 \pm 5$ & $1004+7$ \\
Converter Heat Losses - Watts $(t)$ & $64 \pm 1$ & $87 \pm 1$ \\
Total Heat Input to Converter - Watts ( $t)$ & 818 & 1048 \\
Total Heat Input to Converter - Watts (t) & 818 & 1048 \\
Load Voltage - Volts & 24 & 24 \\
Open Circuit Voltage - Volts & $41.4 \pm 2$ & $53.0+.3$ \\
Power Output - Watts (e) & $62.7 \frac{+1.4}{-1.5}$ & $82.7 \frac{ \pm 2.0}{-2.3}$ \\
Efficiency Percent & $7.70 \frac{ \pm .17}{-.18}$ & $7.92 \frac{ \pm .19}{-.22}$ \\
\hline
\end{tabular}


Table 5-24

SNAP-23A Converter PIMC-2 Thermopile Design

Adjustment Ratios

Design Values: *

N-Leg Simultaneously Pressed

$\begin{array}{cc}\frac{R_{x} / R_{c}}{1.00} & \frac{E_{x} / E_{c}}{1.00} \\ 1.03 & 0.96\end{array}$

P-Leg Bonded

1.03

96

Data Base:

N-Leg Simultaneously Pressed

$\frac{\text { Device }}{\text { SNAP-23A Mod. } 1}$
EMC-1
EMC-2
EMC-3
PMC-1A

Average

Maximum

Minimum

Device

EMC-3

PMC-1A

SNAP-21 A10D6

SNAP-21 A10D8
$\frac{\mathrm{R}_{\mathrm{X}} / \mathrm{R}_{\mathrm{C}}}{0.99}$

0.96

0.97

1.00

0.96

0.98

1. 00

0.96

P-Leg Bonded

$\frac{E_{x} / E_{c}}{1.00}$
0.99
1.00
1.01
1.01

1.00

1.01

0.99
Average

Maximum

Minimum
$\frac{R_{x} / R_{c}}{1.03}$

$\frac{E_{x} / E_{c}}{0.96}$

0.96

0.98

0.97

0.98

1.00

0.96

NOTE: *Adjustment ratios are selected so that if variables which effect thermoelectric performance are pessimistic, the thermoelectric converter will produce the minimum required power output. 


\section{4. 6. 4 PMC -2 Performance Data}

PMC -2 performance data is presented in Table 5-25 for both EOL and BOL temperature conditions. Results show that performance did not meet the design power output requirements of 61 watts. Examination of the normalized $N$ and $P-1 e g$ data, Table 5-26, shows that the poor performance was due to the P-leg with a Seebeck voltage ratio 6 percent below theoretical and a resistance ratio 10 percent above theoretical. A complete listing of PMC -2 initial performance data is included in SNAP-23A Quarterly Report No. 13.

Performance data measured at the end of testing indicated that performance remained relatively stable during the 3000 hours of testing. The final measurement of performance was made after PMC - 2 had been removed from F PMS at Westinghouse and shipped back to $3 \mathrm{M}$. A slight improvement in efficiency was measured at EOL conditions whereas a small decrease in efficiency was noted at BOL condition between the initial to the final measurement.

\section{4. 7 PMC -3}

\subsubsection{Description}

In PMC -3, the hot junction electrode material was changed from plated copper to iron. The change was made to eliminate the potential deleterious reaction between copper from the hot end hardware and the thermoelectric elements which occurred in PMC -1B and PMC -2 as described in Sections 2.3.3.2 and 2.3.3.3.

Other than the change in hot junction electrode material, the thermopile enclosure and thermoelectric couple design was identical to PMC-2. All cold frame follower holes were utilized for the 280 couples. The followers were beryllium oxide with indium foil placed at the cap-follower socket interface to reduce thermal resistance. Leg dimensions, nominal hot junction and cold junction temperatures and other thermopile information is listed in Table 5-4. 
Table $5-25$

SNAP-23A Converter PMC -2 Performance Data

\begin{tabular}{|l|c|l||c|c||c|c|}
\hline & & \multicolumn{1}{|c||}{} & \multicolumn{2}{c||}{ EOL Conditions } & \multicolumn{2}{c|}{ BOL Conditions } \\
\cline { 2 - 6 } \multicolumn{1}{|c|}{ Parameter } & Symbol & Units & Initial (476 Hrs) & Final (3071 Hrs) & Initial (356 Hrs) & Final (2905 Hrs) \\
\hline Net Power Input & Pm & Watts (t) & 784 & 780 & 987 & 978 \\
Power Output & Po & Watts (e) & 57.3 & 57.6 & 77.3 & 76.8 \\
Efficiency & $\eta$ & Percent & 7.31 & 7.38 & 7.99 & 7.85 \\
Open Circuit Voltage & E & Volts & 40.4 & 40.5 & 51.8 & 51.5 \\
Load Voltage & V1 & Volts & 24.0 & 24.0 & 24.0 & 24.0 \\
Load Current & Il & Amps & 2.39 & 2.0 & 3.22 & 3.20 \\
Internal Resistance & Rg & Ohms & 6.86 & 6.87 & 8.64 & 8.60 \\
Hot Junction Temp. & Th & OF & 858 & 858 & 1010 & 10.09 \\
Cold Junction Temp. & Tc & OF & 169 & 170 & 190 & 187 \\
Gross Power Input & Pt & Watts (t) & 808 & 804 & 995 & 1006 \\
& & & & & & \\
\hline
\end{tabular}


Table 5-26

SNAP -23A Converter PMC -2 Performance Data - BOL Conditions (Ratio of Experimental-to-Theoretical Values)

\begin{tabular}{|c|c|c|c|c|c|c|c|c|c|c|}
\hline \multirow{2}{*}{$\begin{array}{l}\text { Test } \\
\text { Hours }\end{array}$} & \multicolumn{3}{|c|}{ Seebeck Ratio } & \multicolumn{3}{|c|}{ Resistance Ratio (1) } & \multicolumn{3}{|c|}{ Power Ratio (2) } & \multirow[b]{2}{*}{$\begin{array}{l}\text { Power Input Bias } \\
\text { Experiment - Calculated }\end{array}$} \\
\hline & $\begin{array}{l}\text { Thermo- } \\
\text { pile }\end{array}$ & $\begin{array}{c}\text { N-Leg } \\
\text { (Typical) }\end{array}$ & $\begin{array}{c}\text { P-Leg } \\
\text { (Typical) }\end{array}$ & $\begin{array}{l}\text { Thermo- } \\
\text { pile }\end{array}$ & $\begin{array}{c}\text { N-Leg } \\
\text { (Typical) }\end{array}$ & $\begin{array}{c}\text { P-Leg } \\
\text { (Typical) }\end{array}$ & $\begin{array}{l}\text { Thermo- } \\
\text { pile }\end{array}$ & $\begin{array}{c}\text { N-Leg } \\
\text { (Typical) }\end{array}$ & $\begin{array}{c}\text { P-Leg } \\
\text { (Typical) }\end{array}$ & \\
\hline 356 & 0.96 & 0.98 & 0.94 & 1.01 & 0.93 & 1.10 & 0.91 & 1.03 & 0.80 & -48 \\
\hline 2905 & 0.95 & 0.97 & 0.93 & 1.01 & 0.96 & 1.06 & 0.89 & 0.98 & 0.82 & -33 \\
\hline
\end{tabular}

(1) Theoretical resistance includes no extraneous resistance allowance

(2) Matched load power ratio $=\frac{(\text { Seebeck Ratio })^{2}}{\text { Resistance Ratio }}$ 


\section{4. 7.2 PMC -3 History}

PMC -3 was placed on short-term test at $3 \mathrm{M}$ and then delivered to Westinghouse to replace PIMC-2 as the converter on FPIMS. The short-term testing included a stability conditioning period of 500 hours where the converter was operated at a hot junction temperature of $1080^{\circ} \mathrm{F}$ to effect a reduced contact resistance at the hot junction. In addition, performance was measured at the following conditions.

- EOL Mapping (Fixed Heat Input, Variable Load Voltage)

- EOL And BOL Design Conditions

- FPMS Mapping (Conditions expected to match the thermal characteristics of the Fueled Prototype Mockup System)

- Contract Specification Conditions

\subsubsection{PMC-3 Performance Predictions}

Performance predictions made for the PMC -3 converter are presented in Table 5-27. These predictions were based on ingradient testing of couples made from thermoelectric materials selected for the manufacture of PMC -3 production hot couples. The method represents a departure from earlier methods utilized to predict converter performance by selecting and ingradient testing of material prior to couple acceptance. The ingradient testing of PMC -3 couples is discussed in Section 2. 3.3.4.

The methods of predicting PMC -3 performance consisted primarily of comparing ingradient $\mathrm{N}-\mathrm{leg}$ and $\mathrm{P}$-leg performance measured in the bell jar to the design Seebeck voltage and resistance ratios which were required for the thermopile to produce 61 watts. Adjustments were also necessary to account for the change to iron electrodes and for the consistently lower resistance observed in the bell jar than in a converter. 
Table $5-27$

SNAP-23A Converter PIM -3 Power Output Predictions

Predicted Power Output $=$ Design Power + Iron Electrode Resistance Adjustment + Bell Jar to Converter Correlation

+ Stability Condition Change + Seebeck Difference

+ Resistance Difference

\begin{tabular}{|c|c|c|c|c|}
\hline & \multicolumn{2}{|c|}{$\begin{array}{l}\text { Based on Initial } \\
\text { No. } 1 \text { and No. } 2 \\
\text { Bell Jar Data }\end{array}$} & \multicolumn{2}{|c|}{$\begin{array}{l}\text { Based on Stability } \\
\text { Conditioned No. } 2 \\
\text { Bell Jar }\end{array}$} \\
\hline & Watts & $\%$ & Watts & $\%$ \\
\hline Design Power & 61 & - & 61 & - \\
\hline $\begin{array}{l}\text { Iron Electrode } \\
\text { Resistance Adjustment }\end{array}$ & -0.6 & -1 & -0.6 & -1 \\
\hline $\begin{array}{l}\text { Bell Jar to Converter } \\
\text { Correlation }\end{array}$ & -1.2 & -2 & -1.2 & -2 \\
\hline $\begin{array}{l}\text { Stability Conditioning } \\
\text { Change }\end{array}$ & +1.5 & +2.5 & N.A. & N.A. \\
\hline Seebeck Difference & -0.6 & -1 & -1.2 & -2 \\
\hline Resistance Difference & +1.2 & +2 & +3.7 & +6 \\
\hline Predicted PMC-3 Power & 61.3 & & 61.7 & \\
\hline
\end{tabular}




\section{4. 7.4 PMC -3 Performance Data}

PMC -3 performance data is presented in Table $5-29$, with a complete listing of PMC -3 initial performance evaluation data included in SNA P-23A Quarterly Report No. 13. Results show the EOL performance meets the design requirements of 61 watts power output. The conversion efficiency was below the 7.7 percent specified in the contract at EOL conditions. However, because the hot junction operating temperature was reduced in the design of PMC -2 and PMC -3 to optimize overall system efficiency, a converter efficiency of 7.7 percent or greater was not expected at EOL conditions.

Normalized data is presented in Table 5-28. A trend in $\mathrm{P}-\mathrm{leg}$ resistance ratio and heat input bias with temperature condition can be noted which tends to improve performance at increased hot junction temperature.

Table $5-28$

SNA P-23A Converter PMC-3 Performance Data

(Ratio of Experimental-To-Theoretical Values)

\begin{tabular}{|l|c|c||c|c||c|c|}
\hline \multirow{2}{*}{} & \multicolumn{2}{|c||}{ Seebeck Ratio } & \multicolumn{2}{c||}{ Resistance Ratio } & \multicolumn{2}{c|}{$\begin{array}{c}\text { Power Input Bias } \\
\text { (Exp-Calculated) } \\
\text { Thermal Watts }\end{array}$} \\
\cline { 2 - 7 } Thermopile & EOL & BOL & EOL & BOL & EOL & BOL \\
\cline { 2 - 7 } N-Leg & 0.97 & 0.97 & 1.01 & 0.98 & 8 & -37 \\
P-Leg & 0.98 & 0.98 & 0.94 & 0.94 & & \\
& 0.96 & 0.96 & 1.10 & 1.03 & & \\
\hline
\end{tabular}

EOL measurement taken at 622 hours.

BOL measurement taken at 668 hours.

These data together with ratio and heat input bias determined at other conditions are shown in Figures 5-24 and 5-25. The negative temperature coefficient of the $\mathrm{P}$-leg resistance ratio is probably caused by a change in hot end contact resistance. The heat input bias trends are similar to those exhibited by PMC -2 . The reason for this trend has not been determined. 
Table 5-29

SNAP-23A Converter PMC-3 Performance Data

\begin{tabular}{|c|c|c|c|c|c|c|}
\hline \multirow[b]{2}{*}{ Parameter } & \multirow[b]{2}{*}{ Symbol } & \multirow[b]{2}{*}{ Units } & \multicolumn{2}{|c|}{ EOL Conditions } & \multicolumn{2}{|c|}{ BOL Conditions } \\
\hline & & & Initial (622 Hrs) & Final $\left({ }^{A}\right)$ & Initial (668 $\mathrm{Hrs})$ & Final $(\mathrm{A})$ \\
\hline Net Power Input & Pin & Watts $(t)$ & 808 & & 1003 & \\
\hline Power Output & Po & Watts (e) & 61.2 & & 82.1 & \\
\hline Efficiency & $\eta$ & Percent & 7.57 & & 8.19 & \\
\hline Open Circuit Voltage & $E$ & Volts & 41.5 & & 52.7 & \\
\hline Load Voltage & VL & Volts & 24.0 & & 24.0 & \\
\hline Load Current & IL & Amps & 2.55 & & 3.42 & \\
\hline Internal Resistance & $\mathrm{Rg}$ & Ohms & 6.87 & & 8.39 & \\
\hline Hot Fame Temp & Thf & ${ }^{\circ} \mathrm{F}$ & 881 & & 1039 & \\
\hline Hot Junction Temp & $\mathrm{Th}$ & ${ }^{\circ} \mathrm{F}$ & 860 & & 1011 & \\
\hline Cold Junction Temp & $\mathrm{Tc}$ & ${ }^{\circ} \mathrm{F}$ & 165 & & 186 & \\
\hline Outer Case Temp & Toc & ${ }^{\circ} \mathrm{F}$ & 144 & & 161 & \\
\hline Gross Power Input & Pt & Watts $(t)$ & 831 & & 1030 & \\
\hline
\end{tabular}

Note: (A) No final EOL or BOL data points could be taken as PMC-3 was on fueled system where heat input could not be adjusted. 


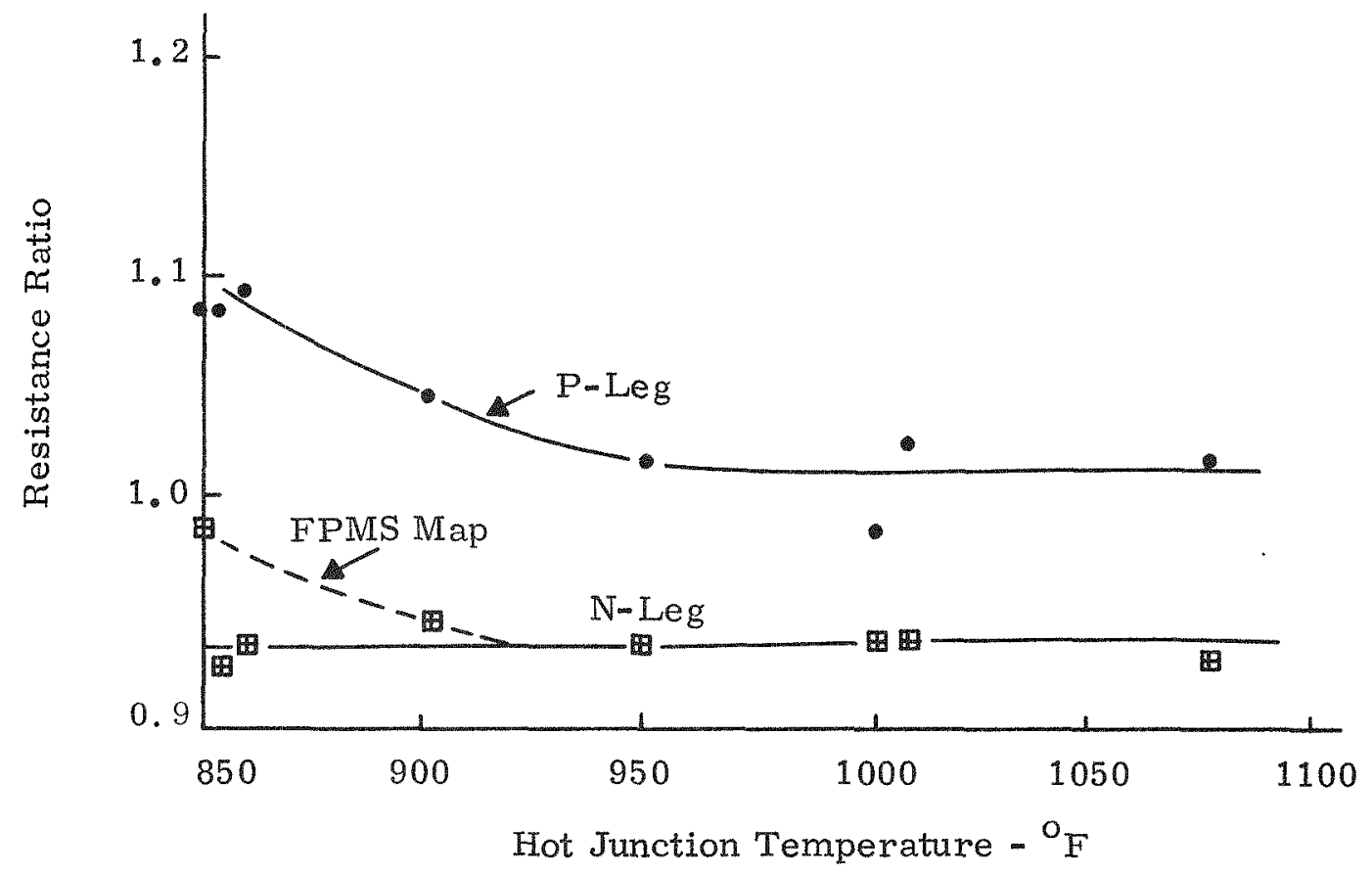

Figure 5-24

SNAP-23A Converter PMC-3 Resistance Ratios 


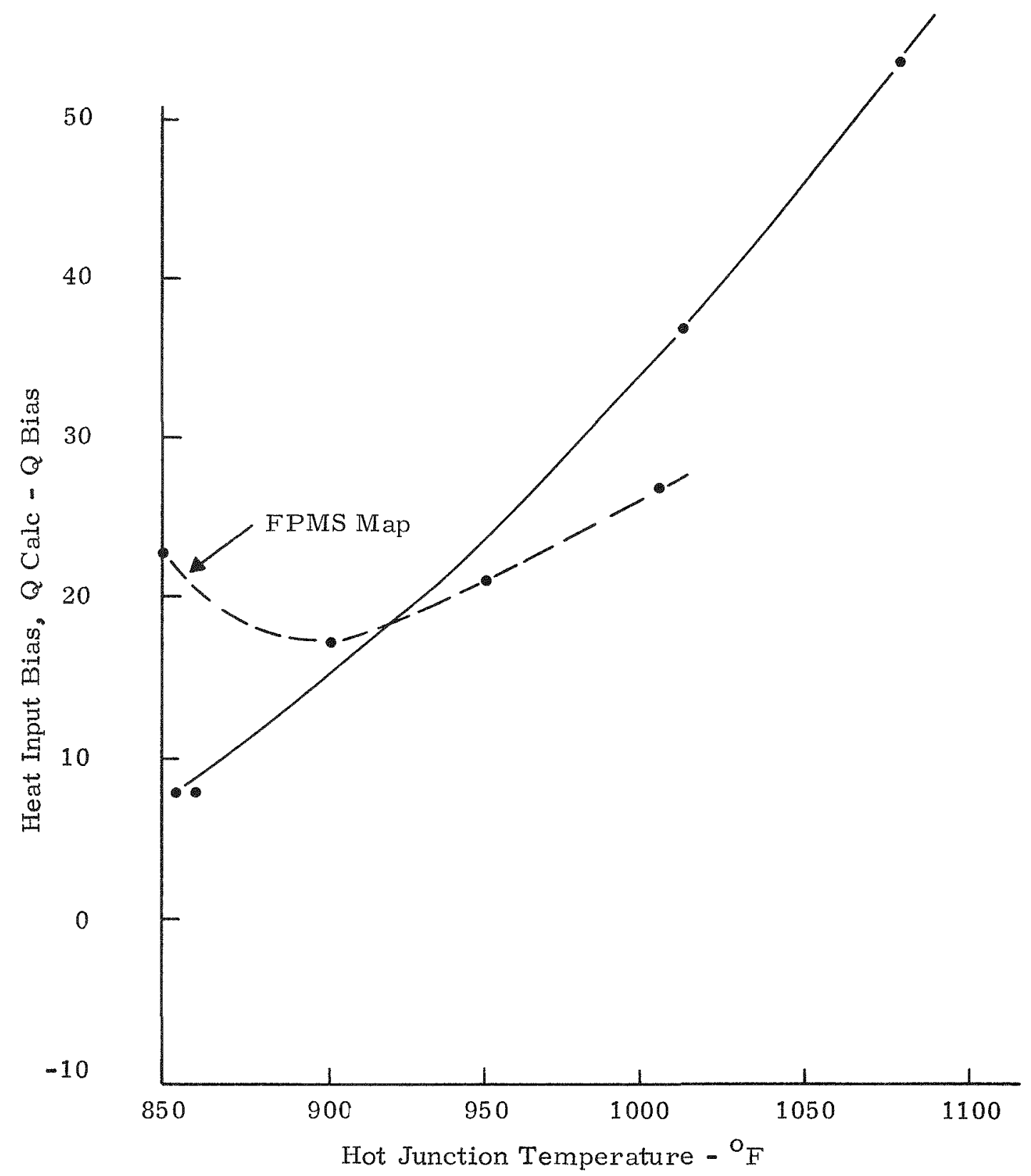

Figure 5-25

SNAP-23A Converter PIMC-3 Heat Input Bias

(Q Calculated Minus Q Experimental) 


\subsection{TELPS MATERIAL CHARACTERIZATION}

A material characterization effort was conducted early in the program to obtain thermoelectric material properties which could be factored into the design data base for SNAP -23A converters. The characterization measurements were made in the TELPS* facility at 3M using the procedures described in SNAP-23A Quarterly Report No. 3. Measurements were made on one set of thermoelectric material batches and as such were intended to define the general characteristics which could be expected in other material batches and not to define the batch-tobatch variation inherent in the manufacturing process.

The thermoelectric properties of practical importance are the Seebeck coefficient $S$, the electrical resistivity $\rho$, and the thermal conductivity $K$, all of which are functions of the temperature. A thermoelectric leg operating in a temperature gradient will exhibit a Seebeck voltage E relative to a given reference material (i.e., iron), a resistance $R$, and conduct heat at the rate of $Q$ watts. The values observed depend upon the thermoelectric properties of the material and the junction temperatures. From a number of such observations made at a series of junction temperatures it is possible to determine values for $S, 0$, and $K$ as point functions of temperature.

\subsubsection{General Description of TELPS Apparatus and Procedures}

Apparatus, test procedures, and numerical data reduction techniques, which were developed under the TELPS program, permit determination of values of the Seebeck coefficient, thermal conductivity, and resistivity of an individual test specimen as a function of temperature over the temperature range of room temperature to $1300^{\circ} \mathrm{F}$. The method is a transient ingradient performance test in which a test leg is subjected to a series of ever increasing temperature gradients each of which are measured for the hot and cold junction temperatures, Seebeck voltage, ingradient resistance, and conducted heat.

*TELPS stands for Thermoelectric Leg Product Specification. The basic equipment and measurement techniques were developed under SNAP -27, Contract A $\mathrm{T}(30-1)-3535$. 
The ingradient performance fixture is essentially a four-probe (two current and two potential) resistivity measuring device of special design to permit measure ments to be made under one dimensional temperature gradient condition. Two Inconel sheathed iron-constantan thermocouples are compressively loaded against opposite ends of the test specimen along its central axis. The iron wires of each thermocouple are used as potential probes. Flat graphite current electrodes are provided with an axial hole 0.090 inch diameter through which 0.065 inch diameter thermocouples pass without touching. Insulating sleeves help ensure that the thermocouples (and thus, the potential probes) do not short out against the current electrode.

Figures 5-26 and 5-27 show the TELPS fixture and TELPS facility.

A more detailed description of the TELPS apparatus and procedure employed in the SNAP -23A thermoelectric materials study is presented in Quarterly Report No. 4.

\subsubsection{Thermoelectric Material Characteristics}

Test measurements were made on three to six samples of each of five types of materials. Four types of material samples for simultaneously pressed segmented legs were obtained as separate segments from the same batches, and received the same manufacturing processing (i.e., sintering) as those legs used in the first Experimental Mockup Converter (EMC-1). In addition, the fifth type of material tested is for the hot segment of separately pressed and bonded P-legs which underwent test in bell jars and 10-couple modules.

The test data was analyzed with the aid of a digital computer to determine the material properties $(\mathrm{S}, \mathrm{K}, \mathrm{pK})$ as functions of temperature in fifth-order polynominal form, e.g. ,

$$
\begin{aligned}
& \mathrm{S}\left(\mu \mathrm{V} /{ }^{\circ} \mathrm{K}\right)=\mathrm{S}_{\mathrm{o}}+\mathrm{S}_{1} \mathrm{~T}+\mathrm{S}_{2} \mathrm{~T}^{2}+\mathrm{S}_{3} \mathrm{~T}^{3}+\mathrm{S}_{4} \mathrm{~T}^{4}+\mathrm{S}_{5} \mathrm{~T}^{5} \\
& \mathrm{~K}\left(\mathrm{watts} / \mathrm{cm}{ }^{\circ} \mathrm{K}\right)=\mathrm{K}_{\mathrm{o}}+\mathrm{K}_{1} \mathrm{~T}+\mathrm{K}_{2} \mathrm{~T}^{2}+\mathrm{K}_{3} \mathrm{~T}^{3}+\mathrm{K}_{4} \mathrm{~T}^{4}+\mathrm{K}_{5} \mathrm{~T}^{5} \\
& \rho \mathrm{K}\left(\mu \Omega \text { watts }^{\circ} \mathrm{K}\right)=(\circ \mathrm{K})_{\circ}+(\circ \mathrm{K})_{1} \mathrm{~T}+(\circ \mathrm{K})_{2} \mathrm{~T}^{2}+(\rho \mathrm{K})_{3} \mathrm{~T}^{3}+(\circ \mathrm{K})_{4} \mathrm{~T}^{4}+(\circ \mathrm{K})_{5} \mathrm{~T}^{5}
\end{aligned}
$$




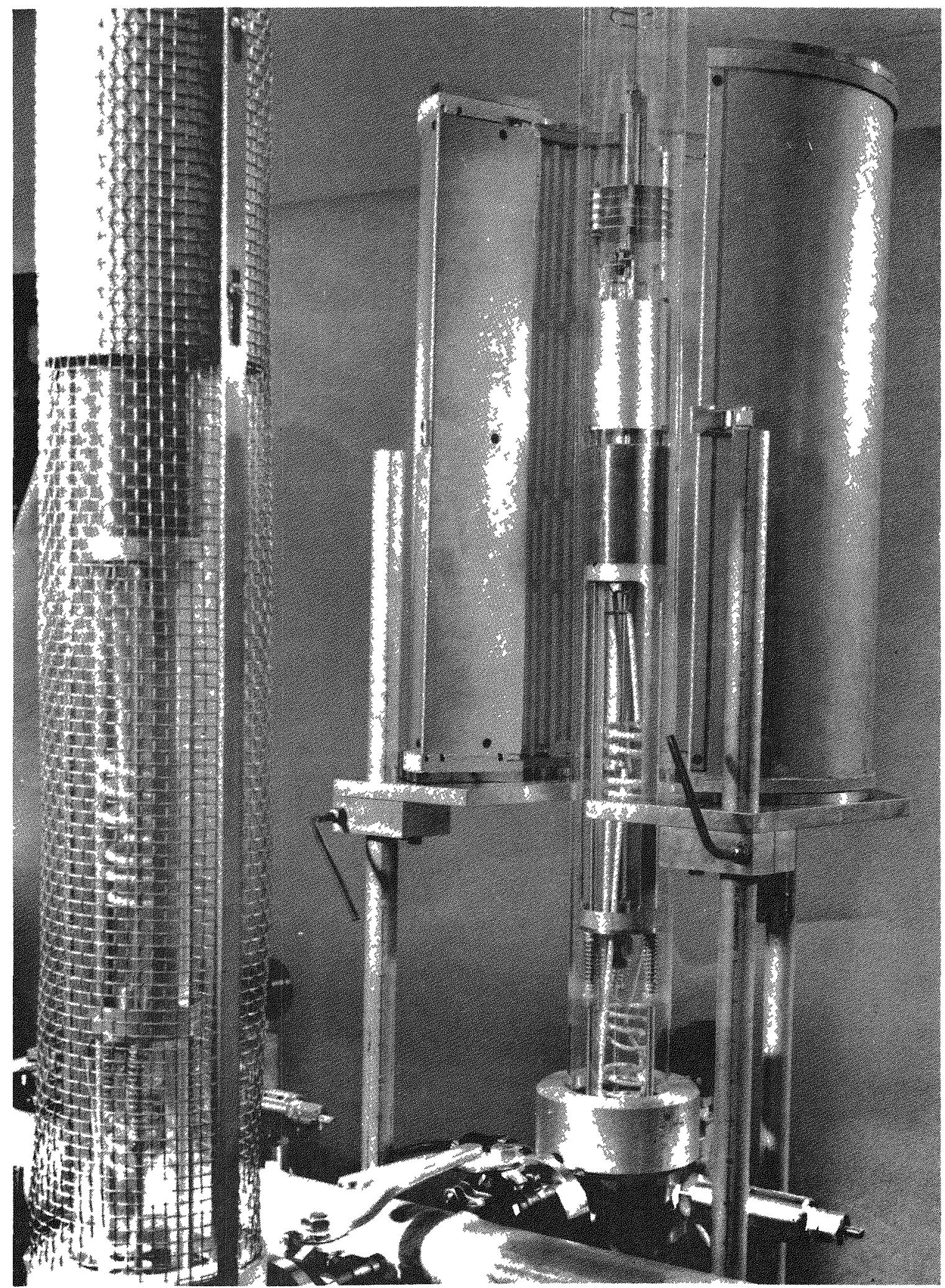

Figure 5-26. Individual TELPS Fixture With Isothermal Furnace Used for Thermocouple Calibration 


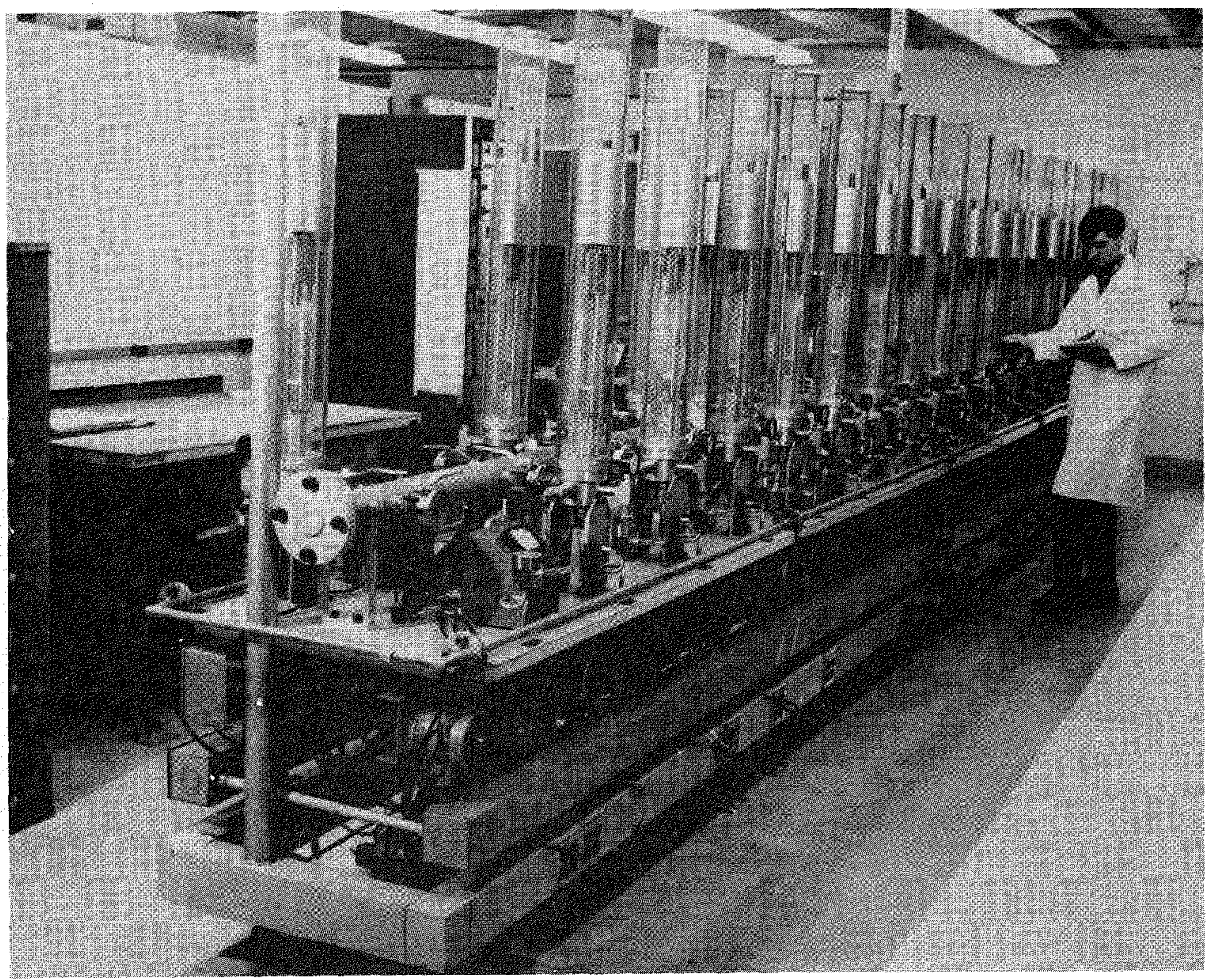

Figure 5-27. TELPS Laboratory 
The material coefficients in this form are used in several digital computer programs employed for the SNAP-23A design and test effort, such as the program described in Quarterly Report No. 1. Figures 5-28 through 5-43 show the material properties $\mathrm{S}, \mathrm{K}, \rho$, as well as dimensionless figure of merit $\left(\mathrm{ZT}=\mathrm{TS}^{2} / \mathrm{K}_{\rho}\right)$ versus temperature for the four materials of simultaneously pressed segmented legs for both SNAP-23 coefficients (dashed line) and the new SNAP -23A coefficients (solid line). Figures 5-44 through 5-47 are similar data for the hot segment material of separately pressed and bonded P-legs.

Validation of the se material coefficients in computer programs for leg and couple design and parametric studies were conducted by analysis involving the comparison of theoretical values with experimental data obtained from 10 -couple module and bell jar tests, from full-scale thermopiles such as the 264-couple Experimental Mockup Converter Nos. 1, 2 and 3, and from several SNAP-21 48-couple generators (particularly the data for separately pressed and bonded legs).

The best measure or criterion for validation of these coefficients is seen in the comparison of experimental Seebeck voltage with computer-calculated (theoretical) Seebeck voltage for a given temperature gradient. As an example, these Seebeck ratios as shown in Table 5-30 for bell jar test data illustrate very close agreement of experimental versus theoretical values (in most cases, only one or two percent difference). A secondary "measure" is seen in the resistance ratios determined similarly. However, the theoretical resistance calculated does not include any allowance for extraneous resistance such as couple electrode resistance and contact resistance. Therefore, this measure for validation of material characterization coefficients will have larger variations than the Seebeck criterion; but with good Seebeck correlation, it can be used effectively to determine extraneous resistance data for design purposes and analysis of test data generated for larger-scale devices. 

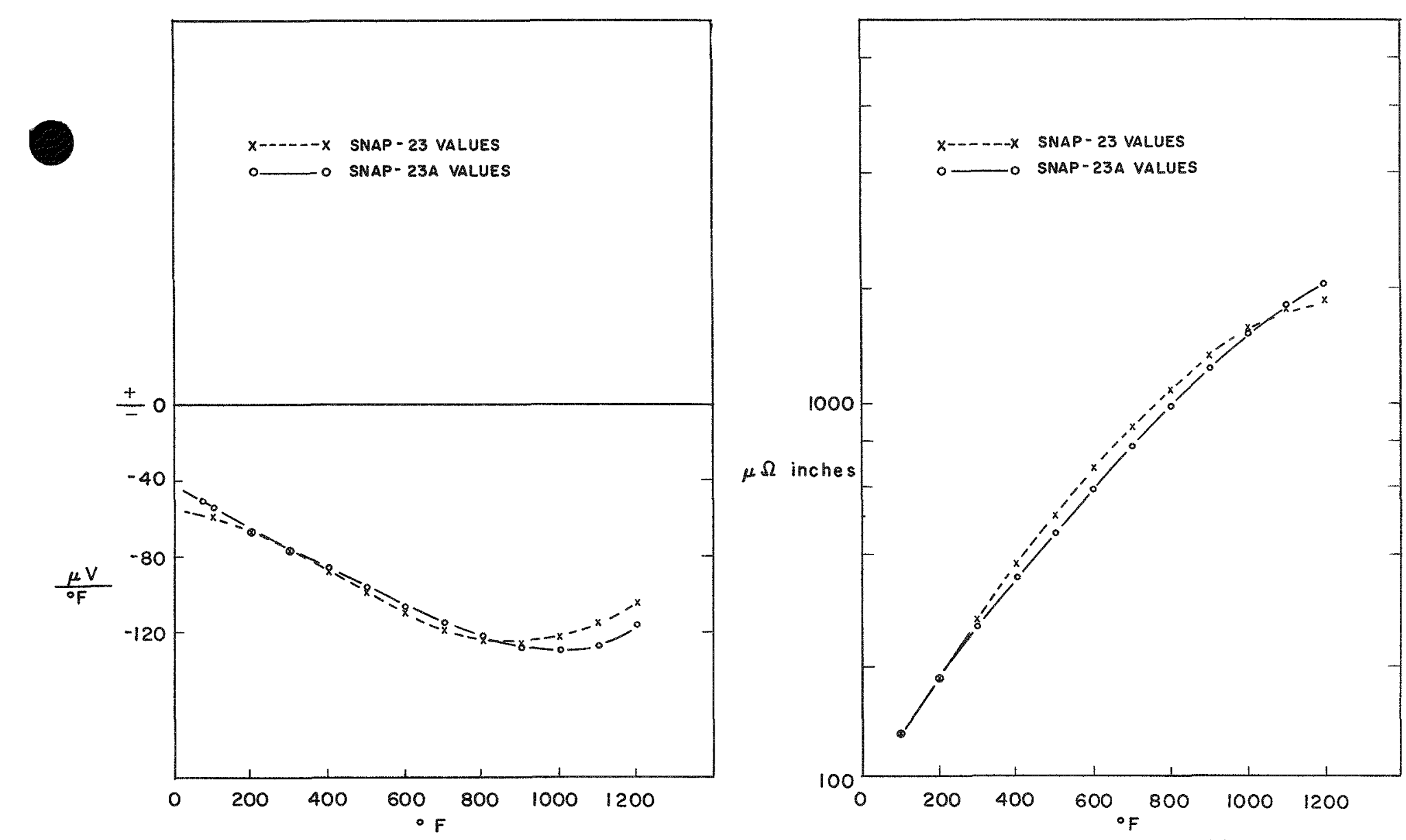

Figure 5-28. Seebeck Coefficient (S)

(N-Leg, Hot Segment

LTN-120, PbTe

ES $1103-3 \mathrm{~N})$
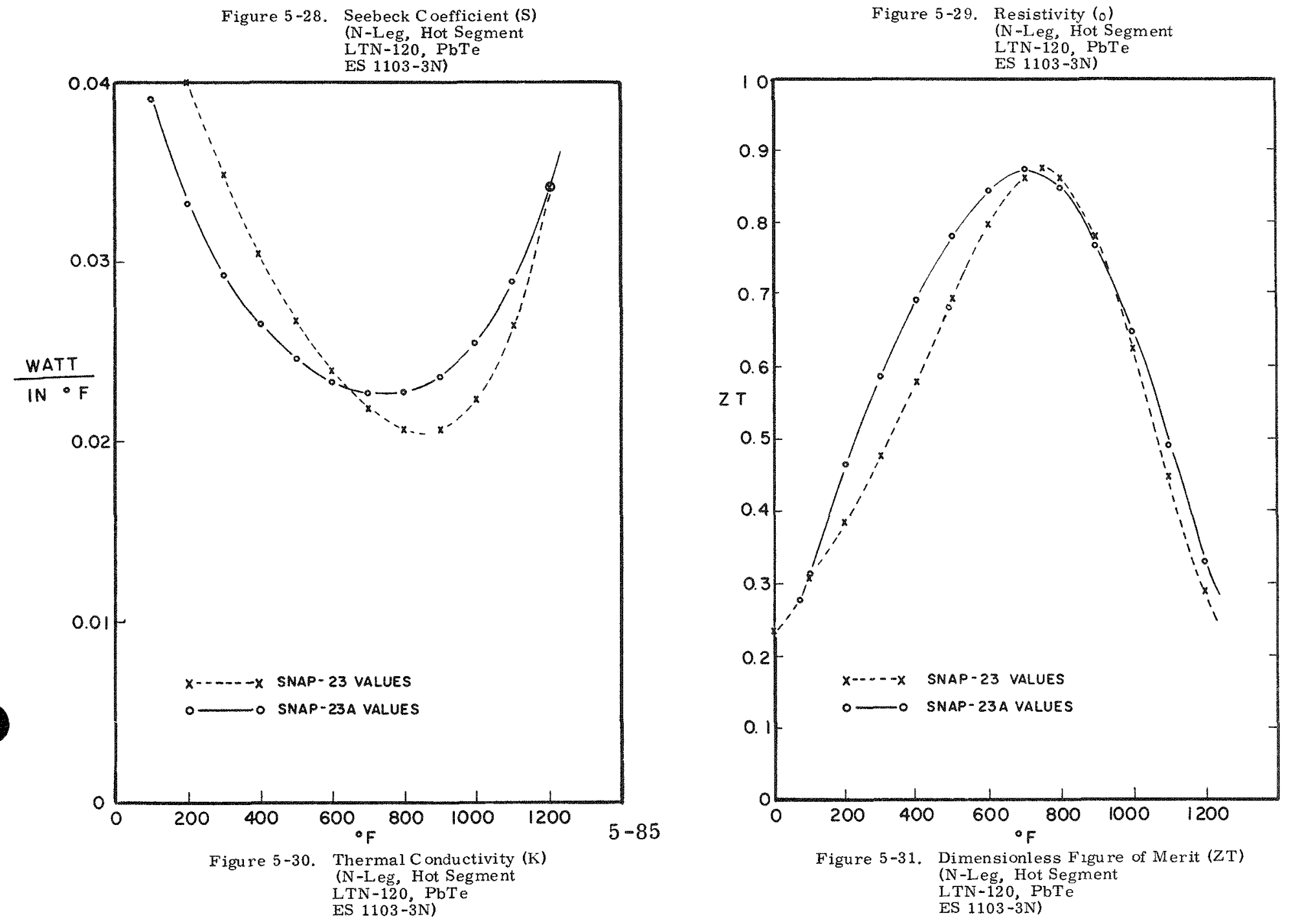

Figure 5-31. Dimensionless Figure of Merit (ZT) (N-Leg, Hot Segment L TN-120, PbTe ES $1103-3 \mathrm{~N}$ ) 

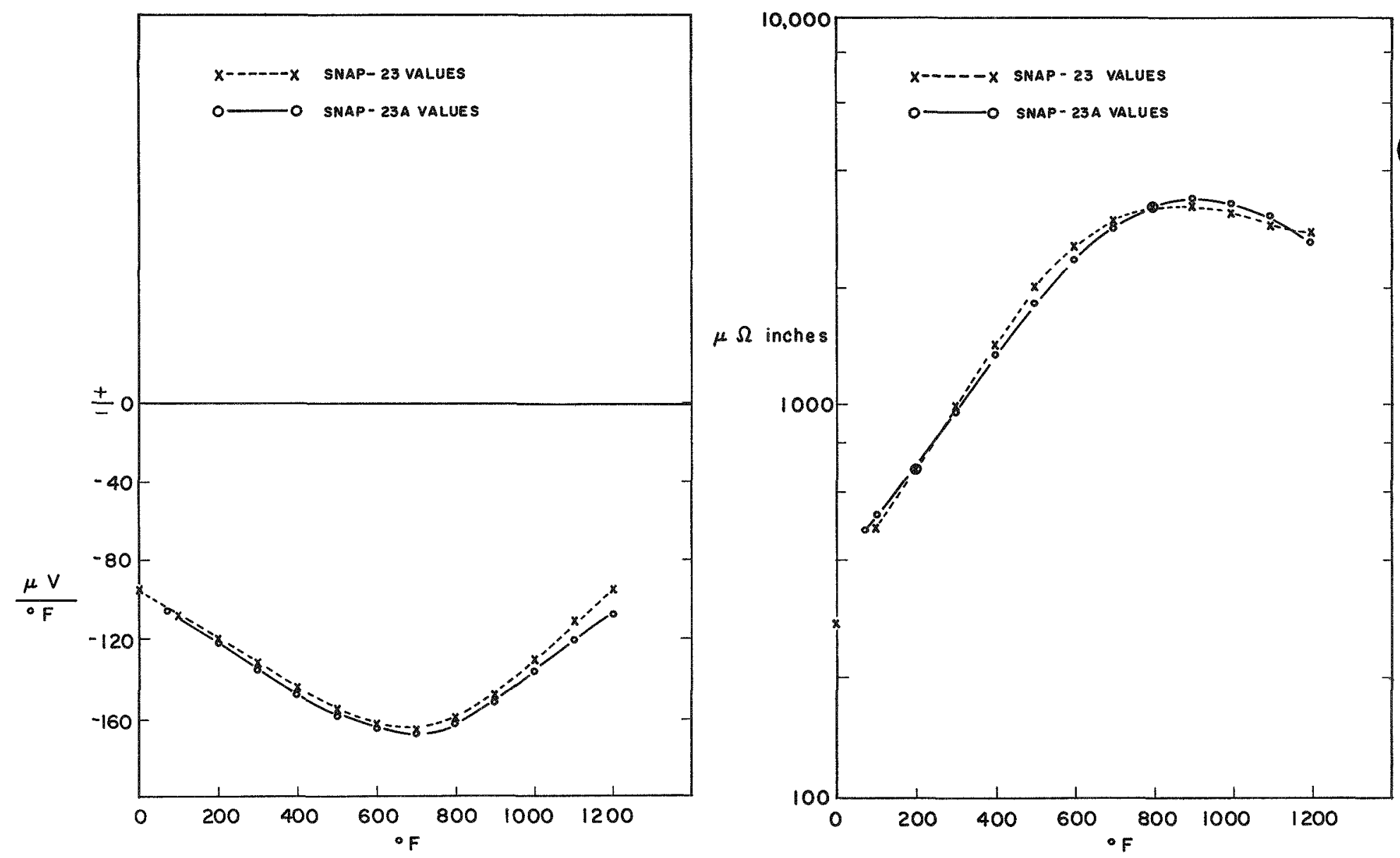

Figure 5-32. Seebeck Coefficient (S) (N-Leg, Cold Segment LTN-400, PbTe

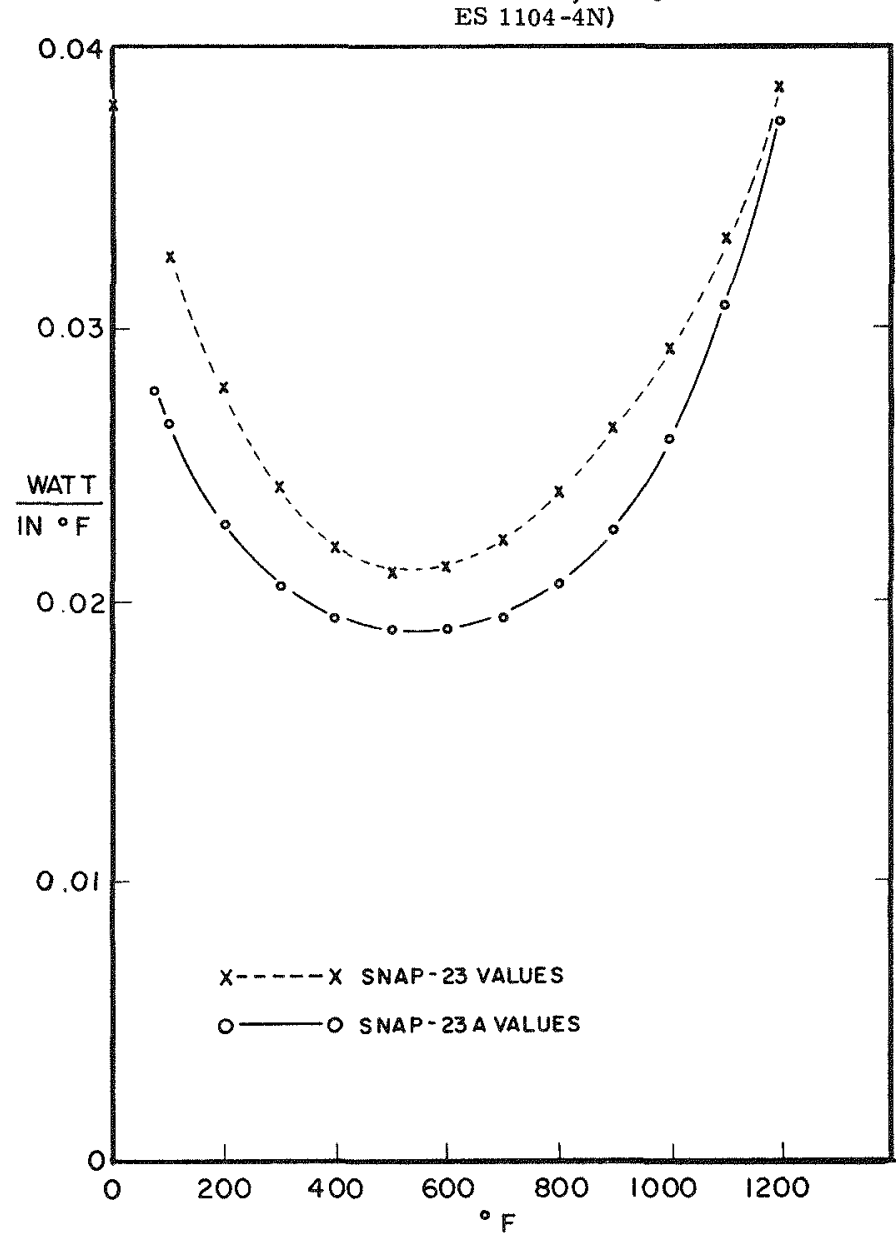

Figure 5-34. Thermal Conductivity $(K)$ (N-Leg, Cold Segment LTN-400, PbTe

Figure 5-33. Resistivity (o) (N-Leg, Cold Segment LTN-400, PbTe ES $1104-4 N$ )

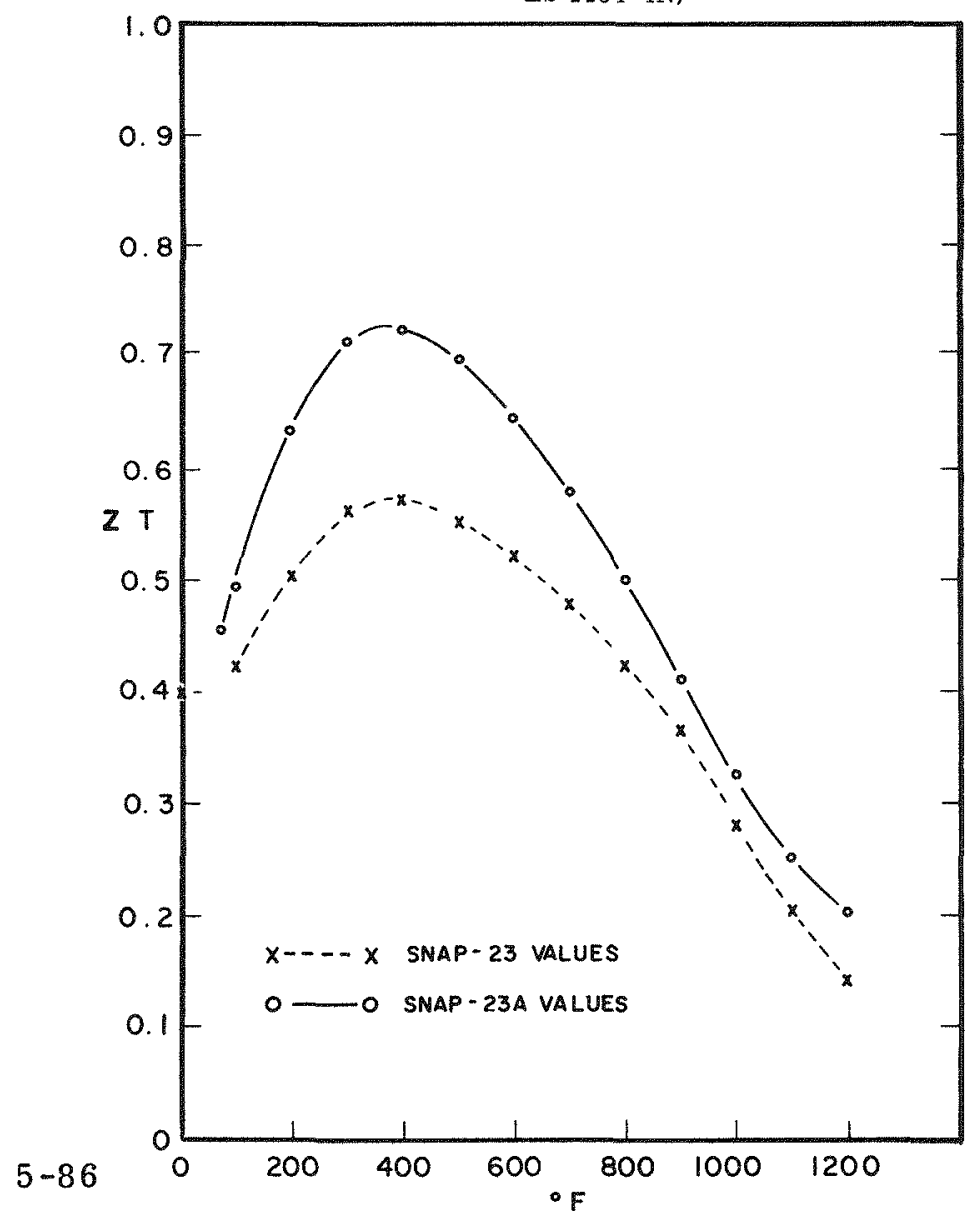

Figure 5-35, Dimensionless Figure of Merit (ZT) (N-Leg, Cold Segment LTN-400, PbT 

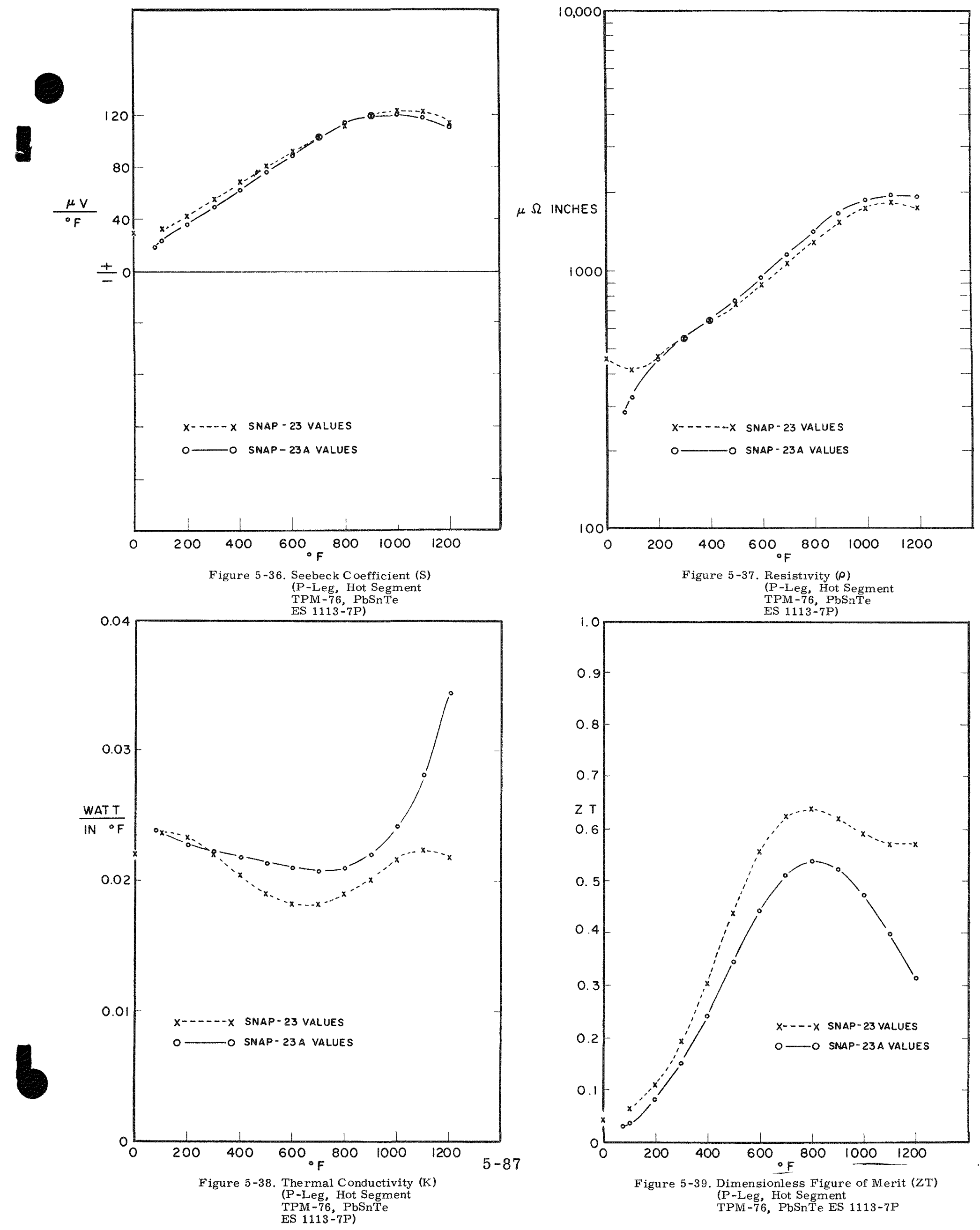


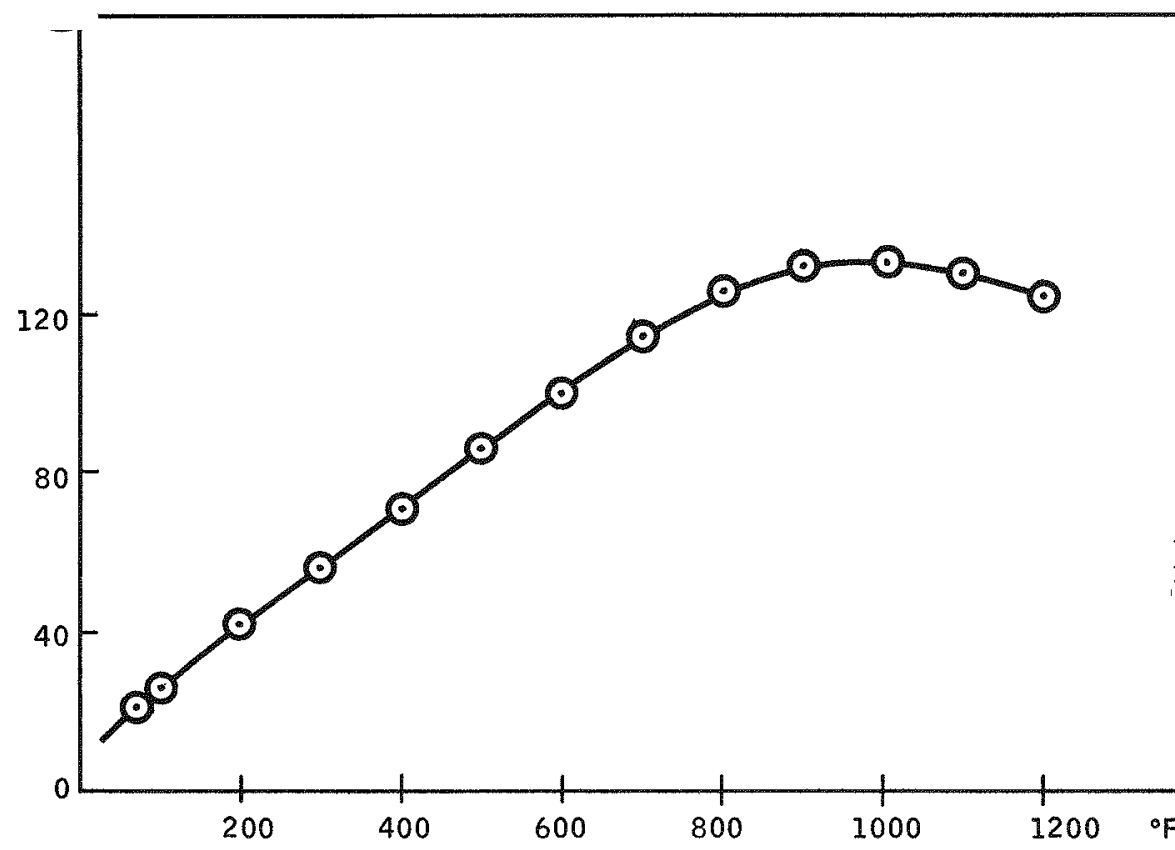

Figure 5-44. Seebeck Coefficient (S) (P-Leg Hot Segment For Separately Pressed and Bonded PbSnTe ES 1110-3P)

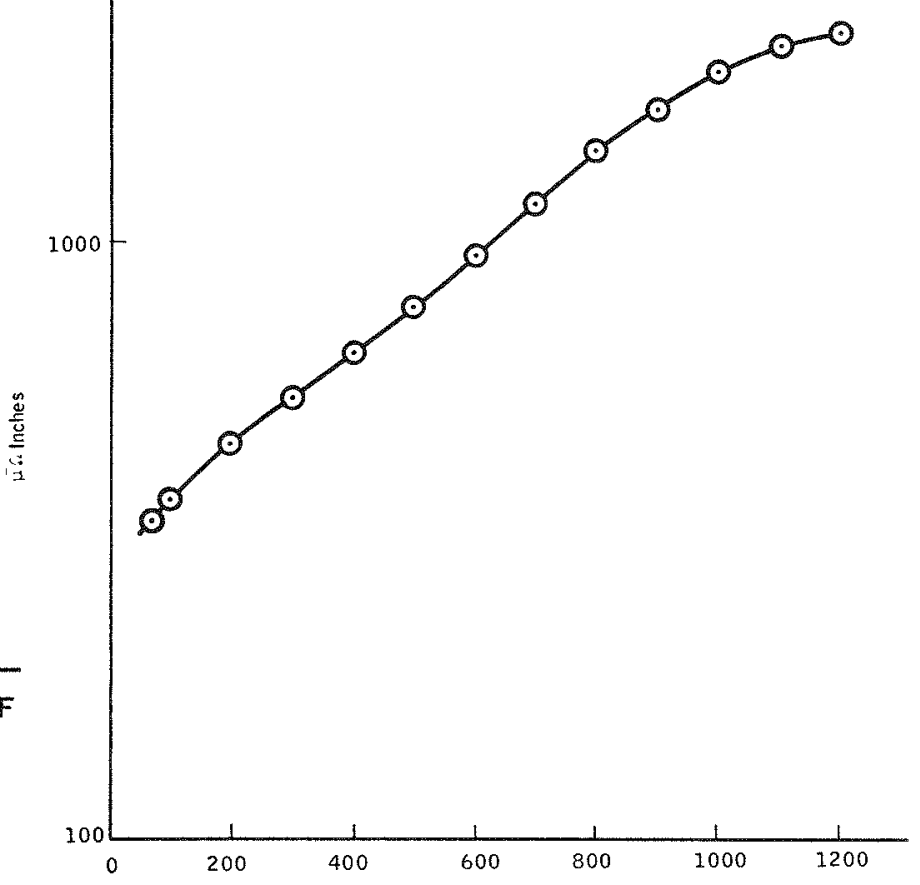

Figure 5-45. Resistivity ( $($ ) (P-Leg, Hot Segment For Separately Pressed and Bonded PbSnTe ES 1110-3P)

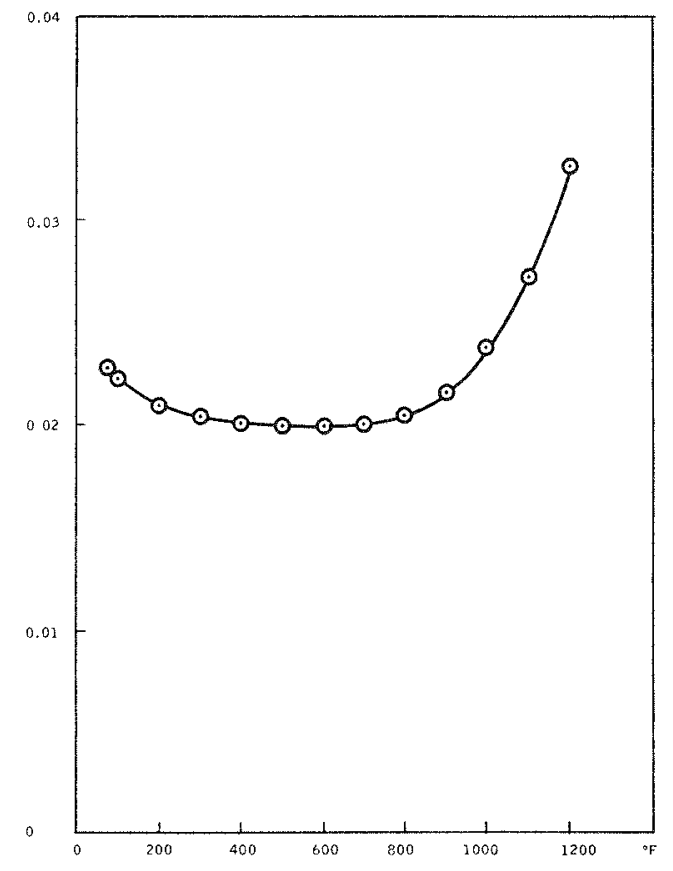

Figure 5-46. Thermal Conductivity (K) (P-Leg, Hot Segment for Separately Pressed and Bonded (PbSnTe ES 1110 3P)

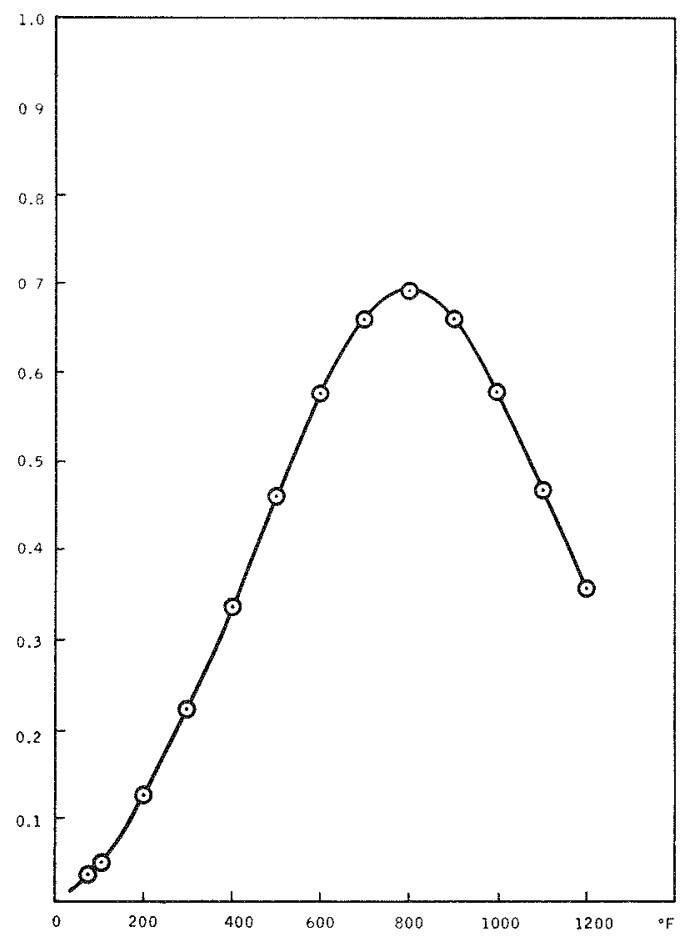

Figure 5-47. Dimensionless Figure of Merit (ZT) (P-Leg, Hot Segment Pressed and Bonded (PbSnTe ES 1110-3P) 
Table $5-30$

$\mathrm{P}$ - and N-Leg Bell Jar Performance Test Data $\left(\mathrm{T}_{\mathrm{h}}=1100^{\circ} \mathrm{F}\right.$,

$\mathrm{T}_{\mathrm{c}}=190^{\circ} \mathrm{F}, 250$ psi Contact Pressure, 50-100 Hour Data

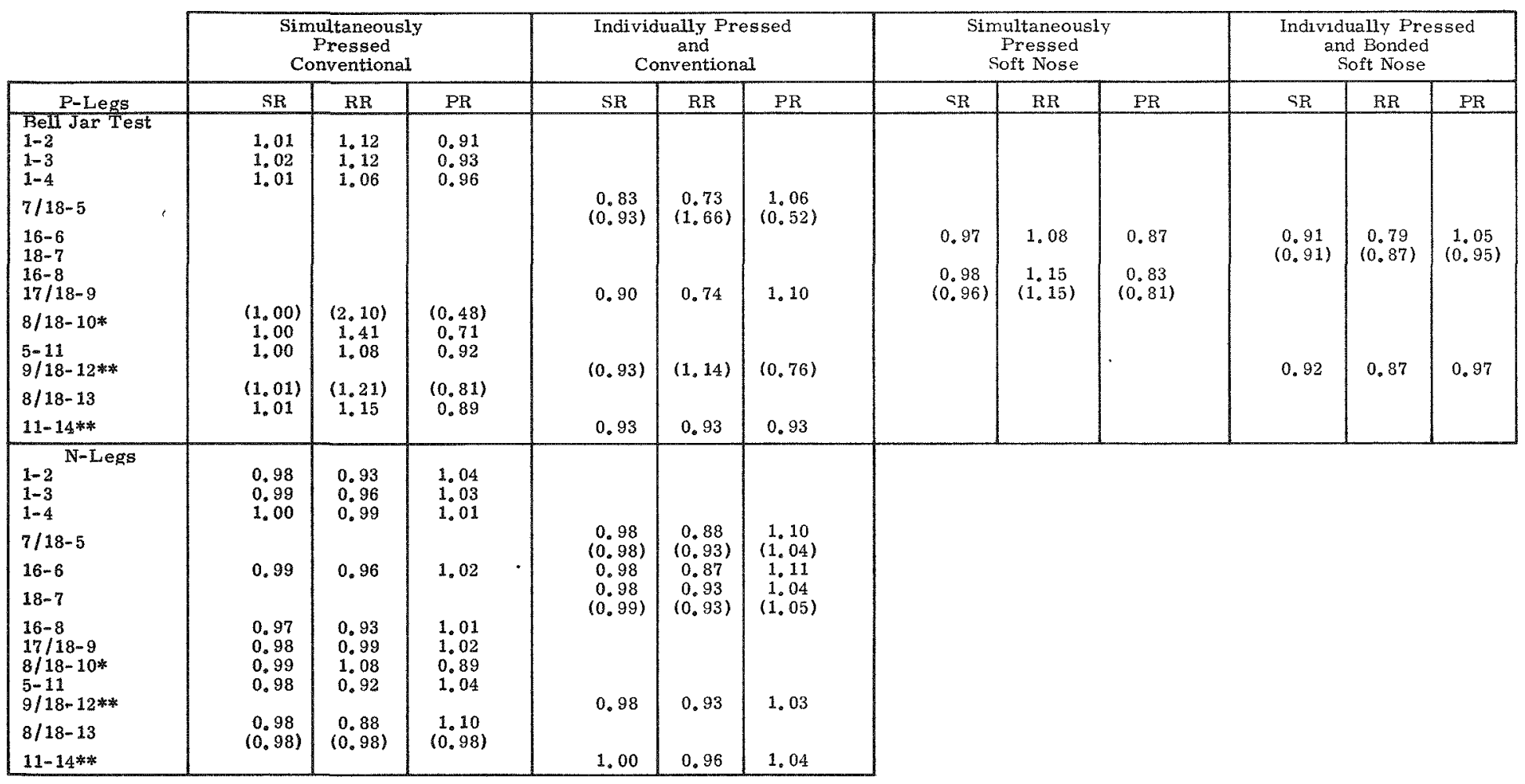

*5 $5^{\circ}$ Nominal Misalignment

$* * 2.5^{\circ}$ Nominal Misalignment

$$
\begin{aligned}
\text { CR: Seebeck ratio } & =\frac{\text { Exper. Seebeck voltage }}{\text { Theo. Seebeck voltage }} \\
\text { RR: Resistance ratio } & =\frac{\text { Exper. resistance }}{\text { Theo. resistance }} \\
\text { PR: Power ratıo } & =\frac{\text { Exper. matched power }}{\text { Theo. matched power }}
\end{aligned}
$$

( ): Molybdenum Contact 


\section{6 CONTINUATION TESTING OF SNAP-23 CONVERTER P2 AND MODULE A3}

During the SNAP-23 program, two prototype converters and two six-couple modules were built by $3 \mathrm{M}$ and placed on test for long-term performance evaluation. Testing of one converter designated 23-P2 and one module designated 23-A 3 continued during the SNAP -23A program.

The physical characteristics and material identification of the elements contained without converter 23-P2 and module 23-A3 are summarized in Table 5-31. A complete description of these elements can be found in Appendix A of SNAP-23 Quarterly Report No. 3 dated May 1965, MMM(3418)-17. The N-legs were manufactured by individually pressing the hot and cold segments and then bonding them together. The P-legs were manufactured by simultaneously pressing the cold and hot segments.

Table 5-31

Thermoelectric Element Data Converter 23-P2 and Module 23-A3

\begin{tabular}{|c|c|c|c|c|c|c|}
\hline Leg & Segment & Material & $L$ & D & $L_{c} / L$ & $L / A$ \\
\hline \multirow{3}{*}{$N$} & Cold & $M-13$ & 0.125 & 0.188 & 0.250 & ----- \\
\hline & Hot & $M-10$ & 0.377 & 0.188 & $--m-m$ & --- \\
\hline & Total & $-\cdots$ & 0.502 & 0.188 & $-\cdots$ & 18.2 \\
\hline \multirow{3}{*}{$\mathrm{P}$} & Cold & $M-29$ & 0.124 & 0.188 & 0.350 & --- \\
\hline & Hot & $M-76$ & 0.232 & 0.188 & $-\cdots-$ & $-\cdots$ \\
\hline & Total & $--\cdots$ & 0.356 & 0.188 & $-\ldots$ & 12.9 \\
\hline
\end{tabular}

L - Total length (inch)

D - Diameter (inch)

Lc - Cold segment length (inch)

A - Cross sectional area (inch) 2 
Long-term operation of Module 23-A3 extended over five years of continuous testing at a hot junction temperature of $1100^{\circ} \mathrm{F}$. Performance data for the instrumented $\mathrm{N}-\mathrm{leg}$ is listed in Table 5-32 and plotted in Figure 5-48. Analysis of data indicates that:

- N-leg Seebeck voltage decreased about $6 \%$ with the primary change occurring after two years.

- N-leg resistance increased $72 \%$ over the five-year period.

These results were factored into degradation analys is study which were used to define operating conditions such as hot junction temperatures which would result in stable operation. 


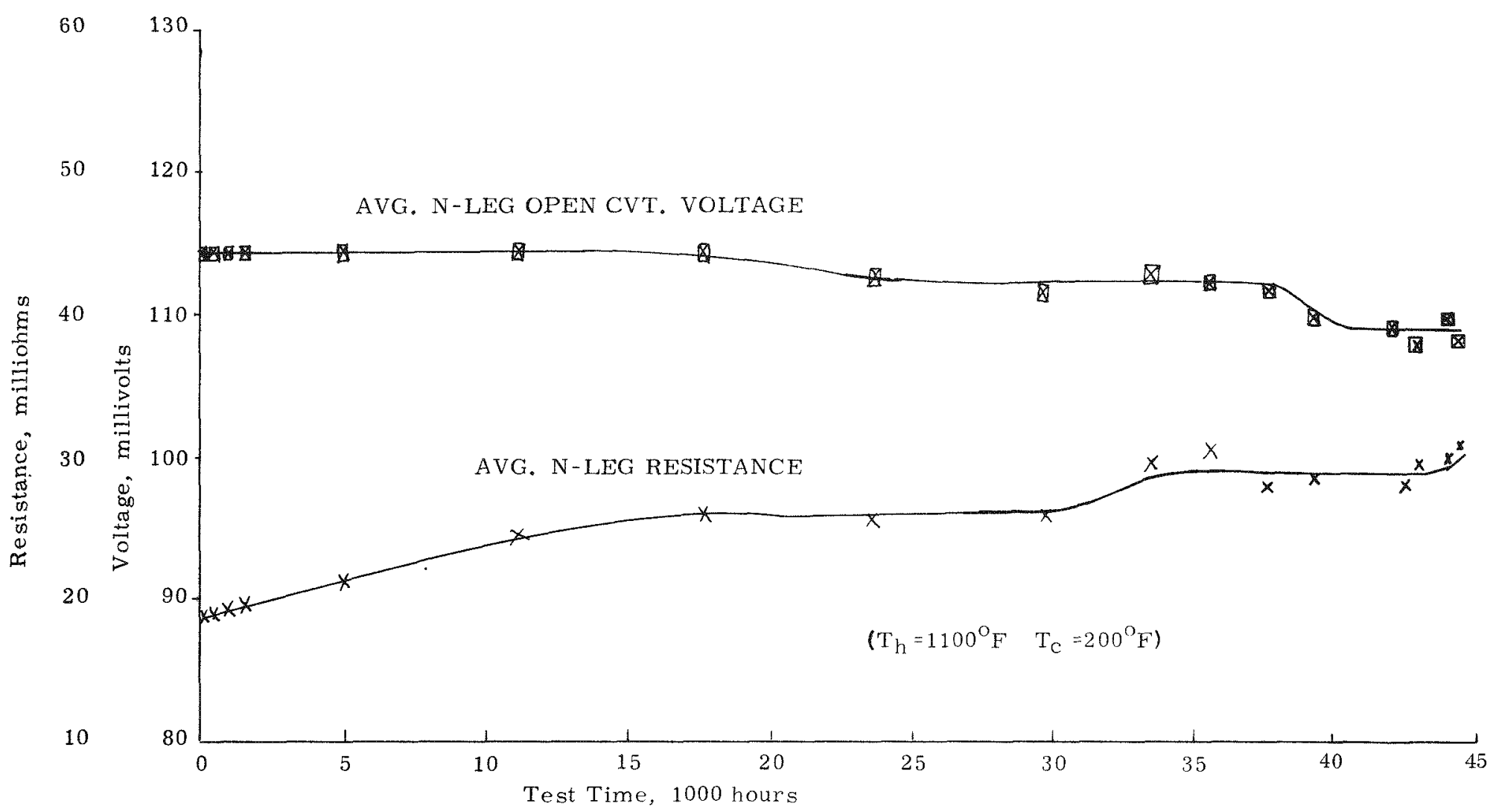

Figure 5-48

SNAP-23 Six-Couple Module 23-A3, N-Leg Performance History

$$
\left(\mathrm{T}_{\mathrm{H}}=11^{\mathrm{O}} \mathrm{F}, \mathrm{T}_{\mathrm{C}}=200^{\circ} \mathrm{F}\right)
$$


Table 5-32

SNAP 23 Six-Couple Module 23-A3 N-leg Performance Data

\begin{tabular}{|r|r|r|r|r|r|}
\hline Hours & $T_{h{ }^{\circ}{ }^{\circ}}$ & $T_{c{ }^{\circ} \mathrm{F}}$ & E, mv & R, mo & I, Amps \\
\hline 90 & 1102 & 190 & 114.2 & 18.8 & 2.84 \\
1,034 & 1104 & 197 & 114.3 & 18.9 & 2.58 \\
1,655 & 1100 & 194 & 114.5 & 19.6 & 2.55 \\
5,065 & 1100 & 191 & 114.5 & 21.3 & 2.58 \\
11,252 & 1100 & 190 & 114.5 & 24.4 & 2.48 \\
17,732 & 1095 & 193 & 114.0 & 26.0 & 2.35 \\
23,000 & 1095 & 190 & 112.5 & 25.4 & 2.36 \\
29,136 & 1100 & 191 & 111.5 & 25.6 & 2.38 \\
35,694 & 1096 & 193 & 111.0 & 30.3 & 2.26 \\
37,779 & 1103 & 184 & 110.5 & 27.7 & 2.33 \\
39,262 & 1100 & 193 & 108.5 & 28.4 & 2.29 \\
42,292 & 1097 & 193 & 108.0 & 28.4 & 2.29 \\
44,422 & 1100 & 193 & 107.5 & 32.2 & 2.22 \\
48,796 & 1100 & 191 & 105.5 & 32.4 & 2.19 \\
\hline
\end{tabular}

Key

$T_{h}$ - Average hot electrode temperature

$\mathrm{T}_{\mathrm{c}}$ - Average cold electrode temperature

E - Average $\mathrm{N}$-leg open circuit voltage

$\mathrm{R}$ - Average $\mathrm{N}$-leg resistance

I - Load current 


\section{8 CONVERTER 23-P2}

Long-term operation of $\mathrm{C}$ onverter $23-\mathrm{P} 2$ extended over three years of continuous testing. Performance data is summarized in Table 5-33 and plotted in Figure 5-49 after normalization to an average hot junction temperature of $1070^{\circ} \mathrm{F}$ and cold junction temperature of $200^{\circ} \mathrm{F}$. N-leg and P-leg performance data is presented in Table 5-34 as the ratio of experimental to theoretical values.

Results from performance data show that thermopile Seebeck voltage and resistance varied by less than six percent with the net result being that power output after three years was equal to initial power output. Examination of the individual leg data in Table 5-34 shows the N-leg Seebeck voltage and resistance decreased, the P-leg Seebeck voltage remained essentially constant and the P-leg resistance increased. The $\mathrm{N}$-leg data from this test was also factored into the degradation analysis model which was used to define optimum PMC -2 and PMC -3 operating conditions. 


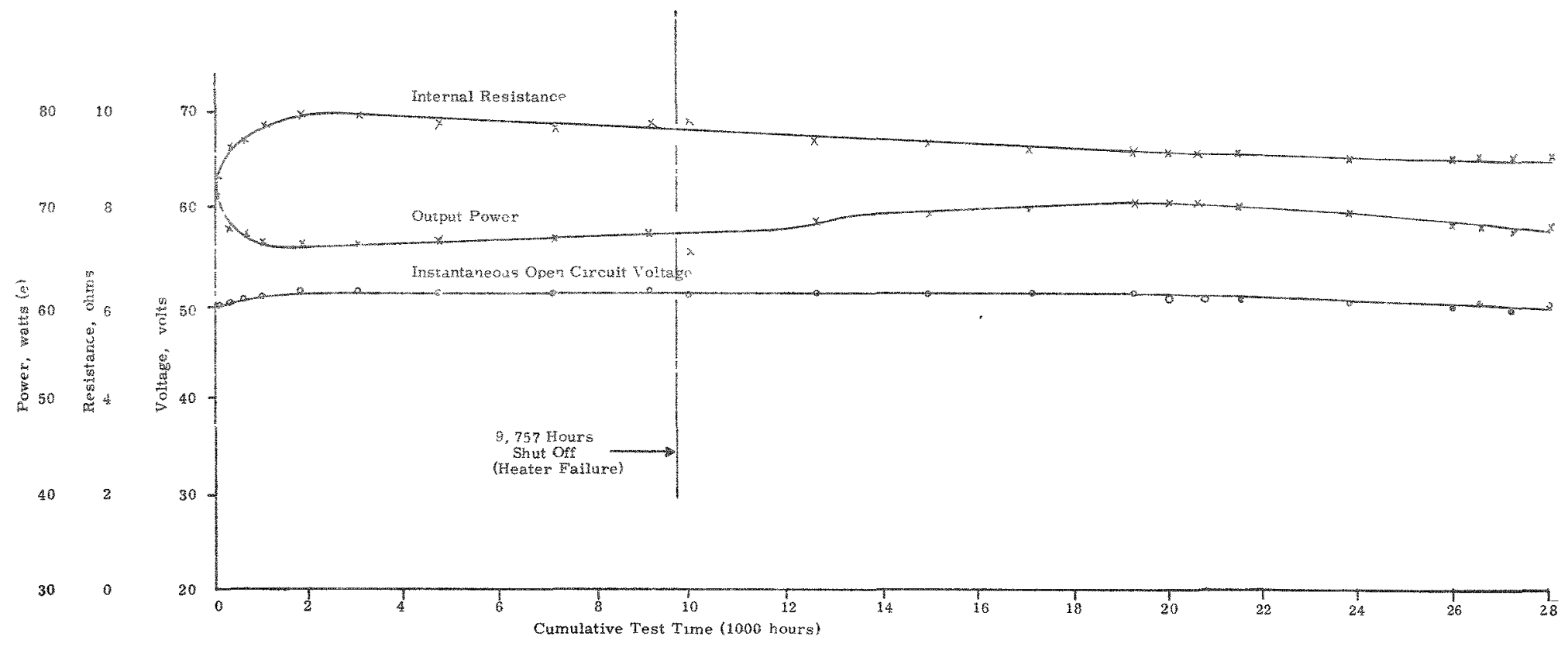

Figure 5-49

SNAP-23 Prototype Converter 23-P2 BOL History

(Normalized Data $\mathrm{T}_{\mathrm{H}}=1070^{\circ} \mathrm{F}, \mathrm{T}_{\mathrm{C}}=200^{\circ} \mathrm{F}$ ) 
Table 5-33

SNAP -2 3 Converter 23-P2 Performance Data

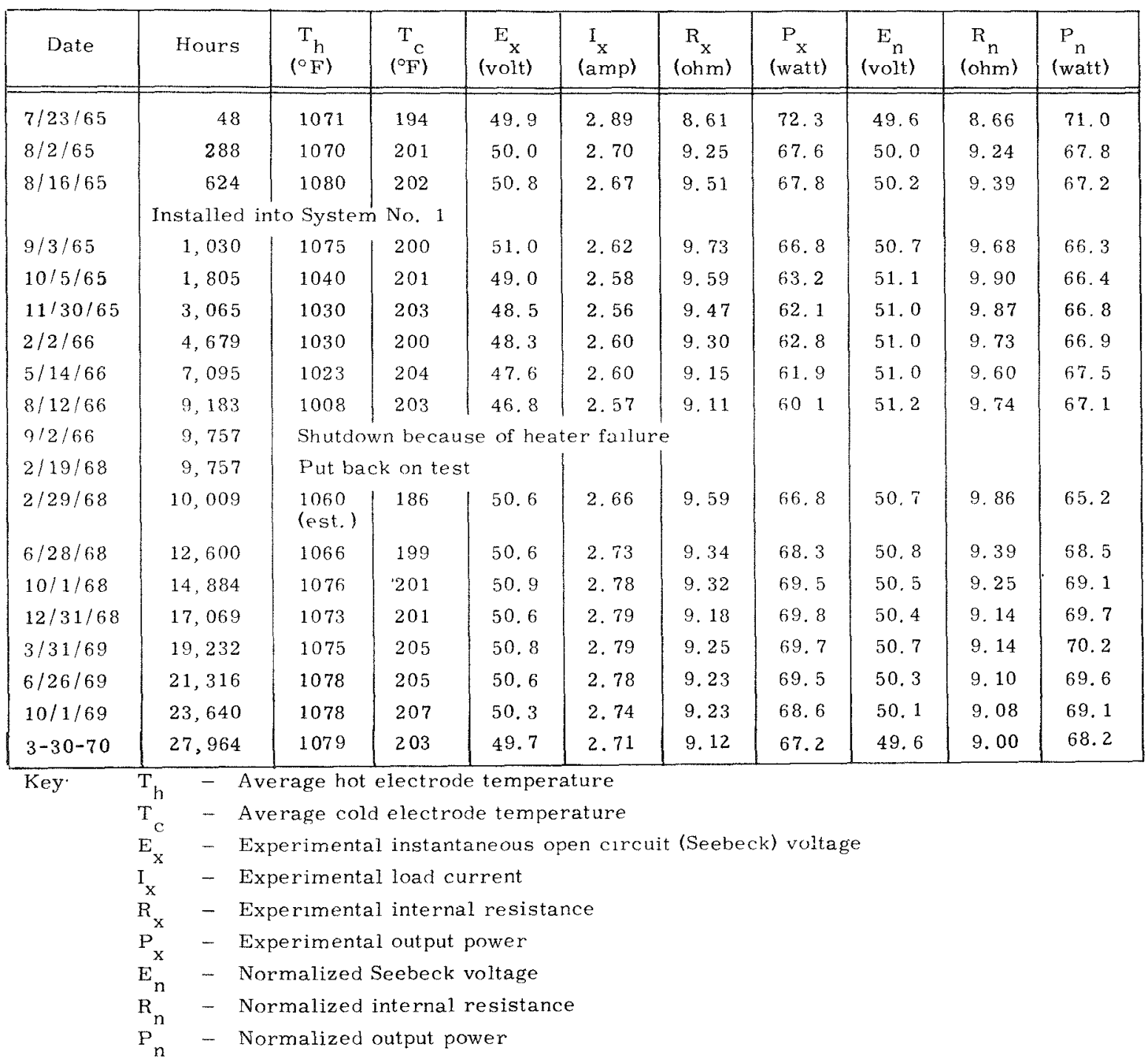


Table 5-34

SNAP-23 Converter 23-P2 BOL Performance Data

\begin{tabular}{|c|c|c|c|}
\hline & Time Evaluated & Seebeck Ratio ${ }^{*}$ & Resistance Ratio \\
\hline Thermopile & $\begin{array}{r}48 \\
14,884 \\
19,232 \\
23,640 \\
25,640 \\
25,831 \\
27,964 \\
32,356\end{array}$ & $\begin{array}{l}0.97 \\
0.99 \\
0.99 \\
0.98 \\
0.98 \\
0.97 \\
0.96\end{array}$ & $\begin{array}{l}1.00 \\
1.07 \\
1.06 \\
1.05 \\
1.05 \\
1.05 \\
1.01\end{array}$ \\
\hline Typical N-Leg & $\begin{array}{r}48 \\
14,884 \\
19,232 \\
23,640 \\
25,831 \\
27,964 \\
32,356\end{array}$ & $\begin{array}{l}1.03 \\
1.01 \\
1.01 \\
0.99 \\
0.98 \\
0.98 \\
.108\end{array}$ & $\begin{array}{l}1.00 \\
0.95 \\
0.95 \\
0.93 \\
0.93 \\
0.92 \\
.0183\end{array}$ \\
\hline Typical P-Leg & $\begin{array}{r}48 \\
14,884 \\
19,232 \\
23,640 \\
25,831 \\
27,964 \\
32,356\end{array}$ & $\begin{array}{l}0.95 \\
0.98 \\
0.98 \\
0.97 \\
0.97 \\
0.96 \\
.0885\end{array}$ & $\begin{array}{l}1.10 \\
1.25 \\
1.21 \\
1.19 \\
1.19 \\
1.17 \\
.0189\end{array}$ \\
\hline
\end{tabular}

* Theoretical resistance values include only $\mathrm{T} / \mathrm{E}$ material resistance. 


\subsection{FIRE TEST MODULES}

\subsection{INTRODUCTION}

A fire safety evaluation of the SNAP-23A system was made to determine if containment of the Strontium-90 fuel would be maintained should the system be subjected to a fire. Analysis showed that peak fuel temperature occurred after a fire and the peak value depended on the change in thermal conductance of the converter. If a substantial reduction in converter thermal conductance should occur during the fire, a fuel temperature excursion might ensue leading to a breach in the containment and fuel release. On the other extreme, if converter thermal conductance should increase as the result of a fire, fuel temperature would peak before melting occurred and fuel containment integrity would be maintained. A test program was undertaken at $3 \mathrm{M}$ to define converter thermal conductance after a postulated fire incident. Results were used by Westinghouse and Hittman Associates to calculate the fuel temperature as a function of time.

The objective of the $3 \mathrm{M}$ Fire Safety Test Program was to determine the overall thermal conductance of the SNAP-23A PMC-2 converter as a function of temperature after the postulated $1475^{\circ} \mathrm{F}$ and $1850^{\circ} \mathrm{F}$ fire transient conditions. To meet this objective, special test modules were fabricated which represented mechanical and thermal characteristics of the SNAP-23A PMC-2 converter. A test stand was also provided to simulate the desired temperature-time profile and measure the 
steady-state thermal conductance of the module. Module data was then analyzed to determine the thermal conductance of a full-scale converter before and after exposure to a $1475^{\circ} \mathrm{F}$ and $1850^{\circ} \mathrm{F}$ fire.

\subsection{TEST DESCRIPTION}

Testing was conducted in a two-phase program. In the first phase, special modules were operated to define fixture tare heat losses, thermal response of the fixture and temperature distribution in the fixture and module. In the second phase, the converter simulation modules were forced to follow the timetemperature profiles calculated for a $1475^{\circ} \mathrm{F}$ and $1850^{\circ} \mathrm{F}$ fire of approximately $1 / 2$ hour duration. Thermal conductance was measured during the heat up and cool down of the simulated fire transient on each module tested during the second phase. SNAP-23A Quarterly Report No. 12 presents a detailed description of the test plans, procedures and deviations. A summary description of the testing follows.

In Phase I testing, the fixture tare heat losses were first determined using a cylinder of Min-K 2000 thermal insulation in place of the converter simulation module. Tests were conducted with the cold side and hot side at equal temperatures where ideally the heat flow through the iron standard should be zero and with the cold side and hot side temperatures at BOL test temperatures. Both conditions were tested with the mid-guard heater energized and with the heater de-energized.

In the next series of tests a dummy module was operated at the cold side timetemperature functions calculated for a $1475^{\circ} \mathrm{F}$ and $1850^{\circ} \mathrm{F}$ fire. The objectives of these tests were to verify the capability of the test fixture to provide the fire test time-temperature profiles and to define input data for the temperature controllers to be used for testing the converter simulation modules. The dummy module was fabricated from materials which would not be damaged during the fire tests and as a consequence could experience several trial tests without a change in thermal characteristics.

The final Phase I tests were run using instrumented converter simulation modules. The testing was conducted at BOL temperature conditions to measure the temperature differences from the hot frame to thermoelectric couple hot 
junction and from the thermoelectric couple cold junction to the outer case. The module results were compared to converter results to determine if adequate similarities existed.

In the second phase $1475^{\circ} \mathrm{F}$ and $1850^{\circ} \mathrm{F}$ fire transient tests, the converter simulation module temperatures were stabilized at PMC-2 BOL hot frame and cold frame temperatures. The heater input and coolant flow were then adjusted to follow the fire transient curves shown in Figures 6-1 and 6-2. At a cold side temperature of $400^{\circ} \mathrm{F}$ and $600^{\circ} \mathrm{F}$, each transient was interrupted to obtain an equilibrium thermal condition for a thermal conductance measurement. These equilibrium thermal conditions were achieved during both the temperature excursion and the cool down portions of the transient so that pre-fire and postfire thermal conductance could be determined. Each module was disassembled following the test to observe the physical changes.

\section{3 MODULE DESIGNS}

The converter simulation module design is shown in Figure 6-3 and described in Table 6-1. The module consists of a six-couple segment of a converter contained in a thin wall stainless steel tube. The tube and components are sized to preserve cold frame length, spacing between the thermoelectric legs, internal couple electrical connections and the distance between the hot frame and cold frame. The mass of cold frame and thermal insulation per couple existing in the converter were also maintained in the module. The module cold frame design duplicates the converter wire and spacer washer arrangement to support the follower springs. The contact pressure between the converter cold frame and outer case, resulting from a shrink fit, is simulated by bolting the cold frame to the outer case. The tube wall is as thin as practical from mechanical strength and fabricability considerations to most nearly approximate the low percentage of total heat input conducted through the converter support cone and lower cover. A pinch-off tube is provided so that converter processing can be simulated. Thermocouples are mounted in the outer case and hot frame to monitor hot and cold interface temperatures. 
The dummy module was constructed with a molybdenum cold frame in place of the aluminum cold frame in the converter. Thermoelectric elements were excluded from the dummy module as was indium foil and other components which were expected to undergo physical or chemical changes during the fire test calibration runs.

The instrumented module was of the same design as the converter simulation module except iron-constantan thermocouples were attached to the cold and hot junction electrodes. These thermocouples together with thermocouples in the hot frame and cold frame defined module temperature distribution.

\subsection{FIXTURE DESIGN}

The primary item of test equipment was the module test stand ( shown in Figure 6-4 with the module mounted in position). The test stand consisted of a cylindrical cold side heater block, an Armco iron thermal conductivity standard with calibrated differential thermocouple wires (constantan) attached at a fixed spacing, and a cold side heat sink. Heaters were affixed to the standard and cold side heater block to vary the hot and cold end temperatures (artificial cooling was provided on the cold side to assure temperature simulation). Guard heaters were used to minimize radial temperature drops and hence radial heat losses from the standard and the module. The test modules were bolted to the test stand with foil placed at the interfaces to minimize interface thermal resistance. The test stand and hermetically sealed module was placed in a bell jar containing a low thermal conductivity gas (argon) to minimize extraneous heat loss. 


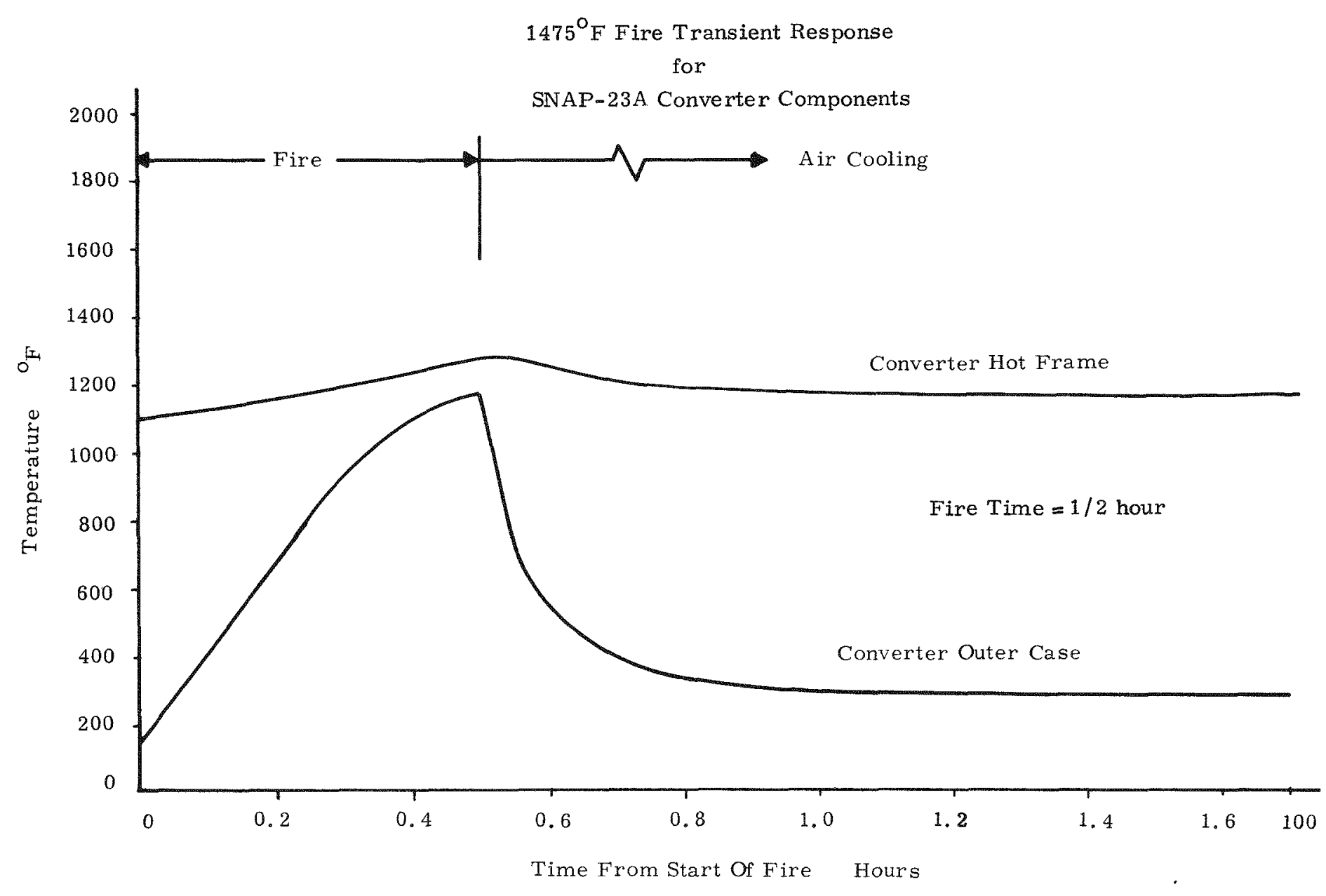

- Figure 6-1.

Calculated Response of SNAP-23A Generator Components During $1475^{\circ} \mathrm{F}$ Half Hour Fire 


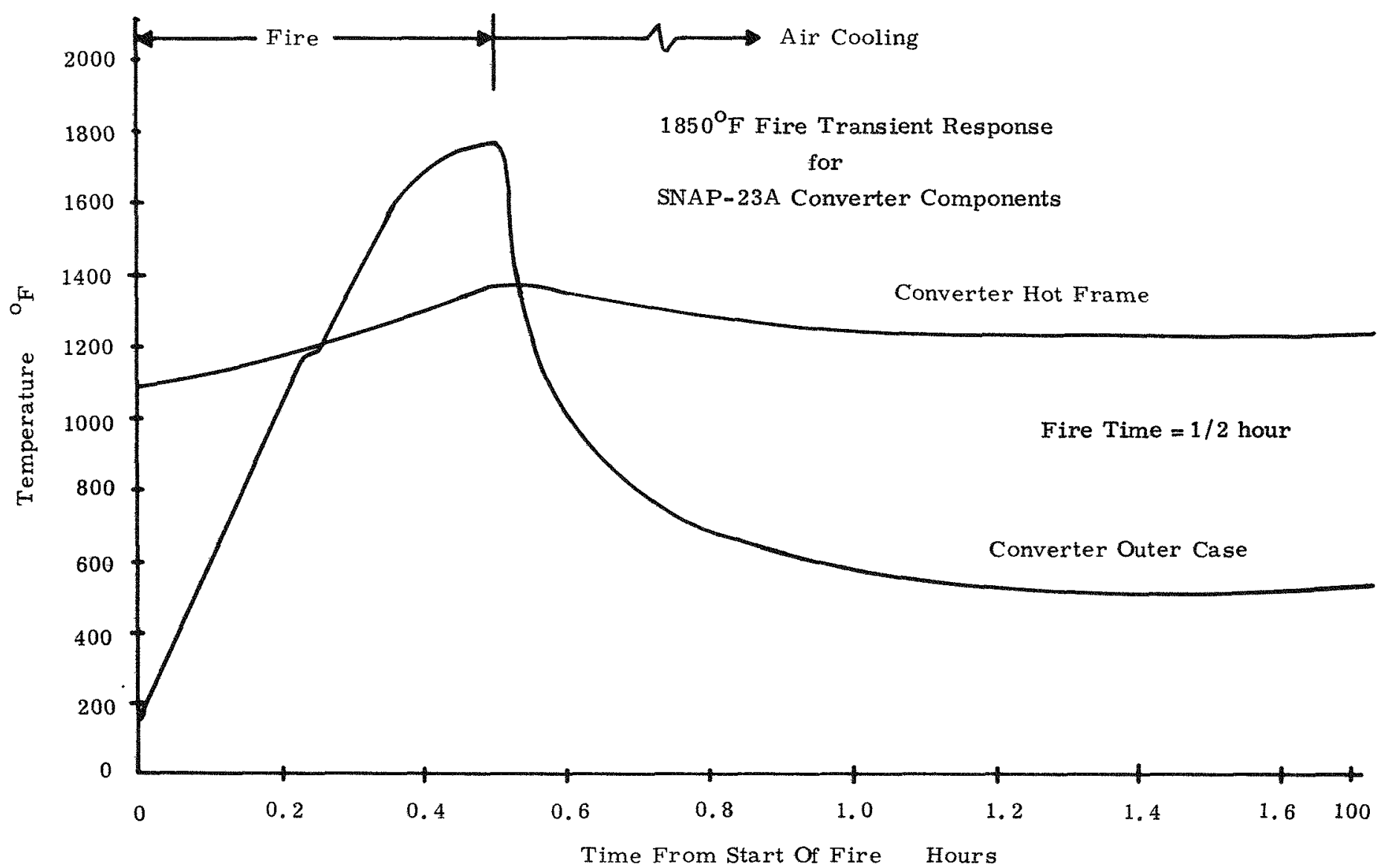

Figure 6-2.

Calculated Response of SNAP-23A Generator

Components During $1850^{\circ} \mathrm{F}$ Half Hour Fire 


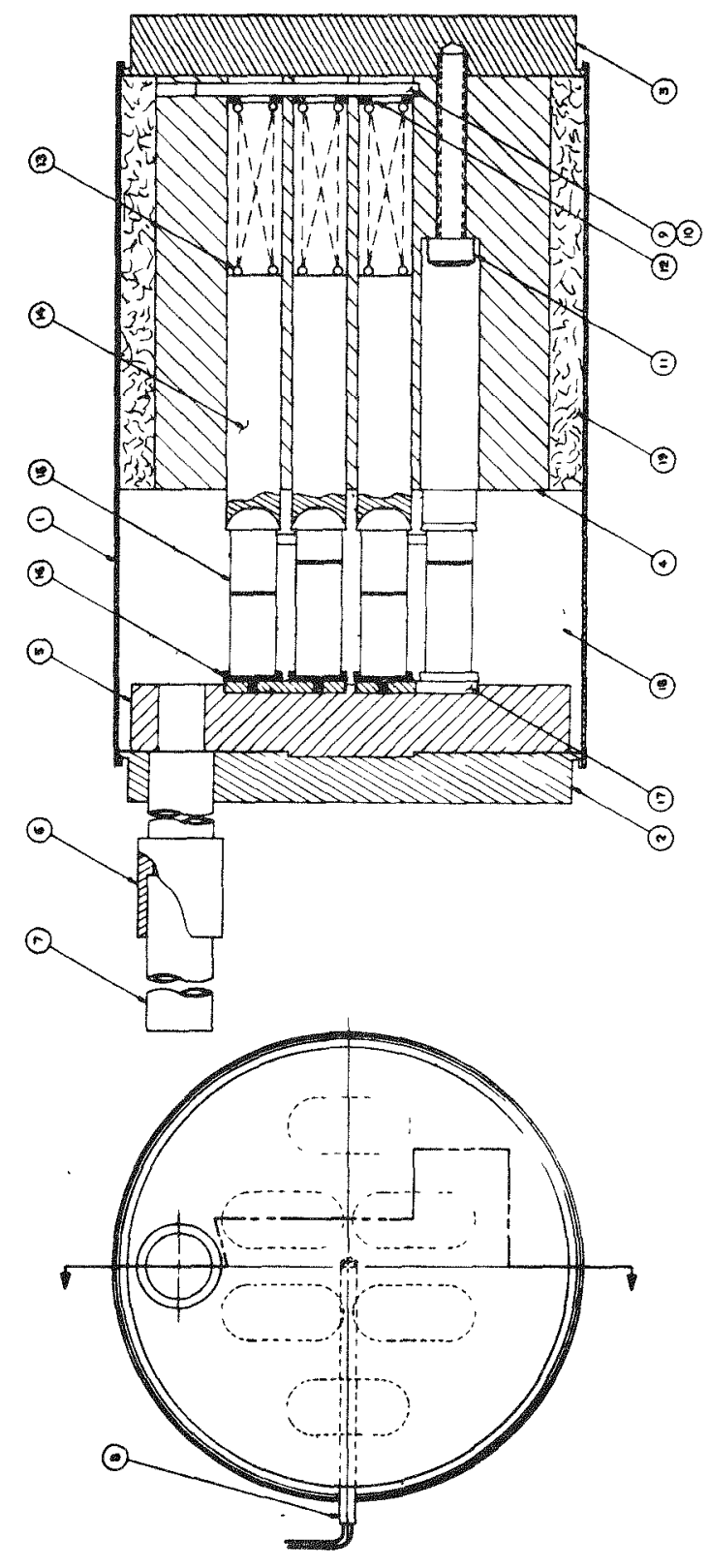

Key

1. Tube

2. Hot Frame

3. Outer Case

4. Cold Frame

5. Insulator

6. Tubulation Fitting

7. Pinch-off Tube

8. Sheathed Thermocouple

9. Support Wire

10.

11. Bolt

12. Support Wire

13. Follower Spring

14. Follower

15. Thermoelectric Couple

16. Hot Button

17. Hot Electrode

18. Min-K-1301 Powdered Insulation

Figure 6-3

Six-couple Fire Module 
Table 6-1

Fire Module Design Summary

\begin{tabular}{|c|c|}
\hline Module Length: & $2,93^{\prime \prime}$ nominal \\
\hline Module Diameter: & $1.86^{\prime \prime}$ nominal \\
\hline No. Couples: & Six \\
\hline Couple Type: & PMC-2 design or equivalent \\
\hline Thermal Insulation: & $\begin{array}{l}\text { a) Min-K } 1301 \text { (powdered) packed } \\
\text { into voids around } \mathrm{T} / \mathrm{E} \text { legs. } \\
\text { b) Microquartz (pad) at outer wall } \\
\text { adjacent to cold frame. }\end{array}$ \\
\hline Cold Frame: & A luminum Type 2024-T4 \\
\hline $\begin{array}{l}\text { Hot Frame and } \\
\text { Cylindrical Wall; }\end{array}$ & Stainless steel type 304 \\
\hline $\begin{array}{l}\text { Outside Case (End } \\
\text { Cover): }\end{array}$ & Inconel 625 \\
\hline Couple Hardware: & Identical to PMC-2 design \\
\hline $\begin{array}{l}\text { Module Orientation } \\
\text { During Test: }\end{array}$ & Axis horizontal \\
\hline Backfill Gas & Argon (10 psia at BOL conditions) \\
\hline
\end{tabular}




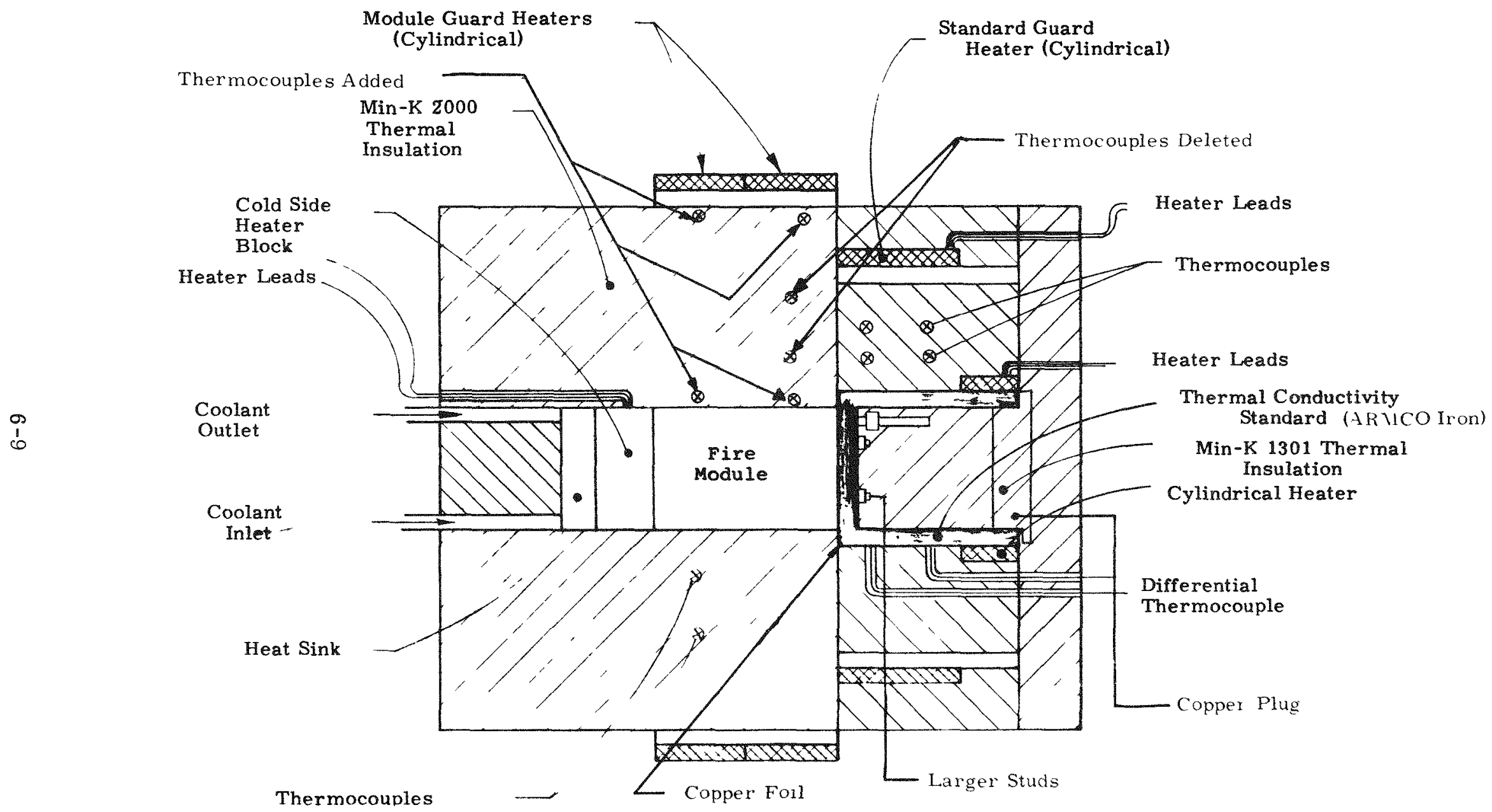

Figure 6-4

Fire Module Test Stand 


\subsection{TEST RESULTS}

\subsubsection{Dummy Module Test}

Results from the initial dummy module test showed a poor mechanical contact to exist between the hot frame and the Armco iron standard. To eliminate this deficiency, copper foil was inserted between the hot frame and Armco iron standard and larger studs were used to allow a greater torque on the hold down nuts. Later results indicated that the above design changes greatly reduced the standard-module interface thermal impedance and the test fixture was judged to be suitable for the program. The time trace of measured cold side temperatures showed that this temperature could be controlled within $\pm 50^{\circ} \mathrm{F}$ of the values of the curve supplied by Hittman Associates (Figures 6-1 and 6-2).

\subsubsection{Instrumented Couple Module Tests}

Table 6-2 is a summary of the data taken during the test with the instrumented couple module. This data shows an adequate similarity between the six-couple module temperature differential and the PMC-2 type converter.

\subsubsection{Fixture Calibration Tests}

Table 6-3 lists results from the fixture calibration tests. Based on these test results and the temperatures for which conductance was to be determined, 1.4 watts was subtracted from the heat flow indicated by the Armco iron standard for all module data reductions. 
6.5.4 $1475^{\circ} \mathrm{F}$ and $1850^{\circ} \mathrm{F}$ Fire Module Test Results

Results from the fire module tests are presented in Tables 6-4 and 6-5 for the three tests which were run. These tests show that the converter thermal conductance would increase 10 to 60 percent if exposed to a $1475^{\circ} \mathrm{F}$ or $1850^{\circ} \mathrm{F}$ fire for $1 / 2$ hour duration. Hittman Associates and Westinghouse used this data to conclude that safe containment of fuel could be assured in a fire incident.

The conductance of the fire module was determined from measured heat flow through an iron standard and measured temperatures at the hot and cold ends of the module. The iron standard was in thermal series with the module and located adjacent to the hot side as illustrated in Figure 6-4. A pair of differential the rmocouples were located on the iron standard to determine the temperature gradient $(\Delta T / \Delta L)$ in the iron. This gradient is then converted to heat flow using the known thermal conductivity $(K)$ of iron and the area $(A)$ of the iron standard $\left(Q=K A \frac{\Delta T}{\Delta L}\right)$. A correction for radial heat losses from the module was made by a calibration experiment.

The effective conductance of a full sized SNAP-23A converter was determined based on measured fire module conductance with adjustments for number of couples and losses through the structures. The conductance of the couples and Min-K surrounding the legs was first determined by substracting the conductance of the outer case from the measured module conductance. This quantity was then multiplied by the ratio of couples in the converter to couples in the module to obtain the respective conductance of the converter without structural losses. The effective conductance equation with the addition of structural losses is shown as Equation $\mathrm{A}$.

$$
K_{\text {conv }}=\frac{280}{6}\left(K_{\text {mod }}-K_{\text {case }}\right)+K_{s c}+K_{l c}
$$

Details of the calculation method together with a sample calculation are shown in SNAP-23A Quarterly Report No. 12 . 


\subsubsection{Post-Test Fire Module Disas sembly}

The modules were disassembled and the following major changes were noted:

- In the $1475^{\circ} \mathrm{F}$ fire module, the cold end segment of the P-leg melted, which was expected since this material has a melting point of $1125^{\circ} \mathrm{F}$. The followers were locked in the cold frame holes but still in contact with the cold caps. The reduced length of the P-legs would account for the increased conductivity observed after the test.

- In the $1850^{\circ} \mathrm{F}$ fire module, the elements ( $N$ and $P$ ) experienced some melting in addition to that noted for the $1475^{\circ} \mathrm{F}$ test. The top side of the aluminum cold frame melted down to the first couple with the molten material running into the follower holes. The followers and some elements were skewed; however, all followers were still in contact with their cold cap. The melting and plastic flow of materials significantly reduced the heat path length which in turn increased the thermal conductivity.

In no case was the outer case of the module breached and the external appearance was normal for a device which had been exposed to a high temperature environment. None of the components appear to have reacted with each other. The included photographs show condition of the internal components after a $1475^{\circ} \mathrm{F}$ incident fire (Figure $6-5)$ and an $1850^{\circ} \mathrm{F}$ incident fire (Figure 6-6). 
Table 6-2

Couple Instrumented Fire Test Module

Comparison With PMC-2 Converter

\begin{tabular}{|c|c|c|}
\hline & $\begin{array}{l}\text { Six-Couple } \\
\text { Module }\end{array}$ & $\begin{array}{c}\text { Average of } \\
\text { Several PMC-2 } \\
\text { Type Converters }\end{array}$ \\
\hline Hot Frame External & 1047 & 1050 \\
\hline $\begin{array}{l}\text { External-Internal } \\
\text { Temperature Difference }\end{array}$ & 35 & 52 \\
\hline $\begin{array}{l}\text { Hot Button } \\
\text { (Average of } 3 \mathrm{~T} / \mathrm{C}^{\prime} \mathrm{s} \text { ) }\end{array}$ & 1012 & 998 \\
\hline $\begin{array}{l}\text { Cold Cap } \\
\text { (Average of } 2 \mathrm{~T} / \mathrm{C}^{\prime} \mathrm{s} \text { ) }\end{array}$ & 185 & 190 \\
\hline $\begin{array}{l}\text { External-Internal } \\
\text { Temperature Difference }\end{array}$ & 37 & 35 \\
\hline Cold Frame External & 148 & 155 \\
\hline
\end{tabular}

Table 6-3

Fire Calibration Module Test Results

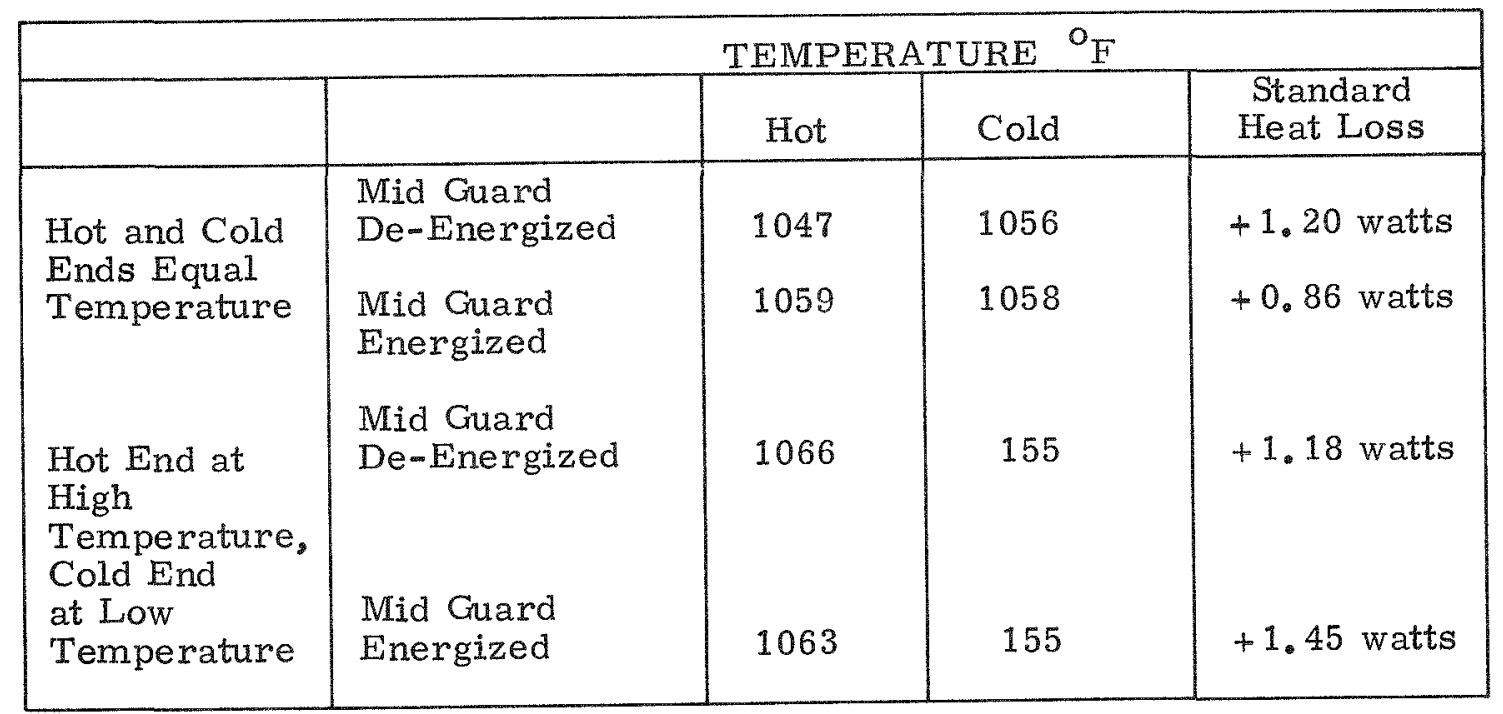


Table 6-4

Fire Test Reduced Data

Test Module Conductance and Predicted Converter Total Conductance

PRE-FIRE

\begin{tabular}{|c|c|c|c|c|c|c|c|c|c|c|}
\hline & \multicolumn{3}{|c|}{$\begin{array}{c}\text { BOL Conditions } \\
(1050 / 155)\end{array}$} & \multicolumn{3}{|c|}{$\begin{array}{l}\text { First Hold Point } \\
\left(400^{\circ} \mathrm{F}\right)\end{array}$} & \multicolumn{3}{|c|}{$\begin{array}{l}\text { Second Hold Point } \\
(600 \circ \mathrm{F})\end{array}$} & \multirow{2}{*}{$\begin{array}{l}\text { Max. ext. } \\
\text { Cold Frame } \\
\text { Temperatures }\end{array}$} \\
\hline & $\begin{array}{c}\text { THEX/ } \\
\text { TCEX } \\
{ }^{\circ} F\end{array}$ & \begin{tabular}{|c|} 
Test \\
Module \\
$W / F$
\end{tabular} & $\begin{array}{c}\text { Conv. } \\
W / F\end{array}$ & $\begin{array}{l}\text { THEX } \\
\text { TCEX } \\
{ }_{F}\end{array}$ & $\begin{array}{c}\text { Test } \\
\text { Module } \\
W / F\end{array}$ & $\begin{array}{c}\text { Converter } \\
W / F\end{array}$ & $\begin{array}{l}\text { THEX / } \\
\text { TCEX } \\
{ }^{\circ} \mathrm{F}\end{array}$ & $\begin{array}{l}\text { Test } \\
\text { Module } \\
W / F\end{array}$ & $\begin{array}{c}\text { Converter } \\
W / F\end{array}$ & \\
\hline $\begin{array}{l}\text { First } \\
1475^{\circ} \\
\text { Test }\end{array}$ & $\begin{array}{c}1053 / \\
160\end{array}$ & 0.026 & 0.83 & $\begin{array}{c}1057 / \\
395\end{array}$ & 0.029 & 0.93 & $\begin{array}{l}1072 / \\
595\end{array}$ & 0.033 & 1.07 & $1152^{\circ} \mathrm{F}$ \\
\hline $\begin{array}{l}1850^{\circ} \mathrm{F} \\
\text { Test }\end{array}$ & $\begin{array}{c}1038 / \\
161\end{array}$ & 0.031 & 1.04 & $\begin{array}{c}1088 / \\
400\end{array}$ & 0.033 & 1.15 & $\begin{array}{c}1130 / \\
601\end{array}$ & 0.036 & 1.23 & $1742^{\circ} \mathrm{F}$ \\
\hline
\end{tabular}

NOTES: - THEX is hot frame external temperature.

- TCEX is cold frame external temperature.

- $\mathrm{W} / \mathrm{F}$ is watts conductance per external temperature differential ${ }^{\circ} \mathrm{F}$.

- 0.94 shown in sample calculations. 
Table 6-5

Fire Test Reduced Data

Test Module Conductance and Predicted Converter Total Conductance

POST-FIRE

\begin{tabular}{|c|c|c|c|c|c|c|c|c|c|}
\hline & \multicolumn{3}{|c|}{$\begin{array}{l}\text { Third Hold Point } \\
\quad\left(600^{\circ} \mathrm{F}\right)\end{array}$} & \multicolumn{3}{|c|}{$\begin{array}{c}\text { Fourth Hold Point } \\
\left(400^{\circ} \mathrm{F}\right)\end{array}$} & \multicolumn{3}{|c|}{$\begin{array}{l}\text { Last Hold Point } \\
\text { (Optional) }\end{array}$} \\
\hline & $\begin{array}{l}\text { THEX/ } \\
\text { TCEX } \\
{ }^{\circ} \mathrm{F}\end{array}$ & $\begin{array}{l}\text { Test } \\
\text { Module } \\
\mathrm{W} / \mathrm{F}\end{array}$ & $\begin{array}{c}\text { Converter } \\
W / F\end{array}$ & \begin{tabular}{|l|} 
THEX/ \\
TCEX \\
${ }^{\circ} \mathrm{F}$
\end{tabular} & \begin{tabular}{|c|} 
Test \\
Module \\
$\mathrm{W} / \mathrm{F}$
\end{tabular} & $\begin{array}{c}\text { Converter } \\
W / F\end{array}$ & $\begin{array}{l}\text { THEX/ } \\
\text { TCEX } \\
{ }^{\circ} \mathrm{F}\end{array}$ & \begin{tabular}{|c|} 
Test \\
Module \\
$\mathrm{W} / \mathrm{F}$
\end{tabular} & $\begin{array}{l}\text { Converter } \\
\mathrm{W} / \mathrm{F}\end{array}$ \\
\hline $\begin{array}{l}\text { First } \\
1475{ }^{\circ} \\
\text { Test }\end{array}$ & $\begin{array}{l}1070 / \\
595\end{array}$ & 0.036 & 1.23 & $\begin{array}{c}1054 / \\
400\end{array}$ & 0.033 & 1. 14 & -.- & -- & -.- \\
\hline $\begin{array}{l}\text { Second } \\
1475^{\circ} \mathrm{F} \\
\text { Test }\end{array}$ & $\begin{array}{c}1172 / \\
604\end{array}$ & 0.036 & 1.22 & $\begin{array}{c}1153 / \\
406\end{array}$ & 0.032 & 1.08 & $\begin{array}{c}1126 / \\
190\end{array}$ & 0.029 & 0.96 \\
\hline $\begin{array}{l}1850^{\circ} \mathrm{F} \\
\text { Test }\end{array}$ & $\begin{array}{c}1104 / \\
600\end{array}$ & 0.052 & 1.99 & $\begin{array}{c}1053 / \\
400\end{array}$ & 0.050 & 1.89 & $\begin{array}{l}960 / \\
202\end{array}$ & 0.051 & 1.97 \\
\hline
\end{tabular}

NOTES: (A) THEX is hot frame external temperature.

(B) TCEX is cold frame external temperature.

(C) $\mathrm{W} / \mathrm{F}$ is watts conductance per external temperature differential o $\mathrm{F}$. 


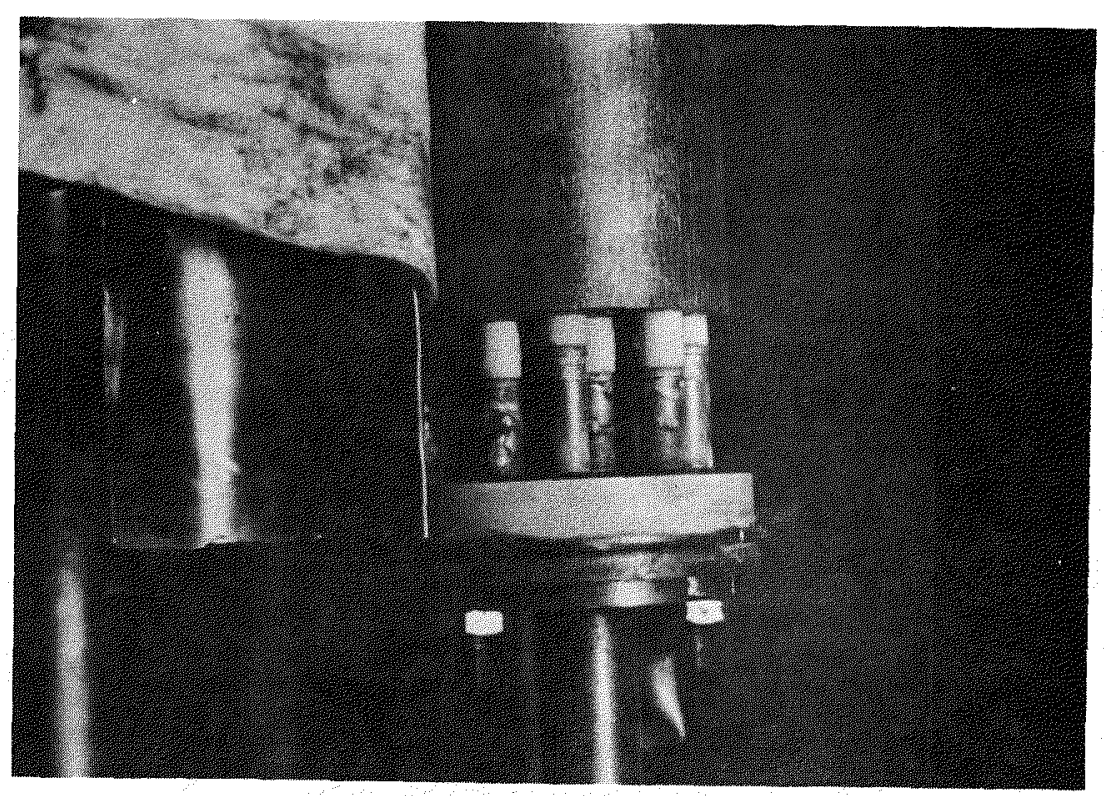

Figure 6-5 Cut-Away View of Fire Module After $1475^{\circ} \mathrm{F}$ Test.

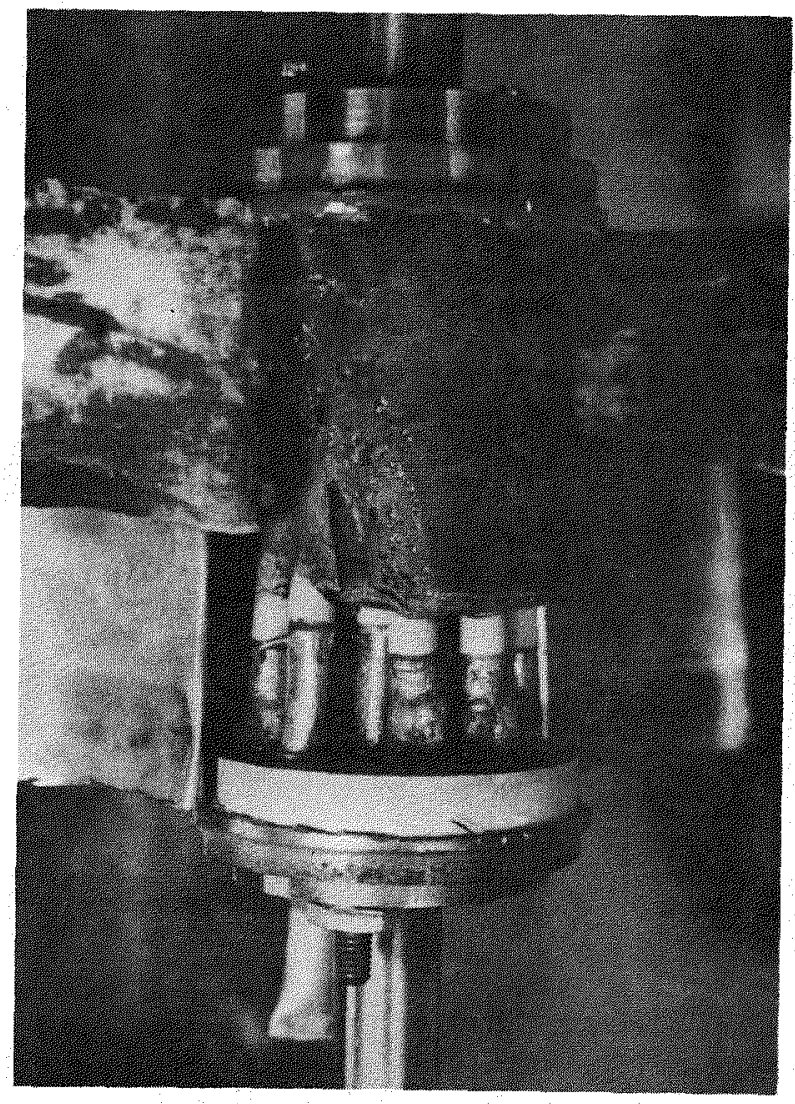

Figure 6-6 Cut-Away View of Fire Module After $1850^{\circ} \mathrm{F}$ Test. 